PASCALE HUGON, JONATHAN STOLTZ

THE ROAR OF A TIBETAN LION

Phya pa Chos kyi seng ge's theory of mind in philosophical and historical perspective 
ÖSTERREICHISCHE AKADEMIE DER WISSENSCHAFTEN

PHILOSOPHISCH-HISTORISCHE KLASSE

SITZUNGSBERICHTE, 897. BAND

BEITRÄGE ZUR KULTUR- UND

GEISTESGESCHICHTE ASIENS, NR. 97

HERAUSGEGEBEN VOM INSTITUT

FÜR KULTUR- UND GEISTESGESCHICHTE ASIENS

UNTER DER LEITUNG VON BIRGIT KELLNER 


\section{The Roar of \\ a Tibetan Lion}

Phya pa Chos kyi seng ge's

theory of mind in philosophical and historical perspective

Pascale Hugon, Jonathan Stoltz 
Angenommen durch die Publikationskommission der philosophischhistorischen Klasse der Österreichischen Akademie der Wissenschaften:

Accepted by the publication committee of the Division of Humanities and Social Sciences of the Austrian Academy of Sciences by:

Michael Alram, Bert G. Fragner, Andre Gingrich, Hermann Hunger, Sigrid Jalkotzy-Deger, Renate Pillinger, Franz Rainer, Oliver Jens Schmitt, Danuta Shanzer, Peter Wiesinger, Waldemar Zacharasiewicz

\section{Veröffentlicht mit Unterstützung}

des Austrian Science Fund (FWF): P23422-G15

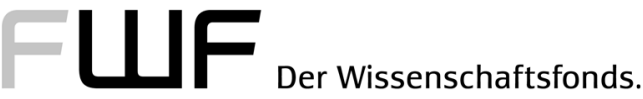

Diese Publikation wurde einem anonymen, internationalen Begutachtungsverfahren unterzogen.

This publication was subject to international and anonymous peer review.

Peer review is an essential part of the Austrian Academy of Sciences Press evaluation process. Before any book can be accepted for publication, it is assessed by international specialists and ultimately must be approved by the Austrian Academy of Sciences Publication Committee.

Die verwendete Papiersorte in dieser Publikation ist DIN EN ISO 9706 zertifiziert und erfüllt die Voraussetzung für eine dauerhafte Archivierung von schriftlichem Kulturgut.

The paper used in this publication is DIN EN ISO 9706 certified and meets the requirements for permanent archiving of written cultural property.

Alle Rechte vorbehalten.

All rights reserved.

ISBN 978-3-7001-8335-8

Copyright (C) 2019 by

Österreichischen Akademie der Wissenschaften, Wien

Austrian Academy of Sciences, Vienna

Druck/Printed: Prime Rate kft., Budapest

https://epub.oeaw.ac.at/8335-8

https://verlag.oeaw.ac.at

Made in Europe 


\section{Contents}

Foreword iii

Acknowledgements $\mathrm{V}$

I. Introduction 1

1. Phya pa's theory of mind in the context of Western phi- 3 losophy (by Jonathan Stoltz)

2. Phya pa's theory of mind in the context of Indo-Tibetan 41 Buddhist intellectual history (by Pascale Hugon)

II. Translation

III. Tibetan text 169

1. Source and editorial conventions 171

2. Critical edition 179

3. Corrections in the manuscript and other particularities of 209 the manuscript reading

4. Marginalia 213

5. Topical outline ( $\mathrm{sa} \mathrm{bcad)} \quad 215$

IV. On cognitions that are not episodes of knowledge 225

1. Non-ascertaining perception (snang la ma nges pa) 227

2. Post-knowledge cognition (bcad pa'i yul can) 239

3. Factive assessment (yid dpyod) 247

4. Mistaken cognition (log shes) 257

5. Doubt (the tshom) 265

6. Definitions 273

V. Supplementary textual resources 283

1. Citations and references in later works 285

2. Parallel passages in the 'Od zer 299 


\section{Tables}

A. Apprehended objects and corresponding awarenesses

B. Apprehended objects and engaged objects - the partial overlap between these objects

C. Apprehended objects and engaged objects - the partial overlap between the episodes of awareness involving these objects

D. The three-fold division of awareness in the Mun sel

E. The seven-fold division of awareness in the Mun sel

F. The twelve-fold division of awareness in the Mun sel

G. The ten-fold division of awareness in the 'Od zer

VII. Appendices

1. Excursuses in the first chapter of the Mun sel 349

2. On inference 355

3. Definitions of knowledge 367

4. Lexicon

VIII. Bibliographical references

1. Abbreviations

2. Primary sources

3. Modern studies

IX. Selected indices

1. Indian names 405

2. Tibetan names 


\section{Foreword}

At the heart of this volume is a translation of large portions of the first chapter of the twelfth-century Tibetan Buddhist scholar Phya pa Chos kyi seng ge's most important philosophical contribution, the Tshad ma yid kyi mun sel, i.e., "Epistemology-The Dispeller of the Mind's Darkness." Since the discovery of a single manuscript of this treatise at Drepung Monastery in Central Tibet nearly twenty years ago, quite a few scholars - including the two of us - have published numerous articles on the positions espoused by Phya pa within this important text. In so doing, this scholarly work has made it possible to move beyond the various "myths" long associated with this author both in the Tibetan and the Western traditions. Yet, the writing of Phya pa has remained, in an important respect, behind a curtain, as it has been limited to scholars having facility with the Tibetan language. The foremost goal of this book is to begin pulling back the curtain on Phya pa's philosophical contributions so that they can be appreciated by a wider audience.

In this book we offer a translation of a segment of the Mun sel that is dedicated to laying out the central features of what can rightly be considered Phya pa's "philosophy of mind and cognition." Our hope is that philosophers without a background in Indian or Buddhist thought will find value in learning more about how this twelfth-century philosopher made sense of the elements and activities of the mind, and that scholars of Indian, Tibetan, and Buddhist studies will gain a deeper appreciation of Phya pa's place within the Buddhist intellectual tradition as well as of the philosophical significance of his ideas. With this hope in mind, our translation of Phya pa's Mun sel is supplemented by two introductory essays, one putting Phya pa's text in philosophical context (I.1) and the other in historical context (I.2).

Translation from Tibetan into English is always a difficult task; and it is even more difficult when the text in question is nearly nine hundred years old; and harder still when the text relies upon technical philosophical vocabulary like that used by Phya pa. Nevertheless, because our translation (in chapter II) aims at readability for a wide philosophical audience, we have chosen to keep the English text as 'clean' as possible. Departing from quasi-standard academic translation conventions within Indo-Tibetan philology, we have consciously avoided the use of brackets marking insertions, by the translators, of terms and information not explicitly present in the Tibetan text itself. In this respect, we have taken an 
approach similar to that adopted by Parimal Patil in his translation of Ratnakīrti's Demonstration of Exclusion (Patil 2011). We believe that this sort of "minimally annotated" translation, unburdened by brackets and references to Tibetan and Sanskrit terms, will provide all readers, and especially those who lack the resources to engage Phya pa's work in the original Tibetan, with a clearer understanding of the author's philosophical views. Yet, for the benefit of scholars who are more philologicallyminded, we also include, immediately after the translation, a critical edition of the translated portions of Phya pa's Mun sel (cf. III). A lexicon is provided (VII, 4), which lists all the technical terms and important expressions in Tibetan along with the English translation we adopted. Some of our choices of translation stand out as they depart from more conventional translations and are, we anticipate, bound to stir up opposition. When deemed necessary, explanations for our translations have been provided in the introduction and the footnotes to the translation, and the rationale for our translations of the key terms pertaining to episodes of awareness that are not knowledge is given in the supplementary study in chapter IV.

Although the translation is based almost entirely on the first chapter of his Mun sel, and, in that regard, constitutes Phya pa's general presentation of awareness, it is abundantly clear that the treatise presupposes a familiarity with many of the philosophical topics that it addresses. Phya pa often cites examples and makes use of terminological conventions for which he provides no background explanation. Phya pa also presupposes, in the first chapter, acquaintance with ideas that are only discussed and clarified in later chapters of the work. Phya pa's treatise is not, in this respect, an introduction for beginners. For this reason, we have included tables (VI), appendices (VII) and supplementary explanations (IV) that help to sort out Phya pa's terminologies and concepts, and that provide additional background information concerning some of the most important matters that he references in this portion of the Mun sel. 


\section{Acknowledgements}

This project was started in summer 2016, when Jonathan Stoltz came to Vienna under the auspices of the Visiting Fellow Program at the Institute for the Cultural and Intellectual History of Asia of the Austrian Academy of Sciences, where Pascale Hugon was at the time active in the project "Early bKa' gdams pa scholasticism-Phya pa Chos kyi seng ge's contribution." Five weeks of intensive work allowed us to prepare the translation and edition of the chosen passages of the Mun sel and to read in detail the parallel passages in Phya pa's 'Od zer (cf. V, 2). Our initial plan was to write an article on Phya pa's philosophy of mind addressed to scholars in the field of philosophy rather than that of Indo-Tibetan Buddhism, supplemented by an English translation of key passages on the topic. As the pages of edition and translation accumulated, we realized that Phya pa's complex system would be better understood by readers if presented in a more comprehensive form. Our joint project, from then on aiming at a monograph, was continued "over the clouds" and via videoconference until its completion in spring 2018.

We wish to thank here the Austrian Science Fund for its generous support both to the stand-alone project "Early bKa' gdams pa scholasticism" (Austrian Science Fund [FWF]: P23422-G15) and to the publication of this monograph, as well as to the Institute for the Cultural and Intellectual History of Asia for hosting Jonathan Stoltz as a Visiting Fellow in 2016. We are also grateful to Dennis Johnson for his careful proofreading of the monograph. Pascale thanks the members of the Institute for providing useful feedback to a preliminary presentation of some of the topics addressed in this monograph at the occasion of the Institute's Research Colloquium in January 2017. Jonathan thanks his colleagues for their regular discussions on the topics addressed in this book, and expresses his gratitude to Sandra Menssen and Matthews Grant for their ongoing support of his research agenda. 

I

Introduction 



\section{Introduction (1): Phya pa's theory of mind in the con- text of Western philosophy}

\section{Introduction}

Epistemology, the science that investigates the nature and scope of knowledge, has a long history within Indian intellectual culture. In the first millennium of the Common Era Buddhist philosophers in India debated extensively among themselves, and clashed repeatedly with thinkers from other philosophical traditions in India, about the nature of logical reasoning and knowledge. ${ }^{1}$ The most central topic in these debates was an investigation of the various means or instruments by which knowledge can be obtained (Skt. pramāna, Tib. tshad ma). Although Buddhist intellectuals in the first half of the first millennium CE were familiar with the study of epistemology, it is the sixth-century Buddhist scholar Dignāga (c. 480-540) who is traditionally regarded as the father of Buddhist epistemology. The seven core works on logic and epistemology composed by Dignāga's successor, Dharmakīrti (c. 600-660), formed the foundation for centuries and centuries of further developments by Buddhist philosophers in both India and Tibet. ${ }^{2}$

The author of the text translated herein, Phya pa Chos kyi seng ge ("cha pa chö kyi seng gé," 1109-1169, hereafter: "Phya pa"), writing about five hundred years after Dharmakìrti, provides us with an important snapshot of early Tibetan Buddhist epistemology. Though Phya pa is clearly indebted to the views of Dignāga and Dharmakīti, there are a great many ways in which Phya pa's theories subtly (or not) depart from what is attested in the works of those two Indian authors. Phya pa's epistemological program shows evidence of being influenced by later Indian and Tibetan exegeses on Dharmakīti's works. In particular, there is ample evidence of Phya pa's familiarity with the epistemological contributions

\footnotetext{
${ }^{1}$ Among the principal opponents of the Buddhists, one finds both thinkers associated with the Nyāya School and those from the Mīmāmsā School, who embodied the Brahmanical orthodoxy of the time. On the historical, social and religious background of these disputes and the resulting developments in logic and epistemology, see Eltschinger 2014.

${ }^{2}$ Among the most important texts here are Dignāga's Pramānasamuccaya and its vrtti (PS and PSV) and Dharmakīrti's Pramānavārttika (PV) and Pramānaviniścaya (PVin).
} 
by his Tibetan predecessor, rNgog Blo ldan shes rab ("ngok lo den shé rap," 1059-1109, hereafter: "rNgog Lo"). rNgog Lo is famed in Tibet both for translating numerous Indian epistemological treatises and for composing his own exegeses on those Indian treatises. In particular, his exegesis of Dharmakīti's Pramānaviniścaya - which was the most influential work by Dharmakīti in twelfth-century Tibet, and the most influential on Phya pa-provides evidence of the influence that Indian commentators subsequent to Dharmakirti had on rNgog Lo's philosophical thought. Among those commentators, one of the greatest influences comes from the eighth-century Buddhist scholar Dharmottara (c. 740-800), whose commentary on Dharmakīrti's Pramānaviniścaya rNgog Lo also translated. Although Phya pa frequently disagrees with the positions taken by (and definitions given by) Dharmottara, he nevertheless makes regular use of a number of theoretical distinctions that were drawn by Dharmottara back in the eighth century. Additional Indian interpreters of Dharmakīti whose works were translated and commented upon by rNgog Lo likewise appear to have been influential on Phya pa's interpretation of Dharmakīrti and on the constitution of his epistemological program.

While the largest portion of Phya pa's most important text, the Tshad ma yid kyi mun sel (hereafter: Mun sel), is dedicated to detailing the nature of knowledge episodes (pramāna, tshad $m a)^{3}$, the first chapter of his text aims to provide a general introduction to, and elucidation of, the nature of cognition and the objects of cognition. ${ }^{4}$ In this way, though the text is,

\footnotetext{
${ }^{3}$ Readers should note that on the preceding page the Sanskrit term pramanna was translated as "means or instruments by which knowledge can be obtained." Within the Buddhist tradition of epistemology, however, the term pramanna is regularly used to refer to the episodes of cognition that result from these means (Skt. pramannaphala). We have chosen to follow B.K. Matilal (see, in particular, Matilal 1986: 100-106) in speaking of these particular episodes of cognition as "knowledge episodes." (These mental episodes are also frequently called "valid cognitions.") Though knowledge is widely represented as a dispositional state within Western philosophical contexts, and this stands in contrast to the emphasis on episodic cognitions within Indian and Tibetan epistemological contexts, this difference alone should not prevent us from extending the term "knowledge" to those instances of cognition that are pramāna/pramānaphala. On the other hand, all readers must be attentive to the fact that how these two traditions theorize about knowledge and frame their claims about knowledge are undoubtedly distinct. For more on this, see $\S 4.2$ below.

${ }^{4}$ For more on the structure of the Mun sel, see III, 5 (topical outline).
} 
overall, certainly a work in epistemology, the first chapter is best understood as offering a cursory account of Phya pa's philosophy of mind. The reader is provided with a classificatory breakdown (two different ones in fact) of cognitive episodes; an account is provided of the different operations or activities that occur within particular episodes of cognition; and most importantly, Phya pa devotes great attention to elucidating the various ways in which these episodes of cognition are related to objects - to external objects, but also to anything else that could be deemed the object of a cognitive episode. This attention to matters such as the constituent elements of perceptual experience, irrespective of whether those experiences are sufficient for knowledge- - let alone his attention to the elements of erroneous cognitions - shows that Phya pa was interested in formulating a general account of the nature of cognition, and was not merely providing this information for instrumental purposes (such as for the purpose of supporting his subsequent theory of knowledge). ${ }^{5}$

Phya pa's theory of cognition is constructed upon the basic premise that all episodes of cognition involve a relation between a cognitive subject (yul can) or awareness (blo) and a cognitive object (yul). His first chapter contains two distinct presentations of the kinds of items that can be regarded as cognitive objects. First, Phya pa describes the objects of cognition from the perspective of appearing, by appealing to apprehended objects (gzung yul). With respect to apprehended objects there are three main forms of awareness, one for each of the three types of apprehended objects. ${ }^{6}$ The second half of the first chapter articulates a seven-fold division of awareness that is founded upon an appeal not just to apprehended objects, but also to intentional objects (zhen yul) and engaged objects ('jug yul). ${ }^{7}$ Throughout both of these presentations, the consistent idea is that a cognitive subject (yul can) bears some relation to a cognitive object $(y u l$ ), and that the different features of this relation (and features of the cognitive object) determine how to classify the form of awareness. In this way, the cognitive object is viewed as, explanatorily, more primitive than the episode of awareness to which it is related.

\footnotetext{
${ }^{5}$ For a brief background on Buddhist theories of the mind, see Dreyfus\&Thompson 2007.

${ }^{6}$ See Mun sel 11 and the corresponding Table A in VI.

${ }^{7}$ See Mun sel 12 and following.
} 
Much of Phya pa's first chapter, and especially the portions translated in this volume, relate to explicating the nature and structure of these cognitive episodes and their objects. Though he does occasionally take up what might be called "excursions" on other topics - most of which have not been translated as a part of this present work ${ }^{8}$ - roughly one-third of the translation pertains to Phya pa's presentation of cognition insofar as it is related to apprehended objects, and two-thirds is connected to his more elaborate account of cognition that brings together the roles played by apprehended objects, intentional objects, and engaged objects.

In the pages that follow, my central goal is to highlight a number of the most pertinent features of Phya pa's account of cognition-features that are hard at work in the portions of the text translated here - and then to draw out the specifically philosophical implications that flow from Phya pa's account. The aim is to put Phya pa's views in conversation with contemporary philosophical discussions of perceptual experience, conception, and knowledge. In doing this, the reader will see not just how rigorous and sophisticated Phya pa's philosophical perspective is, but also that the philosophical themes with which he is engaging in this text, the Mun sel, are of deep and lasting relevance. Within this introduction, the aim is not to demonstrate how Phya pa's account informs or is informed by (let alone in opposition to) that of his philosophical predecessors and successors in India and Tibet. Those historical connections will be emphasized in the second part of the introduction (see I.2).

\section{Perceptual experience}

\subsection{Non-conceptual non-erroneous cognition and the definition of perception}

After his introductory verses, the very first topic addressed by Phya pa is a three-fold division of awareness - a division based on the objects apprehended by those episodes of awareness. Those three types of awareness are: ${ }^{9}$

\footnotetext{
${ }^{8}$ Many of these "excursions" have been, or will be separately addressed in other recent or future publications. See VII, Appendix 1.

${ }^{9}$ These three forms of awareness are briefly described in Mun sel 11(b), and then delineated more fully in sections $112.1,112.2$, and 112.3 , respectively.
} 
- conceptual cognition

- non-conceptual non-erroneous cognition ${ }^{10}$

- non-conceptual erroneous cognition

The second of these three categories of awareness is comprised of, as will be explained below, all episodes of perception (mngon sum). The most fundamental feature of non-conceptual non-erroneous cognitions is that they take real particulars (don rang gi mtshan nyid) as their apprehended objects. As Phya pa tells us, "That which takes as its apprehended object a real particular...these are perceptions, which are non-conceptual" (Mun sel 11).

Phya pa goes on, in his third chapter, to define perception as "being non-erroneous with respect to the apprehended state of affairs" (Mun sel 231.12) and reminds the reader that in such cases what appears to awareness are real entities (dngos po). Notably, although Phya pa believes that perceptual awareness must be non-conceptual, this feature is not an explicit part of his preferred definition of perception. Rather, he contends that its being non-conceptual is something that is implicitly entailed by his definition.

There are, it is important to point out, non-conceptual episodes of awareness that are not instances of perception, and these are the instances of non-conceptual erroneous cognition. Speaking loosely, these nonconceptual erroneous cognitions are ones that contemporary philosophers

\footnotetext{
${ }^{10}$ The expression "non-erroneous" ( $m a$ ' $k h r u l(b a)$ ) is used frequently by Phya pa and others in the Tibetan epistemological tradition. Though there are various applications of the expression, with respect to non-conceptual cognitions, to say that a cognition is non-erroneous can be roughly approximated to contemporary philosophical uses of the term "veridical," as when distinguishing veridical experiences from non-veridical (or falsidical) experiences. See, for example, Siegel 2010: 35-42. In particular, note that the category of non-conceptual non-erroneous cognition roughly aligns with what Siegel would term strongly veridical perceptual experiences.

Having said this, it is important to point out that our use of the term "veridical" in this translation - for which, one should read n. 5 in the translation (II) - carries a sense and extension quite different from how the term is described above, and different from how it is standardly employed in contemporary analytic philosophy of mind.
} 
of mind would label as instances of illusion or hallucination. ${ }^{11}$ In one respect, these sorts of cognitions are held to be erroneous inasmuch as there is no correspondence with the state of affairs to be cognized. ${ }^{12}$ More specifically, however, Phya pa contends that non-conceptual erroneous cognitions are episodes of awareness in which the apprehended object is not a real entity, but is instead something that is superimposed (sgro btags $p a)$ by the mind. ${ }^{13}$

Bringing the above items together, Phya pa takes there to be a very fundamental difference between perception, on the one hand, and illusion/hallucination on the other. In episodes of perception one has an awareness of a real entity-i.e., a real particular is the apprehended object

${ }^{11}$ It is now standard in contemporary analytic philosophy of mind to distinguish three forms of "perceptual experience": (veridical) perception, illusion, and hallucination. In this way, illusion and hallucination stand in contrast to veridical perception, as the former are both experiences that are in some way defective (see Fish 2009 and Siegel 2010: 34-36). On this contemporary model, "perceptual experience" is seen as broader than Phya pa's notion of perception (mngon sum), which, by assumption, must be veridical. (All of this sets aside questions of possible 'veridical illusions,' for which see Siegel 2010: 39).

While contemporary philosophers clearly distinguish instances of illusion (wherein one's sense faculties receive input from an external stimulus, but are somehow or other misled by that stimulus) from instances of hallucination (where there is no external sense stimulus at all), it is not entirely clear that any such careful distinction is made by Phya pa. The examples that are given for nonconceptual erroneous cognitions include both those that would be classified by contemporary analytic philosophers as illusions and those classified as hallucinations. Phya pa does mention, however, non-conceptual erroneous cognitions that are (a) sense cognitions and those that are (b) mental cognitions (see Mun sel 11(b)iii) - a distinction that loosely maps onto the contrast between illusions and hallucinations. In the former case, (a), a frequently cited example is that of a (white) shell appearing as yellow. For the latter, (b), Phya pa typically appeals to experiences within a dream (e.g., Mun sel 11(a)iii).

Additionally, while the erroneous cognitions that Phya pa is concerned with here are one and all non-conceptual, no such explicit restriction is found in contemporary philosophical discussions of perceptual experience. As such, were we to be precise, instead of speaking of illusion and hallucination, Phya pa's category of non-conceptual erroneous cognition includes only non-conceptual episodes of illusion and hallucination.

${ }^{12}$ See Mun sel 112.111.2.

${ }^{13} \mathrm{See}$, in particular, Mun sel 112.3 and 123.411. 
of perception. In episodes of non-conceptual erroneous cognition, on the other hand, the subject does not experience a real entity at all. Phya pa states, "it takes as its object something that is merely superimposed" (Mun sel 112.3). As will be explained more fully below, this is a critically important point of contrast between these two forms of non-conceptual awareness.

One final introductory point needs to be made about Phya pa's basic understanding of perception. On his account, apprehended objects are experienced directly. In the particular case of perception, this means that what appears is a real entity itself, and not a mere "representation" or "aspect" (rnam pa). As Phya pa puts the point, "We assert that external states of affairs are cognized without representations." ${ }^{14}$ In this way, Phya pa's account departs from the more commonly espoused representationalist portrayals of perceptual experience among his Indian Buddhist predecessors. Be that as it may, it is important to emphasize the point that, in perception, real entities are apprehended directly — on Phya pa's view, it is the real, external particulars themselves that appear in episodes of perception.

\subsection{Philosophical implications}

Phya pa's portrayal of non-conceptual experience - including both instances of perception and instances of illusion/hallucination-is remarkable in a number of ways. First and foremost, there is no question that Phya pa is endorsing a direct realist account of perception. In fact, so as to distinguish it from the contemporary intentionalist (or representationalist) theory of perception (to be discussed below), which is held by some of its proponents to be a direct realist theory as well, it would be more appropriate to classify Phya pa's theory of perception as a version of naïve realism. ${ }^{15}$ The term "naïve" may sound disparaging, but Phya

${ }^{14}$ Mun sel 8a7: kho bo cag rnam pa med par phyi rol gyi don rig par smra bas.

${ }^{15}$ Contemporary uses of the terms "direct realism" and "representationalism" in the analytic tradition of philosophy may seem a bit incongruent with earlier uses of those terms within the empiricist tradition of philosophy. In fact, readers whose primary understanding of direct realism and representationalism derives from traditional uses of these terms might find the claim that a theory (of perception) can be both direct realist and representationalist to be inherently contradictory.

The most widely accepted version of perception within contemporary philosophy of mind is intentionalism. That theory claims that the objects of (veridical) 
pa's philosophical account, at least with respect to the nature of apprehended objects and the cognitions apprehending them, is indeed intended to match up with our ordinary, conventional understanding of reality. Of apprehended objects, he tells us that, "Conventionally, these objects exist in a way that accords with worldly consensus" (Mun sel 111.D).

Part and parcel with Phya pa's naïve realism is his contention that, in perception, real (and paradigmatically external) entities appear directly, without the presence of representations. This is of particular relevance, because, by explicitly rejecting a representational theory of perception, he is running counter to the positions most commonly held by his Buddhist philosophical predecessors in India. In fact, Phya pa's account has some affinities with the accounts of perceptual experience typically associated with the Indian Buddhist school of the Vaibhāșika, which is rather dissimilar from what we find endorsed by Dignāga, Dharmakīrti, and later Indian Buddhist epistemologists - let alone many other Tibetan thinkers. ${ }^{16}$ Merely noting that Phya pa's theory of perception runs counter to Dignāga and Dharmakīrti, however, does not go far enough in exposing just how profoundly distinctive Phya pa's views of perception actually were.

In addition to denying that, in perception, objects are experienced by way of representations, Phya pa also contends, as described above, that perception-i.e., non-conceptual non-erroneous cognition - is to be characterized as any cognition that "takes as its apprehended object a real

perception are ordinary, mind-independent objects, and that those objects are indeed perceived directly, i.e., without any intermediary entities. (This stands in contrast to traditional sense-datum theories, in which external objects are only perceived indirectly by way of sense-data or sense impressions, etc.) Yet, intentionalist theories of perception additionally maintain that perceptual experience essentially involves a process of representation, wherein something is represented as $F$ (for one (or many) feature(s) $F$ ). These representations are associated with the (representational/intentional) contents of perceptual experience. The intentionalist theory of perception maintains that the phenomenology of a perceptual experience is determined by its representational content. Yet, at the same time, this theory of perception can affirm that the object experienced (in veridical perception) is an ordinary, mind-independent object. For this reason, intentionalism can still be considered a direct realist theory of perception.

For a fuller account of contemporary intentionalism, see Crane 2001a or (the more abbreviated) Crane 2009.

${ }^{16}$ For more on this, see Hugon 2016c and forthcoming (1). 
particular." This, again, is in contrast to episodes of non-conceptual erroneous cognition-illusions and hallucinations-which apprehend mere superimpositions. This may seem like an obvious difference between perception and (for example) hallucination, but it carries with it incredibly rich consequences.

By characterizing perception as any experience that takes as its apprehended object a real particular, Phya pa is committed to the view that perceptual cognition is, in part, constituted by the particular entity that appears. To say that it is constituted by the particular entity that appears implies each of the following:

a) In episodes of perception, the mind (or awareness) stands in a specific relation to the real entity that is its apprehended object.

b) As such, had the perceived entity been different, it necessarily would have been a different episode of awareness. For example, since perception is constituted by the particular entity that appears, the perception of a particular fire on the top of a mountain pass and the perception of a particular fire at the base of a mountain pass would have to be distinct episodes of awareness, as they are perceptions of materially distinct entities.

c) Likewise, with respect to a perception of a real fire and a hallucination as of a fire, even if those experiences were phenomenally identical - that is, identical in terms of how they appear-they would still, by definition, be fundamentally different kinds of experience. The former would be classified as an episode of perception and the latter as an episode of non-conceptual erroneous cognition. Though they might appear as identical, and thus could be introspectively indistinguishable, that would not make them the same episode of experience, for they are constituted by fundamentally different apprehended objects.

This claim that non-conceptual experiences are, in part, constituted by their appearing objects-where, importantly, the appearing objects of perception are real (often external) particulars - is far from the standard view in contemporary philosophy. The most widely supported theories of perception in analytic philosophy, at present, are various versions of intentionalism. ${ }^{17}$ Intentionalism, like Phya pa's view, is compatible with a

${ }^{17}$ Excellent resources for learning more about intentionalism are Siegel 2010, Byrne 2001, and Pautz 2010. 
direct realist theory of perception, but intentionalism is fundamentally at odds with Phya pa's account of perceptual experience in many other respects. While contemporary intentionalists could agree that what is actually perceived is the (external) object itself, and so it could be a direct realist theory of perception, they would explicitly deny that the experience is "constituted by" the perceived object. Rather, intentionalists maintain that episodes of perception possess some sort of intentional content-or representational content - and that it is these contents that are principally determinative of what kind of experience a person is having. On this view, the mind (or, to modernize the theory, the visual sense organs together with the brain) represents the perceived object in a certain way. When the representational content of two experiences is the same, we could say, according to the intentionalist, that the experiences themselves are the same. This is the case not just for two token perceptions, but also for instances of illusion or hallucination. As long as the mind, in an occurrence of illusion, represents things just as it would in a case of perception, it would be essentially the same experience as one of perception. To summarize, the intentionalist will maintain:

a*) Perception does not entail a constitutive relation between the mind and the object perceived.

$\left.b^{*}\right)$ Two different perceived objects - for example, objects that are spatially discrete - could, nonetheless, give rise to exactly the same perceptual experience. This is due to the fact that the mind could represent those two (numerically distinct) objects in exactly the same ways.

c*) Likewise, the perception of a real fire and the hallucination as of a fire, could, if they are phenomenally indistinguishable, be treated as one and the same experience. Provided that the representational content is the same in the two cases, they would essentially be one and the same experience.

There are, no doubt, additional differences between Phya pa's theory of perception and contemporary intentionalist versions of perception, but these three differences suffice to show that Phya pa does not endorse an intentionalist version of direct realism. Nor, as was mentioned earlier, does Phya pa support a traditional, representationalist version of indirect realism. Rather, he defends a naïve realist theory of perception, and, in 
particular, his account of perceptual experience is one that in current philosophical parlance would be labeled a version of disjunctivism. ${ }^{18}$

Though there are several different versions of disjunctivism that are adopted by contemporary philosophers of mind, one core, shared thesis of disjunctivism is the claim that perception and hallucination are two different kinds of experience. They are claimed to share neither the same object nor have any other factor in common. ${ }^{19}$ When things appear to be a certain way - such as when there appears to be a fire - the disjunctivist will maintain that this appearance is consistent with it either being a perception of a fire or being a hallucination of a fire. Even if the two experiences were indistinguishable, they would still be, according to the disjunctivist, fundamentally different in kind.

This is precisely the kind of account we find endorsed by Phya pa. Perception (i.e., non-conceptual non-erroneous cognition) and illusion/hallucination (i.e., non-conceptual erroneous cognition) are, according to Phya pa, two entirely different types of awareness. Moreover, they are different insofar as two very different kinds of objects appear to the mind and are apprehended in these two types of non-conceptual cognition-real entities are apprehended in perception whereas superimposed items are apprehended in illusion/hallucination.

\subsection{Manifest and non-manifest features}

Given that Phya pa's theory is in accord with the approach of present-day disjunctivists, and is not in conformity with intentionalist theories of perceptual experience, one might ask whether there is anything about the nature of experience that Phya pa would have a difficult time accounting for in his framework. Indeed, there are numerous debates playing out between contemporary philosophers of mind where it appears that intentionalism has the upper hand over naïve realism. ${ }^{20}$ Take, for example, the question of what properties of an object are represented in a given experience. Because intentionalists maintain that perception is accompanied by representational content, proponents of this view can and do argue

${ }^{18}$ For more information on disjunctivism, see, e.g., Brewer 2011, Haddock\&Macpherson 2008, and Fish 2005.

${ }^{19}$ This is what is called the "no common factor" portrayal of disjunctivism, or a rejection of the "highest common factor" conception of experience. For this view, see Hinton 1973.

${ }^{20}$ For illustrations of these debates see, e.g., Byrne 2001, Tye 2007 and Smith 2010. 
that when an object is perceived some of the object's properties are represented and others are not. For example, when I visually perceive a cow (at close distance, under good lighting conditions, etc.), its color and shape may very well be represented to me, but perhaps more abstract properties such as the age of the cow are not represented. Though the cow might, let us assume, be black and white and twelve years old, my mind could represent the cow as black and white without representing it as twelve years old. As such, the intentionalist can maintain that, from perception alone, I can gain knowledge of the cow's color without gaining knowledge of its age.

Since Phya pa does not accept the idea that perception involves the representation of an object's properties or features, he must make sense of examples similar to the above in a different manner. Perception is not, for Phya pa, a matter of the mind possessing intentional or representational content. Instead, as was explained above, it is simply the mind bearing a constitutive relation with a real particular. So how is Phya pa to accommodate the common-sense intuition that, in perception, a person could be aware of a cow's color without being aware of the cow's age? Phya pa does not, in this context, speak of cows or their colors. He does, however, specifically address this sort of concern, and does so by discussing the (visual) perception of blue (or a blue object). He contends that a person can have perceptual knowledge of blue and yet not have perceptual knowledge of the blue entity's impermanence, even though the object is both blue and impermanent (see, in particular, Mun sel 112.2). ${ }^{21}$

Let us look into Phya pa's claims more fully. As mentioned, Phya pa proclaims that, in perception, a real (and paradigmatically external) entity itself is apprehended by the mind — and this object is apprehended directly,

21 The notion of "impermanence" is particularly significant within the Buddhist context. It is a standard principle of Buddhist thought that all real entities are impermanent - that is, that they do not endure for more than a single moment. Instead, what ordinary humans experience as enduring entities are actually just continua of impermanent entities that are, moment by moment, destroyed and (re)created. Nevertheless, though real entities have the property of impermanence, ordinary humans do not have perceptual knowledge of this impermanence; we experience real entities as though they endure through time. Given this framework, Phya pa maintains that the property of 'impermanence' is not perceptually known (or even perceptually knowable) by ordinary human beings. Instead, knowledge of impermanence is established through inferential cognition. For more on this, see VII, Appendix 2.7[b]. 
without the presence of representations. Moreover, Phya pa endorses Dharmakirti's traditional view that when an object appears, all the properties or features of the object appear (Mun sel 112.22 and VII, Appendix 1 (EX4)). As such, when I perceive something blue, not only does the blue appear, so too, all the other properties of the object must appear-including what might be considered "higher level" properties such as the properties of 'being impermanent' and 'being produced.' Yet, Phya pa upholds the view that I can have perceptual knowledge of blue without having perceptual knowledge of impermanence. ${ }^{22}$ But since he rejects the intentionalist's avenue of proclaiming some properties to be represented while others are not represented, Phya pa must provide an alternative explanation for how this difference with respect to knowledge is possible.

The explanation that Phya pa gives is to affirm that some features of the perceived object are "manifest" (rnam ldan) and others "non-manifest" (rnam med). The color and shape of a given object are examples of manifest features, whereas the property of impermanence is a non-manifest feature. ${ }^{23}$ Though the Tibetan terms that Phya pa applies here-rnam ldan and rnam med-are linked to the term used for a representation (rnam $p a$ ), the context suggests that they are being used quite differently. Whereas representations are understood as subjective features that apply to one's cognitive awareness itself, the categories "manifest feature" and "non-manifest feature" apply to the object that is perceived. Phya pa's view is that, in perception, all the properties or features of an object appear, but only some of those features of the object are manifest ones.

In light of this distinction between manifest and non-manifest features, Phya pa contends that an ordinary person can gain perceptual knowledge of only the manifest features of an object. The non-manifest features still appear, and they are, in fact, still perceived, but the perception of these non-manifest features necessarily falls short of what is required for perceptual knowledge. Instead, with respect to these non-manifest features, a person is said to have an episode of non-ascertaining perception (on which more will be said below).

\footnotetext{
22 Phya pa's position here stands in contrast to what is maintained by his Sakya critic, Sa skya Pạ̣dita Kun dga' rgyal mtshan ("sa kya pandita kün ga gyel tsen," 1182-1251). For more on this, see I.2, 4.1 and 4.4.

${ }^{23}$ See Mun sel 112.22 and 112.23.
} 
Phya pa has, thus, fashioned an account of perceptual experience that is able to accommodate the idea that a person can have perceptual knowledge of some features of a perceived object, without having knowledge of other features of the same object, even though it is the real entity itself that is directly perceived, and even though all the features of the object are said to appear to awareness in an episode of perceptual experience. As just mentioned, he accomplishes this by appealing to the distinction between the manifest and non-manifest features of an objectthe former of which can be perceptually known, but the latter of which cannot (they are only known through inferential cognition). Yet, Phya pa's explanation importantly does not appeal to the idea of representational content, the existence of which he explicitly rejects.

\subsection{Three types of perception}

Now that these philosophical comparisons have been articulated, let us return to describing a few other notable features of Phya pa's account of perceptual experience. As mentioned above, Phya pa maintains that not all episodes of perception are instances of perceptual knowledge. Though perception is, by definition, a non-erroneous form of experience, Phya pa still believes that some of these perceptual experiences fall short of what is required for knowledge. In particular, as was noted above, when a person perceives a blue object, all the properties of the object are said to appear, and all the properties are perceived, but non-manifest features such as the object's impermanence are not known (or even knowable) via perception. Instead, the perceptual experience one has of the object's impermanence is, according to Phya pa, classified as an instance of nonascertaining perception.

In general, Phya pa affirms that there are three different forms of perception. There is perceptual knowledge itself (mngon sum tshad ma), non-ascertaining perception (snang la ma nges pa), and post-knowledge cognition (bcad pa'i yul can). ${ }^{24}$ Again, all three of these are forms of perception, and are thus non-erroneous, but only the first kind is an instance of knowledge. It is notable that Phya pa affirms the view that these three forms of perception exist not just for the paradigmatic cases of perceiving external objects (which include all the episodes we have termed "transitive perception") but also for instances of reflexive awareness

\footnotetext{
${ }^{24}$ As will be explained below, post-knowledge cognition actually comes in several different forms, only one subtype of which is perceptual. See Mun sel 123.2.
} 
(rang rig) (Mun sel 122.31). Episodes of non-ascertaining perception are not cases of knowledge because, Phya pa tells us, those episodes are compatible with the presence of superimpositions (sgro 'dogs) —whereas perceptual knowledge is incompatible with the presence of superimpositions. Episodes of post-knowledge cognition, by contrast, are incompatible with superimpositions, but these episodes fall short of knowledge because, by definition, they do not provide novel information. ${ }^{25}$ That is, the object that is perceived in an episode of perceptual post-knowledge cognition is one that has already been known. As such, it is maintained that the postknowledge cognition is not an instance of knowledge.

Phya pa states that there are two subtypes of non-ascertaining perception. One subtype involves the presence of non-manifest features, like that of impermanence, described above. Because a real particular is apprehended by awareness, all the properties of the object are said to appear to awareness. Yet, Phya pa contends, with respect to non-manifest features such as the object's impermanence, the perceiver merely has an episode of non-ascertaining perception. The other subtype of non-ascertaining perception explicitly mentioned by Phya pa involves the presence of manifest features, such as an object's shape or color. Just because these features are manifest does not necessarily guarantee that a person perceiving an object will have perceptual knowledge with respect to all the manifest features. In particular, there can be cases where manifest features appear to awareness, but they fail to be "ascertained" due to a lack of attention or focus. ${ }^{26}$ Phya pa describes this subtype of non-ascertaining perceptions as those in which there is "an appearance but no ascertainment due to not focusing one's mind on the object" (Mun sel 123.11). As an

${ }^{25}$ Though Phya pa often identifies instances of post-knowledge cognition as cases where the "object is already known" (see Mun sel 122.122.22 and 123.21), we must note the importance of Phya pa's account in Mun sel 212.22. There he argues that post-knowledge cognition fails to be an episode of knowledge not because its object is already known, but for reasons having to do with its incapacity to eliminate superimpositions. This matter is taken up in much more detail in I.2, 3.2.2.

${ }^{26}$ The existence of such cases provides us with further evidence that the labels "manifest" (rnam ldan) and "non-manifest" (rnam med), as applied by Phya pa, are used to identify an objective difference in the properties/features in question. Whether a feature is manifest or not is determined by what kind of feature it is, and does not depend on subjective matters such as the cognizer's attention, the quality of one's vision, etc. 
example, he briefly describes a case where blue appears but is not ascertained due to the perceiver in question being fully absorbed in his own thoughts. ${ }^{27}$

In addition to the possibility of non-ascertaining perception, a cognitive agent can have a perceptual experience and yet fail to have knowledge due to the cognitive episode not being novel with regard to the object that is cognized. These are cases of post-knowledge cognition. Phya pa speaks of three different kinds of post-knowledge cognition, two of which are conceptual and one of which is non-conceptual. It is only this last, non-conceptual variety that is a species of perception. This kind of post-knowledge cognition is given the specific designation perceptual post-knowledge cognition (bcad pa'i yul can gyi mngon sum). This form of perception includes, for instance, an episode of awareness apprehending blue that follows immediately after a cognitive agent has just gained perceptual knowledge of blue. In such a case, since the cognizer already possesses perceptual knowledge of blue, the non-conceptual experience that follows this instance of knowledge is one for which superimpositions have already been eliminated. To see more clearly why this episode of awareness should not be considered an episode of knowledge, we must examine Phya pa's account of what it is to be an instance of knowledge. Before turning to the question of knowledge, however, let us first clarify Phya pa's understanding of conceptual cognitions.

\section{Conceptual cognition}

\subsection{The features of conceptual cognition}

In contrast to perceptual cognitions, which apprehend real particulars, conceptual cognitions have as their apprehended objects mere concepts (don spyi) ${ }^{28}$ Though Phya pa does not explicitly define the term "conceptual cognition" (rtog pa) within his Mun sel, it is clear that he understands

\footnotetext{
${ }^{27}$ An additional note in the manuscript points to a third subcategory of nonascertaining perception — one that is explicitly addressed in numerous later texts by Phya pa's successors. For more on this, see n. 51 within the translation (II) as well as IV, 1(b).

${ }^{28}$ The role of concepts (Tib. don spyi) in the Tibetan epistemological tradition, especially in the century following Phya pa - including a defense of the translation "concepts" for the term don spyi-is taken up in Stoltz 2006.
} 
that class of cognitive episodes to be precisely those that have concepts as their apprehended objects. ${ }^{29}$ A much more extensive discussion of the definition of conceptual cognition is provided within Phya pa's commentary on Dharmakīrti's Pramānaviniścaya (hereafter: 'Od zer). There, he seeks to harmonize two ostensibly different ways of characterizing conceptual cognition. On the one hand, one could formalize the connection between conceptual cognition and concepts by defining this form of cognition in such a way that it explicitly references the appearance of concepts. Phya pa does this when he defines conceptual cognition as "that for which concepts appear" ('Od zer 46b5). This way of understanding conceptuality, however, may appear not to match up so perfectly with the standard portrayals of conception offered by Dignāga and Dharmakīrti. Dharmakīrti's primary definition of conceptual cognition within his Pramānaviniścaya is expressed in a manner that highlights the connection between conceptuality and language. Understood in that way, a conceptual cognition is one that is "capable of being mixed with speech." ${ }^{30}$ Though Phya pa discusses both of these ways of understanding conceptuality in his 'Od zer, and argues that they are mutually inclusive, it is evident that he is inclined to promote the first characterization that

${ }^{29}$ Though not explicitly put forward as a definition of conceptual cognition, Phya pa does describe conceptual cognition in terms of apprehending concepts in the midst of his discussion of the definition of perception within the Mun sel (42a1 ff). There he states (42a3): tha snyad pa'i shes pa la grags pa'i don spyi 'dzin pa rtog pa yin la /. "Apprehending a concept" is also the definition of conceptual cognition ascribed to Phya pa by later scholars such as Chu mig pa Seng ge dpal (“chu mik pa seng gé pel," c. 1200-1270) (rNam rgyal A7a7; B9a2).

${ }^{30} \mathrm{PVin}_{\mathrm{Skt}} 1$ 7,7: abhilāpasamsargayogyapratibhāsā pratītih kalpanā; $\mathrm{PVin}_{\mathrm{Tib}} 1$ 40,8: rtog pa ni brjod pa dang 'drer rung ba snang ba'i shes pa. In his 'Od zer, Phya pa cites Dharmakīti's definition as: rjod pa dang 'dres su rung pa snang $p a$ 'i shes pa (46a5), whereas the citation in rNgog Lo's $d K a$ ' gnas $(98,7)$ attests that rNgog Lo's translation read "dang 'drer rung." This difference of phrasing, however, does not entail any difference of understanding. Phya pa also uses the phrasing "'drer rung," for instance in 'Od zer $46 \mathrm{~b} 6$ (rjod pa dang 'drer rung snang pa rtog pa'i mtshan nyid yin du chug kyang). An extensive discussion of the linguistic difficulties associated with interpreting these definitions, including the possibility or likelihood that Tibetan philosophers misinterpreted the original Dharmakīrtian definitions, can be found in Tillemans 1999: 238-240, n. 22. 
focuses on the link between conceptual cognition and its apprehended objects-namely, concepts. ${ }^{31}$

Let us call this Phya pa's mentalistic depiction of conceptual cognition; and let us label the various definitions by Dignāga and Dharmakīti instances of a linguistic depiction of conceptual cognition. To be clear, when properly understood, Phya pa believes these two depictions coincide with one another. Yet, within his Mun sel, and especially within the opening chapter of that text, Phya pa favors the mentalistic depiction of conceptual cognition: the essential feature of conceptual awareness is that it entertains concepts as its apprehended object. The presence or absence of concepts is not, however, the only difference between conceptual and non-conceptual cognition. Phya pa maintains that these two forms of cognition differ in the kinds of operations or activities that occur within these episodes. Non-conceptual cognitions consist in just a single operation-the operation of appearing. Conceptual episodes of cognition, on the other hand, standardly involve not just the operation of appearing, but also the additional operations of directing and of excluding others. ${ }^{32}$ Phya pa does not, unfortunately, provide within his Mun sel a full descriptive or explanatory account of exactly how these three mental operations function. His focus, instead, is on how these operations can be used as a means for providing nuanced assessments of whether specific forms of cognition are or are not to be considered mistaken cognitions $(\log s h e s) .{ }^{33}$

Even without full descriptions, however, it is possible to offer some partial clarification about what Phya pa believes is involved in each of these three operations. For starters, the operation of appearing consists in, not surprisingly, there being an appearance of something to awareness. This operation is present in all episodes of cognition, and this carries with it the implication that all cognitive episodes possess an appearing object - which is precisely what Phya pa calls the apprehended object (gzung yul).

\footnotetext{
${ }^{31}$ A basis for Phya pa's characterization of conceptual cognition in terms of apprehending concepts can indeed be found within Dharmakīrti's Pramānavāarttika $\left(\mathrm{PV}_{\mathrm{Skt}}\right.$ 3.287ab). There Dharmakirti links conceptuality to the apprehension of a verbal object (Skt. śabdārtha, Tib. sgra don), which, for Phya pa, is effectively the same as a concept (don spyi). See Tillemans 1999: 280, n. 27.

${ }^{32}$ See Mun sel 112.111.111 and following.

${ }^{33} \mathrm{Cf}$. IV, 4 and VI, Table D.
} 
The operation of directing (one's mind), by contrast, can only occur within conceptual cognitions because this operation, Phya pa makes it clear to his readers, necessarily involves the use of concepts. When concepts arise in one's mind, we ordinarily take those concepts to represent things in the external world. Expressed in one way, we might say that when, in conceptual cognition, a concept appears to one's mind, there is a directing of the mind toward something external. Expressed differently, we could say that in these cases a concept is conceived as having the nature of something external. So, for example, when a person infers that there is fire on a mountain pass because there is smoke, what appears to one's mind is the concept of fire. But at the same time, that inferential cognition is directed upon, or about, a real, external fire. This happens "When the arising concept of 'fire' is conceived to have the nature of an external fire..." (Mun sel 112.111.111.2). Now, of course, though the concept of 'fire' is taken to represent a real fire on a mountain pass, the concept of 'fire' is not a real fire. And so, in this respect, conceptual cognitions of this sort are said to be instances of mistaken cognition (log shes), for such cognitions conflate items (viz., the concept and the real thing) that are distinct.

Not all episodes of conceptual cognition operate in the above manner, however, for some instances of conceptual cognition involve the directing of the mind toward concepts themselves. That is, Phya pa believes that we can and do reflect on, and draw inferences about, the nature of concepts themselves. ${ }^{34}$ When this occurs, concepts are conceived to have the nature of concepts, and so this operation of directing is not mistaken at all. $^{35}$

That said, Phya pa does not actually support the view that the operation of directing (one's mind) is an essential feature of conceptual cognition, for he briefly mentions the possibility of conceptual cognitions that "are limited to the appearing of concepts" without the operation of directing one's mind or the operation of excluding others (see Mun sel 112.12). Examples of this sort involve certain meditational states, wherein one could entertain concepts, but not have those concepts be taken as being about, or representing, anything at all. Admittedly, Phya

\footnotetext{
${ }^{34}$ Note, for example, inference of form [f] in VII, Appendix 2, 7.

${ }^{35}$ One can note, however, that within the surrounding discussion Phya pa does not carefully distinguish "directing one's mind" from "directing one's mind externally."
} 
pa spends little time discussing this kind of case, and he mentions it only once in the Mun sel. ${ }^{36}$

The final cognitive operation, the operation of excluding others, is dependent on the parallel operation of directing the mind. When a conceptual cognition is directed upon some content, the cognition simultaneously excludes one from directing the mind upon some other content. For example, were I to conceive of something as 'blue,' such a cognition would exclude my conceiving of it as 'non-blue.' The operation of excluding others is important for Phya pa because this operation plays a critical role in determining which conceptual cognitions are instances of knowledge (tshad $m a$ ). The other two operations - the operations of appearing and of directing the mind - by contrast, do not play a definitive role in establishing specific cognitions as being or not being episodes of knowledge. Cognitions - including conceptual cognitions - can be "mistaken" with respect to the operation of appearing and the operation of directing and yet still be instances of knowledge. But this is not so in the case of the operation of excluding others. If, with respect to this last operation, the cognition is "mistaken," then the cognitive episode cannot be an instance of knowledge. Instead, it would be a case of a mistaken determination (log par nges pa).

That said, being unmistaken with respect to the operation of excluding others is not a sufficient condition for being an instance of knowledge. According to Phya pa, there are conceptual cognitions that not only have veridical objects, but also involve directing of the mind toward 'that which is the case' and excluding 'that which is not the case' (Mun sel 121.12), but which are not episodes of knowledge. For example, Phya pa maintains that some forms of cognition "have the criterion of countering superimpositions, in general" but do not counter superimpositions in a way that suffices for the definitional criterion for knowledge (Mun sel 212.22). That is due to the fact that they do not meet knowledge criterion $\mathrm{K} 3$ that will be described more fully in $\S 4$ below.

\subsection{Philosophical implications}

Taking a step back, let us think about some of the more important philosophical consequences of Phya pa's theory of conception. First and foremost, we cannot overstate the significance of Phya pa's invocation of

${ }^{36}$ This form of cognition is part of the ten-fold typology that Phya pa offers within his 'Od zer (28b2-3), see VI, Table G. 
a mentalistic account of conceptual cognition. Again, by this, what is meant is that, in his Mun sel, Phya pa explicitly links conceptual cognition (rtog $p a$ ) to the manifestation of concepts (don spyi), in contrast to a linguistic portrayal of conception that sees conceptual cognitions as any that are capable of being mixed with speech/language. While not denying that there are critical links between these two ways of portraying conceptual cognition, there is little question that Phya pa's mentalistic account offers a simple way by which to account for the difference between conceptual and non-conceptual cognition. In Phya pa's view, conceptual and nonconceptual cognitions can be distinguished simply by way of the kinds of objects that directly appear to awareness. Any cognition having a concept as its apprehended object is a conceptual cognition, and any cognition not encountering concepts is a non-conceptual cognition. There is, therefore, no need to appeal to more complex matters such as language or intentionality in order to distinguish these two forms of mentation.

This is not to say, of course, that there are no other differences between conceptual and non-conceptual cognitions. As shown above, it is only in conceptual cognition that there can be the operation of directing the mind and the operation of excluding others. Yet, while each of these two operations is merely a sufficient condition for conceptuality, neither is, properly speaking, a necessary condition for conceptual cognition. This is shown by the fact that Phya pa affirms the existence of conceptual mental episodes in which there is the appearance of concepts (as part of the operation of appearing) but neither the operation of directing nor the operation of excluding others. Admittedly, this special class of conceptual cognitions that possess only the operation of appearing plays little direct role in Phya pa's larger epistemological theory. (Within his 'Od zer, for example, Phya pa classifies these non-directing conceptual cognitions as being entirely distinct from the more familiar forms of conceptual cognition: inferential cognition, factive assessment, conceptual post-knowledge cognition, conceptual mistaken cognition, or doubt. ${ }^{37}$ ) Nevertheless, the inclusion of this category of conceptual cognitions shows quite clearly that the true mark of conceptuality, according to Phya pa, is rooted in the appearance of concepts and not in other operations or capacities such as intentionality.

${ }^{37}$ These forms of cognition are taken up in $\S 5$ below. For more detail on these types of awareness, see also Mun sel 122 and following, as well as IV. 
This brings us to another important observation about Phya pa's theory of conceptual cognition. On his account, it is important to distinguish conception from items such as 'reasoning' and 'intentionality.' It is true that reasoning requires conceptuality, but not all conceptual cognitions involve the use of reasoning. Here, by 'reasoning' what is meant is any activity whereby a cognizer appeals to reasons or evidence as a means for affirming some state of affairs. Reasoning of this sort occurs in cases of inferential knowledge, but (as will be discussed below) it could also take place in episodes of factive assessment and even (conceptual) mistaken cognition. In each of these forms of cognition, concepts are apprehended and the operations of directing and excluding others occur. Importantly, however, these sorts of activities are not deemed by Phya pa to be essential to conceptual cognition.

Likewise, conceptual cognition does not necessarily entail, on Phya pa's account, the presence of intentionality. Here, by intentionality, what is meant is the 'aboutness' or 'directedness' of cognitions. In the context of Western philosophy, what is now commonly termed "Brentano's thesis" is the assertion that intentionality is the mark of the mental. ${ }^{38}$ In the Buddhist context, we might re-express Brentano's thesis as the claim that all (and only) cognitions have intentionality. If we understand intentionality to be wed to the presence of the operation of directing, then it straightforwardly follows that Phya pa must reject Brentano's thesis.

There are good reasons to think that all cognitions having the operation of directing also possess intentionality. The operation of directing is the process whereby one's awareness is directed upon some content. In doing so, the person conceives of things as being a certain way. For example, when inferring the existence of a fire on a mountain pass, a person conceives of the aggregate of 'mountain pass' and 'fire,' and in so doing one's cognition is directed toward (or 'about') the nature of a real fire. In this regard, it is beyond question that, for Phya pa, all cognitive episodes for which there is the operation of directing (and, a fortiori, the operation of excluding others) possess intentionality. ${ }^{39}$

${ }^{38}$ See Brentano 1874 and its English translation, Brentano 1973.

39 The object that a person's cognition is directed toward is, for Phya pa, the cognition's intentional object (Tib. zhen yul). To call this the intentional object is, for Phya pa, simply to say that it is "what the mind is directed toward" (Mun sel 121.12). To be clear, as employed by Phya pa, the Tibetan expression zhen yul does not pick out any specific kind of entity from an ontological perspective. (Specifically, intentional objects need not be any sort of ontologically shadowy 
But while, in Phya pa's system, the presence of the operation of directing is certainly a sufficient condition for intentionality, it is far from obvious whether it is a necessary condition. Brentano's thesis would have us affirm that even non-conceptual cognitions - for which there is merely the operation of appearing - have intentionality. To be sure, on Phya pa's model of awareness each and every non-conceptual cognition apprehends an object, and this might be taken as grounds for asserting that these nonconceptual cognitions are directed upon or about something - their apprehended objects. Is this relationship between a cognitive episode and its apprehended object indicative of intentionality?

The totality of the evidence, I believe, points away from the conclusion that non-conceptual cognitions possess intentionality on Phya pa's account. As we saw above in the section on perceptual experience, Phya pa's position is that perception does not involve the presence of representations or aspects (rnam pa). Far from possessing the operation of directing, perceptual cognitions are non-representational. Such a view is different from what is observed in many of Phya pa's Buddhist epistemological predecessors. Dharmakirti, for example, maintains that in perception it is representations of real particulars (which are imprinted on the mind) that

mental entities.) In this way, Phya pa's use of the term zhen yul parallels his use of the term gzung yul (apprehended object). There is nothing ontologically distinct that makes something an apprehended object. What makes something an apprehended object is just that it is the object that appears to the mind and that is associated with what Phya pa calls the "operation of appearing" (Mun sel 112.111.111.1). Likewise, what is called an "intentional object" is simply whatever the mind is directed toward by virtue of the operation of directing.

In this regard, the view is similar to that endorsed by numerous contemporary philosophers. See, for instance, Searle 1983, chapter 1 and Crane 2001a, chapter 1. For more on the translation of zhen yul as "intentional object" see Stoltz 2013 and forthcoming. The latter work takes up these matters in much further detail, including an examination of the relationship between intentionality and "accuracy conditions."

This account carries the consequence that, for Phya pa, there can be cases where the intentional object of a given cognition does not exist. When a person, in an episode of mistaken determination, wrongly believes, for example, that there is a fire on the mountain pass, the intentional object simply does not exist, since there is no fire on the mountain pass. (In this case, technically, the intentional object would be the aggregate of 'mountain pass' and 'fire,' but given that this is a mistaken cognition there is no such aggregate in the external world.) 
are apprehended. ${ }^{40}$ Matters are understood differently in Phya pa's theory, for he contends that real particulars are directly experienced. Moreover, as was expressed earlier, perceptual cognitions are, in part, constituted by the objects that are apprehended. As such, on Phya pa's naïve realist theory of perception, it is possible to regard these non-conceptual mental states as being devoid of intentionality. A similar position is adopted by proponents of disjunctivism within the contemporary analytic tradition of philosophy. Bill Brewer, for example, proposes that defenders of disjunctivism reject the (widely-supported) 'content view' of experience, and instead support what he calls an 'object view. ${ }^{41}$ The object view dispenses with the intentionality of perception by maintaining, in its place, that perceptions are constituted by the real, external objects that are perceived. A similar position appears to be adopted here by Phya pa. On his account, perceptual experiences are constituted by their appearing objects, but have no representational content. In turn, there is little support for the conclusion that non-conceptual cognitions possess intentionality at all within Phya pa's theory. Instead, intentionality is to be restricted to cognitive episodes for which there is the operation of directing.

\section{Knowledge}

\subsection{The defining characteristics of episodes of knowledge}

Phya pa defines perception as "being non-erroneous with respect to the apprehended state of affairs" (Mun sel 231.11). This carries the implication that whether some cognitive episode qualifies as an instance of perception is a function of the cognition's apprehended object (gzung yul). Being an episode of knowledge, on the other hand, is not determined by the cognition's apprehended object. It is, rather, linked to a cognition's engaged object ('jug yul). Establishing this very point is a main goal of

\footnotetext{
${ }^{40}$ See Dreyfus 1997a, chapter 19 and Dreyfus\&Thompson 2007: 102-103. This description pertains to the (Sautrāntika) representational external realism that Dharmakīrti ordinarily endorses. In some cases, however, Dharmakīrti shifts to a version of (Yogācāra) representational idealism, wherein he dispenses with the claim that the aspects or representations are caused by real particulars in the external world. On the representational idealist model, the representations are generated instead by 'traces' within one's own mental continuum.
}

${ }^{41}$ Brewer 2008 and Brewer 2011. 
the series of passages contained within section 121 of Phya pa's Mun sel. Engaged objects are cognitive objects for which superimpositions have been excluded (Mun sel 121.13). This is in contrast to apprehended objects, which are identified as simply what appears for a given cognition (Mun sel 121.11).

What this shows is that, although Phya pa's first chapter begins with a long categorization of cognitions as related to apprehended objects, that categorization cannot possibly yield an adequate philosophical account of knowledge itself. One necessary condition for some episode of awareness to be an instance of knowledge is that the cognition excludes/eliminates superimpositions. As such, accounting for knowledge requires an appeal to engaged objects, which is precisely what Phya pa undertakes in the second half of his first chapter of the Mun sel.

Phya pa's stated definition for an episode of knowledge (tshad ma) is (Mun sel 212.14):

that which counters the capacity to produce superimpositions that are incompatible with the way things are, through aspects of awareness that are non-erroneous with regard to a positively discerned state of affairs.

This definition is often abbreviated, by Phya pa, to the much simpler form "understanding something veridical" (bden pa rtogs pa), a phrasing that derives from the Kashmiri thinker Śankaranandana (c. $9^{\text {th }}-10^{\text {th }}$ century).

In his 'Od zer, Phya pa expresses the definition of a knowledge episode a bit differently from how it is phrased in the Mun sel. His definition in the 'Od zer is: ${ }^{42}$

that which, for a veridical state of affairs not previously known, is incompatible with opposite superimpositions, by a mode of apprehension that is non-erroneous with regard to its state of affairs.

Though the wordings of these definitions are different, and though there may be subtle changes in Phya pa's thinking between the compositions of these two texts regarding how best to capture the necessary conditions for knowledge, I shall proceed under the assumption that Phya pa's definitions are to be viewed as equivalent (i.e., that the two definitions are

42 'Od zer 23b1: des na tshad ma'i mtshan nyid ni sngar ma rtogs pa'i don bden pa la don la myi 'khrul ba'i 'dzin stangs kyis bzlog pa'i sgro 'dogs dang 'gal ba yin no //. See VII, Appendix 3, 1 for other formulations of the definition of knowledge episodes in Phya pa's works. 
meant to pick out identical classes of cognitive episodes as satisfying the definition of knowledge). ${ }^{43}$

The three core elements of the latter definition (from the 'Od zer) can be found within the Mun sel in a number of places. They are found together, for example, within Phya pa's elucidation of engaged objects. There, he notes that both perceptual and inferential knowledge episodes are capable of excluding superimpositions, and then he points out that these two forms of cognition share three features in common (Mun sel 121.13):

(K1) The elimination of superimpositions

(K2) With regard to a state of affairs not previously known

(K3) By an apprehension that requires an invariable relation to the state of affairs

Phya pa appeals to the first criterion (K1) to show why episodes of nonascertaining perception (snang la ma nges pa) and doubt (the tshom) are not instances of knowledge (Mun sel 212.22). He appeals to a version of the second criterion so as to distinguish post-knowledge cognition (bcad pa'i yul can) from other types of awareness (Mun sel 123.321), and to show why it is not a kind of knowledge (Mun sel 212.14, reply to second objection). And he appeals to the third criterion to show why mistaken cognition (log shes) and factive assessment (yid dpyod) are not instances of knowledge (Mun sel 212.22).

Using the above account as a model, we can thus characterize Phya pa's definition of knowledge episodes as consisting of three necessary conditions which, when jointly satisfied, are sufficient for knowledge. K1 can be called "the superimpositions criterion," K2 can be thought of as "the novelty criterion," and K3 can be called the "mode of apprehension criterion." 44

\footnotetext{
${ }^{43}$ For more on the differences in Phya pa's formulations of the definition of a knowledge episode between the Mun sel and 'Od zer, see I.2, 3.1 and (especially) 3.2 .

${ }^{44}$ Subsequent authors within the Tibetan epistemological tradition call these three characteristics (K1) the essence (ngo bo), (K2) the characteristic of the object (yul gyi khyad par), and (K3) the characteristic of the mode of apprehension ('dzin stangs kyi khyad par). See Hugon 2011a: 15-16 and, in this volume, I.2, 3.3.
} 


\subsection{Philosophical implications}

With this framework in mind, let us now examine how Phya pa's criteria for knowledge compare with contemporary philosophical discussions of the necessary and sufficient conditions for knowledge. Of the three criteria, the one requiring novelty, $\mathrm{K} 2$, is certainly the furthest from any requirement adopted by contemporary analytic philosophers. The idea that one does not possess knowledge unless the proposition believed is not already known is something that makes little sense within contemporary Western theories of knowledge. On these Western accounts, knowledge is viewed as founded upon beliefs, which are generally treated as dispositional states of an individual. A person may have knowledge of some proposition, where that knowledge persists continuously from, let's say, age five until age eighty. In the Buddhist epistemological tradition within which Phya pa is situated, by contrast, what are at issue are occurrent episodes of cognition. Knowledge is treated as a kind of momentary mental episode, where successive mental episodes form an ever-changing stream of awareness. ${ }^{45}$ Given this very different understanding of the basis of cognition, it makes much more sense on the Buddhist model to restrict knowledge just to those cognitive episodes in which some new information is gained.

\subsubsection{The mode of apprehension criterion}

Much more relevant to contemporary philosophical accounts of knowledge are the other two criteria to which Phya pa appeals. Let us first consider the criterion requiring the right mode of apprehension (K3). This requirement restricts episodes of knowledge to just those cases in which a person's cognition bears an "invariable relation to the state of affairs" cognized. ${ }^{46}$ Here, what is specifically meant by an "invariable relation" is that the cognition would not have occurred if the state of affairs had not been veridical. In order for a cognition to be an instance of knowledge it must not merely be the case that one's episode of cognition is "correct" (i.e., in accord with the state of affairs), it must also be the case that, counterfactually, had the relevant state of affairs not been the case, then no such cognition of that state of affairs would have occurred.

\footnotetext{
${ }^{45}$ For more on this, see Stoltz 2007.

${ }^{46}$ See Mun sel 121.13 and 212.22.
} 
In contemporary parlance, this amounts to a sensitivity criterion for knowledge ${ }^{47}$ It is argued by some philosophers that, over and above having a true belief, knowledge requires that one's beliefs "track" the truth, where one way by which to understand truth-tracking is in terms of a sensitivity condition on knowledge. Standardly, this means that the following counterfactual must be true in order for $\mathrm{S}$ to know that $p$ :

(SENS) If $p$ were not true, $\mathrm{S}$ would not believe that $p$.

Phya pa's mode of apprehension criterion plays a role analogous to the sensitivity criterion above. In order for a cognitive episode to be an instance of knowledge, the cognition must not only be correct, it must also track its state of affairs in such a way that had the state of affairs not existed, the cognition would not have arisen. ${ }^{48}$

As noted in the preceding section, Phya pa states that both factive assessment and mistaken cognition fail criterion K3. The case of mistaken cognition is quite clear. Episodes of mistaken cognition cannot have an invariable relation to the actual state of affairs - that is, they are not sensitive to the truth-for the trivial reason that such episodes of cognition are mistaken. Stated in propositional terms (as could be appropriate for instances of conceptual mistaken cognition), they are cognitions that determine something that is incorrect. Non-conceptual mistaken cognitions, on the other hand, have as their apprehended objects items that are superimposed, and thus those cognitions do arise without a state of affairs to be apprehended being existent. Expressed differently, all episodes of mistaken cognition fail SENS simply because they are cases where the antecedent of SENS is true but its consequent false.

The case of factive assessment is less straightforward. All episodes of factive assessment involve a conceptual determination that "corresponds with the object to be cognized" (Mun sel 123.31), and, as such, they are cognitions that in fact affirm a veridical state of affairs. Yet, Phya pa contends that this type of cognition, though determining a true state of affairs,

${ }^{47}$ For more on the sensitivity restriction on knowledge, see Nozick 1981, Comesaña 2007, and Pritchard 2008. In Nozick's original 1981 publication, he contends that sensitivity requires not just that 'if $p$ were not true, $\mathrm{S}$ would not believe that $p$ ' (called SENS below), but also that 'if $p$ were true, $\mathrm{S}$ would believe that $p$.' In more recent philosophical literature, however, sensitivity is generally linked just to the truth of this first conditional, SENS.

${ }^{48}$ For more on this criterion, and its relation to sensitivity constraints on knowledge, see Stoltz forthcoming, chapter 11. 
does not have an invariable relation to the state of affairs. Thus, the contention is that though an episode of factive assessment affirms something true, it is such that (even) if the state of affairs had not been veridical, the cognition (of that state of affairs) would still have occurred.

On the face of it, this seems correct. To take a standard example of factive assessment, let us suppose that there is water in an old well, and that someone believes there to be water in that old well despite not having any evidence to support this belief (Mun sel 112.11.12). In such a case, though the person's belief happens to be correct - they have made a determination that corresponds with the actual state of affairs-it is intuitively not an instance of knowledge. Phya pa maintains that it fails to be an instance of knowledge precisely because it fails criterion $\mathrm{K} 3$, for, even if there had been no water in the old well, the person still would have believed that there was. (After all, the assessment was made without any reliance on evidence whatsoever.) Applied directly to the sensitivity criterion of knowledge, it is clear that even if a person, without evidence, correctly believes that there is water in an old well, that belief would nonetheless fail the counterfactual conditional in SENS.

The fact that Phya pa endorses something like a sensitivity criterion in order to account for why certain cognitions fail to yield knowledgeincluding cognitions that make correct determinations (i.e., cognitions that are 'true beliefs') — is remarkable in its own right. Yet, in recent years, contemporary analytic philosophy has not been kind to the sensitivity criterion. It is now widely rejected by contemporary epistemologists. Among the criticisms of sensitivity is the worry that we can construct scenarios involving true beliefs satisfying SENS in which there is still the strong intuition that knowledge is absent. In fact, I believe that a parallel problem may exist for Phya pa in connection with his contention that the inclusion of K3 (as a necessary condition for knowledge) suffices to exclude factive assessment. This, however, is a matter that is beyond the purview of this essay. ${ }^{49}$

${ }^{49}$ This concern is taken up in much greater detail in Stoltz forthcoming. To lay out the basic line of reasoning, we need to consider the third subtype of factive assessment described by Phya pa, called "Factive assessment with an uncertified reason" (Mun sel 123.31). In a genuine instance of inferential knowledge, a person knows that $\mathrm{S}$ is $\mathrm{P}$ by virtue of knowing both that that

(A) $\mathrm{S}$ is $\mathrm{R}$ (i.e., that the logical reason, $\mathrm{R}$, is a property of the subject, $\mathrm{S}$ ) and

(B) R entails P. 
(These conditions are spelled out in VII, Appendix 2, 7.4 and 7.5. (A) is what Phya pa calls the phyogs chos [Skt. pakșadharmatā] and (B) is called the khyab $p a$ [Skt. vyāpti].) We might represent this logically with the following argument:
1. $\mathrm{K}(\mathrm{S}$ is $\mathrm{R})$
2. $\mathrm{K}(\mathrm{R}$ entails $\mathrm{P})$
3. $\therefore \mathrm{K}(\mathrm{S}$ is $\mathrm{P})$

In the third subtype of factive assessment, however, one of the above two characteristics - (A) or (B) or both - are not known, but are instead only themselves determined via an episode of factive assessment. In other words, for this third kind of factive assessment, conditions (A) and (B) are both true, but they are not both known to be true.

Now, consider a case like this where a person knows (A) but only determines (B) through factive assessment. For example, let us suppose that the person knows that 'there is smoke on the mountain pass' but only factively assesses that 'wherever there is smoke there is fire' (Re: VII, Appendix 2, 7[a]). In such a case, Phya is committed to the view (correct, in my estimation) that the person's determination that 'there is fire on the mountain pass' is itself thus only an instance of factive assessment. In short:

$$
\begin{array}{ll}
1 * & \mathrm{~K}(\mathrm{~S} \text { is } \mathrm{R}) \\
2^{*} . & \mathrm{FA}(\mathrm{R} \text { entails } \mathrm{P}) \\
3^{*} . & \therefore \mathrm{FA}(\mathrm{S} \text { is } \mathrm{P})
\end{array}
$$

Given the status of $\left(2^{*}\right)$, the cognizer's determination that 'there is fire on the mountain pass' can, itself, only be an instance of factive assessment. Thus far, Phya pa's analysis seems quite reasonable.

Yet, in a case like this, the person's belief/determination that 'there is fire on the mountain pass' would in fact have an 'invariable relation' to that state of affairs. This is because, if ' $\mathrm{S}$ is $\mathrm{P}$ ' were not the case, the person would not have formed the cognition (would not have made the determination) that ' $\mathrm{S}$ is $\mathrm{P}$.'

Why is that? In one respect it is because $\left(1^{*}\right)$ and $\left(2^{*}\right)$ are logically incompatible with the falsity of ' $\mathrm{S}$ is $\mathrm{P}$.' Consider: if $\left(2^{*}\right)$ were true and ' $\mathrm{S}$ is $\mathrm{P}$ ' were false, this would logically imply that ' $\mathrm{S}$ is not $\mathrm{R}$,' and so (1*) could not be true. More intuitively, the idea is as follows: if 'there is fire on the mountain pass' were not the case, then this counterfactual assumption combined with the person's factive assessment that 'wherever there is smoke there is fire' would entail that there could be no smoke on the mountain pass. But if that had been the case, then the person simply would not have formed the determinate judgment in $\left(3^{*}\right)$, i.e., the determination that there is fire on the mountain pass. After all, in this kind of case, the person only made that determination, $\left(3^{*}\right)$, because they knew that there was smoke on the mountain pass-i.e., because $\left(1^{*}\right)$ was true. Thus, in this kind of case (viz., instances of factive assessment with an uncertified reason), the person's cognitive episode is indeed sensitive to the state of affairs in question. Yet, it is also not supposed to be an instance of knowledge. 


\subsubsection{The superimpositions criterion}

The final criterion for a knowledge episode, K1, the superimpositions criterion, is the one that is the most distinctive to Phya pa's theory of knowledge, and also, perhaps, the one that sounds the most obscure when compared to contemporary philosophical accounts of knowledge. The idea that one's cognitions should exclude (or should be incompatible with) false superimpositions is something that one does not explicitly encounter in contemporary Western formulations of knowledge. So too, within the Buddhist epistemological tradition, appealing to the notion of superimpositions in one's definition of knowledge is something that sets Phya pa's theory apart from his predecessors. In particular, Buddhist philosophers prior to Phya pa would have had a difficult time accepting the idea that non-conceptual cognitions could exclude or eliminate superimpositions. Yet, Phya pa insists that this elimination of superimpositions can and does happen in perceptual cognitions, and that this criterion serves to distinguish perceptual knowledge (mngon sum tshad ma) from non-ascertaining perception (snang la ma nges pa).

Perhaps the closest parallel to the superimpositions criterion in contemporary analytic epistemology is the appeal to a condition involving "relevant alternatives." It is now commonly thought that in order for a person to know that something is, for example, a canary, one must know that it is not a goldfinch, not a yellow grosbeak, etc. Similarly, in order to know that something is made of silver, it seems that one must be able to distinguish silver from, for example, mother-of-pearl. More generally, it is appealing to maintain that one necessary condition for knowledge is that the agent is able to rule out relevant alternatives. The inability to distinguish one kind of object or state of affairs from others that are relevantly associated with it suggests that one doesn't actually know that the object or state of affairs in question is the one that actually obtains. Phya pa's invocation of the superimpositions criterion as a necessary condition for knowledge can be seen as an early version of the relevant alternatives requirement found in contemporary formulations of knowledge.

In many respects, Phya pa's account of how K1 works is more detailed and nuanced than what we find in contemporary epistemological appeals to relevant alternatives. As documented in the second part of the introduction (I.2, 3.1.4), Phya pa provides a step-by-step explanation of how superimpositions are eliminated within certain episodes of perception. By contrast, many contemporary epistemologists make only vague appeals 
to the idea that having knowledge requires being able to discriminate the true state of affairs from incompatible, alternative states of affairs; and little emphasis is placed on how that power of discrimination is supposed to work. Nevertheless, the shared intuition that a person cannot have knowledge unless he or she is able to discriminate the actual state of affairs from incompatible alternatives is an incredibly interesting one.

Phya pa's claim that superimpositions need to be eliminated in order for a cognition to be an instance of knowledge is different from "relevant alternatives" formulations in one important respect, however. The very idea of relevant alternatives in contemporary analytic epistemology is employed specifically so as to call attention to the contrast between alternative states of affairs that are relevant to the actual state of affairs and those alternative states of affairs that are not relevant. Knowledge only requires the ability to rule out relevant alternatives, not the irrelevant ones. For instance, it could be argued that in order to know that something is a dog, one must be able to rule out relevant alternatives such as its being a wolf or a fox, but one need not rule out irrelevant, skeptical scenarios such as the possibility that one is just a brain in a vat receiving electrochemical stimulations that make one have the hallucinatory experience as of seeing a dog. ${ }^{50}$

The criterion of excluding superimpositions, as described by Phya pa, however, does not distinguish between relevant versus irrelevant contrary qualities. Instead, the idea is that, in order to know $x$, all superimpositions that are directly incompatible with feature $x$ must be eliminated. ${ }^{51}$ In most contexts, however, Phya pa speaks of eliminating the opposite superimposition. For instance, in order to have perceptual knowledge of blue, one must eliminate the superimposition non-blue.

Summarizing Phya pa's general theory of knowledge, he articulates an account in which episodes of awareness qualify as instances of knowledge provided that (K3) they sensitively track a veridical state of

\footnotetext{
${ }^{50}$ One important feature of these 'skeptical scenarios' is precisely that they are cases that cannot easily be evidentially distinguished from the actual state of affairs. By hypothesis, if a person were a brain in a vat receiving electro-chemical stimulations as of being a normal human being on Earth, one would not be in the epistemic position to recognize that fact. Thus, distinguishing between 'relevant alternatives' and these more exotic 'skeptical scenarios' is important. The claim by contemporary philosophers is that knowledge only requires ruling out - or 'excluding' — relevant alternatives, not exotic skeptical hypotheses.

${ }^{51}$ For more on this see I.2, 3.1.3.iii.
} 
affairs, (K2) they provide novel information, and (K1) they eliminate contrary superimpositions. The portions of Phya pa's text that have been translated in this book are not principally focused on this definition of an episode of knowledge (which is the topic of the second chapter of the Mun $\mathrm{sel}$ ), but that understanding of a knowledge episode is consistently lurking in the background, especially in the seven-fold account of cognitive episodes that Phya pa develops in sections 122 and following.

\section{The seven-fold typology of awareness}

Following the standard Indian Buddhist model, Phya pa endorses the position that there are two types of awareness that are episodes of knowledge (pramāna, tshad ma): perceptual knowledge (mngon sum tshad $\mathrm{ma}$ ) and inferential knowledge (rjes dpag tshad ma). Perceptual knowledge is inherently non-conceptual, whereas inferential knowledge essentially involves conceptuality. Yet, there are numerous other forms of cognition that fall short of being episodes of knowledge for one or more reasons. In particular, each of the three criteria for knowledge that Phya pa endorses- $\mathrm{K} 1, \mathrm{~K} 2$, and $\mathrm{K} 3$ - can fail to be satisfied in some given episode of awareness. Phya pa devotes the last portion of the first chapter of the Mun sel to an elucidation of the five forms of awareness that fail to meet one or more of the three criteria for being an episode of knowledge (Mun sel 123 and following). These five types of awareness that are not episodes of knowledge are: ${ }^{.2}$

1. Non-ascertaining perception (Mun sel 123.1)

2. Post-knowledge cognition (123.2)

3. Factive assessment (123.3)

4. Mistaken cognition (123.4)

5. Doubt (123.5)

Two forms of awareness, doubt and mistaken cognition, fail basic requirements for knowledge. In the case of doubt, such episodes fall short of being instances of knowledge due to their not being partial to a unique state of affairs. They positively discern a state of affairs, but not in a way that delimits the awareness to one state of affairs set apart from that which is directly incompatible with it. For example, Phya pa tells us that one

${ }^{52}$ A detailed discussion of the origins, meanings, and English translations for these five types of cognition can be found in IV. 
might entertain the thought, "Is this permanent or impermanent?"53 Intuitively, the idea seems to be that some episodes of cognition fall short of knowledge because - far from satisfying conditions K1, K2, and K3they do not even engage a unique state of affairs. This sort of case could be likened to, in the contemporary analytic tradition of epistemology, instances of cognition that fail even to meet the threshold of being a belief (where beliefs are understood as cognitive states that affirm the truth of a statement or proposition).

Likewise, mistaken cognition falls short of being an instance of knowledge due to the fact that this form of awareness, while it does positively discern a unique state of affairs, does so incorrectly. In particular, it discerns a state of affairs without being in accord with its object to be cognized. With respect to the three criteria for knowledge, these are cases where the awareness falls short of knowledge because the truth-tracking criterion, $\mathrm{K} 3$, is not met-for the trivial reason that the awareness is not even veridical with respect to its object to be cognized. Importantly, Phya pa defends the view that there are two different types of mistaken cognitions. Some cognitions are mistaken with respect to their apprehended objects, and some are mistaken with respect to their intentional objects. As has been mentioned above ( $\$ 4.1)$, whether some episode of awareness is an instance of knowledge is not determined by the status of the cognition's apprehended object. So, for example, Phya pa endorses the position that all conceptual cognitions are mistaken with regard to their apprehended objects. Yet, conceptual cognitions can still be instances of knowledge. In the case of conceptual cognitions, the relevant necessary condition for knowledge is that the cognition be unmistaken with respect to its engaged object, which in conceptual episodes is the same as the cognition's intentional object. (Conceptual cognitions that are mistaken with regard to their intentional objects would automatically fail condition $\mathrm{K} 3$. This is because they do not track a veridical state of affairs and, as such, could not have veridical engaged objects.) On the other hand, in the case of non-conceptual awareness, being unmistaken with respect to its apprehended object is a necessary condition for knowledge, and it is a sufficient condition for being an episode of perception, but it is not a sufficient condition for being an episode of perceptual knowledge. (Such perceptions must additionally satisfy conditions K1 and K2 in order to be instances of knowledge.) This marks a major departure from the earlier

\footnotetext{
${ }^{53}$ See Mun sel 123.51.
} 
views of earlier thinkers like Dignāga and Dharmakīti, for whom perception simpliciter is an episode of knowledge.

More philosophically interesting are the other three types of awareness that are not instances of knowledge. These forms of mentationnon-ascertaining perception, post-knowledge cognition, and factive assessment-share two key features in common: they all positively discern a unique state of affairs (unlike doubt) and they are all veridical cognitions (unlike mistaken cognition). Nevertheless, each of these fails to be an instance of knowledge because of failing one of the three criteria discussed in $\S 4$ above. Non-ascertaining perception fails criterion K1; post-knowledge cognition fails criterion K2; and factive assessment fails criterion K3. These three types of cognition are important historically for they are largely without precedent in the Indian Buddhist tradition of epistemology (see IV , 1-3 for further details). That is, they are not categorized as distinct forms of awareness in the Indian tradition. This is so despite the fact that many of the illustrations Phya pa uses to exemplify these three forms of cognition are ones that appear in Indian texts, where they are used to exemplify episodes of awareness failing to qualify as knowledge. While there is evidence that Phya pa was not himself the originator of these three categories of cognition, it is of note that his three preferred criteria for knowledge episodes are explicitly articulated in a way that exposes precisely why non-ascertaining perception, postknowledge cognition, and factive assessment should be seen as distinct and fundamental types of awareness.

Table 1: The typology of awareness in relation to the criteria of knowledge

\begin{tabular}{|c|l|}
\hline \multicolumn{2}{|c|}{ (K1) "The superimpositions criterion" } \\
(K2) "The novelty criterion" \\
(K3) "The mode of apprehension criterion"
\end{tabular}

Non-ascertaining perception is a non-conceptual form of cognition that apprehends (indeed, perceives) a veridical object, but falls short of being an instance of knowledge because it is not incompatible with the presence 
of opposite superimpositions. That is, in episodes of non-ascertaining perception, a person has a genuine perception of an object - and, in such cases, all the properties of the object are said to appear-but subjective or objective conditions make it impossible for the person to prevent superimpositions from arising. An example of a subjective condition (that prevents the elimination of superimpositions) would be a case of inattentive perception. Perhaps a person, with eyes wide open, glimpses a blue statue while deeply absorbed in one's own thoughts. Phya pa's view is that blue is perceived, but due to a lack of attentiveness the person would be unable to eliminate the opposite superimposition of the object being non-blue. An example of an objective condition (that prevents the elimination of superimpositions) is the perception of non-manifest properties, such as impermanence (see $\$ 2.3$ ). In such a case, nothing goes wrong with the perceptual cognition-impermanence is indeed apprehended by the cognizer - but knowledge of impermanence is deemed to be possible only through a subsequent act of inferential cognition, not from a mere perception alone.

Post-knowledge cognitions fail criterion K2. They can be non-conceptual-as is the case in an episode of perceiving blue that follows immediately after an episode of perceptual knowledge of blue - or they could be conceptual - as when a person forms the determinate thought "(This is) blue" after correctly perceiving blue. In both cases, the cognition of blue is correct, and in both cases the awareness is incompatible with opposite superimpositions, but the episodes of awareness are not providing novel information. ${ }^{54}$

Factive assessment is a type of conceptual cognition that is likened to inferential knowledge, but in which the sensitivity criterion for knowledge, $\mathrm{K} 3$, is not satisfied. These are cases where a person forms a correct, conceptual judgment - either with or without an appeal to a logical reason-but in which the cognition, though veridical, fails to be invariably concomitant with the true state of affairs. More loosely, and in the terminology of contemporary analytic philosophy, we could say that these cases are ones where a person forms a true belief, but where the belief in question does not sensitively track the truth. So, for example, if a person, through bad evidence (e.g., from falsely believing that there is smoke on a mountain pass, when there is in fact just a cloud of billowing dust) forms

\footnotetext{
${ }^{54}$ On the status of post-knowledge cognition and its relation to criteria $\mathrm{K} 2$ and $\mathrm{K} 1$, see n. 25 and the related discussion in I.2, 3.2.2.
} 
the true belief that there is a fire on said mountain pass, the person still has a belief that is true. But the belief does not sensitively track the truth because, counterfactually, had there been no fire on the mountain pass, the person would still have believed that there was a fire (because of their reliance on the bad evidence). Intuitively, it makes sense to say that, in such a case, the person does not possess knowledge even though they have a true belief. ${ }^{55}$

\section{Conclusion}

There are many other items of philosophical relevance that are addressed by Phya pa in the opening chapter of his Mun sel, but which cannot be adequately discussed here. Some of these items, such as Phya pa's specific account of how superimpositions are eliminated in instances of perceptual awareness (discussed at length in the second part of the introduction, see I.2, 3.1.4), are of both philosophical and historical relevance. Other items, such as Phya pa's detailed discussion of the compatibility and incompatibility between various types of cognition (Mun sel 122.3), are of slightly less historical interest - and appear not to have had a large impact on later epistemological literature - but demonstrate Phya pa's keen sense of intellectual curiosity, and his willingness to explore the philosophical consequences of his epistemological classifications.

It is my hope that, in time, many more philosophical themes developed within Phya pa's Mun sel will be addressed in detail by scholars. The translation provided here is an effort to provide others with a point of entry into the philosophical acuity of early Tibetan epistemology as contained within Phya pa's elucidation of cognition and cognitive objects in twelfth-century Tibetan philosophy.

\footnotetext{
${ }^{55}$ Illustrations of this form of cognition no doubt bear a resemblance to "Gettier scenarios" in contemporary analytic epistemology. For more on the relationship between episodes of factive assessment and the Gettier problem, see Stoltz 2007.
} 



\section{Introduction (2): Phya pa's theory of mind in the con- text of Indo-Tibetan Buddhist intellectual history}

The innovative views of the twelfth-century thinker Phya pa Chos kyi seng ge ("cha pa chö kyi seng gé,"1 1109-1169, hereafter: Phya pa) had a profound impact on the developments of Buddhist philosophy in Tibet, especially in the fields of epistemology, logic, and Madhyamaka philosophy. ${ }^{2}$ Through the centuries, Phya pa remained a prominent figure of reference in the Tibetan tradition both for his supporters and detractors, even those who had not studied his works on a first-hand basis. It is not known to what extent Phya pa's works were circulating in Tibet outside the monastery of gSang phu Ne'u thog ("sang pu neu tok"), of which Phya pa occupied the abbatial seat for 18 years. However, his epistemological works might have traveled all the way to the Tangut kingdom of Mi nyag ("mi nyak," Xixia in Chinese) between the $12^{\text {th }}$ and the $14^{\text {th }}$ century, as did some works of his predecessor rNgog Blo ldan shes rab ("ngok lo den shé rap," 1059-1109). ${ }^{3}$ In the field of epistemology, Phya pa's first-generation students already composed their own works on the subject, and

\footnotetext{
${ }^{1}$ A simplified phonemic transcription is provided in quotation marks for Tibetan personal names, as well as names of places and schools, upon their first occurrence in the body of the text and in the footnotes. The transcription follows the standards of the Tibetan \& Himalayan Library (THL).

${ }^{2}$ On Phya pa's life and works and for bibliographical references, see van der Kuijp 1978, 1983, Tauscher 1999 (ed.): vii-ix, and the information compiled in Hugon 2015-2018.

${ }^{3}$ On the spread of the gSang phu tradition to Mi nyag, see Solonin 2015: 854 and Kano 2016: 208. While a Tangut version of a work by rNgog Blo ldan shes rab entitled The Exposition of the Two Truths According to rNgog lo tsa $\mathrm{ba}$ has been located in Khara Khoto (Solonin 2015: 854) and a copy of his topical outline on the Ratnagotravibhāga (in Tibetan) was also unearthed there (Kano 2008), the possible existence of a Tangut translation of a topical outline of one of Phya pa's works on epistemology, the Mun sel, remains to be confirmed. Kano's mention of such a work is indeed based on the Chinese translation of the Tangut title in the catalogue by Tatsuo Nishida for a text found in Khara Khoto (the Shengli yia chu zhi nen lue shi), but the contents of this work have not yet been examined. This Tangut translation could be dated "to the time between the 1130s (the period in which the work was possibly composed) and 1374 (the destruction of Khara Khoto)." (Kano 2016: 208).
} 
presumably used those rather than Phya pa's works when teaching epistemology in their own monastic colleges. Whether later-generation scholars still had access to Phya pa's works is questionable. Their mention of Phya pa's views are usually paraphrases rather than literal citations. However, Phya pa's works were preserved in gSang phu Ne'u thog at least up to the $15^{\text {th }}$ century. It is probably in gSang phu that the rNying ma ("nying ma") scholar Klong chen Rab 'byams pa Dri med 'od zer ("long chen rap jam pa dri mé ö zer," 1308-1363) had access to them during his studies as a young man. ${ }^{4}$ He notably subsequently re-used (silently) substantial portions from Phya pa's doxographical work, the gZhung lugs rnam 'byed, and from Phya pa's Madhyamaka work, the sNying po, in his own doxography, the Grub mtha' mdzod. ' Gos lo tsā ba gZhon nu dpal ("gö lo tsa ba zhön nu pel," 1392-1481) also mentions in his historical work, the Deb sngon, that he had first-hand access to some of the works of Phya pa. ${ }^{6}$ Phya pa's works were still preserved in gSang phu around 1440, at the time gSer mdog pan chen Śākya mchog ldan ("ser dok panchen shakya chok den," 1428-1507) was studying there. The biography of Śākya mchog ldan by Kun dga' grol mchog ("kün ga dröl chok," b. 1507) informs us that Śākya mchog ldan studied the "phya

${ }^{4}$ Klong chen studied at gSang phu beginning at age nineteen (i.e., from 1326). His teachers in the field of epistemology included the fifteenth abbot Slob dpon bTsan dgon ("lop pön tsen gön") and the sixteenth abbot of the Upper College Chos dpal rgyal mtshan (“chö pel gyel tsen"). See van der Kuijp 2003: 403 and Mathes 2008: 455, n. 479.

${ }^{5}$ See Werner 2014: 37-40 and Hugon forthcoming (2).

${ }^{6}$ In the Deb sngon (405), gZhon nu dpal gives a list of works of Phya pa including: commentaries and summaries on the five works of Maitreya, the Pramānaviniścaya, the Satyadvayavibhanga, the Madhyamakālanikära, the Madhyamakāloka, and the Bodhicaryāvatāra, as well as an epistemological summary called Yid kyi mun sel in verses and with auto-commentary, a short and a long Madhyamaka summary, and a number of unspecified other compositions (rtsom pa mang po mdzad pa 'dra). He then remarks that he himself just saw (kho bos mthong $b a$ ) "those" (de dag) - it is unclear whether this refers only to the Madhyamaka and epistemological summaries, or to the commentaries as well-as well as a doxographical summary and an explanation on the "five bases of objects of cognition" (kho bos mthong ba ni de dag dang / phyi nang gi grub mtha' bsdus pa dang shes bya gzhi lnga'i bshad pa tsam zhig go). It is not known where he was able to see these texts. Vetturini (2007: 13-14) mentions that gZhon nu dpal studied in gSang phu but does not provide the source of this information. 
bsdus,' i.e., Phya pa's epistemological summary, in great detail during the summer teaching session in gSang phu in 1439 with Grags pa bkra shis ("drak pa tra shi"). But it does not seem to have been part of the regular curriculum at this time. Apart from this event, Śākya mchog ldan's studies of epistemology during his first stay in gSang phu focused on Dharmakīrti's Pramānavārttika and the Rigs gter of Sa skya Paṇdita Kun dga' rgyal mtshan ("sa kya pandita kün ga gyel tsen," hereafter: Sa pan, 1182-1251). Sākya mchog ldan is also reported to have later taught one of Phya pa's epistemological treatises, confronting it with another tradition of interpretation following Sa pan's Rigs gter. ${ }^{7}$ Numerous literal citations from Phya pa's works in the writings of Sākya mchog ldan confirm his first-hand access to these sources. ${ }^{8}$

It is only in the 1970s that the contribution of Phya pa was brought forward in Western scholarship. The first article published on this inventive medieval scholar by Leonard van der Kuijp (van der Kuijp 1978) already highlighted philosophy of mind as a characteristic part of Phya pa's system and as an important contribution in the history of Tibetan philosophy. In the absence of first-hand sources, the pioneering studies of Phya pa's thought relied on accounts of his views by fifteenth-century Tibetan authors, in particular Śākya mchog ldan and Go rams pa bSod nams seng ge ("go ram pa sö nam seng gé," 1429-1489). ${ }^{9}$ The rediscovery of eighteen texts by Phya pa that were published in 2006 in a collection of works of the bKa' gdams ("ka dam") school (the $b K a$,

\footnotetext{
${ }^{7}$ See Caumanns 2015: 62-64, 81, 186 and 307.

${ }^{8}$ See V, 1.5 in the present volume for some examples of citations in the epistemological domain on the topic of the typology of awareness. Sākya mchog ldan also seems to have had access to Phya pa's Madhyamaka work, the sNying po. He paraphrases Phya pa's arguments against Candrakīti found in sNying po 125.112 in his $d B u$ ma rgya mtsho. See Hugon forthcoming (2).

${ }^{9}$ In his 1978 paper, van der Kuijp relies on the account of Phya pa's typology of awareness by Go rams pa in his Rigs gter rab gsal. See also the short account of Phya pa's view, based on the same source, in Dreyfus 1997a: 373. Go rams pa's account (see V, 1.6), turns out not to correspond exactly to Phya pa's typology, in particular regarding the terminology being adopted for some of the types of awareness. Phya pa's life and ideas were further discussed in van der Kuijp 1983: chapter 2 .
} 
gdams gsung 'bum) has opened a new path for further research on this fascinating influential scholar. ${ }^{10}$

While the first part of the introduction by Jonathan Stoltz (I.1) focused on the philosophical import of Phya pa's ideas, this part aims at situating more precisely the author and his philosophy of mind in the intellectual history of Indo-Tibetan Buddhism. It highlights the originality of his views against the background of both the Indian founding treatises in the domain of epistemology and previous Tibetan contributions, and draws out the key issues that became the basis for further debate in the Tibetan tradition.

\section{Phya pa's place in the general context of Indo-Tibetan Buddhist intellectual history}

The translation of the Indian corpus from Sanskrit into Tibetan and its transmission to Tibet began in the $7^{\text {th }}-9^{\text {th }}$ centuries at the time known as the "Earlier Diffusion" (snga dar) of Buddhist teachings. It began anew from the $10^{\text {th }}$ century onward during the "Later Diffusion" (phyi dar), whose start is marked, notably, by the visit to Tibet of the Indian Buddhist master Atiśa (c. 982-1054) and the endeavors of the Great Translator Rin chen bzang po ("rin chen zang po," 958-1055). While the status of founding father for the field of epistemology and logic is usually ascribed to the

${ }^{10}$ The bKa' gdams gsung 'bum regroups rare works by bKa' gdams pa scholars (or scholars that were considered to belong to the bKa' gdams pa tradition by the editors) ranging from the $10^{\text {th }}$ to the $15^{\text {th }}$ century. These manuscripts had been preserved notably in 'Bras spungs ("dré pung"), Se ra ("sé ra"), Zha lu, and rGyal rtse dpal 'khor chos sde ("gyan tsé pel khor chö dé") monasteries, as well as in the private collections of Tibetan scholars and at TBRC/BDRC (Karma bde legs [ed.] 2006: 7-10). The texts from 'Bras spungs are part of the private manuscript collection of the Fifth Dalai Lama, Ngag dbang Blo bzang rgya mtsho ("ngak wang lo zang gya tso," 1617-1682), a fabulous collection comprising c. 3,000 bundles of texts (more than 20,000 works) that was housed in the gNas bcu tha khang ("né chu lha khang") and was rediscovered around the year 2000. The texts were catalogued between 2002 and 2003, together with those from 'Bras spungs's Mi dbang tha khang ("mi wang lha khang") (cf. 'Bras spungs dkar chag). At present, the $b K a$ ' gdams gsung 'bum comprises 120 volumes, published between 2006 and 2015. Phya pa's works are contained in the first set of 30 volumes (specifically, vol. 6-9). 
Indian philosopher Dignāga (c. 480-540), it is rather the works of Dharmakīrti (c. $600-660$ or earlier) ${ }^{11}$ that were initially instrumental for Tibetan thinkers. ${ }^{12}$ Dignāga's epistemological works do not appear to have been investigated independently before the $13^{\text {th }}$ century and did not play any significant role in the formative period of Tibetan epistemology. ${ }^{13}$

Dharmakīti's works are commonly referred to by Tibetan scholars as "the seven-fold collection" (sde bdun). Early Tibetan epistemologists divided Dharmakīti's seven works into three major treatises - the Pramānnavārttika (Dharmakīrti's commentary on Dignāga's Pramānasamuccaya), the Pramānaviniścaya, and the Nyāyabindu - and four minor ones - the Hetubindu, Sambandhaparīkșā, Vādanyāya, and Santānāntarasiddhi. ${ }^{14}$ Only the three major treatises played a significant role in Tibet. The Nyayabindu (respectively smaller than the other two major treatises)

${ }^{11}$ Krasser (2012) reopened the debate on the date of Dharmakirti, arguing that Bhāviveka (490/500-570) had knowledge of the views of the Mīmāmsā scholar Kumārila Bhatța and of Dharmakīrti, and suggested to situate their time of activity in the middle of the $6^{\text {th }}$ century.

${ }^{12}$ For a systematic overview of this corpus, see Steinkellner\&Much (eds.) 1985.

${ }^{13}$ Several of Dignāga's works were never translated into Tibetan. Dignāga's Hetucakradamaru (a short work distinguishing valid and invalid logical reasons in inferential reasoning) was already translated at the time of the Earlier Diffusion, but his major work, the Pramānasamuccaya cum vrtti, was only translated (twice) at the end of the $11^{\text {th }}$ century, and a third time around 1100 (see Steinkellner\&Much [eds.] 1985: 5 and 8, van der Kuijp\&McKeown 2013: lxxiv-lxxv). Citations of Dignāga in early epistemological treatises are usually limited to verses of Dignāga's works that are cited in Dharmakīti's works. An exception is Sa skya Pandita, who takes into account specific portions of Dignāga's works on themes not developed by Dharmakīti (see Hugon 2015b: 471, n. 47). The first exegesis of Dignāga Pramānasamuccaya written in Tibet was the one by Dar ma rgyal mtshan bCom ldan Ral gri ("dar ma gyel tsen chom den rel dri," 1227-1305) (van der Kuijp\&McKeown 2013: lxxxvi-xcv). There was a new interest in Dignāga's Pramānasamuccaya starting in the $15^{\text {th }}$ century: at least ten scholars wrote full commentaries on this work, seven to nine of which were written in the $15^{\text {th }}$ century (van der Kuijp\&McKeown 2013: lcv-cv).

${ }^{14}$ This division is made, for instance, by Phya pa's student gTsang nag pa brTson 'grus seng ge ("tsang nak pa tsön drü seng gé," ?-after 1195) and by mTshur ston gZhon nu seng ge ("tsur tön zhön nu seng gé," c. 1150-1210) (see Hugon 2008b: 64), and it is found also in the Tshad bsdus $(2,14-3,17)$. 
received a considerable amount of attention at the time of the Earlier Diffusion and was broadly distributed across the Tibetan empire, an attention that lasted up to the beginning of the Later Diffusion. ${ }^{15}$

As the periodization of Tibetan epistemology proposed by van der Kuijp (1989) highlights, the early centuries of the Later Diffusion, which constitute the "pre-classical period," are marked by the predominance of the study of the Pramannaviniścaya and its commentary (the Pramannaviniścayatīk $\bar{a})$ by the Indian scholar Dharmottara $\left(8^{\text {th }}\right.$ century). ${ }^{16} \mathrm{~A}$ shift of predominance in favor of the Pramānavārttika takes place with and after Sa pan in the $13^{\text {th }}$ century, marking the beginning of the "classical period." The "post-classical" period starts in the $15^{\text {th }}$ century and is characterized by a reappraisal of ideas developed in the pre-classical period and criticism as well as defense of Sa pan's views.

In the pre-classical period to which Phya pa belongs, the most significant contributions to the field of epistemology appear to have been achieved by scholars affiliated or associated with the monastery of gSang phu Ne'u thog in Central Tibet. gSang phu was founded in 1073 by rNgog Legs pa'i shes rab ("ngog lek pé shé rap," $11^{\text {th }}$ century) as a center for upholding the teachings of Atiśa, and as such qualifies as a proto-bKa' gdams pa institution. ${ }^{17}$ But this monastery soon became an important scholastic center emphasizing the study of Buddhist philosophy. This specialization was at odds not only with the orientation of other proto-bKa' gdams pa seats, such as Rwa sgreng ("ra dreng"), but also with Atiśa's own position regarding topics such as logic and epistemology, which he deemed useless in the Madhyamaka pursuit of realizing emptiness. ${ }^{18}$

15 See Hugon 2014: 203-205.

${ }^{16}$ Van der Kuijp distinguishes in the "pre-classical period" an "early phase" marked by the translation of the source texts and the first commentarial writings, and a "later phase" characterized by in-depth studies and exegeses of the Pramannaviniścaya, the priority of the former over the Pramanavārttika, and the emergence of an indigenous type of writing, the "Summaries" (bsdus pa).

17 The "bKa' gdams pa" was first considered a distinct school with the chief students of 'Brom ston rGyal ba'i 'byung gnas ("drom tön gyelwé jung né," 10051064), the disciple of Atiśa who founded Rwa sgreng ("ra dreng").

18 See Hugon 2016a: 306 for references to sources relevant to the question whether scholars affiliated with the monastery of gSang phu should be considered to be bKa' gdams pa. On Atiśa's position regarding logic and epistemology, see Apple 2016: 628. 
gSang phu's second abbot, rNgog Blo ldan shes rab (hereafter: rNgog Lo), paved the way for scholastic developments through his translations (or revisions of existing translations) of Indian treatises, to which he also provided outlines, concise guides, and more extensive commentaries. ${ }^{19}$ Together with Indian pandits, with whom he collaborated during his stay in Kashmir, he was in particular responsible for the Tibetan translation of Dharmakīrti's Pramānaviniścaya and its commentary by Dharmottara, the most influential works in the pre-classical period of Tibetan epistemology.

The only epistemological writings of rNgog Lo that have been recovered so far are the $d K a^{\prime}$ gnas - a commentarial work on the difficult points of the Pramānaviniścaya - and the Rigs thigs 'grel ți ka-a concise guide to the Nyāyabindutīka , Dharmottara's commentary on Dharmakirti's Nyāyabindu. ${ }^{20}$ In my opinion, rNgog Lo's composition of the second work is not so much a sign of an enduring interest in the Nyayyabind $u$ at the time of the Later Diffusion as it is a testimony of rNgog Lo's attention to the views of Dharmottara. Other Indian commentators of Dharmakīrti-notably Prajñākaragupta (c. 800) and Śañkaranandana (c. $9^{\text {th }}-10^{\text {th }}$ century) - were also influential. rNgog Lo's contributions include translations as well as concise guides and exegeses on several individual treatises and commentaries on Dharmakīrti's works by these thinkers. In the extant works of rNgog Lo, one sees him confront their diverging interpretations on difficult topics. It appears that the views of these Indian scholars were essentially known to subsequent Tibetan epistemologists through rNgog Lo's syntheses rather than from the Indian scholars' own works.

Phya pa was schooled in a lineage issuing from rNgog Lo. His initial training in the field of epistemology took place in sTod lung ("tö lung"), where Phya pa studied with rGya dmar ba Byang chub grags ("gya mar ba jang chup drak," fl. c. 1095-1135), who had himself been a pupil of Gangs pa she'u ("gang pa sheu") and Khyung Rin chen grags ("khyung rin chen drak"), two of rNgog Lo's students. ${ }^{21}$ Phya pa became directly

${ }^{19}$ On rNgog Lo's life and works, see Kramer 2007 and Kano 2016: 191-210.

${ }^{20}$ On these works, see Hugon 2014: 196-203.

${ }^{21}$ On rGya dmar ba, see van der Kuijp 1983: 60 and Sørensen\&Hazod 2017: 420, n. 25. The latter lists the relevant sources and enumerates the available information on rGya dmar ba's life and works. 
linked with gSang phu monastery later in his life, and became its sixth abbot. $^{22}$

Phya pa represents what I would like to call a second-generation model of scholarship that one can contrast to the first-generation model represented by rNgog Lo. ${ }^{23}$ A pure product of the Tibetan monastic and scholastic education, Phya pa relied on a Tibetan translation for his interpretations of Dharmakīti's Pramānaviniścaya, which was his main Indian source in the field of epistemology. ${ }^{24}$ His acquaintance with Dharmakīti's other works and the views of other exegetes of Dharmakīrti appears to be fragmentary and indirect, derived from Tibetan accounts, part of which was probably orally transmitted.

To this linguistic separation comes also a formal one. In his works that were later referred to as " $b s d u s p a$," Phya pa adopts a structure of presentation that does not strictly follow the order of the Indian texts he relies upon. He also does not directly refer to those Indian texts.

The English term "summary" is a widespread rendering of the term $b s d u s p a$ in Western scholarship. I adopt it here for the sake of readers who are familiar with this rendering, although it is not completely satisfactory. Indeed, works entitled as such or referred to as being instances of this genre are not necessarily summaries in the sense of abridged presentations. In fact, they are often not brief at all. Apart from some exceptions (such as the Tshad ma'i spyi skad, which properly qualifies as a "summary"), most of the presently extant early texts entitled $b s d u s$ pa better fit the profile of a comprehensive survey of the subject matter than that of a digest. For these, the expression $b s d u s$ pa would thus better be understood as conveying the idea of "gathering together" the topics addressed in the source texts (or at least claiming to do so, since some topics of the Indian treatises are simply left out while typically Tibetan elaborations are included). Such an idea is conveyed, for instance, in the long title of the epistemological work of another abbot of gSang phu, Chu mig pa Seng ge dpal ("chu mik pa seng gé pel," c. 1200-1270), Tshad ma sde bdun gyi

\footnotetext{
${ }^{22}$ On gSang phu's abbatial succession, see van der Kuijp 1987.

${ }^{23}$ See Hugon 2009a: 72-74 and Hugon 2014: 226. Note that the term "generation" is not used here in the strict sense of teacher-disciple chronology. I call Phya pa a "second-generation scholar" although he was not rNgog Lo's direct disciple.

${ }^{24}$ In the case of the Pramannaviniścaya, Phya pa relied on the translation by rNgog Lo, with slight but discernable revisions (see Hugon 2013a for examples of such changes).
} 
don phyogs cig du bsdus pa gzhan gyi phyogs thams cad las rnam par rgyal ba (in short, rNam rgyal), which speaks of "assembling in one place (phyogs cig du bsdus pa) the meaning of the collection of the seven treatises." One can understand in this sense " $b s d u s p a$ " in the expression "de kho na nyid bsdus pa," which is found in the title of several epistemological works. ${ }^{25}$ On the other hand, mTshur ston gZhon nu seng ge ("tsur tön zhön nu seng gé," c. 1150-1210) presents his sGron ma (a work of the same genre as Chu mig pa's rNam rgyal, which however does not use the expression bsdus pa in its title) as an "elucidation of the meaning (of Dharmakīrti's works) in few words" (sGron ma 1b8: 'dir tshig nyung pas don gsal bar bstan par bya'o), i.e., as properly speaking "summarizing" the whole of Dharmakirti's (and Dignāga's) thought. Van der Kuijp (2003: 385) proposed the rendering "epitome" for bsdus pa, and related this genre to the form of commentarial writing by this name in medieval European learning. For comprehensive treatises called $b s d u s p a$, however, an analogy with summoe might be more pertinent. ${ }^{26}$

Despite the difficulties circumscribing this genre, which for the time being I shall term "summary," a relevant distinction must be made between these summaries and commentaries (including various types of commentarial works such as concise guides and explanations of the difficult points of a treatise). Unlike commentaries, summaries present topics without directly referring to a given source text, and they organize them into a structure which is also independent from a particular source text.

\footnotetext{
${ }^{25}$ The expression de kho na nyid bsdus pa might be a reflex of the Sanskrit Tattvasamgraha (cf. van der Kuijp 2003: 381). Epistemological works including this expression in their title are, for instance: Tshad ma'i de kho na nyid bsdus pa (abbreviated here as Tshad bsdus); Tshad ma'i de kho na nyid bsdus pa'i nye bar bsdus pa (abbreviated here as Tshad nye bsdus), a work that is itself based on a treatise entitled Tshad ma sde bdun gyi de kho na nyid bsdus pa (see n. 48); Rigs pa'i snying po de kho na nyid bsdus pa gsal byed nyi ma'i 'od, a work by the Tibetan monk Jñānaśrī (bKa' gdams gsung 'bum, vol. 44, 217-247); Tshad ma'i mdo dang gzhungs lugs sde bdun gyi de kho na nyid bsdus pa rtog ge'i snying po, a work by Śākya mchog ldan (in gSer mdog gsung 'bum, vol. 18).

${ }^{26}$ In this regard, see Sweeney 2017. She characterizes the aspiration of summce as "first, to completely emancipate the subject matter, whether logical, theological, or philosophical, from the structure dictated either by scripture or authoritative sources; and second, to cover completely an entire discipline, often but not always, in summary form" and highlights its role as "a form for the systematic organization of an entire area of study."
} 
Summaries opened the way for the composition of autochthonous manuals that, in the long run, became the primary material for teaching in the introductory course of monastic study ${ }^{27}$ although the composition of commentaries (or hybrid commentaries that include numerus excursuses) was not abandoned. The pair summary/commentary is common for scholars in Phya pa's time and continues to be found in the following centuries. In the field of epistemology, Phya pa himself composed a work belonging to the genre of summary, the Yid kyi mun sel (hereafter: Mun sel), as well as a commentary on Dharmakīrti's Pramānaviniścaya (the 'Od zer). The former is typically referred to in the later tradition as "Phya pa's summary" (phya bsdus). However, this expression also refers, in a loose way, to epistemological summaries by Phya pa's successors that are representative of Phya pa's system.

In comparison with first-generation Tibetan scholars, one can yet add in Phya pa's case to the linguistic and formal separation also a distancing from the Indian sources that is both philosophical - in terms of innovating ideas and original interpretations - and exegetical — as these sources are not systematically posited as an ultimate authority on the subject. Both led to strong criticism from the more conservative scholar Sa pan in the $13^{\text {th }}$ century. Sa pan joined the input from his epistemological studies on the one hand with scholars in the lineage of Phya pa's tradition and on the other with the Indian pandit Sākyaśrībhadra (1140s-1225) (who stayed in Tibet from 1204 to 1214) and junior pandits of his entourage, initiating a competing lineage to the "rNgog lineage" (rngog lugs) which became known as the "Sa [skya pa/skya Paṇitita] lineage" (sa lugs).

The $12^{\text {th }}$ century appears to have been an extremely active intellectual period. In his works, Phya pa addresses the views of his predecessors and of contemporaneous scholars, in the majority of cases without giving their names. The identification of some of these can be achieved through other texts that cite the same views and give the names of their proponents. A precious source of information in this regard is the Tshad bsdus, an epistemological summary which, albeit ascribed to the fourteenth-century scholar Klong chen Rab 'byams pa, appears to have been composed in Phya pa's time or soon after. The so far unidentified author reports the

\footnotetext{
${ }^{27}$ See Dreyfus $1997 \mathrm{~b}$ for an overview of Tibetan monastic education and the role of root-texts, commentaries, and indigenous textbooks, focusing on dGe lugs pa ("gé luk pa") and rNying ma pa ("nying ma pa") institutions.
} 
conflicting views of various individuals on many topics, testifying to ongoing debates involving Phya pa and other scholars whose works are not extant (or who possibly did not author any written works). ${ }^{28}$ Phya pa's legacy was continued in the works of his students - in particular the members of the group of students known as the "Eight Great Lions" (seng chen brgyad $)^{29}$ - and the successive generations of scholars inspired by his epistemological system. As for the contributions of the Eight Great Lions, some of which reportedly authored works of epistemology and founded exegetical traditions of the Pramānaviniścaya, ${ }^{30}$ a single treatise of epistemology by one of them, gTsang nag pa brTson 'grus seng ge ("tsang nak pa tsön drü seng gé," ?-after 1195), is currently available: an extensive commentary on the Pramānaviniścaya (bsDus pa). Another scholar with "Lion" (seng ge) at the end of his name and the author of an extant epistemological summary (sGron $\mathrm{ma}$ ) is mTshur ston gZhon nu seng ge. His name appears in the list of the Eight Great Lions in Sākya mchog ldan's rNgog lo rol mo (5a3, p. 451) instead of gNyal (/gNyal ma) Yon tan seng ge ("nyel yön ten seng gé"). Based on this passage, Jackson (1987: 106) reports that mTshur ston had been a student of Phya pa. But mTshur ston's inclusion in this list is to my knowledge an exception and may be counted as a mistake prompted by mTshur ston's name ending with "seng ge." (Śâkya mchog ldan criticizes in the same text the anachronistic inclusion of 'U yug pa bSod nams seng ge ["u yuk pa sö nam seng gé," ?-1253] in this list, an inclusion that might likewise have been due to his name ending with "seng ge.") mTshur ston nonetheless was at

${ }^{28}$ On the Tshad bsdus, see van der Kuijp 2003. The tentative dating proposed here relies on the observation that the author of the Tshad bsdus had an extensive and precise knowledge of the various views held by Phya pa, his contemporaries, and his predecessors, but is completely silent on the innovations brought by Phya pa's direct student gTsang nag pa. Also, the work is also extremely close in structure and contents to Phya pa's Mun sel and does not display developments commonly attested in other later twelfth-century and thirteenth-century summaries (see $\$ 2.3$ below for some examples with regard to the topic of the typology of awareness).

${ }^{29}$ See van der Kuijp 1978: 356 for the standard list of the Eight Great Lions.

${ }^{30}$ Śākya mchog ldan reports that Bru sha bSod nams seng ge ("dru sha sö nam seng gé") founded an exegetical tradition in sNar thang ("nar tang") (van der Kuijp 1983: 23 and n. 62). A "summary of epistemology" (tshad ma'i bsdus pa) is ascribed to Dan bag pa (also spelled Dan 'bag pa) sMra ba'i seng ge ("den bak pa mawé seng gé") in the Tho yig (No. 11811) (van der Kuijp 1983: 69-70). 
least indirectly linked to Phya pa, as he had been a direct student of gTsang nag pa according to 1 Ho pa kun mkhyen Rin chen dpal ("lho pa kün khyen rin chen pel"), a student and biographer of Sa pan (see Jackson 1987: 115, n. 10). According to the Ngor chos 'byung (57a3-4, p. 315), he was a student of gTsang nag pa and of rMa bya Byang chub brtson 'grus ("ma ja jang chup tsön drü"), who might be identical with rMa bya rTsod pa'i seng ge ("ma ja tsö pé seng gé"), another member of the Eight Great Lions. $^{31}$

Beside the treatises of gTsang nag pa and mTshur ston, numerous other works have now fortunately become available. ${ }^{32}$ The observable family resemblance between them allows one to speak of a mainstream "rNgog lineage" or "gSang phu tradition" of epistemology. One should not, however, succumb to the illusion of a monolithic entity over the manifold individual contributions of the various authors, the in-depth study of which will occupy researchers for many decades.

\section{Tibetan typologies of awareness (blo rigs)}

In Indian Buddhist literature, discussions pertaining to mind (Skt. citta, Tib. sems) and mental factors (Skt. caitta, Tib. sems byung) and lists of the latter are typically part of the Abhidharma corpus. ${ }^{33}$ The leading figures of the epistemological school, Dignāga and Dharmakīrti, as well as their Indian commentators and successors, do not display a particular interest in discussing awareness in general. Indian epistemological treatises focus instead on the specific types of awareness that qualify as "knowledge," in Sanskrit pramāna (Tib. tshad ma). ${ }^{34}$ Arguing against

${ }^{31}$ On rMa bya, see Seyfort Ruegg 2000: Section I §4.2.

32 The bKa' gdams gsung 'bum contains 38 entries for epistemological works. They represent 36 distinct manuscripts (two of which are reproduced twice) of 34 different works (for two of the works there are two different manuscripts).

${ }^{33} \mathrm{~A}$ list of mental factors is found, for instance, in the Abhidharmasamuccaya of Asanga and in the Pañcaskandhaprakarana, a summary of Abhidharma by Vasubandhu, both of which date from c. $4^{\text {th }}-5^{\text {th }}$ century.

${ }^{34}$ In English-speaking scholarship, the term pramāna is also frequently translated as "valid cognition." Other translations such as "reliable cognition" and "instrument of knowledge" are also found. On the choice of translation in this publication, see I.1, 1, n. 3 . 
other (non-Buddhist) philosophical traditions, Dharmakīrti limits the attribution of this status to two types of awareness: perceptual knowledge (Skt. pratyakșa, Tib. mngon sum) and inferential knowledge (Skt. anumā$n a$, Tib. rjes su dpag pa). The definition of knowledge and the identification of instances of knowledge are the key issues in his main treatises. Cases that do not qualify as knowledge are discussed - especially when there is some debate about their status - and some of them are referred to by a specific term (for instance, "doubt"), but there is no attempt at establishing a systematic typology of "non-knowledge episodes" beyond the categories of pseudo-perception and pseudo-inferential cognition. For instance, conceptual cognitions that are derived from improper logical evidence and thus fail to qualify as inferential knowledge are discussed in reference to the faults pertaining to the putative logical evidence-one thus finds in Dharmakirti's works a typology of improper logical evidence (see VII, Appendix 2.6) - and all fall within the general category of pseudo-inferential cognition. They are thus presented as cases that fail to qualify as proper inferential cognition rather than as cases that fail to qualify as knowledge. The same is true of the instances of pseudo-perception.

Tibetan epistemologists preserved in their works the pre-eminence of the investigation of episodes of knowledge, but one also witnesses novelties. Tibetan authors expand the scope of the discussion to a general investigation of awareness in relation with different kinds of objects. Further, they engage in a detailed discussion of episodes of awareness that do not qualify as knowledge, leading to a typology consisting of a closed

Modern scholars frequently use the expression pramānavädin to refer to Buddhist thinkers writing on epistemology, and pramānavāda to refer to the subject matter of the works. This use is not grounded in the Indian tradition. However, my colleague Alessandro Graheli informed me that the related term prāmānyavādin is used in the Nyāyamañjari of Jayanta Bhatța (c. $9^{\text {th }}$ century), a Kashmiri philosopher of the Nyāya school, to refer to Buddhist opponents. But according to Graheli, the term does not seem to be a general epithet denoting Buddhist epistemologists. Rather, Jayanta's usage seems dictated in the two relevant passages by the immediate context.

In Tibetan, tshad ma (the term that translates the Sanskrit pramāna) refers (among other things) to "knowledge" and, metaphorically, to the epistemological school founded by Dignāga and Dharmakīrti (see Jackson 1994: 88). The twelfthcentury scholar rGya dmar ba also reports the figurative use of the term tshad ma to refer to an epistemological treatise ( $d B u$ ma de kho na nyid 2a4: tshad ma'i bstan chos la tshad ma zhes pa). 
set. The definition of knowledge, the very legitimacy of the types being distinguished as instances of awareness that do not qualify as knowledge, as well as their respective definitions, become the subject of subsequent debates.

These innovative aspects in the Tibetan treatment of the topic are well represented in the first chapter of Phya pa's Mun sel, entitled "The elucidation of the divisions of awareness" (blo'i dbye ba nges pa), which deals with awareness in general. A parallel discussion is located in Phya pa's commentary on Dharmakīrti's Pramānaviniścaya ('Od zer), in an extensive excursus induced by the exegesis of the beginning of the first chapter of the Pramānaviniścaya (see V, 2).

While the formal classification of episodes of awareness that do not qualify as knowledge appears to be of Tibetan origin, it does not begin with Phya pa himself. Phya pa is building on a typology and definitions of the respective types that predate him, and he is involved in dialogue (or one might say, in debate) with other contemporaneous scholars who adopt alternative definitions.

\section{1 rNgog Lo's typology of awareness}

The earliest occurrence attested so far in Tibetan literature of a typology of awareness is found in the two available epistemological treatises of rNgog Lo ( $\mathrm{dKa}$ ' gnas and Rigs thigs 'grel ți $\mathrm{ka}$ ). rNgog Lo lists five types of awareness that are not knowledge (tshad ma ma yin pa'i blo lnga): ${ }^{35}$

- non-ascertaining perception (snang la ma nges pa)

- post-knowledge cognition (bcad pa'i yul can)

- mistaken cognition (log shes)

- factive assessment (yid dpyod)

- doubt (the tshom)

rNgog Lo also subsumes these five types within three categories: nonascertaining perception and post-knowledge cognition within the category of non-understanding ( $m a$ rtogs); mistaken cognition and factive

${ }^{35}$ The mention of a five-fold typology of episodes of awareness that are not knowledge in rNgog Lo's $d K a$ ' gnas was first noted in van der Kuijp 2003: 398. The corresponding passage is discussed in van der Kuijp 2009: 219. The relevant portions of both of rNgog Lo's works are investigated in detail in Hugon 2014. On these five categories, see the relevant portions of Phya pa's work edited in III, 2 and translated in II. Additional information is provided in IV. 
assessment within the category of mistaken understanding (log par $r t o g[s] p a) ;{ }^{36}$ and doubt as a third category.

I argue in my study of the relevant passages of rNgog Lo's two works (Hugon 2014) that the five-fold typology is a by-product of rNgog Lo's work of translation-cum-exegesis. More precisely, it was inspired by passages located in the Nyāyabinduțīka and the Pramānaviniśsayațīka , two commentaries by Dharmottara on, respectively, the Nyayabindu and the Pramānaviniścaya by Dharmakīti. rNgog Lo contributed to translating these works of Dharmakīti and Dharmottara into Tibetan (he revised an existing translation in the case of the Nyāyabindu). He also composed a concise guide to the Nyāyabindutīk $\bar{a}$ (the Rigs thigs 'grel ti ka) and included Dharmottara's interpretation in his explanation of the difficult points of the Pramannaviniścaya (the $d K a^{\prime}$ gnas). rNgog Lo identifies the situations discussed by Dharmottara as instances of distinct types of awareness that are not episodes of knowledge, and coins a new technical term for some of these types of awareness. ${ }^{37}$ In my opinion, rNgog Lo is not applying, in his analysis of Dharmottara's works, a typology that was pre-established independently. Rather, such a typology is generated in the process of analyzing and translating Dharmottara's works and is then applied to comment on these works. rNgog Lo discusses Dharmottara's position with respect to this typology as if it was a typology used by Dharmottara himself. He presents his own view using the same framework, pointing out his disagreement with Dharmottara regarding the relation between some of the types.

A similar process is at play for other concepts in rNgog Lo's discussion on knowledge, concepts that become key elements in the Tibetan epistemological tradition. It is worth mentioning here the distinction of various types of objects and the analysis leading to the identification of the object of knowledge, which are instrumental in Phya pa's typology of awareness (see Mun sel 12 and VI, Tables A, B, and C). The distinction between the apprehended object ( $g z u n g y u l$ ) and the engaged object ('jug $y u l$ ) and the analysis of their partial overlap is already found in rNgog Lo's $d K a^{\prime}$ gnas $(30,13-20)$. It occurs there as part of the presentation of

\footnotetext{
${ }^{36}$ On the orthography $\log r t o g s$ found in rNgog lo's works for this category, see Hugon 2014: 215, n. 63 and 234, n. 84.

${ }^{37}$ In particular, one witnesses the unprecedented use of the Tibetan technical terms yid dpyod, bcad pa'i yul can, and snang la ma nges pa.
} 
Dharmottara's position. ${ }^{38}$ In the 'Od zer, Phya pa similarly includes this analysis in the presentation of Dharmottara's position ('Od zer 111.221.1.A2, 20b8-21b7). Like in the case of the five-fold typology of episodes of awareness that are not knowledge, rNgog Lo explains Dharmottara's position by using concepts that are derived from Dharmottara's texts, via the lens of his (rNgog Lo's) interpretation of these texts. That this is not properly speaking Dharmottara's position in Dharmottara's own terms is patent: One does find in Dharmottara's writings (in particular, the Pramānaviniścayațīk $\bar{a}$ and the Laghuprāmānyaparīkṣā) a concern regarding the identification of the object of knowledge among different kinds of objects. But Dharmottara limits this distinction to the objects associated with episodes of knowledge, and he focuses on the difference between the apprehended object (gzung $y u l$ ) and the intentional object (zhen pa'i yul) (which, according to Dharmottara, perceptual knowledge also has), rather than the apprehended object and the engaged object ('jug $y u l){ }^{39}$

In view of the connection between rNgog Lo's work of translation and analysis and the delineating of the types of episodes of awareness that are not knowledge, there is ground to assume that the five-fold typology of such episodes originated with rNgog Lo. A possible influence of the Kashmiri environment in which he studied and translated the relevant texts should not be neglected, but unfortunately this is presently undocumented. These categories and the associated terminology took on a life of their own in Tibetan epistemology and became used as conceptual tools quasi-independently of the Indian background from which they emerged.

\subsection{The definitional criteria of knowledge and the types of awareness that are not knowledge}

When presenting his own view and his interpretation of Dharmottara, rNgog Lo essentially discusses the types of awareness that are not knowledge in terms of the features involved in the definition of knowledge that they fail to illustrate. In Phya pa's works and later works, their definition also reflects the criteria applied to distinguish from one

\footnotetext{
${ }^{38}$ The long section on Dharmottara's position is located in $d K a^{\prime}$ gnas 17-33. rNgog Lo's account is reported by Śākya mchog ldan in Pham byed 2 149a3-6 (p. 297).

${ }^{39}$ See Krasser 1995: 253-255 for a synthesis of Dharmottara's position on this topic in the Laghuprāmānyaparīkșā. See also Hugon 2008b: 141-142.
} 
another the various types of awareness being classified via successive dichotomy (see VI, Tables D, E, and G).

There is a clear correlation between the identification of the definitional criteria of knowledge and the classification of individual cases within the seven-fold typology, which includes two types of knowledge and five types that are not knowledge (VI, Table E). Established definitional criteria allow for the characterization of any given case as being an instance of knowledge or not. On the other hand, there are a number of cases that are predetermined (unanimously in the Buddhist tradition, or for individual authors) as counting or not counting as instances of knowledge. The chosen definitional criteria must be such that they apply to the former and not to the latter.

rNgog Lo bases his identification of the definitional criteria of knowledge on his interpretation of Dharmakīrti's statement on knowledge at the beginning of the Pramānaviniścaya:

Dhk1 "Indeed, someone who proceeds, having positively ascertained an object through these two, is not deceived with regard to (its) causal efficacy."

$\left(\mathrm{PVin}_{\mathrm{Skt}} 1\right.$ 1,10: na hy ābhyām artham paricchidya pravartamāno 'rthakriyāyām visamvvādyate; PVin Tib 1 30,17-18: 'di dag gis don yongs su bcad nas 'jug pa na don bya ba la bslu ba med pa' $i$ phyir ro //)

Other Tibetan scholars (see $\S 4.1$ for an example) draw instead from the Pramānavārttika:

Dhk2 "Knowledge is a cognition that is non-deceiving"

$\left(\mathrm{PV}_{\text {Skt }}\right.$ 2.1a: pramānam avisamvvādi jñānam; Tib.: tshad ma bslu med can shes pa /)

Dhk3 "Or the revealing of an unknown object"

(PV $\mathrm{PVt}_{\text {Skt }}$ 2.5c: ajñātaprakāśo vāa; Tib.: ma shes ${ }^{40}$ don gyi gsal byed kyang /)

Yet others, as in Phya pa's case (see below §3), arrive at their definitional criteria in more unconventional ways.

Tibetan scholars identify different criteria for knowledge and occasionally disagree on the nature of some predetermined cases. This leads to the adoption of alternate definitions for the various types of awareness

${ }^{40}$ See III, 2, n. 27 for the alternative Tibetan rendering of ajñāta as ma rtogs. 
being distinguished. In the Mun sel, Phya pa only points out different positions pertaining to some of them-non-ascertaining perception, factive assessment, and doubt (these are discussed in IV). As the Tshad bsdus and the works of Phya pa's students bear witness, other types of awareness were certainly not exempt from ongoing debates in Phya pa's time.

\subsection{Typologies of awareness in the Tibetan epistemological tradition postdating Phya pa}

rNgog Lo's categorization of episodes of awareness was systematized by subsequent scholars. Phya pa's works provide the earliest available instance of an extensive account on this theme. The topic became an integral part of Tibetan epistemological treatises. Although the material extant today still allows only a fragmentary view on the developments of the Tibetan tradition up to the classical period and into the post-classical period, the available works I have consulted so far all include a chapter or section dealing with awareness in general and establish a typology (or several typologies) of awareness in connection with a typology of objects. They all include in this framework a discussion of episodes of awareness that are not knowledge, which are also examined in relation to the definition of knowledge. The latter is commonly dealt with in a subsequent chapter or section, which first deals extensively with the general theory of definition. ${ }^{41}$

The account that is the closest to Phya pa's presentation in its structure and contents is found in the Tshad bsdus (on which cf. n. 28). Its author, however, also mentions alternative definitions to Phya pa's, and adopts them in some cases. ${ }^{42}$ Similar discussions are also found in the commentary on the Pramānaviniścaya by Phya pa's student gTsang nag pa, in an epistemological summary by the latter's student mTshur ston, ${ }^{43}$ and in the

\footnotetext{
${ }^{41}$ On the Tibetan theory of definition, see Hugon 2009b.

${ }^{42}$ See section 1 (spyir blo tsam gyi rab tu dbye ba) (Tshad bsdus 3-62) and in particular section 123.3 (Tshad bsdus 54-62) on the five-fold typology of episodes of awareness that are not knowledge. Why these five do not qualify as knowledge is discussed in the section on the definition of knowledge (Tshad bsdus 118-119, khyab ches pa spang ba).

${ }^{43}$ On these two scholars, see above $\S 1$ and n. 29. In his extensive commentary on the Pramānaviniścaya, gTsang nag pa includes an excursus on the nature of the episodes of awareness that are not knowledge within his discussion on the definition of knowledge (see bsDus pa 22b6-24a5). mTshur ston's discussion of
} 
later work of the same genre by Chu mig pa. ${ }^{44}$

Other works that became available in the $b \mathrm{Ka}$ ' gdams gsung 'bum collection are more difficult to date precisely, but they commonly feature similar discussions on the types of awareness. Among these works, the epistemological summary by gTsang drug pa rDo rje 'od zer ("tsang druk pa dor jé ö zer," $12^{\text {th }}$ century, hereafter: gTsang drug rdo rje) - the gSal byed - postdates the compositions of Phya pa's direct disciples gTsang nag pa and Dan bag pa, whose views are often quoted. ${ }^{45}$ Its author might be identical with the figure named gTsang drug ("tsang druk") or gTsang pa gru gu ("tsang pa dru gu"), one of the nine spiritual sons of gNyal zhig 'Jam pa'i rdo rje ("nyel zhik jam pé dor jé," ?-1207?), who was himself an abbot of the upper college of gSang phu. ${ }^{46}$ Since gNyal zhig was a student of Dan bag pa, this could explain why the latter is frequently quoted in the gSal byed.$^{47}$ The similarities between the gSal byed and Chu mig pa's rNam rgyal could result from their being the product of the same

awareness follows the broad lines of Phya pa's discussion in the Mun sel in terms of its structure but is closer to gTsang nag pa's account in terms of content. The five-fold typology of episodes of awareness that are not knowledge is discussed within the last of the three pairs of opposite characterizations by which episodes of awareness are classified: engaging positively or via the exclusion of what is other; being conceptual or non-conceptual; being or not being an episode of knowledge (sGron ma 5b2-6a9). They are further discussed in relation to the definition of knowledge in sGron ma 20a8-20b2.

${ }^{44}$ See the first chapter of $r$ Nam rgyal (A1b1-20b6; B1b1-24b5) on awareness in general, and section 123 (blo'i dbye ba, A8a8-10a7; B10a9-12b6) on the sevenfold typology.

${ }^{45}$ The section on awareness in general includes a three-fold division of awareness based on the apprehended object and a seven-fold division based on the trio of the apprehended, the intentional, and the engaged object ( $\mathrm{gSal}$ byed 9a1-11 [folio 11 is missing]). The five types that are not knowledge are discussed in relation to the definition of knowledge in gSal byed 28b6-7.

${ }^{46}$ On gNyal zhig, see Sparham 1996.

${ }^{47}$ On the gSal byed and its author see Hugon 2013b: 674, n. 17. The colophon of the manuscript mentions, along with the identification of the author's bla ma as gNyal pa zhang tshes ("nyel pa zhang tsé"), the yet unidentified dPal ldan rtsang pa 'bre ("penden tsang pa dré"). gTsang drug pa might also correspond to the gTsang pa drug po who was a teacher of bCom ldan ral gri in 1239. If gTsang pa gru gu and gTsang drug po are one and the same person, this would place his time of activity in the late $12^{\text {th }}$ century and up to the first half of the $13^{\text {th }}$ century. 
teaching lineage going back to gNyal zhig — indeed, Chu mig pa was a second-generation student in the teaching lineage of gNyal zhig via sKyel nag Grags pa seng ge ("kyel nak drak pa seng gé")—and even back to Dan bag pa.

Yet another work of interest is the Tshad nye bsdus by Chos kyi bzhad pa ("chö kyi zhé pa"), which, according to its colophon, builds on another work, the Tshad ma sde bdun kyi de kho na nyid bsdus pa by the author's bla ma rDo rje dbang grags ("dor jé wang drak"). ${ }^{48}$ Its structure is similar to the epistemological summaries of gTsang drug rdo rje and Chu mig pa, and the three authors often cite the same sources. It also has features, however, that are not found in these two works but are found in mTshur ston's sGron ma. ${ }^{49}$

${ }^{48}$ The colophon specifies that rDo rje dbang grags's work was composed in a fire-female-ox year of the seventh of the 500-year cycles of the Buddha's teaching (Tshad nye bsdus 21a1-2: tshad ma sde bdun kyi de kho na nyid bsdus pa / zhes bya / bde bar gshegs pa'i bstan pa lnga brgya' bdun pa la [21a2] bab pa'i tshe / me mo glang gi lo la / gte' ra bkra shis dbu mang g(i) dgon par / brul zhugs kyi khur 'dzin cing / sde snod rab 'byams la mang du thos pa'i shag kya'i dge slong / bla ma mkhas pa chen po rdo rje dbang grags kyis sbyar pa las /). The seventh 500-year cycle following the passing of the Buddha corresponds to the years 863 to 1363 according to the calculation of Atiśa, who (unlike modern scholars) placed the Buddha's passing in 2137 B.C. (Seyfort Ruegg 1992: 265266). The same date was calculated by Phya pa, and an approaching one (2133 B.C.) by bSod nams rtse mo ("sö nam tsé mo," 1142-1182), his nephew Sa pan, and the latter's nephew 'Phags pa Blo gros rgyal mtshan ("pak pa lo drö gyel tsen," 1235-1280) (see Seyfort Ruegg 1992: 272-273 and van der Kuijp 2011: 88 for the calculation of Phya pa and other scholars). Relevant candidates for a fire-ox year in this time span would be the years 1157, 1217 and 1277. Chos kyi bzhad pa's work postdates the work of gTsang nag pa (d. after 1195), whom the author mentions nominally on fol. 9a5. A forthcoming study by Matthew Kapstein will provide more detail on the identity of the author of the Tshad nye bsdus. It may be worth noting that the name rDo rje dbang grags - more precisely, "the well-learned monk rDo rje dbang grags" (mang du thos pa'i dge slong rdo rje dbang grags) - appears as that of the donor in a manuscript of Phya pa's synoptic table of the Pramānaviniścaya (bKa' gdams gsung 'bum, vol. 8, 3-23; see also Hugon 2009a). Whether it is the same rDo rje dbang grags as the author of the Tshad nye bsdus remains an open question.

${ }^{49}$ Unlike gTsang drug rdo rje and Chu mig pa, but like mTshur ston (see n. 43), the author indeed discusses the episodes of awareness that are not knowledge as 
The abovementioned works, which range from the $12^{\text {th }}$ to the $13^{\text {th }}$ century, are representative of what can be called the mainstream gSang phu tradition, characterized, among other things, by the very admittance of a five-fold typology of episodes of awareness that are not knowledge. ${ }^{50}$ Their authors subdivide and group the five types in slightly different ways, but they do not add new instances to the five-fold set. However, none of the respective authors repeat exactly Phya pa's typology, the definitions of the respective types, and the instances of the various episodes of awareness. Some differences are minor-terminological changes, ${ }^{51}$ changes in phrasing, examples, and the author's focus - or reflect the need to refine the definitions to include or exclude problematic cases. Other differences testify to a more profound disagreement on core issues. One can also observe a large degree of disagreement regarding the explanation for why each of the five types fails to qualify as knowledge (on the definition of which the authors however roughly agree) ${ }^{52}$ In view of these manifold subsequent developments, we have been especially careful in our translation of the Mun sel to avoid contaminating the understanding of Phya pa's system by retroactively ascribing to him views attested in later works that, even if plausibly matching his own, are not explicit in his works.

part of one of three pairs of opposite characterizations of awareness (conceptual/non-conceptual; engaging positively/via the exclusion of what is other; knowledge/not knowledge) (Tshad nye bsdus 8b1-9a8).

${ }^{50}$ In the Rigs gter (composed in 1219, cf. van der Kuijp 1983: 101 and 303, n. 293), Sa pan reports the five-fold typology as being the view of "most Tibetans" (Rigs gter II 58,22: bod phal cher blo lngar sdud de). This view is also ascribed in a general way to "logicians nowadays" by the author of a short epistemological work ( 8 folios) of uncertain dating, the Tshad ma' $i$ spyi skad, who himself adopts a quite different position on the topic (3a8-9: gcad bya sgro 'dogs kyi blo la deng [em. deng: Ms de] sang dus kyi rtog ge ba rnams [3a9] tshad ma ma yin pa'i blo lnga zhes grags ste). See below and n. 62 for more details.

${ }^{51}$ Some variations (such as yid spyod for yid dpyod) qualify as orthographical variations rather than terminological differences. The main terminological change concerns the type translated here as "post-knowledge cognition": initially designated by the Tibetan term bcad pa'i yul can (rNgog Lo, Phya pa, gTsang nag pa), the term bcad shes or its homonym dpyad shes (and the orthographical variant spyad shes) become the standard in works of the classical period (see IV, $2[\mathrm{a}])$.

${ }^{52}$ See $\S 3.3$ and n. 109. 
In the classical period of Tibetan epistemology, the investigation and categorization of episodes of awareness becomes a distinctive area of study known as blo rigs and an integral part of the monastic curriculum in the dGe lugs ("gé luk") order. The study of blo rigs is based on eponymous autochthonous manuals that echo to a large extent the mainstream system of gSang phu scholars. Well-known instances are the blo rigs by Yongs 'dzin Phur bu lcog Blo bzang tshul khrims byams pa rgya mtsho ("yong dzin pur bu chok lo zang tsül trim jam pa gya tso," 1825-1901), the Yongs 'dzin blo rigs, which is part of the Rigs lam 'phrul gyi lde mig (also known as Yongs 'dzin bsdus grwa), or that by 'Jam dbyangs bzhad pa Ngag dbang brtson 'grus ("jam yang zhé pa ngak wang tsön drü," 1648-1721), the 'Jam dbyangs bzhad pa'i blo rigs.

Such works continue to be composed nowadays in the dGe lugs and bKa' brgyud ("ka gyü") traditions, ${ }^{53}$ and they were popular as well among Sa skya ("sa kya") scholars. ${ }^{54}$

Blo rigs literally means "the kinds (rigs) of awareness (blo)," 55 in other words, a typology of episodes of awareness. This term was not used

${ }^{53}$ A blo rigs by dGe bshes 'Jam dpal bsam 'phal ("gé shé jam pel sam pel," d. 1975), which is used as a teaching manual at the Blo gsal gling ("lo sel ling") college of 'Bras spungs monastery in southern India, together with an oral commentary by Lati Rinbochay, is translated into English in Rinpochay\&Napper 1980. The also recent Blo rtags kyi rnam gzhag rigs gzhung rgya mtsho'i snying po by mKhan Rin po che Tshul khrims rgya mtsho ("khen rin po ché tsül trim gya tso," b. c. 1934) is a blo rigs of the bKa' brgyud tradition (see Tshul khrims rgya mtsho 1997 in the bibliography).

${ }^{54}$ See Onoda 1996: 195.

${ }^{55}$ The spelling "blo rigs" is to be preferred to "blo rig," which is also found frequently (notably in the eponymous work by Yongs 'dzin Phur bu logg) and is listed as an alternate spelling for the former in the Tshig mdzod chen mo (1925). $B l o r i g(s)$ in the sense of "typology of awareness" is to be distinguished from blo rig, which is defined in the Tshig mdzod chen mo as "a cognition having an object" (yul can gyi shes pa). See van der Kuijp 1985: 36-37 for grounds to reject the rendering "awareness and knowledge" adopted for blo rig $(s)$ in Rinpochay\&Napper 1980.

In the classes of bsdus grwa, blo rigs stands as a parallel expression to rtags rigs (literally "the kinds of logical reason"), the third class of bsdus grwa in the broad sense of the term. The expression rtags rigs finds a precedent in the phrasing "rtags kyi rigs" attested in Phya pa's Mun sel (77a2) when dealing with the typology of logical reasons. Here also, Rinpochay\&Napper's translation as "signs and reasoning" must be rejected. 
by rNgog Lo or Phya pa - the latter speaks, rather, of "divisions of awareness" (blo'i dbye ba) - but it is found in the Tshad bsdus and in the work of Phya pa's second-generation student mTshur ston. ${ }^{56}$

In dGe lugs pa monastic education, blo rigs is part of the three classes that constitute the study of bsdus grwa in the broad sense of the term (often translated "Collected Topics"), the corresponding manuals for which started to be composed at least from the $15^{\text {th }}$ century onward ${ }^{57}$ Relevant discussions on mind also take place in some manuals of bsdus grwa (in the restricted sense of the term) in the lesson entitled "subject and object" (yul yul can). ${ }^{58}$

The attribution of a bsdus grwa work to Phya pa is frequently found in modern secondary literature. But as I argued at length elsewhere, that attribution is unsubstantiated. ${ }^{59}$ Phya pa's Mun sel might well have played

${ }^{56}$ See Tshad bsdus 51,20-21: gzung yul dang 'jug yul gnyis ka la ltos nas blo rigs bdun du dbye ba and sGron ma 3a9, which lists the sections entitled "the division into three kinds of awareness based on the apprehended object" (gzung yul la ltos te blo rigs gsum du dbye' $b a$ ) and "the division into ten kinds of awareness based on the object in general" (yul tsam la ltos te blo rigs bcur dbye' ba). The term blo rigs is also found in Sa pan's Rigs gter (II 68,17), where the author criticizes one of the types of awareness "posited as a distinct type of awareness" (blo rigs tha dad du 'jog $\mathrm{na}$ ) by his predecessors.

${ }^{57}$ See Dreyfus 2003 (and in particular 98-110 and 111-148) for a complete presentation of the Tibetan monastic curriculum. On bsdus grwa literature, see Onoda 1996. In the restricted sense of the term, bsdus grwa refers to just the first of the three classes. The third class is entitled rtags rigs and is concerned with the various types of logical reasons in inferential reasoning.

${ }^{58}$ This is, for instance, the seventh lesson of the third part of the Rwa stod bsdus grwa composed by 'Jam dbyangs mChog lha 'od zer ("jam yang chok tha ö zer," 1429-1500), who was abbot of the Rwa ba stod ("ra ba tö") college of gSang phu's lower monastery ( $\mathrm{gling}$ smad), and it also appears as the title of the twentieth lesson of the (non-extant) bTsan po bsdus grwa composed by gSer khang pa Dam chos rnam rgyal ("ser khang pa dam chö nam gyel," $17^{\text {th }}$ century), who was abbot of the same college fourteen abbots after mChog lha 'od zer. It is also the fifth lesson of the bsdus grwa texts composed by 'Jam dbyangs bzhad pa and his disciple Ngag dbang bkra shis ("ngak wang tra shi," 1678-1738). This topic is absent, by contrast, from the bsdus grwa by Yongs 'dzin Phur bu lcog. See Onoda 1992: 61-65.

${ }^{59}$ See Hugon 2008b: 74-90, and in particular 77-80. The source of this mistaken attribution (which was made before Phya pa's works became available) lies in the interpretation of a statement by Klong rdol bla ma Ngag dbang blo bzang 
the role of precursor for compositions of the bsdus grwa genre, but it does not constitute an ancestor of bsdus grwa compositions in terms of structure and contents. In particular, while later blo rigs compositions are undoubtedly inspired by Phya pa's discussion of the topic, they are the product of manifold successive developments and modifications. Evident differences are, notably, the very definition of knowledge, the introduction of types of objects not distinguished by Phya pa, and the addition of elements absent in Phya pa's discussion of the topic, in particular a section on mind and mental factors.

While the five-fold set was broadly (if not unanimously) adopted during the pre-classical period, the beginning of the classical period was marked by Sa pan's rejection of this typology in favor of an alternative system distinguishing only three sorts of awareness that are not knowledge, akin to the division already proposed by rNgog Lo (see above $\$ 2.1$ ):

- non-understanding ( $m a$ rtogs)

- mistaken conception cognition ( $\log r t o g)$

- doubt (the tshom $)^{60}$

However, contrary to rNgog Lo, Sa pan does not accept that five distinct types are subsumed in these three. He rejects, in particular, the legitimacy of factive assessment, non-ascertaining cognition, and post-knowledge cognition as distinct types.

In the classical and post-classical periods, there is a general dichotomy between scholars who embraced the five-fold set - typically, scholars associated with the dGe lugs pa school-and scholars who, following Sa pan, radically rejected it. The whole picture, however, is not limited to these two options. One also finds alternative models that testify to their specific author's original approach and possibly also to the impact of Sa pan's arguments against the five-fold typology.

("long döl la ma ngak wang lo zang," 1719-1794/95) describing a work in eighteen lessons, which was understood to constitute a description of the contents of Phya pa's Mun sel.

${ }^{60}$ Rigs gter I 69,8-27. See van der Kuijp 2009: 220-222 for a translation of this passage. According to Sa pan, these three do not to differ in terms of their essence (ngo bo), but only in terms of the way they apply ('jug tshul). 
For instance, the author of the Tshad ma 'i spyi skad, ${ }^{61}$ a short (8 folios) as yet undated epistemological summary, rejects his contemporaries' view that all elements of the five-fold set have the same status in opposition to the status of knowledge-in his terms, that they are "episodes of awareness consisting in superimposition, which are what is to be eliminated" (gcad bya sgro 'dogs kyi blo), whereas the two "episodes of awareness consisting in knowledge are what eliminates [the superimpositions]" (gcod byed tshad ma'i blo). The author holds in contrast that post-knowledge cognition and factive assessment are actually episodes of awareness that amount to knowledge (tshad ma'i blo khongs su gtogs pa) in that they eliminate superimpositions. ${ }^{62}$

Another more renowned example is Dar ma rgyal mtshan bCom ldan ral gri ("dar ma gyel tsen chom den rel dri," 1227-1305), a scholar who studied in both the gSang phu tradition and the Sa skya tradition. ${ }^{63} \mathrm{He}$ proposes an idiosyncratic six-fold typology of episodes of awareness that are not knowledge. It includes Sa pan's three categories - characterized as being "unlike knowledge" (tshad ma dang mi 'dra ba) —and three types that are "like knowledge" (tshad ma dang 'dra ba), among which one finds post-knowledge cognition. Non-ascertaining perception is discussed as an instance of the category of non-understanding, but the author does not accept factive assessment as a distinct type.

Another such hybrid system is found in the work of mKhas grub rje dGe legs dpal bzang ("khé drup jé gé lek pel zang," 1385-1438), who rejects the distinction between perception and perceptual knowledge, and therefore does not adopt the categories of non-ascertaining perception and perceptual post-knowledge cognition (although he includes conceptual post-knowledge cognition in his typology). mKhas grub also does not accept factive assessment as a distinct type. He and his followers represent one of the two main trends within the dGe lugs pa tradition, the other

\footnotetext{
${ }^{61}$ The name of the author is given as "gNyag" ("nyak") in the manuscript, but is reported as "gNyags" in the catalogue of the $b K a$ ' gdams gsung 'bum. Given the reference to Atiśa at the end of the treatise, its author was presumably affiliated with the bKa' gdams pa school.

${ }^{62}$ See Tshad ma'i spyi skad 3a8-4a4.

${ }^{63}$ On Ral gri's Tshad ma rgyan gyi me tog, see van der Kuijp 1994 and 2003. Ral gri is institutionally affiliated with the bKa' gdams pa. He was a student of the Indian junior pandit Dānaśîla, Sa skya Paṇdita, and Skyel nag Grags pa seng ge (who had been one of Chu mig pa's teachers).
} 
being associated with bsdus grwa compositions. Their divergence when it comes to the typology of mind is tied to their different approach regarding the definitional criteria of knowledge. ${ }^{64}$

The various typologies adopted by authors postdating Phya pa, even the similar ones involving a five-fold set, are undoubtedly worth a separate investigation. A detailed discussion of them, however, has not been included in the present study in order to keep the amount of material manageable. Some of these later typologies and related definitions, in particular those tied to the ones addressed by Phya pa in the Mun sel, are discussed in greater detail in IV, and alternative definitions for the respective types are listed in IV, 6 for the sake of comparison and as evidence for the ongoing evolution in the tradition. In addition, such lists might be helpful in ascertaining the date of composition of other epistemological works, at least in terms of a relative chronology. A brief overview of subsequent developments related to the definition of knowledge can be found below in $\S 3.6$. Phya pa's definitions and the definitions of some of his successors are listed in VII, Appendix 3.

\section{Phya pa's definition of knowledge}

Phya pa's contribution to the development of Tibetan epistemology stands out by its originality and unconventionality, but it is also highly dependent on and influenced by the Indian and Tibetan background on which Phya pa elaborates his ideas. When it comes to defining knowledge, Phya pa is aware of the interpretations of several Indian exegetes of Dharmakīti on the topic: Prajñākaragupta, Devendrabuddhi, Dharmottara, and Śankaranandana. He criticizes the first three and endorses the definition of the fourth, which becomes his "short definition" of knowledge in terms of "understanding something veridical" (see Mun sel 212.14). ${ }^{65}$ The

\footnotetext{
${ }^{64}$ See Dreyfus 1997a: 374-378 and below \$3.6.
}

${ }^{65}$ I discuss this short definition and Phya pa's digression pertaining to the meaning of "veridical" in this context in Hugon 2011a. On the source of this phrasing in Śankaranandana's works, see the discussion in §5.1.1. See $§ 5.2$ for a precedent in rNgog Lo's works. The short definition in terms of bden pa'i don rtogs pa is mentioned by Jayānanda in his Tarkamudgara - a text that this Kashmiri scholar composed in Tibet and translated himself together with Khu mdo sde 'bar ("khu do dé bar") - (verse 2), along with Dharmottara's definition (bcad don thob byed $p a$ ) and the criterion from PV 2.5c (ma rtogs don gsal). Jayānanda refutes it in 
views of Phya pa's Tibetan predecessors and contemporaneous scholars - among whom are rNgog Lo and Phya pa's teacher rGya dmar baalso play a constitutive role, both via influence and reaction.

Against this background, one can identify two points regarding which Phya pa's contribution rightly qualifies as "revolutionary": the scope of knowledge and the nature of knowledge, in particular, for perceptual knowledge. The first point does not stand out prominently in the passages of the Mun sel translated in this publication, although it is linked with Phya pa's "short definition" in terms of "understanding a veridical object" and his interpretation of "veridical" in the sense of "being unopposed" (gnod pa med pa) and "existing according to the natural disposition of the objects to be cognized" (shes bya'i gshis su gnas). I will return to this briefly in the conclusion. My focus will here be on the second point, which is tied to Phya pa's extended version of the definition of knowledge.

The defining characteristics of episodes of knowledge adopted by Phya pa and their philosophical implications were discussed in the first part of the introduction, which also examines the ways in which the five types of awareness that are not episodes of knowledge fail to satisfy these conditions (see I.1, 4). The defining characteristics that Phya pa singles out were referred to in terms of the following three criteria for knowledge:

(K1) The "superimpositions criterion"

(K2) The "novelty criterion"

(K3) The "mode of apprehension criterion"

As for the definition properly speaking, Phya pa states in Mun sel 212.14:

Here, our position is this. The meaning of "Revealing an unknown state of affairs" (PV 2.5c) is: that which counters the capacity to produce superimpositions that are incompatible with the way things are (K1), through aspects of awareness that are non-erroneous with regard to a positively discerned state of affairs (K3). Here, this is what is called "understanding something veridical" (cf. BPP 22).

In what follows, I will first focus on the "superimpositions criterion" (K1), examining the wording adopted by Phya pa, its meaning, and its relation

verses $11 \mathrm{~b}-19$. These definitions are refuted in a similar way by rMa bya Byang chub brtson 'grus, who was a student of Jayānanda and reportedly authored a commentary on the Tarkamudgara, in his De nyid snang ba 432.111 .21 (769771 ), verses $12 \mathrm{~d}-14 \mathrm{a}$. 
with other parts of his system. Then, in connection to this, I will examine whether there is a significant difference between Phya pa's definition of knowledge in the Mun sel and in the 'Od zer. Criterion K1 is indeed formulated differently in the respective texts. The omission of a distinct mention of $\mathrm{K} 2$ in the statement of the extended definition cited above and the role ascribed in this text to K1 for excluding types that do not qualify as knowledge could suggest that K1 in the Mun sel represents a stronger criterion than in the 'Od zer.

\subsection{The "superimpositions criterion" (K1) in the Mun sel}

\subsubsection{Various formulations of K1 in the Mun sel}

In the passages translated in this publication, one finds a variety of formulations for $\mathrm{K} 1$ (which are also attested elsewhere in the Mun sel):

(1) Countering the capacity to produce superimpositions sgro 'dogs skyed pa'i nus pa bzlog pa

(2) Eliminating superimpositions sgro 'dogs bsal/sel pa sgro 'dogs bcad/gcad pa sgro 'dogs gcod byed sgro 'dogs chod

(3) Countering superimpositions sgro 'dogs bzlog pa

(4) Potentially opposing superimpositions sgro 'dogs la gnod du rung

(5) Actually rendering superimpositions powerless/ Rendering actual superimpositions powerless

sgro 'dogs dngos su nus med du byed pa

sgro 'dogs dngos su yod pa nus med du byed pa

(6) Opposing superimpositions

sgro 'dogs la gnod pa

Since (1) is the formulation that Phya pa chooses when stating his own definition of knowledge in the Mun sel, I take it to be Phya pa's final 
formulation of $\mathrm{K} 1$ in this text. ${ }^{66}$ It is, let us note, the only formulation that speaks of the "capacity to produce superimpositions" rather than just "superimpositions." A subsequent discussion (Mun sel 212.14 [b]) reveals that this specification is meant to ensure that the criterion applies in the case of inferential cognition (see below §3.1.4). The same discussion indicates that K1 must account for two options: "potentially opposing superimpositions" (4) and "actually rendering superimpositions powerless" (5) (see §3.1.4.ii).

The more profusely used expressions for K1 simply connote, without specification, the "elimination of superimpositions" $(2)^{67}$ and the "countering of superimpositions" (3). ${ }^{68}$ Of similar meaning, the expression "opposing superimpositions" (6) is not strictly speaking used for criterion $\mathrm{K} 1$; it is part of the formulation of the distinguishing characteristic pertaining to the last three types of awareness in the seven-fold typology: perceptual knowledge, inferential cognition, and factive assessment.

Anticipating the comparison of the definition of knowledge in the Mun sel and in the 'Od zer, it is worth noting that the expression "incompatible with opposite superimpositions" (sgro 'dogs dang 'gal ba) is not used for criterion K1 in the Mun sel. However, "incompatibility with opposite superimpositions" is given as characterizing the nature of episodes of

${ }^{66}$ This formulation finds an echo in the phrasing "eliminating the capacity to produce superimpositions" used to express the definition of knowledge in Mun sel 35b2: mtshan nyid ni don la mi 'khrul pa'i rnam pas gshis dang mi mthun pa'i sgro 'dogs skyed nus sel pa.

${ }^{67}$ Sgro 'dogs sel pa and sgro 'dogs gcad pa (and their alternative forms) are used in a fluctuating way (see, for instance, Mun sel 121.2). They stand for K1 in particular in the definition of the engaged object (Mun sel 121.13) and in the explanation of the way in which perceptual awareness comes to be an episode of knowledge (Mun sel 112.23). The related expression with the verb chod occurs in the phrase "(with regard to an object) for which superimpositions have already been eliminated" (sgro 'dogs chod zin pa) in the definition of post-knowledge cognition. It expresses an idea equivalent to the notion of "(with regard to an object) previously known" (sngar rtogs pa) used to single out post-knowledge cognition in the establishment of the seven-fold typology (see VI, Table E).

${ }^{68}$ This expression is only used as a reformulation of K1 in Mun sel 212.14 (a), a paragraph in which the role of $\mathrm{K} 3$ in the definition is explained as a necessary specification to be attached to K1. The expression also stands for K1 in Mun sel 212.22, where Phya pa implies that factive assessment and mistaken cognition satisfy K1 but not K3. 
transitive and reflexive awareness that qualify as perceptual knowledge (Mun sel 234.1) ${ }^{69}$ Conversely, "compatibility with opposite superimpositions" is the definitional characteristic of non-ascertaining perception that sets it apart from perceptual knowledge (Mun sel 123.12), as well as the feature invoked for its being excluded from knowledge episodes (Mun sel 212.22).

\subsubsection{What are superimpositions?}

The first question one may ask with regard to criterion $\mathrm{K} 1$ is "what are superimpositions"? The Tibetan term sgro 'dogs, which is also used to translate the Sanskrit terms samāropa, adhyāropa, and äropa, connotes a mistaken imputation. This notion has a narrower scope than the terminologically related notion "superimposed" (sgro btags), which denotes a characteristic that applies to all apprehended objects that are not real entities. The mistaken imputations relevant to $\mathrm{K} 1$ are exclusively of a conceptual nature. ${ }^{70}$ The mistake that is involved in the context under consideration is not the basic lack of correspondence between reality and its conceptual representation via superimpositions of universals and properties (the type of mistaken cognition noted $\mathrm{MC}_{1.1}$ in IV, 4). ${ }^{71}$ It is, rather,

${ }^{69}$ In the passage that follows, Phya pa affirms that "incompatibility with superimpositions" prevents the application of these characteristics to non-ascertaining perception and to perceptual post-knowledge cognition (Mun sel 43a6: rang myong pa dang gzhan 'dzin pa snang la ma nges pa dang bcad pa'i yul can la khyab ches pa 'ang ma yin te / sgro 'dogs dang 'gal bas khyad par du byas pas de gzhan la mi 'jug pa'i phyir ro //). The argument is problematic with regard to the latter, because, assuming that "incompatible with directing one's mind in the opposite way" (which is part of the definition of post-knowledge cognition) is coextensive with "incompatible with superimpositions," the latter feature does apply to post-knowledge cognition.

${ }^{70}$ This feature stands out clearly in the controversy in Mun sel 212.14 (b). The opponent points out the fact that inferential cognition cannot coexist with superimpositions, because this would imply the simultaneous existence of two conceptual cognitions in the same mental continuum. Phya pa accepts this fact, and concedes that superimpositions are not actually present at the time of an inferential cognition.

${ }^{71}$ See Mun sel 111 (b) and Mun sel 112.111.112.2. As Phya pa points out in these passages, all conceptual characterizations of entities are actually mistaken in that they represent entities in a way that does not correspond to their nature of being unique and undivided. 
akin to a mistake pertaining to the intentional object, in other words, a mistaken identification of the object (the type noted $\mathrm{MC}_{2 / 3}$ in IV, 4). For instance, the superimposing of the property "permanent" to sound, which is in reality impermanent, is likened to superimposing the category "snake" to a rope. This notion of "superimposition" is thus akin to that of "mistaken determinate awareness" (log par nges pa) $\left(\mathrm{MC}_{2}\right)$. Phya pa seems to assimilate this phenomenon with the operation of "directing" (zhen pa) ${ }^{72}$ a directing that is, in all the examples discussed in the text, towards a feature that does not correspond with the nature of the object. In brief: superimpositions are always mistaken. ${ }^{73}$ This is made explicit in several formulations of $\mathrm{K} 1$ in which superimpositions are qualified as "opposite" (bzlog $p a)$, "incompatible with the way things are" (gnas lugs dang 'gal $b a$ ), and as being "in disagreement with the natural disposition (of things)" (gshis dang mi mthun pa).

\subsubsection{Which superimpositions can be eliminated?}

In the Mun sel, Phya pa does not provide information as to which superimpositions can be eliminated by an episode of knowledge. His input on this issue is limited to specifying conditions for their elimination to take

${ }^{72}$ See in this regard the expression "compatible/incompatible with directing one's mind in the opposite way" (bzlog pa'i zhen pa dang mi 'gal ba/'gal ba) used as a distinguishing criterion in the seven-fold typology. Non-ascertaining perception, which is classified as "compatible with directing one's mind in the opposite way," is later defined as "compatible with opposite superimpositions" (bzlog pa'i sgro 'dogs dang mi 'gal ba), and this "compatibility" is said to be established by observing the engaging in the directing of one's mind towards the opposite (e.g., rtag pa lasogs par zhen pa 'jug pa) (see Mun sel 123.12 and 123.13).

${ }^{73}$ Examples of superimpositions include the superimposition "non-blue" in the case of a blue particular, "blue" in the case of a particular that is not blue, "permanent" in the case of a momentary object such as sound, "not being conventionally true" in the case of a concept, and "non-existence" in the case of existing objects. Regarding the second example (Mun sel 212.22), the elimination of the superimposition "blue" occurs in the context of a mistaken cognition that determines a white shell to be yellow. What is here eliminated (the mistaken superimposition "blue") is thus to be distinguished from what is excluded via the operation of exclusion (cf. Mun sel 112.111.2), which would, in this case, be the correct identification as "white" or "non-yellow." See also in Mun sel 212.14 (b) the example of the mistaken determination "singular" that eliminates the superimposition "multiple," a superimposition which is mistaken as well. 
place; and even these are specified indirectly by spelling out two grounds for the absence of elimination of superimpositions in the case of nonascertaining perception: lack of focus and a feature being non-manifest (rnam pa dang mi ldan pa/rnam pa med pa/rnam med) or not evident (rnam pa ma gsal ba) ${ }^{74}$ Phya pa only provides few examples of such features, the principal one being the feature of impermanence (mi rtag pa) or momentariness (skad cig ma), which cannot be perceptually ascertained by ordinary persons. ${ }^{75}$ The characterization of "impermanence" as non-manifest appears to be exclusively objective; impermanence is a nonmanifest feature even though it can be ascertained by more skilled cognizers (i.e., Noble Beings). However, Phya pa possibly also accepts cases where the characterization as non-manifest is circumstantial. For instance the perception of mother-of-pearl may fail to ascertain this feature due to the distant location of the object, but this feature can be ascertained subsequently by getting closer to the object. ${ }^{76}$

In the 'Od zer (111.221.221), by contrast, Phya pa extensively discusses which superimpositions can be eliminated, doing so by spelling out three restrictions:

${ }^{74}$ On the origin of this notion, see Hugon 2011a: 169, n. 44.

${ }^{75}$ In the 'Od zer, Phya pa also mentions the "efficacy" (nus pa), i.e., the causal efficacy, of an object. See 'Od zer 118a5: rnam myed kyi rgyu nus pa thogs myed "Being a capable unobstructed cause, which is non-manifest." The idea is that one recognizes that an object is "capable of fulfilling an action" by observing the result at the subsequent moment. But the efficacy itself is non-manifest. "Impermanence" and "efficacy" are two properties already described as "non-manifest" (rnam pa dang myed pa) by rNgog Lo (dKa' gnas 138, see Hugon 2011a: 169, n. 44). The idea that "absence or presence of a self" is not manifest (rnam pa dang ldan pa ma yin) also comes up in an opponent's argument (dKa'gnas 271). In Phya pa's works, other features labeled "non-manifest" are that of "being erroneous" or "being non-erroneous" (cf. Mun sel 63b3, 'Od zer 126b8: 'khrul ma 'khrul rnam med yin pas). In the 'Od zer, Phya pa also mentions the features of "being alone" or "not being alone" of a cognition ('Od zer 110a1: zla bcas zla myed rnam myed yin pas myong yang myi nges pa'i phyir), and the feature of "being void of a pot that is not potentially visible" ('Od zer 110b2: snang du myi rung pa'i bum pas dben pa ni rnam myed yin pas yongs su gcod myi nus pa'i phyir).

${ }^{76}$ See the discussion in I.1, 2.3 and IV, 1(b). 


\section{i. Subjective restriction}

The mental continuum in which the superimpositions are eliminated is the same as the mental continuum in which knowledge takes place. In other words, someone's knowledge does not eliminate the mistaken cognitions that other cognizers have.

\section{ii. Temporal restriction}

Superimpositions can only be eliminated between the time the episode of knowledge is generated and the time the compositional factors of memory are impaired. ${ }^{77}$

\section{iii. Objective restriction}

The superimpositions that can be eliminated are only those that are directly incompatible with the positively discerned object, or those characterized by something directly incompatible with it. The incompatibility referred to in this discussion is "conceptual incompatibility" (phan tshun spangs 'gal, literally "incompatibility in such a way that there is mutual rejection"). ${ }^{78}$

The former case is illustrated by the superimposition "non-blue" being eliminated when something blue appears to perception and by the superimposition "non-momentary" being eliminated when something is inferred

\footnotetext{
${ }^{77}$ See IV, 2(b) on the use of this notion by Phya pa's successors for redefining post-knowledge cognition.

${ }^{78}$ Conceptual incompatibility is dealt with later in the 'Od zer (114b2ff.). This section of the 'Od zer is quasi identical to Mun sel 242.324.322.2 (71a7ff.). What is termed here "characterized by something directly incompatible" is a specific instance of what is, in this later section, described in terms of "indirectly incompatible" (brgyud 'gal). "Indirect incompatibility" is defined as the incompatibility between $x$ and $y$ pervaded by non- $x$, for instance between "permanent" and "produced" ('produced' being pervaded by 'impermanent') (see 'Od zer 114b7, Mun sel 71b2-3). When dealing with the ascertainment of incompatibility, Phya pa specifies that the ascertainment of $x$ by an episode of knowledge does not entail the negation of $y$ pervaded by non- $x$ as such (for instance, the perceptual knowledge of 'blue' does not entail the negation of 'permanent,' even though 'permanent' is pervaded by 'non-blue'). It only entails the negation of the indirectly incompatible $y$ that is characterized by non- $x$ (it entails the negation of 'permanent non-blue') (see 'Od zer 115a4-115a6, Mun sel 71b8-72a1). See Hugon 2016b: 891 for a summary of Phya pa's views on incompatibility.
} 
to be momentary. In brief, for an object that has a feature $x$, an episode of knowledge eliminates the superimposition "non- $x$."

A simple case of a superimposition "characterized by something directly incompatible" is a superimposition of the form " $y$ aggregated with non- $x$ " when something that has a feature $x$ is perceived or this feature is inferred. For instance, the superimposition "permanent aggregated with non-blue" (or one could say "permanent [and] non-blue") is eliminated when perceiving something blue.

Further refinements are provided regarding this second category, leading to the distinction between "direct understanding" (dngos su rtogs pa) and "indirect understanding" (shugs la rtogs pa). ${ }^{79}$

One can see clearly in this context how the notion of "elimination (of

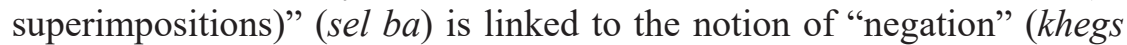
$\mathrm{pa}$ ), and the latter to the notion of "understanding" (rtogs pa) ${ }^{80}$

\subsubsection{How are superimpositions eliminated?}

The expressions used for K1 (see §3.1.1) refer to superimpositions (or the capacity to generate them) being made powerless, opposed, countered, or eliminated. A reader with a Dharmakîrtian background is likely to link

${ }^{79}$ For example ('Od zer 22b1), an inferential cognition that ascertains that an object (one that is the object of a given awareness) is veridical eliminates the superimposition "non-veridical" pertaining to this object. But it also indirectly eliminates the superimposition "having a non-veridical object" with regard to the awareness of the given object. This is possible insofar as "an awareness having a non-veridical object" is characterized by "the object being non-veridical." The inferential cognition thus directly understands that the object is veridical, and indirectly understands that the awareness has a veridical object. The former understanding pertains to an epistemic object (the object) whose concept appears in the inferential cognition, whereas the second pertains to an epistemic object (the awareness) whose concept does not appear in the inferential cognition. The distinction between direct and indirect understanding plays an important role in subsequent developments of Tibetan epistemology. On this topic, see Schwabland 1995 .

${ }^{80}$ In later epistemological works that define knowledge in terms of "understanding a veridical object" and assimilate "understanding" (rtogs pa) to the elimination of superimpositions, the examination of "understanding" is typically carried out through the examination of its object-affirmation and negation (sgrub pa/dgag pa) — and of the methods of understanding involved - direct or indirect. See, for instance, gSal byed 24b5-28b6, Tshad nye bsdus 11b8-13b5, and rNam rgyal A23b6; B27b8ff. 
this idea with Dharmakirti's theory of "exclusion" (apoha) in general, and more precisely with Dharmakīrti's association of the notions of "determining" (niścaya), "having for object the exclusion of what is other" (anyāpohavișaya), and especially "eliminating superimpositions" (samāropavyavaccheda). Indeed, a core idea of Dharmakirti's theory of exclusion (apoha) is that conceptual cognition does not understand (and language does not refer to) its object "positively" (vidhinā), but via a process of exclusion of what is other. For instance, the word "cow" does not denote either a real particular cow or a generic property "cowness," but only the "exclusion of non-cow." In the same way, the determination of an object as "blue," although it appears to consist in a positive characterization, actually amounts to the "exclusion of non-blue."

Dharmakirti's theory of exclusion, however, only pertains to conceptual cognitions. It is thus not surprising that Phya pa has to address upfront the objection that perceptual knowledge cannot eliminate superimpositions given that it is non-conceptual (Mun sel 212.21 [a]). ${ }^{82}$ In his answer, Phya pa presents a three-step causal process through which perceptual knowledge brings about the annihilation of superimpositions:

$\mathrm{t}_{1}$ : Perceptual awareness and superimpositions come into contact.

$\mathrm{t}_{2}$ : Perceptual awareness and powerless superimpositions both exist.

$\mathrm{t}_{3}$ : Perceptual awareness exists, but there are no superimpositions.

Superimpositions are powerless in $t_{2}$, because while their direct causes are superimpositions in $t_{1}$, perceptual awareness in $t_{1}$ acts as a condition. And since superimpositions are powerless in $t_{2}$, they do not cause a next moment of superimpositions in $t_{3}$. Superimpositions have thus been annihilated (i.e., made non-existent). This process does not require perceptual awareness to perform any conceptual operation; it eliminates superimpositions by its mere presence.

${ }^{81}$ For more information on the theory of apoha, see Siderits et al. (eds.) 2011. Dreyfus already noted this possible background and observed that it is remarkable that this important feature of knowledge is actually formulated in negative terms, via the expression "elimination of superimpositions" (Dreyfus 1997a: 367). I return to the question of a possible Dharmakîrtian background for this idea in $\$ 5.1$. One may note that the negative formulation may also be a resonance of the Three-Nature model, in which the "perfected nature" is defined as the "dependent nature void of an imagined nature' (see VI, Table A).

${ }^{82}$ For such an objection by Sa pạn (postdating Phya pa's works) see n. 115. 
Phya pa does not deal in detail with the process involved in the case of inferential knowledge. Since inferential cognition is readily associated with "excluding what is other," the process of eliminating superimpositions is less likely to be found objectionable. The argument in Mun sel 212.14 (b) indicates that Phya also considers the "elimination of superimpositions" by inferential cognition along the lines of a causal process leading to the annihilation of superimpositions. Indeed, this argument is about the situation at $\mathrm{t}_{1}$ : there cannot be contact between inferential cognition and superimpositions, because inferential cognition cannot coexist with superimpositions (this is because two conceptual cognitions cannot take place simultaneously in the same mental continuum) ${ }^{83}$, but there can be contact between inferential cognition and the "capacity to generate superimpositions." It is this capacity that is made powerless, thus ensuring that superimpositions can no longer be generated. What happens at $t_{1}$ in the case of inferential cognition explains the need for the more specific formulation of $\mathrm{K} 1$ as "countering the capacity to generate superimpositions" in the definition of knowledge.

\section{i. Elimination and factual incompatibility}

As demonstrated elsewhere (Hugon 2011a), the three-step process presented by Phya pa for the elimination of superimpositions by perceptual knowledge stands out as an application of the model that Phya pa proposes in a later part of the Mun sel (68a9-72a5) for "factual incompatibility" (Tib. lhan cig mi gnas 'gal, Skt. sahānavasthānalakṣanavirodha, literally "incompatibility consisting in not remaining

\footnotetext{
${ }^{83}$ According to a parallel discussion in the Tshad bsdus (116,7-8), this tenet is supported by Dharmakīrti's statement in PV 3.178. In this verse, Dharmakīrti does not strictly speaking refute the possibility of two simultaneous conceptual cognitions, but he points out that they are not observed in a particular situation: "When there is the experience (of a form) by this very (awareness of a form), one does not observe two simultaneous conceptual cognitions (namely, 'form' and 'experience of form'). By this (rejection of two simultaneous conceptual cognitions), (the awareness of form) is understood to be experienced by another simultaneous cognition (i.e., a non-conceptual one)." (tayaivānubhave drșțtam na vikalpadvayam sakṛt / etena tulyakālānyavijñānānubhavo gatah //). The information supplied in the parentheses in the translation are from the eleventhcentury commentary on this verse by Manorathanandin.
} 
together"). ${ }^{84}$ This type of incompatibility refers to a situation in which two phenomena are such that they cannot coexist (but it can be the case that they are both non-existent). More precisely, in Phya pa's view, the phenomenon with the greater power eliminates the weaker one, i.e., brings about the cessation of its continuum (rgyun zlog par byed pa). Borrowing a model found in Dharmottara's writings, Phya pa explains that this elimination takes place (in standard cases) through a three-step causal process involving successive moments of the respective continua of two states of affairs $\mathrm{X}$ and $\mathrm{Y}$ (for instance a powerful fire and cold):

$\mathrm{t}_{1}: \mathrm{X}$ and $\mathrm{Y}$ come into contact.

$\mathrm{t}_{2}: \mathrm{X}$ and a powerless $\mathrm{Y}$ both exist.

$\mathrm{t}_{3}$ : $\mathrm{X}$ exists but not $\mathrm{Y}$.

When discussing K1 in the Mun sel, Phya pa neither explicitly refers to his theory of factual incompatibility nor, as pointed out at the end of $\$ 3.1 .1$, does he define knowledge in terms of being incompatible with superimpositions. ${ }^{85}$ On the contrary, the notion of "incompatibility" and "elimination" are clearly associated in the discussion on factual incompatibility, as the incompatible phenomenon is described in terms that connote "opposition" (gnod) and "elimination" (sel). ${ }^{86}$ And the definiens of "factually incompatible" is also phrased in terms of "rendering powerless the cause for generating (the next moment of) one's own sort for what is being opposed, via contact with the counteragent, " ${ }^{\prime 87}$ which is not without recalling the specific formulation of $\mathrm{K} 1$ as "countering the capacity to produce superimpositions."

A specific feature of Phya pa's model of factual incompatibility (spelled out both in the 'Od zer and the Mun sel) is that a phenomenon X can qualify as "counteragent of $\mathrm{Y}$ " and as "incompatible with $\mathrm{Y}$ " even when it does not actually come into contact with Y, provided that it would

\footnotetext{
${ }^{84}$ For an outline of Phya pa's theory of incompatibility, see Hugon 2016b: 890 891.

${ }^{85}$ That the notion of "eliminating superimpositions" ( sgro 'dogs sel ba) is to be understood along the model of "factual incompatibility" is pointed out explicitly by gTsang nag pa (see bsDus pa 17a5-6).

${ }^{86}$ In particular, when a phenomenon $\mathrm{X}$ is incompatibly with $\mathrm{Y}, \mathrm{X}$ is termed the gnod byed, and $\mathrm{Y}$ the gnod bya.

${ }^{87}$ Mun sel 68b5-6 = 'Od zer 68b5-6: gnyen po dang phrad pas gnod bya la rang rigs skyed pa'i rgyu nus med du byed pa mtshan nyid du brjod kyi.
} 
cause the annihilation of $Y$ if the two came in contact. Phya pa illustrates this option with the example of a powerful fire (X). It qualifies as a "counteragent of cold (Y)" (and thus as "factually incompatible with cold" and "what eliminates cold") even in a case where there is no cold, for instance, when cold has already been eliminated by sunrays in this particular place. Indeed, this powerful fire would eliminate cold if it came in contact with it. $^{88}$

In the 'Od zer (see below $§ 3.2 .1$, iv), Phya pa explicitly points to this feature of incompatibility to establish that the meaning of K1 includes "potential elimination" of superimpositions. He does not carry out this association in the Mun sel, even though the potential elimination of superimpositions is similarly taken into account.

\section{ii. Potential elimination}

Phya pa specifies the meaning of K1 in Mun sel 212.14 (b) in reply to an opponent who implies that the meaning of K1 should either be restricted to "rendering powerless of actually present superimpositions" or restricted to "potential opposition" and points out absurd consequences for each option. Phya pa's reply to this dilemma is to escape between the horns and maintain that both options should be integrated in the meaning of $\mathrm{K} 1$. This disjunctive interpretation of $\mathrm{K} 1$ enables the criterion to include cases where the process of elimination actually takes place (actual superimpositions, or the actual capacity to generate superimpositions are annihilated) as well as cases where this process is merely potential. In the Mun sel, Phya pa does not specify which cases might be representative of the latter option. In a parallel discussion in the 'Od zer, the wisdom of omniscient beings is pointed out as being an instance of knowledge in spite of there being no contact with an actual capacity to generate superimpositions (see $\$ 3.2 .1$, iv and n. 100). The definition of knowledge can

\footnotetext{
${ }^{88}$ The case of the powerful fire is adduced as a parallel example to establish that "light" (snang $b a$ ) itself can be called a counteragent of "darkness" (mun pa). Mun sel 68b7-8 = 'Od zer 112a3-4: de lta na'ang snang pa gnyen por ma gyur pa'ang ma yin te nyi ma'i 'od kyis grang reg bsal pa'i sa phyogs na mye stobs ldan yod pa nyi mas grang reg bsal pas grang reg dang ma phrad kyang phrad do she na rgyun 'joms pa'i nus pa dang ldan pas grang reg gi gnyen por brjod (Mun sel brjod, 'Od zer rjod) pa ltar / snang pa la'ang mun pa phrad na ('Od zer mun pa phrad na: Mun sel mun pa dang phrad nas) sel pa'i nus pa yod pas bsal ba myed kyang snang pa mun pa'i gnyen po yin no /
} 
only apply to such a case if "potential opposition" of superimpositions is considered.

\subsection{5 "Eliminating superimpositions," "determination," and "excluding what is other"}

It should be emphasized that by allowing perceptual knowledge to eliminate superimpositions Phya pa is not implying that perceptual knowledge involves any conceptual operation. In particular, it neither conceptually determines its object, nor does it perform the associated operation of excluding what is other.

Regarding the first point, perceptual knowledge itself does not "determine" (nges pa) its object in the sense of a conceptual determination, ${ }^{89}$ but it may bring about the arising of a conceptual determination that immediately follows. Such a conceptual determination is a determinate awareness specifically termed "determining cognition" (nges shes). ${ }^{90}$ Such a two-step model of determination is broadly shared among Buddhist epistemologists. It allows one to account for determination taking place in the context of an episode of perception, without running against the very idea of perceptual awareness being "free of conceptualization" (Skt. kalpañapodha, Tib. rtog pa dang bral ba), which is advocated by Dignāga and Dharmakīrti. On account of this model, stating that "perceptual knowledge determines its object" is a metaphorical way of saying that the determining cognition that follows perceptual knowledge determines the object. Being conceptual, this subsequent determining

\footnotetext{
${ }^{89}$ This is not to be confused with the use of the term nges pa by subsequent Tibetan scholars to refer to the elimination of superimpositions (see n. 123).

${ }^{90}$ I suspect that the Tibetan term nges shes is a reflex of the Sanskrit niścayajñāna. For the Sanskrit term, see, for instance, PVSV 28,8 ad PV 1.48: yad rūpādidarśanānantaram alingam niścayajñānam (Tib. nges pa'i shes pa) bhavati. On this notion and the key passages referring to it in Dharmakirti's writings, see Katsura 1993 (the author refers to this determination in terms of "perceptual judgement"). See also Dreyfus 1996 for Dharmakīrti's position and that of some of his interpreters on this point. Note that the term is used differently by other Tibetan authors. For instance, mKhas grub rje uses the term nges shes in a broader sense that covers both inferential cognition and conceptual postknowledge cognition (rGyan mun sel 58a5-6: nges shes kyi mtshan nyid / tshad ma yin pa'ang tshad ma'i stobs kyis drangs ba'i blo gang zhig / rang yul nges pa'i sgo nas 'dzin pa / dbye na / rjes dpag [58a6] tshad ma dang / bcad shes gnyis).
} 
cognition can perform the operation of excluding others, which perception cannot.

When discussing the three "operations" (byed pa) of episodes of awareness - appearing, directing, and excluding others (cf. Mun sel 112.111.111, 112.111.12, 112.112, 112.111.2) - Phya pa clearly associates the operation of "exclusion" ( $\mathrm{sel} p a$ ) or "exclusion of others" (gzhan sel pa) -which is dependent upon the operation of "directing one's mind" (zhen $p a$ ) - with conceptual cognitions only. His principal concern in discussing this operation is with the way certain types of awareness in which there is a given directing of one's mind prevent engaging in a different type of directing or engaging in a different type of awareness. Non-conceptual cognitions, on the other hand, only have the operation of appearing (snang pa) (see VI, Table D). While the operation of excluding others is tied with conceptual cognition and the operation of directing, it is not coextensive with the criterion of being determinate (nges pa). Indeed, doubt is held to perform both the operation of directing and excluding, but it is not a determinate cognition. Having the operation of excluding does not in itself guarantee that there is an elimination of superimpositions that are opposite to the way things are. ${ }^{91}$ The operation of excluding others coincides with the elimination of opposite superimpositions in the case of inferential cognition, but it is the latter that is crucial for this type of awareness being an episode of knowledge. ${ }^{92}$

\footnotetext{
${ }^{91}$ Doubt (whether something is $x$ or non- $x$ ) excludes what is other (insofar as it prevents directing one's mind toward either option being impossible), but it does not eliminate the option that is a mistaken superimposition (for instance, "permanent" when doubting whether sound is permanent or impermanent). As for mistaken cognition consisting in an incorrect determination " $x$," it excludes the correct determination "non- $x$," but it does not eliminate the mistaken superimposition " $x$." See the example in n. 73.

${ }^{92}$ One must thus be careful to distinguish the mention of sel ba as an "operation" (byed pa) (translated throughout as "exclusion [of what is other]"), and sel ba as the causal process annihilating superimpositions (translated throughout as "elimination"). In the 'Od zer, Phya pa opposes the "incompatibility with superimpositions," which is about an episode of knowledge being the counteragent of the superimposition non- $x$, and the operation of "excluding others," which consists in being devoid of a present superimposition ('Od zer 28b4: sgro 'dogs dang 'gal ba ni sgro 'dogs da ltar ba dang bral ba'i gzhan sel ba ni ma yin gyi sgro 'dogs kyi gnyen po byed pa yin la $\left.\right|_{1}$ ).
} 


\subsection{The "superimpositions criterion" (K1) and the "novelty criterion" (K2)}

At the beginning of $\S 3$, three criteria were listed as defining characteristics of knowledge. However, the status of the "novelty criterion" (K2) in the Mun sel deserves closer examination. While there is no doubt that K2 is a necessary condition for knowledge, the question is whether it is a defining criterion in the sense of a characteristic that needs to be explicit in the definition in order to avoid an unwanted overextension of the category of knowledge. Indeed, no such distinct characteristic is stated in the definition of knowledge in Mun sel 212.13. Because the relevant passages in the Mun sel are somewhat ambiguous and leave open the possibility of an alternative reading, I will first present here the more straightforward account found in Phya pa's 'Od zer for the sake of an ensuing comparison and maybe contrast.

\subsubsection{The definition of knowledge in the 'Od zer}

(i) The extended version of Phya pa's definition of knowledge in the 'Od zer makes four criteria- $\mathrm{K} 1, \mathrm{~K} 2, \mathrm{~K} 3$, and $\mathrm{K} 4$ - explicit:

Thus the definition of knowledge is: That which, for a veridical state of affairs (K4) not previously known (K2), is incompatible with opposite superimpositions (K1), in accordance with a mode of apprehension that is non-erroneous with regard to its state of affairs (K3). ${ }^{93}$

K4 echoes the definition in terms of "understanding a veridical object," which in Mun sel was used as the "short definition" and associated with Śankaranandana. In the 'Od zer, Phya pa does not mention Śankaranandana's definition, but the phrasing bden pa rtogs pa frequently comes up in

93 'Od zer 111.221.2, 23b1: sngar ma rtogs pa'i don bden pa la don la myi 'khrul ba'i 'dzin stangs kyis bzlog pa'i sgro 'dogs dang 'gal ba tshad ma'i mtshan nyid yin no /

Another formulation with four criteria is found in 'Od zer 172b7-8: mngon suM la yod pa'i tshad ma tsam du 'jog pa'i rgyu mtshan ni 'dzin stangs kyi rnam pa ${ }_{\text {[172b8] }}$ don myed na mi 'byung bas (K3) sngar ma rtogs pa'i don (K2) gnod myed du bden pa la (K4) sgro 'dogs gcod pa (K1) yin la I

A definition mentioning only $\mathrm{K} 1$ is also found (for instance 'Od zer 67b2: tshad mar mtshon pa'i mtshan nyid sgro 'dogs gcod byed yin). In such cases, $\mathrm{K} 1$ must be understood to include the implicit specifications K2 and K3. 
discussions involving the definition of knowledge (including the main excursus on the topic).

(ii) The four criteria are said to ensure that the definition is not overextensive. Namely, they exclude eight types of awareness of the ten-fold typology (see VI, Table G) as follows:

- K1 excludes non-ascertaining perception, non-conceptual erroneous cognition, non-directing conceptual cognition, and doubt.

- K2 excludes post-knowledge cognition.

- $\mathrm{K} 3$ excludes factive assessment and mistaken cognitions (that satisfy K1).

- K4 excludes mistaken cognition consisting in mistaken determinate awareness, etc. (for instance, determining sound to be permanent). ${ }^{94}$

The disjunction between mistaken cognitions eliminated by K3 and those eliminated by $\mathrm{K} 4$ highlights the fact that mistaken cognitions can be incompatible with wrong superimpositions, which emphasizes the similarity of factive assessment and mistaken cognition. For a mistaken cognition eliminated by K3, Phya pa gives the example of the mistaken cognition of "a single essence," which is incompatible with the likewise mistaken notion of "a multiple essence." It thus satisfies K1. However, the lack of an invariable connection with reality obtains as well for the mistaken cognition "sound is permanent" (which is not as obviously incompatible with wrong superimpositions). And, vice versa, the lack of a veridical, unopposed object is also the case for the mistaken cognition "a single nature." Thus, the explicit mention of K4 is redundant, as all conceptual mistaken cognitions are eliminated from the range of knowledge by K3.

The presence of $\mathrm{K} 4$ in the definition can be explained by looking at how Phya pa's discussion on the topic unfolds in the 'Od zer. He starts the account of his own position ('Od zer 111.221.2, 21b7) by stating a definition with three criteria (K1, K2, K4). In the discussion that follows, he emphasizes K4 (the characteristic pertaining to the object) and K1 (the characteristic pertaining to the apprehending cognition). K2 is, however, not forgotten. It is aggregated to K4 in a brief statement after the meaning of "veridical" in K4 has been defined, ${ }^{95}$ and comes up again as a "characteristic of the object" (yul gyi khyad par) that enables to exclude post-

\footnotetext{
${ }^{94}$ See 'Od zer 111.222.3, 29a8-b1.

95 'Od zer 22a5: de ltar gnod myed du bden pa de'ang tshad mas sngar ma rtogs pa ni tshad ma'i yul yin no //
} 
knowledge cognition (which $\mathrm{K} 1$ cannot) ${ }^{96}$ The discussion pertaining to $\mathrm{K} 1$ reveals the need for the specification pertaining to the mode of apprehension, i.e., K3 (which was not explicit in the initial definition), in order to exclude factive assessment and mistaken cognition (which $\mathrm{K} 1$ as such cannot). Although, as pointed out above, the explicit mention of K3 makes K4 redundant, in conclusion to this discussion Phya pa just adds $\mathrm{K} 3$ to the preceding definition and rephrases the definition of knowledge in a statement featuring the four criteria $\mathrm{K} 1-\mathrm{K} 4$.

(iii) The "superimpositions criterion" (K1) is formulated in the definition cited above in terms of "being incompatible with opposite superimpositions" (bzlog pa'i sgro 'dogs dang 'gal ba). But alternative phrasings are also used as synonyms in the 'Od zer (among which the ones found for $\mathrm{K} 1$ in the Mun sel): "eliminating superimpositions" (sgro 'dogs gcod pa), ${ }^{97}$ "opposing superimpositions" (sgro 'dogs la gnod pa), "being a counteragent of superimpositions" (sgro 'dogs gyi gnyen por gnas pa). In addition, when discussing K1, Phya pa deals with the notion of "incompatibility" through an analysis of "what is to be eliminated" (gcad bya) and the "counteragent that eliminates" (gcod byed gnyen po).

Thus the equivalence between the notion of "incompatibility" and that of "elimination," which stands out in the later section in incompatibility, is made explicit with regard to the meaning of $\mathrm{K} 1$.

(iv) Like in the Mun sel, the three-step model of factual incompatibility is applied to explain how perceptual knowledge satisfies $\mathrm{K} 1$ ('Od zer 111.222.2 [a]). ${ }^{99}$

96 'Od zer 23b1: yul gyi khyad par sngar ma rtogs pa la'ang 'jug pas bcad pa'i yul can bsal pa'i phyir ro //

${ }^{97}$ For instance in the four-criterion definition cited in n. 93.

${ }^{98}$ See 'Od zer 111.221.222, where factive assessment and mistaken cognition are said to satisfy the feature of "opposing superimpositions in general" (sgro 'dogs la gnod pa tsam). In 'Od zer 111.222.3 (29a9-b1), the same types of awareness are characterized as "incompatible with opposite superimpositions" (bzlog pa' $i$ sgro 'dogs dang 'gal ba).

${ }^{99}$ Perceptual knowledge accordingly qualifies as "incompatible with superimpositions" (sgro 'dogs dang 'gal ba), as "counteragent of superimpositions" (sgro 'dogs gyi gnyen po), and as "what renders superimpositions powerless" (sgro 'dogs nus myed du skyed 'khan). 
Another feature of the model of factual incompatibility noted above (§3.1.4.i), namely, that potential elimination of $\mathrm{Y}$ by $\mathrm{X}$ is sufficient for $\mathrm{X}$ to qualify as "incompatible with $\mathrm{Y}$ " or "counteragent of $\mathrm{Y}$," is explicitly brought into the discussion of the meaning of K1 in 'Od zer 111.221.223 (see V, 2 for the Tibetan text of 'Od zer 23a8-9):

Whether superimpositions are present or not in a given mental continuum, an awareness has the status of a counteragent of superimpositions insofar as it has the capacity to definitely render superimpositions powerless if it were to come in contact with them. This is just like a powerful fire is said to be "incompatible with cold" whether it is in contact with cold or not - as when it is located in a place bathed by the hot rays of the sun-insofar as it has the capacity to render cold powerless if it were to come in contact with it. Having such a status of counteragent of superimpositions is what "being an eliminator of superimpositions" means.

An episode of awareness can thus satisfy K1 even when there are no actual superimpositions, including when superimpositions have already been eliminated.

The "potential" understanding of incompatibility allows for the wisdom of omniscient beings (who never have superimpositions) to satisfy $\mathrm{K} 1$ and qualify as knowledge. ${ }^{100} \mathrm{On}$ the other hand, this implies that postknowledge cognition also satisfies K1: it is incompatible with superimpositions, even though superimpositions have already been eliminated (in the same way a powerful fire is incompatible with cold, even when cold has already been annihilated by sunrays). To exclude post-knowledge cognition, it is thus necessary to list $\mathrm{K} 2$ as a distinct defining criterion of knowledge, or as a specification to be attached to K1.

${ }^{100}$ The wisdom of omniscient beings (thams cad mkhyen pa'i ye shes) is a type of awareness that comes into contact neither with actual superimpositions at $t_{1}$ of the three-step causal process of elimination (as in standard cases of perceptual knowledge) nor with the capacity to generate superimpositions (as in the case of inferential cognition). This is because omniscient beings have eliminated the very seed of mental obscuration, which would be responsible for the occurrence of superimpositions. See 'Od zer 111.221.223, 23a7-8 (Tibetan text in V, 2). The way in which the wisdom of omniscient beings, on the other hand, satisfies the criterion of novelty (K2) is an issue which is not addressed in the section under consideration, and this will be left to further inquiry. 


\subsubsection{K1, K2, and the status of post-knowledge cognition in the Mun sel}

(a) The extended definition of knowledge in Mun sel 212.14 (cited at the beginning of §3) only makes explicit K1 ("countering the capacity to produce superimpositions that are incompatible with the way things are") and K3 ("through aspects of awareness that are non-erroneous with regard to a positively discerned state of affairs"). The criterion of novelty (K2) is not featured; it is part, however, of the citation of PV 2.5c that the definition claims to explain. As for the criterion of the object being veridical (K4), it appears in the attached statement of the short definition "understanding something veridical." While the absence of K4 in the extended definition is unproblematic (it is actually redundant), the case of $\mathrm{K} 2$ is more puzzling.

(b) In the 'Od zer, $\mathrm{K} 2$ is invoked to explain why the definition of knowledge does not overextend to post-knowledge cognition (§3.2.1, [ii]) and in particular why post-knowledge cognition does not qualify as knowledge although it satisfies K1 in the sense of "potentially eliminating superimpositions" (§3.2.1, [iv]).

(b1) The passage that corresponds to the latter discussion in the Mun sel is found in the reply to the second objection following Mun sel 212.14. There, Phya pa similarly applies K2 to exclude post-knowledge cognition, saying:

It is not the case that the criterion would be too broad, applying to post-knowledge cognition, because we said "incompatible with superimpositions with regard to something not previously known."

What is curious about this passage is that Phya pa references a statement not found in the Mun sel. Instead, the reference is similar to the wording found in the initial definition in the 'Od zer (21b7), which is expressed in terms of "incompatible with opposite superimpositions with regard to a veridical object not previously known." In contrast, in the Mun sel, (i) Phya pa does not refer to K1 in terms of "incompatibility with superimpositions" and (ii) does not specify "with regard to something not previously known" in his definition. ${ }^{01}$ The closest he gets to the given

${ }^{101}$ Should one choose to disregard the correction of sngar rtogs pa to sngar ma rtogs pa in the manuscript, one could understand the statement being referred to as a reformulation of the definition of post-knowledge cognition. (The latter is defined in the same way in the Mun sel and the 'Od zer as "Engaging in an awareness that is incompatible ('Od zer: engaging via [an awareness] that is 
phrasing is when listing criteria $\mathrm{K} 1, \mathrm{~K} 2$, and $\mathrm{K} 3$ in the definition of the engaged object, where he talks of the two types of knowledge "eliminating superimpositions with regard to a state of affairs not previously known" (Mun sel 121.13).

A charitable solution to these issues would be to understand that (i) Phya pa holds, like in the 'Od zer, the notion of "incompatibility" to be fully coextensive with "elimination" (see \$3.2.1, [iii]) and that (ii) in his definition he meant to have said "... with regard to something not previously known" (like when defining the engaged object); or maybe he thought he did say something similar in his definition insofar as he cited PV 2.5c ("Revealing an unknown state of affairs"). In other words, K2 is meant to be included in the definition, even if it is not explicit (in the same way as, in the 'Od zer, $\mathrm{K} 3$ was meant to be included, even if it was not explicit in the initial phrasing of the definition).

(b2) To complicate the matter, one can observe that in Mun sel 212.22 (which is parallel to the passage of the 'Od zer discussed above in §3.2.1 [ii]) Phya pa does not invoke K2 to exclude post-knowledge cognition from the scope of knowledge-which fares well with its not being included in the definition. In the Mun sel, post-knowledge cognition is excluded from being knowledge by the following argument:

For post-knowledge cognition, there is no contact with a capacity that could produce superimpositions, which is what would have to be eliminated. Thus, it would be contradictory for post-knowledge cognition to be something that counters this capacity.

"Countering the capacity to produce superimposition" is how K1 is phrased in the extended definition in the Mun sel (cf. §3.1.1). Thus the argument is that post-knowledge cognition is excluded by its failure to fulfill $\mathrm{K} 1$, and this failure is due to the absence of the capacity to produce superimpositions (this capacity having been annihilated by a previous episode of knowledge). One could rephrase the argument, in a simplified way, as: "There is no elimination of superimpositions because there are no superimpositions to be eliminated."

While this is a seductive (and quite intuitive) argument, it threatens the internal coherence of the Mun sel. Phya pa accepts in the Mun sel (as

incompatible) with directing one's mind in the opposite way with regard to a state of affairs for which superimpositions have already been eliminated." See IV, 2). But even taken in such a way, the argument is about the object having been known already. 
he does in the 'Od zer) that the notion of "elimination" covers the case of "potential elimination" (i.e., the case where there is not actual superimposition) (see §3.1.4.ii). This means that, strictly speaking, "absence of contact with the capacity to produce superimpositions" or "absence of contact with superimpositions" is not, as such, a reason for K1 not to obtain.

A possible reading that would enable one to make sense of the argument without implying internal contradiction is to understand $\mathrm{K} 1$ to implicitly include the specification that the object must not have been previously known. In such a case, the argument would be about "superimpositions having been previously eliminated" (they are hence no longer "to be eliminated"). The argument dealt with in (b1) could then be understood along this line as well, not as implying the need for a distinct criterion (K2), but as revealing that the requirement of novelty is implicitly included in the meaning of $\mathrm{K} 1$. This would imply that $\mathrm{K} 1$, in the definition of the Mun sel, is not equivalent to "incompatibility with superimpositions" (a feature that post-knowledge cognition satisfies) but a stronger criterion which itself prevents post-knowledge cognition from qualifying as knowledge. This would explain why K2 does not need to be stated separately in the definition of knowledge, and why $\mathrm{K} 1$ is not referred to in terms of "incompatibility with superimpositions" in the Mun sel. In turn, this would not fare well with $\mathrm{K} 2$ being listed as a distinct criterion when defining the engaged object.

Given the brevity of the passages considered and the absence of corroborating discussions elsewhere in the text, it is difficult to assess whether one is dealing with an isolated problematic passage or if there is indeed an attempt, in the Mun sel, to restrict the defining criteria of knowledge to a strong version of $\mathrm{K} 1$ combined with $\mathrm{K} 3$. While it is possible that Phya pa was tempted by the idea that "elimination of superimpositions" does not apply when superimpositions have already been eliminated, ${ }^{102}$ I would however be in favor of dismissing the argument considered in (b2) as a careless mistake - principally because it is in such flagrant opposition to the position Phya pa supports in the section on factual incompatibility - and to treat Phya pa's accounts in the Mun

${ }^{102}$ In connection to this, see Phya pa's explanation as to why perceptual postknowledge cognition does not have an engaged object, which is that "there is no elimination of superimpositions by those episodes of awareness." See n. 36 to the translation of Mun sel 121.2 in II. 
sel and the 'Od zer as being fundamentally equivalent in spite of variations pertaining to the formulation. ${ }^{103}$ As far I know, none of Phya pa's disciples and successors mentioned a difference of approach in Phya pa's various works. ${ }^{104}$ They themselves favor a three-criterion definition (see below) in which $\mathrm{K} 1$ is alternatively referred to in terms of "elimination of superimpositions" or "incompatibility with superimpositions," and K2 stands as a distinct criterion, the role of which is commonly identified as the exclusion of post-knowledge cognition. ${ }^{105}$

\subsection{Phya pa's successors on the definition of knowledge}

In the works of Phya pa's successors who adopt the definition of knowledge in terms of "understanding a veridical object," the three criteria K1, K2, and K3 become "specifications" (khyad par) or "properties" (chos) of "understanding" (rtogs pa):

${ }^{103}$ Apart from the four-criterion definition of the 'Od zer and the two-criterion definition of the Mun sel, a three-criterion definition is found in sNying po 68,1820: mngon sum dang rjes dpag la'ang tshad ma tsam gyi spyi'i mtshan nyid don la mi 'khrul ba'i blos (K3) sngar ma rtogs pa'i don la (K2) sgro 'dogs dang 'gal ba (K1) yod pas tshad ma ma yin par mi 'thad do //

${ }^{104}$ The Tshad bsdus features a discussion on the meaning of rtogs pa (in bden pa rtogs pa) as sgro 'dogs chod pa which is quite similar to the passages of the Mun sel and the 'Od zer considered above. The author concludes that "eliminating of superimpositions" (sgro 'dogs chod pa) is to be understood in the sense of "incompatibility with superimpositions" (sgro 'dogs dang 'gal tsam) but that, in order to avoid over-application of the definition of knowledge to post-knowledge cognition (and to factive assessment), the "elimination of superimpositions" should be combined with the specifications corresponding to K2 (and K3). See Tshad bsdus 115-116.

${ }^{105}$ The only exception known to me is reported by mTshur ston, who mentions in his sGron $m a$ (20a9-b2) a position (different from his own), according to which perceptual post-knowledge cognition is excluded by K1 (along with factive assessment and non-ascertaining perception) and conceptual postknowledge cognition by $\mathrm{K} 2$ or K3. One may also remember that, according to rNgog Lo, both post-knowledge cognition and non-ascertaining perception were instances of "non-understanding" ( $m a$ rtogs); they lack the very nature of rtogs $p a($ see $\$ 2.1)$. 
- K1 (usually formulated in terms of "eliminating superimpositions," sometimes as "being incompatible with superimpositions") is the specification of the nature (ngo bo).

- $\mathrm{K} 2$ is the specification of the object $(y u l)$.

- $\mathrm{K} 3$ is that of the mode of apprehension ('dzin stangs). ${ }^{106}$

The definition of knowledge in terms of "understanding a veridical object, satisfying three properties" (bden pa'i don rtogs chos gsum tshang pa and analogue phrasings) is found in all the works of the pre-classical and classical period which were mentioned in $\$ 2.3$ as being representative of the "mainstream gSang phu tradition" regarding the typology of awareness. ${ }^{107} \mathrm{~A}$ similar version is adopted as well at the beginning of the classical period by bCom ldan ral gri. ${ }^{108}$

While, as mentioned above, these works concord in excluding postknowledge cognition by invoking its failure to satisfy K2, there are discrepancies regarding the role of $\mathrm{K} 1$ and $\mathrm{K} 3$ in excluding types of awareness that are not knowledge. ${ }^{109}$

Discussions on knowledge in works postdating Phya pa (with the exception of the Tshad bsdus, which is closer to Phya pa's presentation) become organized around the notion of "what is to be understood" (rtogs bya) - i.e., the veridical object — and "what makes it understood" (rtogs byed) - i.e., the episode of knowledge. They go into the details of the three specifications of the understanding listed above as well as of the relation between knowledge and superimpositions (debating whether they have the same object, are of the same nature, and are simultaneously present). While the idea of knowledge "eliminating superimpositions" still

${ }^{106}$ See Hugon 2011a: 15-16 and the discussion of these three specifications in Schwabland 1995: 806.

${ }^{107}$ See Tshad bsdus 116; bsDus pa $16 \mathrm{~b} 8$ and 17a2-7; sGron ma 15b8-9; gSal byed 23a7; rNam rgyal 26b4; Tshad nye bsdus 11a3; and the position cited in Rigs gter VIII 203,22-204,15. The author of the Tshad ma'i spyi skad defines knowledge in terms of "what eliminates superimpositions" (sgro 'dogs gcod byed) but does not mention the three specifications.

${ }^{108}$ rGyan gyi me tog 5 .

${ }^{109}$ For instance, gTsang nag pa (bsDus pa 24a3) and mTshur ston (sGron ma 20a8-9) hold that K1 excludes mistaken cognition, doubt, and non-ascertaining perception, and K3 excludes factive assessment. The authors of the gSal byed (28b6) and of the Tshad nye bsdus (15b5) consider instead that K1 excludes factive assessment and $\mathrm{K} 3$ excludes mistaken cognition. 
figures as a key concept, one can witness changes in the understanding of the elimination process. In particular, in the case of perceptual knowledge, the elimination of superimpositions is no longer explained as resulting from a three-step causal process involving perception itself at $t_{1}$, but as a process involving the immediate cause of perception. ${ }^{110}$ Further, the focus of the discussion shifts from the idea of an episode of knowledge that itself eliminates preexisting or coexisting superimpositions to that of an episode of knowledge taking place in the absence of superimpositions and preventing further superimpositions.

While Phya pa linked his short definition to Śankaranandana, ${ }^{111}$ with a few early exceptions, subsequent scholars obviously felt more comfortable referring to Dharmakīrti. Most authors postdating Phya pa thus strive to ground the three specifications of "understanding" by citing passages from Dharmakīrti's works. ${ }^{112}$ Also, over time, a definition repeating the terms of Dharmakīrti's definition- "non-deceiving" or "newly non-

${ }^{110}$ The Tshad bsdus is the only work postdating Phya pa I am aware of in which the three-step causal process is still explicitly invoked to account for the elimination of superimpositions by perception itself (Tshad bsdus 39,10 [the beginning of the relevant passage is missing in the edition] and 117,17-20). gTsang nag pa can also be held to support such a view, given that he acknowledges that perceptual knowledge and superimpositions coexist. But he does not go into the details of the elimination process (bsDus pa 18a5-6). mTshur ston, in contrast to gTsang nag pa, does not accept that they coexist. He does mention a three-step process but holds it to involve the immediate cause of knowledge rather than knowledge itself (sGron ma 17a6-7). This view is also put forward by gTsang drug rdo rje ( $g$ Sal byed 24b2-3), Chu mig pa (rNam rgyal B27b6-7), and Chos kyi bzhad pa (Tshad nye bsdus 11b6-7).

111 The author of the Tshad bsdus also affirms that he accepts the definition of knowledge to be bden pa 'i don rtogs, "like Śankaranandana" (slob dpon bram ze chen po bzhin du). See Tshad bsdus 114,17-19. Sa pan also calls "followers of Śankaranandana" those who take as the definition of knowledge the "understanding of a veridical object with three properties" (see Rigs gter VIII 203,22-23: bram ze'i rjes su 'brang ba rnams ni bden pa'i don rtogs chos gsum ldan te I sngar ma rtogs pa'i don la 'dzin stangs mi 'khrul pas sgro 'dogs sel ba zhes bya $b a$ 'o //). This echoes the account of mTshur ston's own position (see sGron ma 15b6ff.). Śākya mchog ldan identifies the "followers of Śankkaranandana" as "Phya pa, etc." (see Rol mtsho 77b3-4, cited in V, 1.5, R51.13).

112 The gSal byed (23b4-8), rNam rgyal (A22b2-3), and the Tshad nye bsdus (11a3-4) all cite the same passages (with variants), namely: PV 1.49 for K1, PVin 1 Tib. 60,17-18 (Skt. 20,1) for K2, and PVin 1.3 for K3. 
deceiving" (gsar du mi bslu ba) — was preferred to "understanding a veridical object." Chu mig pa already mentions the definition "understanding a veridical object fulfilling three specifications" as being synonymous with the definition "non-deceiving with regard to the state of affairs that is the epistemic object" (gzhal bya'i don la mi slu ba) (rNam rgyal A22b1; B26b4).

Developments later in the $13^{\text {th }}$ century and the influence of Sa pan's criticism of the gSang phu mainstream tradition still remain to be investigated in detail. Various models and definitions of knowledge were adopted in the classical and post-classical period, the examination of which falls outside the scope of this introduction. ${ }^{113}$ A definitive shift appears to take place in the $14^{\text {th }}$ century with the disciples of Tsong kha pa Blo bzang grags pa ("tsong kha pa lo zang drak pa," 1357-1419) and the fifteenth-century bsdus grwa work of mChog lha 'od zer. Regarding the definition of knowledge adopted in the later Tibetan tradition, two interpretations are predominant: that following mKhas grub rje, according to whom knowledge is "that which is non-deceiving and which ascertains its object by its own power," and that following rGyal tshab rje Dar ma rin chen ("gyel tsap jé dar ma rin chen," 1364-1432), who defines knowledge as being "newly non-deceiving"- - a definition also given by dGe 'dun grub pa ("gendün drup pa") (1391-1474/5) and found in dGe lugs pa textbooks. ${ }^{114}$

${ }^{113}$ See Pham byed 2 156b4-6 (p. 312) for a list of the definitions of knowledge which, according to Śākya mchog ldan, marked the course of the development of Tibetan epistemology from the $11^{\text {th }}$ to the $15^{\text {th }}$ century.

${ }^{114}$ Dreyfus (1991: 20) writes of mKhas grub rje: "In short, for mKhas grub, a cognition is valid if, and only if, the experience of the object turns out to bring certainty through its own power and to be uncontradicted by any other items of knowledge that we might acquire." With respect to rGyal tshab rje, Dreyfus (1991: 21) states: "rGyal tshab, who is often considered by later dGe lugs pa scholars as the main authority in logical and epistemological matters, defines valid cognition as "that cognition which is newly reliable" (gsar du mi bslu ba' $i$ shes pa, Thar lam gsal byed 229,15). This definition, which is also given by dGe 'dun grub, has been accepted as standard by the later authors of the textbooks (yig cha) of the important dGe lugs pa monasteries. In opposition to mKhas grub's requirement of epistemical independence, these thinkers insist on a stronger requirement for validity, that of novelty." 


\section{Phya pa's directly active model of perceptual knowledge}

If making the "elimination of superimpositions" the central criterion of knowledge was a significant change from Phya pa's Indian and Tibetan predecessors, positing that this feature applies to perceptual knowledge, and moreover that perceptual knowledge eliminates superimposition itself (see \$3.1.4), was a radical innovation. Just how revolutionary this idea was can be apprehended by considering the scandalized reaction of $\mathrm{Sa}$ pan, who points out that the "exclusion of superimpositions" cannot take place anywhere else than in the conceptual domain, as part of the global "theory of exclusion" developed by Dharmakirti. ${ }^{115}$ The originality of Phya pa's model can be better apprehended by comparing it with two alternative models attested in the Tibetan tradition: a passive model and an indirectly active model of perceptual knowledge. ${ }^{116}$

\subsection{Active vs. passive models of perceptual knowledge}

In an earlier study (Hugon 2011a), I have articulated the difference between Phya pa's model of perceptual knowledge and the one advocated by Sa pan in terms of an "active model" vs. a "passive model." In Sa paṇ's passive model, perceptual awareness does not have to $d o$ anything in order to qualify as knowledge. It only has to be non-deceiving (Tib. mi bslu $b a$, Skt. avisamvādi) and the revealing of something unknown (Tib. $m i$

${ }^{115}$ See Rigs gter IV 212.233.322.21 (Hugon 2008b: 410-411), VIII 205,7-9 (ngo bo'i khyad par sgro 'dogs gcod pas ma khyab ste / mngon sum rtog bral yin pas sgro 'dogs gcod pa med pa'i phyir ro //) and IX.1a (myong bas sgro 'dogs gcod pa 'khrul). One could say that Sa pan's refutation misses the point, because he does not take into consideration any other way of excluding superimpositions than via a conceptual operation. However, his reaction is quite natural for a conservative interpreter of Dharmakīrti.

${ }^{116}$ Note that the trio of models examined below is not exhaustive of the options found in Indian and Tibetan Buddhist epistemological works and that the issues that these models address are not new. Indian interpreters of Dharmakirti already struggled with the questions whether perception performed any ascertainment of its object and whether this was a requirement for it to qualify as knowledge. In particular, Dharmottara (see Krasser 1995) and Jñānaśrīmitra (see McCrea\&Patil 2006) stand, each in their own way, as proponents of an active model of perception. 
shes don gsal, Skt. ajñātaprakāśa). Sa pan relies here on the criteria provided by Dharmakīrti in his Pramānavārttika (see Dhk2 and Dhk3 in $\S 2.2$ ). Being an episode of knowledge does not require that any kind of ascertainment of the object is achieved. Sa pan does state that a conceptual determination is required for transactional usage, ${ }^{117}$ but this determination requirement is about one being able to act upon an episode of perception (i.e., to engage in some activity or avoid some activity involving the object being known), not about the episode of perception qualifying as knowledge. In addition, such conceptual determination cannot be the deed of the perceptual awareness itself, because perception cannot perform a conceptual determination and cannot exclude what is other, for these operations are restricted to conceptual cognitions. They must thus be performed by a subsequent conceptual cognition along the lines of a two-step model.

\subsection{Directly active vs. indirectly active models of perceptual knowledge}

Phya pa's model can further be understood as a "directly active model" in opposition to an "indirectly active model." This opposition is historically relevant given that an indirectly active model was adopted by Phya pa's forerunner rNgog Lo. rNgog Lo's views on the criteria of knowledge can be gathered from his commentary on the relevant passage of the Pramāṇaviniścaya:

Dhk1 Indeed, someone who proceeds, having positively ascertained an object through these two, is not deceived with regard to (its) causal efficacy. ${ }^{118}$

The background of rNgog Lo's position lies in his interpretation of the expression "having positively ascertained the object" (Skt. artham paricchidya, Tib. don yongs su bcad nas) in this passage. According to rNgog Lo, "ascertainment" can be of two sorts: ultimate or conventional. The former consists in the mere vivid appearance of the object; the latter involves the directing of one's mind (zhen par byed $p a$ ) and a determination (nges pa), i.e., a conceptual determination. He argues that the latter

${ }^{117}$ See Rigs gter VIII 207,16 (ad VIII.46ab): kun tu tha snyad pa'i tshad ma'i stobs kyis 'jug ldog byed pa na nges shes 'dran dgos te /), followed by the citation of PV $1.200 \mathrm{ab}$ (see also the discussion regarding the interpretation of this verse in Rigs gter IV, Hugon 2008b: 409).

${ }^{118}$ See $\S 2.2$ for the Sanskrit and the Tibetan. 
is meant in this passage. ${ }^{119} \mathrm{rNg}$ go Lo (who claims to follow Dharmottara's interpretation) thus adopts an active model of perceptual knowledge, in which being active means "conceptually determining the object."120 Because rNgog Lo concedes that directing one's mind is not an operation of perception, he appeals to a two-step model, wherein a mental episode of directing and determining is induced by the perceptual awareness. Perceptual knowledge is thus indirectly active.

rNgog Lo's position is reflected in the opponent's position cited by Phya pa in Mun sel 112.23: "Some say that what makes a perception an episode of knowledge is merely its "bringing about a determinate awareness."

\subsection{In what way is perceptual knowledge "active"?}

It is quite possible that Phya pa adopts the criterion of "eliminating superimpositions" for the definition of knowledge in order to provide a model of knowledge that preserves rNgog Lo's idea of an active perceptual awareness, but without running into the pitfall he sees involved in a model in which being active is about conceptually determining the object, and hence, in the case of perception, about being indirectly active. According to Phya pa, such a model could not account for the two following cases of perception which he recognizes as knowledge but that lack the arising of a subsequent determining cognition (see Mun sel 112.23):

- the perception of omniscient beings (because omniscient beings do not have any conceptual cognitions, a fortiori no subsequent determining cognition)

- reflexive awareness experiencing the last moment of a determinate awareness (because no conceptual cognition arises from this point onward)

\footnotetext{
${ }^{119}$ One may note, in contrast, Śākyabuddhi's understanding of paricchidya in this passage in the sense of the mere appearance of an aspect of the object (Nishizawa 2013: 118).

${ }^{120}$ See $d K a$ ' gnas 31-32.

${ }^{121}$ Phya pa may refer to the position of rNgog Lo himself or his followers. The analogue view that being an episode of knowledge is about directing one's mind is ascribed to "ancient Tibetans" (bod bgres po) in the Tshad bsdus (39,12-13: bod bsgres po ltar zhen pa la tshad mar 'gro ba ni). This view is correlated with the definition of non-ascertaining perception in terms of failing to bring about a determinate awareness. See the opposite view discussed in Mun sel 123.1 (a).
} 
The case involving the perception of omniscient beings provides us an interesting insight into the particularities of Phya pa's religio-philosophical project, which means to include such cases in its framework. The argument might not be seen relevant by rNgog Lo himself, because he could reply that the perception of omniscient beings does not involve a conventional ascertainment, but only an ultimate one (the mere vivid appearance of the object) - hence no determining cognition is needed for it to qualify as an episode of knowledge. However, I suspect that the distinction between ultimate and conventional ascertainment is precisely one of the things that Phya pa finds dissatisfying in rNgog Lo's model. One can also note a lack of unanimity among Tibetan scholars regarding the second case qualifying as knowledge or not. ${ }^{122}$ Nonetheless, these are two cases that Phya pa wants to account for as being genuine episodes of perceptual knowledge in spite of the lack of a subsequent determining cognition.

Phya pa relinquishes the idea that being active is about conceptual determination. Being active is, rather, about eliminating superimpositions. This feature can still be associated with the notion of "ascertainment of the object," but an ascertainment that, in the case of perception, does not amount to a conceptual determination of the object, even if it comes to be referred to by the same term "nges $p a$ " by some subsequent Tibetan scholars. $^{123}$

Further, in contrast to rNgog Lo's model, episodes of knowledge, and in particular perceptual knowledge, are directly active, because they eliminate superimpositions themselves.

Phya pa's move is clearly reflected in the 'Od zer in his gloss on the statement of the Pramānaviniścaya on which rNgog Lo grounded his indirectly active model (Dhk1). In particular, the expression "having positively ascertained," which rNgog Lo interpreted in the sense of a conventional positive ascertainment involving a conceptual determination, is

122 Notably, Chu mig pa admits that the second case is not an episode of knowledge, but a non-ascertaining perception (rNam rgyal A9a4; B11a8).

${ }^{123}$ This use of nges pa is suggested by mTshur ston in sGron ma 5a1 (nges pa zhes bya ba ni de ma yin gyi sgro 'dogs chod pa la brjod pa na). It is also known to Sa pan (Rigs gter IV 212.233.322.21, Hugon 2008b: 410-411: kha cig na re nges pa la gnyis las rtog pas nges pa med kyang rtog med kyis nges pa yod de mngon sum gyis sgro 'dogs gcod pa'i phyir ro zhe na), who rejects this use as "destroying logical conventions." 
glossed by Phya pa as: "having eliminated superimpositions that are directly incompatible or characterized by what is directly incompatible with regard to its own epistemic object." $" 124$

\subsection{Similarities and differences between the respective models}

The similarities and differences between the models considered above are especially visible with respect to two notions: determining cognition (nges shes) and non-ascertaining perception (snang la ma nges pa).

The respective supporters of all three models agree that perception is free of conceptualization and that in the event of a perceptual awareness, an ascertainment of the object in the form of a conceptual determination would have to be carried out by a subsequent determining cognition (i.e., a two-step model is involved). They also agree that a subsequent determining cognition does not always arise immediately. All these points are wellgrounded in Dharmakīti's works. In particular, the last point, which includes what one might call the idea of "partial ascertainment"-a subsequent determination may arise immediately for some features, but not for others - is grounded in Dharmakīrti's discussion, in the Pramānavārttika (in particular PV 1.44-45 [see §5.1.2], as well as in PV 1.58 cum PVSV), of cases in which there is no determination (niścaya) of some feature that immediately arises following the episode of perception due to the presence of a superimposition (samäropa). Another episode of knowledge (typically, an inferential cognition) is thus required to achieve determination. Dharmakīrti mentions that the features determined are those for which there is both the presence of factors of determination (niścayapratyaya) and the absence of causes of errors (bhrāntikārana). In

124 'Od zer 6a7: don yongs su bcad nas zhes bya ba ni rang gi gzhal bya la dngos 'gal dang des khyad par du byas pa'i sgro 'dogs bcad nas so /. Phya pa's gloss on the other key expressions in this passage is also representative of his new definition of knowledge. Notably, "engaging" is glossed as "engaging in conceiving its own epistemic object as veridical"('jug pa na zhes bya ba ni rang gi gzhal bya la bden pa 'i ${ }_{[6 a 8]}$ zhen pa 'jug pa'o /), "causal activity" is glossed as "the natural disposition of the epistemic object" (don bya ba la zhes pa ni gzhal bya de shes bya'i gshis yin pa la'o), and "non-deceiving" is glossed as "not opposed by another episode of knowledge" (slu ba myed pa ni tshad ma gzhan gyi gnod pa myed pa). All the notions involved in these glosses are characteristic of Phya pa's "short definition" of knowledge inspired by Śankaranandana and of Phya pa's interpretation of the term "veridical." 
the first category, he refers exclusively to subjective and contextual criteria, namely, sharpness of mind (buddhipātava), habitual tendency (tadvāsanābhyāsa), and context (prakarana). ${ }^{125}$ Conversely, in presence of causes of errors or absence of the factors of determination, there arises a superimposition and there is no determination. For instance, when ordinary beings perceive an object, the feature "impermanence" is not determined, and there arises the superimposition "permanent" because similar moments of the object appear without interruption. ${ }^{126}$

The two-step model and the possibility of partial ascertainment are articulated with the notion of knowledge in quite different ways in the three Tibetan models considered.

For rNgog Lo, the arising of a determining cognition is a necessary condition for the previous moment of perceptual awareness to qualify as knowledge. Cases where it does not arise still qualify as perception but not as knowledge. This implies a difference between "perception" (mngon sum) and "perceptual knowledge" (mngon sum tshad ma) as well as a special category of perception, termed snang la ma nges pa, the instances of which do not qualify as knowledge because they fail to induce a determining cognition. For rNgog Lo, "ma nges pa" in this expression means that no subsequent determining cognition is induced. A typical instance is the perceptual awareness of something impermanent that does not induce the conceptual determination "impermanent."

${ }^{125}$ See Hugon 2008b: 528, n. 41.

${ }^{126}$ Dharmakirti thereby acknowledges the phenomenon of "partial determination." But he does not suggest that there is a "partial knowledge" with regard to the object (note that the expression "na pratiyate" ["is not understood"] in PV 1.58 is explained in terms of "absence of determination" in the PVSV $[\mathrm{na} \ldots$ niścayo bhavati]). Some of his commentators - namely, Śākyabuddhi (see Hugon 2011a: 170, n. 54) - however will go down this road, thus offering an Indian precedent to the idea of an episode of perception being knowledge with regard to some features of the object and not being knowledge with regard to others. One may ask whether this precedent was known to rNgog Lo and his followers and to what extent it may have influenced them. Note in this regard that rNgog Lo discusses at some length Sākyabuddhi's commentary on a passage that is not directly related to this discussion, but deals with the reason for the absence of the determination "impermanent" ( PVin $_{\mathrm{Tib}} 2$ 38,20-26, citing PVSV 21,6-22) ( $d \mathrm{Ka}$ ' gnas 352-357). See also the parallel excursus in 'Od zer 136a3-b2. 
In Phya pa's and Sa pan's models, in contrast, perceptual awareness qualifies as knowledge independently of the determining cognition that may follow.

For Phya pa, whether a subsequent determination arises or not is irrelevant to whether or not the perceptual episode qualifies as knowledge. Perceptual knowledge being active is entirely a matter of perception itself eliminating superimpositions; and, should a subsequent determination arise, since the object has already been known, the status of that subsequent determining cognition is that of a post-knowledge cognition. The latter is not an episode of knowledge because it does not satisfy the requirement of novelty.

The cases in the other two models (the passive model and the indirectly active model) that are pointed out as instances where there was a failure of a subsequent determining cognition to arise are discussed by Phya pa in terms of cases in which perception itself fails to eliminate superimpositions. The possibility of such failure grounds the distinction between "perception" and "perceptual knowledge." Phya pa retains the term snang la ma nges pa for such cases. But "ma nges pa" now connotes the absence of elimination of superimpositions by perception itself. ${ }^{127}$ This would, a fortiori, imply the absence of a subsequent determining cognition - but this is not pointed out by Phya pa, for whom this feature is not relevant in characterizing such cases in opposition to genuine cases of perceptual knowledge.

For Sa pan, the immediate arising of a determining cognition or the absence thereof does not distinguish cases of perception that are knowledge and cases that are not knowledge. Perception is always an episode of knowledge. But when a determining cognition arises, the episode of perception is "intrinsically determined (rang las nges) to be an episode of knowledge," whereas when no determining cognition arise this must be "extrinsically determined" (gzhan las nges). ${ }^{128}$ Against his predecessors, who invoked "non-manifest features" to account for some of the

${ }^{127}$ In connection to this, non-ascertaining perception is defined as being "compatible with opposite superimpositions" (Mun sel 123.12).

${ }^{128}$ For instance, the perception of something blue and the perception of something impermanent thus both qualify as knowledge. This is determined, for the first, via the arising of the determination "this is blue" that immediately follows the perception; and for the second, its being knowledge with regard to impermanence must be determined by a subsequent inferential cognition that ascertains 
cases when no determining cognition arises (such as the perception of something impermanent), Sa pan argues that "all features are manifest" and that determination or its absence is only a consequence of the context, namely, the presence or absence of causes of errors. For Sa pan, snang la ma nges pa does not have a raison d'être as a distinct category of awareness. All perceptions are episodes of knowledge, whether or not a subsequent determination is immediately induced. And if "determination" should be about perception itself ascertaining its object, then Sa pan is ready to accept that all episodes of perception are snang la ma nges pa, because all episodes of perception are non-ascertaining in this sense. ${ }^{129}$

that the object perceived is impermanent. On the difference between Phya pa's views on the ascertainment of validity and Sa pan's views, see Hugon 2011a: 171. ${ }^{129}$ See Rigs gter VIII 220,19-20: 'o na mngon sum thams cad snang la ma nges par 'gyur ro zhe na /'dod pa yin no zhes bshad zin no // 
Table 2: Summary of the models of perceptual knowledge

\begin{tabular}{|c|c|c|c|}
\hline & $\begin{array}{l}\text { Indirectly active } \\
\text { rNgog Lo }\end{array}$ & $\begin{array}{c}\text { Directly active } \\
\text { Phya pa }\end{array}$ & $\begin{array}{l}\text { Passive } \\
\text { Sa pan }\end{array}$ \\
\hline $\begin{array}{l}\text { Definition of } \\
\text { knowledge }\end{array}$ & $\begin{array}{l}\text { Conventionally posi- } \\
\text { tively ascertaining the } \\
\text { object = directing and } \\
\text { determining }\end{array}$ & $\begin{array}{l}\text { Eliminating superimpo- } \\
\text { sitions (together with } \\
\text { novelty and invariable } \\
\text { relation with the object) }\end{array}$ & $\begin{array}{l}\text { Non-deceiving and } \\
\text { revealing something } \\
\text { unknown }\end{array}$ \\
\hline $\begin{array}{l}\text { Perceptual } \\
\text { knowledge }\end{array}$ & $\begin{array}{l}\text { - Must ascertain its ob- } \\
\text { ject } \\
\text { - Ascertainment is a } \\
\text { conceptual determina- } \\
\text { tion } \\
\text { - Ascertainment carried } \\
\text { out by a subsequently } \\
\text { arising conceptual } \\
\text { cognition } \\
\text { - Failure to induce as- } \\
\text { certainment implies } \\
\text { failure to qualify as } \\
\text { knowledge }\end{array}$ & $\begin{array}{l}\text { - Must ascertain its ob- } \\
\text { ject } \\
\text { - Ascertainment con- } \\
\text { sists in eliminating } \\
\text { superimpositions } \\
\text { - Ascertainment car- } \\
\text { ried out by } \\
\text { perception itself } \\
\text { - Failure to eliminate } \\
\text { superimpositions im- } \\
\text { plies failure to } \\
\text { qualify as knowledge }\end{array}$ & $\begin{array}{l}\text { - Must not ascertain } \\
\text { its object (and can- } \\
\text { not do so itself) } \\
\text { - Every perception is } \\
\text { an episode of } \\
\text { knowledge }\end{array}$ \\
\hline $\begin{array}{l}\text { Non-ascertaining } \\
\text { perception } \\
\text { (snang la ma } \\
\text { nges pa) }\end{array}$ & $\begin{array}{l}\text { Is a perception that fails } \\
\text { to induce a determining } \\
\text { cognition }\end{array}$ & $\begin{array}{l}\text { Is a perception that fails } \\
\text { to eliminate superimpo- } \\
\text { sitions }\end{array}$ & $\begin{array}{l}\text { Is not a legitimate, } \\
\text { distinct type of } \\
\text { awareness }\end{array}$ \\
\hline $\begin{array}{l}\text { Perception of } \\
\text { something im- } \\
\text { permanent (and } \\
\text { suchlike cases) }\end{array}$ & $\begin{array}{l}\text { Is a non-ascertaining } \\
\text { perception }\end{array}$ & $\begin{array}{l}\text { Is a non-ascertaining } \\
\text { perception }\end{array}$ & $\begin{array}{l}\text { Is an episode of } \\
\text { knowledge that is ex- } \\
\text { trinsically determined }\end{array}$ \\
\hline $\begin{array}{l}\text { Determining } \\
\text { cognition (nges } \\
\text { shes)_A con- } \\
\text { ceptual cognition } \\
\text { arising after the } \\
\text { episode of per- } \\
\text { ception }\end{array}$ & $\begin{array}{l}\text { - Is required in order } \\
\text { for a perception to } \\
\text { qualify as knowledge } \\
\text { - Is not itself an episode } \\
\text { of knowledge } \\
\text { - Is a post-knowledge } \\
\text { cognition and a non- } \\
\text { understanding ( } m a \\
\text { rtogs) }\end{array}$ & $\begin{array}{l}\text { - Is not required in or- } \\
\text { der for a perception } \\
\text { to qualify as } \\
\text { knowledge } \\
\text { - Is not itself an epi- } \\
\text { sode of knowledge } \\
\text { - Is a post-knowledge } \\
\text { cognition }\end{array}$ & $\begin{array}{l}\text { - Is not required in } \\
\text { order for a percep- } \\
\text { tion to qualify as } \\
\text { knowledge } \\
\text { - Is required for } \\
\text { transactional usage } \\
\text { - Is not itself an epi- } \\
\text { sode of knowledge } \\
\text { - Is (in general) a } \\
\text { non-understanding } \\
\text { (ma rtogs) }\end{array}$ \\
\hline
\end{tabular}




\subsection{On Phya pa's use of the term "nges pa"}

The previous discussion has highlighted the meaning of the Tibetan term "nges $p a$ " in the sense of a determination that can only be performed by a conceptual cognition. In Phya pa's writings, while this is one of the senses in which the term is used, there are other uses that need to be distinguished, and for which we adopted a different equivalent in the English translation (see II).

\section{Determinate awareness, determination}

The most specific use of the term is in Phya pa's three-fold typology of awareness (see VI, Table D). There, nges pa is presented as a criterion to distinguish conceptual cognitions (rtog $p a$ ), provided that these cognitions involve the directing of one's mind (zhen $p a$ ). We refer to the episodes that fulfill this criterion as "determinate awareness" and to the criterion as "being determinate." It does not corresponds to the criterion of "partiality" used in the seven-fold typology to set doubt apart (see VI, Table E, criterion [1]), because the latter has a broader scope-it can apply both to conceptual and non-conceptual cognitions, whereas "being determinate" is exclusively a property of conceptual cognitions.

This use of "nges pa" excludes doubt, which involves directing one's mind but is not nges pa. ${ }^{130}$ Yet, in some discussions where the category of doubt is not an essential element, nges pa is used alternatively to zhen $p a$ (for instance Mun sel 112.111.111.3).

We also use the term "determination" for nges $p a$ when determinate awareness is further distinguished with regard to its correspondence, or absence thereof, with the object to be cognized. For Phya pa, a "determination" can thus be correct (in the case of inference, factive assessment, and conceptual post-knowledge cognition) or incorrect (in the case of some types of mistaken cognition). ${ }^{131}$

\footnotetext{
${ }^{130}$ Nges pa itself is opposed to the tshom, for instance, in Mun sel 9b5 (nges pa the tshom ma yin pa), $9 \mathrm{~b} 7$ (the tshom nges pa ma yin pas), and 10a7 (the tsom ma yin te nges pa yin).

${ }^{131}$ Note that Sa pan acknowledges these two uses of nges pa (which he terms yang dag pa'i nges pa and log shes kyi nges pa), but considers that the latter is just a metaphorical usage of the term (Rigs gter VIII 207,19-21: ... de tshad ma skyes pa na 'jig pas nges pa btags pa yin pa'i phyir / bshad par bya ba ma yin no //).
} 
A particular type of "determinate awareness" is the one that occurs directly following perception. It is sometimes referred to by Phya pa simply as a "determinate awareness," and occasionally with the more specific term nges shes (or the expression rjes su skyes pa'i nges shes), which we translated as "determining cognition" (respectively, "subsequently arising determining cognition"). ${ }^{132}$

\section{Determination/ascertainment}

A somewhat ambiguous use of nges $p a$ is found in various expressions in which the agent of the verb is knowledge (i.e., tshad mas nges pa), a type of knowledge, or a type of determinate awareness that is not knowledge (in particular factive assessment). Here, nges pa conveys the same idea as the verb 'grub pa, "to establish," which is also used (e.g., tshad mas grub pa).

When the agent is a conceptual cognition, the translation "determined by..." is unproblematic (e.g., rjes dpag gis nges pa "determined by an inferential cognition," yid dpyod kyis nges pa "determined by an episode of factive assessment"). Questions can be raised, on the other hand, when the agent is a non-conceptual cognition, such as reflexive awareness (e.g., rang rig gis nges pa, rang rig pas nges pa). ${ }^{133}$ In cases where such expressions are used in relation to the establishment that defining criteria or characteristics of a logical reason, etc., are established, we have adopted the translation "determined by...." But it is evident that this expression should be understood figuratively and not in the strict sense of a direct conceptual determination. It is not completely clear whether the figurative

\footnotetext{
${ }^{132}$ Phya pa does not direct much attention to this notion in the Mun sel, except when debating with proponents of the indirectly active model of perceptual knowledge.

${ }^{133}$ The ambiguity of such expressions echoes to some extent Dharmakīrti's use of the term niścaya/niścita in connection with knowledge (and in particular, perceptual knowledge), which leaves the door open to a literal interpretation of the term (implying, in particular, that perceptual knowledge itself determines its object) or to a metaphorical interpretation along the line of a two-step model. Indian and Tibetan interpreters exploit this ambiguity to adduce these passages in support of their own position. For some examples, see Nishizawa 2013 for an investigation of the positions of Śākyabuddhi and Arcața. Note, however, that Nishizawa posits in this paper the debatable premise that the divergences between the various interpreters is justified by Dharmakīrti being inconsistent in his writings.
} 
use is to be understood in reference to an indirect determination, i.e., a conceptual determinate awareness induced by the agent, or in reference to the elimination of superimpositions by the non-conceptual episode of awareness (such a use of nges $p a$ is found in the works of Phya pa's successors, cf. n. 123). In other cases, when the establishment pertains to the nature or some feature of the object, we have kept the less specific translation "ascertained."

\section{Elucidation}

Finally, one can note a less 'technical' use of nges pa in numerous section titles that state the points that the author wants to establish. We have translated in such contexts nges par bya ba as "to be elucidated."

\section{Notes on Phya pa's background}

\subsection{The Indian background}

I have until now intentionally refrained from extensively referring to Dharmakīrti's own theory of knowledge and (with a few exceptions) from linking the terms and notions in Phya pa's theory with equivalent Sanskrit terms. One reason for that is that Dharmakîrti's explanation of knowledge gave rise to many conflicting interpretations both in the Indo-Tibetan tradition and among modern scholars. ${ }^{134}$ Another reason is that even when Phya pa uses a terminology that clearly echoes key Sanskrit terms found in Dharmakirti's writings, he may use the Tibetan reflex-terms in a way that is quite different from their use in Indian sources. It is thus important to gain a firm understanding of Phya pa's theory on its own terms before looking at its background. This section does not purport to solve the issue of Dharmakirti's final intent or to establish whether Phya pa 'got Dharmakīrti right.' Rather, the idea is to assess the Indian sources that may have had a direct or indirect influence on the elaboration of his own position and to reflect on Phya pa's treatment of these sources. One must also bear in mind that Phya pa might be accessing these Indian sources through the lens of his Tibetan forerunners. A connected issue in this regard is whether Phya pa was the first to put forward the definition

${ }^{134}$ See Dreyfus 1991 for an outline of various Indian and Tibetan interpretations. Regarding the interpretation of modern scholars, see, for instance, Katsura 1984 and Dunne 2004. 
of knowledge examined above, or whether he was building on the presentation of one or some of his predecessors (see §5.2).

In the exegetical tradition Phya pa is part of, it is customary for scholars to ground their own position by citing or referring to Dharmakīti's words and offering an interpretation of these words supporting their own position, which they do more or less subtly and convincingly. They may exploit the ambiguity of the phrasing of the source text for their own agenda or resort to more extreme exegetical practices to justify the adoption of a position that is at odds with a straightforward and broadly accepted reading of the source text. ${ }^{135}$ Debates between supporters of conflicting positions are thus often framed as debates about the interpretation of some passage of the source text. Typically, for instance, Sa pan, when discussing the issue of perception in relation to determination and the elimination of superimpositions, provides numerous citations from Dharmakīrti's works which he considers to support a passive model of perception and discusses the interpretation of other passages which a hypothetical opponent adduces as evidence against this model. ${ }^{136}$

In contrast, throughout the Mun sel, Phya pa hardly refers to Dharmakirti's source text explicitly. In the passages pertaining to the definition of knowledge, the only explicit references are to Dharmakirti's two verses of the Pramānavārttika (Dhk2 and Dhk3, see §2.2). In this regard, Phya pa can hardly be considered to offer a subtle exegetical strategy. He simply presents his own theory as representing the meaning of these passages, but does not engage in any detailed attempt at justifying in what way his own theory might represent a viable interpretation of the source text, rather than just his own position. ${ }^{137}$

\subsubsection{Phya pa's reference to Śankaranandana}

Phya pa's appeal to Śankaranandana when stating his definition of knowledge (which, one may note, he makes only in the Mun sel but not in the 'Od zer) might be taken as an attempt of indirect justification,

\footnotetext{
${ }^{135}$ For instance, Jñānaśrīmitra characterizes some of Dharmakīrti’s well-known statements as "white lies," which enables him both to legitimate these statements and adopt an opposite position (McCrea\&Patil 2006).

${ }^{136}$ See Hugon 2008b: 407-409.

${ }^{137}$ In the same way, when commenting on the PVin (Dhk1) in the 'Od zer (see n. 124), Phya pa just glosses the key expressions by referring to his own system, without going into a justification of this explanation.
} 
which, for traditionally oriented readers, would have had the merit of at least invoking an Indian foundation for the position being presented. But this reference is in itself peculiar, in particular given that the work of Sankaranandana in which the passage that is the probable source of the short definition "understanding a veridical object" can be located, the Bṛhatprāmānyaparìkșa , was not translated into Tibetan. This work is also not mentioned among the Indian works on which rNgog Lo authored an exegesis. This raises the question of how Phya pa became aware of Śnikaranandana's position on this point - oral transmission via rNgog Lo's pupils being the most likely option. Another question is the extent of Phya pa's awareness of Śankaranandana's position. Is Phya pa's reference to Sankaranandana in this context merely opportunistic (destined to the traditionally oriented reader likely to raise the objection that there is no Indian source supporting this definition)? Or is his position more profoundly inspired by Śankaranandana, and by Śankaranandana's Bṛhatprāmānyaparīkșā in particular? Does one also find support in Śankaranandana's work for Phya pa's interpretation of the short definition- "understanding a veridical object"- (in particular his interpretation of the term 'veridical'), and for Phya pa's extended definition involving criteria $\mathrm{K} 1$ and $\mathrm{K} 3$ in the Mun sel and criteria K1-K4 in the 'Od zer? ${ }^{138}$ This is not impossible, given that Śankaranandana's position is mentioned several times by Phya pa, and that Śankaranandana's works are definitely identifiable as the (direct or indirect) source for other key notions in Phya pa's philosophy of mind, such as the three "operations" (byed pa) associated with conceptual cognitions (see Mun sel 112.111.111 and VI, Table D), whose source can be traced in the Apohasiddhi. ${ }^{139}$ The profuse use of

${ }^{138}$ The reference to Śankaranandana as a source in this regard was criticized by mKhas grub rje as being unfounded. Cf. rGyan mun sel 60b1-3: snga rabs pa dag bram ze chen po // bden pa'i don rtogs chos gsum ldan tshad ma'i mtshan [6062] nyid du bzhed (em. bzhed: rGyan mun sel bzhad) la / da yang chos (em. chos : rGyan mun sel chas) gsum ni yul gyi khyad par sngar ma rtogs pa!' 'dzin stangs kyi khyad par ma 'khrul ba / byed las kyi khyad par sgro 'dogs sel ba'o zhes zer ba ni / tshig gi sgra sgrog pa tsam zhig snying por zad de / bram ze chen po'i gzhung bod du 'gyur [6063] ba gang na yang zur tsam yang med pa'i phyir dang / gzhan yang bram ze de ltar bzhed pa'i khungs gang yang mi snang ba' $i$ phyir ro //. Note that mKhas grub rje is not referring here to Phya pa's definition properly speaking, but to the later version in which criteria K1-K3 are specificities of the "understanding of a veridical object."

${ }^{139}$ See Hugon 2008b: 178-179, n. 131 and 132. 
the notion of "eliminating superimpositions" in this very work could make it a plausible source of inspiration for Phya pa, although one can note at the outset that Śankaranandana does not vouch for the elimination of superimpositions by perception. ${ }^{140}$ An answer to the exact influence of Śankaranandana on Phya pa's definition of knowledge will have to await further studies of the manuscript of the Bṛhatprāmānyaparìsṣa. ${ }^{141}$

\subsubsection{The Dharmakirtian background for the definitional criterion "elim-} inating superimpositions" (K1)

In his criticism of Phya pa's position, Sākya mchog ldan notes that the idea that knowledge requires eliminating superimpositions does not find any support in Dharmakīrti's writings. ${ }^{142}$ While it is true that Dharmakīrti does not properly speaking define knowledge in such a way, Dharmakīrti does relate these two notions in his works. The fact that the expression sgro 'dogs gcod pa would remind readers with a Dharmakīrtian background of the theory of exclusion (apoha) was already evoked above (§3.1.4). More specifically, one may think of passages in which Dharmakīti links the notion of samāropavyavaccheda, (Tib. sgro 'dogs pa rnam par bcad pa/rnam par gcod par byed) with that of apohavisaya (Tib. sel ba'i yul can, "having for its object an exclusion").

A key passage in this regard is PV 1.43-51 cum PVSV in the context of the larger discussion on apoha ${ }^{143}$ Dharmakirti focuses on the cases of inferential cognition (k. 46-47) and of the non-inferential determining cognition that arises after a perception ( $\mathrm{k} .48-49)$. The discussion of the latter, in particular, involves the idea that "determination" (niścaya) and "superimpositions" (samāropa) stand in a relation of "opposition" (Skt. bādhya/bädhaka, Tib. gnod bya/gnod byed).

In this discussion, the attention seems to be on the absence or presence of a superimposition "non- $x$ " as a phenomenon rather than on the content of this superimposition (i.e., "non- $x$ ") being negated. The discussion is not so much about the determination " $x$ " excluding non- $x$, but about the

\footnotetext{
${ }^{140}$ Cf. AAS ad k. 10 (D286a2): mngon sum ni sgro 'dogs sel ba'i byed pa can ma yin no //

${ }^{141}$ See Eltschinger 2006: 93 for preliminary information.

${ }^{142}$ See Pham byed 2 158a4 (p. 315): de yang tshad ma yin na sgro 'dogs gcod pas khyab pa la ni lung yod pa min te / sde bdun nas ma bshad pa'i phyir ro //

${ }^{143}$ See also the conclusion in PV 1.56 cum PVSV. There is no similar discussion in the Pramānaviniścaya.
} 
occurrence of the determination " $x$ " eliminating an existing phenomenon of superimposition as "non- $x$ " (in the case of inferential cognition), ${ }^{144}$ or taking place in the absence of the phenomenon of superimposition (in the case of post-perception determination).

One can note that this passage is precisely the one referred to in epistemological treatises postdating Phya pa who cite Dharmakīrti in support of the specification K1 (cf. n. 112). Could it be that Phya pa indeed built his model on the background of this passage? As a matter of fact, a detailed reading of this passage reveals an understanding of when and how superimpositions arise and are eliminated that is radically different from Phya pa's. Let us consider, for example, the case of the perception of something blue. In Phya pa's understanding, at moment $t_{1}$, there is a contact between perceptual awareness and the superimposition "non-blue." The latter comes to be annihilated, so that perception can be said to have eliminated the superimposition "non-blue." But the situation presented by Dharmakīrti is that the superimposition "non-blue" simply does not arise when perceiving the blue object, because there are no causes of error. A determination ("this is blue") can thus take place immediately after the perception, and its arising in the absence of the superimposition "nonblue" is the reason it is said to "eliminate the superimposition non-blue."

Bearing in mind, in addition, that Dharmakirti limits in this discussion the features of "elimination of superimpositions" and "exclusion of what is other" to conceptual cognitions, such a passage could be considered to have been a source of inspiration, but not of influence properly speaking.

Further, one should keep in mind that Phya pa might have been acquainted with this passage in an indirect way, through the lens of a commentary or an account of this discussion by his Tibetan forerunners. A possible medium could well have been the exegesis on this passage by Śankaranandana in his incomplete commentary on the Pramānavārttika, whose Tibetan translation is ascribed to $\mathrm{rNgog} \mathrm{Lo}$, and part of which rNgog Lo discusses in some detail in his $d K a^{\prime}$ gnas. This is to be left for future investigation. ${ }^{145}$

${ }^{144}$ Dharmakīrti argues against the possibility of an inferential cognition that would not be preceded by a mistaken cognition (i.e., a superimposition). For instance, inferring "fire" from the perception of smoke always presupposes the mistaken cognition "there is no fire."

145 Several key terms of Phya pa's discussion are indeed found in this commentary. Notably, Śankaranandana speaks of determination being "incompatible" ('gal ba) with superimpositions (PVṬ 174b4: de med pa la nges par 'jug pa ni 


\subsection{The Tibetan background}

5.2.1 Tibetan background for the definitional criterion "eliminating superimpositions" (K1)

While the source of criterion K1 might ultimately be found in Indian literature, Phya pa's adoption of this criterion might actually have been influenced by the Tibetan milieu in which he studied and was active. Indeed, a discussion in a Madhyamaka treatise by rGya dmar ba, who had been Phya pa's teacher, reveals that rGya dmar ba already knew of (and, it seems, himself subscribed to) a definition of "understanding" (rtogs pa) in terms of "eliminating opposite superimpositions" (sgro 'dogs gcod pa). ${ }^{146}$ rGya dmar ba even indirectly associates this notion with the idea that "knowledge has for its object the exclusion of others." ${ }^{\text {" }}$ "Phya pa did not accept the latter for all types of knowledge ("exclusion of others" [gzhan sel] amounts to the operation of excluding others, which inferential cognition has, but perceptual knowledge does not have). But once he defines "knowledge" in terms of "understanding of something veridical" it is easy to see how the elimination criterion (associated with "understanding" by rGya dmar ba) would have become part of the definition of knowledge.

What one finds in rGya dmar ba's treatise nicely corroborates the definition of non-ascertaining perception ascribed to "rGya" in the Tshad bsdus (see IV, 1(b) and IV, 6.1 [vii]), which involves the notion of "compatibility with superimpositions," thus suggesting that "rGya" (which I

de dang 'gal bar rtogs pa'i phyir de zlog par nges par byed pa'i phyir ro //); he mentions the idea that a fire is held to be capable of opposing cold even in the absence of cold (PVȚ 174a4: gzhan nyid kyis bzlog zin pas med pa na ni 'di de zlog par byed pa ma yin par mi 'gyur te / grang ba med me la grang ba zlog pa' $i$ nus pa med pa ma yin pa'i phyir ro //); and he uses the term gnyen po ("counteragent") to refer to the state of affairs that counters superimpositions (PVT 175b4). One should also consider the relation between this passage of the PVT and Śankkaranandana's AAS. rNgog Lo presents Śankaranandana's interpretation of the reason why there is no determination of "impermanence" and confronts it with other explanations by Śākyabuddhi and Dharmottara in $d K a$ ' gnas 353-358. ${ }^{146}$ See $d B u$ ma de kho na nyid 6a3: gang las bzlog pa'i sgro 'dogs chod pa nyid de rtogs pa'i mtshan nyid yin te / sngon po las bzlog pa'i sgro 'dogs chod pa nyid sngon po rtogs pa bzhin no //

${ }^{147}$ dBu ma de kho na nyid 6a3: des na tshad ma ni gzhan sel ba'i yul can yin la / 
hence surmise to be rGya dmar ba) held "incompatibility with superimpositions" to be part of the definition of knowledge.

\subsubsection{Tibetan background for the short definition of knowledge}

Phya pa connects the definition of knowledge in terms of "understanding of something veridical" with Śankaranandana. However, Phya pa's adoption of the latter as a short definition might have been prompted by rNgog Lo's discussion on the topic. Indeed, in the $d K a$ ' gnas, rNgog Lo presents his own position as follows:

What establishes a veridical object is knowledge. And, in relation to a convention, it is defined by "non-deceiving." 148

rNgog Lo seems to differentiate here knowledge as a state of affairs - (an awareness) that establishes a veridical object - and the characteristic that defines it as being knowledge, i.e. "being non-deceiving." 149 In other words, "non-deceiving" is the definiens of knowledge, and episodes of awareness that establish a veridical object are definitional instances of knowledge. ${ }^{150}$

148 dKa' gnas 44,13-15: bden pa'i don gtan la 'bebs pa ni tshad ma yin la / de yang tha snyad la ltos te myi slu bas nye bar mtshon pa'o //. See also $d K a$ ' gnas 37,15: myi slu bas nye bar mtshon pa'i bden pa'i don rtogs pa tshad ma'i mtshan nyid yin pa ltar na yang.

${ }^{149}$ The author of the Tshad bsdus ascribes to rNgog Lo the view that: "Being non-deceiving is the witness of understanding a veridical object, because when someone proceeds, i.e., goes forward, having determined, for instance, blue, he or she is not deceived because he or she obtains it (i.e., blue)" (Tshad bsdus 116,19-21: lo tsa ba na re mi slu ba ni bden pa'i don rtogs kyi dpang po yin te sngon po lta bu bcad nas zhugs te phyin pa na de thob pas ma bslus pa'i phyir ro zhes zer ro//).

${ }^{150}$ Śākya mchog ldan reports rNgog Lo's definition of knowledge to be "just being an awareness that is non-deceiving" (mi bslu ba'i rig pa tsam) (Pham byed 2 156b6-7, p. 312). The mention "just" (tsam) implies a contrast with Dharmottara's definition, phrased as "an awareness that is non-deceiving, with three specifications" (mi bslu ba khyad par gsum ldan gyi rig pa) (idem, 156b6). See also Rol mtsho 78b1-4 for an account of Dharmottara's position and the statement that "rNgog Lo also appears to have asserted this very meaning" (lo tsa ba chen po yang don de nyid bzhed par snang ngo). 


\section{Conclusion}

Phya pa's definition of knowledge aims at providing a unified and unifying criterion with regard to all types of knowledge, perceptual and inferential, conventional and ultimate, from the knowledge of ordinary people to that of the omniscient. As hinted at the beginning of $\S 3$, Phya pa's novel definition of knowledge also impacts on the scope ascribed to episodes of knowledge. The short definition of knowledge as "understanding a veridical object" (referred to as being Śankaranandana's, but possibly influenced already by rNgog Lo's discussion of the topic), together with the interpretation of the term "veridical" as "being unopposed" and "existing according to its natural disposition," is a key move in expanding the scope of knowledge to include non-entities and what belongs, in the Madhyamaka framework of the Two Truths, to the realm of ultimate reality. Phya pa's objections against alternative definitions of knowledge by Indian commentators indirectly highlight this concern as well: these alternative definitions are criticized for not enabling one to account for the full range of the epistemic objects that Phya pa wants to take into consideration. Phya pa thus makes a clear move away from a conception of knowledge focusing on worldly interactions with objects capable or not of fulfilling an expected function towards a conception of knowledge that has to do with the awareness of things as they really are, whether it means being able to fulfill a given function, being a hallucination, or being empty. ${ }^{151}$ Indeed, Phya pa's system accounts for "emptiness" being an object of knowledge. Dharmakirti's model has thus be reframed to function in a Madhyamaka framework and to apply at all its levels.

Phya pa's endeavor to classify the various types of awareness that are not knowledge provides important insights into the understanding of the criteria that are constitutive of knowledge. But Phya pa's analysis has further applications beyond his philosophy of mind, in particular in his

\footnotetext{
${ }^{151}$ See Hugon 2011a: 161-164 for a previous discussion on Phya pa's short definition and the meaning of the term "veridical," and Hugon 2011b for a reevaluation of a 'practicalist' interpretation of Dharmakirti's idea of knowledge in view of passages that support the inclusion of non-entities within the range of epistemic objects. Dreyfus (1997a: 301-302) notes that most dGe lugs pa thinkers adopt this interpretation of the criterion of knowledge "in intentional terms" rather than "in pragmatic terms."
} 
theory of argumentation. ${ }^{152}$ Indeed, Phya pa considers it essential, when presenting an argumentative statement in a debate, to take into account the mental state of one's opponent. The proponent could, for instance, opt for an argument by consequence (thal 'gyur) when the opponent has a mistaken cognition about the thesis (for instance, he mistakenly holds sound to be permanent), but he would be better advised stating a direct proof (rang rgyud) if the opponent is in doubt about the thesis or has ascertained it through factive assessment. Further, when stating a direct proof (or a consequence), the proponent should be aware of the mental state of the opponent regarding the characteristics of the logical reason that the statement intends to present. The opponent may already have a vivid knowledge of the respective characteristics, he might have once had an episode of knowledge but subsequently forgotten about it, or he might never have achieved an episode of knowledge. What is to be stated or not by the proponent, and in which way (in order to avoid a redundant or an incomplete statement, which would be occasions for defeat), is thus dependent on a precise identification of the opponent's mental state. ${ }^{153}$

Further research into Phya pa's multifaceted compositions will enable us to understand better how Phya pa combines, in his overall philosophical agenda, epistemological concerns inherited from the Indian Dharmakīrtian tradition, specific issues related to the Madhyamaka enterprise, and other questions related to the general Buddhist framework in which the figures of the Buddha and various beings on the path to enlightenment have to be accounted for when it comes to knowing reality.

${ }^{152}$ On this topic, see Hugon 2011c and Hugon 2013b.

${ }^{153}$ On the problem or achieving such an identification when the proponent does not benefit from an insight above the ordinary, see Hugon 2011c: 120-121. 



\section{II}

Translation 



\section{Epistemology—The Dispeller of the Mind's Darkness}

In Sanskrit: Pramāna manas tamas tānava.

In Tibetan: Tshad ma yid kyi mun pa sel ba. ${ }^{1}$

[EX1: Invocation and introductory verses $]^{2}$

$* * *$ First chapter: Determining the divisions of awareness $* * *$

For the exact determination of the system of knowledge, two items will be presented:

- In general, the division of awareness (1)

- In particular, elucidating the instances of awareness that are episodes of knowledge (2)

\section{In general, the division of awareness}

There are two items:

- The three-fold division of awareness based on the apprehended object (11)

- The seven-fold division of awareness based on both the apprehended object and intentional object (12)

\footnotetext{
${ }^{1}$ The Mun sel is the only work of Phya pa (among the works for which the first page of the manuscript is not missing) that provides a Sanskrit title, and also the only one in which the text proper (not counting the indication on the cover page of the manuscript) starts with the mention of the work's title.

On the Tibetan custom of including bilingual titles for autochthonous works, see Almogi 2005: 51-54. Here, as is often the case in such works, the Sanskrit title provided is not a proper Sanskrit expression. It consists in the juxtaposition of a phonetic equivalent of the Sanskrit translation of each word of the Tibetan title arranged according to the order of the words in the latter: tshad mapramāna; yid-manas; mun pa-tamas; the Sanskrit tānava for the Tibetan sel ba is peculiar. The Sanskrit title may be an echo of the term manastamastānavam (Tib. yid kyi mun pa sbyong bar mdzad) occurring in the introductory verse of Dharmottara's Nyāyabinduțīka .

${ }^{2}$ On this portion of the text and the four other excursuses in the first chapter of the Mun sel that have not been translated here (marked EX1 to EX5), see VII, Appendix 1.
} 


\section{The three-fold division of awareness based on the apprehended object}

(a) In general, apprehended objects, which are those that appear to awareness, are three-fold:

i. Real particulars

These are clearly appearing without being mixed with respect to time or place, and capable of being causally active. They are: what appears as an apprehended object - the five objects (of the senses), the five senses, and what is part of the physical world - as well as all episodes of awareness - namely, mind and mental factors.

ii. Concepts

These are not clearly appearing, since they appear as mixed with respect to time and place, and are incapable of being causally active. They are: what suddenly arises to conceptual cognition - whether past, present or future, near or far, real or unreal, possible or impossible, or anything at all that one contemplates.

iii. The referents of non-conceptual erroneous cognition

These are clearly appearing without being mixed with respect to time and place, but are incapable of being causally active. They are: appearances such as a double moon and an elephant within a dream.

(b) Likewise, awareness is three-fold, because it engages these three objects:

i. That which takes as its apprehended object a real particular This includes: the reflexive awareness that exists for every cognition, the sense cognition in which there is the appearing of one of the five sense objects - form, etc. - together with what accompanies it, ${ }^{3}$ the mental cognition in which there is an appearance of those

\footnotetext{
3 "What accompanies sense cognition" refers to the mental factors (Skt. caitta) associated with the episode of cognition. These include feelings and positive or negative inclinations, such as mindfulness, diligence, hatred, envy, etc. More specifically, Phya pa could be referring to the mental factors that always accompany cognition. According to Vasubandhu's Pañcaskandhaprakarana, those are contact (sparśa), feeling (vedanā), recognition (samjiña), volition (cetanā), and attention (manasikara). Phya pa lists 51 mental factors in his doxography, when presenting the views of the Vaibhāșikas (Grub mtha' 20b2-5). See Rinpochay\&Napper 1980: 36-39 for a list of 51 mental factors divided into six
} 
sense cognitions, together with yogic cognition. ${ }^{4}$ These are perceptions, which are non-conceptual. Because the object is veridical, ${ }^{5}$ the awareness is non-erroneous. The object and awareness are both real entities. They are both dependent (from the perspective of the Three-Nature model). ${ }^{6}$

categories. Lists including 52 mental factors and seven mental factors that always accompany cognition are also found in Abhidharma literature.

${ }^{4}$ Reflexive awareness, sense cognition, mental cognition and yogic cognition are the four types of awareness considered by the forefathers of Buddhist epistemology Dignāga (PS 1.6-7, see Hattori 1968: 27) and Dharmakīrti (PV 3.192-287) when they distinguish the types of perceptual knowledge (Skt. pratyakșa). In the chapter on perception in the Mun sel, Phya pa adopts this four-fold division for perception but holds the three-fold division of transitive awareness into sense cognition, mental cognition and yogic cognition to be merely grounded in scriptures (Mun sel 42a5-7; see also 'Od zer 47a2-5).

${ }^{5}$ The reader should note our (somewhat idiosyncratic) use of the term "veridical" (and its parallel term "falsidical"). Throughout this translation, the term "veridical" is used to translate the Tibetan bden pa (and "falsidical" translates the Tibetan brdzun pa). Here and in most occurrences within this text, to say of something that it is "veridical" is to say that it is causally efficacious, and thus that it applies to real entities (dngos po) alone, whereas a separate understanding of veridical is at work in Phya pa's characterization of veridical engaged objects (see 121.3, n. 41). When used in this manner, it is objects (yul) that either are or are not veridical.

This is mentioned because our use here differs from the standard application of the term(s) veridical (and falsidical) in contemporary philosophy of mind. There, the term "veridical" is applied not to objects but to experiences. Perception, for example, is typically regarded as a kind of veridical experience-in contrast to illusion and hallucination, which are frequently assumed to be nonveridical (or falsidical) kinds of experiences.

In short:

a) The term "veridical" (bden pa) for Phya pa, in most circumstances, approximates what contemporary philosophers of mind would call "real" (in the sense of being causally efficacious).

b) The term "veridical" for contemporary philosophers of mind approximates what Phya pa would call "non-erroneous" ( $m a$ 'khrul ba).

Yet, for Phya pa, having a veridical apprehended object (gzung yul bden pa) is a feature only possessed by non-erroneous cognitions, and so it is largely for this reason that we have used "veridical" to translate the term bden pa.

${ }^{6}$ On the various characterizations of the object and the awareness see VI, Table A. 
ii. That which takes as its apprehended object a concept This includes: mental cognition that is oriented outwards, ${ }^{7}$ together with what accompanies it. This is conceptual cognition. Because the object is falsidical, the awareness is erroneous. The object is unreal, but the awareness is real. (From the perspective of the Three-Nature model) the object is imagined and the awareness is dependent.

iii. That which takes as its apprehended object the referent of a nonconceptual erroneous cognition

This includes: the sense cognition consisting of, for example, the appearance of a double moon, and the mental cognition consisting of, for example, a clear appearance within a dream. This is nonconceptual erroneous cognition. Because the object is falsidical, the awareness is erroneous. The object is unreal, but the awareness is real. (From the perspective of the Three-Nature model) the object is superimposed and the awareness is dependent.

Here, there are two items:

- The three types of objects (111)

- The three types of awareness (112)

\footnotetext{
${ }^{7}$ Phya pa uses the expression "being oriented outwards" on this single occasion in the Mun sel. Later authors, such as Sa skya Pandita (see Hugon 2008b: 531 [d]), make it clear that the qualification "being externally oriented"/"being oriented outwards" (Tib. kha phyir (b)ltas, Skt. bahirmukha) expresses the mind's relation to an object in opposition to "being internally oriented"/"being oriented inwards" (Tib. kha nang (du) bltas, Skt. antarmukha), which is a characteristic of reflexive awareness. The association of the notion of "being oriented outwards" with conceptuality is found in the Abhidharmakośa - more precisely, the association with the types of conceptuality called "conjecture" (Skt. vitarka, Tib. rtog $p a$ ) and "analysis" (Skt. vicāra, Tib. dpyod pa), which are present in any mental state in the so-called "realm of desire" (kämadhātu), which corresponds to the realm human beings live in (see AKBh ad AK I.32ab-33ab, and AK II.33ab). This characterization bears some similarity with the notion of "being directed externally" (phyi rol du zhen pa), on which see below, n. 14 and 15, but the former is attached by Phya pa to conceptual cognition in general, whereas he distinguishes some instances of conceptual cognition in which the latter is lacking.
} 


\section{The three types of objects}

\section{(a) Excursus on the three apprehended objects in various philosophical systems}

\section{[EX2: Refutation of other philosophical systems]}

\section{Our own position}

Thus, mind and mental factors, external objects, the senses, and the physical world, etc., all of these, are real. These all exist as objective and subjective elements, in that they are distinct, simultaneous, and have the same complex of causes. ${ }^{8}$

A double moon, etc., and concepts are unreal, since they are incapable of being causally active.

Conventionally, these objects exist in a way that accords with worldly consensus.

\section{(b) The status of real entities and the way they are apprehended}

The elucidation of real entities involves four items:

- Their being devoid of distinction (1)

- The way distinction is superimposed (2)

- Their being devoid of commonality (3)

- The way commonality is superimposed (4)

\section{Their being devoid of distinction ${ }^{9}$}

- The blue thing itself is not different from its impermanence because it will cease at another moment. And it is not different from its being produced because it was generated by causes.

\footnotetext{
${ }^{8}$ The simultaneity of the object and its cognition and their being the result of the same complex of causes are two tenets that match the model of cognition adopted by Vaibhāṣika philosophers, with whom Phya pa has been associated by later scholars, although he does not himself claim any affinity with the Vaibhāṣika. See Hugon 2016c: $\$ 3.3$.

9 The void of distinction is exemplified by the case of an unspecified real entity (which could be, for example, a lapis-lazuli) which can be described as being "blue," "produced," and "impermanent" and as having the corresponding properties. Some additions were made here and below in the translation to account
} 
- The produced thing itself is not different from its blue because it is excluded from non-blue. And it is not different from its impermanence because it does not abide for another moment.

- The impermanent thing itself is not different from its blue because it is excluded from non-blue. And it is not different from its being produced because it was generated by causes.

Even though the concepts 'blue,' 'produced,' and 'impermanent' appear individually, the real particular is undifferentiated. This is to be viewed in the same way for all the exclusion properties that exist for each essence. $^{10}$

for the ambiguity of the Tibetan formulation, which does not distinguish between a thing instantiating a property and the property being predicated to it. To some extent, in fact, this ambiguity can be used on purpose. For instance, mi rtag pa and byas pa are said to be "substantially identical" (rdzas cig) or "essentially identical" (ngo bo cig) when these terms are understood to refer, respectively, to "the impermanent thing" and "the produced thing" (both of which are, for instance, the lapis-lazuli). But when these terms are used to refer to the properties 'impermanent' and 'produced,' they represent distinct exclusion properties (ldog pa tha dad) and are "conceptually distinct." To make the text intelligible in English, we removed the ambiguity, rendering accordingly, for instance, mi rtag pa, as "the impermanent thing" or respectively as "its impermanence" (i.e., the impermanence of the blue thing).

${ }^{10}$ The term "exclusion property" is used here to translate the Tibetan ldog pa. This term and other terms in this paragraph and the following ones (e.g., $\log p a$ and $\log s a$ ) are linked with Dharmakirti's theory of "exclusion" (Skt. apoha) (see Siderits et al. [eds] 2011). A key notion of this theory is that real entities (which are in themselves unique and undivided) are not categorized on the basis of positive properties existing in reality. Admitting such properties, shared among entities, would commit one to accepting real universals, which Buddhist epistemologists such as Dignāga and Dharmakīrti reject. The latter, rather, invoke as a categorizing principle the exclusion of entities from a counterpart within a conceptually established network of oppositions. Real entities determined to belong to a category $X$ are thus said to be "excluded" (Tib. $\log p a$, Skt. vyāvrtta) from the counterpart non- $X$, for which Phya pa uses below the term $\log s a$, literally "the ground of exclusion." Although a positive corresponding concept ' $x$ ' arises and a positive word " $x$ " is applied (for instance "blue"), the relevant categorizing property is not a positive property $x$, but the "exclusion from non- $x$." Phya pa refers to it in terms of ldog pa (Skt. vyāvrtti) - lit. "exclusion." An entity can be ascribed as many such $\log p a$ as there are counterparts being taken into consideration. Our translation, "exclusion property" is meant to hint to the role these 
If this was not the case, given that in the case of directly incompatible items ( $x$ and non- $x$ ), the negation of the opposite one (non- $x$ ) is the essence of the other $(x)$, there would be faults such as the following:

- If the blue thing was distinct from its impermanence, it would be permanent. And if it was distinct from its being produced, it would be unproduced.

- If the produced thing was distinct from its blue, it would be non-blue. And if it was distinct from its impermanence, it would be permanent.

- If the impermanent thing was distinct from its blue, it would be non-blue. And if it was distinct from its being produced, it would be unproduced.

\section{The way distinction is superimposed}

If these are undifferentiated, how can one account for the worldly practice of distinguishing the elements of an inferential reasoning: the subject, 'blue;' the logical reason, 'produced;' and the property to be proven, 'impermanent'? And how is it that they are stated as distinct in the treatises, which say that 'blue' belongs to the aggregate of form and 'produced,' 'impermanent, 'etc., to the aggregate of compositional factors? ${ }^{11}$

This is a matter of conventions that are superimposed. And in this regard there are two items:

- The origin of the superimposition of distinction (21)

- The representation of the superimposition of distinction (22)

ldog pa play in processes of predication and categorization. Earlier and later authors actually speak of them in terms of "properties." rGya dmar ba, one of Phya pa's teachers, uses in an equivalent manner the two expressions ldog pa tha dad and chos kyi dbye ba. Sa skya Pandita uses the term ldog chos.

${ }^{11}$ The classification of phenomena (Skt. dharma, Tib. chos) into five categories of aggregates (Skt. skandha, Tib. phung po) of physical and mental events - form (Skt. rūpa), feelings (Skt. vedanā), recognition (Skt. samjiña), (volitional) formations (Skt. samskāra) and consciousness (Skt. vijñanna) - goes back to the early Buddhists texts and is dealt with systematically in the Abhidharma in the analysis of the nature of experience and of individual beings, supporting the claim of the absence of a personal self. For an introduction and further bibliographical references, see, for instance, the entry "Skandha (Aggregate)" by Mathieu Boisvert in Buswell (ed.) 2004: vol. 2, 779. 


\section{The origin of the superimposition of distinction}

For a singular essence, distinct mistaken cognitions - conceiving it as non-blue, conceiving it as unproduced, and conceiving it as permanentare to be eliminated, and the singular essence is excluded from the multiple intentional objects of those mistaken cognitions. There is, therefore, the positing of multiple exclusion properties.

\section{The representation of the superimposition of distinction}

Individual concepts arise for these three (i.e., blue, impermanent, and produced).

- The arising concept 'blue' is conceived of as external. Thus, the superimposition 'non-blue' is excluded first. As such, the subject 'blue' is initially established.

- Next, the concept 'produced' arises. It is conceived of as external. Thus, the superimposition 'unproduced' is excluded. As such, the logical reason 'produced' is determined next.

- The concept 'impermanent' arises. But there is no directing of one's mind externally, so the superimposition 'permanent' is not excluded. As such, the property to be proven, 'impermanence,' needs to be established afterward. ${ }^{12}$

In this way, there is superimposing as distinct.

\section{Their being devoid of commonality}

Although one uses the single convention "blue":

- The blue in another place is distinct from the blue in this place.

- The blue in the past, etc., is distinct from the blue in the present time.

12 "Appearing," "directing one's mind," and "excluding" are three operations of conceptual cognition that are discussed below (112.111.111). On the alternative renderings of phyi rol du zhen pa as "conceiving of ... as external" and as "directing one's mind externally" see $\mathrm{n}$. 14. The absence of directing of one's mind in the case of the concept 'impermanent' is to be associated with an episode of doubt preceding the arising of the inferential cognition properly speaking, as the latter will involve the directing of one's mind and the exclusion of the superimposition 'permanent.' Doubt has, in general, the operation of directing one's mind, but not in a determinate way that would be partial to 'impermanent' (see 112.112). 
- The blue of the lotus is distinct from the blue of the lapis-lazuli. ${ }^{13}$ This is because, if they were not distinct, there would be the following consequences:

- When perceiving the blue in this place, one would also perceive the blue in another place.

- When the blue in the past has ceased, the blue in the present would also have ceased.

- When the blue of the lotus has faded, the blue of the lapis-lazuli would also have faded.

\section{The way commonality is superimposed}

If that is so, how does one come to use the single expression "blue" for distinct natures?

It is by way of superimposing.

- The reason for the superimposition is the following: with regard to these individual substances, there is the single superimposition 'non-blue' that is to be eliminated, and the individual substances are excluded from a single counterpart. There is, therefore, superimposing as one.

- The representation of the superimposition is the following: the arising of a single concept for all of the distinct substances.

\section{The three types of awareness}

The division of the subjective element (i.e., awareness) is three-fold:

- Conceptual cognition (112.1)

- Non-conceptual non-erroneous cognition (112.2)

- Non-conceptual erroneous cognition (112.3)

\footnotetext{
${ }^{13}$ These three points spell out the unicity of a particular entity with regard to space, time, and aspect. "Lapis-lazuli" renders here the Tibetan be du rya (calque of the Sanskrit vaidurrya). This term strictly speaking refers to beryl, which can be of various colors (green, blue, rose or yellow). But in epistemological works, vaidurrya is exclusively used to refer to a blue stone. We have thus preferred the term "lapis-lazuli," which makes this feature of the intended example more explicit than "beryl." See Hugon 2008b: 166, n. 98 for references.
} 


\subsection{Conceptual cognition}

Conceptual cognition has two subtypes:

- That which is directed externally ${ }^{14}(112.11)$

- That which is not directed ${ }^{15}(112.12)$

14 The terms "directing" and "directed" have been used here and elsewhere to capture the idea that certain episodes of awareness possess intentionality, and that toward which these episodes of awareness are directed are called "intentional objects" (see 121.12). Because this feature of awareness, for Phya pa, as for Dharmakīrti (see McCrea\&Patil 2006: 307-318), is restricted to episodes of conceptual cognition, it is also natural to speak of this directedness of the mind as cases in which something is "conceived of as" something else. In all these cases, the Tibetan verb employed is zhen pa. Throughout this translation the following conventions have been followed:

- In those cases in which both the grammatical subject and direct object of the verb zhen $p a$ were left implicit-leaving only an indirect object (the "intentional object") specified-we have used the convention "directing one's mind toward <intentional object>."

- In those cases in which the direct object of the verb zhen pa is a concept appearing within an episode of awareness, we have used the convention "<concept $>$ is conceived of as $<$ intentional object $>$ " or " $<$ concept $>$ is conceived to be $<$ intentional object $>$."

${ }^{15}$ The specification "externally" is not repeated at the beginning of 112.11. Being "externally directed" is the prototypical case of a conceptual cognition which is "directed." For instance, this is the case when the appearing concept of a pot is conceived of as being a real, extra-mental pot. When dealing with the second subtype (112.12), Phya pa describes the cognition illustrating it as "not having the operation of directing one's mind externally." He does not suggest that it is directed otherwise. However, when discussing inferential cognition, Phya pa mentions the case when a concept is conceived of as being a concept, hence not as being real and extra-mental (see 112.111.11.2 [c] below). This leaves open the possibility that the mind could be directed, although not externally. This possibility was not discussed in the Indian works of Dharmakîrti, whose focus in this regard was on explaining the way to bridge the gap between cognitions bearing on concepts and reality (see McCrea\&Patil 2006: 307-325). It seems that the division presented here should likewise be regarded as focusing on the distinction between cognitions that are directed (typically, externally) and those that are not directed at all.

In the parallel passage of the 'Od zer, the division is made in terms of presence or absence of conceiving the object as being veridical externally (phyi rol du bden pa'i zhen pa yod pa / med pa). 
112.11 Within conceptual cognitions that are directed, there are two subtypes:

- Determinate awareness (112.111)

- Doubt (112.112)

112.111 Within determinate awareness there are:

- Those in which the determination corresponds with the object to be cognized (112.111.1)

- Those in which the determination does not correspond with the object to be cognized $(112.111 .2)^{16}$

112.111.1 Within this first category there are two types:

- Inferential cognition (112.111.11)

- Factive assessment (as well as post-knowledge cognition) (112.111.12)

\subsubsection{Inferential cognition}

\subsubsection{The three operations}

For inferential cognition there are three operations: ${ }^{17}$

- Appearing (112.111.111.1)

- Directing (112.111.111.2)

- Excluding others (112.111.111.3)

112.111.111.1 With regard to the operation of appearing, this inferential cognition is just a mistaken cognition that is erroneous with respect to the state of affairs that is to be apprehended. ${ }^{18}$ This is because the concepts-

\footnotetext{
${ }^{16}$ The second item is unexpectedly discussed after "Doubt" (112.112) and "Cognitions which are not directed" (112.12).

${ }^{17}$ What follows with respect to these "three operations" is not a full descriptive or explanatory account of how they operate. Rather, Phya pa bypasses descriptions of these notions and moves directly to classifying whether a given form of awareness is mistaken or erroneous from the perspective of the relevant operations. See also the Introduction (I.1, 3.1) and Hugon 2008b: 170-172.

${ }^{18}$ The type of mistaken cognition involved in the operation of appearing is related to the apprehended object. It corresponds to the first form of mistaken
} 
such as 'fire' and 'impermanence'-that appear are imagined (from the perspective of the Three-Nature model).

112.111.111.2 With regard to the operation of directing one's mind, in two cases, (the pair of [a] and [b], as well as [c] below ${ }^{19}$ ), inferential cognition is a mistaken cognition because it is directed in a way that does not correspond to the object to be cognized, like in the case of a rope being conceived of as a snake: ${ }^{20}$

- When directing the mind toward the nature of a real particular:

- When the arising concept of 'fire' is conceived to have the nature of an external fire [a], or

o When the arising concept of 'impermanence' is conceived to have the nature of impermanence as an external property [b].

- When one infers that a double moon can be given the designation "conventionally true," because it does not withstand analysis [c], the arising concept of "the aggregate of double moon and the designation "conventionally true" "21 is conceived to have the nature of a double moon.

In one case inferential cognition is not erroneous, because a verbal object is conceived of as a verbal object: ${ }^{22}$

cognition distinguished below, namely, the apprehension of something superimposed (123.411), here, a concept in the case of inferential cognition. This type is labeled $\mathrm{MC}_{1.1}$ in Table 3 (IV, $4[\mathrm{~b}]$ ).

${ }^{19}$ The instances of inferential reasoning to which [a] through [e], and later [f], refer are explained in more detail in VII, Appendix 2.7.

${ }^{20}$ On this type of mistaken cognition involved in the operation of directing and its relation to the second form of mistaken cognition distinguished later in the text, the incorrect determination of the intentional object (123.412), see Table 3 in IV, $4(\mathrm{~b})$, where this type is labeled $\mathrm{MC}_{2 / 3}$.

${ }^{21}$ The notion of an "aggregate" refers to the combination of the subject and the property to be proven which, together, constitute the thesis of an inferential reasoning. Strictly speaking, it is the "aggregate" that is the object of the inferential cognition, but often (as above in [a] and [b]) the property to be proven is mentioned alone.

22 The notion of a "verbal object" (sgra don) has, for Phya pa, the same meaning as "concept" (don spyi) (the term don spyi is used along with sgra don in the parallel passage of the 'Od zer). The former typically occurs in discussions drawing 
- When one infers that the verbal object 'Luna' ${ }^{23}$ is the direct referent of the word "moon," because it is the apprehended object of a conceptual cognition [d], the appearing concept of "the aggregate of the verbal object "Luna" and direct referent of words' is conceived to have the nature of the verbal object 'Luna.'

112.111.111.3 With regard to excluding others, it is due to this operation that inferential cognition is an instance of knowledge. This is because:

[In b] The determination of something as impermanent excludes one's engaging in the mistaken cognition of its being permanent.

[In a] Directing one's mind toward a fire excludes directing one's mind toward there not being a fire.

[In c] Directing one's mind toward being conventional excludes directing one's mind toward being ultimate.

[In d] Directing one's mind toward being the direct referent of words excludes directing one's mind toward not being the direct referent of words.

Thus, [in e] with respect to the appearing in the mind of the concept of 'emptiness,' which is a mistaken conventionality, and with respect to conceiving of it as emptiness that is perfected (as in the Three-Nature model), inferential cognition is a mistaken cognition. But with respect to excluding the mistaken cognition in which one's mind is directed toward a true reality, inferential cognition is an instance of knowledge. This is expressed also through the example of a child appearing as dead within a dream, which, while being a mistaken cognition, eliminates the superimposition of a child existing. ${ }^{24}$

from Dharmakīrti's works, in which the Sanskrit śabdārtha (which translates in Tibetan as sgra don) is used.

23 The Tibetan reads ri bong can (going back to the Sanskrit expression śaśin), literally "the one which has a hare" or "the one marked with a hare," and refers to the hare-like shape visible on the face of the full moon.

24 This example is found in the Bodhicaryāvatāra by the Indian Buddhist scholar Śāntideva ( $7^{\text {th }}-8^{\text {th }}$ century): “Therefore, when, in a dream, [one's] son has been killed, the conceptual cognition "he does not exist" obstructs the arising of the notion of his existence. But this [conceptual cognition] is false." (BCA 9.141: tasmāt svapne sute naște sa nāstīti vikalpanā / tadbhāvakalpanotpādam vibadhnāti mrșāa ca sā //). 
112.111.112 For these (inferential) cognitions that are endowed with conceptuality there are three items:

- The way real entities exist (112.111.112.1)

- The way awareness apprehends them (112.111.112.2)

- The manner by which they (i.e., inferential cognitions) come to be episodes of knowledge (112.111.112.3)

112.111.112.1 A real entity (such as a fire) exists:

- As fire itself, and

- As devoid of distinction, because it is undifferentiated from producthood and impermanence, and

- As devoid of commonality, because it is not intermixed with fires that are different with respect to time, place, and their specific natures.

112.111.112.2 The way awareness apprehends them is as follows:

- Fire is apprehended as fire.

- But producthood, impermanence, and fire appear as distinct, because the respective concepts arise individually. And this is the opposite of the absence of distinction that pertains to the real entity.

- Real entities that are individualized with respect to their time, place, and specific natures appear commonly, because a single concept of 'fire' arises. And this is in opposition to the real entity being devoid of commonality.

112.111.112.3 The manner by which they come to be episodes of knowledge is, in all the aforementioned cases of inferential cognition, by prohibiting the directing of one's mind in the opposite way, that is, by engaging their object via the exclusion of what is other.

[EX3 On the epistemic object of inferential cognition] 


\subsubsection{Factive assessment (as well as post-knowledge cognition)}

The conceptual cognitions which, though not being instances of knowledge, are determinate awarenesses in which the determination corresponds with the object to be cognized are (i) factive assessment and (ii) post-knowledge cognition. ${ }^{25}$ These also have the three operations:

- From the perspective of appearing, as for the appearing of the concept of 'water in an old well' (in [i]) and the appearing of the concept of 'blue' (in [ii]), these are each mistaken cognitions that are erroneous with regard to the state of affairs to be apprehended.

- From the perspective of conceiving the concepts as external (in [i] and [ii]), they are mistaken cognitions that conflate items that are distinct.

- From the perspective of excluding the consideration that there may be no water in the well (in [i]), it is a factive assessment, and from the perspective of excluding non-blue (in [ii]), it is a postknowledge cognition.

\subsection{Doubt}

Doubt also has the three operations:

- With regard to the appearing of the concept of, for example, 'demon, ${ }^{26}$ doubt is a mistaken cognition that is erroneous with regard to the state of affairs to be apprehended.

- As for conceiving the concept to be the appearance of something external, doubt is a mistaken cognition that conflates items that are distinct.

\footnotetext{
${ }^{25}$ The case that exemplifies (i) is the conceptual determination that there is water in an old well (a determination that follows from neither looking into the well nor from an established triply characterized logical reason - on which see VII, Appendix 2). (ii) is exemplified by the conceptual determination "[this is] blue" that follows the perception of a blue object (i.e., a determining cognition), or which consists in a memory (see 123.21). This is the conceptual type of postknowledge cognition (cf. 122.2).

${ }^{26}$ The word "demon" is used here to translate the Tibetan sha za (lit. "flesheater"), which translates the Sanskrit piśäca. Mentioned in Buddhist and nonBuddhist Indian literature, these "demons" are invoked by philosophers as instances of entities whose existence cannot be either ascertained or refuted by episodes of knowledge of ordinary beings.
} 
- However, conceiving of the existence of a demon as possible excludes conceiving of the existence of a demon as impossible. Based on this operation, it is doubt.

\subsection{Conceptual cognition that is not directed}

Regarding the conceptual cognitions that take as their objects kingdoms within one's mind or totally made up things, as well as those in which one meditates on one's body being that of, for example, a monkey, these cognitions do not at all have the operation of directing one's mind externally nor do they have the operation of excluding others. They are limited to the appearing of concepts, and so are merely mistaken cognitions that are erroneous with regard to the state of affairs to be apprehended.

112.111.2 (As for an episode of determinate awareness in which the determination does not correspond with the object to be cognized,) for instance, when conceiving of sound as permanent, there are the three operations:

- From the perspective of the appearing of the concept of 'the aggregate of "sound" and "permanence",' it is a mistaken cognition that is erroneous with regard to the state of affairs to be apprehended.

- From the perspective of conceiving of this concept as external, it is also a mistaken cognition that conflates items that are distinct.

- From the perspective of excluding what is other-which excludes conceiving of sound as impermanent - it is a mistaken cognition that affirms something that is not the case and denies something that is the case.

And so it is, from all three perspectives, a mistaken cognition. ${ }^{27}$

${ }^{27}$ The type of awareness discussed in this section is also called "mistaken determinate awareness" (log par nges pa) by Phya pa. This form of mistaken cognition corresponds to the category of "incorrect determination of the intentional object" (123.412). It differs from the previously mentioned instances of awareness that are mistaken cognitions from the perspective of conceiving concepts as external in that the operation of exclusion also is a mistaken cognition. Here, the incorrect determination of the intentional object involves the double error of:

1. conflating the type of the object (i.e., conceiving of a concept as being a real particular), as well as, 


\subsection{Non-conceptual non-erroneous cognition}

112.21 Non-conceptual non-erroneous cognition, of which there is reflexive awareness and transitive awareness, ${ }^{28}$ has only the operation of appearing, because it is established by experience that there is no operation of directing one's mind - conceiving of what appears as, for example, blue - nor is there the operation of excluding others - such as the differentiation from non-blue that occurs because of conceiving of something as blue.

\subsection{2}

(a) The established fact that this is the appearance of a real entity itself without the appearance of something superimposed derives from establishing that the apprehended object is a real entity, since it is causally active.

Here, because it is the real entity itself that appears, it is devoid of distinction, and it appears as such. This is because exclusion properties that are essentially identical have no duality of appearing and nonappearing.

It is devoid of commonality and appears precisely as devoid of commonality, because distinct natures appear individually.

(b) As for manifest features, their appearing as devoid of distinction is established by experience. For instance, blue and its shape are experienced as a unitary, not dual, appearance.

Their appearing as devoid of commonality is also established by experience. For instance, the blue of lapis-lazuli and the blue of the

2. misidentifying the nature of the intentional object as it is in reality (e.g., conceiving of sound as permanent).

The former error (1) is common to all conceptual cognitions that are directed externally, but the latter error is specific to this subtype of awareness.

See also the discussion of the various types of mistaken cognition in IV, 4(b). 28 "Transitive awareness" is used here to translate the term gzhan rig (lit. "awareness of something else"), a type of awareness that is not merely aware of itself (like "reflexive awareness") but takes as its object something other than itself. The term don rig (lit. "awareness of an object"), sometimes found instead of gzhan rig, has the same meaning. 
lotus, as well as the blue in this place and the blue in another place, are experienced as appearing individually.

(c) As for non-manifest features (such as momentariness), a moment (of blue) appears individually and as devoid of commonality with the preceding and succeeding moments of blue. This is established (by an inferential cognition) from a logical reason: Since the previous moment of blue has ceased, it does not exist; and so it does not appear. And since the subsequent moment of blue has not come into being, it does not exist; and so it does not appear. Therefore, the present moment of blue cannot be conflated with those two moments, as the present moment alone is appearing.

Concerning, for example, blue and momentariness, which are essentially identical and are devoid of distinction, they appear as devoid of distinction. This is established through the experience that they do not appear individually. And it is determined by an inferential cognition that there is no duality of appearing and non-appearing.

[EX4: Proof that there is no duality of appearing and non-appearing for what is essentially identical]

112.23 As for the manner by which perception comes to be an episode of knowledge, to be a perception is to be non-erroneous with respect to the state of affairs to be apprehended. ${ }^{29}$ Therefore, it would be contradictory for perception to have duality, namely, appearing and non-appearing, with regard to a singular substance. But to be an episode of knowledge is to eliminate opposite superimpositions. Therefore, when one's mind is focused on manifest features, opposite superimpositions are eliminated, and so perception is an episode of knowledge only with regard to manifest features such as 'blue.' But, with regard to appearing non-manifest features such as 'momentariness,' it is not an episode of knowledge.

${ }^{29} \mathrm{Cf}$. (231.12), where "non-erroneous with respect to the state of affairs to be apprehended" is given as the definition of perception. In the present passage, it is identified as the "exclusion property" $(\operatorname{ldog} p a)$ of perception, which we render in the translation in the sense "what it is to be a perception." In 'Od zer 46a1, Phya pa identifies it as 'meaning-exclusion property' (don ldog), i.e., its defining property. 
Some say that what makes a perception an episode of knowledge is merely its "bringing about a determinate awareness.

If that were the case, just like when one determines that an object is veridical through inferential cognition one also determines that the awareness itself evaluates something veridical, so too, when an object is determined to be, for example, blue, the awareness is determined to be, for example, something that has a blue object. Thus, it is impossible for a reflexive awareness experiencing a determinate awareness to be an episode of non-ascertaining perception. Yet, since the reflexive awareness experiencing the last moment of a determinate awareness before it ceases does not "bring about a determinate awareness," according to you it would be an instance of non-ascertaining perception. ${ }^{31}$

Also, in the case of omniscient beings, it is impossible for a determinate awareness to be brought about, because there is never the generation of conceptual cognitions that are erroneous with regard to the state of affairs to be apprehended. Because of this, every perception of omniscient beings would become a non-ascertaining perception. ${ }^{32}$

${ }^{30}$ Phya pa is addressing here the position of rNgog Blo ldan shes rab or his followers (see I.2, 4.2). This position on the nature of knowledge is correlated to the first alternative definition of non-ascertaining perception discussed in (123.1 [a]). ${ }^{31}$ Phya pa distinguishes three kinds of reflexive awareness: knowledge, nonascertaining perception, and post-knowledge cognition (see 122.3 and 122.31). Here the discussion leaves out the third type, focusing on whether the particular type of reflexive awareness considered is an episode of knowledge or of nonascertaining perception. Phya pa's argument excludes the possibility that the reflexive awareness of a determinate awareness would be an episode of nonascertaining perception (a similar argument is found in 'Od zer 59a3-6). It is never "non-ascertaining" even when it does not bring about a determinate awareness in the next moment; it is an episode of knowledge. The opponent's definition, on the other hand, implies that in such a case the reflexive awareness cannot be an episode of knowledge and would qualify as a non-ascertaining perception. Note that this consequence, which according to Phya pa is unacceptable, is however accepted by a later thirteenth-century Tibetan scholar who adopted the position being criticized here, Chu mig pa Seng ge dpal (see IV, 1(b), n. 11).

${ }^{32}$ Phya pa's argument runs on the idea that omniscient beings (i.e., Buddhas) cannot have erroneous cognitions because their reaching this stage of the path to enlightenment presupposes that they have cut off the roots of all obstructionsincluding, notably, ignorance (this is pointed out explicitly in 'Od zer 23a7-8), and thus also error. Hence they cannot have conceptual cognitions, as these are, by nature, erroneous. The issue of the characteristics of the awareness of Buddhas 


\subsection{Non-conceptual erroneous cognition}

Non-conceptual erroneous cognition, in which there is the appearance of, for example, a double moon, is only a mistaken cognition that is erroneous with regard to the state of affairs to be apprehended, because it takes as its object something that is merely superimposed. Indeed, it does not engage a real entity positively, because a real entity does not appear, nor does it engage a real entity via the exclusion of others, because it is not incompatible with opposite superimpositions.

\section{The seven-fold division of awareness based on both the appre- hended object and intentional object}

The division of awareness based on these includes:

- The division of objects (121)

- The seven-fold division of awareness based on those objects (122)

- Specifically laying out the five types of awareness that are not episodes of knowledge (123)

\section{The division of objects}

- The definitions of apprehended object, engaged object, etc. (121.1)

- Distinguishing these objects by reflecting on the partial overlap between apprehended objects and engaged objects (121.2)

- Establishing that the object of knowledge is the engaged object by reflecting on the partial overlap between the episodes of awareness involving these objects (121.3)

\subsection{The definitions of apprehended object, engaged object, etc.}

121.11 The definition of apprehended object is: something such that its own nature itself appears to awareness.

[EX5: On the definition of the apprehended object in the various philosophical systems]

(or, in contrast, the view that mind and mental factors cease upon reaching Buddhahood) is the subject of an intensive debate among Tibetan scholars. Phya pa's original view on this point is discussed in Vose 2009: 120-132. 
121.12 What is called the "intentional object" is: what the mind is directed toward, and the mind being directed toward it excludes engaging in the opposite directing of one's mind.

- For episodes of doubt, directing one's mind toward its possibility excludes its impossibility.

- For mistaken cognition, directing one's mind toward what is incorrect excludes the actual way things are.

- For factive assessment, post-knowledge cognition, and inferential cognition, directing one's mind toward the actual way things are excludes engaging in the opposite directing of one's mind.

121.13 In the case of perception, by focusing one's mind on appearing manifest features, opposite superimpositions are eliminated. And inferential cognition eliminates opposite superimpositions through a reliance on evidence. In these two specific cases there is:

(K1) the elimination of superimpositions,

(K2) with regard to states of affairs not previously known,

(K3) by an apprehension that requires an invariable relation to the state of affairs. ${ }^{33}$

And thus these objects for which superimpositions have been eliminated (in accord with the above) are the epistemic objects of these episodes of awareness. And these are also called the "engaged objects" of those episodes of awareness.

121.2 The two objects - apprehended objects and engaged objects - are distinct: ${ }^{34}$

$(++)$ There exist items that are both the apprehended object and the engaged object. For instance:

${ }^{33}$ See, in relation to (K1)-(K3), the criteria that are presented in Phya pa's definition of knowledge (212.14). See also I.1, 4 and I.2, 3.

${ }^{34}$ See VI, Table B. 
- Blue is the apprehended object of perception, because it is what appears in perception, and it is the engaged object, because perception eliminates for blue the superimposition of non-blue. ${ }^{35}$

- Taking a concept as the subject of a proof, when one proves that it can be given the designation "conventionally true," because it does not withstand analysis [f], the concept is the apprehended object, because the concept appears in the inferential cognition. And it is the engaged object of that inferential cognition because, for that concept, the superimposition of it not being conventionally true is eliminated.

$(+-)$ There exist items that are the apprehended object but not the engaged object. For instance:

o In the inferential cognition that concludes that sound is impermanent $[\mathrm{b}]$, the concept of 'impermanence' is the apprehended object because it is what appears. But it is not the engaged object because there is not, for that concept, the elimination of the superimposition consisting in the apprehension as permanent.

- In a non-ascertaining perception, momentariness is the apprehended object, because it appears, but it is not the engaged object, because the superimposition of permanence is not eliminated.

○ Consider:

- The concept that appears in factive assessment

- The concepts that appear in mistaken cognition, (conceptual) post-knowledge cognition, and doubt

- What appears as a double moon, etc., in non-conceptual erroneous cognition

- The blue that appears in perceptual post-knowledge cognition

\footnotetext{
${ }^{35}$ In this example, Phya pa is using the term "perception" in the restricted sense of "perceptual knowledge." The perception of blue in the form of non-ascertaining perception - such as when a person visually perceives blue without eliminating superimpositions due to being totally absorbed in one's thoughts (see 123.112) is ruled out by the claim that there is an elimination of the superimposition nonblue. The perceptual post-knowledge cognition of blue is ruled out as well, for Phya pa specifies below that in such a case the blue that appears is not the engaged object of this cognition.
} 
These are the apprehended objects of those episodes of awareness, because they are what appears in those episodes. But they are not the engaged objects because, for those objects, there is no elimination of superimpositions by those episodes of awareness. $^{36}$

$(-+)$ There exist items that are the engaged object but not the apprehended object. For instance:

- The impermanence of sound is the engaged object of inferential cognition [b], because, for the impermanence of sound, inferential cognition eliminates the superimposition of permanence. But it is not the apprehended object, because impermanence qua real particular does not appear. ${ }^{37}$

- Concepts and double moons, etc., are the engaged objects of reflexive awareness, because, for those objects, reflexive awareness eliminates the superimposition of non-existence from the perspective of appearance. But they are not the apprehended objects of reflexive awareness, because they do not appear in reflexive awareness. These are the indirect objects of perception. $^{38}$

${ }^{36}$ For the apprehended object to be also the engaged object, it is necessary that (i) elimination of superimpositions takes place and (ii) that it takes place with regard to the object which is also the apprehended object. In the case of inferential cognition the first condition is fulfilled, but not the second, while in the case of non-ascertaining perception the first condition is not fulfilled. It is less clear which criterion fails to apply for the remaining types of awareness listed in the third point, and whether the way they are being grouped has any significance in this regard. In particular, it is questionable in the case of perceptual postknowledge cognition whether Phya pa implies that there is no elimination of superimpositions at all or no elimination of superimpositions characterized by novelty (K2), which is a requirement for the object to qualify as an engaged object (cf. 121.13). On this question, see I.2, 3.2.2.

${ }^{37}$ The example is easier to understand in the case of the inferential cognition of 'fire' [a]: superimpositions are eliminated with regard to a particular fire, but a particular fire does not appear to the inferential cognition. This is the example provided in the parallel discussion in 'Od zer 112.221 (21a4).

${ }^{38}$ What appears in reflexive awareness is the cognition in which these objects appear. The distinction between direct and indirect objects of perception parallels the distinction between direct understanding (dngos rtogs) and indirect understanding (shugs rtogs) (discussed in Mun sel 212.331.142 [36b1-2]). The first is 
$(--)$ There exist items that are neither the apprehended object nor the engaged object. For instance:

- Sound, with respect to a visual cognition. ${ }^{39}$

121.3 With respect to establishing that the object of knowledge is the engaged object by reflecting on the partial overlap between the episodes of awareness involving these objects:

In general, a veridical engaged object is that for which there is no opposition with regard to a positively discerned state of affairs. ${ }^{40} \mathrm{~A}$ veridical apprehended object is that which is capable of being causally active. ${ }^{41}$

explained as "the elimination of superimpositions with regard to a real particular that appears" (rang gi mtshan nyid snang pa la sgro 'dogs sel pa mngon sum gyi dngos rtogs), the second as "the elimination of superimpositions without a real particular appearing” (rang gi mtshan nyid mi snang pa la sgro 'dogs sel pa shugs la rtogs).

${ }^{39}$ An additional note on the manuscript reports the view of some scholars whose

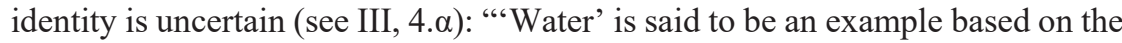
factive assessment (that there is water in the old well), because being an object presupposes that it is taken as a basis."

${ }^{40}$ The notion of "positively discerned state of affairs" corresponds with that of engaged object and epistemic object in the case of perceptual knowledge and inferential cognition. For episodes of awareness that are not knowledge and thus are not considered by Phya pa to have an engaged object and an epistemic object, the expression refers to the apprehended object for non-conceptual cognitions, and to the intentional object of conceptual ones. See also n. 42 on the term "positively discerning."

${ }^{41}$ On the equation of "veridical" with "capable of being causally active" in the case of the apprehended object, see VI, Table A. The definition of "veridical" in terms of "lacking opposition" in the case of the engaged object follows from the discussion elucidating the meaning of "veridical" in the definition of knowledge in terms of "knowing something veridical" (see 212.14). There, Phya pa has a more expansive understanding of veridicality, one that can be applied not just to real entities, but to non-entities as well and, beyond the conventional domain, to the ultimate domain. He rejects the understanding of "veridical" as "capable of being causally active" and as "resisting analysis," which both would limit the range of epistemic objects. He adopts an understanding of "veridical" as "unopposed" (Tib. gnod pa med pa, Skt. *abādhita) or "existing according to the natural disposition of the object to be cognized" (shes bya'i gshis su gnas). The two formulas are combined in the definition of the veridical engaged object in 
$(++)$ There are episodes of awareness having both a veridical apprehended object and veridical engaged object. For instance: Perceptual knowledge has a veridical apprehended object, because a real entity appears, and it has a veridical engaged object, because there is no opposition with regard to the positively discerned epistemic object.

$(-+)$ There are episodes of awareness having a veridical engaged object but not having a veridical apprehended object. For instance: Inferential cognition has a veridical engaged object, because there is no opposition with regard to the positively discerned state of affairs, but it does not have a veridical apprehended object, because a concept, which is unreal, appears.

(+-) There are episodes of awareness having a veridical apprehended object but not having a veridical engaged object. For instance: Non-ascertaining perception has a veridical apprehended object, because a real entity appears, but it does not have a veridical engaged object for which superimpositions have been eliminated.

(--) There are episodes of awareness that have neither a veridical apprehended object nor a veridical engaged object. For instance: The conceptual cognition of a rope as a snake does not have a veridical apprehended object, because, since the concept ('snake') appears, an apprehended object that is a real entity does not appear. And it does not have a veridical engaged object, because there is no snake in external reality.

The object of knowledge is the engaged object.

Having a veridical engaged object is a sufficient condition for being an episode of knowledge. Indeed, a perception having both a veridical engaged object and veridical apprehended object is an episode of knowledge. And inferential cognition, which has a veridical engaged object but no veridical apprehended object, is an episode of knowledge.

Also, having a veridical engaged object is a necessary condition for being an episode of knowledge. Indeed, an episode of awareness such as the conceptual cognition of a rope as a snake, which has neither a veridical apprehended object nor a veridical engaged object, is not an episode of knowledge. So too, non-ascertaining perception, which has a veridical

the 'Od zer ('Od zer 21a5: 'jug yul bden zhes bya ba ni shes bya'i gshis gnod med du gnas pa). For more on this, see Hugon 2011a: 162-165. 
apprehended object but not a veridical engaged object, is not an episode of knowledge.

On the other hand, having a veridical apprehended object is neither a necessary nor sufficient condition for being an episode of knowledge. It is not a sufficient condition, because, although non-ascertaining perception has a veridical apprehended object, it is not an episode of knowledge. And it is not a necessary condition, because, even though inferential cognition does not have a veridical apprehended object, it is an episode of knowledge.

Therefore, the object of knowledge is the engaged object alone.

\section{The seven-fold division of awareness based on the division of objects}

For the seven-fold division of awareness based on the apprehended and engaged objects there are three topics:

- Determining that there are seven types of awareness (122.1)

- Subsuming those seven within the earlier three-fold typology of awareness (122.2)

- Examining the mutual compatibility and incompatibility among the twelve types of awareness (122.3)

122.1 In general, episodes of awareness that positively discern ${ }^{42}$ a state of affairs are of two types:

122.11 Episodes of awareness that discern something not set apart from what is directly incompatible with it, without being partial to either.

- This is doubt. When considering that something may be impermanent one also considers its permanence. As such, impermanence is not set apart from permanence.

122.12 Episodes of awareness that discern something standing apart from what is directly incompatible with it, while being partial to it.

42 "Positively discerning" translates here the Tibetan term yongs su gcod pa, which stands as a broad notion that encompasses both the ideas of "appearing" and "directing." It is to be distinguished from its use in the pair yongs su gcod pa/rnam par gcad pa, where it denotes the positive aspect of a conceptual process, which we translated instead as "positively ascertaining" (see n. 74). 
122.121 Episodes of awareness that discern in a way that does not correspond with the object to be cognized.

- This is mistaken cognition.

122.122 Episodes of awareness that discern in a way that corresponds with the object to be cognized.

122.122.1 Episodes of awareness that are compatible with directing one's mind in the opposite way.

- This is non-ascertaining perception.

122.122.2 Episodes of awareness that are incompatible with directing one's mind in the opposite way.

122.122.21 Episodes of awareness that engage an object already known.

- This is post-knowledge cognition.

122.122.22 Episodes of awareness that engage an object not previously known.

122.122.221 Episodes of awareness that oppose superimpositions by observing a real particular.

- This is perceptual knowledge.

122.122.222 Episodes of awareness that oppose superimpositions without a real particular being observed.

122.122.222.1 Episodes of awareness that rely on evidence.

- This is inferential cognition.

122.122.222.2 Episodes of awareness that do not rely on evidence.

- This is factive assessment. 
Thus, the five episodes of awareness that are not instances of knowledge and the two episodes of awareness that are instances of knowledge total, altogether, seven. ${ }^{43}$

122.2 How are these seven types of awareness to be subsumed under the earlier three-fold typology of awareness? ${ }^{44}$

- The pair of perceptual knowledge and non-ascertaining perception is subsumed under non-conceptual non-erroneous cognition.

- The trio of inferential cognition, factive assessment, and doubt is subsumed under conceptual cognition.

- Mistaken cognition occurs within non-conceptual erroneous cognition and within conceptual cognition.

- Post-knowledge cognition is found within both non-conceptual non-erroneous cognition and within conceptual cognition.

122.3 When one subdivides these seven episodes of awareness they become twelve-fold. ${ }^{45}$ The trio of non-ascertaining perception, (perceptual) post-knowledge cognition, and perceptual knowledge is subdivided into three kinds of reflexive awareness and three kinds of transitive awareness, which sums to six. In mistaken cognition there are two subdivisions, conceptual and non-conceptual, ${ }^{46}$ which brings the sum to eight. There is conceptual post-knowledge cognition, which brings the sum to nine. The

${ }^{43}$ See VI, Table E. The two that are instances of knowledge are perceptual knowledge and inferential cognition. The other five, which are not instances of knowledge, are discussed in detail in (123).

${ }^{44}$ See (112).

${ }^{45}$ See VI, Table F.

${ }^{46}$ Note that this division is not equivalent to Phya pa's later delineation of the two forms of mistaken cognition (123.41). The first of those two (123.411) can be either conceptual or non-conceptual, the second (123.412) exclusively conceptual. On these alternative divisions of mistaken cognition, see further IV, 4(b). A possible explanation for Phya pa utilizing the present sub-divisions (of conceptual versus non-conceptual mistaken cognition) here is that the incompatibility of episodes of cognition is often easily explained by focusing on whether the cognitions are or are not conceptual. It is central to Phya pa's reasoning that conceptual cognitions are incompatible with transitive non-conceptual cognitions. 
trio of inferential cognition, factive assessment, and doubt brings the total to twelve.

As to the way in which these twelve can be classified as mutually compatible and incompatible there are five items to be examined:

- The three episodes of reflexive awareness (122.31)

- The four episodes of non-conceptual transitive awareness $(122.32)^{47}$

- The three episodes of conceptual cognition in which there is a correct determination $(122.33)^{48}$

- (Conceptual) mistaken cognition $(122.34)^{49}$

- Doubt (122.35)

122.31 All episodes of cognition entail reflexive awareness. A reflexive awareness can be:

(i) an instance of non-ascertaining perception with regard to the experience of a non-manifest feature (of the episode of awareness) such as momentariness;

(ii) a post-knowledge cognition with regard to a manifest feature previously known;

(iii) an episode of knowledge with regard to a manifest feature not previously known.

These three forms of reflexive awareness have a shared identity with all cognitions.

\footnotetext{
${ }^{47}$ These four are the three kinds of perceptual transitive awareness (non-ascertaining perception, perceptual post-knowledge cognition, and perceptual knowledge) and non-conceptual mistaken cognition.

48 "Correct determination" (yang dag par nges pa) is used here in place of and in the same sense as "determination corresponding with the object to be cognized" in the three-fold typology (see 112.111.1). The three episodes are inferential cognition, factive assessment, and conceptual post-knowledge cognition.

${ }^{49}$ Non-conceptual mistaken cognition is dealt with in (122.32). Note that in section (122.34) and in the discussion of the other types of awareness, "mistaken cognition" (whether conceptual or non-conceptual) refers exclusively to instances of the first form delineated later in (123.411), namely, those in which the apprehended object is a superimposed concept.
} 
122.32 As for the four episodes of non-conceptual transitive awareness: A single visual cognition can be:

(i) a mistaken cognition - a white shell appearing as yellow;

(ii) a non-ascertaining perception - the appearing of a pot's momentariness;

(iii) a post-knowledge cognition with regard to blue, etc., that has previously been known;

(iv) an episode of knowledge with regard to a specific shape, etc., that has not previously been known. ${ }^{50}$

${ }^{50} \mathrm{~A}$ first problem with this list is that it purports to refer to "a single visual cognition," but is actually based on two distinct situations: the visual cognition of a white shell in (i), the visual cognition of a blue object in (ii) and (iii) (and probably in (iv)). In the mention of Phya pa's view on the compatibility/incompatibility of the various kinds of awareness by the author of the Tshad bsdus, (i) is exemplified by the mistaken cognition of dripping strands of hair (by a person suffering from an eye-disease) when looking at a pot. The example offered on Phya pa's behalf allows him to distinguish the four types of non-conceptual transitive awareness based on the same situation: the visual cognition of a blue pot. (See also the discussion in gTsang drug rdo rje's gSal byed [9a8], illustrating this case by the appearance of something yellow on the edge of the pot for someone afflicted by jaundice). Notably, however, the author of the Tshad bsdus does not himself believe that the other six episodes of non-conceptual awareness - exemplified by (ii) through (vii) - are compatible with non-conceptual mistaken cognition (i) and reports that Phya pa's account of compatibility and incompatibility in the case of non-conceptual transitive awareness has been judged "unappealing." (Tshad bsdus 54,2-5: phya pa ni bum pa'i steng du skra shad la sogs pa 'dzag par snang ba'i shes pa zhig 'byung bas rtog med log shes dang bdun mi 'gal la lnga dang 'gal lo zhes zer te blo la mi 'bab bo zhes gsung ngo //).

This brings us to a second issue: Phya pa himself does not accept that, in the same situation, an episode of non-conceptual mistaken cognition could also be an episode of knowledge. In a later discussion in Mun sel 212.231 (34a5-b2) (parallel in 'Od zer 29b2-8), Phya pa precisely refutes scholars holding such a view:

Some say that episodes of non-conceptual erroneous cognition, such as the appearing of a tree as moving or of a shell appearing as yellow, are also episodes of perceptual knowledge, because they are reliable with regard to some features, such as the shape, etc. $[\ldots]$. 
And the reflexive awareness (of this visual cognition) can be:

(v) a non-ascertaining perception - the appearing of the momentariness of the visual cognition;

(vi) a post-knowledge cognition with regard to a manifest feature of the visual cognition that has previously been known;

(vii) an episode of knowledge with regard to a manifest feature of the visual cognition that has not been previously known.

Therefore, these four types of awareness-comprised of the three types of transitive perception plus non-conceptual erroneous cognitionare compatible with seven kinds of awareness: the four just mentioned and the three types of reflexive awareness.

Regarding the awareness that apprehends a shell as yellow, etc., since there is no 'being non-erroneous with regard to the state of affairs to be apprehended,' one negates that it would be a perception in general, and hence also (a fortiori) that it would be an episode of perceptual knowledge. This is because, when negating the definiens, one negates the definiendum.

It is possible that distinguishing two situations when listing the compatible types of awareness was precisely meant to avoid admitting that the mistaken cognition of the white shell as yellow would be an episode of knowledge with regard to shape (since this is a position that Phya pa refutes), while retaining the idea that "visual cognition in general" could instantiate both types of awareness. But as both would not be instantiated in a single awareness, the mention of "a single visual cognition" remains problematic.

In rNgog Lo's $d K a^{\prime}$ gnas, the scholars holding the view that the mistaken appearing of a white shell as yellow is knowledge with regard to shape are identified as "some student of Dignāga and some non-Buddhist" (dKa' gnas 34,811). In the Tshad bsdus 119,13, the proponent of this view is said to be rGyal ba'i blo gros, probably for rGyal dbang blo gros, i.e., Jinendrabuddhi (c. $8^{\text {th }}-9^{\text {th }}$ century). (For some references on Jinendrabuddhi's theory of "partial validity" [aṃśasaṃvādavāda], see Franco 2006: 225-226). Analyzing this case, rNgog Lo adopted a more nuanced position than Phya pa as he concluded that the awareness in which there is the appearing of 'yellow' in the case of a white shell cannot be an episode of knowledge with regard to the object of the particular sense faculty involved (i.e., anything that has to do with vision, including shape), but can be an episode of knowledge with regard to the co-existing object of another sense faculty such as touch. It can, for instance, be knowledge with regard to the shell being 'large' or 'soft.' (See $d K a$ ' gnas 46,8-14). 
But since being a non-conceptual transitive episode of awareness is incompatible with being a conceptual transitive episode of awareness, the above four are incompatible with five kinds of awareness: inferential cognition, factive assessment, doubt, conceptual mistaken cognition, and conceptual post-knowledge cognition.

122.33 When one concludes, from the presence of smoke, that there is a sandalwood fire on the mountain pass, the awareness can be:

(i) an inferential cognition with regard to mere fire;

(ii) a factive assessment with regard to sandalwood fire;

(iii) a post-knowledge cognition with regard to just being a mountain pass;

(iv) a mistaken cognition based on the concept 'fire.'

And there also can be the three types of reflexive awareness just as before.

Therefore, these three, factive assessment, (conceptual) postknowledge cognition, and inferential cognition, are compatible with seven kinds of awareness: the three just mentioned, conceptual mistaken cognition, and the three types of reflexive awareness.

But since a determinate awareness is not an episode of doubt, and since, with regard to transitive episodes of awareness, being conceptual is incompatible with being non-conceptual, the above three are incompatible with five kinds of awareness: doubt, the three types of transitive perception, and non-conceptual erroneous cognition.

122.34 In five types of cognition-inferential cognition, factive assessment, doubt, conceptual post-knowledge cognition, conceptual mistaken cognition - there is a conceptual mistaken cognition that apprehends a concept. And there are also the three previously mentioned types of reflexive awareness.

Therefore, conceptual mistaken cognition is compatible with eight kinds of awareness: the five conceptual cognitions and the three types of reflexive awareness.

But since what is a conceptual cognition cannot be a non-conceptual transitive episode of awareness, conceptual mistaken cognition is incompatible with four kinds of awareness: the three types of transitive perception and non-conceptual erroneous cognition. 
122.35 In episodes of doubt there are the three previously mentioned types of reflexive awareness, and there is also the conceptual mistaken cognition that apprehends a concept.

Therefore, doubt is compatible with five kinds of awareness: the three types of reflexive awareness, conceptual mistaken cognition, and doubt itself.

But since being a conceptual cognition is incompatible with being a non-conceptual episode of transitive awareness, doubt is incompatible with the three types of transitive perception and non-conceptual erroneous cognition. And since doubt is not a determinate awareness, it is incompatible with inferential cognition, factive assessment, and conceptual post-knowledge cognition. As such, it is incompatible with seven kinds of awareness.

\section{Specifically laying out the five types of awareness that are not episodes of knowledge}

For all five types of awareness that are not episodes of knowledge there are three topics to be elucidated for each:

- Its nature (123.x1)

- Its definition (123.x2)

- The episode of knowledge that determines that the definition applies (123.x3)

\subsection{Non-ascertaining perception}

123.11 There are two forms of non-ascertaining perception: cases where there is an appearance but no ascertainment due to the object being a nonmanifest feature (123.111), and cases where there is an appearance but no ascertainment due to not focusing one's mind on the object (123.112). ${ }^{51}$

123.111 First, when a real entity appears to perception, the present momentariness that is substantially identical with the real entity, which is a

\footnotetext{
${ }^{51}$ An additional note on the manuscript (see III, 4. $\beta$ ) reads: "And they come to three forms together with the case where there is an appearance but no ascertainment due to being overwhelmed by causes of error." Such a third category was distinguished by Phya pa's successors and is usually exemplified by the example
} 
momentariness that is not mixed with the momentariness that precedes or follows it, appears to perception. However, its not being mixed is not ascertained, since the feature that consists in its being unmixed is not clearly appearing. This is because other similar moments arise and exist uninterruptedly.

123.112 Second, for instance, a case where blue, etc., appears but it is not ascertained because one is absorbed in one's thoughts.

123.12 The definition of non-ascertaining perception is: the appearing of a real particular, and compatible with opposite superimpositions. This excludes, by the first criterion, all those types of awareness that are not episodes of perception, and, by the second criterion, perceptual knowledge and (perceptual) post-knowledge cognition.

\subsection{3}

- As for its compatibility with opposite superimpositions, this is determined by reflexive awareness, which experiences the engaging in the directing of one's mind toward, for example, permanence in the case of a real entity appearing. ${ }^{52}$

- As for the appearing of momentariness, when, taking as one's subject the state of affairs that appears, one determines that it is momentary through a logical reason such as its being produced [b], the awareness also is indirectly established as one that apprehends something momentary. Or, although mother-of-pearl was not initially ascertained, when it is subsequently ascertained that the object is mother-of-pearl by getting closer to it, the previous awareness is also indirectly established as one for which mother-of-pearl appeared.

of mother-of-pearl appearing and being determined to be silver. Phya pa mentions the mother-of-pearl case below (123.13) without clarifying which subtype of non-ascertaining perception it belongs to. See IV, 1(b).

${ }^{52}$ The "directing of one's mind toward permanence" is not performed by the perceptual awareness (which, being non-conceptual, is devoid of the operation of directing) but by a conceptual episode, which is simultaneous with it or possibly subsequent to it and amounts to the superimposition 'permanent.' 
(a) Some assert as the definition of non-ascertaining perception "not bringing about a determining cognition, but appearing."

This is not correct. It is too broad because it would apply to reflexive awareness that experiences the last moment of a determinate awareness before it ceases, which is a reflexive awareness that is an instance of knowledge, and to the perception of omniscient beings. ${ }^{53}$

(b) Alternatively, some say "the appearing of a real particular, and coexisting with a superimposition."

This too is incorrect. It is too narrow because, if this is speaking of "coexisting with an actual superimposition," it would not apply to the appearing of momentariness at a time when one's mind is not focused on permanence. And if this is speaking of "coexisting with a potential superimposition," it would not apply to cases of non-ascertaining perception in which there is an appearing of momentariness when one already knows that something is momentary through inferential cognition. ${ }^{54}$

\subsection{Post-knowledge cognition}

123.21 Post-knowledge cognitions are, for an object already known:

\footnotetext{
${ }^{53}$ Compare with the corresponding discussion of an opponent's position on the feature that makes perception an episode of knowledge in (112.23) above. An interlinear note on the manuscript of the sGron ma by mTshur ston gZhon nu seng ge, who also cites this definition, attributes it to "rtag" or "stag," probably r/sTag pa Kha che ("tak pa kha ché"). A note on the manuscript of the gSal byed by gTsang drug rdo rje links this definition with Dharmottara. See IV, 1(b) for the references.

${ }^{54}$ It is unclear whether the expression "not focused on permanence" is an (awkward) way of referring to the absence of the actual superimposition of 'permanence' (one would have expected, rather, an expression such as "directing one's mind towards permanence") or indicates that an appeal is being made to the second form of non-ascertaining perception (123.112), which is linked to not focusing one's mind. (Indeed, this second form of non-ascertaining perception is only illustrated with the absence of focus regarding appearing manifest properties.) Possibly, Phya pa is implying that the absence of focus also prevents the actual occurring of a superimposition.
}

See also the parallel discussion considering the options "actual superimpositions" and "potential superimpositions" in (212.14 [b]) below. 
- Engaging in perception capable of bringing about a directing of one's mind..$^{55}$

- Engaging in a conceptual cognition that is a memory.

- A subsequently arising determining cognition.

There cannot be instances of inferential cognition that are episodes of post-knowledge cognition. This is because, on the one hand, if one has previously ascertained, for instance, that sound is momentary, the mental state derived from a logical reason is not an instance of inferential cognition, because the logical reason would not fulfill the criterion of 'being a property of the subject,' since there would not be a desire to know (whether the subject has the property to be proven). ${ }^{56}$ On the other hand, if one concludes something not previously ascertained, it could not be an instance of post-knowledge cognition.

(a) Objection: Although the first moment of inferential cognition that arises from a reliance on the determination of the triple characteristic of a logical reason is an episode of knowledge, the second moment and so on are post-knowledge cognitions. But since these follow from the previous apprehension of the logical reason, they are also instances of inferential cognition. Thus, there are instances of inferential cognition that are episodes of post-knowledge cognition. ${ }^{57}$

Reply: The ascertainment in the first moment follows the logical reason, since it emerges from the apprehension of the logical reason. But,

\footnotetext{
${ }^{55}$ The specification "capable of bringing about a directing of one's mind" is meant to imply some sort of "ascertainment" in order to eliminate non-ascertaining perception. Phya pa cannot invoke here "ascertainment" in the sense of "the capacity to eliminate opposite superimpositions," as the latter is absent in postknowledge cognition (see 212.22). He thus invokes a feature that is common to perceptual post-knowledge cognition and perceptual knowledge, and absent in non-ascertaining perception, the capacity to give rise to a determining cognition. See however, above, Phya pa's rejection of the identification of the feature "bringing about a determining cognition" with "ascertainment" when distinguishing non-ascertaining perception from perceptual knowledge.

${ }^{56}$ See VII, Appendix 2, sections 4 and 6 on the features required for a logical reason to be valid and the corresponding faults.

${ }^{57}$ The same view is ascribed to a scholar called g. Yor gnyan ("yor nyen") in the Tshad bsdus and in an interlinear note in the Tshad nye bsdus. Sākya mchog ldan
} 
though the ascertainment in the second moment, etc., is an ascertainment that follows the first moment, it is not an ascertainment that follows the logical reason. This is because it does not arise directly from the apprehension of the logical reason.

If it did qualify as an ascertainment that follows a logical reason due to its arising indirectly from the apprehension of the logical reason, then consider the yogic perception in which, by meditating on the emptiness that has been determined by an inferential cognition, emptiness comes to appear clearly. ${ }^{58}$ This also would become an inferential cognition for which there is understanding coming from a logical reason, because it indirectly arises from the apprehension of a logical reason.

(b) Objection: In the case of a locus where fire is observed, the conclusion, from smoke, that there is fire, is a post-knowledge cognition, but it is also an inferential cognition.

Reply: This is not an inferential cognition. This is because, given that the logical reason does not have the characteristic of 'being a property of the subject' - since there is no desire to know pertaining to the locus (having or not having the property to be proven) - this awareness is not based on a logical reason endowed with the three characteristics.

123.22 The definition of post-knowledge cognition is: engaging in an awareness that is incompatible with directing one's mind in the opposite way with regard to a state of affairs for which superimpositions have already been eliminated.

123.23 What determines that the definition applies is as follows:

- As for the superimpositions already having been eliminated, this is determined by the reflexive awareness that experiences the earlier awareness (in which the superimpositions were eliminated).

reports that the view that an inferential cognition can be a post-knowledge cognition was held by rGya dmar ba (see V, 1, R52.4). Later scholars who adopt this view refer to Dharmottara in support of this option (see Rinbochay\&Napper 1980: 86). See IV, 2(b) for more details.

${ }^{58}$ On the theory of yogic perception in Dharmakīrti's system, which is applied here to a topic that is characteristic of Madhyamaka philosophy (i.e., the realization of emptiness), see Dunne 2006. Phya pa deals with yogic perception in Mun sel 232.5 (42b1-43a1) and 'Od zer 112.24 (64b5-66a4). 
- And the incompatibility with directing one's mind in the opposite way is determined by the reflexive awareness of that awareness itself (i.e., post-knowledge cognition).

\subsection{Factive assessment}

123.31 Factive assessment is not a non-conceptual cognition: it is a conceptual cognition.

It is not an episode of doubt: it is a determinate awareness.

It is not a mistaken determinate awareness: it is a determinate awareness in which the determination corresponds with the object to be cognized.

It is not a determinate awareness of something already known: it is a determinate awareness of something concealed and not previously known, such as the impermanence of sound. ${ }^{59}$

It is not a determinate awareness that is based on having determined, by an episode of knowledge, that a logical reason is a property of the subject and entails the property to be proven. Therefore, there are three subtypes:

(i) Factive assessment lacking a reason

A determinate awareness of, for example, sound being impermanent, without being based on either a valid logical reason or a pseudo-logical reason.

\footnotetext{
59 The idea that the object must be "concealed" is absent from the definition of factive assessment in the Mun sel (123.321), but is included in the definition in the 'Od zer. There the role of this criterion is said to be the elimination of perceptual knowledge (but it actually eliminates all perceptions). This role is already fulfilled in the Mun sel by the mention of factive assessment being a conceptual cognition. The inclusion of the mention "concealed" in this sentence makes better sense if the Tibetan term nges $p a$ is understood in the general sense of "ascertainment" rather than the specific sense of "determinate awareness." The order in which the features of factive assessment are discussed however corresponds to that of the characteristics used to distinguish conceptual cognitions in the three-fold typology; it is therefore more natural to understand nges pa here in the sense of "determinate awareness," a subtype of conceptual cognition, like in the definition of factive assessment below, in which it is given as a criterion that excludes all perceptions and doubt (123.321). See the discussion in IV, 3(b).
} 
(ii) Factive assessment having a mistaken reason

A determinate awareness of a veridical thesis ${ }^{60}$ from taking as one's logical reason a property for which its being a property of the subject or its entailing the property to be proven is not found in reality. Namely, a determinate awareness (of sound being impermanent $)^{61}$ :

- Based on an unestablished logical reason, such as the property of being visible.

- Based on an inconclusive logical reason, such as the property of being an epistemic object.

(iii) Factive assessment with an uncertified reason

Deducing a veridical thesis from having determined, via factive assessment, that a potential logical reason is a property of the subject or that it entails the property to be proven. Such as:

- The determination of 'being produced' being a property of sound, via factive assessment.

- The determination that 'being produced' entails 'being impermanent,' via factive assessment.

For mistaken cognitions that determine a non-veridical thesis, like 'sound being permanent':

- There are those that are lacking a reason.

- There can be those having a mistaken reason. Namely, those which are

○ Based on an unestablished logical reason, such as the property of being visible.

- Based on a contradictory logical reason, such as the property of being produced.

- Based on an inconclusive logical reason, such as the property of being an epistemic object.

\footnotetext{
${ }^{60}$ The thesis (Tib. bsgrub bya, literally "what is to be proven") consists in the aggregate of the subject and the property to be proven. See VII, Appendix 2.3.

${ }^{61}$ For the remainder of this section, Phya pa is using as his basic case the stock example of seeking to establish that sound is impermanent (see VII, Appendix 2. $7[\mathrm{~b}]$ ). Mistaken reasons and uncertified reasons (see [iii] below) are instances of pseudo-logical reasons, on which see VII, Appendix 2.6.
} 
- But those that have an uncertified reason are not possible. ${ }^{62}$

For factive assessment there cannot be those that are based on a contradictory logical reason. This is for the following reason. Since factive assessment determines a veridical thesis, the subject is a similar instance. And so, if the logical reason does not occur in the similar instances, it could not be a property of the subject, and if the logical reason does occur in the similar instances, it would not entail the opposite of the property to be proven. ${ }^{63}$

\subsection{Definition ${ }^{64}$}

\subsection{Presenting one's own position}

The definition of factive assessment is: a determinate awareness of a veridical state of affairs not previously known, that is not based on having determined, via an episode of knowledge, the characteristics of a logical reason.

- The criterion 'determinate awareness' eliminates all three types of perception and doubt.

- The criterion 'veridical' eliminates mistaken cognition. ${ }^{65}$

- The criterion 'not previously known' eliminates post-knowledge cognition.

${ }^{62}$ This case is not possible, because if there were a reason which, even if currently uncertified, could potentially be established, the conclusion derived from this reason would be true. It could not, therefore, be a mistaken cognition.

${ }^{63}$ For Phya pa, a "similar instance" is an instance that is qualified by the property to be proven. This is the case for the subject when the thesis - the aggregate of the subject and the property to be proven-is veridical. A "contradictory reason" only qualifies instances that are qualified by the opposite of the property to be proven, i.e., "dissimilar instances." See VII, Appendix 2.4 and 2.6.

${ }^{64}$ A marginal note (see III, 4. $\gamma$ ) specifies that this section includes three subdivisions: "presenting one's own position" (123.321), "refuting the position of others" (123.322), and "rejecting objections with regard to one's own position" (123.323).

${ }^{65}$ Strictly speaking, the non-conceptual form of mistaken cognition is also eliminated by the preceding criterion 'being a determinate awareness,' which presupposes 'being conceptual.' 
- The criterion 'not based on having determined, via an episode of knowledge, the characteristics of a logical reason' eliminates inferential cognition.

\subsection{Refuting the position of others ${ }^{66}$}

Some assert (D1) “directing one's mind toward a state of affairs, while being partial to it, without relying on either experience or a logical reason "67 as the definition of factive assessment.

Parallel assertion (D2): Likewise, why not assert "directing one's mind without relying on experience" as the definition of factive assessment?

Reply (D2): This is too broad. It would apply to inferential cognition. Parallel reply (D1): Likewise, the previous definition would be too broad. It would apply to the mistaken cognition that determines sound to be permanent.

Retort (D1): In terms of its substance, mistaken cognition is an episode of factive assessment. Thus, although the definition applies to mistaken cognitions, it is not too broad. This is just like, although the definition of

${ }^{66}$ The opponent's objection is discussed here by way of an argumentative pattern profusely used by Phya pa, which Hugon (2008a) has termed "argumentation by parallels." It consists in introducing into the discussion of a topic pertaining to a given domain (noted here D1) a parallel domain (noted D2), which is often a more basic one, in which the relationship between the elements is easier to grasp, or a domain less prone to controversy. The method of argumentation consists, for the person answering an initial objection, in reduplicating any statement of the opponent in the parallel domain. Thus, objections in D1 are turned into similar objections in D2, and defenses for these objections in D2 become similar defenses in D1. The argument thus develops in intersecting zig-zag patterns.

In our translation, left aligned statements constitute the core argument pertaining to D1, indented the statements the parallel argument in domain D2. Statements in italics are those ascribed to the opponent. Statements in regular font are by Phya pa, but should not be regarded as representing his own view. They are statements parallel to the opponent's previous statement, meant to lead to the next step of the argument.

${ }^{67}$ This definition is ascribed in various texts to Phya pa's teacher rGya dmar ba. See IV, 3(b). 
impermanence applies to things that arise from effort, it is not too broad. ${ }^{68}$

Parallel retort (D2): In terms of its substance, inferential cognition is an episode of factive assessment. Thus, although the definition applies to inferential cognition, it is not too broad, just like above.

Objection (D2): How would one differentiate inferential cognition and factive assessment?

Parallel objection (D1): How would one differentiate mistaken cognition and factive assessment?

Reply (D1): They are differentiated, because, although they are substantially identical, they are conceptually distinct. ${ }^{69}$ This is because, from the perspective of analyzing incorrectly, the episode of awareness is a mistaken cognition, but from the perspective of being a determinate awareness that does not rely on experience or a logical reason, the episode of awareness is a factive assessment. This is just like, although 'arising from effort' and 'impermanent' are substantially identical, they are conceptually distinct, and therefore can be, respectively, the logical reason and that for which it is a logical reason (in a proof).

Parallel reply (D2): Inferential cognition and factive assessment are differentiated, because, although they are substantially identical, they are conceptually distinct. This is because, from the perspective of being a determinate awareness that relies on a triply-characterized logical reason, the episode of awareness is an inferential cognition.

${ }^{68}$ The definition of "impermanent" is "not remaining in the second moment" (dus gnyis par mi sdod pa) (see Mun sel 13a5). Things that arise from effort (such as pots, etc.) constitute a subcategory of things that are impermanent, and thus also have the property of 'not enduring for a second moment.' But the latter is not their definition, because it also applies to impermanent things that do not arise from effort (such as lightning or the sound of a river).

69 "Conceptually distinct" renders here the expression ldog pa tha dad (lit. "distinct exclusion properties") in reference to Phya pa's explanation of the process by which multiples properties are being conceived for a singular substance, which involves the appearing of distinct concepts to conceptual cognition (see 111.2). In the analogy, the exclusion properties 'arising from effort' and 'impermanent' are being distinguished for a singular substance (for instance, a pot). But 'arising from effort' and 'impermanent' are said to be "substantially identical" insofar as it is the same substance (e.g., the pot) which is something that arises from effort and something that is impermanent (see 111.1). 
But from the perspective of being a determinate awareness that does not rely on experience, the episode of awareness is a factive assessment.

Objection (D2): From the point of view of what is determinedsound being impermanent-the awareness would be both an episode of knowledge and not an episode of knowledge.

Parallel objection (D1): From the point of view of what is to be determined - the aggregate of sound and permanence - the awareness would be both a mistaken cognition and not a mistaken cognition. ${ }^{70}$

\subsection{Rejecting objections with regard to one's own position}

Objection (D1): If it is the case that factive assessment entails determining a veridical object, then it must entail that the object is veridical. This being the case, is there (1) entailment due to essential identity, (2) entailment due to causality, or (3) entailment without dependence?

- If (1), then an episode of factive assessment would become material, since it would have a shared identity with a material object.

- If (2), then an episode of factive assessment would become an episode of knowledge, since the awareness would be invariably related to a positively discerned state of affairs.

- If (3), there would be the possibility of a logical reason lacking dependence, since entailment would be acceptable for that which lacks dependence.

\footnotetext{
${ }^{70}$ This conclusion follows in Phya pa's system, in which factive assessment is posited as being a non-mistaken cognition. But it does not necessarily follow in the system of the opponent, if the latter holds, like Phya pa implies, that factive assessment is a broader category that includes mistaken cognition as a subtype. The same episode of awareness can be, in the opponent's system, characterized as mistaken cognition and as factive assessment without implying that it would be both mistaken and non-mistaken, because the opponent's definition of factive assessment does not entail that it is non-mistaken. Note, however, that the opponent's mention of "state of affairs" in the definition might have precisely served the purpose of indicating the non-mistaken nature of factive assessment. If this is indeed the case, the opponent cannot be said to hold the view that factive assessment is a broader category. He could still hold that it is a type of awareness that is substantially identical with mistaken cognition - the two being introspectively undistinguishable - but would not hold that the definition of factive assessment applies to cases of mistaken cognition.
} 
Parallel objection (D2): Similarly, for (the thesis that) being a conceptual cognition entails that the apprehended object is a concept, is there (1) entailment due to essential identity, (2) entailment due to causality, or (3) entailment without dependence?

- If (1) or (2), the concept would be a real entity, since:

o In the first case, the concept would be substantially identical with conceptual cognition, and

- In the second case, it would be the cause of the conceptual cognition.

- If (3), there would be the possibility of a logical reason lacking dependence, since it would bring about entailing and entailed items that lack dependence.

Reply (D2): Since we do not assert either of these two forms of dependence (between concepts and conceptual cognition), concepts would not become real entities. And although these are entailing and entailed items that lack dependence, this is not a case where the former one is a logical reason, because the latter is not something to be inferred. Indeed, when determining an awareness to be a conceptual cognition, one also determines the object to be a concept. Thus, there would not be the possibility of a logical reason lacking dependence.

Parallel reply (D1): Since we do not accept either of the two forms of dependence between factive assessment and a veridical object, there are neither of the first two faults. And although these two are entailing and entailed items that lack dependence, when determining an awareness to be an episode of factive assessment, one has already determined that the object is veridical, and thus it is not something to be inferred. Thus, there would not be the possibility of a logical reason lacking dependence. ${ }^{71}$

123.33 The episode of knowledge that determines that the definition applies is as follows:

- As for its being a determinate awareness of something not previously ascertained, this is established by reflexive awareness.

${ }^{71}$ For a detailed discussion of this particular argument, see Stoltz 2009. 
- As for its not relying on the determination of the characteristics of a logical reason via an episode of knowledge:

- In the case of factive assessment lacking a reason, it is established by reflexive awareness.

- In the case of factive assessment having a mistaken reason, it is established by an episode of knowledge that observes the logical reason's faults.

- In the case of factive assessment with an uncertified reason, it is established by determining that the cognition that apprehends the characteristics of the logical reason is an instance of factive assessment.

- As for the state of affairs being veridical, this is determined subsequently by an episode of knowledge ascertaining that state of affairs.

\subsection{Mistaken Cognition}

123.41 Mistaken cognition has two forms:

- Apprehension of something superimposed (123.411)

- Incorrect determination of the intentional object (123.412)

123.411 The first form is a mistaken cognition in reference to the apprehended object being something superimposed. Namely:

- Non-conceptual erroneous cognition in which there is an appearance as of a double moon, etc.

And, from the perspective of their apprehending a concept:

- Inferential cognition

- Factive assessment

- Conceptual post-knowledge cognition

- Doubt

- Mistaken determinate awareness

123.412 As for the incorrect determination of the intentional object, this is conceiving of sound as permanent, etc. 
123.42 The definition of mistaken cognition is: positively discerning a state of affairs incorrectly. ${ }^{72}$

123.43 What determines that the definition applies is as follows:

- As for its positively discerning a state of affairs, this is determined by reflexive awareness.

- As for being incorrect, this is determined by an episode of knowledge that opposes the object being veridical in the way it has been positively discerned.

\subsection{Doubt}

123.51 The consideration "Is this permanent or impermanent?"- this is doubt.

123.52 The definition of doubt is: that which includes the consideration of another alternative being possible.

123.53 As for what determines that the definition applies, this is determined by reflexive awareness itself.

(a) ${ }^{73}$ Some say (D1) that doubt does not have the operation of excluding others. $^{74}$

72 Phya pa's use of the expression "positively discerning" (yongs su gcod pa) in this definition corresponds to that in the seven-fold typology, which ranges over both the operations of "appearing" and "directing" (see n. 42), so as to cover the various types of mistaken cognition.

${ }^{73}$ See n. 66 on the structure of this argument "by parallels."

74 The opponent that Phya pa has in mind could be his predecessor rNgog Lo, who supported the view that doubt does not "negatively ascertain" (rnam par gcod $p a$ ), and hence also does not "positively ascertain" (yongs su gcod pa) anything, or Phya pa's teacher rGya dmar ba, who reportedly also held such a view. See IV, 5(b) for more details. In this argument, the Tibetan term yongs su gcod pa is used as a correlate of rnam par gcod pa (matching the use of the Sanskrit term pariccheda in opposition to vyavaccheda). The two correlates typically represent, respectively, the positive and negative sides of a determining process (e.g., "this is blue' / 'this is not non-blue'). This use of yongs su gcod pa (which we translated as "positively ascertaining") is different from its use by Phya pa in the 
This is incorrect. In that case,

Parallel objection (D2): The determinate awareness of blue would not have the operation of excluding others.

Reply (D2): That determinate awareness does exclude non-blue, because if it did not exclude non-blue it would not be acceptable for it to positively ascertain blue.

Parallel reply (D1): Doubt excludes the impossibility of sound being permanent, because if it did not exclude the impossibility of this, it would not be acceptable for it to positively ascertain the possibility of this.

(b) Some say that the exclusion of a third alternative by an episode of doubt in which one ponders, "Is it a pile of stones or a person?", is an exclusion of others. ${ }^{75}$

This is not the case. Take the determinate awareness that something is just a pile of stones. In saying that it is neither a person nor some third alternative, there is a determination that it is not some third alternative. Therefore, though this is not an episode of doubt, it excludes a third alternative.

When one has the doubt, "Is it a person, or a pile of stones, or some third alternative?", even though this is an episode of doubt, there is no determination that it is not some third alternative, and so it does not exclude a third alternative.

Therefore, the exclusion of a third alternative is an exclusion of others for a determinate awareness, but not an episode of doubt.

\section{$* * *$ End of the first chapter $* * *$}

seven-fold typology (see 122.1), where we translated it as "positively discerning" (see n. 42).

${ }^{75}$ The same view is ascribed in the Tshad bsdus $(60,18-20)$ to an anonymous "senior Tibetan" (bod bgres po kha cig). 


\section{$* * *$ Second chapter: Elucidating the definition of knowledge and its types ***}

\section{In particular, elucidating the instances of awareness that are epi- sodes of knowledge}

$[\ldots]$

\subsection{Our own position (regarding the definition of knowledge)}

Here, our position is this. The meaning of "Revealing an unknown state of affairs" $" 76$ is: that which counters the capacity to produce superimpositions that are incompatible with the way things are (K1), through aspects of awareness that are non-erroneous with regard to a positively discerned state of affairs (K3). ${ }^{77}$ Here, this is what is called "understanding something veridical." 78

\section{$[\ldots]$}

(a) Objection: If there is a countering of superimpositions by an awareness that "understands something veridical," would it be (i) countering through experience, (ii) countering through a reliance on a logical reason, (iii) countering through these two together, or (iv) countering in general?

If (i), then the definition would be too narrow, as it would not apply to inferential cognition.

If (ii), then the definition would be too narrow, as it would not apply to perception. ${ }^{79}$

${ }^{76}$ This is part of Dharmakīti's definitions of knowledge in Pramānavārttika 2.5c (ajñātārthaprakāśo vā), which Phya pa quoted earlier in Mun sel 212.11 (32a3). ${ }^{77}$ Compare with the criteria given in (121.13). See the discussion in I.1, 4 and I.2, 3 . ${ }^{78}$ In an earlier passage, Phya pa associates the definition of knowledge as "understanding something veridical" (bden pa rtogs pa) with the Indian philosopher Śaṅkaranandana (Mun sel 212.11 [32a3]: bram ze chen pos bden pa rtogs pa la 'dod pa). This is supported by Sañkaranandana's Bṛhatprāmānyaparīkșā, k. 22 (see Hugon 2011a: 161, n. 14 and the discussion in I.2, 5).

${ }^{79}$ Here, Phya pa explicitly points out that if interpretation (ii) had been implied by the definition of knowledge, then the definition would (wrongly) not apply to perception at all. This carries the immediate (but unstated) consequence that the definition, a fortiori, could not apply to the narrower category of perceptual knowledge. For an analogous, but explicit, use of the same kind of reasoning see Mun sel 212.231 (34a6-7), which has been earlier quoted in n. 50 . 
Option (iii) is impossible.

If (iv), then, since the determination that sound is impermanent by an episode of factive assessment counters the superimposition 'permanence,' and the determination as singular counters the superimposition 'multiple,' the definition would be too broad, as it would apply to these two. ${ }^{80}$

Reply: It is none of those four. It is a countering of superimpositions through those aspects that are non-erroneous with regard to the state of affairs. The way of apprehending that is non-erroneous with regard to the state of affairs exists only for perception and inferential cognition, but not for factive assessment. This is because, at a time when the object is not yet established, there is no difference between factive assessment and mistaken cognition in terms of the awareness's way of apprehending.

(b) Objection: Is countering superimpositions the rendering powerless of actual superimpositions, or is it just the potential opposition of superimpositions? ${ }^{81}$

If it is the former, then since two conceptual cognitions cannot occur simultaneously, at the time of the inferential cognition, there is no superimposition. As such, the criterion of actually opposing superimpositions is too narrow, because it does not apply to inferential cognition.

If it is the latter, the criterion would be too broad, because it would apply to perceptual post-knowledge cognition.

Reply: It is (in some cases) the actual rendering powerless. Although there are no superimpositions per se at the time of inferential cognition,

${ }^{80}$ According to the parallel discussion in the 'Od zer (111.221.222), the second type of determination to which the definition would apply is an episode of mistaken cognition - for instance, the mistaken determination of an entity being ultimately permanent opposes the (also incorrect) superimposition 'ultimately impermanent.' The example provided in the Mun sel is found in 'Od zer 29a9, where the determination 'singular' illustrates a mistaken cognition which is incompatible with the mistaken cognition that apprehends as 'multiple.' (This is because, in the Madhyamaka framework, things are in reality neither singular nor multiple). See also the parallel discussion in Mun sel 212.22, in which Phya pa gives the example of the mistaken determinate awareness "yellow" pertaining to a white shell which, although mistaken, eliminates the mistaken superimposition 'blue.' ${ }^{81}$ On the issue whether actual or potential superimpositions are meant in K1, see also the discussion in Mun sel 123.1 [b]. 
since there is the capacity for them to be generated, it is that capacity that is opposed by inferential cognition.

It is (in other cases) the potential opposition to superimpositions. But it is not the case that the criterion would be too broad, applying to postknowledge cognition, because we said "incompatible with superimpositions with regard to something not previously known." ${ }^{\text {"2 }}$

\subsection{Rejecting faults of that definition}

There are three items:

- Rejecting the fault of the definition being too narrow (212.21)

- Rejecting the fault of the definition being too broad (212.22)

- Rejecting misconceptions regarding the basis of definition (212.23)

\subsection{Rejecting the fault of the definition being too narrow}

(a) Objection: If the awareness that "understands something veridical" must be a determinate awareness (since it eliminates superimpositions), then the definition is too narrow, since it would not apply to perception, which is non-conceptual.

Reply: When perception and a superimposition come into contact, the superimposition - which acts as cause - and the perception - which acts as condition-generate, in the second moment, a superimposition that is powerless. As a result of this, in the third moment, the superimposition has ceased. When this is the case, what renders it powerless is the perception. Thus, what eliminates a superimposition is that perception. The determining cognition is a post-knowledge cognition, because it occurs

\footnotetext{
${ }^{82}$ Phya pa is referring here to the definition of knowledge including the criterion $\mathrm{K} 1$ and the criterion of novelty (K2). Note, however, that the formulation of K1 in terms of "incompatibility with opposite superimpositions" is not used elsewhere in the Mun sel, and that the definition of knowledge in the Mun sel (212.14) does not make K2 explicit. This phrasing corresponds, rather, to that of the definition of knowledge in the 'Od zer. Alternatively, one could reject the scribal correction on the manuscript and read "incompatible with opposite superimpositions with regard to something previously known," which could be understood as a rephrasing of the definition of post-knowledge cognition (123.22). For further discussion of this argument, see I.2, 3.2.2.
} 
after the superimposition has been eliminated. Thus, the definition does not fail to apply to perception. ${ }^{83}$

(b) ${ }^{84}$ Objection (D1): Since, from the perspective of the concept, inferential cognition is a mistaken cognition that is erroneous with respect to its apprehended object, the definition, "understanding something veridical," would be too narrow, since it would not apply to inferential cognition.

Parallel objection (D2): From the perspective of the seed, the sprout is subsequently arising. Thus the sprout would not be the cause of a visual cognition of the sprout.

Reply (D2): From the perspective of the seed, which is the reference point, the sprout is subsequently arising, and so it is incompatible with it being the cause of the seed. But we do not assert that the sprout is a cause from this perspective.

As for the argument that, from the perspective of the seed, since the sprout is subsequently arising, it is not the cause of the visual cognition, the entailment is not established.

If one were to argue that, from the perspective of visual cognition, since the sprout is subsequently arising, it is not the cause of visual cognition, the argument lacks a logical reason. ${ }^{85}$

Parallel reply (D1): From the perspective of the concept, there is no "understanding something veridical" for inferential cognition. Thus, if one argues that inferential cognition is not, from this perspective, an instance of knowledge, one is proving what has already been established, because, from this perspective, it is a mistaken cognition.

As for the argument that, from the perspective of the external object, inferential cognition is not an episode of knowledge, since, from the perspective of the concept, there is no "understanding something veridical," there is no entailment.

If one were to argue that inferential cognition is not an instance of knowledge from the perspective of the external object, since, from the perspective of the external object, there is no "understanding of something veridical," then the logical reason is not established. This is because,

\footnotetext{
${ }^{83}$ On Phya pa's ascription to perceptual knowledge of the capacity to eliminate superimpositions see Hugon 2011a: 166-167 and I.2, 3.1.3.

${ }^{84}$ See n. 66 on the structure of this argument "by parallels."

${ }^{85}$ Namely, the property put forward as a logical reason does not fulfill the required characteristic of being a property of the subject (see VII, Appendix 2.6).
} 
from the perspective of the external object, inferential cognition has the previously stated definition.

\subsection{Rejecting the fault of the definition being too broad}

This definition is not too broad, as it does not apply to the five previously described types of awareness that are not episodes of knowledge.

- For post-knowledge cognition, there is no contact with a capacity that could produce superimpositions, which is what would have to be eliminated. Thus, it is contradictory for post-knowledge cognition to be something that counters this capacity. ${ }^{86}$

- For doubt and non-ascertaining perception, they are simply not incompatible with opposite superimpositions. ${ }^{87}$

- In accordance with, for example, the countering of the superimposition 'permanence,' through the episode of factive assessment that determines sound to be impermanent, and the countering of the superimposition 'blue,' through the mistaken cognition that determines a white shell to be yellow, ${ }^{88}$ factive assessment and mistaken cognition, respectively, have the criterion of countering superimpositions, in general. But, they do not have the definitional criterion of eliminating superimpositions by an apprehension that is non-erroneous with regard to the state of affairs (K3), since there is no contradiction in such episodes of awareness arising in the absence of the state of affairs.

$[\ldots]$

$* * *$ End of the second chapter $* * *$

\footnotetext{
${ }^{86}$ Phya pa is not explicitly advocating here the failure to fulfill the criterion of novelty (K2), but instead points to the failure to satisfy (K1). On the issues raised by the interpretation of this argument in relation with the discussion in Mun sel 212.14 (b), see I.2, 3.2.2.

${ }^{87}$ It follows from this that they fail to satisfy K1.

${ }^{88}$ Note that this form of mistaken cognition corresponds to a mistaken determinate awareness (for which see 112.111.2 and 123.412), which is to be distinguished from the example of a white shell appearing as yellow, which is a non-conceptual mistaken cognition (112.3).
} 


\section{$* * *$ Third chapter: Elucidating perceptual knowledge $* * *$}

\section{The specific elucidation of perception}

$[\ldots]$

\subsection{Presentation of our own position (on the definition of per- ception that eliminates the dissimilar types)}

Thus, its being non-erroneous is considered from the perspective of the apprehended object, and its being a perception is also considered from the perspective of the apprehended object. Therefore, the definition of perception is "being non-erroneous with respect to the state of affairs to be apprehended." And the appearing of a real entity is perception.

All the dissimilar types are excluded by this definition, and so "devoid of conceptuality" is not a criterion that serves to exclude the dissimilar types. ${ }^{89}$

$[\ldots]$

\subsection{The nature of knowledge episodes (in the case of perceptual knowledge)}

An experience of mind itself incompatible with superimpositions - this is an episode of knowledge which is a reflexive awareness.

The apprehension of something else being incompatible with superimpositions - this is an episode of knowledge which is a transitive awareness.

$[\ldots]$

\section{$* * *$ End of the third chapter ***}

\footnotetext{
${ }^{89}$ See also 'Od zer 112.113 (46a1-2). The discussion focuses on the role of the two properties mentioned in Dharmakīrti's definition of perception in PVin 1.4: "non-erroneous" (Skt. abhrānta, Tib. ma 'khrul pa) and "devoid of conceptuality" (Skt. kalpanāpoḍha, Tib. rtog pa dang bral pa/rtog bral). According to Phya pa, Dharmakīrti's inclusion of the second property is meant to eliminate the mistaken conceptions of non-Buddhist philosophers (Naiyāyikas in particular) regarding perception. With regard to eliminating the dissimilar types, the second property is redundant.
} 
$* * *$ Fourth chapter: Elucidating inferential cognition ***

\section{The specific elucidation of inferential cognition}

$[\ldots]$

\section{The definition of inferential cognition}

The definition of inferential cognition is "concluding, through observing some property in a given locus, what is determined to be entailed by that property." This is understanding from a logical reason endowed with the three characteristics. ${ }^{90}$

This preceding definition, together with "understanding something veridical," is the definition of inferential knowledge. ${ }^{91}$

$[\ldots]$

${ }^{90}$ This formulation goes back to Dharmakīti's definition of inferential cognition. In PVin 2.1, Dharmakīti defines "inference for oneself" as "the 'vision' of a state of affairs from a triply characterized logical reason" (Skt. trirūpāl lingato 'rthadrk, Tib. tshul gsum rtags las don mthong yin). "Vision" is rephrased as "knowledge" (Skt. jñanna, Tib. rtogs pa) in the auto-commentary (PVin 2 Skt. 46,3; Tib. 1,25-2,1).

91 "Understanding something veridical" is the definition of knowledge (see 212.14). Unlike in the case of perception, all episodes of inferential cognition are also episodes of inferential knowledge. This is pointed out explicitly by Phya pa in 'Od zer 78a2-3. 


\section{III}

Tibetan text 



\section{Source and editorial conventions}

A single cursive manuscript of Phya pa's Tshad ma yid kyi mun sel (abbreviated: Mun sel) was recovered in the library of the gNas bcu temple, part of 'Bras spungs monastery in Tibet. ${ }^{1}$

Our edition relies on two sets of images that are available for this manuscript: the black and white reproduction of the manuscript in the $b \mathrm{Ka}$, gdams gsung 'bum collection (vol. 8, 434-626), ${ }^{2}$ and the scans of a photocopy of the same manuscript by the Buddhist Digital Resource Center (previously Tibetan Buddhist Resource Center [TBRC], vol. No. 2077, Work Number 12171). The former set of images is referred to as the "KDSB version," the latter as the "TBRC version." The two versions differ in legibility. The TBRC version has, in most cases, a better resolution and a clearer reading. But some of the marginal notes near the edges of the folios are only visible in the KDSB version. Additionally, the KDSB version bears the mark of the intervention of one (or more) modern reader(s), who added, in particular, small circles marking the beginning of some sections. Occasional differences between the readings of these two sets in the passages edited in this volume are noted in $\$ 3$ below.

The manuscript consists of 97 folios (not 96 as reported in the 'Bras spungs dkar chag). The folios are numbered with numbers written in letters in the left margin on the recto from 1 up to 96 on the last folio ( $g o$

\footnotetext{
${ }^{1}$ The manuscript is listed with the catalogue number 016329 in the 'Bras spungs dkar chag: vol. 2,1449 . The discovery of this text was mentioned in van der Kuijp 2003: 386. Preliminary remarks on its structure and contents are found in Hugon 2008b: 39-45.

${ }^{2}$ Scans of the $b K a$ ' gdams gsung 'bum are also accessible in open access via the Buddhist Digital Resource Center (TBRC W1PD89051). Note that folios 87a and $86 \mathrm{~b}$ are misplaced in the reproduction of the manuscript in the $b \mathrm{Ka}$ ' gdams gsung 'bum, which prints the folios in the following order: 86a (p. 606), 87b (p. 607), 87a (p. 608), 86b (p. 609), 88a (610). This misplacement is repeated in the edition published in Lhasa (see Mun sel-Lhasa in the bibliography). This edition includes some editorial emendations (that are not explicitly noted by the editors) and a partial normalization of the orthography according to the rules of classical Tibetan. Being printed in $d b u$ can, it has the advantage of making the basic text accessible to readers of Tibetan not familiar with old cursive script. But as it is not properly speaking a critical edition, it has not been taken into consideration in our editing work.
} 
drug (bzhugs) (s.ho $\left.)^{?}\right){ }^{3}$ An additional folio marked "pre-28" (nyer brgyad $\left.g(\text { ong } m a)^{\text {? }}\right)$ contains the portion of text that belongs between the end of fol. $27 \mathrm{~b}$ and the beginning of fol. $28 \mathrm{a}{ }^{4}$

The original size of the manuscript according to the 'Bras spungs dkar chag is $64 \times 10.2 \mathrm{~cm}$. There are nine lines on each folio (exceptions: 8 lines on $28 b, 10$ on $57 b$, and 4 on $96 a$ ).

The first folio bears the title of the work (tshad ma yid kyi mun sel zhes bya ba bzhugs_s.ho/) and the indications "phyi" (which marks it as a text brought from the outside), "zha" (the marker for epistemological works) and " 11 " (the bundle number). ${ }^{5}$

The title is also stated in the colophon (96a3), together with a statement of authorship, ${ }^{6}$ and at the end of each chapter.

According to the calligrapher's colophon (96a4), the text was transcribed by mKhas pa'i 'byung gnas bSod nams dpal ("khé pé jung né sö nam pel") at Bri'u las gTsug lag khang ("driu lé tsuk lak khang"). The type of the cursive (dbu med) script is identified as 'bru tsha in the 'Bras spungs dkar chag.

The orthographic particularities of the manuscript, most of which are not systematic, ${ }^{7}$ include:

- the occasional palatalization of $m a$ by the subscript letter $y a$ (frequent on the first folio, it is rarely found afterwards)

- the superabundant use of the suffix letter 'a (e.g., gzhi', dbye' ba)

- the flexible use of prefixes for verbal forms and their derivatives (for example: gzung yul/bzung yul, gzung don/bzung don, gcad pa ' $i$ yul can/bcad pa'i yul can)

\footnotetext{
${ }^{3}$ The number on the recto of the first folio ( $g$ cig) is not visible in the KDSB version and is only faintly visible in the TBRC version.

${ }^{4}$ The image of this additional folio is placed correctly between fol. $27 \mathrm{~b}$ and fol. 28a in the KDSB version, but appears after fol. $28 \mathrm{~b}$ in the TBRC version.

${ }^{5}$ This signature is not visible in the KDSB version.

${ }^{6}$ Mun sel 96a3: tshad ma yid kyi mun pa sel pa zhes bya ba blo gsal zhing rigs par smra bas rtog ge ngan pa'i gzhung 'jig pa brtul zhugs mchog la legs par gnas pa'i dge slong chos kyi seng ges nye bar sbyar ba // rdzogs s.hō //

${ }^{7}$ The absence of systematic orthography may be due to the scribe copying from a manuscript with older orthographical conventions and reproducing those only on occasion, or simply due to the existence of alternative acceptable conventions at the time the text was transcribed.
} 
- the form of the particle pa/ba and after final -ng (e.g., mthong pa, snang $p a$ ) and final $-l$ (e.g., sel pa, but one finds both 'khrul pa and 'khrul ba)

- the form of the la don after final -b (e.g., kun $r d z o b d u$ ) and final $-g$ (e.g., $c i g d u$ )

- the flexible spelling for some words (e.g., the tsom/the tshom)

- spelling consistently differing from classical Tibetan (e.g., lasogs pa instead of la sogs pa, log rtogs instead of $\log r t o g$ )

- the consistent use of a tsheg before a shad

- enclitics ('ang, 'am, ' $i$, ’o) appearing as a separate syllable.

The present edition preserves all these orthographical particularities. We corrected, however, the intermixed use of $l d o g$ for bzlog in order to remove ambiguity. ${ }^{8}$

One also finds the following particularities, especially in the interlinear and marginal notes:

- use of the bindu for final $-m$

- reversed $i$ (gigu log)

- numerals written with numbers rather than being spelled out, and numerals used for their phonetic value (e.g., skad 1 for skad cig)

- abbreviations; for instance, a consonant present at the end of a syllable and at the beginning of the next one is only written once (for example, med de is written med with a vowel ' $e$ ' above ' $d$ ')

The text was corrected by the scribe or another reader by way of deletions and insertions. Deletions were carried out by one or two small strokes, by erasing, by crossing, or by circling or parentheses-like signs when the passage to be deleted runs over several lines. Insertions were written below the line (in $d b u$ med, or in dbu can in the case of single letters being added), or on the top or bottom of the folio in the case of longer passages, often with a reference sign.

\footnotetext{
${ }^{8}$ Also emended in the edition was the spelling bcas pa' $i$ yul can, which, unlike the alternative forms gcad pa'i yul can and bcad pa'i yul can, has to be viewed as a scribal mistake.
} 
Our emendations are indicated in the footnotes, with the exception of emendations pertaining to punctuation, which have been made directly in the text with the use of the specific symbol "'" for additional shad.

Citations in the text are identified in the footnotes.

Corrections of the manuscript (deletions and insertions) by the scribe or another reader are reported in $\S 3$ when the resulting reading was identical with the reading chosen in the critical edition. Otherwise they appear in the footnote indicating our emendation. Also listed in $\S 3$ are the cases where the reading of the manuscript is unclear.

Insertions that we understood to be glosses or additions (rather than corrections making up for a passage omitted by the copyist) are listed in $\S 4$.

The division of the text into paragraphs is editorial. Some sentences have been divided by line-breaks for the sake of clarity. Corresponding divisions into paragraphs and lists have been adopted in the translation.

The titles and their number, as well as letters and numbers for various items (which appear in bold), are editorial. When two titles separated by a slash are listed for a section, the first title is the one given by Phya pa when all the items of a division were first listed and the second title is the one used when Phya pa reaches the given division in the text. When only one title is listed, it corresponds to a unique title used on either or both of these occasions.

The title numbering reflects the hierarchical organization of the text intended by the author.

The body of the text of the Mun sel is divided into five chapters:

Chapter I: Determining the divisions of awareness (blo'i dbye ba nges pa)

Chapter II: Elucidating the definition of knowledge and its types (tshad ma'i mtshan nyid dbye' ba rnam par nges $p a)$

Chapter III: Elucidating perceptual knowledge (mngon sum gyi tshad ma rnam par nges pa)

Chapter IV: Elucidating inferential cognition (rjes su dpag pa rnam par nges pa)

Chapter V: Elucidating the way to present an argumentative statement (rtsod pa'i ingag gi tshul rnam par nges pa) 
The title and ordinal numbering of each chapter is indicated at the end of the chapter. ${ }^{9}$ This five-fold division is combined with a hierarchical organization into section and subsections, indicated by arabic numerals $(1,11,111,111.1$, etc.) in the edition, which is outlined in $\S 5$. This structure is typically indicated in the text by mentioning, at the beginning of a section (resp. subsection) the number of items to be considered and listing these items (in Tibetan: $s a b c a d$ ). ${ }^{10}$ These are then considered in order. ${ }^{11}$ When coming to the given item in the text, its place in the list of items of the division it is part of is indicated by an ordinal number (first, second, etc.) and/or by repeating the item's title. But these indications are sometimes omitted (as for instance in section 112.3).

Some of the divisions noted in the table are not explicitly listed in the text as divisions but were introduced by the editors for the sake of clarity, in one case (the subdivisions of [123.32]) following the indication in a marginal note. They are, for instance, divisions (a)/(b) under (11); enumerations of items noted (i), (ii), (iii); divisions indicated with roman letters (x.A, x.B, etc.) when the views of several scholars or schools are discussed; thematic divisions not marked as such by the author, such as for the sections distinguished in (112.111.11) or in (112.2). For these editorial divisions, the title provided is editorial. These editorial divisions may themselves involve further subdivisions, some of which are also editorial, some other are made by the author.

The passages that have been critically edited in this volume belong for the most part to the first chapter of the work. A few pertinent passages from other chapters have been provided in complement.

Five excursuses, noted [EX1]...[EX5], which are not directly relevant to the issue of the divisions of awareness, have been left out of the edition (and the translation) in the present volume. They are summarized in VII, Appendix 1, together with references to existing critical editions, translations, and related studies.

\footnotetext{
${ }^{9}$ For instance, for the first, by the phrase: tshad ma yid kyi mun pa sel pa las blo' $i$ dbye ba nges pa'i le'u ste dang po'o //

${ }^{10}$ On this technique applied by Tibetan scholars (and in particular by Phya pa) for organizing their own texts as well as the contents of Indian works, see Hugon 2009a, §3.1.

${ }^{11}$ There is one exception in the passage considered here: section (112.111.2), which should come up before (112.112), is actually placed after (112.112) and (112.12).
} 
Citations or references to Phya's views in later works are referred to in the text by superscript references of the form R1.1...R8. The corresponding passages can be found in IV, 1 . We have limited ourselves here to positions nominally ascribed to him - in the works themselves or in interlinear notes written on the manuscript - in a selection of texts: The Tshad bsdus, mTshur ston's sGron ma, gTsang drug rdo rje's gSal byed sgron ma, and Chu mig pa's rNam rgyal, have been selected for their temporal proximity to Phya pa. References in Śākya mchog ldan's works have been considered as well, given his firsthand access to Phya pa's texts. Upon closer examination, however, a number of Śākya mchog ldan's references introduce examples, categories and terminological conventions that appear to come from the later tradition. Similarly, the account of the division of awareness ascribed to "ancient scholars, Phya pa, etc." by Go rams pa in his Rigs gter rab gsal (edited and translated in van der Kuijp 1978) is not a literal account of Phya pa's Mun sel or 'Od $z e r$, but a similar presentation, which he probably draws from a later source. ${ }^{12}$ Definitions quoted in the Rigs gter (on which Śākya mchog ldan and Go rams pa are commenting) are not included here, because-as the commentator Glo bo mkhan chen bSod nams lhun grub ("lo bo khen chen sö nam lhün drup," 1456-1532) correctly assesses - they are essentially based on mTshur ston's sGron ma. ${ }^{13}$

A large part of the discussion in the Mun sel has a parallel, in the form of a long excursus, within Phya pa's commentary on Dharmakīti's Pramānaviniścaya ('Od zer 20b3-29a8) (see V, 2.1 for more details). The relevant passages of this excursus are referenced in the edition next to the titles, in smaller script, by using curly brackets with the indication " $\mathrm{Od}$ zer," followed by the number of the corresponding section and the folio

\footnotetext{
${ }^{12}$ Indeed, Go rams pa modifies the subdivision of the seven types of awareness in such a way that the five instances that are not episodes of knowledge are introduced first, followed by the two that are episodes of knowledge. The second section of Go rams pa's account of opposing views is not explicitly linked with 'Phya pa, etc.' but can be assumed to be ascribed to the same. Note in particular, in this second section, Go rams pa's use of the term bcad shes for post-knowledge cognition (see IV, 2[a]), which is not found in Phya pa's works.

${ }^{13}$ Cf. Rigs gter nyi ma II 53,8-9 on yid dpyod (gzhung 'dir byung ba'i phyogs snga ma'i tshig ris rnams ni mtshur ston gzhon nu seng ge'i tshad ma shes rab sgron me na yod do //), 59,13-16 on snang la ma nges pa (... zhes mtshur ston gzhon nu seng ge zer ro //), 62,16-20 on dpyad pa'i yul can (... zhes mtshur ston la sogs pa zer ro //).
} 
numbering in the 'Od zer. The topical outline of this excursus in the 'Od zer can be found in V, 2.b, and the edited text in V, 2.a (with cross-references to the parallel passages in the Mun sel). Parallel passages in the 'Od $z e r$ that are not part of this excursus have not been edited in this appendix, but a reference to them is provided in footnotes within the edition of the Mun sel.

The numerous parallel discussions in works postdating Phya pa have not been noted in the edition. References to some of them are provided in I.2, 2.3 .

Technical terms and their English translation are listed in the lexicon (VII, Appendix 4).

The following signs and conventions are used in the edition of the Tibetan text in $\S 2$. These same conventions are applied throughout the volume when other texts are cited.

\section{In the text}

I blo'i dbye ba Chapter number and title

112.21 byed pa $S a$ bcad number and section title (according to the text)

(a)

A

i.

EX1 (1b1-4)

[D1], [D2]

$\{$ 'Od zer...\}

[a]...[f]

${ }^{\alpha}{ }^{\varepsilon}{ }^{\varepsilon}$

R1.1 $\ldots{ }^{\mathrm{R} 8.1}$

$[\cdots[3165] \ldots]$

[1b5]

Dotted underline

Underline

Italics
Subsection (editorial)

Subsection introducing the position of a specific scholar (editorial)

Item number in a list or a set

Title and extent of section left out of the edition (summarized in VII, Appendix 1)

Marks to distinguish statements pertaining to "Domain 1" and statements pertaining to "Domain 2" in arguments by parallel (see II, 123.322, n. 66)

Reference to a parallel passage in the 'Od zer (see V, 2)

References to set examples of inferential reasoning (see VII, Appendix 2.7)

Marks an insertion consisting in a gloss or addition to the text (listed in $\S 4$ below)

Marks a reference to this passage in a later text (listed in $\mathrm{V}, 1$ )

Portion of the text left out of the edition

Folio and line number

Marks an emendation explained in the footnote

Name or anonymous person whose views are reported in the text

Mark sentences and paragraphs representing objections

Punctuation added by the editors 


\section{In the apparatus (i.e., footnotes, §3, and §4)}

\langle\rangle$\quad$ Contain character(s) added by the editors

$<>$ Contain character(s) inserted by the scribe or a reader below the line or in the top or bottom margin for longer passages

\{\} Contain character(s) deleted by the scribe or a reader by erasing

() Contain unclear characters

()? Contain characters whose reading is uncertain

$\rightarrow \quad$ Indicates a modification by the scribe, such as writing a word over something deleted, or transforming a written character by modifying its form

$\times \quad$ Space (which could in some cases be the result of a deletion)

M Bind $u$, typically used to note a final $-m$ (found in interlinear notes only)

i $\quad$ Reversed $i$ (gigu log)

tsheg (only noted in the case of a correction by the scribe)

.. $\quad$ Illegible character (notably as the result of a deletion by erasing)

To transcribe abbreviations in which a consonant present at the end of a syllable and at the beginning of the next one is only written once. For instance: med_de 


\section{Critical edition}

[1b1] rgya gar skad du / phra ma na ma naḥ ta maḥ tā na ba nā ma $a^{\mathrm{i}} / /$ bod skad du / tshad ma yid kyi mun pa sel ba zhes bya ba //

EX1 (1b1-4)

tshad ma'i tshul ji lta ba bzhin du nges par byed pa na / spyir blo tsam gyi

5 dbye ba dang / bye brag du tshad ma'i blo nges par ${ }_{[1 b 5]}$ bya ba gnyis kyis rnam par gzhag go //

\section{I blo'i dbye ba nges pa}

\section{1 spyir blo tsam gyi dbye ba}

dang po'ang gzung yul la ltos nas blo gsum du dbye' ba dang / gzung pa

10 dang zhen pa'i yul gnyi' ga la ltos nas blo bdunn ${ }^{1}$ du dbye ba gnyis kyis nges par bya'o //

\section{1 gzung yul la ltos nas blo gsum du dbye' ba}

dang po ni

\section{(a) yul gsum \{'Od zer 111.222.1.a (23b2-4)\}}

15 spyir blo la snang pa gzung pa'i yul la gsum ste | don rang gi mtshan nyid dang don spyi dang rtog myed 'khrul pa'i dmigs pa'o / ${ }^{R 51.1}$

\section{i. don rang gi mtshan nyid}

dang po ni yul dus ma 'dres par gsal la don byed nus pa ste : yul lnga dang ${ }_{[1 \mathrm{~b} 6]}$ dbang po lnga dang snod kyi 'jig rten du bcas pa'i gzung char snang pa dang ! sems dang sems las byung pa'i blo mtha' dag go //

\section{ii. don spyi}

don spyi ni yul dus 'dres par snang pas ${ }^{\mathrm{ii}}$ mi gsal zhing don byed mi nus pa ste !' 'das pa dang ma 'ongs pa dang da ltar dang thag nye ba dang ring pa dang dngos po dang dngos med dang shes bya la srid pa

${ }^{1}$ Em. bdun : Ms mdun 
dang mi srid pa dang gang ${ }^{\mathrm{iii}}$ yid la byas kyang rtog pa la wal ${ }^{2}$ gyis 'char ba rnams so //

\section{iii. rtog med 'khrul pa'i dmigs pa}

rtog med 'khrul pa'i dmyigs [1b7] pa ni yul dus ma 'dres par gsal yang don byed mi nus pa ste zla ba gnyis dang rmyi lam gyi glang po lasogs pa snang pa rnams yin no //

(b) blo gsum \{'Od zer 111.222.1.b (24a9-28b3)\}

de ltar yul gsum la 'jug pas blo 'ang gsum ste /

i. don rang gi mtshan nyid gzung yul du byed pa \{'Od zer 111.222.1.b.1 (24a9-b1)\}

don rang gi mtshan nyid gzung yul du byed pa shes pa mtha' dag la yod pa'i rang rig dang ! gzugs lasogs pa lnga snang pa'i dbang po'i shes pa 'khor bcas dang ! de dag snang pa'i yid mal 'byor pa'i shes pa dang bcas pa ni rtog myed ${ }_{[1 b 8]}$ kyi mngon sum ste / yul bden pas blo ma 'khrul ba dang / yul dang blo gnyi ga dngos po yin la gzhan dbang yang yin no //

\section{ii. don spyi gzung yul du byed pa \{'Od zer 111.222.1.b.3 (26b2)\}}

don spyi gzung yul du byed pa kha phyir ltas kyi yid 'khor bcas ni rtog pa ste $\mathrm{R}^{\mathrm{R} .1, \mathrm{R} 4.1, \mathrm{R} 7.1}$ / yul brdzun pas blo 'khrul pa dang / yul dngos med la blo dngos po dang | yul kun brtags la blo gzhan dbang du gnas pa yin no //

iii. rtog med 'khrul pa'i dmigs pa gzung yul du byed pa \{'Od zer 111.222.1.b.2 (26b2)\}

rtog med 'khrul pa'i dmyigs pa gzung yul du byed pa zla ba [1b9] gnyis snang lasogs pa'i dbang shes dang rmyi lam gsal snang lasogs pa'i yid shes ni rtog med 'khrul $\mathrm{pa}^{3}$ ste / yul brdzun pas ${ }^{\text {iv }}$ blo 'khrul pa dang / yul dngos po myed kyang blo dngos po dang / yul sgro btags la blo gzhan dbang yin no //

de la yul gsum nges par bya ba dang / blo gsum nges par bya ba gnyis las /

\footnotetext{
${ }^{2}$ Em. wal : Ms ("*)? 1 . The uncertain character is similar to $w a$ on fol. 96 a4 but with a hook on top. It resembles rtsa in other scripts (but not in this manuscript).

${ }^{3}$ Em. pa : Ms pa'i
} 


\section{1 yul gsum nges par bya ba}

\section{(a)}

EX2 (1b9-3b2) \{'Od zer 111.222.1.a (23b4-24a9)\}

D \{'Od zer 111.222.1.a.D (24a9)\}

5 des na sems dang sems byung phyi rol gyi yul dang dbang po dang snod kyi 'jig rten lasogs pa thams cad dngos po ste ; tha dad dus mnyam tshogs pa cig pas yul dang yul can du gnas pa yin la / zla ba gnyis lasogs pa dang don spyi don byed mi nus pas dngos med [3b3] yin te / tha snyad duv 'jig rten la grags pa bzhin du gnas so //

10 (b) $\{$ 'Od zer 111.222.1.b.122.1 (24b3-4)\}

dngos po 'di tha dad kyis stong pa dang / tha dad sgro 'dogs pa'i tshul dang / rjes 'gros stong pa dang / rjes 'gro sgro 'dogs pa'i tshul bzhis nges par bya'o //

\section{1 tha dad kyis stong pa}

15 dang po ni

- sngon po 'di nyid dus gzhan na 'gag pas mi rtag pa las gzhan ma yin la ! rgyus bskyed pas byas pa las gzhan ma yin pa dang /

- byas pa nyid sngo ma yin las log pas sngon po las gzhan ma yin pa ${ }^{4}$ dang ! [3b4] dus gzhan du mi gnas pas mi rtag pa las gzhan ma yin la /

20 - mi rtag pa nyid sngo ma yin las log pas sngon po las gzhan ma yin pa dang ! rgyus bskyed pas byas pa las gzhan ma yin te!

sngon po dang byas pa dang mi rtag pa zhes don spyi so sor snang yang rang gi mtshan nyid dbyer med pa yin te : de bzhin du ngo bo re re la yod pa'i log pa thams cad la blta'o //

25 de lta ma yin na dngos 'gal la bzlog pa bkag pa ${ }_{[365]}$ de'i ngo bo yin pas

- sngon po mi rtag pa las tha dad na rtag pa dang ! byas pa las tha dad na ma byas par'gyur la!

- byas pa sngon po las tha dad na sngo ma yin dang mi rtag pa las tha dad na rtag par' gyur ba dang /

30 - mi rtag pa'ang sngon po las tha dad na sngo ma yin dang | byas pa las tha dad na ma byas par 'gyur ba lasogs pa'i nyes pa yod do //

${ }^{4}$ Em. sngon po 〈las gzhan ma yin pa $\rangle$ : Ms sngon po 


\section{2 tha dad sgro 'dogs pa'i tshul ${ }^{5}$}

gnyis pa ni

'o na de dag dbyer med na 'jig rten na'ang sngon po chos can byas pa gtan [3b6] tshigs dang mi rtag pa bsgrub bya'o zhes tha dad du 'byed la I

5 bstan chos las kyang sngon po gzugs kyi phung po dang byas pa mivi rtag pa lasogs pa 'du byed kyi phung po zhes tha dad du brjod pa ji ltar yin zhe nal

de ni sgro btags pa'i tha snyad de $\mid$ de'ang tha dad sgro 'dogs pa'i sa bon dang / sgro 'dogs pa'i rnam pa gnyis so //

\section{1 tha dad sgro 'dogs pa'i sa bon}

dang po ni ngo bo cig la sngo ma yin du zhen pa dang ma byas par zhen pa dang rtag par zhen pa'i log shes ${ }_{[3 b 7]}$ tha dad bsal du yod cing log shes kyi zhen yul du ma las log pas ldog pa du mar 'jog pa yin no //

\section{2 sgro 'dogs pa'i rnam pa}

15 gnyis pa ni de gsum la don spyi so sor shar te!

- sngon po'i don spyi shar ba phyi rol du zhen pas sngo ma yin du sgro 'dogs pa dang por bsal bas chos can sngon po sngar grub pa la!

- bar du byas pa'i don spyi shar te $\mid$ de phyi ${ }^{\text {vii }}$ rol du zhen pas ma byas pa'i sgro 'dogs chod pas rtags byas pa bar du nges pa dang /

- mi rtag pa'i ${ }_{[3 b 8]}$ don spyi shar te $\mid$ phyi rol du zhen pa med de $\mid$ rtag pa'i sgro 'dogs ma bsal bas bsgrub bya mi rtag pa phyis bsgrub dgos so zhes tha dad du sgro 'dogs pa yin no //

\section{3 rjes 'gros stong pa}

gsum pa rjes 'gros stong pa ni sngon po zhes cig du tha snyad byed kyang 25 - yul 'di' $i$ viii sngon po las yul gzhan gyi sngon po tha dad la!

- dus da ltar gyi sngon po las 'das pa lasogs pa'i sngon po tha dad pa dang !

- be du rya'i sngon po las ud pa la'i sngon po tha dad pa [3b9] yin te / tha mi dad yin na

\footnotetext{
${ }^{5} \mathrm{Cf}$. the related passages in 'Od zer 102a1-3 (commenting on PVin Skt $_{2.20 \mathrm{ab}}$

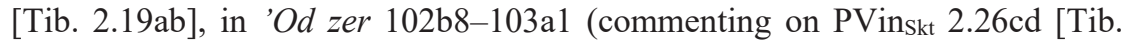
$2.25 \mathrm{~cd}$ ]), and 'Od zer 108a5-b5 (commenting on PVin ${ }_{\text {Skt }} 2$ 56,12-57,10 [Tib. 10,15-11,5], including the verses PVin 2.29-31).
} 
- yul 'di'i sngon po mthong pa ltar gzhan gyi sngon po 'ang mthong pa dang /

- 'das pa'i sngon po 'gags pa na da ltar gyi sngon po 'ang 'gags pa dang / - ud pa la'i sngon po rnyings pa na be du rya'i sngon po rnyings pa lasogs par thal ba'i phyir ro //

\section{4 rjes 'gro sgro 'dogs pa'i tshul}

bzhi pa rjes 'gro sgro 'dogs pa'i tshul ni

'o na de ltar rang bzhin tha dad la sngon po zhes cig du brjod pa ji ltar yin zhe na

sgro btags nas te!

- [4a1] sgro 'dogs pa'i rgyu mtshan ni rdzas so so ba de rnams la sngo ma yin gyi sgro 'dogs cig bsal du yod cing log sa cig las log pas cig du ${ }^{6}$ sgro 'dogs pa yin la /

- sgro 'dogs pa'i rnam pa ni rdzas tha dad rnams la 'ang don spyi cig 'char ba yin no // //ix

\section{2 blo gsum nges par bya ba \{'Od zer 111.222.1.b (24a9-28b3)\}}

gnyis pa yul can gyi dbye ba ni rtog pa dang / rtog med ma 'khrul pa dang / rtog med 'khrul pa gtan la dbab pa gsum $\mathrm{mo}^{\mathrm{x}} / /$

\section{1 rtog pa \{'Od zer 111.222.1.b.3 (26b2-28b2)\}}

20 [4a2] dang po rtog pa la gnyis te / phyi rol du zhen pa dang ma zhen pa'o //

112.11 phyi rol du zhen pa / zhen pa \{'Od zer 111.222.1.b.32 (26b3)\}

zhen pa la 'ang nges pa dang the tshom gnyis so //

\subsection{1 nges pa}

nges pa la'ang shes bya dang mthun par nges pa dang / mi mthun par nges pa'o //

\subsection{1 shes bya dang mthun par nges pa}

dang po la'ang rjes dpag dang yid dpyod gnyis las

\footnotetext{
${ }^{6}$ Em. cig 〈las log pas cig $\rangle$ du : Ms cig du (cf. the parallel discussion in Tshad bsdus 28,4-5: sgro 'dogs pa'i rgyu mtshan ni log pa me ma yin zhes bya ba gcig las log pas so /; and 41,3-4: gcig du sgro 'dogs pa ni gnyis las sa bon ni log pa sngo ma yin gcig las log pas so //)
} 


\subsubsection{1 rjes dpag}

112.111.111 byed pa gsum \{'Od zer 111.222.1.b.322.222.a (26b7-27a3)\}

rjes dpag la byed pa gsum ste / snang pa dang / zhen pa dang / gzhan sel pa'o //

\subsubsection{1 snang pa}

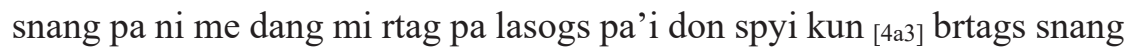
pas de ni bzung don la 'khrul pa'i log shes kho na'o //

\subsubsection{2 zhen pa}

zhen pa ni

[a] me'i don spyi shar ba phyi rol gyi me'i ngo bor zhen la [b] mi rtag pa'i don spyi shar ba phyi rol gyi mi rtag pa'i ngo bor zhen pa lasogs pa rang gi mtshan nyid kyi ngo bor zhen pa'ang yod la /

[c] zla ba gnyis dpyad mi bzod pas kun rdzob kyi bden pa'i tha snyad dpags pa na ${ }^{7}$ zla ba gnyis dang kun rdzob kyi bden pa'i tha snyad tshogs pa'i don spyi [4a4] shar ba zla ba gnyis kyi ngo bor zhen pa yod de!

de gnyis thag pa la sbrul du zhen pa ltar shes bya dang mi mthun par zhen pas log shes yin la /

[d] ri bong can gyi sgra don la rtog pa'i gzung yul yin pas sgra'i dngos

kyi brjod byar dpags pa na ri bong can gyi sgra don dang dngos kyi brjod bya'i tshogs pa'i don spyi shar ba ${ }^{\mathrm{xi}}$ ri bong can gyi sgra don gyi ngo bor zhen te?

de ni sgra don la sgra don du zhen pa yin pas 'khrul pa ma [4a5] yin no //

\subsubsection{3 gzhan sel pa / sel pa}

sel pa ni

[b] mi rtag par nges pas rtag pa'i log shes de la 'jug pa bsal ba dang !

[a] mer zhen pas me med du zhen pa bsal ba dang!

[c] kun rdzob du zhen pas don dam du zhen pa dang !

[d] dngos kyi brjod byar zhen pas dngos kyi brjod bya ma yin par zhen pa bsal bas

de tshad ma yin no //

\footnotetext{
${ }^{7}$ Em. na : Ms dang
} 
\{'Od zer 111.222.1.b.322.222.a.3 (27a3)\}

des na [e] stong nyid kyi don spyi log pa'i kun rdzob blo la snang pa dang ${ }^{8}$ de stong pa nyid yongs su grub par zhen pa log shes [4a6] yin yang bden pa'i dngos por zhen pa'i log shes sel pa tshad ma yin pa rmyi lam gyi bu

5 shi bar snang pa'i log shes kyis bu yod pa'i sgro 'dogs sel pa'i dpes kyang gsungs so //

\subsubsection{2 \{'Od zer 111.222.1.b.322.222.b (27a5-7)\}}

rtog bcas de la'ang dngos po'i gnas lugs dang / blo'i 'dzin stangs dang / tshad mar 'gyur ba'i tshul gsum gyis nges par bya'o //

$10 \quad$ 112.111.112.1 dngos po'i gnas lugs

dang po ni

- me nyid dang !

- byas pa mi rtag pa dang dbyer med pas tha dad pas stong [4a7] pa dang /

- yul dang dus dang rang bzhin tha dad pa'i me ma 'dres pas rjes su 'gro bas stong par gnas so //

\subsubsection{2 blo'i 'dzin stangs}

- blo'i 'dzin stangs ni me la mer'dzin la /

- byas mi rtag dang me $\mathrm{e}^{\mathrm{xii}}$ don spyi so sor 'char bas tha dad kyis stong pa las bzlog ste tha dad du snang pa dang!

20 - yul dang dus dang rang bzhin so so ba rnams la me ${ }^{\text {xiii, }}$ i don spyi cig 'char bas rjes 'gros stong pa las kyang bzlog ste thun mong par snang pa yin no //

\subsubsection{3 tshad mar'gyur ba'i tshul}

[4a8] tshad mar 'gyur ba'i tshul ni thams cad kyang bzlog pa'i zhen pa bkag 25 ste gzhan sel pas 'jug go //xiv

EX3 (4a8-6a3) \{'Od zer 111.222.1.b.322.222.c (27a7-28b2)\}

\subsubsection{2 yid dpyod / yid dpyod dang bcad pa'i yul can}

rtog pa tshad ma ma yin yang shes bya dang mthun par nges pa ni yid dpyod dang bcad pa'i yul can te $!$ de dag la'ang byed pa gsum yod pa las

30 - snang pa'i ${ }_{[6 a 4]}$ cha la khron pa rnying pa'i chu dang sngon po'i don spyi snang pa ni gzung don $1 \mathrm{a}^{\mathrm{xv}}$ 'khrul pa'i log shes yin la!

\footnotetext{
${ }^{8}$ Em. $\langle$ dang $\rangle$
} 
- don spyi phyi rol du zhen pa ni tha dad sre ba'i log shes yin zhing ${ }^{\mathrm{xvi}}$ /

- khron pa na chu med pa'i dogs pa sel pa yid dpyod dang sngo ma yin sel pa bcad pa'i yul can yin no //

\subsection{2 the tshom \{'Od zer 111.222.1.b.321 (26b3) and 111.222.33 (29a4-5)\}}

5 the tshom la'ang byed pa gsum las

- sha za lasogs pa'i don spyi snang ${ }^{\text {xvii }}$ pa gzung pa'i don la 'khrul pa'i log shes dang !

- de phyi rol snang par [6a5] zhen pa sre ba'i log shes yin yang

- sha za yod srid par zhen pas ${ }^{\text {xiii }}$ mi srid pa sel pa'i cha nas the tshom yin no //xix

\subsection{2 ma zhen pa \{'Od zer 111.222.1.b.31 (26b3)\}}

yid kyi rgyal srid dang nye bar brtags pa'i don yul du byed pa dang rang gi lus spre'u lasogs par bsgom pa'i rtog pa la ni phyi rol du zhen pa dang gzhan sel pa gtan med $\mathrm{de}^{\mathrm{xx}}$, don spyi snang pa kho nar zad pas gzung don 15 la 'khrul pa'i log shes kho na'o //

\subsection{2 shes bya dang mi mthun par nges \{'Od zer 111.222.1.b.322.1 (26b4)\}}

sgra rtag par zhen pa lasogs pa'ang byed pa gsum [6a6] las ${ }^{9}$

- sgra dang rtag pa tshogs pa'i don spyi snang pa'i cha nas gzung don la 'khrul pa'i log shes so //

20 - de phyi rol du zhen pa'ang tha dad sre ba'i log shes so //

- sgra la mi rtag pa sel pa'i gzhan sel nixi ${ }^{\mathrm{xxi}}$ shes bya la mi srid pa ${ }^{10}$ bsgrub cing srid pa 'gog pa' $\mathrm{i}^{\mathrm{xxi}} \log$ shes te!

log shes cha gsum du gnas pa yin no //

\section{2 rtog med ma 'khrul pa \{'Od zer 111.222.1.b.1 (24a9-b1)\}}

\subsection{1 byed pa}

rang rig pa dang gzhan rig pa'i rtog med ma 'khrul pa la ni sngon po lasogs par zhen pa'i zhen pa [6a7] dang sngon por zhen pas sngo ma yin las phyed pa lasogs pa'i gzhan sel med par myong pas grub pas snang pa'i byed pa kho na yin la!

\footnotetext{
${ }^{9} \mathrm{Em} . \mathrm{la}\langle\mathrm{s}\rangle: \mathrm{Ms}$ la

${ }^{10}$ Em. pa : Ms pas
} 


\subsection{2 blo'i 'dzin stangs \{'Od zer 111.222.1.b.122.2 (24b4-6)\}}

\section{(a)}

de'ang sgro btags mi ${ }^{\text {xxiii }}$ snang par dngos po nyid snang pa ni gzung pa don byed pas dngos por grub pa'i shugs la grub pa yin no //

5 de'ang dngos po nyid snang pas tha dad kyis stong pa la de ltar snang ste ! ngo bo gcig gi ldog pa la snang mi snang cha gnyis myed pa'i phyir ro // rjes 'gros stong pa la'ang rjes 'gros ${ }_{[6 a 8]}$ stong pa nyid du snang te $\mid$ rang bzhin tha dad so sor snang pa'i phyir ro //

\section{(b)}

10 de'ang rnam pa dang ldan pa rnams ni tha dad kyis stong par snang ${ }^{\text {xiv }}$ pa'ang myong pas grub ste | sngon po dang de'i dbyibs dag cha gnyis med par cig du snang par myong pa bzhin no //

rjes 'gros stong parr ${ }^{11}$ snang pa yang myong pas grub ste | be du rya dang ud pa la'i sngon po dang yul 'di dang gzhan gyi sngon po so sor snang par myong pa bzhin no //

(c)

rnam pa med pa la skad cig snga phyi'i sngon po rjes 'gros stong [6a9] zhing so sor snang pa rtags las te! snga ma 'gags pas med pas mi snang la phyi ma ma skyes pas te med pas mi snang pas de gnyis dang da ltar ba sre mi srid de da ltar ba kho na snang pa yin no //

sngon po dang skad cig ma lasogs pa ngo bo gcig cing tha dad kyis stong pa la'ang tha dad kyis stong par snang ste ? so sor mi snang par myong pas grub la snang mi snang cha gnyis med par rjes dpag gis nges te /

EX4 (6a9-8a2) \{'Od zer 111.222.1.b.122.2 (24b6-26a9)\}

112.23 mngon sum tshad mar 'gyur ba'i tshul \{'Od zer 111.222.1.b.122.3 (26a9-b2)\}

mngon sum tshad mar 'gyur ba'i tshul ni mngon [8a3] sum gyi ldog pa ni gzung pa'i don la ma 'khrul pa yin pas de la rdzas cig la snang mi snang cha gnyis 'gal yang tshad ma ni bzlog. ${ }^{12}$ pa'i sgro 'dogs sel pa yin pas rnam ldan la yid gtad na bzlog pa'i sgro 'dogs sel bas sngon po lasogs pa

\footnotetext{
${ }^{11} \mathrm{Em} . \mathrm{pa}\langle\mathrm{r}\rangle:$ Ms pa

${ }^{12}$ Em. bzlog : Ms ldog
} 
rnam ldan kho na la tshad ma yin gyi skad cig ma lasogs pa rnam med snang pa la tshad ma ma yin no //

kha cig mngon sum tshad mar 'gro ba nges pa [8a4] drangs pa kho nas yin no zhes zer ba

5 de'i ltar na rjes su dpag pas yul bden par nges $\mathrm{pa}^{\mathrm{xxv}}$ na blo rang nyid kyang bden pa 'jal bar nges pa ltar yul sngon po lasogs par nges pa na blo sngon po'i yul can lasogs par ${ }^{\mathrm{xxvi}}$ nges pas nges pa myong pa'i rang rig la snang $\mathrm{la}^{\mathrm{xxvii}}$ ma nges pa mi srid pa yin na nges pa 'gag ka ma myong pa des nges pa drangs pa med pas khyed kyi ltar na snang la ma nges par 'gyur ro //

$10\left[{ }_{805]}\right.$ thams cad mkhyen pa la'ang gzung don la 'khrul pa'i rtog pa gtan mi skye bas nges pa 'dren pa mi srid pa'i phyir thams cad mkhyen pa' $i$ mngon sum thams cad kyang snang la ma nges par' gyur ro //

\section{3 rtog med 'khrul pa \{'Od zer 111.222.1.b.2 (26b2)\}}

zla ba gnyis lasogs pa snang pa'i rtog med 'khrul pa ni dngos po mi snang

15 pas bsgrub pas kyang dngos po la mi 'jug la bzlog pa'i sgro 'dogs dang 'gal ba med pas gzhan sel pas kyang dngos po [8a6] la mi 'jug ste ! sgro btags pa kho na yul du byed pas gzung don la 'khrul pa'i log shes kho na'o //

gzung yul la ltos nas blo gsum du dbye ba'o //

$/ /$ xxviii

2012 gzung pa dang zhen pa'i yul gnyi' ga la ltos nas blo bdun du dbye ba / gzung yul zhen yul gnyi ga la ltos nas blo bdun du dbye ba

gzung yul zhen yul gnyi ga la ltos nas blo bdun du dbye ba ni yul gyi dbye ba dang / de la ltos nas bloxix bdun du dbye ba dang / tshad ma ma yin pa'i blo lnga bye brag du gtan la dbab pa gsum gyis nges par bya ba'o //

25121 yul gyi dbye ba \{'Od zer 111.221.1.A2 (20b8-21a8)\}

dang po'ang gzung yul [8a7] dang 'jug yul lasogs pa'i mtshan nyid dang / yul gyi mu bzhi bsams pas tha dad rnam par gzhag pa dang / yul can gyi mu bzhi bsams pas tshad ma'i yul 'jug pa'i yul yin par bsgrub pa'o //

\section{1 gzung yul dang 'jug yul lasogs pa'i mtshan nyid}

$30 \quad$ 121.11 gzung yul gyi mtshan nyid \{'Od zer 111.221.1.A2 (20b8-9)\}

de'ang gzung yul gyi mtshan nyid ni gang zhig rang gi ngo bo nyid blo la snang pa ste $/$ R51.2 


\section{EX5 (8a7-8b3)}

\subsection{2 zhen yul gyi mtshan nyid}

- the ${ }^{\mathrm{xxx}}$ tsom gyis srid par ${ }_{[8 \mathrm{~b} 4]}$ zhen pas mi srid pa sel pa dang!

- log shes kyis phyin ci log du zhen pas gnas lugs sel pa dang !

- yid dpyod dang gcad pa'i yul can dang rjes dpag gis kyang gnas lugs la zhen pas bzlog ${ }^{13}$ pa'i zhen pa 'jug pa sel te!

der zhen pas zhen pa gzhan 'jug pa bsal pa ni zhen pa'i yul zhes bya'o //

\subsection{3 'jug yul gyi mtshan nyid \{'Od zer 111.221.1.A2 (20b9-21a1)\}}

$\mathrm{de}^{\mathrm{xxxi}}$ bye brag mngon sum la ${ }^{\mathrm{xxxii}}$ rnam ldan snang pa la yid gtad pas bzlog 10 pa'i sgro 'dogs sel pa ${ }_{[8 b 5]}$ dang rjes dpag gis rtags kyi rjes su 'brangs pas bzlog pa'i sgro 'dogs bsal pa rnams ni don med na mi 'byung pa'i 'dzin pas sngar ma rtogs pa'i don la sgro 'dogs bsal pa yin pas blo de'i gzhal bya yin te de la blo de' $i^{\text {xxxiii }}$ 'jug pa'i yul zhes kyang bya'o //

\section{2 yul gyi mu bzhi bsams pas tha dad rnam par gzhag pa \{'Od zer}

gnyis pa ni

$(++)$ gzung pa'i yul dang 'jug pa'i yul gnyi ga yin pa'ang yod de /

- sngon po de mngon sum la snang pas mngon sum gyi gzung yul yang yin la mngon ${ }_{[8 b 6]}$ sum gyis de la sngon po ma yin pa'i sgro 'dogs bsal pas 'jug yul yang yin pa dang /

- don spyi chos can du byas te dpyad mi bzod pas kun rdzob kyi bden pa'i tha snyad bsgrubs pa na rjes dpag de la don spyi tsam snang pas gzung yul yang yin la don spyi de la kun rdzob kyi bden pa ma yin pa'i sgro 'dogs bcad pas rjes dpag de'i 'jug yul yang yin pa lta bu'o //

$(+-)$ gzung yul yin la 'jug yul ma yin pa yang yod de !

- sgra [8b7] mi rtag par dpog pa'i rjes dpag la mi rtag pa'i don spyi snang pas $^{\text {xxxiv }}$ de gzung yul yin yang don spyi la rtag par 'dzin pa'i ${ }^{\text {xxxv }}$ sgro 'dogs bcad pa med pas 'jug yul ma yin pa'am /

- snang la ma nges pa la skad cig ma snang pas de gzung yul yin yang rtag pa'i sgro 'dogs ma bsal bas 'jug yul ma yin pa dang !

- yid dpyod la don spyi snang pa dang log shes dang bcad ${ }^{14}$ pa'i yul can dang / the tsom la don spyi snang pa dang rtog med 'khrul pa la

\footnotetext{
${ }^{13}$ Em. bzlog : Ms ldog

${ }^{14}$ Em. bcad : Ms bcas
} 
zla ba gnyis [8b8] lasogs par snang pa dang gcad pa'i yul can gyi ${ }^{15}$ mngon sum la sngon po snang pa rnams blo de dag la snang pas de dag gi gzung yul yin yang blo de rnams kyis yul de rnams la sgro 'dogs bcad pa med pas 'jug yul ma yin pa lta bu'o //

(-+) 'jug yul yin la gzung yul ma yin pa' ang yod de !

- sgra'i mi rtag pa la rjes dpag gis rtag pa'i sgro 'dogs bsal pas de rjes dpag gi ${ }^{16}$ 'jug pa'i yul yin yang mi rtag pa'i ${ }_{\text {[8b9] }}$ don rang gi mtshan nyid rjes dpag la mi snang pas gzung pa'i yul ma yin pa dang /

- rang rig pas don spyi dang zla ba gnyis lasogs pa la snang tshod du med pa'i sgro 'dogs bcad pas de dag rang rig pa'i 'jug pa'i yul yin yang rang rig la de dag mi snang pas rang rig gi gzung pa ma yin pa lasogs pa mngon sum gyi shugs kyi yul rnams ${ }^{\text {xxxvi }}$ lta bu'o $/ /^{R 51.3}$

(- -) gnyi ga ma yin pa'ang yod de !

- mig gi rnam shes la ltos [9a1] nas sgra lta bu'o $/ /^{\alpha}$

des na yul gnyis tha dad du gnas so //

\section{3 yul can gyi mu bzhi bsams pas tshad ma'i yul 'jug pa'i yul yin par bsgrub pa / yul can gyi mu bzhi bsams pas tshad ma'i yul 'jug yul du bsgrub pa \{'Od zer 111.221.1.A2 (21a5-8)\}}

gsum pa yul can gyi mu bzhi bsams pas tshad ma'i yul 'jug yul ${ }^{\text {xxxvii }}$ du bsgrub pa ni spyir 'jug yul bden pa ni yongs su bcad pa'i don la gnod pa med pa yin la / gzung yul bden pa ni don byed nus pa yin $\mathrm{pa}^{17}$ las

$(++)$ blo la gnyi ga bden pa dang ldan pa yod de dngos po snang pas gzung yul yang bden la yongs su [9a2] gcad pa'i gzhal bya la gnod pa med pas 'jug yul yang ${ }^{\text {xxxviii }}$ bden pa lta bu'o //

25 (-+) 'jug yul bden pa dang ldan la gzung yul bden pa dang mi ldan pa yang yod de $\mid$ rjes dpag yongs su bcad pa'i don la gnod pa med pas 'jug yul bden yang don spyi dngos med snang pas gzung yul bden pa med pa lta bu'o //

(+-) gzung yul bden pa dang ldan la 'jug yul bden pa dang mi ldan pa'ang yod de $\mid$ snang la ma nges pa dngos po snang pas [9a3] gzung

\footnotetext{
${ }^{15}$ Em. gyi : Ms gyis

${ }^{16} \mathrm{Em}$. gi : Ms gis

${ }^{17} \mathrm{Cf}$. 'Od zer 45b4: yul yang 'jug yul bden pa ni gnod myed du bden pa yin la gzung yul bden pa ni sgro ma btags par gnas pa yin no / and 'Od zer 45b8-9: gzung yul bden pa ni don byed nus pa yin la / 'jug yul bden pa [45b9] ni gnod myed du bden pa yin te.
} 
pa bden yang sgro 'dogs gcad pa'i 'jug yul bden pa dang mi ldan pa lta bu'o //

(- -) gnyi ga bden pa dang mi ldan pa'ang yod de ; thag pa la sbrul du rtog pa don spyi snang pas gzung pa dngos po'ang mi snang la phyi rol na sbrul med pas 'jug yul bden pa'ang med pa lta bu'o //

tshad ma'i yul ni 'jug yul yin te !

gnyi ga bden pa'i mngon sum tshad ma yin pa dang ! gzung pa bden pa med kyang 'jug yul bden pa rjes [9a4] dpag tshad ma yin pa'i phyir tshad ma 'jug yul bden pa'i rjes su 'gro ba la gnyi ga bden pa med pa'i thag pa

10 la sbrul du rtog pa lasogs pa tshad ma ma yin pa dang ! gzung pa bden pa yod kyang 'jug yul bden pa med pa' $i^{18}$ snang la ma nges pa tshad ma ma yin pa'i phyir 'jug yul log na tshad ma ldog pa'i phyir ro //

gzung yul dang rjes su 'gro ldog byed pa ma yin te ? snang la ma nges pa la gzung pa bden pa yod ${ }_{[9 a 5]}$ kyang tshad ma ma yin pas rjes 'gro med pa dang | rjes dpag la gzung pa bden pa log kyang tshad ma ${ }^{\text {xxxix }}$ yin pas ldog pa'ang med pa'i phyir ro //

des na tshad ma'i yul ni 'jug yul kho na yin no $/ /^{x 1}$

\section{2 de la ltos nas blo bdun du dbye ba / yul gnyis po de la ltos nas blo bdun du dbye ba}

20 yul gnyis po de la ltos nas blo bdun du dbye $\mathrm{x}^{\mathrm{xli}}$ ba la gsum ste / blo bdun du grangs nges pa dang / de dag blo gsum du bsdu ba dang / blo bcu gnyis la 'gal mi 'gal brtag pa'o //

\section{1 blo bdun du grangs nges pa}

dang po ni spyir don yongs su [9a6] gcod pa la gnyis te dngos' 'gal las tha

25 dad du ma phyed pa phyogs cig ma yin par gcod pa dang / tha dad par gnas pa phyogs cig du gcod pa'o //

\subsection{1 dngos 'gal las tha dad du ma phyed pa phyogs cig ma yin par gcod pa}

dang po ni the tsom te mi rtag par dogs pa nyid na rtag par yang dogs pas de las tha dad du ma phyed pa'i phyir ro //

${ }^{18}$ Em. pa'i : Ms pas 


\subsection{2 tha dad par gnas pa phyogs cig du gcod pa}

gnyis pa la'ang gnyis te / shes bya dang mi mthun par yongs su gcod pa dang mthun par gcod pa'o //

122.121 shes bya dang mi mthun par yongs su gcod pa \{’Od zer $5 \quad$ 111.222.1.b.322.1 (26b4)\}

dang po ni log shes so //

\subsection{2 shes bya dang mthun par yongs su gcod pa}

gnyis pa la'ang bzzlog ${ }^{19}$ pa'i ${ }_{[9 a 7]}$ zhen pa dang mi 'gal ba dang 'gal ba gnyis las

122.122.1 bzlog pa'i zhen pa dang mi 'gal ba \{'Od zer 111.222.1.b.11 (24b1)\} dang po ni snang la ma nges pa'o //

\subsection{2 bzlog pa'i zhen pa dang 'gal ba}

gnyis pa la'ang rtogs zin pa la 'jug pa dang sngar ma rtogs pa la 'jug pa gnyis las

122.122.21 rtogs zin pa la ’jug pa \{'Od zer 111.222.1.b.121 (24b2-3) and 111.222.1.b.322.21 (26b4-5)\}

dang po ni gcad pa'i yul can no //

\subsubsection{2 sngar ma rtogs pa la 'jug pa}

gnyis pa la'ang rang gi mtshan nyid mthong pas sgro 'dogs la ${ }^{\text {xlii }}$ gnod pa 20 dang ma mthong pas gnod pa gnyis las ${ }^{\text {xliii }}$

122.122.221 rang gi mtshan nyid mthong bas sgro 'dogs la gnod pa \{'Od zer 111.222.1.b.122 (24b3)\}

dang po ni mngon sum tshad ma'o //

122.122.222 rang gi mtshan nyid ma mthong bas sgro'dogs la gnod pa

25 gnyis pa la'ang rtags kyi rjes su 'brangs pa dang ma [9a8] 'brangs pa gnyis las

${ }^{19}$ Em. bzlog : Ms ldog 
122.122.222.1 rtags kyi rjes su 'brangs pa \{'Od zer 111.222.1.b.322.222 (26b7)\} dang po ni rjes dpag yin la

122.122.222.2 rtags kyi rjes su ma 'brangs pa \{'Od zer 111.222.1.b.322.221 $(26 \mathrm{~b} 5)\}$

5 gnyis pa yid dpyod yin te ${ }_{\mid}^{\mid R 6.1}$

de ltar na tshad ma ma yin pa'i blo lnga tshad ma'i blo gnyis te blo bdun du grangs nges pa yin no $/ /^{\mathrm{R} 51.4, \mathrm{R} 51.5, \mathrm{R} 52.1}$

\section{2 de dag blo gsum du bsdu ba}

gnyis pa ni

10 blo bdun po de dag kyang sngar gyi ${ }^{x l i v}$ blo gsum po gang du'du zhe na / - mngon sum tshad ma dang snang la ma nges pa gnyis po ni rtog med ma 'khrul par'du la!

- rjes dpag dang yid dpyod dang the tshom gsum rtog par 'du ba dang !

- log shes ni rtog med [9a9] 'khrul pa rnams dang rtog pa la srid la ${ }^{x l v}$ !

15 - gcad pa'i yul can ni rtog med ma 'khrul pa dang ${ }^{\text {xlvi }}$ rtog pa gnyi ga la yod do //

\section{3 blo bcu gnyis la 'gal mi 'gal brtag pa}

gsum pa ni blo de dag la'ang phye na blo bcu gnyis su 'gyur ro //

snang la ma nges pa dang gcad pa'i yul can dang mngon sum tshad ma

20 gsum ni rang rig gsum dang gzhan rig gsum ste drug dang ! log shes la rtog bcas rtog med gnyis te brgyad dang / rtog pa gcad pa'i yul can te dgu dang / [9b1] rjes dpag dang yid dpyod dang the tsom gsum ste bcu gnyis las phan tshun 'gal ba dang mi 'gal ba 'du ba'i tshul ni rang rig gsum dang / gzhan rig rtog med bzhi dang ${ }^{x l v i i}$ / yang dag par nges pa'i rtog pa gsum

25 dang / log shes dang / the tsom dpyad pa lnga'o //

\subsection{1 rang rig gsum}

dang po ni shes pa thams cad la rang rig gis khyab la de'ang - skad cig ma lasogs pa rnam med myong pa la snang la ma nges pa dang ! - rnam ldan sngar rtogs pa la gcad pa'i yul can dang !

- sngar ma [9b2] rtogs pa la tshad ma yin ${ }^{\text {xlviii }}$ pas rang rig gsum po thams cad dang bdag cig pa yin no // 


\subsection{2 gzhan rig rtog med bzhi}

gnyis pa ni mig gi shes pa cig la

- dung ser por snang pa log shes dang!

- bum pa'i skad cig ma snang pa snang la ma nges pa dang!

5 - sngon po lasogs pa sngar rtogs pa la bcad pa'i yul can dang !

- dbyibs kyi khyad par lasogs pa sngar ma rtogs pa la tshad ma dang / rang rig la ${ }^{20}$

- mig shes kyi skad cig ma snang ${ }^{x l i x}$ pa snang la [963] ma nges pa dang !

- mig shes kyi rnam ldan sngar rtogs zin pa la bcad pa'i yul can dang !

10 - sngar ma rtogs pa la tshad ma yin pas

gzhan rig gi mngon sum gsum dang rtog med 'khrul pa bzhi po ni bzhi po dang rang rig gsum ste bdun dang mi 'gal la /

gzhan rig rtog med yin na gzhan rig rtog par 'gal bas rjes dpag dang yid dpyod dang the tsom dang rtog bcas kyi log shes dang rtog pa bcad pa'i [964] yul can lnga dang 'gal ba yin no //R1.1

\subsection{3 yang dag par nges pa'i rtog pa}

gsum pa ni du ba las la la tsan dan gyi me dpags pa na

- me tsam la rjes dpag dang!

- tsan dan gyi me la yid dpyod dang!

20 - la tsam la bcad pa'i yul can yin la!

- me'i don spyi la ltos nas log shes yin pa dang !

de la rang rig gsum yang snga ma bzhin du yod pas

yid dpyod dang bcad pa'i yul can dang rjes dpag gsum ni gsum po nyid dang rtog bcas ${ }_{[9 b 5]}$ kyi log shes dang rang rig gsum ste bdun dang mi 'gal

$25 \mathrm{la} /$

nges pa the tshom ma yin pa dang , gzhan rig rtog pa yin na rtog med du 'gal bas the tshom dang gzhan rig gi mngon sum gsum dang rtog med 'khrul pa ste lnga dang 'gal lo //

\subsection{4 log shes}

30 bzhi pa ni rjes dpag dang yid dpyod dang the tshom dang rtog pa bcad pa'i yul can dang rtog bcas log shes lnga char la'ang don spyi 'dzin pa'i rtog bcas kyi log shes yod la ${ }_{i}$ de la ${ }_{[9 b 6]}$ 'ang rang rig gsum snga ma bzhin du yod pas

${ }^{20}$ Em. la : Ms gis 
rtog bcas log shes ni rtog pa lnga dang rang rig gsum ste brgyad dang mi 'gal la!

rtog pa yin na gzhan rig rtog med du mi 'gyur bas gzhan rig gi mngon sum gsum dang rtog med 'khrul pa dang bzhi dang 'gal lo //

\section{$5 \quad 122.35$ the tshom}

lnga pa ni the tshom la rang rig gsum snga ma bzhin du yod la don spyi 'dzin pa'i rtog bcas kyi log shes kyang yod pas

the tsom ni rang rig gsum dang rtog [9b7] bcas kyi log shes dang the tsom nyid de lnga dang mi 'gal la!

10 rtog pa gzhan rig gi rtog med du 'gal bas gzhan rig gi mngon sum gsum dang rtog med 'khrul pa dang yang 'gal la! the tshom nges pa ma yin pas ${ }^{\text {li }}$ rjes dpag dang yid dpyod dang rtog pa bcad pa'i yul can dang yang 'gal bas bdun dang 'gal ba yin no //lii

\section{3 tshad ma ma yin pa'i blo lnga bye brag du gtan la dbab pa}

15 gsum pa tshad ma ma yin pa'i blo lnga bye brag du gtan la dbab pa la lnga ${ }^{\text {liii }}$ po thams cad kyang ngo bo dang mtshan nyid dang [9b8] de nges pa'i tshad ma gsum gsum gyis nges par bya ba las

\section{1 snang la ma nges pa}

\subsection{1 ngo bo}

20 snang la ma nges pa ni gnyis te / yul rnam pa dang mi ldan pas snang yang ma nges pa dang | yul la yid ma gtad pas snang yang ma nges pa'o $/ \beta^{\beta}$

\subsection{1 yul rnam pa dang mi ldan pas snang yang ma nges pa}

dang po ni dngos po mngon sum la snang pa na de dang rdzas cig pa'i da ltar gyi skad cig ma de snga phyi gnyis dang ma 'dres pa'i skad cig ma 25 de mngon sum la snang yang 'dra ba gzhan 'byung dang yod pa bar med pas ma 'dres pa'i [9b9] rnam pa ma gsal bas ma 'dres par ma nges pa lta bu'o //

\subsection{2 yul la yid ma gtad pas snang yang ma nges pa}

gnyis pa ni sngon po lasogs pa snang yang rtog pa nang du bsdus pas de ma nges pa lta bu'o // ${ }^{\mathrm{R} 51.6, \mathrm{R} 52.2, \mathrm{R} 6.2}$ 


\subsection{2 mtshan nyid \{'Od zer 111.222.1.b.11 (24b1)\}}

snang la ma nges pa'i mtshan nyid ni don rang gi mtshan nyid snang pa dang bzlog pa'i sgro 'dogs dang mi 'gal ba ${ }^{\mathrm{R} 2.1, \mathrm{R} 51.7, \mathrm{R} 52.3, \mathrm{R} 6.3}$ gnyis kyis mngon sum ma yin pa dang tshad ma dang bcad pa'i yul can sel pa yin no //

\subsection{3 de nges pa'i tshad ma \{'Od zer 111.222.35 (29a7-8)\}}

de'ang bzlog pa'i sgro 'dogs dang mi 'gal bar ni dngos [10a1] po snang pa na rtag pa lasogs par zhen pa 'jug par myong pa'i rang rig pas nges la / skad cig ma snang pariv ni snang pa'i don chos can du byas nas byas pa 10 lasogs pa $^{\text {lv' }}$ i rtags kyis skad cig mar nges pa na blo 'ang skad cig 'dzin par shugs la grub pa 'am / sngar nya phyis ma nges kyang phyis thag nye bas ${ }^{\text {lvi }}$ nya phyis su nges pa na blo snga ma'ang nya phyis snang par shugs la grub pa yin no //

\section{(a)}

15 kha cig nges shes ${ }_{[10 \mathrm{a} 2]}$ mi 'dren zhing snang pa snang la ma nges pa'i mtshan nyid du'dod pa!

de mi rigs te nges pa 'gag ka ma myong pa'i rang rig tshad ma dang thams cad mkhyen pa'i mngon sum la khyab ches pa'i phyir ro //

\section{(b)}

20 yang kha cig don rang gi mtshan nyid snang zhing sgro 'dogs dang ${ }^{\text {lvii }}$ lhan cig pa zhes brjod pa'ang mi rigs te / sgro 'dogs dngos dang lhan cig pa la brjod na rtag pa la yid ma gtad pa'i dus kyi skad cig snang pa la ma khyab ${ }_{[10 a 3]}$ la sgro 'dogs skyer rung dang lhan cig pa la brjod na'ang rjes dpag gis skad cig mar rtogs $^{\text {lviii }}$ pa na skad cig ma snang pa'i snang la ma nges pa la ma khyab pa'i phyir ro //ix

\section{2 bcad pa'i yul can}

\subsection{1 ngo bo}

\section{\{'Od zer 111.222.1.b.322.21 (26b4-5)\}}

bcad pa'i yul can ni sngar rtogs pa la zhen pa 'dren nus kyi mngon sum 'jug pa dang dran pa'i rtog pa 'jug pa dang rjes su skyes pa'i nges shes rnams yin no //R6.4 
\{'Od zer 111.222.32 (29a1-29a4)\}

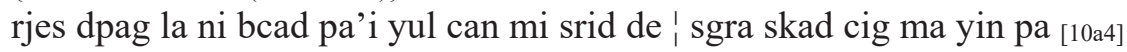
lasogs pa sngar nges pa na rtags la shes 'dod med pas phyogs chos ma tshang pas phyis rtags de la dpog pa rjes dpag ma yin la : sngar ma nges pa dpog na bcad pa'i yul can du mi 'thad pa'i phyir ro // $\mathrm{R51.8, \textrm {R } 5 2 . 4}$

(a)

tshul gsum nges pa la rten nas skyes pa'i rjes dpag gi skad cig ma dang po tshad ma yin yang gnyis pa lasogs pa bcad pa'i yul can yin la |de 'ang sngar gyi rtags 'dzin gyi rjes su 'brangs pas rjes dpag yin te! des na rjes

10 dpag la bcad pa'i yul can yod do zhe nal

skad cig dang po'i nges pa rtags 'dzin las byung pas rtags kyi rjes su 'brang pa yin gyi gnyis pa lasogs pa'i nges pa ni skad cig ${ }^{1 x}$ dang po'i rjes su 'brangs pa'i nges pa yin gyi rtags kyi rjes su 'brangs pa'i nges pa ma yin te rtags 'dzin las dngos su skyes [10a5] pa med pa'i phyir ro //

15 brgyud nas skyes pas rtags kyi rjes su 'brang pa'i nges par 'gyur na rjes dpag gis stong pa nyid nges pa goms pa las gsal snang du gyur pa'i rnal 'byor gyi mngon sum yang brgyud nas rtags 'dzin las skyes pas rtags las rtogs pa'i rjes dpag du 'gyur ro/i

\section{(b)}

20 gal te me mthong pa'i gzhi la du ba las me dpog pa bcad pa'i yul can yin yang rjes dpag yin no zhe ${ }_{[10 \mathrm{a}]}$ na

rjes dpag ma yin te rtsod gzhi' la shes 'dod med pas phyogs chos med pa na blo tshul gsum dang ldan pa'i rtags la rten pa ma yin pa'i phyir ro //

\subsection{2 mtshan nyid \{'Od zer 111.222.1.b.121 (24b2-3) and 111.222.32 (28b9-29a1)\}}

25 bcad pa'i yul can gyi mtshan nyid ni sgro 'dogs chod zin pa'i don la bzlog pa'i zhen pa dang 'gal ba'i blo 'jug pa'o // ${ }^{\mathrm{R} 1.2, \mathrm{R} 51.9, \mathrm{R} 52.5, \mathrm{R} 6.5}$

\subsection{3 nges byed \{'Od zer 111.222.32 (29a1)\}}

nges byed ni sgro 'dogs chod zin par blo snga ma myong pa'i rang rig gis

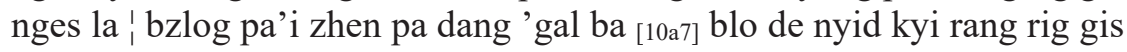
nges so //

\section{3 yid dpyod}

yid dpyod ni 


\subsection{1 ngo bo \{'Od zer 111.222.1.b.322.221 (26b5-7)\}}

rtog med ma yin te rtog pa yin la!

de'ang the tsom ma yin te nges pa yin zhing !

de'ang log par nges pa ma yin te shes bya dang mthun par nges pa yin la !

5 de'ang sngar rtogs zin pa nges pa ma yin te ma rtogs pa'i lkog gyur sgra mi rtag pa lasogs pa nges ${ }^{1 x i}$ pa yin ${ }^{21}$ la /

de'ang phyogs chos dang khyab pa tshad mas nges pa la rten nas nges pa ma yin ${ }_{[10 a 8]}$ pas / de la gsum ste!

\section{i. rgyu mtshan med pa'i yid dpyod}

10 sgra mi rtag pa lta bu rtags dang rtags ltar snang pa gang la'ang ma rten par nges pa ${ }^{\text {lxii }}$ rgyu mtshan med pa'i yid dpyod do //

\section{ii. log pa'i rgyu mtshan can gyi yid dpyod}

myig gi gzung bya lta bu ma grub pa 'am gzhal bya lta bu ma nges pa la brten nas nges pa phyogs chos dang khyab pa dngos po la med pa rtags

15 su bzung nas bsgrub bya bden pa nges pa log pa'i rgyu mtshan can gyi yid dpyod do //

\section{iii. rgyu mtshan gtan la ma phebs pa'i yid dpyod}

byas pa yid dpyod ${ }_{[10 a 9]}$ kyis nges pa 'am de la mi rtag pas khyab pa yid dpyod kyis nges pa lta bu ${ }^{\text {lxii }}$ phyogs chos dang khyab pa yid dpyod kyis nges pa las bsgrub bya bden pa dpog pa rgyu mtshan gtan la ma phebs pa'i yid dpyod do //R51.10,R52.6,R6.6

sgra rtag pa lta bu bsgrub bya mi bden pa nges pa'i log shes la ni

- rgyu mtshan med pa'ang yod la!

- mig gi bzung bya lta bu ma grub pa dang byas pa lta bu 'gal ba dang gzhal bya lta bu ma nges pa la ${ }_{[10 b 1]}$ brten pa'i log pa'i rgyu mtshan can srid kyi ${ }^{\text {lxiv }}$ !

- rgyu mtshan gtan la ma phebs pa'i log shes mi srid do //

yid dpyod la ni 'gal ba'i rtags la rten pa mi srid de de bsgrub bya bden pa nges pa $^{22}$ yin pas rtsod gzhi mthun phyogs yin la

${ }^{21} \mathrm{Em}$. yin : Ms yid dpyod yin

${ }^{22}$ Em. bsgrub bya bden pa nges pa : Ms bsgrub byed (bya bden) $<$ pa nges $>$ pa 
phyogs chos med la zhugs na rtags la ${ }^{\text {lxv }}$ bzlog pas khyab pa med pa'i phyir ro //R51.11

\subsection{2 mtshan nyid ${ }^{\gamma}$}

\subsection{1 rang lugs dgod pa \{'Od zer 111.222.34 (29a5-6)\}}

yid dpyod kyi mtshan nyid ni sngar ma rtogs pa'i don bden pa rtags tshad mas nges pa ${ }_{[10 \mathrm{~b} 2]}$ la ma brten par nges pa ste $/{ }^{\mathrm{R} 51.12, \mathrm{R} 52.7, \mathrm{R} 6.7}$

- nges pas ni mngon sum gsum dang the tsom gcod do /

- bden pas log shes gcod do /

- sngar ma rtogs pas bcad pa'i yul can gcod do /

- rtags tshad mas nges pa la ma rten pas rjes dpag gcod pa yin no / $/^{R 7.2}$

\subsection{2 gzhan lugs dgag pa}

${ }^{\delta}$ [D1] kha cig myong pa dang rtags la ma rten par don phyogs cig du zhen pa yid dpyod kyi mtshan nyid du'dod pa!

[D2] de lta na myong pa la ma rten pa'i zhen pa yid dpyod du cis mi ${ }_{[10 \mathrm{~b} 3]}$ 'dod!

[D2] 'o na rjes dpag la khyab ches so zhe na /

[D1] snga ma ltar na'ang sgra rtag par nges ${ }^{\text {lxvi }}$ pa'i log shes la khyab ches so /

[D1] de'ang yid dpyod kyi rdzas yin pas de la zhugs pa khyab ches ma yin te mi rtag pa'i mtshan nyid rtsol byung la zhugs pa ${ }^{23}$ khyab ches ma yin pa bzhin no zhe na/

[D2] rjes dpag kyang yid dpyod kyi rdzas yin pas de la zhugs pa khyab ches ma yin te snga ma bzhin no /

[D2] 'o na rjes dpag [10b4] dang yid dpyod gnyis su ji ltar dbye zhe nal

[D1] 'dir yang log shes dang yid dpyod gnyis su ji ltar dbye /

[D1] rdzas cig kyang phyin ci log du dpyod pa'i cha nas log shes yin la myong pa dang rtags la ma brten par nges pa'i cha nas yid dpyod yin pas ldog pa tha dad pas tha dad du dbye ste rtsol byung dang mi rtag pa rdzas cig kyang ldog pa tha dad pas rtags dang rtags can 'thad pa bzhin no zhe nal

${ }^{23}$ Em. pa : Ms pas 
[D2] rdzas cig kyang [10b5] tshul gsum la brten te nges pa'i cha nas rjes dpag yin la dpyod yin pas ldog pa tha dad pas gnyis su dbye ste snga ma nyid bzhin no //

[D2] 'o na nges bya ${ }^{24}$ sgra mi rtag pa la ltos nas blo de tshad ma dang tshad ma ma yin pa gnyi' gar 'gyur ro zhe na /

[D1] nges bya sgra dang rtag pa tshogs pa la ltos nas blo de log shes dang log shes ma yin pa gnyi gar $_{[10 \mathrm{~b} 6]}$ 'gyur ro $/ /^{\mathrm{R} 1.3}$

\subsection{3 rtsod pa spang pa}

${ }^{\varepsilon}$ [D1] 'o na yid dpyod la ${ }^{\text {lxvi }}$ yul bden pa nges pas khyab na yul bden pas kyang khyab dgos na bdag cig pas khyab pam de las byung pas khyab pa 'am 'brel pa med kyang khyab /

dang po ltar na yid dpyod yul bems po dang bdag cig pas bems por 'gyur la /

gnyis pa ltar na blo de yongs su bcad pa'i don laviii med na mi 'byung pas tshad mar 'gyur ba dang /

gsum pa ltar na 'brel med ${ }_{[10 \mathrm{~b}]}$ la khyab pa 'thad pas 'brel med kyi rtags srid par'gyur ro zhe na/

[D2] 'o na rtog pa la gzung pa don spyis khyab pa'ang bdag cig pas sam de las byung nas sam 'brel pa med kyang khyab /

dang po gnyis ${ }^{\text {Ixix }}$ tar na don spyi rtog pa dang rdzas cig pa 'am rtog pa'i rgyu yin pas dngos por 'gyur la !

gsum pa ltar na 'brel med kyi khyab bya dang khyab byed byung pas 'brel med kyi rtags srid par' gyur ro /

[D2] gal $_{[10 \mathrm{~b} 8]}$ te 'brel pa gnyis mi 'dod pas dngos por yang mi 'gyur la / 'brel med kyi khyab bya dang khyab byed yin yang rtags ${ }^{l x x}$ ma yin te blo rtog par nges pa na yul don spyi'ang nges pas dpag tu med pa'i phyir ro 25 des na 'brel med kyi rtags srid par milxi 'gyur ro zhe nal

[D1] yid dpyod kyang yul dang 'brel pa gnyis khas mi len pas nyes pa dang po gnyis med la / 'brel med kyi khyab bya dang khyab byed yin yang blo yid dpyod du nges [10b9] pa na yul bden pa'ang nges zin te dpag tu med pa'i phyir 'brel med kyi rtags srid par yang mi 'gyur ro //R1.4

\footnotetext{
${ }^{24}$ Em. bya : Ms byang

${ }^{25} \mathrm{Em} . /$ : Ms //
} 


\subsection{3 nges byed kyi tshad ma \{'Od zer 111.222.34 (29a7)\}}

nges byed kyi tshad ma 'ang sngar ma nges pa nges par rang rig gis grub $1 a^{1 \times x i i}$ । rtags tshad mas nges pa'i rjes su ma 'brangs par yang

- rgyu mtshan med pa'i yid dpyod la rang rig dang !

- log pa'i rgyu mtshan can la rtags kyi skyon mthong pa'i tshad ma dang !

- rgyu mtshan gtan la ma phebs pa la rtags 'dzin yid dpyod du nges [11a1] pa las yin no //

10 don bden par ni phyis don de nges pa'i tshad mas nges pa yin no //

\section{4 log shes \{'Od zer 111.222.31 (28b7-8)\}}

\subsection{1 ngo bo}

log shes la gnyis te / sgro btags 'dzin pa dang zhen yul la phyin ci log du nges pa'o //

\section{$15 \quad$ 123.411 sgro btags 'dzin pa}

dang po ni zla ba gnyis lasogs par snang pa'i rtog med 'khrul pa dang ! rjes dpag dang yid dpyod dang rtog pa bcad pa'i yul can dang the tsom dang log par nges pa rnams kyi 'ang don spyi 'dzin pa'i cha nas [11a2] bzung pa sgro btags la dmigs pa'i log shes yin no /i

\subsection{2 zhen yul phyin ci log du nges pa \{'Od zer 111.222.1.b.322.1 (26b4)\}}

zhen yul phyin ci log du nges pa ni sgra rtag par zhen pa lasogs pa'o //

\subsection{2 mtshan nyid \{'Od zer 111.222.31 (28b7)\}}

log shes kyi mtshan nyid ni don phyin ci log du yongs su gcod pa'o / $/{ }^{R 1.5, R 8.1}$

\subsection{3 nges byed kyi tshad ma \{'Od zer $111.222 .31(28 \mathrm{~b} 8)\}$}

25 nges byed kyi tshad ma'ang don de dag yongs su bcad par rang rig pas nges la!

phyin ci log yin par ni ji ltar yongs su bcad pas bden pa la gnod pa'i tshad mas nges pa yin no //

\section{5 the tshom \{'Od zer 111.222.33(29a4-5)\}}

\subsection{1 ngo bo \{'Od zer 111.222.1.b.321 (26b3)\}}

[11a3] 'di rtag pa 'am mi rtag ces dogs pa the tsom mo // 


\subsection{2 mtshan nyid}

de'i mtshan nyid kyang mtha' gzhan du srid pa'i dogs pa dang bcas pa'o //R1.6

\subsection{3 nges byed}

5 nges par byed ${ }^{26}$ pa'ang rang rig nyid kyis nges ${ }^{1 x x i i i}$ so //

(a)

[D1] kha cig 'di la gzhan sel pa'i byed pa med par smra ba de ni mi rigs te /

[D2] de lta na sngon por nges pa la yang gzhan sel pa med par' gyur ro /

[D2] des sngo ma yin bsal te ma bsal na sngon po yongs su bcad

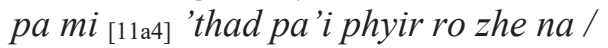

[D1] the tsom gyis kyang rtag pa mi srid pa bsal te ma $^{\text {lxxiv }}$ bsal na srid pa yongs su bcad pa nyid mi 'thad pa'i phyir ro //R1.7

15 (b)

kha cig mtho' yor ram mi zhes pa'i the tshom gyis gsum pa bsal palxxv gzhan sel yin no zhes zer ba

de ni ma yin te mtho' yor kho nar nges te mi yang ma yin la gsum pa'ang ma yin zhes pa na gsum pa ma yin par nges pa yod pas the [11a5] tsom med

20 kyang gsum pa sel la /

mi 'am mtho' yor 'am gsum pa 'am zhes the tsom za na the tshom yod kyang gsum pa ma yin par nges pa med pas gsum pa mi sel ba'i phyir gsum pa sel ${ }^{1 \times x v i}$ pa de ni nges pa'i gzhan sel yin gyi the tsom ma yin no //

tshad ma yid kyi mun pa sel pa las blo'i dbye ba nges pa'i le'u ste \ dang po'o //

${ }^{26}$ Em. byed : Ms 'byed 


\section{II tshad ma'i mtshan nyid dbye' ba rnam par nges pa}

\section{2 bye brag du tshad ma'i blo nges par bya ba / bye brag du tshad ma'i blo gtan la dbab pa}

$[\ldots[33 \mathrm{a} 4] \cdots]$

212.14 rang gi lugs \{'Od zer $111.221 .2(21 \mathrm{~b} 7-8)(23 \mathrm{~b} 1-2)\}$

des na rang gi lugs ${ }^{1 \times x v i i}$ ni 'di yin te / ma rtogs don gyi gsal byed ${ }^{27}$ zhes $^{28}$ bya ba'i don ni / yongs su bcad pa'i don la mi 'khrul pa'i blo'i rnam pas gnas [33a5] lugs dang 'gal ba'i sgro 'dogs skyed pa'i nus pa bzlog pa ste / de la bden pa rtogs pa $^{29}$ zhes bya'o //R1.8,R51.13,R52.8,R52.9,R52.10

(a) $\{$ 'Od zer 111.221.222(22b6-8)\}

'o na de rtogs pas sgro 'dogs bzlog pa yin na myong pas bzlog pa'am! rtags la rten nas bzlog pa 'am / de gnyis tshogs pas bzlog pa'am / bzlog pa tsam yin /

dang po ltar na rjes dpag la ${ }_{[33 b 5]}$ ma khyab la /

gnyis pa ltar na mngon sum la ma khyab cing!

gsum pa mi srid pa dang /

bzhi pa ltar na yid dpyod kyis sgra mi rtag par nges pas kyang rtag pa'i sgro 'dogs bzlog la / bdag cig du nges pas kyang du ma'i sgro 'dogs bzlog pas de dag la khyab ches so zhe na /

bzhi ka ltar ma yin te don la mi 'khrul pa'i rnam pas sgro 'dogs bzlog pa yin la / don la mi 'khrul [33b6] pa'i 'dzin stangs ni mngon sum dang rjes dpag kho na la yod kyi yid dpyod la med de yul ma grub pa'i dus na yid dpyod dang log shes la blo'i 'dzin stangs khyad med pa'i phyir ro /i

\footnotetext{
${ }^{27}$ Dharmakīrti, Pramānavāarttika 2.5c, Skt. ajñātārthaprakāśo vā. The canonical Tibetan version reads: ma shes don gyi gsal byed kyang /. The reading ma rtogs (instead of ma shes) in the Tibetan version of this verse is also found in the Tshad bsdus (106,9), mTshur ston's sGron ma (14b8), and Chu mig pa's rNam rgyal (A22a7; B26a9); ma shes is found, on the other hand, in gTsang nag pa's bsDus pa (16b7).

${ }^{28}$ Em. 〈zhes〉

${ }^{29}$ Cf. Śan்karanandana, Bṛhatprāmānyaparīkșā 22: pramāṇam avisaṃvādi jūānaṃ sā hi sadarthitā (see Hugon 2011a: 161, n. 14).
} 
(b) $\{$ 'Od zer 111.221.223 (23a6-23b1)\}

'o na sgro 'dogs dngos su yod pa nus med du byed pa 'am /lxviii gnod rung tsam yin!

dang po ltar na rtog pa gnyis cig char du mi 'jug pas rjes dpag gi dus na sgro 'dogs med pas dngos su gnod pa byed pas [33b7] de la ma khyab po/

gnyis pa ltar na bcad pa'i yul can gyi mngon sum la ha cang khyab po zhe na I

dngos su nus med du byed pa yin la rjes dpag gi dus na sgro 'dogs nyid med kyang skyed pa'i nus pa yod pas de la rjes dpag gis gnod pa yin no / yang na ${ }^{\text {lxxix }}$ sgro 'dogs la gnod du rung pa yin la bcad pa'i yul can la khyab ches pa'ang ma yin te sngar ma rtogs ${ }^{1 \times x x}$ pa la sgro 'dogs dang [33b8] 'gal zhes brjod pa'i phyir ro //

\section{2 de'i nyes pa spang pa / mtshan nyid kyi nyes pa spang pa}

mtshan nyid kyi nyes pa spang pa la gsum ste / ma khyab pa spang pa dang / khyab ches pa spang pa dang / mtshan gzhi la log rtogs dgag pa'o //

212.21 ma khyab pa spang pa \{'Od zer $111.222 .2(28 \mathrm{~b} 3-7)\}$

dang po ni

(a) \{'Od zer 111.222.2 (a) (28b3-5)\}

gal te bden pa rtogs pa de nges pa yin na mngon sum rtog pa med pas de la ma khyab po zhe na/

mngon sum dang sgro 'dogs phrad de sgro 'dogs kyis rgyu dang mngon sum gyis rkyen byas [33b9] te skad cig gnyis pa la sgro 'dogs nus med bskyed pas gsum pa la ldog pa yin pa na nus med du skyed pa mngon sum yin pas sgro 'dogs gcod byed ni de yin la / nges shes sgro 'dogs gcad pa'i rjes la 'jug pas bcad pa'i yul can yin no / des na mngon sum la ma khyab pa med do $/{ }_{1}^{\mathrm{R} 52.11, \mathrm{R} 52.12}$

(b) \{'Od zer 111.222.2 (b) (28b5-7)\}

[D1] rjes dpag don spyi la ltos na gzung pa la 'khrul pa'i log shes yin pas de [34a1] la bden pa rtogs pas ma khyab po zhe na/

[D2] myu gu sa bon la ltos te phyis 'byung yin pas myig gi rnam shes kyi rgyu ma yin par 'gyur ro /

[D2] ltos sa sa bon la ltos te phyis 'byung yin yang sa bon gyi rgyur 'gal te de ${ }^{\text {lxxi }}$ rgyur khas mi len la I 
sa bon la ltos te phyis 'byung yin pas mig gi rnam shes kyi rgyur ma yin par lxxii sgrub pa khyab pa mi 'grub cing!

mig gi rnam shes la ltos te phyis 'byung yin pas mig shes [34a2] kyi rgyu ma yin par sgrub na gtan tshigs med do zhe na /

5 [D1] don spyi la ltos nas ${ }^{\text {lxxxiii }}$ bden pa rtogs pa med pas de la ltos nas tshad ma ma yin par bsgrub na grub pa la sgrub ste ; de la ltos nas log shes yin pa'i phyir ro /

don spyi la ltos nas bden pa rtogs pa med pas phyi rol la ltos te tshad ma ma yin par sgrub na khyab pa med la /

10 don phyi rol pa la ltos te bden pa rtogs pa med pas phyir rol la tshad ma ma [34a3] yin par sgrub na gtan tshigs ma grub ste : phyi rol la ltos nas sngar bshad pa'i mtshan nyid yod pa'i phyir ro //

\subsection{2 khyab ches pa spang pa \{'Od zer 111.222.3 (29a8-b1)\}}

gnyis pa ni mtshan nyid de sngar bshad pa'i tshad ma ma yin pa'i blo lnga

15 la khyab ches pa'ang ma yin te /

- bcad pa'i yul can la ni bcad bya sgro 'dogs skyed rung gi nus pa dang phrad pa med pas de bzlog byed du 'gal la /

- the tshom dang snang la ma nges pa bzlog pa'i sgro 'dogs dang 'gal ba tsam ${ }_{[34 a 4]}$ ma yin la/

20 - sgra mi rtag par nges pa'i yid dpyod kyis rtag pa'i sgro 'dogs bzlog pa dang ! dung ser por nges pa'i log shes kyis sngon po'i sgro 'dogs bzlog pa lasogs pa'i tshul gyis log shes dang yid dpyod la sgro 'dogs bzlog tsam yod kyang don med kyang de lta bu'i blo 'byung pa la 'gal ba med pas don la mi 'khrul pa'i 'dzin pas sgro 'dogs sel pa ma yin no //

$25[\ldots[41 \mathrm{~b} 4] \ldots]$

tshad ma yid kyi mun pa sel pa zhes bya ba las tshad ma'i [41b5] mtshan nyid dbye' ba rnam parnges ${ }^{30}$ pa'i le'u ste / gnyis pa'o // //

${ }^{30}$ Em. rnam par nges : Ms rnam par nges par nges 


\section{III mngon sum gyi tshad ma rnam par nges pa}

23 mngon sum gtan la dbab pa / mngon sum bye brag du gtan la dbab pa

$[\cdots[42 \mathrm{a} 1] \cdots]$

5231.12 rang gi lugs rnam par gzhag pa / rang gi lugs ${ }^{31}$

gnyis pa rang gi lugs ni des na ma 'khrul ba 'ang gzung yul la ltos nas yin la mngon sum [42a2] du 'ang gzung yul la ltos nas brtsi bas gzung don la ma 'khrul pa mngon sum gyi mtshan nyid de ${ }_{1}^{\mid R 52.13, R 52.14, R 6.8}$ dngos po snang pa mngon sum yin no //

10 rigs mi mthun pa mtha' dag des bsal pas rtog pa dang bral pa ni rigs mi mthun pa sel byed ma yin no $/ /^{R 3.2}$

$[\ldots[43 \mathrm{a} 3] \cdots]$

\section{1 tshad ma'i rang bzhin}

dang po ni rang myong pa $^{32}$ sgro 'dogs dang 'gal ba rang rig gi tshad ma

15 yin la | gzhan 'dzin pa sgro 'dogs dang 'gal ba gzhan rig gi tshad ma'o //

$[\cdots[43 \mathrm{a} 7] \cdots]$

tshad ma yid kyi mun pa sel pa las mngon sum gyi tshad ma rnam par nges pa'i le'u ste / le'u gsum pa'o //

${ }^{31}$ Cf. 'Od zer 111.222.1.b.1, 24a9 and 'Od zer 46a1-2: mtshan nyid nye bar gzung pa'i dgos pa ni mngon sum gyi don ldog gzung don la ma 'khrul ba nyid yin pa dang rigs myi mthun pa mtha' dag kyang de nyid kyis gcod nus pas mtshan nyid ni gzung don la ma 'khrul ba dngos yin la / rtog bral nyid du smos pa ni mngon sum yul nye ba nges pa'i rtog par 'dod pa rigs pa can lasogs pa'i log [46a2] rtog dgag pa'i phyir khyab byed la mngon sum gi mtshan nyid gyi ming gis btags pa yin no //

${ }^{32}$ Em. pa : Ms pas 


\section{IV rjes su dpag pa rnam par nges pa}

24 rjes dpag gtan la dbab pa / rjes su dpag pa bye brag du gtan la dbab pa

$[\cdots[43 \mathrm{a} 8] \cdots]$

\section{$5 \quad 241$ rjes dpag gi mtshan nyid}

dang po ni chos 'ga' zhig rtsod gzhi la mthong pas de'i khyab byed du nges pa dpog pa ste $/{ }^{R 1.9}$ tshul gsum pa'i rtags las rtogs pa'o $/ 1_{1}^{133}$

[43a9] de nyid bden pa rtogs pa dang tshogs pa ni rjes dpag tshad ma'i mtshan nyid do //34

$10 \quad[\cdots[81 \mathrm{~b} 8] \cdots]$

tshad ma yid kyi mun pa sel pa las rjes su dpag pa rnam par nges pa'i le'u ste | bzhi pa'o //

${ }^{33}$ Cf. 'Od zer 78a1: tshul gsum dang ldan pa'i mtshan gzhi rgyu mtshan du bzung nas gzhal bya rtogs pa ni rjes su dpag pa'i mtshan nyid de.

${ }^{34} \mathrm{Cf}$. 'Od zer 78a2: rjes dpag tshad mar mtshon pa'i mtshan nyid ni tshul gsuM dang ldan pa'i mtshan gzhi rgyu mtshan du bzung nas bden pa'i don rtogs pa ste. 



\section{Corrections in the manuscript and other particular- ities of the manuscript reading}

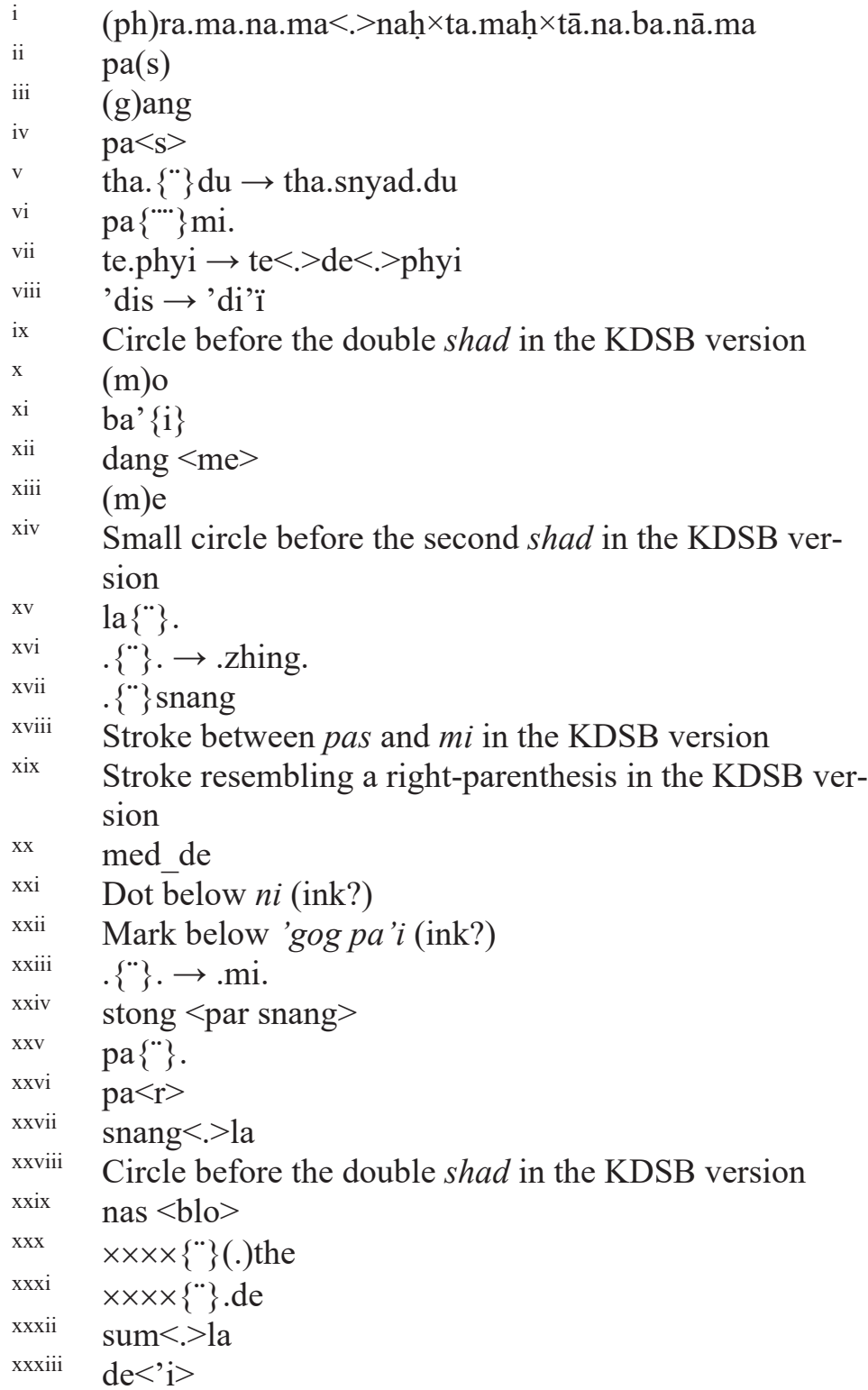




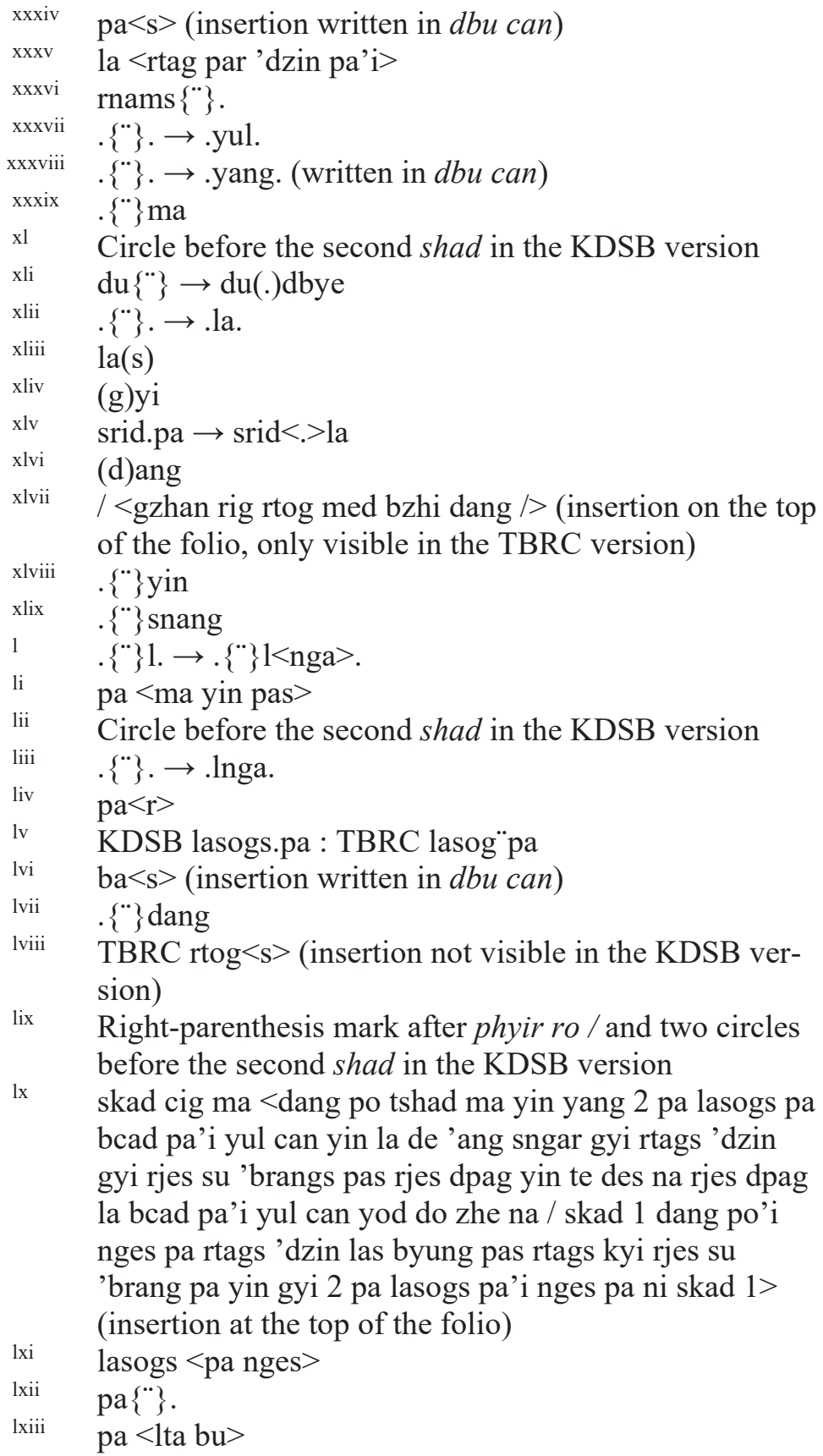




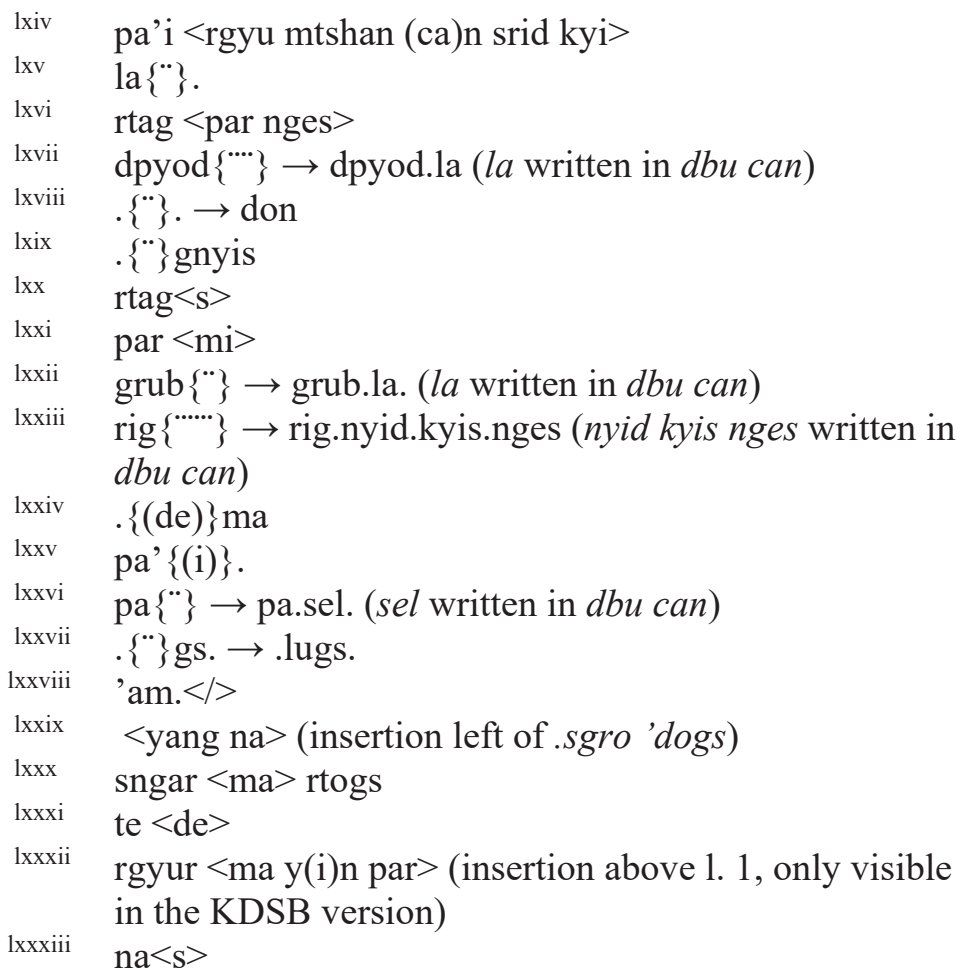





\section{Marginalia}

${ }^{\alpha}$ Addition on top of folio 9a: (yul) yin pa gzhir byed dgos pas yid dpyod la ltos nas chu lta (b)u la dpe (bya)? (zhang)? gsung

'Zhang' might refer to the scholar who made this statement. This abbreviation could refer to Zhang tshes spong Chos kyi bla ma ("zhang tsé pong chö kyi la ma"), a disciple of rNgog Lo and instructor of Phya pa, as well as Phya pa's ordination abbot. This is a likely option given that this scholar is also identified in the Tshad bsdus in relation with his definition of 'doubt' (see V, 1.1, R1.6), which would indicate that he was involved in the discussions pertaining to the various types of awareness. Another option would be Zhang tshal pa (or Zhang 'tshal pa) ("zhang tsel pa"), who is listed among the group of disciples of Phya pa called "The Three Who Attained Spiritual Goal-realization" (grub thob mi gsum). 'Zhang' might also refer to Zhang thang sag pa 'Byung gnas ye shes ("zhang tang sak pa jung né yé shé"), who was one of the four main disciples of Pa tshab Nyi ma grags ("pa tsap nyi ma drak," $11^{\text {th }}$ $12^{\text {th }}$ century) and the founder of Thang sag ("tang sak") monastery. He was the author of Madhyamaka commentaries. Yet another 'Zhang' who might have been involved in epistemological discussions is Zhang sna chung ston pa ("zhang na chung tön pa"), a senior contemporary of rNgog Lo, provided he corresponds to the scholar referred to as 'sna chung ston pa' in the Tshad bsdus (352,18-19).

${ }^{\beta}$ Addition on the bottom of folio 9b: 'khrul pa'i rgyu mtshan gyis zil gyis mnan pas snang yang ma nges pa dang gsuM mo /

This third category appears to be a later addition to the text. It is ascribed to "Phya pa's Summary" by Śākya mchog ldan in the Rol mtsho (cf. V, 1.5, R51.6; see also Go rams pa's R6.2 in V, 1.6), but the same author mentions only two categories (matching the ones listed in the Mun sel) in his account of Phya pa's position in the Pham byed (cf. V, 1.5, R52.2).

${ }^{\gamma}$ Addition at the top of folio 10b: yid dpyod kyi (mtshan nyid la) gsuM ste / rang lugs dgod pa / gzhan lugs (dg)ag pa / rang lugs la brtsod pa spang pa '(o) / dang p(o) n(i) /

We considered this to be an addition rather than a correction because the marks gnyis pa and gsum pa for the next subdivisions are not explicit in the text either but are also added in interlinear notes (see $\delta$ and $\varepsilon$ ) and the titles for the subsections do not occur in the text itself.

${ }^{\delta}$ Addition between the two preceding shad on 10b2: 2 pa ni

${ }^{\varepsilon}$ Addition between the two preceding shad on 10b6: 3 pa ni 



\section{Topical outline (sa bcad)}

Sections of the Mun sel that are not included in the present edition and translation appear in smaller font in the table. They are listed for a better understanding of the structure of the text and the place of the edited and translated sections therein. The last column on the right gives the folio and line number on which the item is discussed (not the place where it is first listed).

Title

[EX1] Invocation, introductory verses

1 In general, the division of awareness (spyir blo tsam gyi dbye ba)

11 The three-fold division of awareness based on the apprehended object (gzung yul la ltos nas blo gsum du dbye ba)

(a) The three types of objects (yul gsum)

i Real particulars (don rang gi mtshan nyid)

ii Concepts (don spyi)

iii The referents of non-conceptual erroneous cognition (rtog med 'khrul pa'i dmigs pa)

(b) The three types of awareness (blo gsum)

i That which takes as its apprehended object a real particular (don rang gi mtshan nyid gzung yul du byed $p a)$

ii That which takes as its apprehended object a concept (don spyi gzung yul du byed pa)

iii That which takes as its apprehended object the referent of a non-conceptual erroneous cognition (rtog med 'khrul pa'i dmigs pa gzung yul du byed pa)

111 The three types of objects (yul gsum nges par bya $b a)$

(a) Excursus on the three apprehended objects in various philosophical systems 
[EX2] Refutation of other philosophical systems
A The position of proponents of non-representational idealism (sems tsam rnam pa med par smra ba)
B The position of proponents of representational idealism (sems tsam rnam bcas su smra ba)
C The position of the representationalist position of Sautrān- tika, etc. (rnam bcas mdo sde pa lasogs pa)
D Our own position

(b) The status of real entities and the way they are apprehended

1 Their being void of distinction (tha dad kyis stong pa)

2 The way distinction is superimposed (tha dad sgro 'dogs pa'i tshul)

21 The origin of the superimposition of dis-

$3 \mathrm{~b} 6$ tinction (tha dad sgro 'dogs pa'i sa bon)

22 The representation of the superimposition of distinction (sgro 'dogs pa'i rnam pa)

3 Their being devoid of commonality (rjes 'gros stong $\mathrm{pa}$ )

4 The way commonality is superimposed (rjes 'gro sgro 'dogs pa'i tshul)

112 The three types of awareness (blo gsum nges par bya $b a)$

112.1 Conceptual cognition (rtog pa) $4 \mathrm{a} 2$

112.11 That which is directed externally (phyi rol $4 \mathrm{a} 2$ du zhen pa / zhen pa)

\subsection{Determinate awareness (nges pa)}

112.111.1 Those in which the determination corresponds with the object to be cognized (shes bya dang mthun par nges pa)

112.111.11 Inferential cognition (rjes dpag) 
112.111.111.1 Appearing (snang pa) $\quad 4 \mathrm{a} 2$

112.111.111.2 Directing (zhen pa) 4a3

112.111.111.3 Excluding others 4a5

(gzhan sel pa / sel pa)

112.111.112

$4 \mathrm{a} 6$

112.111.112.1 The way real entities $\quad 4 a 6$ exist (dngos po'i gnas lugs)

112.111.112.2 The way awareness apprehends them (blo ' $i$ 'dzin stangs)

112.111.112.3 The manner by which $4 a 8$ they (i.e., inferential cognitions) come to be episodes of knowledge (tshad mar 'gyur ba'i tshul)

112.111.113 [EX3] Excursus on the object of $4 \mathrm{a} 8$ inference

112.111.12 Factive assessment (as well $6 \mathrm{a} 3$ as post-knowledge cognition) (yid dpyod / yid dpyod dang bcad pa'i yul can)

112.112 Doubt (the tshom) $6 \mathrm{a} 4$

112.12 That which is not directed (ma zhen pa) $6 \mathrm{a} 5$

112.111.2 Those in which the determination $6 \mathrm{a} 5$ does not correspond with the object to be cognized (shes bya dang mi mthun par nges)

112.2 Non-conceptual non-erroneous cognition (rtog $6 \mathrm{a} 6$ med ma 'khrul pa)

112.21 The operations ([byed pa]) $6 \mathrm{a} 8$

112.22 The way awareness apprehends ([blo' $i \quad 6 \mathrm{a} 8$ 'dzin stangs])

[EX4] Proof of the appearance as empty of distinction

112.23 The manner by which perception comes to be an episode of knowledge (mngon sum tshad mar 'gyur ba'i tshul) 
112.3 Non-conceptual erroneous cognition (rtog med $8 \mathrm{a} 5$ 'khrul pa)

12 The seven-fold division of awareness based on both the $8 \mathrm{a} 6$ apprehended object and intentional object (gzung pa dang zhen pa'i yul gnyi' ga la ltos nas blo bdun du dbye ba I gzung yul zhen yul gnyi ga la ltos nas blo bdun du dbye ba)

121 The division of objects (yul gyi dbye ba) $8 \mathrm{a} 6$

121.1 The definitions of apprehended object, en$8 \mathrm{a} 7$ gaged object, etc. (gzung yul dang 'jug yul lasogs pa'i mtshan nyid)

121.11 The definition of apprehended object ([gzung yul gyi mtshan nyid])

[EX5] On the definition of the apprehended object in the various philosophical systems

121.12 The definition of intentional object ([zhen yul gyi mtshan nyid])

121.13 The definition of engaged object (['jug yul gyi mtshan nyid])

121.2 Distinguishing these objects by reflecting on the partial overlap between apprehended objects and engaged objects (yul gyi mu bzhi bsams pas tha dad rnam par gzhag pa)

121.3 Establishing that the object of knowledge is the engaged object by reflecting on the partial overlap between the episodes of awareness involving these objects (yul can gyi mu bzhi bsams pas tshad ma'i yul 'jug pa'i yul yin par bsgrub pa / yul can gyi mu bzhi bsams pas tshad ma'i yul 'jug yul du bsgrub pa)

122 The seven-fold division of awareness based on those two objects (de la ltos nas blo bdun du dbye ba / yul gnyis po de la ltos nas blo bdun du dbye $b a$ )

122.1 Determining that there are seven types of awareness (blo bdun du grangs nges pa) 
122.11 Episodes of awareness that discern some-

$9 \mathrm{a} 6$ thing not set apart from what is directly incompatible with it, without being partial to either (dngos 'gal las tha dad du ma phyed pa phyogs cig ma yin par gcod pa)

122.12 Episodes of awareness that discern some$9 \mathrm{a} 6$ thing standing apart from what is directly incompatible with it, while being partial to it (tha dad par gnas pa phyogs cig du gcod pa)

122.121 Episodes of awareness that discern in a $9 \mathrm{a} 6$ way that does not correspond with the object to be cognized (shes bya dang $m i$ mthun par yongs su gcod pa)

122.122 Episodes of awareness that discern in in a way that corresponds with the object to be cognized (shes bya dang mthun par yongs su gcod pa)

122.122.1 Episodes of awareness that are compatible with directing one's mind in the opposite way (bzlog pa'i zhen pa dang $m i$ 'gal ba)

122.122.2 Episodes of awareness that are incompatible with directing one's mind in the opposite way (bzlog pa'i zhen pa dang 'gal ba)

122.122.21 Episodes of awareness that engage an object already known (rtogs zin pa la 'jug pa)

122.122.22 Episodes of awareness that engage an object not previously known (sngar ma rtogs pa la 'jug pa)

122.122.221 Episodes of awareness that oppose superimpositions by observing a real particular (rang gi mtshan nyid mthong bas sgro 'dogs la gnod pa) 
122.122.222 Episodes of awareness that oppose superimpositions without a real particular being observed (rang gi mtshan nyid ma mthong bas sgro 'dogs la gnod pa)

122.122.222.1 Episodes of aware$9 \mathrm{a} 8$ ness that rely on evidence (rtags kyi rjes su 'brangs pa)

122.122.222.2 Episodes of awareness that do not rely on evidence (rtags kyi rjes su ma 'brangs pa)

122.2 Subsuming those seven within the earlier $9 \mathrm{a} 8$ three-fold typology of awareness (de dag blo gsum du bsdu ba)

122.3 Examining the mutual compatibility and incompatibility among the twelve types of awareness (blo bcu gnyis la 'gal mi 'gal brtag $p a)$

122.31 The three episodes of reflexive awareness (rang rig gsum)

122.32 The four episodes of non-conceptual,

$9 \mathrm{~b} 2$ transitive awareness (gzhan rig rtog med bzhi)

122.33 The three episodes of conceptual cognition in which there is a correct determination (yang dag par nges pa'i rtog $p a)$

122.34 Mistaken (conceptual) cognition ( $\log$ shes)

122.35 Doubt (the tshom)

$9 \mathrm{~b} 1$

$9 \mathrm{~b} 4$

$9 \mathrm{~b} 5$

$9 \mathrm{~b} 6$

123 Specifically laying out the five types of awareness $9 \mathrm{~b} 7$ that are not episodes of knowledge (tshad ma ma yin pa'i blo lnga bye brag du gtan la dbab pa)

123.1 Non-ascertaining perception (snang la ma nges pa) 
123.11 Its nature (ngo bo)

$9 \mathrm{~b} 8$

123.111 Cases where there is an appearance $9 \mathrm{~b} 8$ but no ascertainment due to the object possessing a non-manifest feature (yul rnam pa dang mi ldan pas snang yang ma nges pa)

123.112 Cases where there is an appearance but no ascertainment due to not focusing one's mind on the object (yul la yid ma gtad pas snang yang ma nges $\mathrm{pa}$ )

123.12 Its definition (mtshan nyid)

123.13 The episode of knowledge that deter$9 \mathrm{~b} 9$ mines that [the definition applies] (de nges pa'i tshad ma)

123.2 Post-knowledge cognition (bcad pa'i yul can) 10a3

$123.21 \quad$ Its nature (ngo bo) $10 \mathrm{a} 3$

$123.22 \quad$ Its definition (mtshan nyid) 10a6

123.23 What determines [that the definition ap- 10a6 plies] (nges byed)

123.3 Factive assessment (yid dpyod) 10a7

$123.31 \quad$ Its nature (ngo bo) $10 \mathrm{a} 7$

i Factive assessment lacking a reason $\quad 10 \mathrm{a} 8$ (rgyu mtshan med pa'i yid dpyod)

ii Factive assessment having a mistaken rea- $10 \mathrm{a} 8$ son (log pa'i rgyu mtshan can gyi yid dpyod)

iii Factive assessment with an uncertified rea- $10 \mathrm{a} 8$ son (rgyu mtshan gtan la ma phebs pa'i yid dpyod)

123.32 Its definition (mtshan nyid)

$10 \mathrm{~b} 1$

123.321 Presenting our own position (rang $10 \mathrm{~b} 2$ lugs dgod pa)

123.322 Refuting the view of others (gzhan $10 \mathrm{~b} 2$ lugs dgag pa) 
123.323 Rejecting objections (rtsod pa

$10 \mathrm{~b} 6$ spang pa)

123.33 The episode of knowledge that deter-

$10 \mathrm{~b} 9$ mines [that the definition applies] (nges byed kyi tshad $\mathrm{ma}$ )

123.4 Mistaken cognition (log shes)

123.41 Its nature (ngo bo)

123.411 Apprehension of a superimposition (sgro btags 'dzin pa)

123.412 Incorrect determination of the inten- 11a2 tional object (zhen yul phyin ci log du nges $p a)$

123.42 Its definition (mtshan nyid)

123.43 The episode of knowledge that determines [that the definition applies] (nges byed kyi tshad ma)

123.5 Doubt (the tshom)

123.51 Its nature (ngo bo)

$123.52 \quad$ Its definition (mtshan nyid) $11 \mathrm{a} 3$

123.53 What determines [that the definition ap- 11a3 plies] (nges byed)

\section{II}

2 In particular, elucidating the instances of awareness that are episodes of knowledge (bye brag du tshad ma'i blo nges par bya ba / bye brag du tshad ma'i blo gtan la dbab pa)

21 The definition of knowledge in general (spyi'i mtshan nyid)

211 In general, how to indicate a definiendum through the definiens (spyir mtshan nyid kyis mtshon bya mtshon pa'i tshul)

212 In particular, elucidating the definition of knowledge (bye brag du tshad ma'i mtshan nyid nges par bya ba / bye brag du tshad ma'i mtshan nyid gtan la dbab pa)

212.1 Apprehending the definition that we accept (rang gi 'dod pa'i mtshan nyid gzung $p a$ ) 
212.11 Refuting the assertion of Prajñākaragupta (rgyan mdzad pa 'i 'dod pa dgag pa)

212.12 Refuting Devendrabuddhi (slob dpon lha dbang blo dgag pa)

212.13 Refuting Dharmottara (slob dpon chos mchog dgag pa)

212.14 Our own position (rang gi lugs)

212.2 Rejecting faults of that definition (de'i nyes pa spang pa / mtshan nyid kyi nyes pa spang pa)

212.21 Rejecting the fault of the definition being too narrow (ma khyab pa spang pa)

212.22 Rejecting the fault of the definition being too broad (khyab ches pa spang pa)

212.23 Rejecting misconceptions regarding the basis of definition (mtshan gzhi la log rtogs dgag pa)

231 The definition that is common (to all four types of perception) (thun mong gi mtshan nyid)

231.1 The definition that eliminates the dissimilar types (rigs mi mthun gcod pa'i mtshan nyid)

231.11 Refutation of the positions of others (gzhan gyi lugs $\operatorname{dgag} p a)$

231.12 Presentation of our own position (rang gi lugs rnam par gzhag pa / rang gi lugs)

231.2 The definition that eliminates misconceptions $(\log r t o g s$ sel pa'i mtshan nyid) 
233 The scope (of perception and inferential cognition) (spyod yul / mngon sum dang rjes su dpag pa'i spyod yul)

234 The result of knowledge (tshad ma'i 'bras bu / tshad ma dang 'bras bu)

234.1 The nature of knowledge episodes (tshad ma' $i$ rang bzhin)

234.2 The nature of the result ('bras bu'i rang bzhin)

234.3 They being what is to be established and what establishes (sgrub bya bsgrub byed kyi don)

234.4 Refutation of the result of knowledge according to the representationalists (rnam bcas pa'i tshad 'bras dgag pa)

24 The specific elucidation of inferential cognition (rjes dpag gtan la dbab pa / rjes su dpag pa bye brag du gtan la dbab pa)

241 The definition of inferential cognition (rjes dpag gi mtshan nyid)

242 Reflecting on correct logical reasons and pseudo-logical reasons (gtan tshigs dang gtan tshigs ltar snang bsam pa) ...

243 The nature of the probandum, the object of the capacity of the logical reason (rtags kyi nus yul bsgrub bya'i rang bzhin)

244 Division of proving and refuting statements (bsgrub pa dang sun 'byin pa'ingag gi dbye ba)

245 How to present such statements in the form of a consequence (ngag de thal 'gyur du dgod pa'i tshul) 


\section{IV}

On cognitions that are not episodes of knowledge 

This chapter aims to provide additional information regarding each of the five types of awareness that do not qualify as knowledge. It provides clues regarding the origin of these categories and the associated terminology (building on a previous discussion in Hugon 2014) and explains our choice of translation. The various understandings of these categories among Tibetan scholars are also discussed, focusing on the issues raised by Phya pa in the Mun sel and those relevant to the constitution of Phya pa's own position.

\section{Non-ascertaining perception (snang la ma nges pa)}

\section{(a) Terminology}

The term snang la ma nges pa appears to have been originally coined as a descriptive term for the corresponding instances of awareness. Depending on how one understands the role of the particle $l a$, one may understand these as cases for which there is no determination with regard to what appears, or cases in which there is the appearing (of something) and no determination (of it). The definitions of snang la ma nges pa cited by Phya pa support the idea that the corresponding instances of awareness are characterized by the conjunction of two criteria (one corresponding to snang, the other to ma nges pa), but this characterization may differ from the original intent of the expression.

This category and the corresponding term seem to be issued from rNgog Lo's reading of Dharmottara's discussions about the function and the result of knowledge. In his Rigs thigs 'grel ti ka, after identifying the passages of the Nyāyabinduți ka dealing with the non-application of the definition of knowledge to mistaken cognition, doubt, and factive assess-

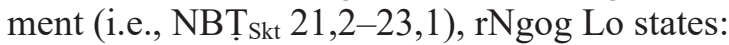

bCad pa'i yul can and snang la ma nges pa are not discussed here.

This is because the analysis of these cases has been established previously when stating that the indication of an object of engagement is the function of knowledge; indeed, these two do not have the function of indicating the object of engagement. ${ }^{1}$

In rNgog Lo's exegesis of the passage indicated here, which can be iden-

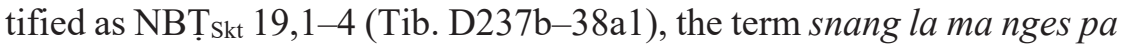

${ }^{1}$ See Hugon 2014: 234 (Tibetan text) and 219 (translation). 
does not come forth, nor does the notion of nges $\mathrm{pa}$. The discussion focuses, rather, on the idea of "understanding" (Skt. adhigati, adhigama; Tib. rtogs pa), which is identified as the result of knowledge (pramānaphala) and that through which the function of knowledge (pramannavyāparra) is fulfilled. ${ }^{2}$ Contrapositively, episodes of awareness that do not provide understanding are not knowledge.

But in a parallel passage in the Pramānaviniścayațikā, Dharmottara states that "the function of knowledge is fulfilled with regard to the engaged object because an appearance that is determined is indicated" (Tib. snang ba nges par byas pa ni bstan pa yin pa'i phyir). ${ }^{3}$ It is uncertain which Sanskrit expression nges par byas pa actually translates in this passage. The following sentence of the Pramānaviniścayați kā, which discusses the case of a mistaken identification of the object that appears (e.g., the identification of a mirage as "water"), features the Tibetan nges pa for the Sanskrit avasāya. This could suggest that the expression nges par

${ }^{2}$ Cf. NBṬ ${ }_{\mathrm{Skt}}$ 19,1: ata eva cārthādhigatir eva pramānaphalam /; Tib. D37b6-7: de bas na don rtogs pa kho na tshad ma'i 'bras bu yin la / and NBT ${ }_{\mathrm{Skt}}$ 19,2: tathā ca saty arthādhigamāt samāptah pramānavyāpārah /; Tib. D37b7: de ltar na don rtogs par 'gyur ba'i phyir tshad ma'i bya ba rdzogs pa yin no //

${ }^{3}$ PVinṬ(a) 15,7-12: don thob par byed pa ni tshad ma yin la / de yang 'jug par byed pa nyid yin gyi gzhan ni ma yin no // 'jug par byed pa yang 'jug pa'i yul ston par nyid yin par brjod de / des na snang ba nges par byas pa ni bstan pa yin pa'i phyir 'jug pa'i yul la tshad ma 'i bya ba yongs su rdzogs pa yin no //“"Causing one to obtain (Skt. prāpakatvam) the object' is what it is to be knowledge. And this, in turn, amounts just to 'motivating' (literally 'making one act,' Skt. pravartakatvam) and not something else. 'Motivating' is said to be just 'indicating the engaged object' (Skt. pravrttivișayapradarśakatvam). Thus, the function of knowledge with regard to the engaged object is completely fulfilled because an appearance that is determined is indicated."

In yet another parallel passage in his short Prāmānyaparìkșā, Dharmottara refers, for the fulfillment of the function of knowledge, to the engaged object being indicated, the person being motivated, and the object being obtained. PPar II 5,15-6,3: gang gi tshe 'dis 'jug pa'i yul rab tu bstan pa de'i tshe skyes bu rab tu 'jug cing don kyang thob pa'i phyir tshad ma'i bya ba yongs su rdzogs pa yin no //. Krasser (1991, Teil 2: 38) translates: "Wenn das Handlungsobjekt von dieser (gültigen Erkenntnis) aufgezeigt ist, dann ist der Mensch motiviert und der Gegenstand einer, der erreicht gelassen worden ist (prāpita). Damit ist die Funktion der gültigen Erkenntnis völlig abgeschlossen.” 
byas pa, which has been translated here as "determined" could translate avasita. But niścita or niścetavya are also possibilities. ${ }^{4}$

It might be this passage of the Pramānaviniścayațīk $\bar{a}$ that suggested the use of the expression snang la ma nges pa, connoting the absence of "determination" (nges pa) rather than the absence of "understanding" (rtogs pa). rNgog Lo did, however, classify this type (together with bcad pa'i yul can) in the overhead category of "non-understanding" (ma rtogs). But when explaining why it does not qualify as knowledge, he picks up, rather, on the absence of positive ascertainment (yongs su gcod pa) associated with the absence of determination (nges pa) (see below).

\section{(b) Understanding of the category}

There is actually no definition or even an example of an instance of this category in rNgog Lo's works. It is merely discussed in terms of not being an instance of knowledge. In the $d K a^{\prime}$ gnas, rNgog Lo explains the case of snang la ma nges pa together with post-knowledge cognition:

Although these two ultimately have the function of intelligence (rig pa), they cannot be conventionally designated as "ascertainers" (yongs su gcod byed) because there is no determination (nges $p a$ ) of something that was not previously known. ${ }^{5}$

In this argument, one must undoubtedly understand that "there is no determination" is the reason for excluding snang la ma nges pa, and the absence of determination "of something that was not previously known" is the reason for excluding post-knowledge cognition.

\footnotetext{
${ }^{4}$ In rNgog Lo's translation of the Pramānaviniścayațikā, one finds nges par byas pa (D88b1) translating niścetavyah (PVinṬ 3 84b4). In another passage, nges pa'am / nges par byas su zin kyang (D68b2) translates avasito niścito pi (PVinṬ 3 65a3) (although one could have expected the terms in the reverse order). In the translation of the Nyāyabinduțīka, one finds once nges par bya ba (D64b6) for niścetavya $(162,8)$.

${ }^{5} d K a$ ' gnas (see Hugon 2014: 232-233 for the edition of the whole passage): don dam par rig pa'i byed pa yod kyang / sngar ma rtogs pa nges pa myed pas yongs su gcod byed kyi tha snyad du bya ba ma yin la /. See Hugon 2014: 214 for a brief preliminary discussion. In the Rigs thigs 'grel ti ka, both are classified as "nonunderstanding" on account of "lacking the function of conventional understanding" (tha snyad pa'i rtogs pa'i byed pa dang bral ba yin pas). See Hugon 2014: 234 for the edition of the relevant passage and p. 219 and 222 for a discussion.
} 
rNgog Lo held ascertainment (yongs su gcod pa), in the form of a conceptual determination (nges pa), to be a requirement for knowledge (see, I.2, 4.2). In the case of perception, this determination is provided by a subsequent determining cognition. Correlatively, cases of snang la ma nges $p a$ are thus cases where no such subsequent determining cognition occurs. rNgog Lo might thus potentially be credited with the definition of snang la ma nges pa that Phya pa cites in Mun sel 123.1(a) (cf. §6.1 [i] in this chapter):

Some assert as the definition of snang la ma nges pa "not bringing about a determining cognition, but appearing."

This definition is also cited by gTsang nag pa (cf. 6.1 [ix]) and by mTshur ston (6.1 [xi]). An interlinear note on the manuscript of mTshur ston's work attributes this view to "rtag pa" or "stag pa," who can probably be identified as rTag/sTag pa Kha che ("tak pa kha ché"), a disciple of Khyung Rin chen grags and bKa' gdams pa teacher of epistemology and Madhyamaka. ${ }^{6}$ gTsang drug rdo rje, who also cites this definition (6.1 $[\mathrm{xv}])$, attributes it to "some commentator"- a marginal note provides the nominal reference "chos," i.e., Dharmottara.

Phya pa rejects this definition by using the same argument that he uses to reject the position that the arising of a subsequent determining cognition is a requirement for perceptual knowledge (cf. Mun sel 112.23). ${ }^{7}$

${ }^{6} \mathrm{rTag} / \mathrm{sTag}$ pa Kha che ba and rGya dmar ba Byang chub grags, the two principal students of Khyung (see Vetturini 2007: 333), are referred to together as "the pair, rGya and sTag" (rgya stag gnyis) (Deb sngon 163, Vitali 2015: 543 and n. 56). rTag pa Kha che was also a disciple of Rwa Lo tsā ba rdo rje grags (Deb sngon 456, Cuevas 2015: 61, n. 25). He taught epistemology and Madhyamaka in Upper Nyang (nyang stod). Among his students one finds lHa rje rgya nag ("lhar jé gya nak") (Deb sngon 163) and rMe'u dgongs mdzod ri khrod chen po ("meu gong dzö ri trö chen po," 1038-1096) (Kværne 1973: 31).

In the Tshad bsdus, four other views are ascribed to someone called "sTag pa" (pp. 113, 142, 240, 266; cf. van der Kuijp 2003: 416). But the author of the Tshad bsdus does not discuss the definition of snang la ma nges pa under consideration. A view on the nature of the logical reason is also ascribed to "sTag pa" in an interlinear note on the manuscript of the $d B u$ ma de kho na nyid of rGya dmar ba (23b2).

${ }^{7}$ Note that the notion "unable to bring about a determining cognition" (nges shes 'dren mi nus pa) is associated by Phya pa with "non-ascertaining perception" in 'Od zer 59a4 when commenting on the prose passage following PVin $1.19 \mathrm{~d}$. Since elsewhere in the 'Od zer his views on snang la ma nges pa concord 
Phya pa also criticizes a second alternative definition in Mun sel 123.1(b) (6.1 [ii]):

Alternatively, some say "the appearing of a real particular, and coexisting with a superimposition."

This definition is rarely cited by later scholars. ${ }^{8}$ It is likely to have been an alternative option that was not well-known or broadly adopted, and even not held to be significant.

Yet another definition is cited in the Tshad bsdus and is ascribed to "rGya" (6.1 [vii]):

An appearing that is compatible with superimpositions.

The author of the Tshad bsdus notes the problem that this formulation does not specify that a real particular appears, thus opening the door to the definitional criterion applying to cases other than perception. ${ }^{9}$

The second alternative definition cited by Phya pa and the definition ascribed to "rGya" in the Tshad bsdus (6.1 [ii] and [vii]) are interesting in that they explicitly bring into play the notion of "superimpositions." One may thus hypothesize that their proponents favored a corresponding notion as one criterion in their definition of knowledge. This would imply, in particular in the case of the definition ascribed to "rGya" (presumably Phya pa's teacher rGya dmar ba), a precedent for a criterion of knowledge along the lines of Phya pa's $\mathrm{K} 1$ as it is formulated in the 'Od zer (see I.2, 3.2.1).

Phya pa himself adopts as the definition of snang la ma nges pa (Mun sel 123.12) (6.1 [iii]):

with that in the Mun sel, this may be explained as the result of a re-use from some other work supporting this definition of snang la ma nges pa (possibly rNgog Lo's commentary).

${ }^{8}$ So far we have found only a single citation of this definition - in gTsang drug rdo rje's gSal byed (cf. 6.1 [xiv]).

${ }^{9}$ Tshad bsdus 54,18-19: rgya na re sgro 'dogs dang mi 'gal ba'i snang ba yin no zhes zer te mngon sum ma yin pa la snang la ma nges pa yod dam med dpyad par bya'o // 
The appearing of a real particular, and compatible with opposite superimpositions. ${ }^{10}$

This definition may be seen as an adaptation of what was reportedly rGya's definition, making explicit the requirement that a real particular appears, a requirement that excludes all types of awareness that are not perceptual.

This requirement was integrated by the majority of Phya pa's successors with one notable exception. Chu mig pa, after refuting a definition similar to Phya pa's definition (6.1 [xvii]), states a definition that does not include this requirement $(6.1$ [xviii]):

An apprehending cognition which does not bring about a determining cognition with regard to the appearing object.

Chu mig pa exploits the whole range of the notion of "appearing" in distinguishing three subtypes of snang la ma nges pa (rNam rgyal A9a4; B11a9):

- Perceptual (mngon sum snang la ma nges pa). For instance, a cognition apprehending something blue, to which something momentary appears.

- Conceptual (rtog pa snang la ma nges pa). For instance, a conceptual cognition to which a verbal object that is like an illusion (sgyu ma lta bu, Skt. māyopama) appears.

- Non-conceptual and erroneous (rtog med 'khrul pa snang la ma nges $p a$ ). For instance, the cognition apprehending a double moon to which the aspect of a double moon that is like an illusion appears.

The first type corresponds to the standard understanding of snang la ma nges $p a$, in which there is the appearing of a real particular. In the other two types, what appears is not an entity. Chu mig pa thus explicitly endorses the extension of the category of snang la ma nges pa to cases that are not perceptions - an extension which, as the author of the Tshad bsdus noted with regard to the definition ascribed to rGya dmar ba (see above), could be held to be problematic.

${ }^{10}$ Phya pa states his definition in the same terms in the 'Od zer (6.1 [iv], [v], [vi]). Despite the slight modifications of formulation, he always includes the two criteria of the particular appearing, and of the compatibility with opposite superimpositions. 
One can note that Chu mig pa also does not adopt the criterion of being "compatible with opposite superimpositions," espousing instead the criterion of "not bringing about a determining cognition." This phrasing was found in the first alternative definition refuted by Phya pa. Chu mig pa adopts this phrasing in full awareness of Phya pa's criticism. ${ }^{11}$

As discussed in the introduction (I.2, 4.4), Sa pan, who supported a passive model of perception, rejected the very legitimacy of snang la ma nges $p a$ as a category of awareness that is not knowledge distinct from perception. Phya pa does not confront any analogue position, which may indicate that the active perception model was in majority shared by his Tibetan forerunners and contemporaries.

Interestingly, an objection that corresponds to Sa pan's criticism is addressed by Chu mig pa:

Some say: It is not correct to posit perceptual snang la ma nges pa as an awareness that is not knowledge, because it is knowledge. This is because all perceptions are knowledge. ${ }^{12}$

One may add this passage to a growing list of evidence that tends to indicate that Chu mig pa's work was composed after Sa pan's Rigs gter, or at least under some influence of a tradition of interpretation stemming from Sa pan's questioning of the mainstream views flowing from scholars associated with gSang phu monastery.

Sa pan's criticism was also taken seriously by some authors in the later dGe lugs pa tradition, who, following mKhas grub rje, shied away from distinguishing perception from perceptual knowledge and thus did not acknowledge snang la ma nges pa as a distinct type of awareness (see I.2, 2.3). On the other hand, in blo rigs texts by other dGe lugs pa authors, one can observe that snang la ma nges pa is typically preserved as a distinct category among those episodes of awareness that do not qualify as knowledge, in spite of the fact that the definition of knowledge does not make explicit a criterion equivalent to the notion of "ascertainment" in

\footnotetext{
${ }^{11}$ Chu mig pa addresses in particular Phya pa's objection that the last moment of the reflexive awareness of a determining cognition would be snang la ma nges pa (see Mun sel 123.1 [a]). Contrary to Phya pa, Chu mig pa accepts that this is indeed a case of snang la ma nges pa. See rNam rgyal A9a4; B11a8.

${ }^{12}$ rNam rgyal A9a4-5; B11a9-b1: kha 1 mngon sum snang la ma [A9a5][B11b1] \{A ditto $m a\}$ nges pa de tshad ma ma yin pa'i blor byed pa de mi 'thad de $\{\mathrm{A}$ de mi 'thad de, B mi 'thad do\} / tshad ma yin pa'i phyir te / \{A phyir te /, B phyir ro /f mngon sum thams cad tshad ma yin pa'i phyir ro zhe na/
} 
rNgog Lo's indirectly active model or that in Phya pa's directly active model. ${ }^{13}$

\section{Subdivisions}

A question arose in the course of our edition of the Mun sel regarding the number of types that Phya pa recognizes for this category. Indeed, only two types are listed in the text (Mun sel 123.11):

(i) No ascertainment due to the object being a non-manifest feature. For example: "momentariness" when perceiving an entity;

(ii) No ascertainment due to not focusing one's mind. For example: "blue" when being absorbed in one's thoughts.

But a third one is given in an interlinear note (see III, 4. $\beta$ ):

(iii) No ascertainment due to being overwhelmed by causes of error.

We considered the interlinear note to represent an additional remark rather than the insertion of a portion of text skipped by the copyist. The text indeed announces two types (gnyis te), and each of those is given an illustration, whereas there is no illustration for case (iii) in the note.

The subdivisions of non-ascertaining perception are not spelled out in Phya pa's 'Od zer. In his Pham byed, Śākya mchog ldan reports that Phya pa divided snang la ma nges pa into two categories, namely (i) and (ii) above (see V, 1, R52.2). But the illustration mentioned by Śâkya mchog ldan for the second type (an auditory perception failing to ascertain "sound" when the mind is drawn towards a beautiful form) reveals the influence of the later tradition. In his Rol mtsho (see V, 1, R51.6), Sākya mchog ldan refers to three subcategories of snang la ma nges pa in "Phya pa's summary" (phya bsdus), giving as an example of the third: a visual perception of mother-of-pearl in the case the latter is mistaken to be silver. This is also the example given for the third category by Go rams pa in his

${ }^{13}$ For instance, in dGe bshes 'Jam dpal bsam 'phel's blo rigs work (Rinbochay\&Napper 1980), knowledge is defined as "a newly non-deceiving awareness" (7b4: gsar du mi slu ba'i rig pa), and there is no mention of "elimination of superimpositions" or of another form of "ascertainment" being involved. Still, snang la ma nges pa is accepted as a type of awareness that is not knowledge, defined as "an awareness in which the real particular which is the own engaged object of this [awareness] clearly appears, but which is unable to bring about a determinate cognition in its regard" (6b3: rang gi 'jug yul du gyur pa'i rang mtshan gsal bar snang yang de la nges pa 'dren mi nus pa'i rig pa). 
account of the views of "previous scholars such as Phya pa, etc." (see V, 1, R6.2).

The three-fold division is well attested in the works of Phya pa's students and close successors: ${ }^{14}$

- gTsang nag pa identifies as a third category the case where "the feature is clearly appearing and the mind is focused, but there is no determination due to causes of errors," giving as an example the case where a rope appears but is conceptually determined to be a snake. ${ }^{15}$

- mTshur ston lists the same third category as gTsang nag pa, with the rope/snake example together with the example of mother-ofpearl appearing, but being determined to be silver. ${ }^{16}$ In both cases, the cause of error is explained in term of "having perceived something similar" (chos mthun pa mthong pa), namely, a mother-ofpearl is white, like silver, and a rope is variegated, like a snake.

- The mother-of-pearl/silver case also figures as an example of a third category in the Tshad bsdus, a category that is described in terms of a specific cause of error: the object being distant (thag ring ba'i stobs kyis snang la ma nges $p a){ }^{17}$

While a third category is not explicitly distinguished in the Mun sel, Phya pa does mention the case of mother-of-pearl as an instance of snang la ma nges pa (Mun sel 123.13). This raises the question of whether (like

\footnotetext{
${ }^{14}$ In addition to the instances cited below, see also gTsang drug rdo rje's gSal byed. The third category is termed yul chos mthun pas 'khrul nas snang la ma nges pa $(9 \mathrm{~b} 8)$ and is also exemplified by the silver/mother-of-pearl example (10a1-2).

${ }^{15}$ bsDus pa 23a3: gsal ba la yid gtad kyang 'khrul pa'i rgyu mtshan gyis mi nges par 'gyur te / thag pa snang pa las sbrul du rtog pa lta bu'o //

${ }^{16}$ sGron ma 5b7-8: gsuM pa ni \{='khrul pa'i rgyu mtshan gyis zin pa'i snang la ma nges pa\} chos mthun pa mthong pa las rtog pa nya phyis la dngul du 'khrul pa'i tshe mig shes la nya phyis kar po snang yang ma nges pa lta bu'o // de bzhin du rtog pa thag pa'i khra bo la sbrul du 'khrul pa'i tshe mig shes la thag pa snang yang ma nges pa lasogs pa rgya cher shes par bya'o // de dag gi tshe mig shes ni dkar po tsam [5b8] dang khra bo tsam la tshad mar 'gyur pa yin no //

${ }^{17}$ Tshad bsdus 54,21-55,1: thag ring ba'i stobs kyis snang la ma nges pa ni thag ring po na nya phyis snang yang nges ma nus pa lta bu ste /
} 
his successors) he conceived of it as a case distinct from the two categories he listed as subdivisions of snang la ma nges pa (which, in such a case, would not be exhaustive), or whether he meant this case to be subsumed in one of these two categories. In the eventuality of the second option, since the appearing of the mother-of-pearl is obviously not a case of inattentive perception (ii), it should be assimilated with (i). If the example of the mother-of-pearl is strictly speaking a case where there is no ascertainment due to the object being a non-manifest feature, this would imply that the character of being "manifest" or "non-manifest" is not purely objective, but can be circumstantial. Indeed, when dealing with this example, Phya pa explains that one can "subsequently ascertain that the object is mother-of-pearl by getting closer to it." This suggests that, given the proper spatial location, "mother-of-pearl" is a manifest feature in the same way "pot" or "blue" would be, a feature which can be ascertained by perceptual knowledge. Let us note that, in contrast, in the prototypical example of the first category of snang la ma nges pa, the perception of something impermanent, "impermanence" is characterized by Phya pa as a "non-manifest feature" even in situations where an ascertainment of it can nevertheless be achieved (such as in episodes of reflexive awareness of skilled cognizers, i.e., "Noble Beings"). ${ }^{18}$

\section{(c) Translation}

In modern scholarship (including in previous publications by the authors of the present volume), the term snang la ma nges pa is found translated as "unascertained appearing," "indeterminate appearing," "unascertained appearance," "undetermined appearance" and suchlike expressions, or more literally oriented expressions such as "indeterminate (cognition) as

\footnotetext{
${ }^{18}$ This is pointed out in the 'Od zer when discussing reflexive awareness: "With regard to non-manifest features such as "impermanence," etc., the reflexive awareness of ordinary persons is usually a non-ascertaining perception, but there are circumstances where non-manifest features such as "efficacy," etc. are ascertained via the ascertainment of the effect. As for Noble Beings, (their reflexive awareness) is perceptual knowledge even with regard to non-manifest features." ('Od zer 59a4-5: skad cig lasogs pa rnam myed la ni so so'i skye bo'i rang rig phal cher snang la ma nges pa yin la! nus pa lasogs pa'i rnaM myed 'bras bu nges pa'i shugs la nges pa'i skabs kyang yod de / 'phags pa rnams ni rnam myed la'ang mngon sum tshad [59a5] mar 'gyur ba'o /)
} 
to what is present" (van der Kuijp 1978), "nonascertainment of what is apparently present" (van der Kuijp 2009) or "awareness to which the object appears but is not ascertained" (Rinbochay\&Napper 1980). Dreyfus (1997a) renders it as "inattentive cognition," which, however, only connotes one of the subcategories of snang la ma nges pa (that in which there is an absence of focus).

In our translation, we chose "non-ascertaining perception," thus departing from an attempt at a literal rendering of the term in favor of a concise expression which conveys in a more precise way the type of cognition involved, based on the (almost unanimously) shared notion that snang la ma nges pa is a subtype of perception which differs from perceptual knowledge in that it does not have the feature that makes perceptual knowledge "active." Phrasing the latter specificity in terms of being "non-ascertaining" allows for our rendering to fit the various understandings of nges pa adopted by supporters and detractors of this category of awareness.

In light of the above-mentioned fact that Chu mig pa also accepts instances of snang la ma nges pa that are not perceptual, our translation of "non-ascertaining perception" cannot be extended to Chu mig pa's account. One would have there to adopt a more literal translation for this term. 



\section{Post-knowledge cognition (bcad pa'i yul can)}

\section{(a) Terminology}

\section{Origin}

The origin of the technical term bcad pa 'i yul can ${ }^{19}$ for this category appears to be the translation of the Sanskrit term adhigatavisaya, a possessive compound meaning "whose object has been understood." This expression is found in the passage below from Dharmottara's Nyayabindutīk $\bar{a}$, which is also where, according to rNgog Lo's concise guide to this text (Rigs thigs 'grel ți ka), Dharmottara excludes this category from being an instance of knowledge:

Therefore, knowledge has for its object something that has not yet been understood (Skt. anadhigatavișaya, Tib. ma bcad pa'i yul can). A person is incited to act and an object is obtained by means of the very cognition by which the object is first understood (Skt. prathamam adhigato 'rthah, Tib. thog ma nyid du don rtogs pa). And with regard to this (object), then, what else would be achieved by another cognition? Therefore, [a cognition] whose object has already been understood (Skt. adhigatavișaya, Tib. bcad pa'i yul can) is not knowledge. ${ }^{20}$

Here, Dharmottara restricts the "understanding of the object" (arthädhigati) — which he identified as the result of knowledge (see n. 2 above) - to the initial (prathamam) understanding of the object, and expresses what amounts to a "criterion of novelty."

In this passage of the Nyāyabinduți ka $\bar{a}$, one finds two concurrent translations for adhigata (in bold in fn. 20): the Tibetan rtogs pa, which

${ }^{19}$ The spelling gcad pa'i yul can is also frequently used in the manuscript of the Mun sel (but less often than bcad pa'i yul can), but never in that of the 'Od zer. ${ }^{20} \mathrm{NBT}_{\mathrm{Skt}}$ 19,2-4: ata eva cānadhigatavișayam pramānam / yenaiva hi jūānena prathamam adhigato 'rthah / tenaiva pravarttitah puruṣah / prāpitaś cārthah / tatraiva cātha kim anyena jñānenādhikam kāryam / ato 'dhigatavișayam apramānam; Tib. D37b7-38a1: de bas na ma bcad pa'i yul can ni tshad ma yin te/ shes pa gang gis thog ma nyid du don rtogs pa de nyid kyis skyes bu bcug par gyur cing don dang phrad par gyur pa yang yin te / don de kho na la ni shes pa gzhan gyis lhag pa ci byar yang med do // de bas na bcad pa'i yul can ni tshad ma ma yin no // 
matches the translation of adhigati in the earlier sentence on the result of knowledge, and the Tibetan bcad pa in the expressions bcad pa' $i$ yul can (for the Sanskrit adhigatavisaya) and ma bcad pa'i yul can (for the Sanskrit anadhigatavisaya). The latter translation appears specific to the Nyāyabinduțīka . In a parallel discussion in Dharmakīti's Hetubindu

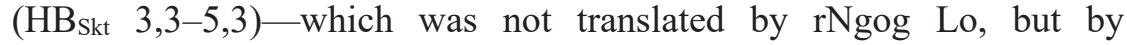
Prajñāvarman and dPal brtsegs rakșita ("pel tsek rakșita") around the beginning of the $9^{\text {th }}$ century - the phrase anadhigatärthavisayam pramannam $\left(\mathrm{HB}_{\mathrm{Skt}} 3,12\right)$ is translated don ma rtogs pa'i yul can tshad ma yin $\left(\mathrm{HB}_{\mathrm{Tib}}\right.$ 34,13). And the related phrase anadhigatavisayatvāt pramānasya in Dharmakīti's Pramānaviniścaya (PVin ${ }_{\text {Skt }} 120,1$ ) is translated by $\mathrm{rNgog}$ Lo as tshad ma ni ma rtogs pa'i yul can yin pa nyid kyi phyir (PVin ${ }_{\mathrm{Tib}} 1$ $60,17-18){ }^{21}$

rNgog Lo thus departs in his translation of the Nyāyabinduțik $\bar{a}$ from the more standard translation rtogs pa for adhigata (resp. ma rtogs pa for anadhigata), adopting instead the term bcad pa (resp. ma bcad pa). But he only does so for the two expressions in the passage under consideration. ${ }^{22}$ As previously suggested (Hugon 2014: 222), this particular choice of translation might be related to rNgog Lo's understanding of the definitional criterion of knowledge, which he takes to be expressed in the Pramānaviniścaya by the Sanskrit expression paricchidya, which rNgog Lo translates as yongs su gcod byed (see I.2, 4.2, Dhk1)—bcad pa being the past form of gcod pa. Interestingly, in his commentary on the Nyayabinduti $\bar{k} \bar{a}$, Durvekamiśra associates the meaning of adhigati/adhigata with that of paricchitti/paricchinna. ${ }^{23}$

${ }^{21}$ One also finds ma rtogs (presumably for the Sanskrit anadhigata) in the translation of a similar phrase in Dharmottara's PVinṬ 1. See PVinṬ(a) 9,15-16: tshad ma thams cad ni ma rtogs pa'i don can kho na yin no //

${ }^{22}$ Given the predominance of rtogs $p a$ as a translation elsewhere, it could be speculated that the translation bcad pa in the Nyāyabindutīk $\bar{a}$ represents one of the modifications brought by rNgog Lo to the previous translation of the text by Dharmāloka. Unfortunately, this hypothesis cannot be verified as the passage under discussion is not part of the incomplete manuscript of this earlier translation (on which see Lasic 2006).

${ }^{23}$ See DhP 19,8 ad NBT Țt 19,1: ata evāsmād eva kāranād arthasyādhigatih pa-

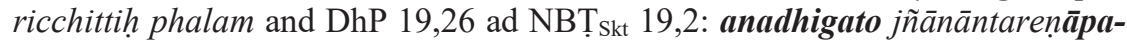
ricchinno vișayo 'rtho yasya tat pramānam bhavati / 


\section{Evolution}

While rNgog Lo, Phya pa and gTsang nag pa use the term bcad pa'i yul can for this category, a terminological change is attested as early as mTshur ston, who already uses both bcad pa'i yul can (once spelled dpyad pa'i yul can) and bcad shes. Sa pan does as well (with a marked preference for bcad shes), and Chu mig pa uses the homonyms bcad shes/dpyad shes/spyad shes exclusively. ${ }^{24}$ The latter become the standard in works of the classical period.

It is possible that the first change, from bcad pa' $i$ yul can to bcad shes, resulted from the understanding of bcad pa'i yul can as bcad pa'i shes pa rather than, as in rNgog Lo's use of the term, as the translation of the Sanskrit possessive compound adhigatavișaya. In other words, it would result from ignorance of the origin of the term. As for the other readings, they seem to have been a mere consequence of homonymy. They are not coextensive with any significant difference in the understanding of this category of awareness. ${ }^{25}$ It is only at a later period that the various spellings became the object of etymological discussions. As revealed in Lati Rinbochay's oral commentary (Rinbochay\&Napper 1989), in such discussions "bcad" in bcad shes is related to the meaning "eliminated," which is taken to refer to the elimination of superimpositions by the preceding episode of knowledge. As such, it is related to Phya pa's definition of knowledge, and not to that of rNgog Lo, with whom the term for this category originated.

\section{(b) Understanding of the category}

The passage of the Nyāyabinduțīka to which the term bcad pa'i yul can owes its origin discusses the requirement of novelty in a general way. But a subsequent sentence regarding perception makes it clear that one of the cases that this requirement targets is the determinate cognition following

\footnotetext{
${ }^{24}$ This is always spelled bcad shes in manuscript A of the rNam rgyal, whereas manuscript B has the readings dpyad shes and spyad shes.

${ }^{25}$ On the alternative use of bcad shes and dpyad shes, see van der Kuijp 1985: 37. See also the preceding note on the concurrent use of these two spellings in different manuscripts of the same text.
} 
a perceptual episode. ${ }^{26}$ The corresponding passage of the Hetubindu in which the phrase anadhigatavișayam pramannam also occurs $\left(\mathrm{HB}_{\mathrm{Skt}} 3,3-\right.$ 5,3 ) is likewise concerned with determinate cognitions (niścaya) that are characterized as "recollected" (smārta), which grasp something that has already been grasped, and correspond to determining cognitions that follow a perception. A particular case in the context of an inferential process is the cognition of the logical reason (lingajñanam) that arises from the perception of, for instance, smoke (when inferring the presence of fire). Dharmakīrti denies the status of knowledge to such cognitions. The discussion in the Hetubindu extends to moments of perception following an initial perceptual episode which Dharmakirti, on the contrary, holds to be knowledge.

Phya pa, in his enumeration of the three types of bcad pa'i yul can, preserves the distinction between two kinds of awareness following an initial perception - (i) another (moment of) perception or (ii) a determining cognition-but classifies both as bcad pa'i yul can. As the second is dealt with by Dharmakīrti in terms of "recollecting determination" (smārto niścayah), "memory" (smrti) and "recognition" (pratyabhijūā), ${ }^{27}$ this opens the door to extending the category, as Phya pa does, to any conceptual episode of memory.

Tibetan scholars in Phya pa's time appear to agree that, in the case of perception, the moments following the initial perception still qualify as "perception" even if they do not qualify as "perceptual knowledge." But what about the moment(s) following an initial moment of inferential cognition? Some authors consider that they still qualify as "inferential cognition" although not as "knowledge" and acknowledge the possibility of an inferential cognition being bcad pa'i yul can. Phya pa rejects the claim that they even qualify as "inferential cognition" (see Mun sel 123.21). The cases of perceptual knowledge and inferential knowledge are thus not parallel.

The debate around the possibility of an inferential bcad pa'i yul can appears to stem from sTod lung-associated scholars: the proponent of the opposite view is identified as a scholar called g. Yor gnyan ("yor nyen")

\footnotetext{
${ }^{26} \mathrm{NBT}_{\text {Skt }}$ 20,1-3: tatra yo 'rtho dṛștatvena jũātah sa pratyakșena pravrttivișayzkrtah / yasmād yasminn arthe pratyakșasya sākșāt kāritvavyāpāro vikalpenānugamyate tasya pradarśakam pratyakṣam / tasmād drṣtatayā jñātah pratyakṣadarśitah /

${ }^{27}$ See Katsura 1993: 70-72.
} 
in the Tshad bsdus ${ }^{28}$ and in an interlinear note of the Tshad nye bsdus (8b5), and as rGya dmar ba by Śākya mchog ldan (see V, 1, R52.4). g. Yor gnyan flourished in the first half of the $12^{\text {th }}$ century and was teaching epistemology to Phag mo gru pa rDo rje rgyal po ("pak mo dru pa dor jé gyel po," 1110-1170) in sTod lung around 1137 (van der Kuijp 2003: 417). Phya pa, who had been studying under rGya dmar ba in sTod lung from c. 1129 onward and taught Phag mo gru pa as well (van der Kuijp 1983: 60), was possibly directly acquainted with g.Yor gnyan.

In passages related to the notion of adhigatavișaya (resp. anadhigatavișaya), Dharmakīti and Dharmottara only consider episodes of awareness that follow an episode of knowledge. bCad pa'i yul can is also restricted to such cases for Phya pa, as shown by the argument that one can actually prove that an episode of awareness is knowledge by establishing that the subsequent cognition is an episode of bcad pa' $i$ yul can. ${ }^{29}$ The majority of Tibetan scholars also discuss bcad pa' $i$ yul can in such terms, and many even include the specification of the object having been previously understood "by an episode of knowledge" in their definition. ${ }^{30}$

There are a few exceptions, however: gTsang nag pa and mTshur ston consider a broader notion of "understanding" (rtogs pa) that is not limited to knowledge but also applies to factive assessment. ${ }^{31}$ Accordingly, they distinguish as a subtype of bcad pa'i yul can a conceptual cognition following factive assessment. ${ }^{32}$ mTshur ston even explicitly rejects a definition involving the notion of "a state of affairs already understood by an episode of knowledge," arguing that it would not apply to cognitions following factive assessment. ${ }^{33}$

${ }^{28}$ Tshad bsdus 56,19-20: g.yor gnyan na re rjes dpag gi rgyun yin pas phyis kyi bcad shes de rjes dpag yin no zhes 'dod pa ni mi rigs te /

${ }^{29}$ See in this regard the argument in Mun sel 37a5-6.

${ }^{30}$ Neither in the Mun sel nor the 'Od zer does Phya pa add this specification in his definition, but the author of the Tshad bsdus ascribes to him a definition that includes it. Cf. below 6.2 (iii).

${ }^{31}$ This contrasts with rNgog Lo's categorization of factive assessment as a case of non-understanding ( $m a$ rtogs).

${ }^{32}$ bsDus pa 23a4-5: de yang tshad ma gnyis dang yid dpyod ${ }_{[23 a 5]}$ kyi rjes su skyes pa'i rtog pa dang mngon sum gyi rgyun rtog pa myed pa'o //. sGron ma 6a1-2: dper brjod na gsuM ste / [6a2] mngon suM tshad ma'i rjes su skyes pa dang / rjes dpag gi rjes su skyes pa dang / yid dpyod kyi rjes su skyes pa'i bcad shes so // ${ }^{33}$ See $s$ Gron ma 5b9-6a1. 
Phya pa's successors - as early as gTsang nag pa - consider it possible, properly speaking, to know (again) something that had been understood before. The category of bcad pa'i yul can is limited to cases where the previous understanding is still vivid, and the subsequent cognition is indeed redundant. They refer in this regard to a notion that is found in PVin 1, namely the notion of "aggregates of vision not having decayed" (after an episode of perceptual knowledge). ${ }^{34}$ They re-formulate the definition in corresponding terms, so that the object is characterized as "an object for which the function of (the previous) understanding has not been impaired." ${ }^{35}$ This formulation is still found in the definitions contained in the Don gnyer mun sel ascribed to Tsong kha pa (6a1) and in dGe 'dun grub's Tshad ma rigs rgyan (434). But starting with the Rwa stod bsdus grwa $\left(15^{\text {th }}\right.$ century), the definition in terms of "awareness that understands something that was already understood" (rtogs zin rtogs pa'i rig pa) becomes predominant. ${ }^{36}$

Chu mig pa (rNam rgyal A9b3-4; B11b9) points out the abovementioned passage of the Pramānaviniścaya as evidence for the legitimacy of a perceptual type of this category of awareness (i.e., mngon sum dpyad shes) in answer to an anonymous objection which, like the objection against snang la ma nges pa that Chu mig pa also addresses (see §1(b) above), might be reflecting Sa pan's criticism of this category. ${ }^{37}$

${ }^{34}$ PVin $_{\text {Skt }} 1$ 20,2-3: abhraștadarśanasamskārasya gṛītagrahaṇasya smārtād aviśeșāt/; PVin Tib 1 60,19-20: mthong ba'i 'du byed ma nyams pa'i gzung ba 'dzin pa ni dran pa las khyad par med pa'i phyir ro //

${ }^{35} \mathrm{Cf}$. 6.2 (vi) and (ix). A similar characterization of the object is also found in the definitions of gTsang drug rdo rje (6.2 [xi]), Chu mig pa (6.2 [xv]), and Chos kyi bzhad pa (6.2 [xvi]). This is also the formulation known to Sa pan, cf. Rigs gter II 65,12-13: sngar rtogs zin gyi byed pa ma nyams pa la bzlog phyogs kyi sgro 'dogs dang 'gal bar 'jug. Note that this point is prefigured (although not exploited by Phya pa) by the mention of the temporal restriction pertaining to the elimination of superimpositions by an episode of knowledge in the 'Od zer. Namely, superimpositions are eliminated between the time the episode of knowledge is generated and the time the compositional factors of memory are impaired. See I.2, 3.1.3.ii.

${ }^{36}$ See Rwa stod bsdus grwa (479), as well as, for instance, 'Jam dbyangs bzhad pa'i blo rigs (10a2), Klong rdol ming grangs (12a7), and Yongs 'dzin blo rigs (14b1).

${ }^{37}$ rNam rgyal A9b3-4; B11b9: kha 1 mngon sum \{A sum, B 3\} dpyad shes med ces zer ba ni. 
Sa pan, in his general criticism of this category (for which he uses the term bcad shes), points out that the various cases of bcad shes actually amount to "non-understanding," "mistaken understanding," or "knowledge" and thus have no legitimacy as a distinct category. The basic argument is that a bcad shes simply amounts to a "non-understanding" ( $m a$ rtogs pa): the object of knowledge being momentary, it is no longer there to be understood at the time of the bcad shes, and since it has already been understood, there is nothing left to be understood, on account of which the subsequent cognition could be an "understanding." 38 Perceptual bcad shes is thus refuted on account of the momentariness of the object of perception: there cannot be a second perceptual awareness taking as its object the same object as the preceding one. Perception is always novel. The argument against conceptual bcas shes relies on the rejection of the status of agent in the absence of a patient or of an action to be performed. As Sa pan says: "The ax is not a 'cutter' once the tree has already been cut." 39

\section{(c) Translation}

The most frequent translations found in modern scholarship for the term bcad pa' $i$ yul can or for the corresponding expression in later works, bcad shes/dpyad shes, is "subsequent cognition" (Dreyfus 1997a, Stoltz 2009, Hugon 2011a). One also finds "cognition" (van der Kuijp 1978), "subsequent cognizer" (Rinbochay\&Napper 1980), "determinative cognition" (van der Kuijp 2009), and "[cognition] whose object has been discriminated" (Hugon 2014).

While "subsequent cognition" highlights the temporal feature that characterizes this type of awareness (it comes after another cognition), it fails to convey its connection with the criterion of novelty, namely, it does not render explicit the fact that the previous cognition has already achieved knowledge of the object (whether conceived in terms of "understanding" or "elimination of superimpositions"). We were tempted by the

\footnotetext{
${ }^{38}$ See Rigs gter II 65,18-66,9, and in particular 65,22-24. Reduction of bcas shes to a mistaken understanding is adduced in answer to the idea of an understanding that makes one remember something previously understood. Reduction to knowledge is adduced for a special case of bcas shes qua memory when yogic practitioners infer a previous experience based on a present memory.

${ }^{39}$ Rigs gter II 65,23-24: shing bcad zin pas sta re gcod byed ma yin pa.
} 
translation "redundant cognition," which reflects well Phya pa's understanding of this category in contrast to the novelty of knowledge episodes, up to the connotation of such types of awareness as useless, at least with regard to what is expected of a knowledge episode. Such episodes do have a use, however. For instance, conceptual cognitions following perceptual knowledge provide a conceptual determination of the object. But such a use of determining cognitions (nges shes) is hardly pointed out by Phya pa, who merely mentions this aspect when discussing the views of proponents of the indirectly active model. We abandoned this translation in mid-course to avoid implying any derogatory connotation which, although fitting in Phya pa's case, might not have been implied by other authors.

We ultimately opted for the translation "post-knowledge cognition," in spite of the fact that this translation is problematic for authors such as gTsang nag pa and mTshur ston, who extend this category of cognitions to episodes that follow factive assessment (which is not knowledge), in which case one should rather speak of "post-understanding cognition." These two authors' uses appear to be idiosyncratic exceptions.

Correspondingly, we have rendered the distinguishing criterion that sets aside post-knowledge cognition in the seven-fold typology, which Phya pa phrases as "rtogs ma zin la 'jug pa," as "engaging an object not previously known." In the same way, we rendered as "known" rather than "understood" the verb rtogs pa in Phya pa's formulation of criterion K2 in the definition of the engaged object (Mun sel 121.13). 


\section{Factive assessment (yid dpyod)}

\section{(a) Terminology}

While it is very clear which textual passages in the Nyāyabindutīk $\bar{a}$ and the Pramānaviniścayatīka prompted the idea of this distinct category of awareness, the origin of the term yid dpyod is still in question. ${ }^{40}$ It is possible that the term yid dpyod was coined in opposition to yid gnyis (literally, "dual thought"), an expression that denotes "doubt" and is used (rather than the tshom) to translate the Sanskrit samśaya in the very passage of the Nyāyabindutīk $\bar{a}$ that motivated rNgog Lo's application of the category yid dpyod (see $\$ 5$ below).

\section{(b) Understanding of the category}

In view of the above hypothesis regarding the terminology, the category of yid dpyod could have initially simply connoted episodes of awareness involving a "decision" in opposition to an ambivalent hesitation, although not a decision that relied on any proper evidence (i.e., not following a perception, and not being derived from a valid logical reason). On such a view, yid dpyod would be a category that includes both episodes of incorrect determinate awareness (i.e., one form of mistaken cognition, which is noted $\mathrm{MC}_{2}$ in $\S 4$ below) and of correct determinate awareness (for which there would be no specific term).

This overarching category of yid dpyod is precisely the conception that Phya pa addresses when criticizing, in Mun sel 123.322 (cf. also 6.3 [i]), the definition of factive assessment in the following terms:

Directing one's mind toward a state of affairs, while being partial to it, without relying on experience or a logical reason.

Also cited by gTsang nag pa (6.3 [vii]) and mTshur ston (6.3 [viii]), such a definition is ascribed in various texts to Phya pa's teacher rGya dmar ba. ${ }^{41}$ But in the absence of more precise, first-hand information, we cannot conclusively assess whether rGya dmar ba indeed was a supporter of

\footnotetext{
${ }^{40}$ See Hugon 2014: 224 for a previous discussion.

${ }^{41}$ It is ascribed in the Tshad bsdus (6.3 [vi]) and gTsang drug rdo rje's gSal byed (6.3 [xi]) to a scholar identified as "rGya." Glo bo mkhan chen (Rigs gter nyi ma
} 
yid dpyod as an overarching category or whether he just adopted a definition that turns out to be too broad.

(Hypothetical) proponents of the overarching view and those who, like Phya pa, conceive of yid dpyod exclusively as a mental episode consisting in a correct determination, would both acknowledge that yid dpyod is intrinsically identical with mistaken cognition. Whether the determination is "correct" or "incorrect" can only be extrinsically ascertained.

Some degree of commonality between yid dpyod and mistaken cognition already stands out in rNgog Lo's discussion. rNgog Lo speaks of yid dpyod as "having the nature of mistaken cognition" and "being subsumed in mistaken cognition," because in both cases there is no ascertainment of an invariable relation with the state of affairs. ${ }^{42}$ rNgog Lo however supported the notion of yid dpyod being restricted to correct determination rather than an overarching category or a category actually coextensive with mistaken cognition. The cases dealt with by Dharmottara that rNgog Lo classifies as yid dpyod are all instances of correct determination. Yid dpyod being subsumed within mistaken cognition is due to the fact that one cannot intrinsically reject the option that it is a mistaken cognition.

The definition adopted by Phya pa and the place ascribed to yid dpyod in the typologies of awareness show that he was less keen to highlight its similarity with mistaken cognition than its similarity with inference, from which it differs only by virtue of a single criterion: relying or not on correct logical evidence. However, the similarity with mistaken cognition surfaces in several occasions. For instance, both are excluded from being episodes of knowledge by the same criterion K3 (Mun sel 212.22). There Phya pa points out that some mistaken cognitions, like instances of factive assessment, are actually able to eliminate wrong superimpositions. Also, the discussion of the subtypes of yid dpyod (Mun sel 123.31) draws out a similar classification of the subtypes of mistaken cognitions: those lacking a reason, and those derived from incorrect logical evidence. The difference between the two sets of subtypes is grounded in the idea that yid dpyod determines a veridical thesis, whereas mistaken cognition establishes a non-veridical one.

Against the view that yid dpyod provides a determination, or even a correct determination, some Tibetan scholars focused rather on the absence of proper justification and subsumed instances of such episodes of

$53,3-5)$ specifies that its author is "sTod lung rGya mar ba byang chub grags." ${ }^{42}$ See Hugon 2014: 214 and 220. 
awareness under doubt. This is the position that was ascribed to Dharmottara by rNgog Lo. ${ }^{43}$ This was also notably the position defended by Sa pan, who rejected the legitimacy of this category. For Sa pan, such episodes of awareness are unable to bring about any type of decisive understanding. Conversely, a factive mental episode must be knowledge. ${ }^{44}$

The abovementioned definition ascribed to rGya dmar ba still served as the basis for other scholars who built on it. The addition of the explicit criterion of the object being veridical (don bden pa) prevented the fault pointed out by Phya pa. ${ }^{45}$ The addition of the criterion of novelty to rGya dmar ba's definition is linked with Byang chub skyabs ("jang chup kyap") in the Tshad bsdus. ${ }^{46}$

One may note that Phya pa phrases his own definition of yid dpyod in different terms in the Mun sel and the 'Od zer, and explains the role of the various criteria in a slightly different way in each text.

In the Mun sel (123.321), yid dpyod is defined with four criteria. ${ }^{47}$

\footnotetext{
${ }^{43}$ On rNgog Lo's presentation of Dharmottara's position and his direct or indirect criticism of it, see Hugon 2014: 214-215 and 220-221.

${ }^{44}$ On Sa pan's arguments, see Stoltz 2007: 407-411 and Stoltz 2009.

${ }^{45}$ See for instance the definitions of gTsang drug rdo rje (6.3 [xii]), of the Rwa stod bsdus grwa (480), and of Klong rdol bla ma (Klong rdol ming grangs 12b7). While those definitions insist on the object being veridical (yul bden pa), the Tshad ma' $i$ spyi skad (4a3) reports the definition of yid dpyod in a unique manner as a "righteous establishing awareness" (gtan la 'bebs pa'i blo gsha' ma).

${ }^{46}$ Tshad bsdus 58,5-6: gsar du zhes pa ni rtog pa bcad pa'i yul can bcad par byang chub skyabs bzhed la I

${ }^{47}$ The citation of the definition of the Mun sel in Śākya mchog ldan's Rol mtsho $(\mathrm{V}, 1, \mathrm{R} 51.12)$ includes the criterion of the object being concealed (lkog gyur) as a fifth criterion. But this criterion does not figure in the Mun sel in the list of criteria that exclude other types of awareness from satisfying the definition, nor when Phya lists the episodes of knowledge establishing each criterion. The notion of the object being concealed appears when identifying the nature, but it does not play a role in excluding anything. Note in addition that Glo bo mkhan chen cites Phya pa's position (V, 1, R7.2) in a way that is quasi-literally identical with the version of the Mun sel, but without any mention of the object being concealed, thus suggesting that this criterion was added by Śākya mchog ldan under the influence of the wording of the definition in the 'Od zer (see below) or that by other scholars.
} 
These are shown to exclude all other types of awareness as follows: ${ }^{48}$

[1] a determinate awareness - excludes doubt ${ }^{(1)}$ and the three types of perception $\left({ }^{(3)},{ }^{(4 b)},{ }^{(5)}\right)$

[2] of a veridical state of affairs - excludes mistaken cognition ${ }^{(2)}$

[3] not previously known - excludes post-knowledge cognition ${ }^{(4)}$

[4] that is not based on a logical - excludes inferential cognition ${ }^{(6)}$ reason

The types of awareness listed as "excluded" are recognizable as the six other types in the seven-fold typology (see V, Table E), with the additional subdivision of post-knowledge cognition ${ }^{(4)}$ into a perceptual type ${ }^{(4 b)}$-implicitly included within the "three types of perception" eliminated by the first criterion - and a conceptual type ${ }^{(4 a)}$ implicitly included (as well as ${ }^{(4 b)}$ ) in the mention of "post-knowledge cognition" eliminated by the third criterion. The four criteria adduced in the definition are difficult to read as effecting a step-by-step narrowing-down of the category (as in the seven-fold typology). Criterion [2] excludes mistaken cognition in general, while non-conceptual erroneous cognition would actually also be excluded by criterion [1]. Criterion [3] is said to exclude postknowledge cognition in general, and thus overlaps with criterion [1] in excluding perceptual post-knowledge cognition, one of the three types excluded by the latter.

In the 'Od zer (111.222.34), yid dpyod is defined with a different phrasing of the four criteria present in the Mun sel and the addition of another criterion - the object being concealed (lkog gyur). ${ }^{49}$ The five criteria are here shown to exclude all the other types as follows:

\footnotetext{
${ }^{48}$ The order in which the criteria are listed here corresponds to the order adopted by Phya pa when explaining which type of awareness each criterion eliminates. This order is reflected in the English translation of the definition proper, although it does not correspond to the order the criteria appear in the phrasing of the definition in Tibetan. Cf. Mun sel 123.321 (and 6.3 [ii] in this chapter): yid dpyod kyi mtshan nyid ni sngar ma rtogs pa'i don bden pa rtags tshad mas nges pa la ma brten par nges pa.

49 'Od zer 111.222 .34 (6.3 [iii]): lkog gyur bden pa rtags kyi rjes su ma 'brangs par gsar du nges pa. See n. 47 on this criterion in the citations of the definition of the Mun sel by Sākya mchog ldan.
} 
[1] concealed object

[2] veridical object

[3] not based on evidence

[4] determinate awareness

[4+5] novel determinate awareness
- excludes perceptual knowledge ${ }^{(3)}$

- excludes mistaken cognition ${ }^{(7)}$

- excludes inferential cognition ${ }^{(10)}$

- excludes doubt ${ }^{(6)}$, non-ascertaining perception ${ }^{(1)}$, non-conceptual erroneous cognition ${ }^{(4)}$, non-directing conceptual cognition ${ }^{(5)}$

- excludes conceptual post-knowledge cognition following an inferential cognition ${ }^{(8 \mathrm{~b})}$

The types of awareness listed as "excluded" are, recognizably, taken from the ten-fold typology (see V, Table G). However, one may observe that perceptual post-knowledge cognition - type ${ }^{(2)}$ of the ten-fold typology-is missing here. As for conceptual post-knowledge cognition - type ${ }^{(8)}$ - only one sort of it is accounted for, namely, that following an inferential cognition (the more significant type, conceptual cognition following a perception, is not mentioned here). In addition to these omissions, one may note that, like in the Mun sel, the way the criteria are said to exclude the other types is not systematical. The criteria are listed here in the order in which they appear in the Tibetan phrasing of the definition, but the mention of what they exclude is incomplete. The criterion "concealed object" [1] would actually exclude all perceptions, but only perceptual knowledge is mentioned as being excluded by it. As for the criterion "veridical object" [2], it would also exclude non-conceptual erroneous cognition ${ }^{(4)}$, which is instead said to be excluded by the criterion of "being a determinate awareness" [4]. One cannot rule out the possibility that the text is faulty, and that the reading lkog gyur zhes pas mngon sum tshad ma gcod la ("the object being concealed excludes perceptual knowledge") should be corrected to ... mngon sum thams cad gcod la ("... excludes all perceptions"). This would explain why perceptual knowledge and perceptual postknowledge cognition are not mentioned as excluded by the subsequently mentioned criterion [4] and, for the latter, also [5]. ${ }^{50}$

\footnotetext{
${ }^{50}$ One may consider in this regard the definition adduced in the Tshad bsdus, which also counts five criteria, but with the criterion "not based on experience" instead of the criterion "the object being remote." Tshad bsdus 58,1-2 (cf. 6.3 [v]): myong ba dang rtags la ma brten par don bden pa gsar du nges pa. "Not based on experience" [1] is said to exclude perception; "not based on a logical reason" [2] excludes inferential cognition; "veridical" [3] excludes mistaken cognition; "novel" [4] excludes conceptual post-knowledge cognition; "determinate awareness" [5] excludes non-ascertaining perception and doubt (i.e., what is left of the types that have not been excluded yet).
} 
Due to the imprecision in both texts, the scope of the criterion expressed in Tibetan as "nges pa" in these two texts (criterion [1] in the Mun sel, [4] in the 'Od zer) could appear as a debatable topic. In the Mun sel, a preceding discussion determining the nature of yid dpyod (Mun sel 123.31) clearly indicates that yid dpyod is nges pa in the sense of "being a determinate awareness." Yid dpyod is characterized as being:

[1'] not a non-conceptual cognition

[2'] not doubt

[3'] not a mistaken determinate awareness

[4'] not a determinate awareness of something already known

[5'] not a determinate awareness that is based on having determined, by an episode of knowledge, that a logical reason is a property of the subject and entails the property to be proven $\rightarrow$ a conceptual cognition

$\rightarrow$ a determinate awareness

$\rightarrow$ a determinate awareness in which the determination corresponds with the object to be cognized

$\rightarrow$ a determinate awareness of something concealed and not previously known

This characterization follows a strict order, narrowing down the notion of yid dpyod within the category of conceptual cognition, in way similar to that in the three-fold typology, but with the addition of criteria [4'] and [5'] that are not present in the three-fold typology. A determinate awareness is a subtype of cognitions that are "directing," which is itself a subtype of those cognitions that are "conceptual." Therefore, "being a determinate awareness," as a definitional criterion, excludes cognitions that are non-conceptual, those that are non-directing, and those that are not determinate. "Non-directing" episodes are not considered in the seven-fold typology, on which the present list of types of awareness relies, and are thus left out of the discussion. When commenting on the defining criteria in the Mun sel, Phya pa only mentions the exclusion of doubt (the only instance of non-determinate conceptual cognition) and perceptual cognitions (one of the two types of non-conceptual cognitions). This is not, obviously, because non-conceptual erroneous cognitions are held to be determinate, but because Phya pa leaves to the criterion "veridical state of affairs" the role of excluding non-conceptual 
erroneous cognitions together with other mistaken cognitions. This is understandable given that, in the seven-fold typology, non-conceptual erroneous cognition is not listed as a type distinct from mistaken cognition (it is distinguished as a subtype of the latter in the twelve-fold typology, see V, Table F).

One can unproblematically understand the criterion nges $p a$ in the same sense in the 'Od zer, and we have translated it accordingly, above (see criterion [4]). Under this reading, and if one does not want to correct the text as suggested above, it would be the case that, like in the Mun sel, Phya pa does not mention all the episodes excluded by this criterion, leaving this task to other criteria for perceptual knowledge-which is eliminated by [1] — and for perceptual post-knowledge cognition — which Phya pa omits to discuss.

There is, however, another possible interpretation. The four types of awareness that are excluded in the 'Od zer by the criterion nges pa happen to be mentioned together again when Phya pa explains which of the criteria for knowledge do not apply to the eight types of awareness of the ten-fold typology that do not qualify as knowledge. There, he says that these four types - doubt ${ }^{(6)}$, non-ascertaining perception ${ }^{(1)}$, non-conceptual erroneous cognition ${ }^{(4)}$, and non-directing conceptual cognition ${ }^{(5)}$ are not knowledge because they lack the criterion of being incompatible with superimpositions (sgro 'dogs dang 'gal ba) (i.e., they lack K1) ${ }^{51}$ It would thus also be possible to understand "nges $p a$ " in the definition of factive assessment as connoting the "incompatibility with superimpositions," hence in the extended sense of an ascertainment that is not limited to conceptual determination. The definition in the 'Od zer could thus be read as:

The novel ascertainment of something remote and veridical, which is not based on a logical reason.

In such a case, the criterion of "the object being remote" [1] would not be redundant with [4] with regard to perceptual knowledge. As perceptual knowledge is incompatible with superimpositions, it would need to be excluded by a criterion other than "ascertainment." Thus, this reading of

\footnotetext{
${ }^{51}$ See the end of the superordinate section ('Od zer 111.222.3), 29a8-9: snang la ma nges pa dang rtog myed 'khrul pa dang bden zhen myed pa'i rtog pa dang the tsom rnams la ni sgro 'dogs dang 'gal ba nyid myed /
} 
nges $\mathrm{pa}$ fares better with the presence of the additional criterion [1], which is otherwise redundant.

One can envisage that in the 'Od zer, Phya pa wants to highlight "incompatibility with superimposition" rather than "being a determinate cognition" as a distinctive criterion, because the discussion is subsumed under the larger question of which of the criteria for knowledge do or do not apply to the respective types of awareness in the ten-fold typology. This connotation of nges $p a$ would, however, be surprising here. Indeed, while such a use is attested in the works of Phya pa's successors, ${ }^{52}$ Phya pa does not explicitly associate the notion of nges $p a$ with that of "incompatibility with superimpositions" or "elimination of superimpositions." While it remains possible that he is precisely doing so in the passage under consideration, one can, as indicated above, just as well make sense of the definition by understanding nges pa in the sense of "being a determinate cognition." 54

${ }^{52}$ See I.2, 4.3, n. 123.

${ }^{53}$ He may at most be understood to do so implicitly when defining non-ascertaining perception, as the expression ma nges pa comes to be associated with the defining criterion of "compatibility with superimpositions."

${ }^{54}$ The difference between the Mun sel and the 'Od zer regarding the phrasing of the definition of factive assessment and the role of the defining criteria does not provide any compelling evidence in favor of the claim of a fundamental difference regarding the model of perceptual knowledge adopted by Phya pa in the respective texts, as argued in Nishizawa 2016. (According to Nishizawa, Phya pa supports in the 'Od zer the view that perception is "object-ascertaining" and in the Mun sel the view that it is not, because nges pa, in the definition of yid dpyod, is said to exclude perceptual knowledge in the latter but not in the former. It is not entirely clear what the author means by "object-ascertaining," which he essentially presents as a feature that is not present in cases of snang la ma nges $p a$.) Indeed, there is no evidence in the two texts of any difference pertaining to the model of perception adopted by Phya pa. In both texts, perception is not a conceptual determinate awareness. And in both texts, the definition of knowledge and the category of non-ascertaining perception support a directly active model of perception in which perception, in order to qualify as knowledge, has to ascertain its object, not in the sense of conceptually determining it (directly or indirectly), but in the sense of eliminating superimpositions (or being incompatible with superimpositions). Accordingly, in both texts, snang la ma nges pa is defined as "compatible with superimpositions." 


\section{Subdivisions}

While the division of yid dpyod into three types is standard, it is worth noting that rNgog Lo identifies three subtypes in the $d K a$ ' gnas, but four in the Rigs thigs 'grel ți ka. There, in addition to the subtypes

i. without a reason,

ii. with a mistaken reason,

iii. with a correct reason which is not established,

rNgog Lo adds in this text the case of yid dpyod

iv. with a correct reason which is established but forgotten.

This difference is interesting given that in the Nyāyabindutīk $\bar{a}$ there are no illustrations of yid dpyod. Both the three-fold and the four-fold division are thus based on the same passage of the PVinT (D5b3-7), which also offers support for the terminology used by rNgog Lo for the different kinds, including the fourth that is singled out only in the Rigs thigs 'grel ti $\mathrm{ka}^{55}$

Given the predominance of the three-fold division in subsequent epistemological works and the fact that the four-fold subdivision is never mentioned by subsequent scholars, this might be an indication that the Rigs thigs 'grel ti $\mathrm{ka}$ was composed earlier than the $d K a$ ' gnas and possibly did not have a large impact. ${ }^{56}$

\section{(c) Translation}

The translation of yid dpyod adopted here- "factive assessment"-was first suggested in Stoltz 2007. It clearly reflects a key feature of such episodes which is explicit in the definitions of this type of awareness from Phya pa onward: their having a true object. Other translations found in modern scholarship include "reflection-as-an-ego-act" (van der Kuijp

\footnotetext{
${ }^{55}$ See Hugon 2014: 220, n. 73. Support for the fourth subtype comes from the case provided by Dharmottara where it is concluded that there is fire based on the perception of smoke which one does not remember to be determined as the effect of fire.

${ }^{56}$ The author of the Spyi skad accepts four kinds of factive assessment. The fourth variety is not the one rNgog Lo distinguished in the Rigs thigs 'grel ti $\mathrm{ka}$, but is instead exemplified by "The dawning of an understanding from hearing, reflecting, and practicing authoritative treatises" (4a2: bka' bstan bcos la thos bsam byas nas go ba shar ba yang yid dpyod yin no).
} 
1978), "correct assumption" (Dreyfus 1997a), "correctly assuming consciousness" (Rinbochay\&Napper 1980), "supposition" (van der Kuijp 2009), and "presumption" (Hugon 2014). 


\section{Mistaken cognition (log shes)}

\section{(a) Terminology}

According to rNgog Lo's Rigs thigs 'grel ți ka, Dharmottara deals with the category that rNgog Lo calls log pa'i shes $p a$ in the passage of the Nyāyabinduți $k \bar{a}$ dealing with cognitions other than perceptual knowledge and inferential cognition. Dharmottara says:

In some cases the object indicated by a cognition other than these two episodes of knowledge is a complete delusion (Skt. atyantaviparyastah, Tib. shin tu phyin ci $\log p a)$, just like water in the case of a mirage. ${ }^{57}$

In this passage, it is the object that is characterized as "a complete delusion." It is possible that by the expression log pa'i shes pa rNgog Lo originally wanted to refer to "the cognition of something deceptive," and that the characteristic of the object was later reported to the cognition, which became known as a "mistaken cognition" (log shes). But rNgog Lo might also have been using $\log p a$ ' $i$ shes $p a$ in the sense of $\log$ shes. Instead of the Sanskrit expression viparyasta, he might also have had in mind (provided that rNgog Lo had a Sanskrit expression in mind, which is plausible, but not obligatory) an expression such as mithyājñāna, for which log $p a$ ' $i$ shes $p a$ is attested as a translation five times in the Nyāyabinduțīka .

\section{(b) Understanding of the category}

The author of the Tshad bsdus reports three different definitions of $\log$ shes. ${ }^{58}$ The first is ascribed to Phya pa, the second to Byang chub skyabs, and the third to rGya. However, given that it is the third and not the first that corresponds to Phya pa's definition in the Mun sel and the 'Od zer, we tentatively propose to correct these attributions as follows:

\footnotetext{
${ }^{57} \mathrm{NBT}_{\mathrm{skt}}$ 22,1: ābhyām pramānāahbyām anyena ca jñānena darśito 'rthah kaścid atyantaviparyastah / yathā marīcikāsu jalam /; Tib. D38a4: tshad ma gnyis las gzhan pa'i shes pas bstan pa'i don ni smig rgyu la chu bzhin du kha cig shin tu phyin ci log pa yin la /. See Hugon 2014: 217.

${ }^{58}$ Tshad bsdus 61,11-16.
} 
rGya dmar ba

- Taking as its object a non-veridical state of affairs (don mi bden pa yul du byed pa $)^{59}$

Byang chub skyabs - Taking as its object something that does not correspond to the state of affairs (don dang mi mthun pa yul du byed $p a)^{60}$

Phya pa

- Positively discerning a state of affairs incorrectly (don la phyin ci log tu yongs su gcod pa $)^{61}$

\section{Subdivisions}

One should be aware of the different connotations attached to the term $\log$ shes, which are often not specified in discussions involving this category. Phya pa distinguishes in Mun sel 123.4 two forms of "mistaken cognition," which pertain respectively to the apprehended object and to the intentional object. To define both of them together, Phya pa uses the criterion "positively discerning a state of affairs incorrectly." Phya pa's use of the term yongs su gcod pa ("positively discerning") in his definition corresponds to a broad understanding of the term also attested in his seven-fold typology, where all cognitions are characterized as don yongs su $\operatorname{gcod} p a .^{62}$

${ }^{59} \mathrm{Cf}$. 6.4 (iii). A similar definition is cited and refuted by gTsang nag pa (cf. 6.4 [vi]).

${ }^{60}$ Cf. 6.4 (iv). A similar definition is cited by Chu mig pa (6.4 [xiii]) and in the Tshad nye bsdus (6.4 [xv]), where it is however ascribed to Phya pa. The author of the Tshad bsdus mentions as the justification for adopting the second definition over the first that "it is difficult to assess the boundary between veridical and non-veridical" (Tshad bsdus 61,12-13: bden mi bden gyi sa mtshams dka' bas). Byang chub skyabs is credited with the same remark with regard to the definition of knowledge (see Tshad bsdus 115,12-14).

${ }^{61}$ Cf. 6.4 (v). This corresponds to the definition found in Mun sel (6.4 [i]) and 'Od zer (6.4 [ii]): don phyin ci log tu yongs su gcod pa. Note that in the sevenfold division, the distinguishing criterion that singles out mistaken cognition is formulated in terms similar to Byang chub skyab's definition, namely, shes bya dang mi mthun par yongs su gcod pa (Mun sel 122.121).

${ }^{62}$ Phya pa thus escapes the fault reported in the Tshad bsdus, that "gcod" taken in the sense "leading to a determining cognition" would not allow the definition to apply to "non-conceptual mistaken cognitions" (rtog med log shes). Tshad bsdus 61,15-16: gcod pa zhes bya ba nges shes 'dren pa la zer na rtog med log shes la ma khyab bo // zhes zer ro // 
- According to the first form $\left(\mathrm{MC}_{1}\right)$, any awareness whose apprehended object is something superimposed (in other words, is not a real particular) is a log shes. This includes two subtypes: cognitions that apprehend a concept-i.e., all types of conceptual awareness $\left(\mathrm{MC}_{1.1}\right)$ - as well as non-conceptual erroneous cognitions, which apprehend hallucinatory/illusory items $\left(\mathrm{MC}_{1.2}\right)$.

- The second form $\left(\mathrm{MC}_{2}\right)$ captures the more intuitive idea of an incorrect determination, for instance, for a Buddhist, the determination of sound as permanent. Apart from this standard example, a number of other cases discussed elsewhere in the text fall into this form.

Earlier in the Mun sel, when dealing with the three-fold typology, Phya pa formulates other specifications pertaining to log shes, in relation with the operations of the various types of awareness. With regard to each of those three operations - the operations of appearing, directing, and excluding others - it is possible that the episode of awareness could be a $\log$ shes:

- With respect to the operation of appearing, Phya pa speaks of "mistaken cognitions that are erroneous with respect to the state of affairs that is apprehended" (gzung don la 'khrul pa'i log shes). This type is related to the nature of the apprehended object, and thus corresponds to $\mathrm{MC}_{1}$.

- By contrast, the form of $\log$ shes associated with the operation of directing $\left(\mathrm{MC}_{3}\right)$ is related to the intentional object of a (conceptual) cognition. Here, an awareness is said to be a log shes due to the apprehended object - a concept — being conceived of as a real particular. This form of $\log$ shes is found in all episodes of conceptual cognition, except for the narrow case of inferential cognitions in which one's mind is directed upon concepts themselves (see Mun sel 112.111.111.2 [d]). It is sometimes formulated in terms of being "directed in a way that does not correspond to the object to be cognized" (shes bya dang mi mthun par zhen) and in other places as "mixing up things that are different" (tha dad sre ba). ${ }^{63}$

${ }^{63}$ In his gSal byed (7a6-7), gTsang drug rdo rje distinguishes four different forms of "mixing together/conflating things that are different" (tha dad 1 du bsre ba): (1) temporally conflating (snga spyi 1 du bsre ba), (2) conflating similar types (rigs mthun 1 tu bsre ba), (3) conflating what appears and what is conceived 
Phya pa does not consider this case, $\mathrm{MC}_{3}$, to be essentially different from the case of incorrect determination, $\mathrm{MC}_{2}$. He states that the mistake with respect to the operation of directing $\left(\mathrm{MC}_{3}\right)$ is "just like in the case of a rope being conceived of as a snake." It is worth making a distinction, however, because the mistaken cognition linked here with the operation of directing requires only that the awareness is directed, not that it is a determinate awareness. All conceptual cognitions (except one specific kind of inference), including doubt, are log shes in the form of $\mathrm{MC}_{3}$ with respect to the operation of directing. ${ }^{64}$

On the other hand, the type of mistake associated with conceiving of sound as being permanent, or when conceiving of a rope as being a snake $\left(\mathrm{MC}_{2}\right)$ is only present when the awareness is determinate, and, further, when the determination does not correspond with the object to be cognized (shes bya dang mi mthun par nges) (Mun sel 112.111.2). Phya pa also uses the expression "mistaken determinate awareness" (log par nges $p a$ ) to pick out such cases.

- The difference between $\mathrm{MC}_{2}$ and $\mathrm{MC}_{3}$ becomes clearer when we turn to the operation of exclusion. There, it is only when there is an "affirmation of something that is not the case and denial of something that is the case" (shes bya la mi srid pa bsgrub cing srid pa

(snang brtags 1 tu bsre ba), and (4) conflating word and object (ming don 1 tu $b s r e b a$ ). The form of mixing or conflating relevant in the context of the operation of directing is the third form: conflating what appears (a concept) and what it is conceived to be (a real particular). Cf. also the passage in the 'Od zer ('Od zer 111.222.1.b.322.222.a.1, 26b9), where Phya pa discusses the mistake involved in the operation of directing in the case of inferences [b] and [e1] in these very terms: snang brtags bsre ba'i log shes yin no.

${ }^{64}$ Some later texts, including bsDus pa (23b3-4), sGron ma (6a8), and gSal byed (10b6), offer an alternative category of log shes in place of Phya pa's category of incorrect determinations $\left(\mathrm{MC}_{2}\right)$. This alternative category is described as those instances of log shes that are "erroneous with respect to their intentional objects" (zhen yul la 'khrul ba'i log shes). This latter category is undoubtedly meant to include instances of Phya pa's $\mathrm{MC}_{2}$ - for the illustrations these later texts offer for cognitions within this category are all instances of incorrect determinationbut the wording "with respect to their intentional objects" would appear to apply to Phya pa's $\mathrm{MC}_{3}$ as well. As such, we can think of this category of "log shes that are erroneous with respect to their intentional objects" as picking out the conjunction of Phya pa's $\mathrm{MC}_{2}$ and $\mathrm{MC}_{3}$ —which we can call $\mathrm{MC}_{2 / 3}$. 
'gog $\mathrm{pa}$ ) that the episode of awareness is classified as a $\log$ shesand these cases are precisely those that are $\mathrm{MC}_{2}$.

What stands out in this discussion is a sort of "fascination" with the idea that an episode of awareness can be a log shes from several perspectives, but still qualify as knowledge.

Immediately after enumerating the seven-fold typology of cognitions (Mun sel 122.1), Phya pa then proceeds to show that these seven types of cognitions can be further subdivided into a grand total of twelve different forms of cognition. Among these twelve forms of cognition are two subtypes of $\log$ shes: conceptual $\log$ shes and non-conceptual $\log$ shes. These two subtypes are not, in fact, equivalent to the distinction between $\mathrm{MC}_{1}$ and $\mathrm{MC}_{2}\left(\right.$ or $\left.\mathrm{MC}_{3}\right)$. Instead, it appears that Phya pa is taking the categories of conceptual and non-conceptual log shes to be subclassifications within $\mathrm{MC}_{1}$. In particular, conceptual log shes corresponds to $\mathrm{MC}_{1.1}$ and nonconceptual $\log$ shes corresponds to $\mathrm{MC}_{1.2} .^{65}$

That this is the case can be seen from Phya pa's clarifications of how these two forms of $\log$ shes relate to the other ten forms of cognition in the twelve-fold typology. When discussing the place of conceptual $\log$ shes within the twelve-fold categorization, Phya pa argues that it is mutually compatible with other forms of conceptual cognition, including inferential cognitions. More explicitly, Phya pa believes that a given conceptual cognition can be, at one and the same time, both an instance of inferential knowledge and an instance of conceptual log shes. But since inferential cognitions are, by necessity, determinate cognitions that are correct with regard to their intentional objects, they cannot simultaneously be instances of mistaken determinate cognition (log par nges pa). Instead, what makes a conceptual mistaken cognition compatible with inferential cognition is, as Phya pa tells the reader, simply the fact that it "apprehends a concept" (Mun sel 122.33). This shows that when he is referencing conceptual log shes in this passage, Phya pa is definitely not thinking of mistaken determinate cognition $\left(\mathrm{MC}_{2}\right)$, but is instead referring to conceptual cognitions that apprehend concepts $\left(\mathrm{MC}_{1.1}\right)$.

Phya pa's twelve-fold typology of cognition-within which we find this distinction between conceptual and non-conceptual $\log s h e s-$ is claimed to arise from subsuming the seven-fold typology (Mun sel 122)

${ }^{65}$ The categorical division between conceptual vs. non-conceptual $\log$ shes is largely absent from the presentations given within later texts in this period. The only other text making use of this distinction is the Tshad bsdus (pp. 53 and 61). 
within the earlier three-fold typology of awareness (Mun sel 112). Because that three-fold typology has at its heart the distinction between conceptual cognitions and non-conceptual cognitions, it is not surprising that Phya pa finds it valuable, within that context, to distinguish conceptual vs. non-conceptual log shes. Moreover, because the three-fold typology of cognitions is grounded in differences pertaining just to the apprehended objects (gzung yul) of those cognitions, it is understandable why Phya pa's contrast between conceptual and non-conceptual log shes is to be understood as involving subclassifications within $\mathrm{MC}_{1}$.

Table 3: Summary of the various types of mistaken cognition

\begin{tabular}{|c|c|c|}
\hline $\mathrm{MC}_{1}$ & $\begin{array}{l}\text { Mistaken with respect to the appre- } \\
\text { hended state of affairs }\end{array}$ & \\
\hline $\mathrm{MC}_{1.1}$ & $\begin{array}{l}\text { Mistaken with respect to an appre- } \\
\text { hended concept }\end{array}$ & $\begin{array}{l}\text { Conceptual cognition } \\
\text { "sound" }\end{array}$ \\
\hline $\mathrm{MC}_{1.2}$ & $\begin{array}{l}\text { Mistaken with respect to an appre- } \\
\text { hended referent of a non-concep- } \\
\text { tual erroneous cognition }\end{array}$ & $\begin{array}{l}\text { Cognition of a double } \\
\text { moon }\end{array}$ \\
\hline $\mathrm{MC}_{2 / 3}$ & $\begin{array}{l}\text { Mistaken with respect to the intentional } \\
\text { object }\end{array}$ & \\
\hline $\mathrm{MC}_{2}$ & $\begin{array}{l}\text { Mistake pertaining to the identifica- } \\
\text { tion of the object or its properties- } \\
\text { i.e., a determinate awareness in } \\
\text { which the determination does not } \\
\text { correspond to the object to be cog- } \\
\text { nized }\end{array}$ & $\begin{array}{l}\text { Determining 'sound' } \\
\text { as being permanent }\end{array}$ \\
\hline $\mathrm{MC}_{3}$ & $\begin{array}{l}\text { Mistake pertaining to conceiving of } \\
\text { a concept as a real particular-i.e., } \\
\text { a conceptual awareness that is di- } \\
\text { rected in a way that does not corre- } \\
\text { spond to the object to be cognized, } \\
\text { conflating items that are distinct }\end{array}$ & $\begin{array}{l}\text { Conceiving of the } \\
\text { concept 'sound' as } \\
\text { being a real sound }\end{array}$ \\
\hline
\end{tabular}


Some of Phya pa's successors noted that the application of the term $\log$ shes to such a variety of cases (or more) ${ }^{66}$ was misleading, and consequently also rejected a single definition of $\log$ shes. ${ }^{67}$ This did not bother others who, however, adopted definitions that differed from Phya pa's. ${ }^{68}$ Some authors restricted the notion of $\log$ shes to the type $\mathrm{MC}_{2 / 3}{ }^{69}$

\section{(c) Translation}

Log shes is also translated "false cognition" (van der Kuijp 1978, Dreyfus 1997a, Stoltz 2009), "wrong consciousness" (Rinbochay\&Napper 1980), "erroneous cognition" (van der Kuijp 2009), and "wrong cognition" (Hugon 2014).

The translation "false cognition" is not optimal, as that wording, insofar as it parallels standard uses of "false belief," may wrongly suggest a

${ }^{66}$ In addition to the distinction between a mistake pertaining to the apprehended object and a mistake pertaining to the intentional object, every cognition taking as its object conventional reality (which does not withstand analysis) is also called a "mistaken cognition."

${ }^{67}$ This view is mentioned by gTsang drug rdo rje (cf. 6.4 [ix]) and by Chu mig pa (6.4 [xii]). An interlinear note on the manuscript of the former ascribes this view to "dan," i.e., Phya pa's student Dan bag pa sMra ba'i seng ge. Chos kyi bzhad pa also shared this view (cf. 6.4 [xvii]) and proposes a distinct definition for each of the three cases he distinguishes (which are the same as the ones in the view reported by Chu mig pa) in Tshad nye bsdus 9a7-8.

${ }^{68}$ Only slightly differing from Phya pa's are the definitions don phyin ci log $d u$ bcod pa in the Tshad ma'i spyi skad (3b1), rang yul phyin ci log tu 'dzin pa (as a definition of $\log$ rtogs) in bCom ldan ral gri's Tshad ma rgyan gyi me tog (39), rang yul phyin ci log tu 'dzin pa'i blo in dGe 'dun grub pa's Tshad ma rigs rgyan (433), or rang yul la phyin ci log tu zhugs pa'i rig pa in Yongs 'dzin blo rigs (18a5). Other tendencies of definition involve the notion of "a superimposed object" as in the bsDus pa (6.4 [vii]) and the sGron ma (6.4 [viii]). Others draw on the traditional understanding of "error" and invoke the discrepancy between what exists and what is cognized, as in Chu mig pa's rNam rgyal (6.4 [xiv]) and the Don gnyer mun sel ascribed to Tsong kha pa (6a3: de ma yin pa la der 'dzin pa' $i$ shes pa).

${ }^{69}$ See for instance the definition rang gi zhen yul la 'khrul pa'i rig pa found in the Rwa stod bsdus grwa (482) and Klong rdol ming grangs (13b3), or the definition rang gi 'dzin stangs kyi zhen yul la 'khrul ba'i rig pa in the 'Jam dbyangs bzhad pa'i blo rigs (12b6). 
more restricted application - such as $\mathrm{MC}_{2}$ alone - than is implied by Phya pa's broad use of the term. In order to cover all the various forms of this type of awareness, it is better to employ a more general term such as "mistaken" or "wrong." 


\section{Doubt (the tshom)}

\section{(a) Terminology}

This category of awareness is referred to with the term the tshom (also spelled the tsom) by rNgog Lo and in all subsequent works dealing with the typology of mind. But in the Rigs thigs 'grel ti ka rNgog Lo also uses the term yid gnyis when dealing with the classification of episodes of awareness he ascribes to Dharmottara (cf. Hugon 2014: 234). rNgog Lo indicates that Dharmottara rejects the application of the definition of knowledge to doubt (yid gnyis) in the following passage of the Nyāyabinduțika :

In some cases it (i.e., the object indicated by a cognition other than perception and inference) is not determined as being real or unreal, like the object of doubt (Skt. samśaya, Tib. yid gnyis). And there does not exist in the world an object that is linked with both existence and non-existence. Therefore, such an object cannot be obtained. ${ }^{70}$

In this passage, the Sanskrit samśaya is translated as yid gnyis. Elsewhere in the Nyayabindutīka , both the tshom and yid gnyis are found to translate Sanskrit terms connoting "doubt" (samśaya, áśànka, sandeha, and related forms). The two Tibetan terms are clearly used as synonyms. But yid gnyis appears to be an older translation of Sanskrit terms connoting "doubt" - at least in the translation of Dharmottara's Nyāyabindutīk $\bar{a}^{71}$ — which then gave precedence to the tshom at the time rNgog Lo revised it or through a subsequent revision.

\footnotetext{
${ }^{70} \mathrm{NBT}_{\mathrm{skt}}$ 22,2-3: kaścid aniyato bhāvābhāvayoh / yathā saṃśayārthah / na ca bhāvābhāvābhyām yukto 'rtho jagaty asti / tatah prāptum aśakyas tādriśah /; Tib. P45b4-5: kha cig ni yid gnyis kyi don bzhin du dngos po dang dngos po med pa ma nges pa yin la / dngos po dang dngos po med pa gnyi ga dang ldan pa'i don yang 'gro ba na yod pa ma yin pa de bas na de dang 'dra ba phrad par mi nus so //. The reading in D presents some problems. D38a4-5: kha cig ni yid gnyis kyi don bzhin ni yid gnyis ni don bzhin du dngos po dang dngos po med pa ma nges pa yin la / dngos po dang dngos po med pa gnyi ga'i don dang ldan pa'i 'gro ba yang yod pa ma yin la de bas na de dang 'dra ba phrad par mi nus so. See Hugon 2014: 218-220.

${ }^{71}$ In contrast, the expression yid gnyis never occurs in the Tibetan translation of Vinītadeva's Nyāyabinduțīka by Jinamitra and Ye shes sde that dates from c. 800 .
} 
In the canonical Tibetan translation one can find 71 occurrences of the tshom za ba and 22 of the tshom, while yid gnyis za ba occurs twice and yid gnyis thrice.

- In two cases, yid gnyis, resp. yid gnyis za ba, occurs together with the tshom za ba in the same sentence. This is clearly meant to avoid repeating the same Tibetan term when the sentence has two different Sanskrit words or two different forms of the same verb connoting doubt. $^{72}$

- In two cases, the two translations appear in the same sentence or connected sentences for the very same Sanskrit expression. ${ }^{73}$ In one such

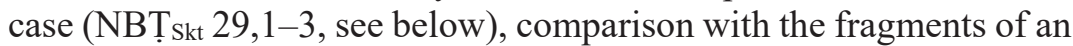
earlier translation of the Nyāyabinduțik $\bar{a}$ by Dharmāloka found in Tabo monastery demonstrates a process of revision at play. ${ }^{74}$ Indeed, Dharmāloka's translation twice uses yid gnyis to translate the Sanskrit sāśank $\bar{a}$ in the same passage, whereas the canonical translation has the tshom for the first occurrence and yid gnyis for the second.

Sanskrit:

(a) yatraiva hi prekșāvanto 'rthinah sāsáaìkāh / tat parīkṣyate

(b) tena tatra na sāśànkä arthinah / atas tan na prīkșanīyam 75

${ }^{72} \mathrm{NBT}_{\mathrm{Skt}}$ 193,1: tasyāśrayanasya sandehe sandigdhah; Tib. D74a1 (= P89b8): gzhi de la the tshom za ba ni yid gnyis za ba'o //. NBT Țt 214,14: anvayavyatirekarūpayoh sandehāt samśayahetuh /; Tib. D80b3-4 (= P98a6-7): rjes su 'gro ba dang ldog pa'i tshul de nyid la the tshom za ba'i phyir yid gnyis kyi rgyu yin no // ${ }^{73}$ One case is NBṬ skt 195,5-6: api tu tadviparìtah samisayah / sādhyaitarayoh samíayahetur anaikāntika uktah //; Tib. P90b8: 'on kyang phyin ci log tu the tshom za ba yin te / bsgrub par bya ba dang cig shos la yid gnyis za ba'i gtan tshigs ni ma nges pa zhes bstan to //. The Tibetan text in D is faulty. D74b5: 'on kyang phyin ci log tu the tshom za ba yin te / nges pa ni gcig kho nar cig shos pa yid gnyis za ba'i gtan tshigs ni ma nges pa zhes bstan to /l. Nges pa ni gcig kho nar appears to be a dittography of the translation of eko 'nta ekänto in the preceding sentence.

${ }^{74}$ This comparison was made possible thanks to Horst Lasic generously providing access to his transcription of this material. See Lasic 2006 for a discussion of the earlier translation and its revision by rNgog Lo.

${ }^{75}$ Translation: "Indeed, intelligent people looking for some result examine only that with regard to which they have a doubt. [...] Thus, those looking for some result do not have doubt with regard to it. Therefore, it does not have to be examined (by them)." 
Dharmāloka's translation:

(a) rtog pa dang ldan pa rnams / gang 'dod pa de yid gnyis su gyurd na / de brtag par bya ba yin no /

(b) des na don 'dod pa'i rnams de la yid gnyis myed do / de'i phyir de brtag par bya ba ma yin no //

Citation in rNgog Lo's Rigs thigs 'grel ti ka:

(b) don du gnyer ba rnams yid gnyis myed pa de'i phyir de brtag par bya ba ma yin no //

Canonical translation $(\mathrm{D} 39 \mathrm{a} 1-2=\mathrm{P} 46 \mathrm{~b} 3-4)$ :

(a) rtog pa dang ldan pa rnams gang la don du gnyer ba rtog pa dang ldan pa the tshom za ba de nyid ni brtag par bya ba yin no //

(b) des na de la don du gnyer ba rnams yid gnyis med de / de'i phyir de brtag par bya ba ma yin no //

This could suggest that rNgog Lo ordered a modification of the translation of sáśànka , which was carried out in (a), but not for the second occurrence in (b). This may have been due to the lack of diligence or intelligence of the copyist in charge of including rNgog Lo's revisions into the text, which, as cogently argued by Lasic (2006), stands out in a number of passages. Indeed, a number of other passages in which the same Sanskrit word for "doubt" occurs twice also have the tshom twice in the translation.

Against the hypothesis of a sloppy copyist regarding this passage, one may note that in rNgog Lo's citation of the second passage (b) in his Rigs thigs 'grel ti ka-which at best testifies to his own translation - the translation of the Sanskrit arthinah has been changed from don 'dod pa'i rnams to don du gnyer ba rnams, but yid gnyis is preserved for sāśank $\bar{a} h$. Thus the copyist may have correctly understood rNgog Lo's indications for the revision as implying a modification of the first occurrence of yid gnyis only. Further counter-evidence would lie in the fact that rNgog Lo's paraphrase of Dharmottara's explanation on this point in the $d K a^{\prime}$ gnas also uses the term yid gnyis - this is the only occurrence of the term in the whole $d K a^{\prime}$ gnas. ${ }^{76}$

\footnotetext{
${ }^{76}$ dKa' gnas 18,2-10: dang po ni slob dpon chos mchog na re /... dang po ni dpyad bya ma yin te /... rtog pa dang ldan pa blang bya nyid du nges pas yid gnyis myed pa'i phyir bstan chos su yang de dpyad par bya ba ma yin no //
} 
Unfortunately, the Tabo fragments do not contain any other occurrences of the tshom or yid gnyis. And the citations of the Nyayabindu$\underline{t} \bar{k} \bar{a}$ by rNgog Lo in his Rigs thigs 'grel ți ka count only one other occurrence of the tshom, where the canonical translation reads the

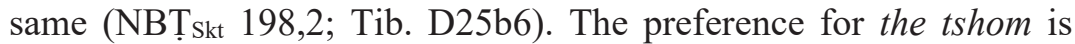
clear in rNgog Lo's translation of the Pramannaviniścaya and the Pramānaviniścayați $k \bar{a}$ (at least as it is attested in the canon), in which the term yid gnyis is never used in this sense. ${ }^{77}$

- The fifth occurrence of yid gnyis in the canonical translation of the Nyāyabinduți $\bar{a} \bar{a}$ is attested for samiśaya in the very passage that $\mathrm{rNgog}$ Lo identifies in his Rigs thigs 'grel ti $\mathrm{ka}$ as the place where Dharmottara discusses the category of doubt (see above NBT skt $_{22,2-3}$; Skt. and Tib. in n. 70). rNgog Lo only cites the beginning of this passage (i.e., kha cig ni) as marker, but the fact that he uses the term yid gnyis to refer to doubt in this context strongly suggests that his translation of this passage also read yid gnyis.

Apart from this passage, rNgog Lo uses the tshom wherever else he is talking about doubt in the Rigs thigs 'grel ti ka. In particular, when he presents his own classification of awareness - which differs from the one he ascribes to Dharmottara-rNgog Lo uses the term the tshom for the category of doubt.

In view of the above remarks, one can tentatively suggest the following scenario: rNgog Lo relied on Dharmāloka's translation when studying the Nyāyabinduți $k \bar{a}$. In this translation, in the passage which rNgog Lo identi-

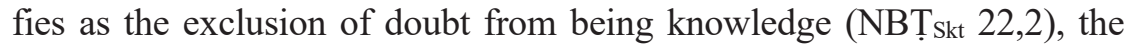
term yid gnyis translates samśaya. rNgog Lo thus initially calls yid gnyis the category of awareness consisting in doubt. But he is already in the process of revising the translation of the Nyāyabindutīk $\bar{a}$, changing yid gnyis to the tshom, and using the latter in his own explanations. He does not, however, change this translation in at least two cases (the reason for this remains obscure).

His translation of the Pramānaviniścaya and ${ }^{\circ} t \bar{k} k \bar{a}$ and the composition of the $d K a^{\prime}$ gnas occur subsequently. Yid gnyis is not used anymore to translate Sanskrit expressions connoting doubt, and the tshom is also used by rNgog Lo in his discussions. Even when paraphrasing Dharmottara's

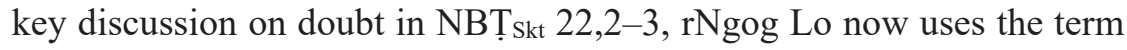

${ }^{77}$ In PVinṬ 3 one finds the expression yid gnyis su gyur (D29b5) for tulārụ̈̆ha (27b4). 
the tshom rather than yid gnyis (although the latter is included in the canonical translation of this passage of the Nyāyabinduți kāa). But a vestige of the use of yid gnyis nevertheless remains in his paraphrase of another view of Dharmottara, the source of which is one passage of the Nyayabinduțīka in which rNgog Lo retained Dharmāloka's translation yid gnyis.

\section{(b) Understanding of the category}

In the Mun sel, the debates around the category of "doubt" pertain to its having, or not, the operation of exclusion (see Mun sel 123.5 [a] and [b]). The former position would follow from the idea that the operation of exclusion is correlated with the operation of directing one's mind (zhen pa), which doubt has. The latter view, on the other hand, ties the operation of exclusion with the criterion of being determinate (nges pa), which doubt is not. Those who deny that doubt has the operation of exclusion argue that doubt does not exclude the incorrect option non-x (in the way that episodes of determinate awareness that correctly determine do) and also does not exclude the correct option $x$ (in the way episodes of determinate awareness that incorrectly determine do).

The latter view was held by rNgog Lo and, reportedly, by rGya dmar ba as well. ${ }^{78}$ In his $d K a^{\prime}$ gnas and his concise guide, rNgog Lo asserts that doubt neither ascertains positively nor negatively. ${ }^{79}$ More precisely, because it does not ascertain negatively-this implies that it does not exclude anything - it cannot ascertain positively. According to rNgog Lo, doubt thus fails to be an episode of knowledge because it lacks the "positive ascertainment" (which implies a conceptual determination) that rNgog Lo takes to be a criterion for knowledge. ${ }^{80}$ Some students of Phya pa such as Dan bag pa reportedly also adopted the view that doubt does not have the function of exclusion. ${ }^{81}$

\footnotetext{
${ }^{78}$ Tshad bsdus 60,7-9: rgya na re the tshom la gzhan sel med de the tshom gyis gang yang yongs su ma bcad par gang yang rnam par mi chod pas so //

${ }^{79}$ rNgog Lo criticizes what he understands to be Dharmottara's position, that doubt ascertains an object that is both $x$ and non-x. Since no such object exists in reality, doubt amounts, according to Dharmottara, to a mistaken cognition.

${ }^{80}$ See Hugon 2014: 214 and 220.

${ }^{81} \mathrm{Cf}$. gTsang drug rdo rje's gSal byed $8 \mathrm{~b} 3:<$ dan $>$ kha 1 na re the tshom la gzhan sel med gzhan sel yod na nges par thal rtog pa 'ang nges par 'jog pa gzhan sel gyis 'jog pa'i phyir zhes zer ba. The insertion "dan" refers to Dan bag pa.
} 
Phya pa defends the former view, that doubt has the operation of exclusion, but accepts that neither $x$ nor non- $x$ is excluded. What, then, is excluded? According to Phya pa, the operation of conceiving of the intentional object as possible excludes conceiving of it as impossible. ${ }^{82}$ Phya pa accepts that the operation of exclusion, which amounts to a "negative ascertainment," implies "positive ascertainment" (for rnam par gcod pa and yongs su gcod pa are coextensive), and thus that these both apply in the case of doubt. Simply, these two sides of ascertainment do not pertain to $x$ (or to non-x), they pertain to the possibility of $x$ (respectively, the possibility of $n o n-x){ }^{83}$

Although doubt thus has the operation of exclusion, since this exclusion pertains to the "possibility" only, it does not correspond to the "elimination of opposite superimposition" that is a requirement for knowledge. Doubt is compatible with the opposite superimposition (non-x, provided that $x$ is the correct option) precisely because the possibility of this option non- $x$ is preserved, given the definition of doubt as "that which includes the consideration of another alternative being possible."

Phya pa does not refute any alternative definitions of doubt. But according to the Tshad bsdus $(59,20-60,1)$, Phya pa's definition was also held by "Zhang tshes" (presumably, Zhang tshes spong Chos kyi bla ma, who had been Phya pa's ordination abbot and one of his teachers) (cf. 6.5 [iii]) and was different from the definition by "rGya" (rGya dmar ba), "engaging via an awareness that has a double-pointed aspect" (6.5 [iv]). This latter definition will be adopted by Phya pa's student gTsang nag pa (6.5 [v]) and reportedly by Dan bag pa, another of Phya pa's foremost disciples (6.5 [vii]).

Since Phya pa does not engage in a refutation of this definition, it is possible that he did not consider it as essentially different from his own. Phya pa's example of doubt in the form "Is this permanent or impermanent" spells out a "double-pointed awareness" in which two contradictory options $x$ and non- $x$ are both held to be possible. Still, Phya pa sometimes

${ }^{82}$ Mun sel 121.12: "For episodes of doubt, directing one's mind toward its (i.e., the intentional object's) possibility excludes its impossibility."

${ }^{83}$ This would be like saying that doubt is not a determinate awareness with regard to its intentional object but is a determinate awareness with regard to the possibility of its intentional object. In the parallel passage of the 'Od zer (29a4-5), Phya pa more mildly expresses the requirement of "excluding conceiving as non$x$ " for "conceiving as $x$," which applies in the same way to $x=$ "blue" and to $x=$ "possible." 
exemplifies an episode of doubt by mentioning only one possible option, e.g." "the demon could exist in reality." ${ }^{84}$ This could suggest that he considered that, in an episode of doubt, the directing of the mind is toward one of the two options, without however being partial to this option in such a way that the other option is no longer held possible. This interpretation would correspond to the definition of doubt held by Sa pan: "Although one takes it to be $x$, being non- $x$ is possible." ${ }^{, 85}$

\section{(c) Translation}

"Doubt" is a standard translation for the tshom. An alternative translation found in modern literature is "doubting consciousness" (Rinbochay\&Napper 1980).

${ }^{84}$ See Mun sel 121.112: "Conceiving of the existence of a demon as possible excludes conceiving of the existence of a demon as impossible." See also Mun sel 123.53: "Doubt excludes the impossibility of sound being permanent."

${ }^{85}$ Rigs gter II 71,2: der 'dzin na yang de min srid //. In this definition, Sa pan's intention is surely not to imply that, from an ontological perspective, the option 'it is non- $x$ ' is possibly true/correct. That is, his definition is not to be read as the conjunction of (a) it is possibly true that it is non-x, but (b) the cognizer takes it to be $x$. Such a reading of Sa pan's definition would wrongly entail that any contingently correct, non-doubting cognition would be an instance of doubt.

Instead, what Sa pan likely has in mind is that $\left(\mathrm{b}^{*}\right)$ the cognizer takes something to be $x$, and yet also ( $\mathrm{a}^{*}$ ) the cognizer takes it to be possible that it is non$x$. In this way, the person's mind is directed toward one particular option $(x)$, but the other option (non-x) is still held to be possible. In other words, the invocation "being non- $x$ is possible" is to be treated as indicating an epistemic possibility as opposed to an ontological possibility. This reading is confirmed by Sa pan's later remark that "...when one thinks 'it is possibly a true state of affairs' or 'it is possibly a false state of affairs,' the awareness is an instance of doubt" (Rigs gter II 71,11: ...blo ni don bden yang rung brdzun yang rung brtags na the tshom yin no //). 



\section{Definitions}

Provided below are the definitions of the five types of cognition that are not episodes of knowledge found in Phya pa's Mun sel and 'Od zer, the definitions criticized by Phya pa, as well as definitions found in a selection of other epistemological works (definitions by the authors of these works, or definitions of other scholars that they discuss). Those testify to the evolution of these notions within the Tibetan tradition, and should be helpful for assessing the place of additional material.

The definitions in the tables below follow the chronological order of the works they appear in (that order is in part tentative). Definitions cited by the respective authors are listed before the author's own definition. When the author of the work referred to in the last column is not the proponent of the given definition, the identification of the proponent provided in the text appears in quotation marks (e.g., "kha cig," "Phya pa"). A question mark indicates that the definition is discussed without being introduced as someone's position. Identifications provided in marginal notes appear within pointed brackets.

Definitions are grouped into categories (A, B...) based on the definitional criteria they mention, regardless of the literal formulation of these criteria, unless the latter grounds the rejection of a definition in favor of another. Potentially relevant differences in formulation are noted in parentheses.

\subsection{Non-ascertaining perception (snang la ma nges pa)}

\section{Groups of definitions}

A - i, ix, xi, xv, xviii: Appearing; not bringing about a determining cognition

B - ii, xiv: Appearing (ii: appearing particular); coexisting with a superimposition

C - vii, xii: Appearing; compatibility with superimpositions

D - iii, iv, v, vi viii, x, xiii, xvi, xvii, xix: Appearing particular; compatibility with superimpositions (x: non-elimination of superimpositions) 


\begin{tabular}{|c|c|c|c|c|}
\hline $\mathrm{i}$ & A & "kha cig" & nges shes mi 'dren zhing snang pa & $\begin{array}{l}\text { Mun sel } \\
123.1 \text { (a) }\end{array}$ \\
\hline ii & $\mathrm{B}$ & "kha cig" & $\begin{array}{l}\text { don rang gi mtshan nyid snang zhing } \\
\text { sgro 'dogs dang lhan cig pa }\end{array}$ & $\begin{array}{l}\text { Mun sel } \\
123.1 \text { (a) }\end{array}$ \\
\hline iii & $\mathrm{D}$ & Phya pa & $\begin{array}{l}\text { don rang gi mtshan nyid snang pa } \\
\text { dang bzlog pa'i sgro 'dogs dang mi } \\
\text { 'gal ba }\end{array}$ & $\begin{array}{l}\text { Mun sel } \\
123.12\end{array}$ \\
\hline iv & $\mathrm{D}$ & Phya pa & $\begin{array}{l}\text { don rang gi mtshan nyid snang yang } \\
\text { bzlog pa'i sgro 'dogs dang myi 'gal } \\
\text { ba }\end{array}$ & $\begin{array}{l}\text { 'Odzer } \\
111.222 .1 . b . \\
11,24 \mathrm{~b} 1\end{array}$ \\
\hline $\mathrm{v}$ & $\mathrm{D}$ & Phya pa & $\begin{array}{l}\text { sgro 'dogs dang myi 'gal zhing don } \\
\text { rang gi mtshan nyid snang pa }\end{array}$ & $\begin{array}{l}\text { 'Odzer } \\
33 \mathrm{~b} 5-6\end{array}$ \\
\hline vi & $\mathrm{D}$ & Phya pa & $\begin{array}{l}\text { sgro 'dogs dang myi 'gal ba'i rang gi } \\
\text { mtshan nyid snang pa }\end{array}$ & $\begin{array}{l}\text { 'Odzer } \\
33 \mathrm{~b} 8\end{array}$ \\
\hline vii & $\mathrm{C}$ & "rGya" & $\begin{array}{l}\text { sgro 'dogs dang mi 'gal ba'i snang } \\
\text { ba yin }\end{array}$ & $\begin{array}{l}\text { Tshad bsdus } \\
54,18-19\end{array}$ \\
\hline viii & $\mathrm{D}$ & $\begin{array}{l}\text { (author un- } \\
\text { known) }\end{array}$ & $\begin{array}{l}\text { bzlog pa'i sgro 'dogs dang mi 'gal } \\
\text { zhing don rang gi mtshan nyid snang } \\
\text { ba }\end{array}$ & $\begin{array}{l}\text { Tshad bsdus } \\
54,15-16\end{array}$ \\
\hline ix & A & "kha cig" & snang yang nges pa 'dren mi nus pa & $\begin{array}{l}\text { bsDuspa } \\
22 \mathrm{~b} 7\end{array}$ \\
\hline $\mathrm{x}$ & $\mathrm{D}$ & gTsang nag pa & $\begin{array}{l}\text { rang gi mtshan nyid snang yang sgro } \\
\text { 'dogs mi sel pa }\end{array}$ & $\begin{array}{l}\text { bsDuspa } \\
\text { 22b8 }\end{array}$ \\
\hline xi & A & $\begin{array}{l}\text { "kha cig"" } \\
<(\text { rtag pa)? }\end{array}$ & $\begin{array}{l}\text { snang pa'i don la nges shes 'dren mi } \\
\text { nus pa yin }\end{array}$ & $\begin{array}{l}\text { sGron ma } \\
5 \mathrm{~b} 3-4\end{array}$ \\
\hline xii & $\mathrm{C}$ & $\begin{array}{l}\text { "kha cig" } \\
<\text { phya rgya }>\end{array}$ & $\begin{array}{l}\text { sgro 'dogs dang mi 'gal ba'i snang } \\
\text { pa yin }\end{array}$ & $\begin{array}{l}\text { sGron ma } \\
5 \mathrm{~b} 4\end{array}$ \\
\hline xiii & D & mTshur ston & $\begin{array}{l}\text { rang gi mtshan nyid snang pa'i don } \\
\text { la sgro 'dogs dang mi 'gal ba }\end{array}$ & $\begin{array}{l}\text { sGron ma } \\
5 \mathrm{~b} 5\end{array}$ \\
\hline xiv & $\mathrm{B}$ & "kha cig" & $\begin{array}{l}\text { sgro 'dogs dang lhan cig (em. lhan } \\
\text { cig : Ms lhan) pa'i snang ba }\end{array}$ & $\begin{array}{l}\text { gSal byed } \\
9 \mathrm{~b} 4\end{array}$ \\
\hline $\mathrm{xV}$ & A & $\begin{array}{l}\text { "ti ka byed } \\
\text { kha } 1 \text { "<chos> }\end{array}$ & $\begin{array}{l}\text { nges shes 'dren mi nus pa'i snang ba } \\
1 \text { yin }\end{array}$ & $\begin{array}{l}\text { gSal byed } \\
9 \mathrm{~b} 6\end{array}$ \\
\hline xvi & $\mathrm{D}$ & gTsang drug & $\begin{array}{l}\text { don rang gi mtshan nyid snang zhing } \\
\text { sgro 'dogs dang mi 'gal bar 'jug pa } \\
\text { yin }\end{array}$ & $\begin{array}{l}\text { gSal byed } \\
9 \mathrm{~b} 7\end{array}$ \\
\hline xvii & $\mathrm{D}$ & "kha cig" & $\begin{array}{l}\text { don rang gi mtshan nyid snang zhing } \\
\text { sgro 'dogs dang mi 'gal bar 'jug pa } \\
\text { yin }\end{array}$ & $\begin{array}{l}\text { rNam rgyal } \\
\text { A8b9; } \\
\text { B11a3-4 }\end{array}$ \\
\hline
\end{tabular}




\begin{tabular}{|l|l|l|l|l|}
\hline xviii & A & Chu mig pa & $\begin{array}{l}\text { 'dzin pa gang zhig snang yul la nges } \\
\text { shes mi 'dren pa }\end{array}$ & $\begin{array}{l}\text { rNam rgyal } \\
\text { A9a3; } \\
\text { B11a8 }\end{array}$ \\
\hline xix & D & $\begin{array}{l}\text { rDo rje dbang } \\
\text { grags/ } \\
\text { Chos kyi } \\
\text { bzhad pa }\end{array}$ & $\begin{array}{l}\text { don rang mtshan snang zhing sgro } \\
\text { 'dogs dang mi 'gal ba (zhes bzhed) }\end{array}$ & $\begin{array}{l}\text { Tshad nye } \\
\text { bsdus 8b2 }\end{array}$ \\
\hline
\end{tabular}

\subsection{Post-knowledge cognition (bcad pa'i yul can)}

\section{Terms used for the category}

- bcad pa'i yul can: i-ix,

- bcad shes: $\mathrm{x}, \mathrm{xi}, \mathrm{xii}-\mathrm{xiii}$ (ms. A), xiv-xv (ms. A)

- spyad shes: xii (ms. B)

- dpyad shes: xiii (ms. B), xv (ms. B)

- bcad pa yul can: xvi, xvii

\section{Groups of definitions}

A - i, ii, iii: Superimpositions already eliminated; incompatibility with engaging in the opposite way (iii: incompatibility with opposite superimpositions)

B - iv: Superimpositions already eliminated; subsequent apprehension

C - v, vii, $x$, xii: Object already understood

D - viii, xvi: Object already understood by an episode of knowledge

E - xiii: Previous understanding of the object; incompatibility with superimpositions

F - vi, ix, xi, xiv: Unimpaired previous understanding (vi: unimpaired understanding; xi: unimpaired aggregates of previous elimination of superimposition); incompatibility with superimpositions

$\mathrm{G}-\mathrm{xv}$, xvii: Unimpaired previous understanding by an (xvii: one's own) episode of knowledge; incompatibility with superimpositions 


\begin{tabular}{|c|c|c|c|c|}
\hline $\mathrm{i}$ & $\mathrm{A}$ & Phya pa & $\begin{array}{l}\text { sgro 'dogs chod zin pa'i don la bzlog } \\
\text { pa'i zhen pa dang 'gal ba'i blo 'jug } \\
\text { pa }\end{array}$ & $\begin{array}{l}\text { Mun sel } \\
123.22\end{array}$ \\
\hline ii & $\mathrm{A}$ & Phya pa & $\begin{array}{l}\text { sgro 'dogs chod zin pa'i don la bzlog } \\
\text { pa'i zhen pa dang 'gal bas 'jug pa }\end{array}$ & $\begin{array}{l}\text { 'Odzer } \\
111.222 .1 . b \\
121,24 \mathrm{~b} 2 \\
\text { and } \\
\text { 111.222.32, } \\
\text { 29a1 }\end{array}$ \\
\hline iii & $\mathrm{A}$ & "Phya pa" & $\begin{array}{l}\text { tshad mas sngar sgro 'dogs chod pa'i } \\
\text { don la bzlog pa'i sgro 'dogs dang } \\
\text { 'gal bas 'jug pa }\end{array}$ & $\begin{array}{l}\text { Tshad bsdus } \\
56,2-3\end{array}$ \\
\hline iv & $\mathrm{B}$ & $?$ & $\begin{array}{l}\text { tshad mas sngar sgro 'dogs chod zin } \\
\text { pa'i don la phyis yang bltab nas } \\
\text { 'dzin pa yin }\end{array}$ & $\begin{array}{l}\text { Tshad bsdus } \\
55,21-56,1\end{array}$ \\
\hline $\mathrm{V}$ & $\mathrm{C}$ & $?$ & sngar rtogs zin la 'jug pa tsam & $\begin{array}{l}\text { bsDus pa } \\
23 \mathrm{a3}-4\end{array}$ \\
\hline vi & $\mathrm{F}$ & gTsang nag pa & $\begin{array}{l}\text { rtogs pa'i byed pa ma nyams pa'i } \\
\text { don la sgro 'dogs dang 'gal bar 'jug } \\
\text { pa }\end{array}$ & $\begin{array}{l}\text { bsDus pa } \\
23 \mathrm{a} 4\end{array}$ \\
\hline vii & $\mathrm{C}$ & $?$ & sngar rtogs zin la 'jug pa tsam & $\begin{array}{l}\text { sGron ma } \\
\text { 6al }\end{array}$ \\
\hline viii & $\mathrm{D}$ & "kha cig" & $\begin{array}{l}\text { tshad mas sngar rtogs zin pa'i don la } \\
\text { yang 'jug pa yin }\end{array}$ & $\begin{array}{l}\text { sGron ma } \\
5 \mathrm{~b} 9\end{array}$ \\
\hline ix & $\mathrm{F}$ & mTshur ston & $\begin{array}{l}\text { sngar rtogs pa'i byed pa ma nyams } \\
\text { pa'i don la sgro 'dogs dang 'gal bar } \\
\text { 'jug pa }\end{array}$ & $\begin{array}{l}\text { sGron ma } \\
\text { 6al }\end{array}$ \\
\hline $\mathrm{x}$ & $\mathrm{C}$ & "kha cig" & sngar rtogs zin la 'jug pa & $\begin{array}{l}\text { gSal byed } \\
\text { 10a4 }\end{array}$ \\
\hline $\mathrm{xi}$ & $\mathrm{F}$ & gTsang drug & $\begin{array}{l}\text { sngar sgro 'dogs chod zin gyi 'du } \\
\text { byed ma nyams pa'i don la sgro } \\
\text { 'dogs dang 'gal bar'jug pa }\end{array}$ & $\begin{array}{l}\text { gSal byed } \\
10 \mathrm{a} 4-5\end{array}$ \\
\hline xii & $\mathrm{C}$ & "kha cig" & sngar rtogs zin gyi don la 'jug pa & $\begin{array}{l}\text { rNam rgyal } \\
\text { A9a7; } \\
\text { B11b4 }\end{array}$ \\
\hline xiii & $\mathrm{E}$ & "kha cig" & $\begin{array}{l}\text { sngar rtogs zin gyi don la sgro 'dogs } \\
\text { dang 'gal bar 'jug pa }\end{array}$ & $\begin{array}{l}\text { rNam rgyal } \\
\text { A9a8; } \\
\text { B11b5 }\end{array}$ \\
\hline
\end{tabular}




\begin{tabular}{|l|l|l|l|l|}
\hline xiv & F & 'kha cig" & $\begin{array}{l}\text { sngar rtogs kyi byed pa ma nyams } \\
\text { pa'i don la sgro 'dogs dang 'gal bar } \\
\text { 'jug pa }\end{array}$ & $\begin{array}{l}\text { rNam rgyal } \\
\text { A9a9 (not } \\
\text { found in B) }\end{array}$ \\
\hline xv & G & Chu mig pa & $\begin{array}{l}\text { rang gi tshad mas sngar rtogs kyi } \\
\text { byed pa ma nyams pa'i don la sgro } \\
\text { 'dogs dang 'gal bar 'jug pa }\end{array}$ & $\begin{array}{l}\text { rNam rgyal } \\
\text { A9a-b1; } \\
\text { B11b6 }\end{array}$ \\
\hline xvi & D & $?$ & $\begin{array}{l}\text { tshad mas sngar rtogs zin gyi don la } \\
\text { 'jug pa }\end{array}$ & $\begin{array}{l}\text { Tshad nye } \\
\text { bsdus 8b4 }\end{array}$ \\
\hline xvii & G & $\begin{array}{l}\text { rDo rje dbang } \\
\text { grags/Chos } \\
\text { kyi bzhad pa }\end{array}$ & $\begin{array}{l}\text { rang gis tshad mas sngar rtogs kyi } \\
\text { byed pa ma nyams pa'i don la sgro } \\
\text { 'dogs dang 'gal bar 'jug pa }\end{array}$ & $\begin{array}{l}\text { Tshad nye } \\
\text { bsdus 8b4 }\end{array}$ \\
\hline
\end{tabular}

\subsection{Factive assessment (yid dpyod)}

\section{Terms used for the category}

- yid dpyod: i-ix, xiii-xv

- yid spyod: xi, xii

\section{Groups of definitions}

A - i, iv, vi, viii, xi: Not based on experience or evidence; determinate (i: engaging while being partial; xi: determining while being partial)

B - ix, xiii: Not based on experience or evidence; determinate (xiii: determining while being partial); having a veridical object

$\mathrm{C}-\mathrm{v}$, xii: Not based on experience or evidence; determinate; having a veridical object; novel

D - vii: Not based on experience or evidence; determinate; novel

E - ii: Not based on evidence; determinate; having a veridical object; novel

F - iii, x, xv: Not based on evidence; determinate; having a veridical object (x, xv: corresponding to reality); novel; having a concealed object

$\mathrm{G}$ - xiv: Compatible with superimpositions; determining while being partial; having a veridical object 


\begin{tabular}{|c|c|c|c|c|}
\hline $\mathrm{i}$ & A & "kha cig" & $\begin{array}{l}\text { myong pa dang rtags la ma rten par } \\
\text { don phyogs cig du zhen pa }\end{array}$ & $\begin{array}{l}\text { Mun sel } \\
123.322\end{array}$ \\
\hline ii & $E$ & Phya pa & $\begin{array}{l}\text { sngar ma rtogs pa'i don bden pa } \\
\text { rtags tshad mas nges pa la ma brten } \\
\text { par nges pa }\end{array}$ & $\begin{array}{l}\text { Mun sel } \\
123.321\end{array}$ \\
\hline iii & $\mathrm{F}$ & Phya pa & $\begin{array}{l}\text { lkog gyur bden pa rtags kyi rjes su } \\
\text { ma 'brangs par gsar du nges pa }\end{array}$ & $\begin{array}{l}\text { 'Odzer } \\
111.222 .34 \\
29 \mathrm{a} 5\end{array}$ \\
\hline iv & $\mathrm{A}$ & "rGya" & $\begin{array}{l}\text { myong ba dang rtags (em. rtags : } \\
\text { rtag) la ma brten par don nges tsam } \\
\text { yin }\end{array}$ & $\begin{array}{l}\text { Tshad bsdus } \\
57,7-8\end{array}$ \\
\hline $\mathrm{V}$ & $\mathrm{C}$ & $\begin{array}{l}\text { (author un- } \\
\text { known) }\end{array}$ & $\begin{array}{l}\text { myong ba dang rtags la ma brten } \\
\text { par don bden pa gsar du nges pa }\end{array}$ & $\begin{array}{l}\text { Tshad bsdus } \\
58,1-2\end{array}$ \\
\hline vi & $\mathrm{A}$ & $?$ & $\begin{array}{l}\text { myong pa dang rtags la ma rten par } \\
\text { nges pa tsam }\end{array}$ & $\begin{array}{l}\text { bsDus pa } \\
23 \mathrm{a} 6\end{array}$ \\
\hline vii & $\mathrm{D}$ & gTsang nag pa & $\begin{array}{l}\text { rtags dang myong pa myed par } \\
\text { sngar ma rtogs pa'i don nges pa }\end{array}$ & $\begin{array}{l}\text { bsDuspa } \\
23 \mathrm{a} 6\end{array}$ \\
\hline viii & $\mathrm{A}$ & "kha cig" & $\begin{array}{l}\text { myong pa dang rtags la ma brten } \\
\text { par don nges tsam yin }\end{array}$ & $\begin{array}{l}\text { sGron ma } \\
6 \mathrm{a} 3\end{array}$ \\
\hline ix & B & "kha cig" & $\begin{array}{l}\text { myong ba }<\text { dang }>\text { rtags la ma brten } \\
\text { par don bden pa }\{\text { gsar } d u\}^{86} \text { nges pa } \\
\text { yin }\end{array}$ & $\begin{array}{l}\text { sGron ma } \\
6 \mathrm{a} 4 \text { (mar- } \\
\text { ginal note) }\end{array}$ \\
\hline $\mathrm{x}$ & $\mathrm{F}$ & mTshur ston & $\begin{array}{l}\text { rtags kyi rgyu mtshan la ma brten } \\
\text { par sngar ma rtogs pa'i rkog gyur la } \\
\text { don dang mthun par nges pa }\end{array}$ & $\begin{array}{l}\text { sGron ma } \\
6 \mathrm{a} 4\end{array}$ \\
\hline xi & $\mathrm{A}$ & $\begin{array}{l}\text { "gzhan dag" } \\
<\text { rgya }>\end{array}$ & $\begin{array}{l}\text { myong ba dang rtags la ma brten } \\
\text { par don mtha' } 1 \text { tu nges pa }\end{array}$ & $\begin{array}{l}\text { gSal byed } \\
10 \mathrm{a} 6-7\end{array}$ \\
\hline xii & $\mathrm{C}$ & gTsang drug & $\begin{array}{l}\text { myong ba dang rtags la ma rten par } \\
\text { sngar ma rtogs pa'i don bden pa } \\
\text { nges pa }\end{array}$ & $\begin{array}{l}\text { gSal byed } \\
10 \mathrm{a} 7\end{array}$ \\
\hline xiii & B & "kha cig" & $\begin{array}{l}\text { myong ba (A ba, B pa) dang rtags } \\
\text { la ma rten (A rten, B brten) par don } \\
\text { bden pa mtha' } 1 \text { du nges pa (A pa, } \\
\mathrm{B}<\text { pa }>\text { ) yin }\end{array}$ & $\begin{array}{l}\text { rNam rgyal } \\
\text { A9b5-6; } \\
\text { B12a2 }\end{array}$ \\
\hline
\end{tabular}

${ }^{86}$ This expression is circled with a dotted line on the manuscript, probably indicating that it must be deleted. Indeed, the argument against this definition is that it would apply to conceptual post-knowledge cognition (which the mention of "novelty" would prevent). 


\begin{tabular}{|l|l|l|l|l|}
\hline xiv & G & Chu mig pa & $\begin{array}{l}\text { sgro 'dogs dang mi 'gal zhing don } \\
\text { bden pa mtha' cig (B cig, A 1) du } \\
\text { nges pa }\end{array}$ & $\begin{array}{l}\text { rNam rgyal } \\
\text { A9b6-7; } \\
\text { B12a3-4 }\end{array}$ \\
\hline xv & F & $\begin{array}{l}\text { rDo rje dbang } \\
\text { grags/ } \\
\text { Chos kyi } \\
\text { bzhad pa }\end{array}$ & $\begin{array}{l}\text { rtags kyi rgyu mtshan la ma brten } \\
\text { par sngar ma rtogs pa'i lkog gyur } \\
\text { don dang mthun par nges pa }\end{array}$ & $\begin{array}{l}\text { Tshad nye } \\
\text { bsdus 8b6 }\end{array}$ \\
\end{tabular}

\subsection{Mistaken cognition (log shes)}

\section{Groups of definitions}
A - i, ii, v: Positively discerning incorrectly
B - iii, vi: Having a non-veridical object
C - iv, xiii, xv: No correspondence with the state of affairs
D - xi: No correspondence with the state of affairs; engaging while being partial
E - vii, viii, $\mathrm{x}$, xvi: Having something superimposed as its object
F - xiv: Taking as something what is not that
$\mathrm{G}-\mathrm{ix}$, xii, xvii: There is no general definition for this category

\begin{tabular}{|l|l|l|l|l|}
\hline i & A & Phya pa & $\begin{array}{l}\text { don phyin ci log du yongs su gcod } \\
\text { pa }\end{array}$ & $\begin{array}{l}\text { Mun sel } \\
123.42\end{array}$ \\
\hline ii & A & Phya pa & $\begin{array}{l}\text { don phyin ci log du yongs su gcod } \\
\text { pa }\end{array}$ & $\begin{array}{l}\text { Od zer } \\
111.222 .31 \\
28 \mathrm{~b} 7\end{array}$ \\
\hline iii & B & "Phya pa"87 & don mi bden pa yul du byed pa yin & $\begin{array}{l}\text { Tshad bsdus } \\
61,11-12\end{array}$ \\
\hline iv & C & $\begin{array}{l}\text { "Byang chub } \\
\text { skyabs" }\end{array}$ & $\begin{array}{l}\text { don dang mi mthun pa yul du byed } \\
\text { pa yin }\end{array}$ & $\begin{array}{l}\text { Tshad bsdus } \\
61,12-13\end{array}$ \\
\hline v & A & "rGya"88 & $\begin{array}{l}\text { don la phyin ci log tu yongs su gcod } \\
\text { pa }\end{array}$ & $\begin{array}{l}\text { Tshad bsdus } \\
61,13-14\end{array}$ \\
\hline vi & B & "kha cig" & mi bden pa'i yul can & $\begin{array}{l}\text { bsDus pa } \\
23 \mathrm{~b} 2\end{array}$ \\
\hline
\end{tabular}

\footnotetext{
${ }^{87}$ This attribution to "Phya pa" should instead be attached to the definition (v), and "rGya" to the definition (iii).

${ }^{88}$ See n. 87.
} 


\begin{tabular}{|c|c|c|c|c|}
\hline vii & $\mathrm{E}$ & gTsang nag pa & rang gis sgro btags pa yul byed pa & $\begin{array}{l}\text { bsDus pa } \\
23 \mathrm{~b} 3\end{array}$ \\
\hline viii & $\mathrm{E}$ & mTshur ston & rang yul sgro 'dogs pa & $\begin{array}{l}\text { sGron ma } \\
6 \mathrm{a} 8\end{array}$ \\
\hline ix & $\mathrm{G}$ & $\begin{array}{l}\text { "kha cig" } \\
<\text { dan }>\end{array}$ & spyi'i mtshan nyid med & $\begin{array}{l}\text { gSal byed } \\
\text { 10b4 }\end{array}$ \\
\hline $\mathrm{x}$ & $\mathrm{E}$ & $\begin{array}{l}\text { "chos kyi } \\
\text { spyan can } \\
\text { dag" }\end{array}$ & $\begin{array}{l}\text { 'dzin stangs rang gis sgro btags pa } \\
\text { yin }\end{array}$ & $\begin{array}{l}\text { gSal byed } \\
10 \mathrm{~b} 4-5\end{array}$ \\
\hline $\mathrm{xi}$ & $\mathrm{D}$ & gTsang drug & $\begin{array}{l}\text { 'dzin stangs don gyi gnas lugs dang } \\
\text { mi mthun par mtha' } 1 \text { tu 'jug pa yin }\end{array}$ & $\begin{array}{l}\text { gSal byed } \\
10 \mathrm{~b} 5\end{array}$ \\
\hline xii & G & "kha cig" & $\begin{array}{l}\text { log shes spyi'i mtshan nyid cig (B } \\
\text { cig, A 1) med }\end{array}$ & $\begin{array}{l}\text { rNam rgyal } \\
\text { A9b9; } \\
\text { B12a7 }\end{array}$ \\
\hline xiii & $\mathrm{C}$ & "kha cig" & don dang mi mthun par'dzin pa & $\begin{array}{l}\text { rNam rgyal } \\
\text { A10a2; } \\
\text { B12a9 }\end{array}$ \\
\hline xiv & $\mathrm{F}$ & Chu mig pa & de ma yin la der 'dzin pa & $\begin{array}{l}\text { rNam rgyal } \\
\text { A10a3; } \\
\text { B12b1 }\end{array}$ \\
\hline $\mathrm{XV}$ & $\mathrm{C}$ & "Phya pa" & don dang mi mthun par'dzin pa & $\begin{array}{l}\text { Tshad nye } \\
\text { bsdus 9a3 }\end{array}$ \\
\hline xvi & $\mathrm{E}$ & $\begin{array}{l}\text { "Tsang nag } \\
\text { pa" }\end{array}$ & rang yul sgro 'dogs pa & $\begin{array}{l}\text { Tshad nye } \\
\text { bsdus } 9 \mathrm{a} 5\end{array}$ \\
\hline xvii & G & $\begin{array}{l}\text { rDo rje dbang } \\
\text { grags/Chos } \\
\text { kyi bzhad pa }\end{array}$ & $\begin{array}{l}\text { spyi mtshan nyid (em. mtshan nyid } \\
\text { : Ms mtshan) mi btub pa }\end{array}$ & $\begin{array}{l}\text { Tshad nye } \\
\text { bsdus } 9 \mathrm{a} 7\end{array}$ \\
\hline
\end{tabular}




\subsection{Doubt (the tshom)}

\section{Groups of definitions}
A - i, ii, iii, vi, x: Including consideration of another alternative
B - iv, v, vi, vii: Awareness having a double-pointed aspect
$\mathrm{C}-$ viii, ix, xi: Engaging without being partial

\begin{tabular}{|c|c|c|c|c|}
\hline $\mathrm{i}$ & $\mathrm{A}$ & Phya pa & $\begin{array}{l}\text { mtha' gzhan du srid pa'i dogs pa } \\
\text { dang bcas pa }\end{array}$ & $\begin{array}{l}\text { Mun sel } \\
123.52\end{array}$ \\
\hline ii & A & Phya pa & $\begin{array}{l}\text { mtha' gzhan du srid pa'i dogs pa } \\
\text { dang bcas pa }\end{array}$ & $\begin{array}{l}\text { 'Odzer } \\
111.222 .33, \\
29 \mathrm{a} 4\end{array}$ \\
\hline iii & $\mathrm{A}$ & $\begin{array}{l}\text { "Zhang tshes } \\
\text { dang Phya pa" }\end{array}$ & $\begin{array}{l}\text { mtha' gzhan du srid pa'i dogs pa } \\
\text { dang bcas pa }\end{array}$ & $\begin{array}{l}\text { Tshad bsdus } \\
59,21-60,1\end{array}$ \\
\hline iv & $\mathrm{B}$ & "rGya" & blo rtse gnyis kyi rnam pas 'jug pa & $\begin{array}{l}\text { Tshad bsdus } \\
59,20\end{array}$ \\
\hline $\mathrm{v}$ & $\mathrm{B}$ & gTsang nag pa & yul la rtse gnyis su 'jug pa & $\begin{array}{l}\text { bsDuspa } \\
\text { 23b4 }\end{array}$ \\
\hline vi & $\begin{array}{l}\mathrm{A} \\
\mathrm{B}\end{array}$ & mTshur ston & $\begin{array}{l}\text { yul la rtse gnyis su 'jug pa'am / } \\
\text { mtha' gzhan du srid par dogs pa } \\
\text { dang bcas pa }\end{array}$ & $\begin{array}{l}\text { sGron ma } \\
6 \mathrm{a} 9\end{array}$ \\
\hline vii & $\mathrm{B}$ & $\begin{array}{l}\text { "kha cig" } \\
<\text { dan }>\end{array}$ & blo rtse 2 kyi rnam pas 'jug pa & $\begin{array}{l}\text { gSal byed } \\
10 \mathrm{~b} 7-8\end{array}$ \\
\hline viii & $\mathrm{C}$ & gTsang drug & $\begin{array}{l}\text { mtha' } 1 \text { tu ma nges par zhen pa } 1 \\
\text { yin }\end{array}$ & $\begin{array}{l}\text { gSal byed } \\
10 \mathrm{~b} 8\end{array}$ \\
\hline ix & $\mathrm{C}$ & Chu mig pa & don mtha' 1 du ma nges par zhen pa & $\begin{array}{l}\text { rNam rgyal } \\
\text { A10a4; } \\
\text { B12b2-3 }\end{array}$ \\
\hline $\mathrm{x}$ & A & $\begin{array}{l}\text { rDo rje dbang } \\
\text { grags/Chos } \\
\text { kyi bzhad pa } \\
\text { <rtsang 'bre> }\end{array}$ & $\begin{array}{l}\text { mtha' gzhan du 'dzin pa'i dogs pa } \\
\text { dang bcas pa }\end{array}$ & $\begin{array}{l}\text { Tshad nye } \\
\text { bsdus 9a8 }\end{array}$ \\
\hline $\mathrm{xi}$ & $\mathrm{C}$ & $?$ & mtha' gcig du ma nges par zhen pa & $\begin{array}{l}\text { Tshad nye } \\
\text { bsdus 9a8 } \\
\text { (marginal } \\
\text { note) }\end{array}$ \\
\hline
\end{tabular}



V

Supplementary textual resources 



\section{Citations and references in later works}

\subsection{Citations and references in the Tshad bsdus}

\section{R1.1 - Cf. Mun sel 122.32}

54,2-5: phya pa ni bum pa'i steng du skra shad la sogs pa 'dzag par snang ba'i shes pa zhig 'byung bas rtog med log shes dang bdun mi 'gal la lnga dang 'gal lo zhes zer te blo la mi 'bab bo zhes gsung ngo //

\section{R1.2 - Cf. Mun sel 123.22}

$56,2-4$ : phya pa na re tshad mas sngar sgro 'dogs chod pa'i don la bzlog pa'i sgro 'dogs dang 'gal bas 'jug pa zhes pa la 'dod de

\section{R1.3 - Cf. Mun sel 123.322}

57,9-20: 'di ni khyab ches pa ste /

[D2] de lta na myong ba la ma brten par don nges tsam yid dpyod kyi mtshan nyid yin par'dod pa gang gis 'gog //

[D2] de lta na rjes dpag kyang yid dpyod du thal lo zhe na /

[D1] snga ma ltar na'ang sgra rtag par'dzin pa'i log shes kyang yid dpyod du thal lo //

[D1] 'dod de sgra rtag par 'dzin pa'i ldog pa nas log shes dang myong ba dang rtags la ma brten par don nges pa'i ldog pa nas yid dpyod kyang yin pas so zhe na/

[D2] snga ma'ang 'dod de me med kyi sgro 'dogs chod pa'i ldog pa nas rjes dpag dang myong ba la ma brten par don nges pa'i ldog pa nas yid dpyod kyang yin pas so //

[D2] rjes dpag tshad ma yin pa dang yid dpyod tshad ma ma yin par gnyis yid shes gcig gis ldog pa la 'gal lo zhe na/

[D1] log shes don mi bden pa yul du byed pa dang yid dpyod don bden pa yul du byed pa gnyis kyang yid shes gcig gi ldog pa gcig la 'gal lo zhes phya pa zer te /

\section{R1.4 - Cf. Mun sel 123.323}

58,8-59,1: blo yid dpyod du 'gro ba la don bden pas khyab bam ma khyab /

phyi ma ltar na don bden pa nges pas kyang ma khyab pas yid dpyod kyi mtshan nyid ma khyab par 'gyur ro //

dang po ltar na 'brel ba yod pas khyab bam 'brel ba med kyang khyab / 
yod nas khyab na 'brel bas bskyed pa'i rtogs pa yin pa'i phyir tshad mar thal la /

med kyang khyab na 'brel med kyi khyab bya ni he du dang / 'brel med kyi khyab byed ni bsgrub bya'i chos su gyur pas rtags gsum du grangs nges nyams par thal te 'brel med kyi rtags byung bas so // zhe na / de'i lan ni blo yid dpyod du 'gro ba la don bden pas khyab pas mtshan nyid kyis ma khyab pa'ang med la / 'brel ba med kyang khyab pas tshad mar yang mi 'gyur ro //

de ltar na rtags kyi grangs nges nyams so zhe na /

khyab bya khyab byed byung tsam la rtags dang bsgrub bya'i chos kyis ma khyab ste / dper na blo rtog par 'gro ba la yul don spyi snang bas khyab pas rtog pa'i phyir don spyi snang ba yin zhes dpag du mi rung ste rtags dang rtags can med pa de bzhin du blo yid dpyod du ni nges pa na don bden par yang nges zin pas rtags dang rtags can med pas so zhes phya pa zer ro //

\section{R1.5 - Cf. Mun sel 123.42}

61,11-16: log shes la gsum las mtshan nyid ni don mi bden pa yul du byed pa yin no zhes phya pa zer kyang bden mi bden gyi sa mtshams dka' bas don dang mi mthun pa yul du byed pa yin no zhes byang chub skyabs gsung ngo // rgya na re don la phyin ci log tu yongs su gcod pa zhes bya ba yin no zhes zer te gcod pa zhes bya ba nges shes 'dren pa la zer na rtog med log shes la ma khyab bo // zhes zer ro //

\section{R1.6 - Cf. Mun sel 123.52}

59,21-60,1: zhang tshes dang phya pa ni mtha' gzhan du srid pa'i dogs pa dang bcas pa'o zhes zer ro //

\section{R1.7 - Cf. Mun sel 123.53 (a)}

60,13-18: de la phya pa na re the tshom la gzhan sel yod de / de lta ma yin na ${ }^{1}$

[D2] sngon po 'dzin pa'i myig gi rnam shes la yang gzhan sel med par 'dod pa gang gis 'gog //

[D2] sngon por yongs gcod la grub pa na sngo ma yin rnam gcad la khegs pas gzhan sel yod do zhe na I

[D1] mi yin srid tho yor yin srid ces srid par yongs gcod la gzung pa ni mi srid pa rnam gcad la khegs pas gzhan sel yod do zhes zer ro //

\footnotetext{
${ }^{1}$ Em. na : Tshad bsdus 60,14 no
} 


\section{R1.8 - Cf. Mun sel 212.14}

117,1-9: phya pa na re gnod med kyi mi slu ba dang bden pa'i don rtogs gnyis gcig ste rnam 'grel nas gnod med 'di ni mi slu ba'o ${ }^{2}$ zhes bshad la / rnam nges nas kyang dngos po 'dzin pa kho na ni tshad ma'i mtshan nyid ma yin te de'i mtshan nyid ni mi slu ba yin pa'i phyir ro $/ /^{3}$ de ni rang gi yul la gnod pa yod pa dang med pa las de yod pa dang med pa nyid du rnam par gzhag go zhes gnod pa yod na mi slu ba ma yin la / gnod pa med na mi slu ba yin pas gnod med kyi mi slu ba dang bden pa'i don rtogs shig yin no //'on kyang sngar mi slu ba sun phyung ba ni slob dpon chos mchog 'dod pa lta bu'i don thob byed kyi nus ba bkag pa yin no zhes zer ro //

\section{R1.9 - Cf. Mun sel 241}

175,11-12: yang phya pa na re rjes dpag gi mtshan nyid khyab bya nges pa la brten nas khyab byed nges pa'o zhes kyang 'dod do //

\subsection{Citation in an interlinear note in the sGron ma}

R2.1 - Cf. Mun sel 123.12

5b4: yang kha cig < phya rgya> sgro 'dogs dang mi 'gal ba'i snang pa yin no zhes zer ba ${ }^{4}$

\subsection{References in interlinear notes in gTsang drug rdo rje's gSal byed}

\section{R3.1 - Cf. Mun sel 11 (b) ii}

7a2: kha 1 na re $<$ phya $>$ rtog pa'i mtshan_nyid ${ }^{5}$ don spyi 'dzin pa yin_no zhes zer ba

\section{R3.2 - Cf. Mun sel 231.12}

34b2: yang kha 1 na re <phya $>$ gzung don la ma 'khrul bas mngon suM gyi rigs mi mthun mtha' dag sel ba yin te / dgag bya mngon suM ltar

\footnotetext{
${ }^{2}$ PV 1.215c, cited in 'Od zer 111.221.223 (23b2).

${ }^{3} \mathrm{Cf}$. PVin 11,10 , referred to in 'Od zer (idem).

${ }^{4}$ Cf. also Tshad bsdus 54,18-19: rgya na re sgro 'dogs dang mi 'gal ba'i snang ba yin no zhes zer te.

5 The manuscript has the abbreviation mtshid for mtshan nyid.
} 
snang 2 ka gzung don la 'khrul ba yin pa'i phyir | rtog bral ni log rtogs sel ba'i mtshan_nyid ${ }^{6}$ yin_no zhes zer /

\subsection{Reference in Chu mig pa's rNam rgyal}

R4.1 - Cf. Mun sel 11 (b) ii

A7a6-7; B9a2: chos kyi seng ge na re rtog pa'i mtshan nyid ni don spyi 'dzin pa yin no (B om. no) zer ro //

\subsection{References in the works of Śākya mchog Idan}

\subsection{In Rol mtsho}

R51.1 - Cf. Mun sel 11 (a)

5a3: phya bsdus las / spyir blo la snang ba'i gzung yul la gsum ste / don rang gi mtshan nyid dang / don spyi dang / rtog med 'khrul pa'i dmigs pa'o //

\section{R51.2 - Cf. Mun sel 121.11}

5a3-5: [phya bsdus las...] de la gzung yul gyi mtshan nyid ni / gang zhig rang gi ngo bo nyid blo [5a4] la snang ba ste /

\section{R51.3 - Cf. Mun sel 121.2}

10b1-2: phya bsdus las / ji skad du / rang rig pas don spyi dang / zla ba gnyis la sogs pa snang tshod du med pa'i sgro 'dogs bcad pas / de dag [10b2] rang rig gi 'jug yul yin kyang / rang rig la de dag mi snang bas / rang rig gi gzung yul ma yin pa lta bu'o // zhes 'jug yul yin la / gzung yul ma yin pa'i dper brjod du bshad pas so //

\section{R51.4 - Cf. Mun sel 122.1}

17b4: slob dpon phya pa na re / tshad min gyi blo thams cad sngar grangs nges pa yin te /

yid dpyod snang la ma nges dang //

bcad shes log shes the tshom lnga //

${ }^{6}$ The manuscript has the abbreviation mtshid for mtshan nyid. 
zhes zer ro $/ /^{7}$

\section{R51.5 - Cf. Mun sel 122.1}

17b4-18a2: phya bsdus las ${ }_{[17 b 5]}$ spyir don yongs su gcod pa la gnyis te / dngos 'gal las tha dad du ma phyed pa phyogs gcig ma yin par gcod pa dang / tha dad par phyed pa phyogs gcig tu gcod pa'o //

dang po ni the tshom ste / mi rtag par dogs pa nyid na rtag par yang dogs [17b6] pas / de las tha dad du ma phye ba'i phyir ro //

gnyis pa la gnyis te / shes bya dang mi mthun par yongs su gcod pa dang / mthun par gcod pa'o //

dang po ni log shes so //

gnyis pa la'ang / bzlog pa'i zhen pa dang mi 'gal ba dang / 'gal [17b7] ba gnyis las /

dang po ni snang la ma nges pa'o //

gnyis pa la / sngar rtogs zin la 'jug pa dang / sngar ma rtogs pa la 'jug pa gnyis las /

dang po ni / bcad pa'i yul can no //

gnyis pa la'ang / rang gi mtshan nyid mthong bas ${ }_{[18 a 1]}$ sgro 'dogs la gnod pa dang / ma mthong bas gnod pa gnyis las /

dang po ni mngon sum tshad ma'o //

gnyis pa la / rtags kyi rjes su 'brangs pa dang / ma 'brangs pa gnyis las / dang po ni rjes dpag [18a2] dang /

gnyis pa ni yid dpyod do //

de ltar tshad min gyi blo lnga / tshad ma gnyis te bdun du grangs nges pa yin no // [...zhes 'chad par byed do // $]^{8}$

\section{R51.6 - Cf. Mun sel 123.11}

18a5-6: [phya bsdus las...] dbye na / yul rnam pa dang mi ldan pas snang la ma nges pa bum pa'i skad cig snang ba lta bu dang / yul la yid ma [18a6] gtad pa yid gzugs mdzes la chags dus kyi sgra 'dzin lta bu dang / 'khrul pa'i rgyu mtshan can nya phyis la dngul du 'khrul ba'i dus kyi mig shes lta bu'o // [...zhes 'chad par byed do //]

\footnotetext{
${ }^{7}$ The verse lines are from the beginning of the second chapter of the Rigs gter (II 58,23-24), where they represent the view held by "most Tibetans" (bod phal cher blo lngar sdud de /... / zhes zer ro //).

${ }^{8}$ This is a literal citation of the Mun sel. Minor differences are marked with wavy underline. Compare with R52.1.
} 
R51.7 - Cf. Mun sel 123.12

18a4-5: [phya bsdus las...] snang la ma ${ }_{[18 a 5]}$ nges pa la mtshan nyid ni / don rang gi mtshan nyid gsal bar snang zhing / zlog phyogs kyi sgro 'dogs dang mi 'gal ba'o // [...zhes 'chad par byed do //]

\section{R51.8 - Cf. Mun sel 123.21}

18a7-18b1: [phya bsdus las...] dbye na mngon sum bcad shes dang / rtog par gyur pa'i bcad shes gnyis so //

rjes dpag tu gyur pa'i bcad shes mi srid pa'i tshul ni rjes dpag gi rgyun phyi ma rnams bcad pa'i yul can yin kyang rjes dpag ma yin [18b1] te / de'i rten gtan tshigs yang dag med pa'i phyir / de las brgyud nas skyes pa tsam gyis chog na / rnal 'byor mngon sum yang rjes dpag tu ha cang thal lo // zhes 'chad par byed do //

\section{R51.9 - Cf. Mun sel 123.22}

18a6-7: [phya bsdus las...] bcad shes la mtshan nyid ni / sgro 'dogs chod zin pa'i ngo la ldog phyogs kyi zhen pa ${ }_{[18 \mathrm{a} 7]}$ dang 'gal ba'i blo 'jug pa'o // [...zhes 'chad par byed do //]

\section{R51.10 - Cf. Mun sel 123.31}

18a3-4: [phya bsdus las...] dbye na / gtan tshigs yang dag dang ltar snang gang rung la ma brten par sgra mi rtag par nges pa lta bu rgyu mtshan med pa'i yid dpyod dang / ma grub pa'am ma nges pa'i rtags la brten pa log pa'i rgyu mtshan can gyi yid dpyod dang / [18a4] tshul gsum tshad mas ma nges kyang yid dpyod kyi nges pa la brten nas / byas pa'i rtags kyis sgra mi rtag par nges pa lta bu'o // [...zhes 'chad par byed do //]

\section{R51.11 - Cf. Mun sel 123.31}

18a4: [phya bsdus las...] 'gal rtags la brten pa'i yid dpyod ni mi srid de / de'i bsgrub bya bden pa mi srid pa'i phyir ro // [...zhes 'chad par byed do //]

\section{R51.12 - Cf. Mun sel 123.321}

18a2-3: de dag las \{i.e., phya bsdus las\} / yid dpyod kyi mtshan nyid ni / sngar ma rtogs pa'i lkog gyur gyi don bden pa rtags tshad ma la ma brten $\operatorname{par}_{[18 a 3]}$ nges pa'o // [...zhes 'chad par byed do //] 


\section{R51.13 - Cf. Mun sel 212.14}

77b3-4: phya pa la sogs pa bram ze'i rjes 'brang rnams ni / bden pa'i don rtogs chos gsum ldan tshad ma'i mtshan nyid yin la / gsum ${ }_{[77 b 4]} \mathrm{ni} /$ yul gyi khyad par sngar ma rtogs pa'i don la 'jug pa / 'dzin stangs kyi khyad par don la mi 'khrul ba / ngo bo'i khyad par sgro 'dogs sel ba'o // zhes gsung ngo $/ /^{9}$

\subsection{In Pham byed II}

\section{R52.1 - Cf. Mun sel 122.1}

37b3-7: rigs pa'i dbang phyug phywa pa 'di ltar bzhed do //

spyir [37b4] blo thams cad gnyis su'dus te / dngos 'gal las tha dad du ma phye ba phyogs gcig ma yin par gcod pa dang / tha dad par gnas pa phyogs gcig tu gcod pa'o // dang po ni the tshom mo//

gnyis pa la gnyis te / shes [37b5] bya dang mi 'thun par gcod pa dang / 'thun par gcod pa'o //

dang po ni / log shes so //

gnyis pa la / bzlog pa'i zhen pa dang mi 'gal ba dang 'gal ba gnyis /

dang po ni / snang la ma nges pa'o //

gnyis pa la sngar rtogs [3766] zin la 'jug pa dang / sngar ma rtogs pa la 'jug pa gnyis /

dang po ni bcad pa'i yul can no //

gnyis pa la / rang gi mtshan nyid mthong bas sgro 'dogs la gnod pa dang / ma mthong bas gnod pa'o/l dang po ni / [37b7] mngon sum tshad ma'o //

gnyis pa la rtags kyi rjes su 'brangs pa dang ma 'brangs pa'o// dang po ni / rjes dpag go// gnyis pa ni yid dpyod do/l/ de ltar na tshad min gyi blo lnga / tshad ma gnyis te bdun du grangs nges pa yin_no //

[...zhes bzhed do // $]^{10}$

\footnotetext{
${ }^{9}$ The formulation including the mention of the "three specificities" (khyad par gsum, chos gsum) does not go back to Phya pa himself, but is found in the works of his disciples, such as gTsang nag pa. See Hugon 2011a: 162, n. 16.

${ }^{10}$ Compare with R51.5. Here also, this is a literal citation of the Mun sel. The few differences are marked with wavy underline.
} 


\section{R52.2 - Cf. Mun sel 123.11}

38a1-2: [rigs pa'i dbang phyug phywa pa 'di ltar bzhed do //...] dbye na gnyis te / yul gyi rnam pa dang mi 'gal ba'i snang ba la ma nges pa [38a2] dang / yid ma gtad pa'i de'o //

dang po ni / mngon sum gyi sgra rang mtshan mthong ba na de'i skad cig snang yang ma nges pa lta bu'o //

gnyis pa ni yid gzugs mdzes la lhag par chags dus kyi sgra 'dzin nyan shes lta bu'o // [...zhes bzhed do //]

\section{R52.3 - Cf. Mun sel 123.12}

38a1: [rigs pa'i dbang phyug phywa pa 'di ltar bzhed do //...] snang la ma nges pa'i mtshan nyid ni don rang gi mtshan nyid gsal bar snang zhing sgro 'dogs dang mi 'gal bar 'jug pa'i rig pa'o // [...zhes bzhed do //]

\section{R52.4 - Cf. Mun sel 123.21}

38a3-6: [rigs pa'i dbang phyug phywa pa 'di ltar bzhed do //...] de la dbye na / mngon sum dang / rtog pa gnyis so // phyi ma la'ang gnyis te / mngon sum gyis ${ }_{[38 \mathrm{a} 4]}$ drangs pa dang / rjes dpag gis drangs pa gnyis so // 'o na mngon sum dang / bcad shes kyi gzhi 'thun srid pa bzhin du rjes dpag dang bcad shes kyi'ang gzhi 'thun srid dam zhe nal

rgya dmar gyis de bzhed mod kyang [38a5] mi 'thad de / rjes su dpag pa'i skad cig ma gnyis pa phan chad rjes dpag ma yin te / rtags 'dzin las dngos su ma skyes pa'i phyir dang / rtags las gzhal bya rtogs pa'i blo ma yin pa'i phyir dang / rjes dpag [38a6] skad cig dang po'i rgyun goms pa las gzhal bya rtogs pa yin pa'i phyir / [ . .zhes bzhed do //]

\section{R52.5 - Cf. Mun sel 123.22}

38a3: [rigs pa'i dbang phyug phywa pa 'di ltar bzhed do //...] bcad shes kyi mtshan nyid ni / sgro 'dogs chod zin pa'i don la bzlog pa'i zhen pa dang 'gal bar 'jug pa'i blo / [ ...zhes bzhed do //]

\section{R52.6 - Cf. Mun sel 123.31}

38a7-b2: [rigs pa'i dbang phyug phywa pa 'di ltar bzhed do //...] dbye na /

rtags yang dag dang ltar snang gang la yang ma brten par sgra mi rtag par nges pa lta bu rgyu mtshan med pa'i yid dpyod ' ma grub pa'am / ma nges pa'i rtags la brten nas sgra mi rtag par nges [38b1] pa lta bu / rgyu mtshan gyi phyin ci log gi yid dpyod dang / byas pa'i rtags kyis sgra mi rtag par sgrub pa'i tshul gsum tshad mas ma shes kyang yid dpyod kyis shes nas / 
sgra mi rtag par nges pa lta bu / rgyu mtshan gtan [38b2] la ma phab ${ }^{11}$ pa'i yid dpyod do // zhes bzhed do //

\section{R52.7 - Cf. Mun sel 123.321}

38a6-7: [rigs pa'i dbang phyug phywa pa 'di ltar bzhed do //...] yid dpyod kyi mtshan nyid ni / myong ba dang rtags yang dag la ma brten par sngar ma rtogs pa'i lkog gyur gyi don bden pa gsar [38a7] du nges pa'i blo'o // [...zhes bzhed do //]

\section{R52.8 - Cf. Mun sel 212.14}

149b4-5: [slob dpon phya pas...] khong rang gi lugs la tshad ma'i mtshan nyid sngar ma rtogs pa'i don bden pa la mi 'khrul ba'i 'dzin stangs kyis bzlog pa'i sgro 'dogs dang [149b5]' gal ba'o // gzhung las mi bslu bar gsungs pa yang yul shes bya'i gshis su gnas shing / gnod med du bden pa la bya dgos pa yin te / ji skad du / gnod med 'di'i mi bslu ba'o // zhes gsungs pa ltar ro //2

\section{R52.9 Cf. Mun sel 212.14}

151b1: phywa pas ni mi bslu ba'i don bden pa'i don rtogs la bzhed pas

\section{R52.10 Cf. Mun sel 212.14}

156b7: bden pa'i don rtogs chos gsum ldan de'i mtshan nyid du 'jog pa phya pa'i lugs dang $/^{13}$

\section{R52.11 - Cf. Mun sel 212.21 (a)}

149b5-150a1: [slob dpon phya pas... khong rang gi lugs la...] mtshan [149b6] nyid des mngon sum la ma khyab pa'i skyon med de / mngon sum tshad mas sgro 'dogs gcod pa de'i tshe / mngon sum gyis gcod ky $1^{14}$ nges shes kyis gcod pa min te / skad cig dang por mngon sum dang sgro 'dogs phrad / sgro [149b7] 'dogs kyis ${ }^{15}$ nyer len gyi rgyu dang mngon sum gyis lhan cig byed rkyen byas te skad cig gnyis par sgro 'dogs nus med du skyes / gsum pa la bzlog pa'i phyir / nges shes ni sgro 'dogs log rjes su

\footnotetext{
${ }^{11}$ Em. ma phab : Pham byed phab

${ }^{12}$ The wording of the passage cited corresponds to 'Od zer 111.221.2 (23b1-2).

${ }^{13}$ Cf. n. 9.

${ }^{14}$ Em. kyi : Pham byed kyis

${ }^{15}$ Em. kyi $\langle\mathrm{s}\rangle$ : Pham byed kyi
} 
skyes pa'i bcad pa'i yul can [150a1] yin pas sgro 'dogs gcod byed min no zhes gsung ngo //

\section{R52.12 - Cf. Mun sel 212.21 (a)}

158a2-3: slob dpon phya pa ni mngon sum tshad ma'i nye rgyu dang sgro 'dogs gnyis / dang por tshogs / gnyis pa la nus med du byas / gsum pa la sgro 'dogs bzlog pa yin pas / [158a3] sgro 'dogs log rjes kyi nges shes sgro 'dogs kyi gnyen po ma yin par bzhed do //16

\section{R52.13 - Cf. Mun sel 231.12}

188b5: [de la phya pas dgag pa mdzad pa ni ...zhes pa'i skyon brjod nas] rang gi lugs la rtog pa dang bral zhing gzung yul la ma 'khrul ba'i rig pa mngon sum gyi mtshan nyid dang / myongs stobs kyis sgro 'dogs gcod pa'i rig pa de mngon sum gyi tshad ma'i mtshan nyid yin zhes gzung ngo $/ /^{17}$

\section{R52.14 - Cf. Mun sel 231.12}

194b2-3: slob dpon phya pa na re / sngar ma rtogs pa'i don la myong stobs [184b3] kyi sgro 'dogs gcod par byed pa'i rig pa de mngon sum gyi tshad ma'i mtshan nyid / rtog pa dang bral zhing ma 'khrul ba'i rig pa de mngon sum tsam gyi mtshan nyid / [...zhes gsung ngo /// $]^{18}$

\subsection{References in Go rams pa's Rab gsal}

\section{R6.1 - Cf. Mun sel 122.1}

35b1-5: sngon gyi mkhas pa phya pa sogs na re / blo rigs thams cad the tshom / log shes / snang la ma nges pa / bcad shes / yid dpyod / mngon

\footnotetext{
${ }^{16}$ The expressions "tshogs" and "gnyen po" hint to the 'Od zer (111.222.2 (a)) as the source of this citation.

${ }^{17}$ Such a statement, ascribed in the Rigs gter (IX 226,11) to "Tibetans" (bod rnams), is not found either in the Mun sel or the 'Od zer. See also R6.8. A similar definition is found in gTsang nag pa's bsDus pa 37b6-7: mngon sum tshad ma' $i$ mtshan nyid ni sngar ma rtogs pa'i dngos po snang pa'i stobs kyis sgro 'dogs gcod pa zhes brjod zin to //. See also bsDus pa 36a8: dngos po myong pa'i stobs kyis sgro 'dogs sel pa zhes bya ba mngon sum tshad ma'i don khas blangs pa nyid la.
}

${ }^{18}$ See the previous note. 
sum tshad ma / rjes dpag tshad ma dang bdun du 'dus [35b2] pa yin te / blo de la rang yul mtha' cig tu 'dzin mi nus pa dang / nus pa gnyis las / dang po ni / the tshom / gnyis pa la yul gyi gnas tshul dang mi mthun par 'dzin pa dang / mthun par'dzin pa gnyis las / dang po la $\log [35 \mathrm{~b} 3]$ shes /

gnyis pa la log phyogs dang 'dzin stangs mi 'gal bar 'jug pa dang / 'gal bar'jug pa gnyis las / dang po ni / snang la ma nges pa /

gnyis pa la sngar rtogs zin gyi don la 'jug pa dang / sngar ma rtogs pa la [35b4] 'jug pa gnyis las /

dang po ni bcad shes /

gnyis pa la / rgyu mtshan la ma ltos par 'jug pa dang / rgyu mtshan la ltos nas 'jug pa gnyis las /

dang po ni / yid dpyod /

gnyis pa la myong stobs kyis 'jug pa dang / ${ }_{[35 b 5]}$ rtags stobs kyis 'jug pa gnyis las /

dang po ni / mngon sum tshad ma /

gnyis pa ni rjes dpag tshad ma'o //

The statements that follow are included in Go rams pa's account of opposing views but, unlike R6.1, they are not explicitly linked with "Phya pa, etc." They can however be assumed to refer to the views of the same scholars as in the aforementioned division of awareness. The terminological variations from Phya pa's definitions and divisions are, however, evident and correspond largely to the ones found in the text of the Rigs gter on which Go rams pa is commenting (which are based on mTshur ston's sGron ma). Go rams pa's account of the opposing views is provided below for the sake of comparison.

\section{R6.2 - Cf. Mun sel 123.11}

36a2-4: dbye na yul rnam pa mi gsal ba'i dang / [36a3] yid ma gtad pa'i dang / 'khrul pa'i rgyu mtshan gyis zin pa'i snang la ma nges pa'i blo gsum las /

dang po ni / tshur mthong gi rgyud kyi sngo 'dzin dbang po'i mngon sum de sngon po'i skad cig ma la snang la ma nges pa yin pa lta bu'o //

gnyis [36a4] pa ni / rtog pa nang du bsdus pa'i gnas skabs kyi gzugs 'dzin gyi mig shes lta bu'o // 
gsum pa ni / yid nya phyis la dngul du 'khrul pa'i gnas skabs kyi nya phyis 'dzin pa'i mig shes lta bu'o //

\section{R6.3 - Cf. Mun sel 123.12}

36a2: snang la ma nges pa'i blo'i mtshan nyid / log phyogs kyi sgro 'dogs dang mi 'gal bar don rang gi mtshan nyid snang ba'i blo /

\section{R6.4 - Cf. Mun sel 123.21}

36a5-6: dbye na mngon sum bcad shes dang / rtog pa bcad shes gnyis las dang po ni / sngo 'dzin dbang mngon skad cig gnyis pa man ${ }_{[36 a 6]}$ chad yin no //

gnyis pa ni / mngon sum gyi rjes su skyes pa'i nges shes dang / rjes dpag gi rjes su skyes pa'i dran shes lta bu yin no //

\section{R6.5 - Cf. Mun sel 123.22}

36a4-5: bcad shes kyi mtshan nyid / [36a5] sngar rtogs zin byed pa ma nyams pa'i don la log phyogs kyi sgro 'dogs dang 'gal bar 'jug pa'i rig pa /

\section{R6.6 - Cf. Mun sel 123.31}

35b6-36a2: dbye na / rgyu mtshan med pa'i yid dpyod / rgyu mtshan phyin ci log gi yid dpyod / rgyu mtshan ma nges pa'i yid dpyod dang gsum las /

dang po ni / pha [36a1] mes kyi khron pa rnying pa na chu yod do snyam du 'dzin pa'i blo lta bu'o //

gnyis pa ni / ma nges pa dang / ma grub pa'i rtags la brten nas sgrub bya bden pa mtha' gcig tu dzin pa'i blo lta bu'o //

gsum pa ni / tshul gsum [36a2] ma nges kyang byas pa'i rtags las sgra mi rtag par'dzin pa'i blo lta bu'o //

\section{R6.7 - Cf. Mun sel 123.321}

35b5-6: yid dpyod la mtshan ${ }_{[35 \mathrm{~b} 6]}$ nyid ni / rtags la ma brten par lkog gyur gyi don bden pa gsar du nges pa'i rig pa /

\section{R6.8 - Cf. Mun sel 231.12}

138b5-6: phya pa sogs mngon sum [138b6] dang mngon sum tshad ma so sor phye nas dang po'i mtshan nyid rtog pa dang bral zhing ma 'khrul ba'i 
rig pa / phyi ma'i mtshan nyid / sngar ma rtogs pa'i don la myong stobs kyis sgro 'dogs gcod pa zhes gsungs pa... ${ }^{19}$

\subsection{References in Glo bo mkhan chen's Rigs gter nyi ma}

R7.1- Cf. Mun sel 11 (b) ii

182,1: slob dpon cha pa don spyi 'dzin pa zhes brjod kyang

R7.2 - Cf. Mun sel 123.321

53,5-8: slob dpon cha pa na re / sngar ma rtogs pa'i don bden pa rtags tshad mas nges pa la ma brten par nges pa ste /

- nges pas ni mngon sum dang the tshom gcad do //

- bden pas log shes gcad do //

- sngar ma rtogs pas bden pa'i yul can gcad do //

- rtags tshad mas nges pa la ma brten pas rjes dpag gcad ces gsungs so //

\subsection{Reference in Chos kyi bzhad pa's Tshad nye bsdus}

\section{R8.1- Cf. Mun sel 123.42}

9a3: log shes kyi spyi'i mtshan_nyid ${ }^{20}$ ni don dang mi mthun par 'dzin pa la phya pa bzhed pa

\footnotetext{
${ }^{19}$ See n. 17.

${ }^{20}$ The manuscript has the abbreviation mtshid for mtshan nyid.
} 



\section{Parallel passages in the 'Od zer}

\subsection{Introductory remarks}

The goal of this section is to provide evidence of the passages of Phya pa's 'Od zer that parallel the discussion carried out in the portions of the Mun sel edited and translated in this volume. These passages are part of a long excursus on definition and, in particular, the definition of knowledge ('Od zer 6a8-35a9), which follows the word-commentary on the beginning of PVin 1 (the prose passage following PVin 1.1a). Some sections of the 'Od zer that have no parallel in the Mun sel but offer pertinent information related to the topic have been included as well. Crossreferences indicated in curly brackets should allow an easy comparison of the parallel passages in the respective texts.

The edition follows the same conventions as that of the Mun sel (cf. III, 1). Among the paleographic characteristics of the manuscript, one should note the frequent use of the bind $u$ instead of a final $-m$ and of the abbreviation thaMd ( $M$ standing for the bindu) for thams cad. Those have not been recorded among the scribal particularities in $\$ 2.4$, and have been normalized in the edition.

The passages of the 'Od zer have been critically edited, but are not translated, precisely due to the parallelism with the corresponding sections of the Mun sel, which would have led to an unnecessary duplication of the work of translation, even if the parallelism is not "absolute." Indeed, even in the parallel passages, there is no instance of literal text reuse between Phya pa's two works. That is worth noting because Tibetan authors, including Phya pa, were prone to resort to re-using parts of their predecessors' works in their own compositions, ${ }^{21}$ as well as to re-using parts of their own works, ${ }^{22}$ but this is not the case in the portions of text considered here. ${ }^{23}$

\footnotetext{
21 There is, in particular, evidence that Phya pa re-used parts of rNgog Lo's epistemological treatises when composing the 'Od zer. See Hugon 2015 b.

22 See for instance Phya pa's discussion on incompatibility ('gal ba), which is virtually literally identical in Mun sel 68a9-72a5 and 'Od zer 111b5-115b1, or his discussion related to the proof of momentariness (Mun sel 62b6-66b2, 'Od zer 126a4-130a1).

${ }^{23}$ A similar remark was made regarding the two available works of epistemology of rNgog Lo, in which the author never formulates things in the exact same way,
} 
The structure of the discussion has a part to play in the difference between the respective formulations, because the respective sections are discussed in a different order in the two texts:

- In the Mun sel, Phya pa begins with a discussion of episodes of awareness in general in the first chapter. He examines their various features in relation to different types of objects (apprehended object, intentional object, engaged object) and identifies which of these features are involved in defining episodes of knowledge. The discussion leads to the definition of knowledge, which is dealt with in the second chapter (after a long, independent discussion on "definition").

- In contrast, in the 'Od zer, Phya pa begins with the definition of knowledge (preceded, here also, by an independent investigation of "definition" in general), and addresses episodes of awareness that do not qualify as knowledge in a subsequent section entitled "Rejecting the faults of the definition," 24 a parallel (shorter) version of which is also found in the Mun sel after the definition of knowledge.

The information pertaining to the types of awareness that are not episodes of knowledge (including their definition, establishment that the definition applies, subtypes) is thus dispatched differently in the two texts over the various places they are discussed.

In the Mun sel, two typologies of awareness are proposed: a three-fold typology based on the apprehended object, and a seven-fold typology (consisting of two types that are knowledge and five types that are not knowledge) based on both the apprehended and the intentional object. The former is relevant to an investigation of mind in general (but already identifies features delineating episodes of knowledge), whereas the second more specifically takes into account the criteria playing a role in the definition of knowledge. In the 'Od zer, Phya pa only presents one typology of awareness, a ten-fold typology which is primarily based on the

even when dealing with the very same topics. See Hugon 2014: 207.

${ }^{24}$ This structure corresponds to that of rNgog Lo's discussion in the $d K a$ ' gnas. The close relation between 'Od zer and rNgog Lo's $d K a$ ' gnas (possibly also with rNgog Lo's lost, extensive commentary on the Pramānaviniścaya) is demonstrated in Hugon 2015b: 460-464 by illustrating Phya pa's literal re-use of rNgog Lo's text. 
apprehended object (like the three-fold typology of the Mun sel), but then proceeds by subdivisions that recall the seven-fold typology in the Mun sel (see VI, Table E). The eight types of awareness within that ten-fold typology that are not episodes of knowledge are later reduced to five types. The ten-fold typology in the 'Od zer and the seven-fold typology in the Mun sel roughly appeal to the same criteria, but not in the same order. The number of types differs - seven (or twelve with the subdivisions) vs. ten-because the ten-fold typology only includes some of the subtypes listed in the twelve-fold typology derived from the seven-fold typology ${ }^{25}$ and includes subtypes not listed separately in the twelve-fold typology. ${ }^{26}$ There is no discussion of the mutual compatibility and incompatibility of the various subtypes.

As mentioned, the initial focus in the 'Od zer is the definition of knowledge and not an investigation of awareness in general. Still, the key notions defined in this regard in the Mun sel - the typology of objects and their definition - are also found in the 'Od zer. They are, however, located within the discussion of Dharmottara's view on the definition of knowledge, just like in rNgog Lo's $d K a$ ' gnas ${ }^{27}$ The notion of three "operations" (byed pa), which, in the Mun sel, is instrumental in discussing all of the subtypes of conceptual cognition in the three-fold typology, is also found in the 'Od zer. But these operations are only discussed in relation to the various types of inferential cognition.

In the 'Od zer, the presentation of Phya pa's own position on the definition of knowledge is more extensive than in the Mun sel. In particular, Phya pa discusses there in more detail criterion (K1) and provides additional specifications regarding which superimpositions can be eliminated by an episode of knowledge (an issue that is completely absent in the Mun

\footnotetext{
${ }^{25}$ Namely, it does not distinguish the reflexive and the transitive version of nonascertaining perception and of non-conceptual post-knowledge cognition.

${ }^{26}$ Notably: non-directing conceptual cognition. This subtype was distinguished in the Mun sel in the framework of the three-fold typology, but does not appear in the seven-/twelve-fold typology.

${ }^{27}$ Note that it must be viewed as these two scholars' representation of Dharmottara. Indeed, Dharmottara himself does introduce a distinction of objects when dealing with knowledge, but he distinguishes the apprehended object from the intentional object. Dharmottara, in addition, holds that perception has an intentional object, which rNgog Lo and Phya pa do not accept. See Hugon 2008b: 141-142. See also the discussion in I.2, 3.2 as to what this indicates in terms of the historical process that led to the use of these notions by Tibetan scholars.
} 
sel). This difference may be due to the nature of the initial focus in the 'Od zer on the definition of knowledge. But it can also have to do with the relative chronology of the composition of the 'Od zer and the Mun sel, which remains in question. ${ }^{28}$

While Phya pa's accounts of knowledge in the 'Od zer and the Mun sel are, generally speaking, consistent with one another, as discussed in $\$ 3.2$ of the introduction (I.2), the phrasing and meaning of criterion K1 is a point regarding which there appears to be a slight difference between the two texts. The Mun sel leans in the direction of a "strong" version of $\mathrm{K} 1$ that presupposes "novelty" (K2), whereas the 'Od zer proposes a "weaker" version of K1 that does not presuppose it. But this does not entail any crucial difference regarding the general system of knowledge and the types of awareness being distinguished. In both works, Phya pa identically puts forward an original criterion of knowledge and an interpretation of it that supports the adoption of a directly active model of perceptual knowledge.

\subsection{Topical outline (sa bcad)}

The subdivisions listed below belong to section III of the 'Od zer: The nature of the treatise. ${ }^{29}$ The titles indicated in smaller font are not part of the text edited in $\$ 2.3$ below, but are given to make clear the hierarchical structure of the passage. Ellipses indicate the presence of further subdivisions that are not recorded in the present outline.

${ }^{28}$ The fact the 'Od zer provides more detail than the Mun sel is not conclusive to assume its anteriority (based on the argument that the Mun sel would not need to repeat these details already presented elsewhere by the author). Indeed, one can also envisage that reactions to the Mun sel prompted the author to develop his presentation in a subsequent composition.

${ }^{29}$ The four main divisions of the work are: (I) bstan bcos rtsom pa'i rgyu (1b52b3), (II) rang gi bstan bcos kyi 'bras bu dgos 'brel (2b3-4a8), (III) bstan bcos kyi rang bzhin (4a8-196b5), (IV) bstan bcos kyi don nges pa mdo' mdzad pa'i dgongs pa rdzogs pa la bspro ba bskyed pa (196b6-9). 
1 The means of determining oneself the epistemic object (rang gis gzhal bya nges pa'i thabs)

11 The means of understanding something perceptible (mngon gyur rtogs pa' $i$ thabs)

111 General presentation of knowledge (tshad ma spyi'i rnam gzhag / tshad ma spyi i rnam par gzhag pa)

111.1 Concise presentation of the divisions ( $r a b$ du dbye' ba mdor gzhag pa) ...

111.2 Teaching the common definition as a member of the determination of the divisions (dbye' ba'i nges pa'i yan lag du thun mong gi mtshan nyid bstan pa)

111.21 How to indicate a definiendum through a definiens (mtshan nyid kyis mtshon bya mtshon pa'i tshul)

111.22 In particular, laying out the definiens of knowledge (bye brag du tshad ma'i mtshan nyid gtan la dbab pa)

111.221 Apprehending the definiens that we ourselves accept (rang gi 'dod pa'i mtshan nyid gzung pa)

111.221.1 Refuting the position of others (gzhan gyi lugs dgag pa)

A Master Dharmottara (slob dpon chos mchog)

A1 Objection of the non-Buddhist materialists ( $m u$ stegs 'jig rten rgyang phan pa dag gi rgol ba)

A2 Master Dharmottara's answer (slob dpon chos mchog gi lan)

The distinction between apprehended object and $20 \mathrm{~b} 8$ engaged object ( gzung yul dang 'jug yul gyi khyad par)

A3 Faults in Dharmottara's position (de la nyes pa)

B Prajñākaragupta (rgyan mdzad pa)

C Devendrabuddhi (lha'i d bang po blo gros)

111.221.2 Presenting our own position (rang gi lugs rnam $21 \mathrm{~b} 7$ par gzhag pa)

111.221.21 The specificity of the object, being veridical (yul bden pa'i khyad par) 
i. "Veridical" is not "withstanding analysis" $21 \mathrm{~b} 8$

ii. "Veridical" is not "not superimposed" 22a2

iii. Our own position 22a4

111.221.22 How the subject (awareness) is incompatible 22a5 with superimpositions (yul can sgro 'dogs dang 'gal ba'i tshul)

111.221.221 The nature of the superimpositions that are to 22a6 be excluded (gcad bya sgro 'dogs gyi rang bzhin)

i. The person (gang zag) 22a6

ii. The time $(d u s) \quad 22 \mathrm{a} 6$

iii. The aspect (rnam pa) 22a6

iii.1 Elimination of superimpositions that are di- $22 \mathrm{a} 7$ rectly incompatible with the positively discerned object (yongs su bcad pa'i don dang dngos 'gal [gyi sgro 'dogs sel])

iii.2 Elimination of superimpositions that are characterized by direct incompatibility (dngos 'gal gyis khyad par du byas pa'i sgro 'dogs sel ba)

iii.21 Characterized in the substance itself (rdzas de nyid la khyad par du byas par sgro 'dogs sel ba)

iii.22 Characterized in another substance (rdzas 22b1 gzhan la khyad par du byas par sgro 'dogs sel ba)

111.221.222 The nature of the counteragent that is what ex- $22 \mathrm{~b} 6$ cludes (gcod byed gnyen po'i rang bzhin)

111.221.223 How it is incompatible with the [superimposi- $23 \mathrm{a} 6$ tions] (de dang 'gal ba'i tshul)

111.222 Rejecting the faults of the definiens (mtshan nyid kyi nyes pa spang $\mathrm{pa}$ ) 
111.222.1 In general, the division between knowledge and $23 b 2$ what is not knowledge (spyir tshad ma dang tshad ma ma yin pa'i dbye ba)

(a) Division of apprehended objects (gzung yul gyi $23 b 2$ dbye ba)

D Our own position ([rang lugs])

(b) Divisions of awareness based on the apprehended object ([gzung yul la ltos nas blo'i dbye ba])

b.1 Awareness which takes as its apprehended object a real particular (don rang gi mtshan nyid gzung yul du byed pa'i blo)

b.11 Not incompatible with opposite superimposi$24 \mathrm{~b} 1$ tions (bzlog pa'i sgro 'dogs dang myi 'gal ba)

b.12 Incompatible with opposite superimpositions ([bzlog pa'i sgro 'dogs dang] 'gal ba)

b.121 Incompatible with opposite superimpositions with regard to an object previously known (sngar rtogs zin pa la sgro 'dogs dang 'gal ba)

b.122 Incompatible with opposite superimpositions with regard to an object not already known (rtogs ma zin pa la sgro 'dogs dang 'gal ba / ma rtog pa'i don la sgro 'dogs dang 'gal ba)

b.122.1 The way real entities exist (dngos po'i gnas lugs)

b.122.2 The way awareness apprehends them (blo' $i$ 'dzin stangs)

$24 b 3$

$24 \mathrm{~b} 4$

b.122.3 The manner by which it comes to be an ep$26 \mathrm{a} 9$ isode of knowledge (tshad mar 'gyur ba'i tshul)

b.2 Awareness which takes as its apprehended object the referent of a non-conceptual erroneous 
cognition ([rtog med 'khrul pa'i dmyigs pa 'dzin pa'i blo])

b.3 Awareness which takes as its apprehended ob$26 \mathrm{~b} 2$ ject a concept ([don spyi 'dzin pa'i blo])

b.31 That which does not conceive of its object being veridical externally (phyi rol du bden pa'i zhen pa myed pa)

b.32 That which conceives of its object being veridical externally ([phyi rol du bden pa ${ }^{\prime}$ zhen pa] yod pa / phyi rol du zhen pa)

b.321 That which conceives with the possibility of another option (mtha' gzhan du srid par zhen pa)

b.322 That which conceives without the possibility of another option ([mtha' gzhan $d u$ ] myi srid par zhen pa / mtha' cig tu zhen $p a$ )

b.322.1 Those in which conceiving does not correspond with the object to be cognized (shes bya dang myi mthun par zhen $p a$ )

b.322.2 Those in which conceiving corresponds with the object to be cognized (shes bya dang mthun par zhen $p a$ )

b.322.21 Those which direct with regard to an object previously known (sngar rtogs zin pa la zhen pa)

b.322.22 Those which direct with regard to an object not already known (rtogs ma zin pa la zhen pa)

b.322.221 Those which direct without relying on valid evidence (yang dag pa'i rtags kyi rjes su ma 'brangs pa'i zhen pa)

i. Factive assessment lacking a reason (rgyu mtshan myed pa'i yid dpyod) 
ii. Factive assessment having a mistaken

$26 \mathrm{~b} 5$ reason (log pa'i rgyu mtshan can gyi yid dpyod)

iii. Factive assessment with an uncertified

$26 \mathrm{~b} 6$ reason (rgyu mtshan gtan la ma phebs pa'i yid dpyod)

b.322.222 Those which direct by relying on valid $26 \mathrm{~b} 7$ evidence (yang dag pa'i rtags kyi rjes su 'brangs nas zhen $p a$ )

a.1 Based on a subject that is a real entity $26 \mathrm{~b} 7$ (chos can dngos po la rten pa)

The three operations ([byed pa gsum] $\quad 26 \mathrm{~b} 8$

i. Appearing (snang pa) $26 \mathrm{~b} 8$

ii. Directing (zhen pa) $26 \mathrm{~b} 9$

iii. Excluding (sel ba) $26 \mathrm{~b} 9$

a.2 Based on a subject that is superimposed $27 \mathrm{a} 1$ ([chos can] sgro btags la rten pa / gzhi kun brtags la 'jug pa) The three operations ([byed pa gsum]) 27a2

i. Appearing (snang pa) $27 \mathrm{a} 2$

ii. Directing (zhen pa) $27 \mathrm{a} 2$ iii. Excluding (sel ba) $27 \mathrm{a} 2$

a.3 Based on a subject that includes both $27 \mathrm{a} 3$ ([chos can] gnyis ga'i khyab byed la rten pa / gnyi' ga'i khyab byed gzhir gyur pa)

The three operations ([byed pa gsum]) 27a3

i. Appearing (snang pa) 27a3

ii. Directing (zhen pa) 27a4

iii. Excluding (sel ba) 27a4

(b) 27a5 
b.1 The way real entities exist (dngos po'i $27 \mathrm{a} 5$ gnas lugs)

b.2 The way awareness apprehends them 27a6 (blo'i 'dzin stangs)

b.3 The manner by which it (i.e., inferen- 27a7 tial cognition) comes to be an episode of knowledge (tshad mar 'gyur ba'i tshul)

(c)

111.222.2 Rejecting the fault of the definition being too nar$28 \mathrm{~b} 3$ row, not including awarenesses that are episodes of knowledge (tshad ma'i blo la ma khyab pa spang pa)

$28 \mathrm{~b} 3$

(b)

$28 \mathrm{~b} 5$

111.222.3 Rejecting the fault of the definition being too broad, including awarenesses that are not episodes of knowledge (tshad ma ma yin pa'i blo la khyab ches pa spang pa / tshad ma ma yin pa'i blo la khyab ches spang pa)

111.222.31 Mistaken cognition (log shes)

111.222.32 Post-knowledge cognition (bcad pa'i yul can) $28 \mathrm{~b} 9$

111.222.33 Doubt (the tshom)

$29 \mathrm{a} 4$

111.222.34 Factive assessment (yid dpyod) 29a5

111.222.35 Non-ascertaining perception (snang la ma 29a7 nges pa)

111.222.4 Refuting mistaken notions regarding the definitional instance (mtshan gzhi la log par rtogs pa dgag pa)

111.223 Reflecting on the episode of knowledge that determines that the definition applies (mtshan nyid nges par byed pa'i tshad ma bsam pa) 
112 The definition of perception (mngon sum gyi mtshan nyid)

113 Pseudo-perception (mngon sum ltar snang pa)

114 Presenting the result of knowledge / Knowledge and its result (tshad ma 'bras bu gtan la dbab pa / tshad ma dang 'bras bu) ...

12 The means of understanding something concealed / Inference-for-oneself (lkog gyur rtogs pa'i thabs / rang gi don gyi rjes su dpag pa) ...

2 The means of generating an understanding for someone else / Disputation statements, i.e., inference-for-others (gzhan la rtogs pa skyed pa'i thabs / rtsod pa'i ngag gzhan gyi don gyi rjes su dpag pa)

\subsection{Text of the parallel passages on blo rigs in 'Od zer (20b3-29b1)}

\subsection{2 bye brag du tshad ma'i mtshan nyid gtan la dbab pa}

bye brag du tshad ma'i mtshan nyid gtan la dbab pa la gsum ste / rang gi 'dod pa'i mtshan nyid gzung pa dang / mtshan nyid kyi nyes pa spang pa dang / mtshan nyid nges par byed pa'i tshad ma bsam pa'o/।

\subsection{1 rang gi 'dod pa'i mtshan nyid gzung pa}

[20b4] dang po la gzhan gyi lugs dgag pa dang / rang gi lugs rnam par gzhag pa gnyis so /

$[\ldots[20 \mathrm{~b} 8] \cdots]$

\section{[gzung yul dang 'jug yul gyi khyad par] \{Mun sel 121\}}

'o na gzung yul thob pa'i nus pa myi srid kyang 'jug yul thob pa'i nus pa myi srid pa ma yin na gzung yul dang 'jug yul la khyad par ci yod ce na I \{Mun sel 121.11\}

gzung yul ni blo de la $^{30}$ don de'i ngo bo nyid snang pa ste / rtog pa la don spyi snang pa dang ! rtog myed 'khrul pa la zla ba gnyis [20b9] lasogs pa

${ }^{30}$ Em. de $\langle$ la $\rangle$ : Ms de 
sgro btags gsal pa'i rnam par snang pa dang ' gzhan rig gi mngon sum la gzugs lasogs pa phyi rol kyi skad cig snang pa dang / rang rig la shes pa'i ngo bo'i skad cig myong pa rnams yin no //

\{Mun sel 121.13\}

'jug yul ni blo des don de la bzlog pa'i sgro 'dogs bsal pa ste / mngon sum gyis mngon du gyur pa'i don rnams la bzlog pa'i sgro 'dogs bcad pa 'am / rjes dpag gis lkog [21a1] du gyur pa'i don la bzlog pa'i sgro 'dogs bcad pa dag yin no //

\{Mun sel 121.2\}

de'ang mu bzhir 'gyur te /

$(++)$ gzung yul dang 'jug yul gnyi ga yin pa ni

- mngon sum la sngon po snang nas sngo ma yin gyi sgro 'dogs bcad pa na sngon po tsam po de blo la snang pas gzung yul yang yin la de la sngo ma yin gyi sgro 'dogs bcad pas 'jug yul yang yin pa'am /

- rjes dpag gis don spyi [21a2] chos can du bzhag ste dpyad myi bzod gyis kun rdzob gyi tha snyad bsgrub pa na don spyi dang kun rdzob kyi tha snyad kyi tshogs don de rjes dpag gi rtog pa la snang pas gzung yul yang yin la ma tshogs pa'i sgro 'dogs bcad pas 'jug yul yang yin pa lta bu'o //

(+-) gzung yul yin la 'jug yul ma yin pa ni

- du ba las mye bsgrub pa'i rjes dpag la de'i don spyi snang pa na don spyi blo la snang [21a3] pas gzung yul yin la don spyi la sgro 'dogs bcad pa myed pas 'jug yul ma yin pa 'am!

- mngon sum la skad cig ma snang pa de gzung yul yin yang rtag pa'i sgro 'dogs ma chod pas 'jug yul ma yin pa 'am!

- log shes la zla ba gnyis snang pas gzung yul yin yang gnyis myed kyi sgro 'dogs ma chod pas 'jug yul ma yin pa lta bu'o //

$(-+)$ 'jug yul yin la gzung yul [21a4] ma yin pa ni

- rjes dpag gis phyi rol gyi me'i dngos po la mye ma yin gyi sgro 'dogs bcad pas 'jug yul yin la mye'i dngos po snang pa myed pas gzung yul ma yin pa 'am!

- rtog pa myong pa'i rang rig gis yul rtag pa'i don spyi la rtag par myi snang pa'i sgro 'dogs bcad pas 'jug yul yin yang rtag pa'i don spyi rang rig la myi snang pas gzung yul ma yin pa lta bu'o //

$(--)$ [21a5] gnyi ga ma yin pa ni

- myig shes la sgra mi snang pas gzung yul yang ma yin la sgra la sgra ma yin gyi sgro 'dogs bcad pa myed pas 'jug yul yang ma yin pa lta bu'o // 
\{Mun sel 121.3\}

de la gzung yul bden zhes bya ni don byed nus pa yin la |' 'jug yul bden zhes bya ba ni shes bya'i gshis gnod myed du gnas pa'o/!

des na blo la'ang mu bzhir gnas te

(+-) gzung yul bden la 'jug [21a6] yul bden pa myed pa ni snang la ma nges pa ste de'i gzung pa dngos po yin la 'jug yul gtan myed pa'i phyir ro /4

$(-+)$ 'jug yul bden pa dang ldan la gzung yul bden pa myed pa ni rjes dpag ste de'i gzhal bya gnod myed du bden yang gzung yul don spyi don byed myi nus pa'i phyir ro /i

$(++)$ gnyis ga bden pa dang ldan pa ni mngon sum tshad ma ste / gzung pa'ang dngos po yin la [21a] gzhal bya'ang gnod myed du bden pa' $i$ phyir ro /!

(- -) gnyi ga bden pa myed pa ni zla ba gnyis 'dzin ste / gzung pa'ang sgro btags dngos myed yin la 'jug yul gtan myed pa'i phyir ro //

de la 'jug yul bden pa mngon sum dang rjes dpag tshad ma yin ${ }^{\mathrm{i}}$ la / 'jug yul bden pa myed pa'i snang la ma nges pa'i mngon sum dang zla ba gnyis 'dzin tshad ma ma yin pas [21a8] tshad ma ni 'jug yull ${ }^{31}$ bden pa dang rjes su 'gro ldog byed kyi gzung yul bden pa yod kyang snang la ma nges pa tshad ma ma yin pas gzung yul bden pa dang rjes su 'gro ba'ang myed la / gzung yul bden pa myed kyang rjes dpag la tshad ma ma log pas gzung yul dang ldog pa'ang myed pa'i phyir tshad ma'i yul ni gzung yul ma yin te 'jug yul kho na yin no //

$[\cdots[21 \mathrm{~b} 7] \cdots]$

\subsection{2 rang gi lugs rnam par gzhag pa $\{$ Mun sel 212.14\}}

gnyis pa rang gi lugs rnam par gzhag pa ni sngar ma rtogs pa'i don bden pa la bzlog pa'i sgro 'dogs dang 'gal ba tshad ma'i mtshan nyid yin no / de'ang yul bden pa'i khyad par dang / yul can sgro 'dogs dang 'gal ba'i tshul gnyis kyis nges [21b8] par bya'o /

$[\ldots[22 \mathrm{a} 4] \ldots]$

\subsubsection{1.iii. [rang lugs]}

des na shes bya'i gshis su gnas shing gnod myed du bden pa ni bden pa ste /

${ }^{31}$ Em. 'jug yul : Ms 'jug la 
$[\ldots[22 \mathrm{a} 5] \cdots]$

de ltar gnod myed du bden pa de'ang tshad mas sngar ma rtogs pa ni tshad ma'i yul yin no //

\subsubsection{2 yul can sgro 'dogs dang 'gal ba'i tshul}

yul can sgro 'dogs dang 'gal ba'i tshul yang gcad bya sgro 'dogs gyi rang bzhin dang / gcod byed gnyen po'i rang bzhin [22a6] dang / de dang 'gal ba'i tshul gsum gyis nges par bya'o /i

\subsubsection{1 gead bya sgro 'dogs gyi rang bzhin}

dang po $\mathrm{ni}^{32}$

\section{i. gang zag}

gang zag ni tshad ma rgyud la skyes pa'i gang zag la yod pa'i sgro 'dogs sel gyi gang zag gzhan la yod pa myi sel lo/i

\section{ii. dus}

dus kyang tshad ma skyes nas dran pa'i 'du byed ma nyams pa'i bar du 'jug pa'i sgro 'dogs sel gyi tshad ma ma skyes pa dang rjed pa'i dus na 'jug pa'i sgro 'dogs myi sel lo/!

\section{iii. rnam pa}

sgro 'dogs kyi rnam pa'ang [22a7] yongs su bcad pa'i don dang dngos 'gal dang dngos 'gal gyis khyad par du byas pa'i sgro 'dogs sel gyi gzhan myi sel lo/!

\section{iii.1 yongs su bcad pa'i don dang dngos 'gal}

dngos 'gal gyi sgro 'dogs sel ba ni mngon sum la sngon po snang pa na sngo ma yin du sgro 'dogs pa sel ba dang । rjes dpag gis myi rtag par nges pa na rtag pa'i sgro 'dogs sel ba lta bu'o //

\section{iii.2 dngos 'gal gyis khyad par du byas pa}

dngos 'gal gyis khyad par du byas pa'i sgro 'dogs sel ba'ang rdzas de nyid la [22a8] khyad par du byas par sgro 'dogs sel ba dang / rdzas gzhan la

${ }^{32}$ Em. ni : Ms na 
khyad par du byas par sgro 'dogs sel ba'o /।

\section{iii.21 rdzas de nyid la}

dang po ni sngon por mthong pa'i rdzas la sngo ma yin bsal ba na sngo ma yin dang tshogs pa'i rtag pa dang myi rtag pa lasogs pa sel ba dang ! skad cig mar dpags pa'i gzhi la skad cig ma ma yin pa bsal pa na skad cig ma ma yin pa dang tshogs pa'i sngon po dang sngo ma yin lasogs [22a9] pa mtha' dag khegs pa ltar dgag byas khyad par du byas pa khegs pa dang / shes bya tsam dang don dam pa'i dngos po tshogs pa khegs pa na shes byas khyad par du byas pa'i ma mthong pa'i shes bya dang yang don dam pa'i dngos po dang tshogs pa khegs pa ltar tshogs pa bkag pa'i dgag gzhis khyad par du byas pa dang tshogs pa ${ }^{33}$ khegs gnyis yin no /

'gal ba yin yang dngos 'gal gyis khyad par [22b1] du ma byas na tshad ma des myi khegs te / sngon po nges pa na rtag pa tsam myi khegs pa bzhin no //

\section{iii.22 rdzas gzhan la}

rdzas gzhan la khyad par du byas pa'i sgro 'dogs sel ba ni blo myi bden pa'i yul can yin pa de yul bden pa ma yin pas khyad par du byas pas rjes dpag dang gzhan rig pas yul la myi bden pa dngos su khegs pa na blo la myi bden pa'i yul can shugs la khegs pa dang /

[22b2] rtag pa'i rnam par myi snang pa ni blo rtag 'dzin myed pa la ltos pas blo rtag 'dzin du myed pa rang rig pas khegs pa na yul rtag pa'i rnam par myi snang pa shugs la khegs pa dang /

byas pa la myi rtag pas ma khyab pa'ang byas pa rtag pa la 'jug pa yin la / byas pa rtag pa la 'jug pa' ang rtag pa byas ${ }^{34}$ pa'i 'jug sa yin pas khyad par du ${ }^{35}$ byas pas gnod pa can gyis rtag pa byas pa'i 'jug sa yin pa dngos [22b3] su khegs pa na byas pa rtag pa la 'jug pa po yin pa shugs la khegs pas byas pa la myi rtag pas khyab pa nges pa lta bu'o //

de la dngos 'gal khegs pa rnams ni spyir tshad ma de gzhal bya de nyid la blo kha phyogs pa'i stobs kyis khegs la / bye brag du mngon sum la gzhal bya de snang pas bzlog pa khegs pa dang | rjes dpag gis gzhal bya de

\footnotetext{
${ }^{33}$ Em. tshogs $\langle\mathrm{pa}\rangle:$ Ms tshogs

${ }^{34} \mathrm{Em}$. 〈rtag pa $\rangle$ byas : Ms byas

${ }^{35} \mathrm{Em} . \operatorname{par}\langle\mathrm{du}\rangle:$ Ms par
} 
dpags te de'i don spyi snang pa'i stobs [22b4] kyis sgro 'dogs bcad pa na dngos su rtogs ${ }^{36}$ pa zhes bya la /

dngos 'gal gyis khyad par du byas pa rnams ni spyir gzhal bya gzhan la blo kha phyogs pas sgro 'dogs sel ba dang / bye brag du mngon sum la gzhal bya gzhan snang pa'i stobs kyis sgro 'dogs sel ba yin zhing | rjes dpag gis gzhan gyi don spyi snang pas sgro 'dogs sel ba yin pas shugs la rtogs pa zhes bya ste /

rdzas de [22b5] ma yin pa la dngos 'gal gyis khyad par du byas pa bkag pa rnams ni mngon sum la'ang rang gi mtshan nyid snang pa myed la rjes dpag la'ang don spyi snang pa gtan myed pa'i phyir dang /

rdzas de nyid la dngos 'gal gyis khyad par du byas pa bkag pa rnams ni rjes dpag la dgag bya'i don spyi myi snang pas bkag pa'i don spyi snang pa gtan myed pa'i phyir dang ! mngon sum la bkag pa'i rang gi mtshan nyid snang [22b6] yang de rnam myed yin pas snang pa de sgro 'dogs gyi gnyen po maii yin pa'i phyir /

spyir gzhal bya de la blo kha phyogs nas sgro 'dogs chod pa dang / mngon sum la gzhal bya de nyid snang pa'i stobs kyis sgro 'dogs chod pa dang / rjes dpag la gzhal bya de'i don spyi shar nas sgro 'dogs chod pa myed pas dngos su rtogs pa ni ma yin no //

\subsubsection{2 gcod byed gnyen po'i rang bzhin \{Mun sel 212.14 (a)\}}

gcod byed gnyen po'i rang bzhin yang

- sgro 'dogs la gnod [22b7] pa tsam ma yin te / yid dpyod kyis sgra mi rtag par nges pas rtag pa'i sgro 'dogs la gnod pa dang / log shes kyis dngos po don dam par rtag par nges pas myi rtag pa'i don dam du sgro 'dogs pa la gnod kyang tshad ma ma yin pa'i phyir ro /i

- myong pa'i stobs kyis sgro 'dogs sel ba ma yin te / rjes dpag la ma khyab pa'i phyir ro /!

- rtags stobs kyis sgro 'dogs sel ba ma yin te mgnon sum $_{[22 b 8]}$ la ma khyab pa'i phyir ro /!

- myong pa 'am rtags kyi stobs kyis sgro 'dogs sel zhes kyang brjod par myi bya ste / shes bya'i mtshan nyid rtag pa 'am myi rtag pa zhes brjod pa ltar mtshon bya cig mtshon pa la mtshan nyid gnyis rnam par brtag pa myi rung pa'i phyir ro //

des na yongs su bcad pa'i don myed na myi 'byung pa'i 'dzin stangs kyis sgro 'dogs dang 'gal ba ste /

$[\ldots[23 a 1] \ldots]$

${ }^{36}$ Em. rtogs : Ms khegs 
tshad ma thams cad rang gi gzhal bya myed na myi 'byung pa'i 'dzin stangs kyis bzlog pa'i sgro [23a2] 'dogs dangiii 'gal ba yin no /।

$[\ldots[23 a 6] \cdots]$

\subsubsection{3 de dang 'gal ba'i tshul \{Mun sel 212.14 (b)\}}

gsum pa sgro 'dogs dang 'gal ba'i don yang

- sgro 'dogs mngon du gyurr ${ }^{37}$ dang phrad de sgro 'dogs kyis rgyu byas tshad mas rkyen byas pas sgro 'dogs nus pa myed par byas nas dngos su zlog pa la rjod pa ma yin te / de lta bu mngon sum la yod kyang rjes dpag la myed pas tshad ma'i mtshan nyid la ma khyab par 'gyur [23a7] ba'i phyir ro / rjes dpag la yod na ni mi rtag par nges pa'i rjes dpag dang rtag pa'i sgro 'dogs phrad na rtog pa gnyis gcig char du 'jug par thal ba'i phyir ro //

- sgro 'dogs skyer rung pa'i nus pa dang phrad nas de la gnod pa'ang ma yin te / thams cad mkhyen pa'i ye shes sgro 'dogs skyer rung pa'i nus pa dang phrad pa myed pas tshad ma ma yin par thal ba'i phyir ro / phrad pa yod na ni thams cad mkhyen [23a8] pas sgrib pa'i sa bon ma spangs par' gyur ro /!

- sgro 'dogs la tshad ma'i rgyus gnod pa'ang ma yin te rgyu rtags 'dzin pa'i rtog pa'ang sgro 'dogs kyi rtog pa dang rgyud ${ }^{38}$ gcig la 'tshogs pa myed pa'i phyir dang / rgyus gnod pa'ang tshad ma yin na mngon sum gyi rjes la 'byung pa'i nges pa'ang tshad mar 'gyur ba'i phyir ro //

des na mye stobs ldan de grang reg dang phrad dam ma phrad pa [23a9] nyi ma tsha ba'i 'od kyis khyab pa'i sa na gnas kyang rung ste grang reg dang phrad na de nus pa myed par byed pa'i nus pa de la yod pas grang reg dang 'gal bar rjod pa ltar / rgyud de la sgro 'dogs yod dam myed kyang rung ste sgro 'dogs dang phrad na nges par nus pa myed par byed pa'i nus pa yod pas sgro 'dogs gyi gnyen por gnas pa de sgro 'dogs gcod par byed pa'i don yin no $/$ i

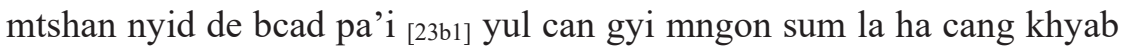
pa'ang ma yin te / yul gyi khyad par sngar ma rtogs pa la'ang 'jug pas bcad pa'i yul can bsal pa'i phyir ro /I

\footnotetext{
${ }^{37}$ Em. gyur : Ms rgyu

${ }^{38}$ Em. rgyu $\langle d\rangle$ : Ms rgyu
} 
des na tshad ma'i mtshan nyid ni sngar ma rtogs pa'i don bden pa la don la myi 'khrul ba'i 'dzin stangs kyis bzlog pa'i sgro 'dogs dang 'gal ba yin no //

myi slu ${ }^{39}$ zhes rjod pa'ang yongs su bcad pa'i don la gnod pa myed [23b2] pa yin pas don snga ma nyid las ma 'das ste ! gnod myed 'di ni myi slu $\mathrm{ba}^{40}$ zhes gsungs pa yin no //

\subsection{2 mtshan nyid kyi nyes pa spang pa}

mtshan nyid kyi nyes pa spang pa ni bzhi ste / spyir tshad ma dang tshad ma ma yin pa'i dbye ba dang / tshad ma'i blo la ma khyab pa spang pa dang / tshad ma ma yin pa'i blo la khyab ches pa spang pa dang / mtshan gzhi la log par rtogs pa dgag pa'o //

\subsection{1 spyir tshad ma dang tshad ma ma yin pa'i dbye ba} dang po yang

\subsection{1.a gzung yul gyi dbye ba $\{$ Mun sel 11.a\}}

blo tha dad pa de bzung pa [23b3] tha dad pa'i dbang gis yin pas blo'i gzung pa la gnyis te /

- yul dang dus dang rang bzhin 'dres pa'i rnam pa can myi gsal ba ni don spyi zhes bya ste rtog pa'i gzung pa'o / de ni sgro btags dngos myed kho na yin no /i

- yul dus ma 'dres par gsal bar snang pa ni rtog myed kyi gzung pa yin no / de la gnyis las

- gsal la don byed myi nus pa ni rtog myed 'khrul pa'i dmigs pa [23b4] yin no /i

- shes pa dang yul dang dbang po dang snod kyi 'jig rten lasogs pa gsal la don byed nus pa ni don rang gi mtshan nyid yin te / mngon sum gyi gzung pa yin no /i

de ltar don spyi dang don rang gi mtshan nyid dang rtog myed 'khrul pa'i dmyigs pa gsum la'ang

${ }^{39} \mathrm{Cf}$. PVin 1 1,10: na hy ābhyām artham paricchidya pravartamāno 'rthakriyāyām visamvādyate; Tib. 30,17-18: 'di dag gis don yongs su bcad nas 'jug pa na don bya ba la bslu ba med pa'i phyir ro //

${ }^{40}$ PV 1.215: pratyakșeṇānumānena dvividhenāpy abādhanam / drșțādrșțārthayor asyāvisamvvādas tadarthayoh //; Tib.: mthong dang ma mthong dngos po yi // don de dag la mngon sum dang // rjes su dpag rnam gnyis kyis kyang // gnod med 'di yi mi slu ba'o // 
$[\ldots[24 a 9] \ldots]$ \{Mun sel $[\mathrm{EX} 2]\}$

\subsection{1.a.D [rang lugs] $\{$ Mun sel 111.a.D\}}

de bas na don spyi dang rtog myed 'khrul pa'i dmigs pa ni dngos myed yin la pa sems dang sems las byung pa ni dngos po yin no //

\subsection{1.b [gzung yul la ltos nas blo'i dbye ba] \{Mun sel 11.b\}} de ltar gzung cha gsum po de las

\subsection{1.b.1 don rang gi mtshan nyid gzung yul du byed pa'i blo \{Mun} sel 11.b.i and 112.2$\}$

don rang gi mtshan nyid gzung yul du byed pa'i blo ni mngon sum yin te | gzung don [24b1] la ma 'khrul ba'i phyir ro /4

de la gnyis te bzlog pa'i sgro 'dogs dang myi 'gal ba dang / 'gal ba'o/।

\subsection{1.b.11 bzlog pa'i sgro 'dogs dang myi 'gal ba \{Mun sel 122.122.1} and 123.12 \}

dang po ni sngon po snang pa na de'i skad cig ma snang yang skad cig ma ma yin pa'i sgro 'dogs dang myi 'gal ba lta bu'o /

de ni don rang gi mtshan nyid snang yang bzlog pa'i sgro 'dogs dang myi 'gal ba'i mtshan nyid yod pas snang la ma nges pa yin no //'

\subsection{1.b.12 bzlog pa'i sgro 'dogs dang 'gal ba}

bzlog pa'i sgro 'dogs [24b2] dang 'gal ba la'ang gnyis te / sngar rtogs zin pa la sgro 'dogs dang 'gal ba dang / rtogs ma zin pa la sgro 'dogs dang 'gal ba'o/!

111.222.1.b.121 sngar rtogs zin pa la sgro 'dogs dang 'gal ba $\{$ Mun sel 122.122 .21 and 123.22$\}$

dang po ni sngar rtogs zin pa'i sngon po la phyis sngon por snang pas sngon po ma yin pa'i sgro 'dogs dang 'gal ba lta bu ste / sgro 'dogs chod zin pa'i don la bzlog pa'i zhen pa dang 'gal bas 'jug pa'i mtshan nyid yod pas bcad pa'i yul can yin [24b3] no /। 


\subsection{1.b.122 rtogs ma zin pa la sgro 'dogs dang 'gal ba / ma rtog pa'i don la sgro 'dogs dang 'gal ba \{Mun sel 122.122.221\}}

ma rtog pa'i don la sgro 'dogs dang 'gal ba ni sngar rtogs ma zin pa'i sngon po snang nas sngo ma yin gyi sgro 'dogs dang 'gal ba lta bu'o / de ni mngon sum tshad ma yin no//

de la gsum ste / dngos po'i gnas lugs dang / blo'i 'dzin stangs dang / tshad mar 'gyur ba'i tshul lo //

\subsection{1.b.122.1 dngos po'i gnas lugs \{Mun sel 111.b.1, 111.b.3, 112.111.112.1\}}

dngos po'i gnas lugs kyang

- sngon por gnas pa dang de dang bdag gcig pa'i byas pa dang myi rtag pa [24b4] lasogs pa dang dbye ba gtan myed pas tha dad kyis stong par gnas pa dang /

- yul gzhan gyi sngon po dang skad cig snga phyi lasogs pa dus gzhan gyi sngon po dang be dur rya dang ud dpal la lasogs pa rang bzhin gzhan gyi sngon po rnams dang rdzas gcig pa gtan myed pas rjes su 'gro bas stong pa yin no /i

\subsection{1.b.122.2 blo'i 'dzin stangs \{Mun sel 112.22\}}

blo'i 'dzin stangs kyang dngos po'i gnas lugs ji lta ba bzhin du 'dzin pa yin te /

- [24b5] Sngon po la sngon por 'dzin pa myong pa nyid kyis nges so /

- rang bzhin tha dad dang yul tha dad pa'i sngon po myi sre bar 'dzin pa yang mngon sum nyid kyis nges so /!

- da ltar gyi sngon po snang pa na 'das pa dang ma 'ongs pa'i sngon po ni myed pas myi snang la / myi snang pa'i phyir de dang sre pa myed do zhes rjes dpag gis nges so //

- tha dad myed pa dag kyang

- rnam ${ }^{41}$ pa dang ldan pa rnams gcig du snang pa ni myong pa [24b6] nyid kyis nges so /

- rnam pa dang myi ldan pa rnams dang rnam ldan bdag gcig pa snang myi snang cha gnyis myed par rjes dpag gis nges te / de'ang rtags dgod pa dang / brtsad pa spang pa gnyis kyis nges par bya'o/I

$[\ldots[26 a 9] \ldots]$ \{Mun sel $[\mathrm{EX} 4]$ \}

${ }^{41}$ Em. rnam : Ms (s)na $\left\{{ }^{*}\right\}$ 


\subsection{1.b.122.3 tshad mar 'gyur ba'i tshul \{Mun sel 112.23\}}

tshad mar 'gyur ba'i tshul ni snang pa na bdag nyid thams cad kyis snang yang gang bzlog pa'i sgro 'dogs dang 'gal ba'i cha nas tshad ma yin gyi sgro 'dogs dang myi 'gal na tshad ma ma yin te / sngon po snang pas sngo ma yin ${ }^{\text {iv }}$ [26b1] gyi sgro 'dogs dang 'gal bas sngon po la tshad ma yin zhing myi rtag pa snang yang rtag pa'i sgro 'dogs dang myi 'gal bas myi rtag pa la tshad ma ma yin pa $^{42}$ bzhin no $/ 1$

kha cig zhen pa 'dren nus na tshad ma yin la myi nus na tshad ma ma yin no zhes zer ba

de'i ltar na nges shes 'gag ka ma myong pa'i rang rig zhen pa myi 'dren pa dang ! thams cad mkhyen pa'i mngon sum zhen pa myi 'dren pa [26b2] de tshad ma ma yin par'gyur ro //

\subsection{1.b.2 [rtog med 'khrul pa'i dmyigs pa 'dzin pa'i blo] \{Mun sel} 11.b.iii and 112.3$\}$

ma 'dres par gsal yang don byed myi nus pa zla ba gnyis lasogs pa snang pa ni rtog myed 'khrul pa ste gzung don la 'khrul pa'i log shes kho na yin no //

\subsection{1.b.3 [don spyi 'dzin pa'i blo] \{Mun sel 11.b.ii and 112.1\}}

yul dang dus dang rang bzhin 'dres pa thun mong pa'i rnam pa sgro btags pa'i don spyi 'dzin pa ni rtog pa'o/।

de la gnyis te phyi rol du bden pa'i zhen pa myed pa dang yod pa'o /

\subsection{1.b.31 phyi rol du bden pa'i zhen pa myed pa \{Mun sel 112.12 \}}

[26b3] dang po ni dbul po dag gis rgyal srid kyi don spyi yul du byas nas de nyid myi bden par shes pa lta bu ste / gzung don la 'khrul pa'i log shes kho na yin no /I

\subsection{1.b.32 phyi rol du bden pa'i zhen pa yod pa / phyi rol du zhen pa $\{$ Mun sel 112.11\} \\ phyi rol du zhen pa'ang mtha' gzhan du srid par zhen pa dang / myi srid par zhen pa'o/!}

${ }^{42}$ Em. tshad ma $\langle\mathrm{ma}\rangle$ yin pa : Ms tshad ma yin pa 
111.222.1.b.321 mtha' gzhan du srid par zhen pa \{Mun sel 112.112 and $123.51\}$

dang po ni sngon po 'di rtag yang srid myi rtag yang srid snyam pa ste the tsom gyi shes pa yin no /i

111.222.1.b.322 [mtha' gzhan du] myi srid par zhen pa / mtha' cig tu zhen pa

mtha' cig tu zhen pa la'ang [26b4] shes bya dang myi mthun par zhen pa dang mthun par zhen pa gnyis so /।

111.222.1.b.322.1 shes bya dang myi mthun par zhen pa \{Mun sel 112.111.2, 122.121 and 123.41$\}$

dang po ni sgra rtag par zhen pa lta bu ste shes bya la myi srid pa sgro 'dogs pa'i log shes yin no/!

\subsection{1.b.322.2 shes bya dang mthun par zhen pa}

shes bya dang mthun par zhen pa la'ang sngar rtogs zin pa la zhen pa dang rtogs ma zin pa la zhen pa gnyis so //

111.222.1.b.322.21 sngar rtogs zin pa la zhen pa \{un sel 122.122 .21 and $123.21\}$

dang po ni rjes su skyes pa'i nges shes dang 'das pa'i don dran pa lasogs pa ste / bcad pa'i yul [26b5] can gyi shes pa yin no /।

\subsection{1.b.322.22 rtogs ma zin pa la zhen pa}

rtogs ma zin pa la zhen pa la'ang yang dag pa'i rtags kyi rjes su ma 'brangs pa'i zhen pa dang / yang dag pa'i rtags kyi rjes su 'brangs nas zhen pa'o //

111.222.1.b.322.221 yang dag pa'i rtags kyi rjes su ma 'brangs pa'i zhen pa $\{$ Mun sel 122.122.222.2 and 123.3\}

dang po ni

\section{i. rgyu mtshan myed pa'i yid dpyod}

rgyu mtshan la ma brten par sgra myi rtag ces nges pa lta bu rgyu mtshan myed pa'i yid dpyod dang ! 


\section{ii. log pa'i rgyu mtshan can gyi yid dpyod}

myig gi gzung bya la brten nas sgra myi rtag par dpog pa dang gzhal bya la brten [26b6] nas sgra mi rtag par dpog pa lta bu ma grub pa dang ma nges pa la brten nas bsgrub bya bden pa nges pa log pa'i rgyu mtshan can gyi yid dpyod dang !

\section{iii. rgyu mtshan gtan la ma phebs pa'i yid dpyod}

byas pa la brten nas myi rtag pa dpog kyang phyogs chos sam khyab pa 'am gnyi ga tshad mas ma nges par yid dpyod gyis nges pa la brten nas bsgrub bya bden pa nges pa rgyu mtshan gtan la ma phebs pa'i yid dpyod gsum ste yid dpyod gyi shes pa ${ }_{[26 b 7]}$ yin no //

\subsection{1.b.322.222 yang dag pa'i rtags kyi rjes su 'brangs nas zhen pa $\{$ Mun sel 122.122.222.1\}}

gnyis pa ni phyogs chos dang khyab pa tshad mas nges pa'i byas pa la brten nas myi rtag par nges pa lta bu ste /

\subsection{1.b.322.222.a \{Mun sel 112.111.111\}}

de la'ang chos can dngos po la rten pa dang / sgro btags la rten pa dang / gnyi ga'i khyab byed la rten pa gsum mo /।

\section{a.1 chos can dngos po la rten pa}

dang po ni

sgra la byas pas myi rtag pa dpog pa lta bu [b] gzhan dbang la gzhan dbang nyid dpog pa dang /

dngos po la gcig dang du bral gyis [26b8] stong nyid dpog pa lta bu [e1] gzhan dbang la yongs su grub pa dpog pa gnyis so /।

\section{[byed pa gsum]}

de gnyis ka [b,e1] la'ang snang pa dang zhen pa dang gzhan sel ba'i byed pa gsum las

\section{i. snang pa}

dang po ni [b] sgra dang myi rtag pa'i tshogs don gyi don spyi dang [e1] dngos po dang stong nyid gyi tshogs don gyi don spyi snang ste sum ma yin pas gzhan dbang nyid kyang myi snang la bden pa mthong pa'i mngon sum ma yin pas gzhan dbang gi [2669] chos nyid yongs su grub 
pa'ang myi snang ste ! kun brtags kho na snang pa yin pas gzung don la 'khrul pa'i log shes yin no/!

\section{ii. zhen pa}

zhen pa ni don spyi snang pa de [b] sgra dang myi rtag pa tshogs pa'i ngo bor zhen pa 'am [e1] dngos po dang stong pa nyid tshogs pa'i ngo bor zhen te kun brtags la [b] gzhan dbang dang [e1] yongs su grub du zhen pas snang brtags bsre ba'i log shes yin no /।

\section{iii. sel ba}

sel ba ni de ltar [27a1] don spyi snang pa des [b] sgra dang myi rtag pa tshogs pa myed pa'i dogs pa sel zhing [e1] dngos po la bden pa'i dngos po yod pa'i dogs pa sel te!

- shes bya'ang [b] sgra rtag pas dben la ${ }_{\mid}^{1}$ [e1] dngos po don dam pa'i dngos pos dben zhing

- blos kyang [b] sgra la rtag pa'i dogs pa sel la pa'i dngos po yod pa'i dogs pa sel bas

tshad ma kho na'o //

\section{a.2 [chos can] sgro btags la rten pa / gzhi kun brtags la 'jug pa}

gzhi kun brtags la 'jug pa ni ri bong can [27a2] gyi sgra don la rtog pa'i gzung yul yin pas zla ba'i sgra'i dngos kyi brjod bya dpog pa lta bu [d] ste /

\section{[byed pa gsum]}

\section{i. snang pa}

snang pa ni ri bong can gyi don spyi dang sgra'i dngos kyi brjod bya'i tshogs pa'i don spyi snang ste / kun brtags snang pas gzung don la 'khrul pa'i log shes kho na'o/!

\section{ii. zhen pa}

zhen pa ni snang pa de don spyi'i ngo bo nyid du zhen ste / de la ni 'khrul pa myed do /i

\section{iii. sel ba}

sel ba ni ri bong can gyi don spyi la sgra'i dngos kyi [27a3] rjod bya ma yin pa'i dogs pa sel te! 
- shes bya'ang dngos kyi rjod bya ma yin pas dben la

- blos kyang dngos kyi rjod bya ma yin pa sel bas tshad ma kho na'o/।

\section{a.3 [chos can] gnyis ga'i khyab byed la rten pa / gnyi' ga'i khyab byed gzhir gyur pa \{Mun sel 112.111.111.3 [d]\}}

gnyi' ga'i khyab byed gzhir gyur pa ni shes bya tsam la cig dang du bral khyab byed du yod pas stong pa nyid khyab byed du yod pa dpog pa [e2] lta bu ste !

\section{[byed pa gsum]}

\section{i. snang pa}

snang pa ni shes bya dang stong pa nyid kyi tshogs don gyi don spyi snang ste / de'ang snga ma ltar [27a4] gzhan dbang dang yongs grub snang par myi 'thad pas kun brtags kho na snang pa'i phyir gzung don la 'khrul pa'i log shes yin no //

\section{ii. zhen pa}

zhen pa ni don spyi ${ }^{43}$ de nyid shes bya dang stong pa nyid tshogs par zhen te de'ang kun brtags kho na'i rang bzhin yin pa la shes bya spyi'i rang bzhin du zhen pas log shes yin no /!

\section{iii. sel pa}

sel ba ni shes bya la bden pa'i dngos po yod pa'i dogs pa sel te! - shes [27a5] bya'ang bden pa'i dngos pos stong la - blos kyang bden pa'i dngos po bsal bas shes bya dang mthun pa'i phyir tshad ma kho na yin no //

\subsection{1.b.322.222.b \{Mun sel 112.111.112\}}

de ltar rjes su dpag pa de la'ang dngos po'i gnas lugs dang / blo'i 'dzin stangs dang / tshad mar 'gyur ba'i tshul gsum las /

\section{b.1 dngos po'i gnas lugs}

dngos po'i gnas lugs ni sgra mi rtag par dpog pa lta bu [b] la - myi rtag par gnas pa dang $/^{\mathrm{v}}$

\footnotetext{
${ }^{43}$ Em. zhen pa ni don spyi : Ms zhen pa’i don d" spyi
} 
- byas pa dang myi rtag pa lasogs [27a6] pa dbyer myed pas tha dad kyis stong pa dang?

- sgra dang bum pa'i myi rtag pa dang yul 'di dang gzhan gyi myi rtag pa dang ? dus da ltar dang 'das ma 'ongs kyi myi rtag pa phan tshun dben pas rjes su 'gro bas stong par gnas pa yin no /I

\section{b.2 blo'i 'dzin stangs}

blo'i 'dzin stangs ni

- mi rtag pa la de nyid du 'dzin pas de dang mthun la /

- dbyer myed pa la sgra dang myi rtag pa dang byas pa tha dad du snang zhing myi rtag pa so so ba rnams la [27a7] myi rtag pa tsam zhes don spyi gcig du 'dzin pas tha dad gyis stong pa dang rjes 'gros stong pa dang ma mthun te | tha dad dang rjes 'gro'i don spyi'i 'dzin pa yin no /i

\section{b.3 tshad mar 'gyur ba'i tshul}

tshad mar 'gyur ba'i tshul ni sgra'ang rtag pas dben la blos kyang rtag pa'i dogs pa sel bas gzhan sel ba'i cha kho na la tshad ma yin no //

\subsection{1.b.322.222.c $\{$ Mun sel $[E X 3]\}$}

\section{$[\ldots[2862] \cdots]$}

de ltar

- rtog myed ma 'khrul ba la snang la ma nges pa dang bcad pa'i yul can dang mngon sum tshad ma gsum dang /

- [2863] rtog myed 'khrul pa gcig kho na dang /

- rtog pa la zhen pa myed pa dang the tsom gyi zhen pa dang log par zhen pa dang bcad pa'i yul can gyi zhen pa dang / yid dpyod dang rjes dpag drug ste

blo bcu tham par dbye ba ni spyir tshad ma dang tshad ma ma yin pa'i dbye ba'o //

\subsection{2 tshad ma'i blo la ma khyab pa spang pa \{Mun sel 212.21 \}}

gnyis pa tshad ma'i blo la ma khyab pa spang pa ni

(a) $\{$ Mun sel 212.21 (a)\}

gal te mngon sum tshad ma rtog [28b4] pa myed pa yin pas gzhan sel ba myed pa'i phyir sgro 'dogs dang 'gal ba myed pas sngar bshad pa'i mtshan nyid kyis de la ma khyab po zhe na I 
sgro 'dogs dang 'gal ba ni sgro 'dogs da ltar ba dang bral ba'i gzhan sel ba ni ma yin gyi sgro 'dogs kyi gnyen po byed pa yin la mngon sum rtog pa myed pa yin yang skad cig dang po la mngon sum dang sgro 'dogs tshogs la gnyis pa [28b5] la sgro 'dogs gyis rgyu byas mngon sum gyis rkyen byas te sgro 'dogs nus myed du bskyed nas gsum pa la sgro 'dogs $\operatorname{ldog}^{\mathrm{vi}}$ pa na sgro 'dogs gyi gnyen po mngon sum kho na yin te ' sgro 'dogs nus myed du skyed 'khan mngon sum yin pa'i phyir ro //

(b) $\{$ Mun sel 212.21 (b) $\}$

yang rjes su dpag pa ni rtog pa yin la de'i yul ni don spyi yin pas yul bden pa myed pa'i phyir bden pa rtogs pas de la [28b6] ma khyab po zhe na I

gzung yul don spyi yin yang de la ltos nas tshad mar rjod pa ma yin te ! de la ltos nas log shes kho na'o/!

tshad ma ni 'jug yul la ltos nas yin la !'jug yul ni dngos po 'am sgro btags sam myed dgag tsam yin yang rung ste ! shes bya'i gshis gnod myed du bden pa thams cad la yod pa'i phyir bden pa rtogs pas rjes dpag la ma khyab pa ma yin ${ }^{\mathrm{vii}}{ }_{[28 \mathrm{~b} 7]}$ no //

\subsection{3 tshad ma ma yin pa'i blo la khyab ches pa spang pa / tshad ma ma yin pa'i blo la khyab ches spang pa \{Mun sel 212.22\}}

gsum pa tshad ma ma yin pa'i blo la khyab ches spang pa ni blo lhag ma brgyad po'ang lngar ${ }^{44}$ 'du ste /

\subsubsection{1 log shes $\{$ Mun sel 123.4$\}$}

rtog myed 'khrul pa dang rtog pa thams cad gzung don la 'khrul pa yin la : zhen yul phyin ci log du gcod pa'i log shes kyang zhen yul la ltos te log shes yin pas de thams cad la don phyin ci log du yongs su gcod pa zhes bya ba'i mtshan nyid yod pas log shes su 'du ba yin no /।

- [28b8] de dag kyang don yongs su gcod par ni rang rig gis nges la ! - phyin ci log du gcod par ni yul la gnod pa yod pa'i tshad mas nges so /

gal te sgra rtag par zhen pa dag mi rtag pa las phyin ci log du gcod pas don phyin ci log du gcod pa yin na gzung don la 'khrul pa dag don phyin ci log du ji ltar gcod ce na /

${ }^{44}$ Em. lngar : Ms sngar 
de dag gi gzung pa blo la ma ltos par phyi rol na myed bzhin [28b9] du blo la ma ltos par phyi rol na yod pa lta bur snang pas don phyin ci log du gcod pa yin no//

gzung pa de dag rang rig gi shugs la gzhal ba ni blo la ltos pa'i rnam par gzhal bas bden pa yin la ' 'di dag gis ni blo la ma ltos pa'i rnam par bzung pas bzung pa de brdzun pa yin no /!

\subsubsection{2 bcad pa'i yul can \{Mun sel 123.2$\}$}

rtogs zin 'jal ba'i mngon sum dang rtogs zin yongs su gcod pa'i rtog pa ni [29a1] sgro 'dogs chod zin pa'i don la bzlog pa'i zhen pa dang 'gal bas 'jug pa yin pas bcad pa'i yul can du 'du ste /

- sngar rtogs zin pa 'jal ba'i tshad ma snga ma'i rang rig gis nges la!

- bzlog pa'i zhen pa dang 'gal bas 'jug pa ni de nyid myong pa'i rang rig pas nges pa yin no //

rjes su dpag pa la ni bcad pa'i yul can yod pa ma yin te rtogs [29a2] ma zin na ni de la 'jug pa'i rjes dpag tshad ma yin pas bcad pa'i yul can ma yin la / don de sngar rtogs zin na rtags de shes 'dod med pa'i ma grub pa yin pas rtags la tshul gsum myed pas blo tshul gsum rtags las don shes kyi rjes dpag du myi 'thad pa'i phyir ro /i

rjes dpag gis skad cig dang po la sgra mi rtag par nges nas skad cig gnyis pa phan chad la sgra myi rtag [29a3] par nges pa ni bcad pa'i yul can yin yang de dag la rtags kyi rjes su 'brangs nas nges pa'i rjes dpag gi mtshan nyid myed pa yin te rtags 'dzin las dngos su ma skyes pa'i phyir ro /i rtags 'dzin las brgyud nas skyes pas rtags kyi rjes su 'brangs nas rtogs pa yin na rjes dpag gis stong pa nyid du nges pa'i rgyun goms par byas pa

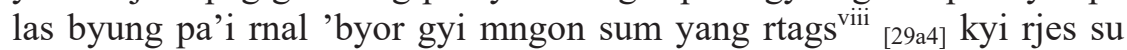
'brangs nas rtogs par thal bar 'gyur ro /!

de ltar blo gnyis ni bcad pa'i yul can yin no //

\subsubsection{3 the tshom $\{$ Mun sel 112.112 and and 123.5$\}$}

sgra rtag kyang srid myi rtag kyang srid ces zhen pa ni mtha' gzhan du srid pa'i dogs pa dang bcas pa yin pas the tsom ste $\mid$ mtshan nyid de'ang rang rig gis nges so $/$ ।

the tsom des kyang rtag $\mathrm{pa}^{\mathrm{ix}}$ srid par zhen pa na myi srid pa'i zhen pa sel bas gzhan sel ba yod pa yin te [29a5] srid par zhen pas myi srid par zhen pa myi sel na sngon por zhen pas kyang sngo ma yin myi sel bar 'gyur ro // 


\subsubsection{4 yid dpyod $\{$ Mun sel 123.3 \}}

sngar bshad pa'i rgyu mtshan myed pa dang log pa'i rgyu mtshan can dang rgyu mtshan gtan la ma phebs pa'i yid dpyod gsum la yid dpyod nyid du mtshon pa'i mtshan nyid ni lkog gyur bden pa rtags kyi rjes su ma 'brangs par gsar du nges pa ste /

- lkog gyur zhes [29a6] pas mngon sum tshad ma gcod la!

- bden pa zhes pas sgra rtag par zhen pa'i log shes lasogs pa gcod cing !

- rtags kyi rjes su ma 'brangs zhes pas rjes dpag gcod pa dang!

- nges pa zhes pas the tsom dang snang la ma nges pa dang rtog myed 'khrul pa dang bden zhen myed pa'i rtog pa rnams gcod cing!

- gsar du nges zhes pas rjes dpag gi rjes la 'byung pa'i bcad pa'i yul can gcod pa yin no //

- [29a7] lkog gyur gsar du nges pa ni rang rig gis grub la !

- bden par ni phyis kyi tshad mas nges shing!

- rtags kyi rjes su ma 'brangs par ni !

- rgyu mtshan myed pa'i yid dpyod la rang rig gis nges la /

- log pa'i rgyu mtshan can la rtags kyi skyon mthong pas nges shing!

- rgyu mtshan gtan la ma phebs pa la ni rtags 'dzin tshad ma ma yin par shes pa'i tshad mas nges so //

\subsubsection{5 snang la ma nges pa \{Mun sel 123.13 \}}

snang la ma nges pa' $i$ [29a8] mtshan nyid sngar bshad pa de yang

- sgro 'dogs dang myi 'gal bar ni rang rig gis nges la !

- yul skad cig ma snang par ni gzung yul de skad cig mar dpog pa'i rjes dpag gis shugs la nges pa yin no /

\section{\{Mun sel 212.22\}}

de ltar tshad ma ma yin pa'i blo lnga po dag la sngar bshad pa'i mtshan nyid khyab ches pa ma yin te!

- snang la ma nges pa dang rtog myed 'khrul pa dang bden zhen myed pa'i rtog pa dang the tsom [29a9] rnams la ni sgro 'dogs dang 'gal ba nyid myed la!

- bcad pa'i yul can la ni sngar ma rtogs pa'i don la 'jug pa myed cing !

- sgra rtag par zhen pa'i log shes lasogs pa la ni yul gnod myed du bden pa myed pa dang ! 
- yid dpyod kyis bzlog pa'i sgro 'dogs dang 'gal ba dang ! bdag gcig yin pa'i log shes kyis bdag du mar 'dzin pa'i log rtogs dang 'gal ba lasogs ${ }^{45}$ pa la ni [29b1] 'dzin stangs don myed na myi 'byung pas bzlog pa'i sgro 'dogs dang 'gal ba myed pa'i phyir ro //

\subsection{Corrections in the manuscript and other particularities of the manuscript reading}

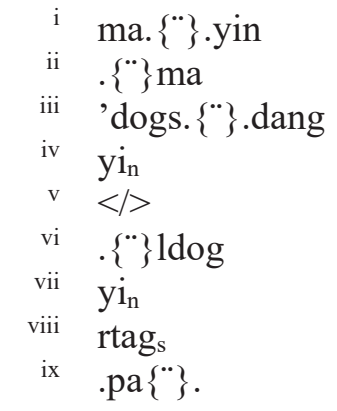

${ }^{45} \mathrm{Em} .\langle$ la $\rangle \operatorname{sogs}:$ Ms sogs 
VI

Tables 

Table A: Apprehended objects and corresponding awarenesses

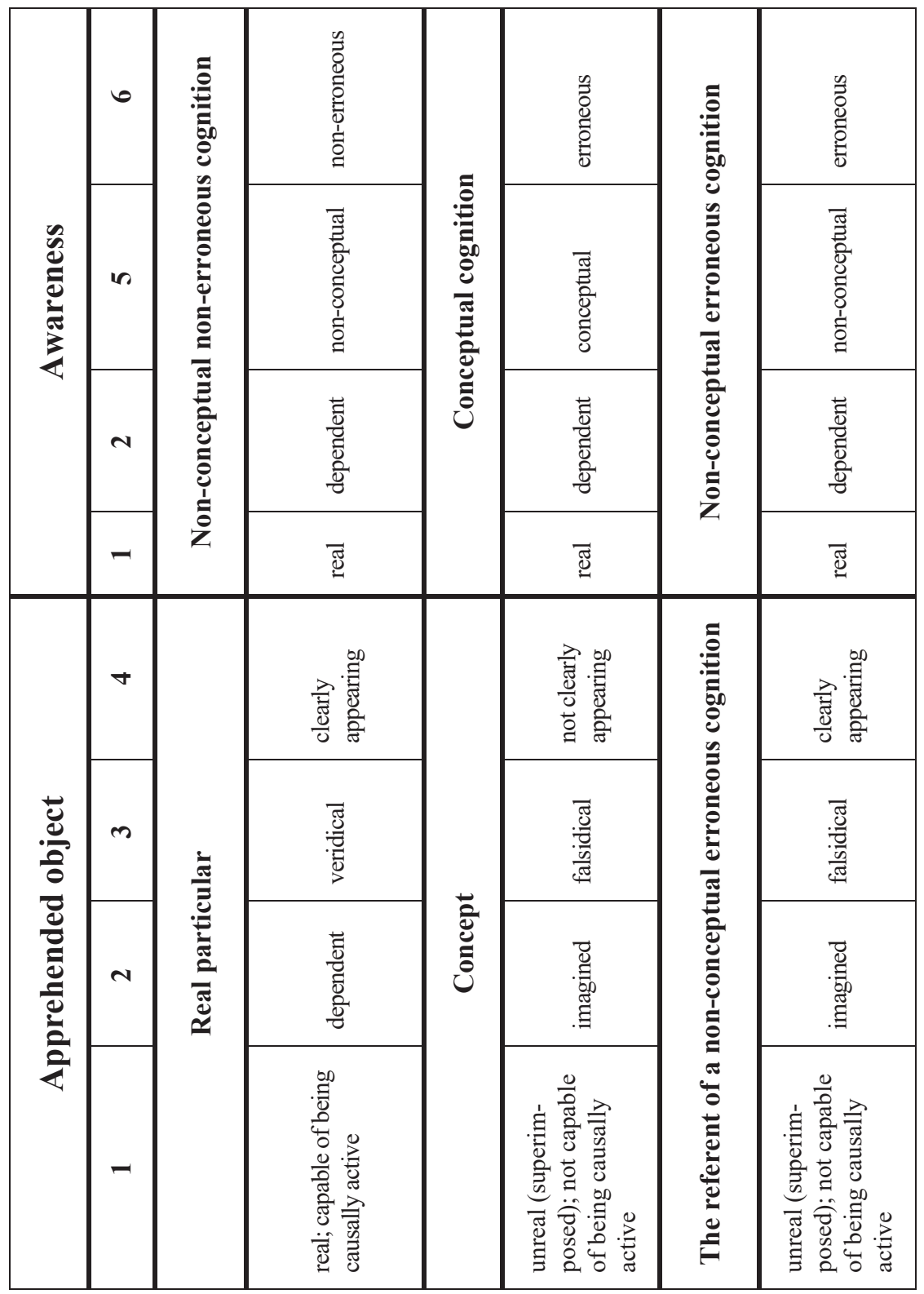


The three apprehended objects and the corresponding three types of awareness are characterized from the perspective of several different sets of properties:

\section{(1) Real/Unreal}

In agreement with a core postulate of Dharmakīti's system, the reality of the object is associated with its being capable of being causally active. ${ }^{1}$ Accordingly, being unreal is linked to not being capable of being causally active. Only particulars are real. Objects that are not real are also described as 'superimposed' (sgro btags); they are mere mental imputations.

\section{(2) The Three-Nature framework}

The characterizations 'dependent,' 'imagined,' and 'perfected' are related to the model of the Three Natures (Skt. trisvabhāva) developed by Indian Buddhist idealist philosophers such as Asanga and Vasubandhu (both c. $4^{\text {th }}-5^{\text {th }}$ century). The 'dependent' (Skt. paratantra) nature is that of phenomena that are causally conditioned. The 'imagined' (Skt. parikalpita) nature is the mere product of conceptual construction but is not founded on regular causes. The 'perfected' (Skt. parinispanna) nature is the ultimate truth. It cannot be defined but can be conceived as the dependent nature void of any imagined nature. ${ }^{2}$ In the discussion of the three apprehended objects, Phya pa uses 'superimposed' (sgro btags) as a synonym of 'imagined' (kun brtags).

\section{(3) Veridical/Falsidical}

The qualification 'veridical' in the case of the apprehended object is correlated by Phya pa with its being capable of being causally active (see Mun sel 121.3). ${ }^{3}$

\footnotetext{
${ }^{1}$ The key passages in this regard are found in Dharmakirti's PV 3.1-3 (translated in Dunne 2004: 391-392; see also Franco\&Notake 2014: 4 and 29-37). Dharmakirti holds that what is capable of being causally active is ultimately real, and links this capacity exclusively with particulars (svalakșana). The type of causal efficacy observed in everyday life (such as a seed producing a sprout) may be considered by other philosophers to be merely conventional, but one cannot deny the capacity of being causally active altogether.
}

${ }^{2}$ See Wood 1991: 31-60 and Thakchoe 2017 (\$3.1).

${ }^{3}$ Note that this link between being 'veridical' and being causally active extends only to its application to apprehended objects (see the translation in II, n. 5). In 
The qualifications pertaining to (1), (2), and (3) are correlated. Given that all episodes of awareness are themselves real particulars and hence causally active, they all qualify as 'real' and 'dependent' when considered from the point of view of their status as apprehended objects (namely, the apprehended object of a reflexive awareness). Although Phya pa does not point this out specifically, all episodes of awareness would consequently also qualify as 'veridical' from this point of view. ${ }^{4}$

\section{(4) Clearly/Not clearly appearing}

Apprehended objects are defined as objects whose nature appears to awareness (Mun sel 121.11). This appearing is qualified as "clear" when the object is "not mixed with respect to time or place," that is, there is the appearing of an object at a specific time and place. For instance, the appearing of an elephant in front of me at the present moment (whether the elephant is real or the product of a hallucination), in contrast to the appearing of an elephant whose spatial and temporal location are not specific. This distinction could have originated from the interpretation of PVin 2.7 (going back to PS 1.2) via Dharmottara's commentary. ${ }^{5}$

the context of engaged objects, on the other hand, the qualification 'veridical' does not involve having causal powers, but the idea of 'lacking opposition.' This latter sense is at work in Phya pa's definition and explication of factive assessment (Mun sel 123.3). There, in particular, he writes of "a veridical thesis" (Mun sel 123.31), "a veridical states of affairs" (Mun sel 123.321), and "a veridical object" (Mun sel 123.323). In none of those cases is the application associated with being causally active. (For a more detailed discussion, see the translation in II, n. 41).

${ }^{4}$ In the sense operable in this context, to say that an episode of awareness is 'veridical' does not mean that the content or object of that awareness is real or true; it means only that the episode of awareness is causally active - a feature shared by all instances of awareness. This usage thus stands in contrast to current philosophical (and psychological) uses of the expression "veridical experience," wherein the idea is that the content of the experience corresponds with reality. (For more on contemporary philosophical uses of 'veridical,' see, for example, Siegel 2010, chapter 6.) This latter (contemporary) usage corresponds most properly with Phya pa's appeal to being "non-erroneous with regard to the state of affairs" (see, e.g., Mun sel 112.23).

${ }^{5}$ Dharmakīrti states: "The Teacher (Dignāga) has said that the object (of the two types of knowledge) is distinct because, since the appearing is distinct (Skt. pratibhäsasya bhinnatvād, Tib. snang ba tha dad pas), it cannot apply to just one." 


\section{(5) Non-conceptual/Conceptual}

The qualification in these terms only pertains to awareness. It is correlated with the qualification of the apprehended object according to set (4). Support in Dharmakirti's system for this correlation can be found in PV $3.298 \mathrm{~cd}-299 .^{6}$

\section{(6) Non-erroneous/Erroneous}

Phya pa correlates this qualification of awareness to the qualification of the apprehended object according to set (3). ${ }^{7}$ It is thus also correlated to the object being real or unreal (1), and dependent or imagined (2). Being "non-erroneous" or "erroneous" is simply a matter of whether what is apprehended exists in reality or is merely a mental imputation.

(PVin $_{\text {Skt }} 2$ 48,9 with PVin 2.7). In PVinT 2, Dharmottara comments on the distinction of appearing in terms of the two incompatible aspects of "clearly appearing" and "unclearly appearing" (PVinT 2 D179a1: gsal bar snang ba dang mi gsal bar snang ba rnam pa 'gal ba gnyis po). See Hugon 2008b: 146, n. 38. See also the verses referred to in (5) above and n. 6.

${ }^{6}$ In these verses, Dharmakīrti links "clearly appearing mind" (Skt. dhīh sphutabhāsin̄̄, Tib. gsal bar snang ba can blo) with "non-conceptual" (Skt. nirvikalpā, Tib. rtog med), and the other case, i.e., what does not appear clearly (Skt. na bhāseta parisphuțam), with "conceptual” (Skt. vikalpikā, Tib. rtog pa). See Hugon 2008b: 179, n. 134.

${ }^{7} \mathrm{Cf}$. in this regard 'Od zer 45b4: ma 'khrul ba'i don ni yul bden na blo ma 'khrul ba yin la yul brdzun na blo 'khrul pa yin no // 


\section{Table B: Apprehended objects and engaged objects- the partial overlap between these objects}

\begin{tabular}{|c|c|c|}
\hline & Apprehended object & Not apprehended object \\
\hline $\begin{array}{c}\text { Engaged } \\
\text { object }\end{array}$ & $\begin{array}{l}\text { 1. Blue (in perception) } \\
\text { 2. A concept (in an inferential cog- } \\
\text { nition concluding that concepts } \\
\text { are conventionally true [f]) }\end{array}$ & $\begin{array}{l}\text { 1. The impermanence of sound } \\
\text { qua real particular (in infer- } \\
\text { ential cognition [b]) } \\
\text { 2. Concepts and double moons } \\
\text { (in episodes of reflexive } \\
\text { awareness) }\end{array}$ \\
\hline $\begin{array}{c}\text { Not engaged } \\
\text { object }\end{array}$ & $\begin{array}{l}\text { 1. The concept of 'impermanence' } \\
\text { (in an inferential cognition con- } \\
\text { cluding that sound is imperma- } \\
\text { nent [b]) } \\
\text { 2. Momentariness (in an episode of } \\
\text { non-ascertaining perception) } \\
\text { 3. The concepts appearing in epi- } \\
\text { sodes of factive assessment, } \\
\text { (conceptual) mistaken cognition, } \\
\text { (conceptual) post-knowledge } \\
\text { cognition, and doubt } \\
\text { 4. The appearance of a double } \\
\text { moon (in non-conceptual errone- } \\
\text { ous awareness) } \\
\text { 5. Blue (in perceptual post- } \\
\text { knowledge cognition) }\end{array}$ & 1. Sound (in a visual cognition) \\
\hline
\end{tabular}




\section{Table C: Apprehended objects and engaged objects- the partial overlap between the episodes of awareness involving these objects}

\begin{tabular}{|c|l|l|}
\hline & $\begin{array}{c}\text { Awareness with veridical } \\
\text { apprehended object }\end{array}$ & $\begin{array}{c}\text { Awareness without } \\
\text { veridical apprehended } \\
\text { object }\end{array}$ \\
\hline $\begin{array}{c}\text { Awareness } \\
\text { with veridical } \\
\text { engaged object }\end{array}$ & $\begin{array}{l}\text { Episodes of perceptual } \\
\text { knowledge }\end{array}$ & $\begin{array}{l}\text { Episodes of inferential } \\
\text { cognition }\end{array}$ \\
\hline $\begin{array}{c}\text { Awareness } \\
\text { without } \\
\text { veridical } \\
\text { engaged object }\end{array}$ & $\begin{array}{l}\text { Episodes of non-ascertaining } \\
\text { perception }\end{array}$ & $\begin{array}{l}\text { Episodes of mistaken } \\
\text { determination }\end{array}$ \\
\hline
\end{tabular}

Phya pa devotes a large amount of space to the project of distinguishing apprehended objects (gzung yul) from engaged objects ('jug yul). By definition, an apprehended object is "something such that its own nature appears to awareness" (Mun sel 121.11) and engaged objects are those for which "there is the elimination of superimpositions, with regard to states of affairs not previously known, by an apprehension that requires an invariable relation to the state of affairs" (Mun sel 121.13).

Sections (121.2) and (121.3) in the Mun sel show in detail that being an apprehended object is not coextensive with being an engaged object, and that being an episode of awareness with a veridical apprehended object is not coextensive with being an episode of awareness with a veridical engaged object. To demonstrate these points, Phya pa provides examples of items that fall into one category but not the other, items that fall into both categories, and items that fall into neither. These examples are not meant to be exhaustive, and, in fact, additional examples are provided in Phya pa's 'Od zer (see V, 2.3). 


\section{Table D: The three-fold division of awareness in the Mun sel}

\begin{tabular}{|l|l|l|l|}
\hline \multirow{2}{*}{ Awareness } & \multicolumn{3}{|c|}{ Operations } \\
\cline { 2 - 3 } & Appearing & Directing & Excluding \\
\hline
\end{tabular}

(I) Conceptual cognition

\begin{tabular}{|c|c|c|c|c|c|c|}
\hline & \multicolumn{2}{|c|}{ Not directing } & $\begin{array}{l}\text { Non-directing } \\
\text { conceptual } \\
\text { cognition }\end{array}$ & $\mathrm{MC}_{1.1}$ & - & - \\
\hline [1] & \multicolumn{6}{|c|}{ Directing } \\
\hline & \multirow{2}{*}{ [2] } & $\begin{array}{l}\text { Not being } \\
\text { determinate }\end{array}$ & Doubt & $\mathrm{MC}_{1.1}$ & $\mathrm{MC}_{3}$ & Doubt \\
\hline & & \multicolumn{5}{|c|}{ Being determinate } \\
\hline & \multirow{5}{*}{ [3] } & $\begin{array}{l}\text { Not } \\
\text { determining in } \\
\text { correspondence } \\
\text { with the object } \\
\text { to be cognized }\end{array}$ & $\begin{array}{l}\text { Mistaken } \\
\text { cognition } \\
\text { (Mistaken } \\
\text { determinate } \\
\text { awareness, } \\
\left.\mathrm{MC}_{2}\right)\end{array}$ & $\mathrm{MC}_{1.1}$ & $\mathrm{MC}_{3}$ & $\begin{array}{l}\text { Mistaken } \\
\text { cognition } \\
\left(\mathrm{MC}_{2}\right)\end{array}$ \\
\hline & & \multirow{4}{*}{$\begin{array}{l}\text { Determining in } \\
\text { correspondence } \\
\text { with the object } \\
\text { to be cognized }\end{array}$} & $\begin{array}{l}\text { Post- } \\
\text { knowledge } \\
\text { cognition }\end{array}$ & $\mathrm{MC}_{1.1}$ & $\mathrm{MC}_{3}$ & $\begin{array}{l}\text { Post- } \\
\text { knowledge } \\
\text { cognition }\end{array}$ \\
\hline & & & $\begin{array}{l}\text { Factive } \\
\text { assessment }\end{array}$ & $\mathrm{MC}_{1.1}$ & $\mathrm{MC}_{3}$ & \begin{tabular}{|l} 
Factive \\
assessment
\end{tabular} \\
\hline & & & \multirow[t]{2}{*}{$\begin{array}{l}\text { Inferential } \\
\text { cognition }\end{array}$} & \multirow[t]{2}{*}{$\mathrm{MC}_{1.1}$} & $\begin{array}{c}{[\mathrm{a}][\mathrm{b}][\mathrm{c}][\mathrm{e}]} \\
\mathrm{MC}_{3}\end{array}$ & \multirow[t]{2}{*}{ Knowledge } \\
\hline & & & & & $\begin{array}{c}{[\mathrm{d}]} \\
\operatorname{not} \mathrm{MC}_{3}\end{array}$ & \\
\hline \multicolumn{4}{|c|}{$\begin{array}{l}\text { (II) Non-conceptual non-erroneous } \\
\text { cognition }\end{array}$} & not $\mathrm{MC}_{1}$ & - & - \\
\hline \multicolumn{4}{|c|}{$\begin{array}{l}\text { (III) Non-conce } \\
\text { cognition }\end{array}$} & $\mathrm{MC}_{1.2}$ & - & - \\
\hline
\end{tabular}


This table represents the various features attached by Phya pa to the basic three-fold division of awareness discussed in Mun sel 112, which is based on the apprehended object (see Table A and Table B).

Conceptual cognitions are divided according to three successive, nested criteria:

[1] Directing (zhen pa)

[2] Being determinate (nges pa)

[3] Determining in correspondence with the object to be cognized (shes bya dang mthun par nges)

- These criteria are not involved in characterizing non-conceptual cognitions, which all lack directing. ${ }^{8}$

- The analysis also considers which of the three operations (byed $p a$ ) - appearing (snang ba), directing (zhen pa), and excluding (sel $b a$ ) - are present for the various types of awareness.

- All types of awareness have the operation of appearing, which is a matter of their grasping their apprehended object.

- The presence of the operation of directing is coextensive with the fulfillment of the criterion of directing [1], which presupposes that the cognition is conceptual (I).

- The operation of excluding is copresent with the operation of directing. ${ }^{9}$ It is thus also limited to conceptual cognitions. But it is not correlated with the criterion of being determinate [2], because the operation of excluding is also found for doubt. "Exclusion of what is other" is expressed in a variety of ways, most commonly as the "exclusion of non-x" or "exclusion of directing one's mind toward being non-x." Doubt is a special case where what is excluded is the impossibility of the other option, and mistaken cognition is an instance where what is excluded is something that is actually the case.

\footnotetext{
${ }^{8}$ In the table, the mental states appear in an order that differs from Phya pa's presentation in order to highlight the presence/absence of the respective criteria. ${ }^{9}$ See, in relation to that, the definition of the intentional object in Mun sel 121.12: "what the mind is directed toward, and the mind being directed toward it excludes engaging in the opposite directing of one's mind."
} 
- The operation of excluding is not coextensive with the elimination of superimpositions, for the latter is found also in some case of nonconceptual non-erroneous cognition (II) (these are not divided here).

Another point investigated by Phya pa is the status of each awareness with respect to each operation. More precisely, it can be asked: is the awareness a mistaken cognition or not from this perspective? In this context, one should be aware of the different connotations attached to the term "mistaken cognition" (log shes) (see IV, 4[b] for more details). In the context of the three-fold typology, Phya pa's intention in highlighting the characterization as a "mistaken cognition" is to demonstrate that being a "mistaken cognition" with regard to the operation of appearing $\left(\mathrm{MC}_{1}\right.$ in the summarizing table in IV, 4[b]) or with regard to the operation of directing pertaining to the type of the apprehended object $\left(\mathrm{MC}_{3}\right)$ does not have any impact on an awareness being an episode of knowledge. Its being an episode of knowledge is linked, in the case of conceptual cognitions, with the operation of excluding. All conceptual cognitions that are directed have the operations of directing and excluding. But they have different statuses with respect to the operation of excluding. Only inferential cognition has the status of knowledge in this regard.

In the case of inferential cognition and non-conceptual non-erroneous cognition, Phya pa adds a paragraph explaining in what way these come to qualify as episodes of knowledge (Mun sel 112.111.112.3 and 112.23). For inferential cognition it is through "engaging the object via the exclusion of what is other" and "countering the directing of one's mind in the opposite way." This is correlated with the operation of excluding. For perceptual knowledge, this is by "eliminating opposite superimpositions" when the mind is focused on manifest features. How this elimination (which is not to be confused with the operation of excluding) comes about for a non-conceptual cognition, through a causal process, is explained later when dealing with the definition of knowledge (see Mun sel 212.21). 


\section{Table E: The seven-fold division of awareness in the Mun sel}

\begin{tabular}{|c|c|c|c|c|c|c|c|c|c|c|c|c|}
\hline & $\stackrel{\overline{0}}{\hat{\Xi}}$ & & 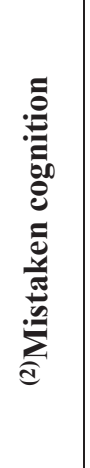 & & 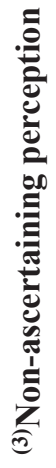 & & 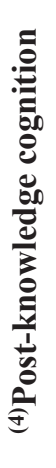 & & 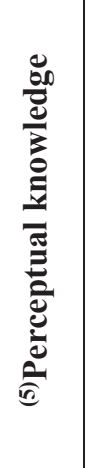 & & 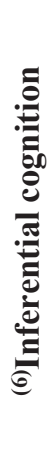 & 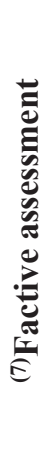 \\
\hline \multirow{7}{*}{ 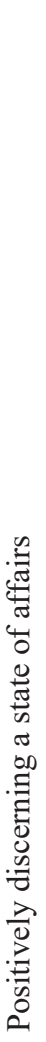 } & \multirow{6}{*}{ 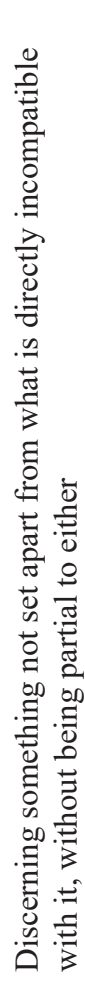 } & \multirow{6}{*}{ 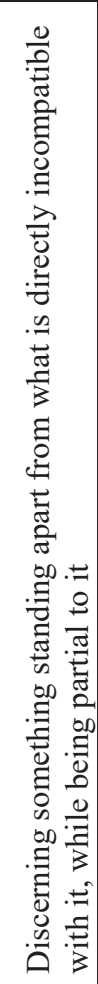 } & \multirow{5}{*}{ 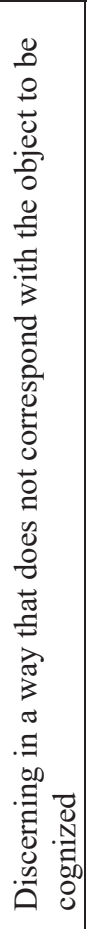 } & \multirow{5}{*}{ 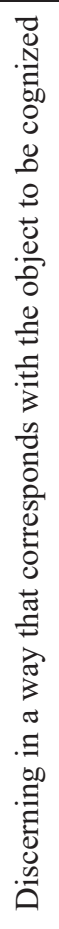 } & \multirow{4}{*}{ 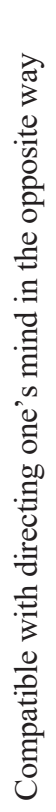 } & \multirow{4}{*}{ 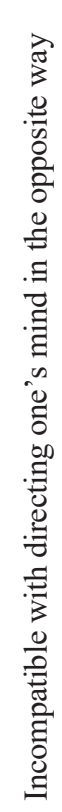 } & \multirow{3}{*}{ 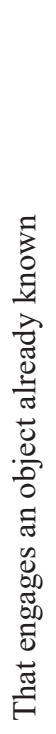 } & \multirow[t]{3}{*}{ 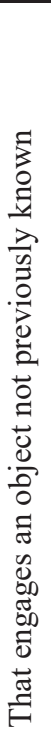 } & \multirow[t]{2}{*}{ 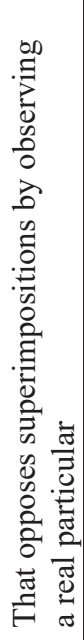 } & \multirow[t]{2}{*}{ 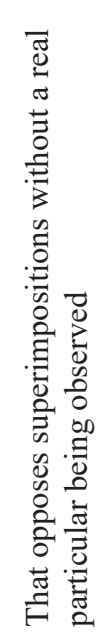 } & 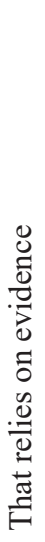 & 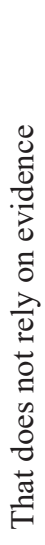 \\
\hline & & & & & & & & & & & \multicolumn{2}{|c|}{6} \\
\hline & & & & & & & & & \multicolumn{2}{|c|}{$\sqrt{n}$} & & \\
\hline & & & & & & & \multicolumn{2}{|c|}{$\Xi$} & & & & \\
\hline & & & & & \multicolumn{2}{|c|}{$m$} & & & & & & \\
\hline & & & $\mathrm{N}$ & & & & & & & & & \\
\hline & \multicolumn{2}{|c|}{$\Xi$} & & & & & & & & & & \\
\hline
\end{tabular}


This typology is said to be based both on the apprehended and engaged objects. Unlike the three-fold typology, it does not primarily divide episodes of awareness based on their apprehended object, but considers successive criteria that are related to various types of objects, without specifying which ones. This enables Phya pa in particular to list under the same heading types of awareness that admit of conceptual and non-conceptual subtypes, or have subtypes related to different objects. The ambiguities are lifted in the subsequent reduction to the types distinguished in the three-fold typology (Mun sel 122.2) and in the expansion to a twelve-fold division (Mun sel 122.3).

The distinguishing criteria are: ${ }^{10}$

[1] The partiality criterion

[2] The correspondence criterion

[3] The incompatibility with opposite directing criterion

[4] The novelty criterion

[5] The experience criterion

[6] The evidential criterion

Among the distinguishing criteria, [3] corresponds to K1 (incompatibility with opposite superimpositions), [4] to K2 (novelty), and [5] and [6] are two criteria that guarantee $\mathrm{K} 3$ (the mode of apprehension such that there is an invariable relation to the state of affairs).

${ }^{10}$ The terminology is adapted from the list of criteria identified and discussed in Stoltz 2013: 413 in the case of the similar typology proposed by gTsang drug rdo rje in the gSal byed. 


\section{Table F: The twelve-fold division of awareness in the Mun sel}

\begin{tabular}{|c|c|c|c|c|}
\hline & Conceptual & \multicolumn{2}{|c|}{$\begin{array}{l}\text { Non-conceptual } \\
\text { non-erroneous }\end{array}$} & $\begin{array}{l}\text { Non-conceptual } \\
\text { erroneous }\end{array}$ \\
\hline${ }^{(1)}$ Doubt & 1 & & & \\
\hline${ }^{(2)}$ Mistaken cognition & $\underline{\underline{2}} \underline{\underline{c}}$ & & & $2 n$ \\
\hline \multirow[t]{2}{*}{${ }^{(3)}$ Non-ascertaining perception } & & $3 r$ & reflexive & \\
\hline & & $3 \mathrm{t}$ & transitive & \\
\hline \multirow[t]{2}{*}{ (4)Post-knowledge cognition } & \multirow[t]{2}{*}{$\underline{4 c}$} & $4 r$ & reflexive & \\
\hline & & $4 t$ & transitive & \\
\hline \multirow[t]{2}{*}{${ }^{(5)}$ Perceptual knowledge } & & $5 r$ & reflexive & \\
\hline & & $5 \mathrm{t}$ & transitive & \\
\hline${ }^{(6)}$ Inferential cognition & $\underline{6}$ & & & \\
\hline (7)Factive assessment & $\underline{7}$ & & & \\
\hline
\end{tabular}

In Mun sel 122.2, Phya pa subsumes the seven types of awareness (see Table E) within the three-fold division of awareness (see Table D), represented here in the three columns "conceptual," "non-conceptual nonerroneous," "non-conceptual erroneous." As some of the seven types can be conceptual or non-conceptual, and non-conceptual episodes are divided into "reflexive" and "transitive," this leads to the twelve-fold division spelled out in Mun sel 122.3.

In this paragraph, Phya pa also deals with the mutual compatibility and incompatibility among the twelve, which can be summarized as follows:

\begin{tabular}{|l|l||l|l|}
\hline Section & Type $(\mathrm{s})$ & Compatible with & Incompatible with \\
\hline 122.31 & $3_{r}, 4_{r}, 5_{r}$ & $\underline{\mathbf{1}}, \underline{\underline{\mathbf{2}}}, 2_{\mathrm{n}}, 3_{\mathrm{t}}, 4_{\mathrm{t}}, 5_{\mathrm{t}}, 3_{r}, 4_{r}, 5_{r}, \underline{\mathbf{4}}, \underline{\mathbf{6}}, \underline{\mathbf{7}}$ & \\
\hline 122.32 & $2_{\mathrm{n}}, 3_{\mathrm{t}}, 4_{\mathrm{t}}, 5_{\mathrm{t}}$ & $2_{\mathrm{n}}, 3_{\mathrm{t}}, 4_{\mathrm{t}}, 5_{\mathrm{t}}, 3_{r}, 4_{r}, 5_{r}$ & $\underline{\mathbf{1}}, \underline{\underline{\mathbf{2}}}, \underline{\mathbf{4}}, \underline{\mathbf{6}}, \underline{\mathbf{7}}$ \\
\hline 122.33 & $\underline{\mathbf{4}}, \underline{\mathbf{6}}, \underline{\mathbf{7}}$ & $\underline{\underline{\mathbf{2}}}, 3_{r}, 4_{r}, 5_{r}, \underline{\mathbf{4}}, \underline{\mathbf{6}}, \underline{\mathbf{7}}$ & $\underline{\mathbf{1}}, 2_{\mathrm{n}}, 3_{\mathrm{t}}, 4_{\mathrm{t}}, 5_{\mathrm{t}}$ \\
\hline 122.34 & $\underline{\underline{\mathbf{2}}}$ & $\underline{\underline{\mathbf{c}}}, \underline{\underline{\mathbf{c}}}, 3_{r}, 4_{r}, 5_{r}, \underline{\mathbf{4}}, \underline{\mathbf{6}}, \underline{\mathbf{7}}$ & $2_{\mathrm{n}}, 3_{\mathrm{t}}, 4_{\mathrm{t}}, 5_{\mathrm{t}}$ \\
\hline 122.35 & $\underline{\mathbf{1}}$ & $\underline{\mathbf{1}} \underline{\underline{\mathbf{2}}}, 3_{r}, 4_{r}, 5_{r}$ & $2_{\mathrm{n}}, 3_{\mathrm{t}}, 4_{\mathrm{t}}, 5_{\mathrm{t}}, \underline{\mathbf{4}}, \underline{\mathbf{6}}, \underline{\mathbf{7}}$ \\
\hline
\end{tabular}

There is mutual incompatibility between every conceptual cognition (numbers in bold) and every non-conceptual cognition (non-bold), with the exception of the non-conceptual reflexive cognitions (numbers in italics), which are compatible with everything. 
Among conceptual cognitions (in bold), there is mutual incompatibility between doubt (dotted underline) and three of the determinate cognitions (single underline), on account of doubt not being a determinate awareness. However, doubt is held to be compatible with conceptual mistaken cognition (double underline) on account of its having a concept for its apprehended object (as do the other three determined cognitions). The "conceptual mistaken cognition" at play here is thus just an awareness apprehending a concept $\left(\mathrm{MC}_{1.1}\right.$, see IV, $\left.4[\mathrm{~b}]\right)$, not an incorrect determination $\left(\mathrm{MC}_{2}\right)$. 


\section{Table G: The ten-fold division of awareness in the 'Od zer}

\begin{tabular}{|c|c|c|c|c|}
\hline \multicolumn{5}{|c|}{ Taking as its apprehended object a real particular $=$ Perception } \\
\hline \multicolumn{3}{|c|}{ Not incompatible with opposite superimpositions } & \multicolumn{2}{|c|}{$\begin{array}{l}\text { (1) Non-ascertaining } \\
\text { perception }\end{array}$} \\
\hline \multicolumn{3}{|c|}{ Incompatible with opposite superimpositions } & & \\
\hline \multirow[t]{2}{*}[1.2]{} & \multicolumn{2}{|c|}{ With regard to an object previously known } & \multicolumn{2}{|c|}{$\begin{array}{l}\text { (2) }(\text { Perceptual) post- } \\
\text { knowledge cognition }\end{array}$} \\
\hline & \multicolumn{2}{|c|}{ With regard to an object not already known } & \multicolumn{2}{|c|}{ (3)Perceptual knowledge } \\
\hline \multicolumn{3}{|c|}{$\begin{array}{l}\text { Taking as its apprehended object the } \\
\text { referent of a non-conceptual erroneous } \\
\text { cognition = Non-conceptual erroneous } \\
\text { cognition }\end{array}$} & \multicolumn{2}{|c|}{$\begin{array}{l}\text { (4) Non-conceptual } \\
\text { erroneous cognition }\end{array}$} \\
\hline \multicolumn{5}{|c|}{ Taking as its apprehended object a concept $=$ Conceptual cognition } \\
\hline \multicolumn{3}{|c|}{$\begin{array}{l}\text { Which does not conceive of its object being } \\
\text { veridical externally }\end{array}$} & \multicolumn{2}{|c|}{$\begin{array}{l}\text { (5) Non-directing } \\
\text { conceptual cognition }\end{array}$} \\
\hline \multicolumn{3}{|c|}{$\begin{array}{l}\text { Which conceives of its object being veridical } \\
\text { externally }\end{array}$} & & \\
\hline \multirow{2}{*}{ [3.2] } & \multicolumn{2}{|c|}{$\begin{array}{l}\text { Which conceives with the possibility of an- } \\
\text { other option }\end{array}$} & \multicolumn{2}{|l|}{${ }^{(6)}$ Doubt } \\
\hline & \multicolumn{2}{|c|}{$\begin{array}{l}\text { Which conceives without the possibility of } \\
\text { another option }\end{array}$} & & \\
\hline \multirow{2}{*}{ [3.3] } & \multicolumn{2}{|c|}{$\begin{array}{l}\text { In which conceiving does not correspond } \\
\text { with the object to be cognized }\end{array}$} & \multicolumn{2}{|c|}{$\begin{array}{l}{ }^{(7)} \text { Mistaken cognition } \\
\left(\mathrm{MC}_{2}\right)\end{array}$} \\
\hline & \multicolumn{2}{|c|}{$\begin{array}{l}\text { In which conceiving corresponds with the } \\
\text { object to be cognized }\end{array}$} & & \\
\hline \multirow{2}{*}{ [3.4] } & \multicolumn{2}{|c|}{$\begin{array}{l}\text { Which directs with regard to an object } \\
\text { previously known }\end{array}$} & \multicolumn{2}{|c|}{$\begin{array}{l}{ }^{(8)} \text { (Conceptual) post- } \\
\text { knowledge cognition }\end{array}$} \\
\hline & \multicolumn{2}{|c|}{$\begin{array}{l}\text { Which directs with regard to an object } \\
\text { not already known }\end{array}$} & & \\
\hline \multirow[t]{2}{*}[3.5]{} & $\begin{array}{l}\text { Which directs withou } \\
\text { evidence }\end{array}$ & trelying on valid & \multicolumn{2}{|c|}{${ }^{(9)}$ Factive assessment } \\
\hline & \multicolumn{2}{|c|}{ Which directs by relying on valid evidence } & \multicolumn{2}{|c|}{${ }^{(10)}$ Inferential cognition } \\
\hline & & \multicolumn{3}{|c|}{$\sim$} \\
\hline & & Appearing & Directing & Excluding \\
\hline & $\begin{array}{r}{[\mathrm{a}][\mathrm{b}]} \\
{[\mathrm{e} 1][\mathrm{e} 2]} \\
\end{array}$ & $\begin{array}{l}\text { Mistaken } \\
\text { cognition }\left(\mathrm{MC}_{1.1}\right)\end{array}$ & $\begin{array}{l}\text { Mistaken } \\
\text { cognition }\left(\mathrm{MC}_{3}\right)\end{array}$ & Knowledge \\
\hline & & $\begin{array}{l}\text { Mistaken } \\
\text { cognition }\left(\mathrm{MC}_{1.1}\right)\end{array}$ & $\mathrm{Not}_{\mathrm{MC}}$ & Knowledge \\
\hline
\end{tabular}


This typology is primarily based on the apprehended object and thus starts off with the same items as the three-fold division in the Mun sel (Table D) (cf. V, 2: 'Od zer 111.222.1.b1, ${ }^{\circ} . \mathrm{b} 2$ and $^{\circ} . \mathrm{b} 3$ ). But it then proceeds to distinguish three types for non-conceptual non-erroneous cognition (there is no subdivision of this type in the three-fold division in the Mun sel) and six types for conceptual cognition (the same as the ones listed in the threefold division in the Mun sel), using distinguishing criteria similar to the ones used in the three-fold division in the Mun sel and some from the seven-fold division (Table E). These criteria are, for non-conceptual nonerroneous cognitions:

[1.1] The incompatibility with superimpositions criterion

[1.2] The novelty criterion

and for conceptual cognition:

[3.1] The directing criterion

[3.2] The partiality criterion

[3.3] The correspondence criterion $^{11}$

[3.4] The novelty criterion

[3.5] The evidential criterion

[1.1] amounts to K1, which is discussed further for perceptual knowledge in a specific paragraph; [1.2] corresponds to $\mathrm{K} 2$; [1], which is equivalent to the "manifestation criterion" in the seven-fold division, guarantees K3 in the case of perceptual knowledge.

[3.1], [3.2], and [3.3] correspond to the three criteria of directing, being determinate, and determining in a way that corresponds to the object to be known, which are applied to conceptual cognition in the three-fold division in the Mun sel. [3.4] amounts to K2, [3.5] guarantees K3. K1 is made explicit in the discussion of the status of inferential cognition with respect to the three operations and in a specific paragraph.

The ten-fold division in the 'Od zer lists the seven types found in the seven-fold division in the Mun sel, but distinguishes already the conceptual and non-conceptual forms of post-knowledge cognition (2 and 8) and the conceptual and non-conceptual forms of mistaken cognition (4 and 7), and singles out non-directing conceptual cognition (5), which is also a

\footnotetext{
${ }^{11}$ Note that this criterion is more restricted than the "correspondence criterion" in the seven-fold typology. It does not concern the correspondence pertaining to the apprehended object, only the one pertaining to the intentional object.
} 
variety of mistaken cognition. In the Mun sel, non-directing conceptual cognition is mentioned in the discussion of the three-fold typology, but it does not count as a distinct type in the seven-fold and the twelve-fold typologies. 
VII

Appendices 



\section{Appendix 1: Excursuses in the first chapter of the Mun sel}

Five passages in the first chapter of the Mun sel that were not directly relevant to the topic of Phya pa's philosophy of mind have been left out of the present edition and translation. The content of these digressions is summarized below and references are provided to existing editions and/or translations or related studies.

\section{EX1 (1b1-4): Invocation and introductory verses}

After giving the title of the work in Sanskrit and Tibetan, Phya pa pays his respects to the Bodhisattva Mañjughoșa ('Jam pa'i dbyangs) and to his religious teachers (bla ma rnams) with the traditional formula "I bow down to..." (...la phyag 'tshal lo). This is followed by four verses, each consisting of four lines of fifteen syllables (two syllables are missing in the first line of the fourth verse). The first two are verses of invocation. The second two present the purpose of the treatise: extending Dignāga and Dharmakirti's endeavor in the field of epistemology, and providing tools to progress on the path to omniscience.

This part of the text is critically edited and translated in the "infosheet" prepared for the Mun sel by Pascale Hugon and Kazuo Kano in the framework of the project "A gateway to early Tibetan scholasticism - The bKa' gdams gsung 'bum collection," currently hosted at www.ikga.oeaw.ac.at/KDSB.

\section{EX2 (1b9-3b3): Refutation of other philosophical systems (regarding the status of objects)}

This passage discusses the status ascribed to the apprehended objects that Phya pa distinguishes from the point of view of three philosophical standpoints: representational idealism, non-representational idealism and representational external realism. Phya pa refutes these three systems. The position he adopts (stated in Mun sel 111(a)D) is characterized by Phya pa himself in terms of "non-representational external realism." 
Phya pa's position and his arguments against the other systems are investigated in detail in Hugon 2016c. This publication also includes a critical edition and a translation of this passage of the Mun sel and of the parallel passages contained in the 'Od zer, in Phya pa's doxography, and in his summary of Madhyamaka ( $s$ Nying po).

\section{EX3 (4a8-6a3): On the epistemic object of inferential cog- nition}

In this passage, Phya pa presents and criticizes the views of Dharmottara, Śankaranandana, and a third scholar (who can be identified as rGya dmar ba) and presents his own view on the topic of the object of inferential cognition. The question is whether the epistemic object of the three types of inferential cognition - based on a logical reason qua essential property, qua effect, or qua non-apprehension (see, in this chapter, Appendix 2.5)is a "simple negation" (med dgag) or a "negation with a positive retainer" (ma yin dgag). ${ }^{1}$ An important issue that lies in the background of Phya pa's discussion is the status of the Madhyamaka proof of emptiness based on the logical reason 'neither one nor many,' the constitutive elements of which can be interpreted as being either simple negations or negations with a positive retainer.

The positions of the scholars considered are summarized in the table below. Phya pa's view is that the epistemic object that is directly known in an inferential cognition is the aggregate of the subject and the property to be proven, i.e., the thesis. For instance, in the classical examples illustrating the three types of inferential reasons, they are the aggregate of 'sound' and 'impermanence' (for an inferential cognition based on a logical reason qua essential property), the aggregate of 'mountain pass' and 'fire' (for a logical reason qua effect), and the aggregate of 'entity' and 'emptiness' (for a logical reason qua non-apprehension). ${ }^{2}$ Such an aggregate is always a negation with a positive retainer unless both members of the aggregate, the subject and the property, are simple negations. The epistemic object that is indirectly known is the negation of the aggregate of the subject and the negandum. For instance, the negation

\footnotetext{
${ }^{1}$ On these notions in Phya pa's system and the choice of the English rendering, see Hugon 2015a: 62-64.

${ }^{2}$ Cf. Appendix 2.7, [b], [a], and [e], respectively.
} 
of the aggregate of 'sound' and 'permanence,' the negation of the aggregate of 'mountain pass' and 'non-fiery entity,' and the negation of the aggregate of 'entity' and 'ultimate entity.' The negation of an aggregate is always a simple negation. For more details, see the analysis of this section in Hugon 2015a.

Table 4: The identification of the epistemic object

\begin{tabular}{|c|c|c|c|}
\hline & $\begin{array}{l}\text { Logical reason qua } \\
\text { essential property }\end{array}$ & $\begin{array}{l}\text { Logical reason qua } \\
\text { effect }\end{array}$ & $\begin{array}{l}\text { Logical reason qua } \\
\text { non-apprehension }\end{array}$ \\
\hline Dharmottara & Simple negation & Simple negation & Simple negation \\
\hline Śańkaranandana & $\begin{array}{l}\text { Negation with positive } \\
\text { retainer }\end{array}$ & $\begin{array}{l}\text { Negation with positive } \\
\text { retainer }\end{array}$ & $\begin{array}{l}\text { Negation with positive } \\
\text { retainer }\end{array}$ \\
\hline $\begin{array}{l}\text { Anonymous } \\
\text { (rGya dmar ba) }\end{array}$ & $\begin{array}{l}\text { Negation with positive } \\
\text { retainer }\end{array}$ & $\begin{array}{l}\text { Negation with positive } \\
\text { retainer }\end{array}$ & Simple negation \\
\hline Phya pa & $\begin{array}{l}\text { Directly } \\
\text { Negation with positive } \\
\text { retainer } \\
\text { Indirectly } \\
\text { Simple negation }\end{array}$ & $\begin{array}{l}\text { Directly } \\
\text { Negation with positive } \\
\text { retainer } \\
\text { Indirectly } \\
\text { Simple negation }\end{array}$ & $\begin{array}{l}\text { Directly } \\
\text { Negation with positive } \\
\text { retainer } \\
\text { (Simple negation when } \\
\text { the subject and the } \\
\text { property are both } \\
\text { simple negations) } \\
\underline{\text { Indirectly }} \\
\text { Simple negation }\end{array}$ \\
\hline
\end{tabular}

\section{EX4 (6a9-8a2): Proof that there is no duality of appearing and non-appearing for what is essentially identical}

In this excursus, Phya pa presents the details of the reasoning proving that there is no duality of appearing for features such as 'blue' and 'impermanent' (or 'momentary'). This proof, in turn, establishes that 'blue' and 'momentariness,' which are essentially identical and are devoid of distinction, appear as devoid of distinction. This is part of the establishment that in non-conceptual non-erroneous cognitions, the appearance corresponds to the way things are.

The inferential proof establishing the lack of duality is based on the logical reason 'being substantially identical' or 'being a unique substance' ( $r d z a s$ cig pa). To be valid, this logical reason must satisfy the characteristics of (a) applying to the subject and (b) entailing the property to be proven (see Appendix 2.4). 
The former, (a), can be established by resorting to the arguments that establish relations of substantial identity, which are extensively discussed in another context, that of the Buddhist proof of momentariness, and are not repeated there.

With regard to the latter, (b) - that 'being substantially identical' (rdzas cig) or 'being essentially identical' (ngo bo cig) entails the absence of the duality of appearing and non-appearing-Phya pa examines in detail the notion of "unity" or "identity" (cig) involved in the logical reason 'being a unique substance' (Mun sel 112.222.3). He spells out the various notions of conventional and ultimate 'unity' and 'multiplicity' in a gradual scale, starting with the non-Buddhists, then introducing the views of the Srāvaka Buddhists of the Lesser Vehicle, then of the Buddhists following the Higher Vehicle, first Buddhist idealists, then proponents of the system of the Middle Way (Madhyamaka), in Phya pa's words "those who analyze reality" (de kho na dpyod pa rnams). The logical reason 'being a unique substance' is qualified, from the point of view of the last system, in terms of a 'conventional unity' that involves parts. These parts are not, as argued, those constituted by 'appearing features' and 'non-appearing features,' but instead as temporal parts pertaining to the entity; even a single moment of an entity has a beginning, a middle and an end.

Phya pa also rejects a number of pseudo-parallels with the case of 'blue' and 'impermanence' appearing to perception:

- In Mun sel 112.222.1, he shows that 'appearing features' and 'nonappearing features' are incompatible for a single entity, but 'apprehending a concept' and 'not apprehending a concept' are not incompatible for a single cognition.

- In Mun sel 112.222.2, he shows that 'determining blue' and 'not determining impermanence' are not incompatible for a single cognition.

- In Mun sel 112.222.4, he shows that the case of the property 'appearing' for 'blue' and 'impermanent' is not similar to the case of the property 'being empty' for 'entities' and 'what is impermanent' when considering the inference establishing pervasive emptiness in the Madhyamaka system. 
- In Mun sel 112.222.5, he shows that the case of 'blue' and 'impermanent' that both appear in a perceptual cognition is not similar to the case of 'audible' and 'sound' when concluding 'impermanence' in an inferential cognition.

This portion of the Mun sel is transcribed almost entirely in Hugon 2008b: 718-722. A parallel discussion in gTsang nag pa's bsDus pa (117b2118b4) can be found in Hugon 2008b: 725-726, and that in mTshur ston's s Gron ma (4a7-5a3) on pp. 731-733. The similar (but shorter) discussion of this point in the Tshad ma rigs gter by Sa skya Pandita is edited and translated in French on pp. 400-407.

\section{EX5 (8a7-8b3): On the definition of the apprehended ob- ject in the various philosophical systems}

Phya pa defines the apprehended object as "something such that its own nature itself appears to awareness" (Mun sel 121.11). In this excursus, he argues that his own definition of the apprehended object also applies in the philosophical system of the idealists (both representationalists and non-representationalists) but not in the philosphical system of the proponents of representational external realism instantiated in the Sautrāntika model. In this model, one must distinguish the apprehended object of reflexive awareness from the apprehended object of transitive awareness. The first is the object of experience and has the nature of consciousness. It is defined as "revealing itself." The second is defined as "the cause that directly projects an aspect similar to itself to consciousness." Sautrāntikas do not accept that erroneous cognitions have an apprehended object.

This excursus is critically edited and translated in Hugon 2016c (Part II, Appendix V). 



\section{Appendix 2: On inference}

The portions of the Mun sel translated in this volume include many references to inference. References are made not only to inferential cognition as a type of knowledge and as a member of the various typologies of awareness being discussed, but also to various examples of inferential reasoning, as well as to the characterization of the logical reason as valid or fallacious in arguments. All these references presuppose that the reader is already acquainted with Phya pa's theory of inference. The latter, however, is only taken up in the fourth chapter of the Mun sel, of which we have only translated a single section presenting the definition of inferential cognition (cf. Mun sel 241).

To allow non-specialists to get oriented within this topic and to follow the relevant arguments in the translation without burdening the latter with lengthy footnotes, this appendix provides a general introduction to the main features of the theory of inference in Buddhist epistemology, and points out some elements that are specific to Phya pa's version of this theory. The explanations provided below are limited to explaining the notions and examples that appear in the passages of the first chapter of the Mun sel that we have translated. Readers are referred to the publications indicated in footnotes for further reading and more extended biographical references.

Because the focus of this appendix is on Phya pa's theory, the Tibetan expression for technical terms is given first in parenthesis, followed by the Sanskrit term.

\section{Inferential cognition as an episode of knowledge}

Phya pa's theory of inference largely draws from that of the Indian Buddhist thinker Dharmakīti. ${ }^{3}$

Inference (Tib. rjes dpag, Skt. anumāna) is one of the two types of episodes of knowledge accepted by the Buddhists. While the other type of knowledge, perception (Tib. mngon sum, Skt. pratyakșa) - more specifically for Phya pa, perceptual knowledge (Tib. mngon sum tshad ma) -

\footnotetext{
${ }^{3}$ For an introduction to Dharmakīrti's theory, see, for instance, Hayes\&Gillon 1991. Hugon 2011c, which deals with Phya pa's theory of argumentation (in particular, proofs), includes a number of observations on his theory of inference.
} 
only knows objects that are directly present to the cognizer, inference allows knowing objects that are "concealed" (Tib. lkog gyur, Skt. parokșa). This includes objects that are not directly perceived, such as a fire on a mountain pass in the typical example of inferential reasoning (see below, $7[a])$. Inference also allows the determination of some features of perceptible objects that cannot be determined through perception alone, such as an object's impermanence (which are the features that Phya pa terms "non-manifest").

Although Phya pa provides distinct definitions for inferential cognition (rjes dpag) and for inferential knowledge (rjes dpag tshad ma), he contends that all episodes of inferential cognition are episodes of knowledge (see Mun sel 241).

\section{Inferential cognition vs. proof statement}

In works of Buddhist logic, inference refers, strictly speaking, to a cognition-hence our translation "inferential cognition" for rjes dpag. It is a conceptual mental state that arises from an inferential process, in which a conclusion is derived from evidence termed a "logical reason" (Tib. rtags or gtan tshigs, Skt. linga or hetu). Inferences are also often referred to as "proofs," but Buddhist logicians distinguish what they term "inferencefor-oneself" - the inferential cognition arrived at by a cognizer on the basis of evidence-from "inference-for-others"-which consists in a statement meant to allow an interlocutor to generate such an episode of knowledge. A particularity of the latter that fundamentally differentiates it from an Aristotelian syllogism is that the conclusion must not be stated. ${ }^{4}$

\section{The elements of inferential reasoning}

The inferential process rests on the articulation of three elements: the subject or locus, the logical reason, and the property to be proven. Strictly speaking, an inferential cognition consists in the knowledge of the thesis, which consists in the aggregate (Tib. tshogs pa, Skt. samudāya) of the subject and the property to be proven. Authors often, however, loosely

\footnotetext{
${ }^{4}$ On this question and more generally on "inference-for-others" in Buddhist logic see Tillemans 1999, chapter 4 "On Parārthānumāna, Theses and Syllogisms." On Phya pa's prescriptions for proof-statements, see Hugon 2011c.
} 
speak of an inferential cognition knowing the property to be proven (for instance, the inferential cognition of 'fire' rather than the inferential cognition of 'fire on the mountain pass'). Phya pa himself uses the term bsgrub bya (literally "what is to be proven") to refer either to the property to be proven (elsewhere more precisely termed Tib. bsgrub bya'i chos, Skt. sādhyadharma) or to the thesis. ${ }^{5}$

\section{The criteria of a valid logical reason: the three charac- teristics}

Buddhist logicians hold that the cognition derived from evidence qualifies as an episode of knowledge if it relies on a valid logical reason. A valid logical reason is defined as a logical reason that fulfills three characteristics (Tib. tshul gsum, Skt. trairūpya) ${ }^{6}$

1. "Being a property of the subject" (Tib.phyogs chos, Skt.pakșadharmatā) The logical reason must be ascertained to be present in the locus. (A further implicit requirement is involved in this first characteristic: there must be a "desire to know" pertaining to the locus. Namely, whether the locus is or is not qualified by the property to be proven must not be already ascertained.)

2. "Positive entailment" (Tib. rjes su 'gro ba, Skt. anvaya)

The logical reason must be ascertained to be present only in "similar instances" (Tib. mthun phyogs, Skt. sapakșa).

3. "Negative entailment" (Tib. ldog pa, Skt. vyatireka)

The logical reason must be ascertained to be completely absent in "dissimilar instances" (Tib. mi mthun phyogs, Skt. vipakșa, asapakșa).

Each of these characteristics involves a factual criterion and an epistemic criterion. The latter consists in the requirement that the factual criterion

\footnotetext{
${ }^{5}$ See Hugon 2015a: 66-67 on the relevance of distinguishing the two. The term bsgrub bya in the sense of the aggregate of the subject and the property to be proven, which corresponds to the Sanskrit sādhya, is often left untranslated by modern scholars, or rendered with the Latin term probandum. To avoid resorting to a term foreign to English-speaking philosophical scholarship (see Matilal 1990: 128-129), we have adopted the rendering "thesis." It should be clear, however, that for Buddhist logicians, the "thesis" is not a proposition or a statement, but the contents of this statement.

${ }^{6}$ Kajiyama 1958: 364-360, Kajiyama 1966: 58-56, Chi 1969, Gillon 1986, Hayes 1988: 142-154, Hayes\&Gillon 1991, Hugon 2004.
} 
be "ascertained." This means that it must be determined by the cognizer via an episode of knowledge. For instance in the inference that there is fire on the mountain pass via the logical reason 'smoke,' for the first characteristic to be established, there must be smoke on the mountain pass (factual criterion) and the cognizer must have determined the presence of smoke on the mountain pass through a visual perception (epistemic criterion).

The interpretation of the three characteristics gave rise to a large debate in the Tibetan tradition. ${ }^{7}$ Dharmakīti defined similar and dissimilar instances in terms of being "similar to the subject" and "dissimilar from the subject," respectively, with regard to the qualification by the property to be proven. Some scholars viewed this phrasing as a ground to exclude the subject from the domain of similar instances (arguing that something cannot be "similar" to itself) and dissimilar instances.

Authors such as Sa skya Pandita who adopted a "tripartitionist view," according to which the subject constitutes a third domain outside the disjoint domains of similar and dissimilar instances, claimed to be more faithful to the letter of Dharmakirti's works. But they had difficulties accounting for the three characteristics as a sufficient condition for the validity for the logical reason. They were thus caught between exegetical and logical concerns and failed to satisfactorily bridge the gap between the two.

Phya pa (and, following his lead, scholars of the dGe lugs pa school in general), favored instead the logical angle from the outset, adopting a "bipartitionist" view according to which similar instances and dissimilar instances are disjoint and exhaustive, i.e., they include the subject. This required redefining "similar instances" as "instances qualified by the property to be proven" and "dissimilar instances" as "instances not qualified by the property to be proven."

\section{Entailment}

The second and third characteristics of the logical reason stated above are held to be logically equivalent. They are often regrouped under a single condition that we translate with the term "entailment" (Tib. khyab pa,

\footnotetext{
${ }^{7}$ On this debate, and Phya pa's position, see Hugon 2004 and Hugon 2008b: 270-311 (in French).
} 
Skt. vyāpti). ${ }^{8}$ The "entailment" is also spelled out in terms of everything that is qualified by the logical reason being qualified by the property to be proven.

In Buddhist logic, the notion of "entailment" goes hand in hand with the idea that there must be an "essential connection" (Tib. rang bzhin gi 'brel, Skt. svabhavvapratibandha) between the logical reason and the property to be proven. This essential connection can be of two types: identity or causality. Based on this point, Buddhist logicians distinguish three main kinds of logical reasons, which are then further subdivided (especially the third):

1. Essential property (Tib. rang bzhin, Skt. svabhāva): proving the qualification by another essential property

2. Effect (Tib. 'bras bu, Skt. kärya): proving the presence of the cause

3. Non-apprehension (Tib. mi/ma dmigs pa, Skt. anupalabdhi) of an entailed item: proving the absence of an entailing item or non-qualification by an entailing item

\section{Pseudo-logical reasons}

A logical reason is fallacious if it fails to fulfill one or more of the three characteristics listed in $\S 4$ above. This may be due to either the factual criterion and/or the epistemic criterion failing to obtain. In such a case the evidence is termed a "pseudo-logical reason" (Tib. gtan tshigs ltar snang, Skt. hetvābhāsa) and the resulting cognition does not qualify as an episode of knowledge.

The main categories of pseudo-logical reasons are:

(i) Unestablished - Failing to satisfy characteristic 1 (Tib. ma grub pa, Skt. asiddha)

(ii) Inconclusive - Failing to satisfy characteristic 2 or 3 (Tib. ma nges pa, Skt. anaikāntika)

\footnotetext{
${ }^{8}$ Though in many scholarly works these two terms, khyab pa and vyāpti, are translated with the English noun "pervasion," we have used the translation of "entailment," which is much more common in contemporary logic. When expressed as verbs in logical contexts, the terms "entails" and "pervades" actually carry converse meanings. In particular, to say that "item A entails item B," means the same thing as "item B pervades item A."
} 
(iii) Contradictory

(Tib. 'gal ba, Skt. virodha)
- Failing to satisfy characteristics 2 and 3 , but would satisfy characteristics 2 and 3 for the contradictory of the property to be proven

An example of (i) is the property 'visible' posited to prove that sound is impermanent (indeed, sound is not visible). A special case of (i) is when there is no 'desire to know' pertaining to the subject. For instance, when proving that there is fire in a locus where fire can be observed.

An example of (ii) is the property 'being an epistemic object' or 'being an object of cognition' posited to prove that sound is impermanent (for this property is also found among dissimilar instances, and thus fails to satisfy 2).

An example of (iii) is the property 'produced' posited to prove that sound is permanent (this property satisfies characteristics 2 and 3 with regard to impermanence).

In Phya pa's system, the conclusion derived from a pseudo-logical reason can be either a mistaken cognition-if the determined thesis is non-veridical - or a factive assessment - if the determined thesis is veridical (see Mun sel 123.31). In these cases, Phya pa speaks of the putative evidence being a "mistaken reason" (log pa'i rgyu mtshan) when one of the characteristics does not obtain factually and of it being an "uncertified reason" (rgyu mtshan gtan la ma phebs pa) when characteristics 1, 2 and 3 obtain factually but not all of them are ascertained by the cognizer. ${ }^{9}$ (In this last case, the episode of awareness cannot be a mistaken cognition.)

\section{Examples of inference mentioned by Phya pa}

Phya pa typically discusses the various types of inferential cognitions by using stock examples, notably for the kinds distinguished above in $\S 5$. Other instances are inferences with specific features. For those, Phya pa draws his examples from discussions in Dharmakīti's works and from the Madhyamaka background.

The letters [a]...[f] refer to the marking of the various examples in the translation and the edition. They are, in particular, found in Mun sel 112.111.111.2.

\footnotetext{
${ }^{9}$ Note that if the mistaken reason corresponds to type (iii), the determination cannot be an episode of factive assessment.
} 
[a] "There is fire on the mountain pass because there is smoke."

Subject: Mountain pass

Logical reason: Smoke

Property to be proven: Fire

Thesis: Aggregate of 'mountain pass' and 'fire'

This is the stock-example for inferential cognition based on a logical reason qua effect - type (2) in $\$ 5$ above.

[b] "Sound is impermanent because it is produced."

Subject: Sound

Logical reason: Produced

Property to be proven: Impermanent

Thesis: Aggregate of 'sound' and 'impermanent'

This is the stock-example for inferential cognition based on a logical reason qua essential property - type (1) in $\S 5$ above.

The momentariness, or impermanence, of all things is a central tenet for Buddhists. Things only exist for one instant, after which they cease. Continua existing over several moments are not held to be real. Only the instantaneous thing is real. Proving the momentariness of things and refuting their permanence becomes a concern for Buddhist logicians starting with Vasubandhu, and developing in the works of Dharmakirti and his successors. ${ }^{10}$ In particular, there is a move already between Dharmakīrti's earlier works and his later works from proving impermanence via the logical reason "produced"-which is associated with the proof of impermanence relying on destruction being causeless (vināśitvānumā$n a$ ) - to proving it via the logical reason "existence" (sattvānumāna). ${ }^{11}$ The two concepts 'produced' and 'existent' are coextensive.

[c] "A double moon can be given the designation 'conventionally true,' because it does not withstand analysis."

Subject: Double moon

Logical reason (essential property): Not withstanding analysis

Property to be proven: Fit to have the designation 'conventionally true'

\footnotetext{
${ }^{10}$ On this topic, see Mimaki 1976.

${ }^{11}$ On this point, see Steinkellner 1968.
} 
Thesis: Aggregate of 'double moon' and 'the designation "conventionally true""

This example relies on the Madhyamaka framework of the Two Truths, which distinguishes what is "ultimately true" and what is "conventionally true." "Not withstanding analysis" is the definiens given by Phya pa for conventional truth. ${ }^{12}$

In Phya pa's system, a definition involves a three-member framework composed of a definitional instance, a definiens, and a definiendum, which is parallel to the three-member framework of inferential reasoning. ${ }^{13}$ With respect to the definiens "not withstanding analysis," the designation "conventionally true" is the definiendum which is fit to be applied to a definitional instance that has the definiens. These elements of a definition can be used in a definitional inference: the definiens can play the role of a logical reason to prove that a subject is fit to have the designation of the corresponding definiendum.

[d] "The verbal object 'Luna' is the direct referent of the word "moon," because it is the apprehended object of a conceptual cognition."

Subject: Verbal object 'Luna'

Logical reason (essential property): Being the apprehended object of a conceptual cognition

Property to be proven: Being the direct referent of the word "moon"

Thesis: Aggregate of "verbal object "Luna" and "being the referent of the word "moon"

The background for this discussion goes back to Dignāga's discussion of fallacious theses. ${ }^{14}$ Dignāga holds that one can appeal to linguistic conventions (literally "a proposition commonly recognized through verbal knowledge," Skt. śäbdaprasiddha) to refute fallacious theses such as "that which has a rabbit is not the moon." This thesis indeed contradicts

${ }^{12}$ See sNying po 16,5-6 (1.2.1.1.1): mthar thug 'jal ba'i yul du mi bden la ma dpyad pa'i bsam ngor bden pa kun rdzob kyi bden pa'i mtshan nyid do //

${ }^{13}$ On Phya pa's theory of definition, see Hugon 2009b.

${ }^{14}$ See Tillemans 2000 on PV 4.109ff. and pp. 219-228 ("Dharmakīrti on prasiddha and yogyatä') for a detailed discussion of this issue. The main points are summarized here. 
the Sanskrit linguistic convention according to which the word śaśin (literally "that which has a rabbit") refers to the moon (and vice versa).

Dharmakirti reinterpreted this thesis to mean "śaśin is not the referent of the word candra" (candra being the usual Sanskrit expression to refer to the moon). According to Dharmakirti, this is a fallacious thesis not only because there is a linguistic convention according to which the word candra does designate "that which has a rabbit," i.e., the moon, but because anything can be the referent of the word candra. Indeed, a word is not predetermined to designate certain things and not others.

The inference [d] reflects the argument one finds in this regard in Durvekamiśra's sub-commentary on NB 3.51 (as translated in Tillemans 2000: 223):

Whatever entity is the object of a conceptual cognition can be designated by an agreed upon word, just like the entity having branches and so forth [can be designated] by the word 'tree.' Now, śaśin is the object of a conceptual cognition.

According to Tillemans's discussion, this argument hinges on the idea of "universal fitness": 'being the object of a conceptual cognition' is a sufficient condition to have the fitness to be named by any word one wishes. But more precisely, in view of the expression "agreed upon word," and in particular of the example, this argument should be viewed as expressing the idea of a "universal fitness restricted by linguistic conventions." It establishes that śaśin can be designated by the agreed upon word "moon," just like an entity having branches and so forth can be designated by the agreed upon word "tree."

When Phya pa mentions this inference, the notion of "fitness" is not included in the formulation of the property to be proven, but there is little doubt that this example refers to the background discussion by Dharmakirti, which is taken up later in the Mun sel when Phya pa explains the "elimination of the thesis via what is commonly recognized" (Mun sel 79b8ff.). Phya pa explains that this type of elimination amounts to an "elimination of the thesis by an inferential cognition in which a property depending on language is derived." 15 Such inferential cognitions are of two types:

${ }^{15}$ Mun sel 80a1: sgra la ltos pa'i chos dpog pa'i rjes dpag gis dam bcas pa la bsal pa grags pas bsal pa te. 
- deriving 'being the direct referent of words' from the logical reason 'being the apprehended object of a conceptual cognition' (as in the present example [d])

- deriving 'being the intentional referent of words' from any logical reason

The "direct referent of words" (sgra'i dngos kyi brjod bya) is, according to Phya pa, the concept that appears in conceptual cognition (for instance, the concept of "pot' for the word "pot"). The "intentional referent" (zhen pa'i brjod bya) is what the cognizer conceives the word to be referring to (for instance, a real pot can be conceived as the referent of the word "pot").

These two types of inferential cognition deal with the basic principle of what a word refers to, relying on the idea that any word can a priori refer in such a way. They are distinguished from inferential cognitions that rely on posited linguistic conventions linking a definiens and a definiendum (Mun sel 80a3-4). For instance, deriving the definiendum "cow" from the definiens "the collection of hump, dewlap, etc."

The former inferential cognitions are associated with the common establishment of "agreement regarding communication" (brda'i grags pa), the latter with the common establishment of "agreement regarding transactional usage" (tha snyad kyi grags pa). ${ }^{16}$

[e] "Entities/All things are empty of an own nature, because they are neither one nor many."

Subject: Entities/All things

Logical reason: Neither one nor many

Property to be proven: Empty

Thesis: Aggregate of 'entity' and 'empty'

16 This second type is also presented in reference to a "non-deviant exclusion of what is other," a notion introduced by Phya pa when dealing with the definiendum in the section on definition (see Mun sel 25b7-8). What is derived in the second type of inferential cognition is said to be the "fitness to be conceived of by a word that is a non-deviant exclusion of what is other" (Mun sel 80a4: gzhan sel phyin ci ma log pa'i sgras zhen rung dpog pa) or the "fitness to be expressed through directing via a non-deviant exclusion of what is other that distinguishes between two directly incompatible things" (Mun sel 80a3: dngos 'gal las tha dad du byed pa'i gzhan sel phyin ci ma log pas zhen nas brjod du rung pa dpog pa). 
The inferential reasoning establishing emptiness is a key argument for Madhyamaka philosophers. ${ }^{17}$ The argument revolves around the idea that in order not to be empty, an entity must have a nature that is either one or many. But a singular nature is refuted by showing that entities can be divided into parts (spatial parts for external entities, temporal parts for external entities and mental events). The refutation of a multiple nature follows from the refutation of a singular nature.

This argument also figures prominently in Phya pa's discussions on inference in his epistemological works and in his Madhyamaka works. ${ }^{18}$ According to Phya pa, there are several possible interpretations of the elements of this inference (in particular the logical reason and the property to be proven). The logical reason can accordingly be variously classified as an instance of "essential property" (type (1) in §5) or "non-apprehension" (type (3) in §5).

Within the 'Od zer, in a passage parallel to of the example mentioned in the Mun sel, Phya pa distinguishes a version of this inference in which the subject is "real entities" [e1] and a version in which the subject is "the objects to be cognized in general" (shes bya tsam) [e2], which includes both real entities and superimpositions.

[f] "A concept can be given the designation 'conventionally true,' because it does not withstand analysis."

Subject: Concept

Logical reason (essential property): Not withstanding analysis

Property to be proven: Fit to have the designation 'conventionally true'

Thesis: Aggregate of 'concept' and 'the designation "conventionally true"

This inference has the same logical reason and property to be proven as in [c], but the subject is here "a concept." It is mentioned in Mun sel 121.2 to exemplify the case of an apprehended object that is also the engaged object of a cognition. This is the case here because the appearing concept is conceived of as a concept, and opposite superimpositions are eliminated with regard to the concept. Inference [d] could have been mentioned instead, as it has the same features in this regard.

${ }^{17}$ A classic presentation for this argument is found for instance in the Madhyamakālañkāra of Śāntarakșita and the Madhyamakāloka of his pupil Kamalaśīla. See Tillemans 1982 and 1983 and Keira 2004 for more details.

${ }^{18}$ See Hugon 2015a. 



\section{Appendix 3: Definitions of knowledge}

Listed below are the various versions of Phya pa's definition of knowledge and a selection of definitions by his predecessors and successors.

\section{Phya pa's definitions}

i-Mun sel 212.14

yongs su bcad pa'i don la mi 'khrul pa'i blo'i rnam pas gnas lugs dang 'gal ba'i sgro 'dogs skyed pa'i nus pa bzlog pa

ii - Mun sel 35b2

don la mi 'khrul pa'i rnam pas gshis dang mi mthun pa'i sgro 'dogs skyed nus sel pa

iii - 'Od zer 111.221.2, 21b7

sngar ma rtogs pa'i don bden pa la bzlog pa'i sgro 'dogs dang 'gal ba

iv - 'Od zer 111.221.2, 23b1

sngar ma rtogs pa'i don bden pa la don la myi 'khrul ba'i 'dzin stangs kyis bzlog pa'i sgro 'dogs dang 'gal ba

$\mathrm{v}-{ }^{\prime}$ Od zer $67 \mathrm{~b} 2$

sgro 'dogs gcod byed yin

vi - 'Od zer 172b7-8

mngon suM la yod pa'i tshad ma tsam du 'jog pa'i rgyu mtshan ni 'dzin stangs kyi rnam pa ${ }_{[172 b 8]}$ don myed na mi 'byung bas sngar ma rtogs pa'i don gnod myed du bden pa la sgro 'dogs gcod pa yin la / vii - sNying po 68,18-20

mngon sum dang rjes dpag la'ang tshad ma tsam gyi spyi'i mtshan nyid don la mi 'khrul ba'i blos sngar ma rtogs pa'i don la sgro 'dogs dang 'gal ba yod pas tshad ma ma yin par mi 'thad do //

\section{Definitions by Tibetan authors who precede or are con- temporaneous with Phya pa}

i - "Byang chub skyabs," cited in Tshad bsdus 115,14

don thob byed kyi nus pa mi slu ba yin 


\section{Definitions by Phya pa's successors}

i-Tshad bsdus 114,18

bden pa'i don rtogs

ii - Tshad bsdus 116,16-18

sngar ma rtogs pa'i shes bya la 'dzin stangs kyi rnam pa don med na mi 'byung ba'i stobs kyi sgro 'dogs gcod byed ces bya ba'o //

iii - gTsang nag pa, bsDus pa $16 \mathrm{~b} 8$

sngar ma rtogs pa'i don rtogs pa

iv - mTshur ston, sGron ma 15b6-9

bden pa'i don rtogs ... [15b8] ... rtogs pa'i mtshan nyid ni sngar ma rtogs pa'i don la 'dzin stangs mi 'khrul pas sgro 'dogs sel pa zhes bya ba'i ngo bo dang / yul dang / [15b9] 'dzin stangs kyi khyad par gsuM dang ldan pa

$\mathrm{v}$ - gTsang drug rdo rje, gSal byed 23a7

bden pa'i don rtogs yin de yang ci lta bu zhe na rtogs pa chos 3 tshang ba 1 yin te / rtogs pa rang gi ngo bo sgro 'dogs gcod byed dang | yul gyi khyad par sngar ma rtogs pa la 'jug pa dang |' dzin stangs kyi khyad par don la mi 'khrul ba

vi - Chu mig pa, rNam rgyal A22b1-3; B26b4-6

bden pa'i don rtogs chos 3 tshang pa'am (B pa'am, A ba 'aM) / gzhal bya'i don la mi slu ba ste de 2 rnam grangs pa yin no // gsum (A gsum, B 3) gang zhe na / ngo bo'i khyad [A22b2] par sgro (B sgro : A sgra)'dogs gcod byed (A gcod byed: B gcod par byed pa ste / rnam 'grel las / ... [B2665] ... ces_so //) !'dzin stangs kyi khyad par (A par: B par ni) don la mi 'khrul ba (A ba : B ba te / 'di las ... zhes so //) / yul gyi khyad par sngar ma rtogs pa la 'jug pa'o // (A pa'o // dang po mtshan nyid yin par / rnam 'grel las /... ces so // gnyis pa mtshan nyid yin par [A22b3]' di las ... ces so // 3 pa mtshan nyid yin par /'di las ... zhes so // : B pa te / [B2666]' di las ... zhes so //)

vii - rDo rje dbang grags/Chos kyi bzhad pa, Tshad nye bsdus 11a3-4

rtogs pa chos 3 ldan tshad ma'i mtshan nyid du gsal te / rtogs pa rang gi ngo bo sgro 'dogs sel pa yin te / ... yul gyi khyad par sngar ma rtogs pa la 'jug pa ste / ... [11a4] ...' 'dzin stangs kyi khyad par don la mi 'khrul pa yin te / 


\section{Appendix 4: Lexicon}

\section{Tibetan-English equivalents}

$\begin{array}{ll}\text { TIBETAN } & \text { ENGLISH } \\ \text { kun brtags } & \text { Imagined } \\ \text { kun rdzob } & \text { Conventional } \\ \text { kun rdzob kyi bden pa } & \text { Conventionally true } \\ \text { lkog gyur } & \text { Concealed } \\ \text { kha phyir ltas kyi yid } & \text { Mental cognition that is oriented } \\ & \text { outwards } \\ \text { khyab pa } & \text { Entailment (of the property to be } \\ & \text { proven) } \\ \text { khyab bya } & \text { Entailing item } \\ \text { khyab byed } & \text { Entailed item } \\ \text { 'khrul pa } & \text { Erroneous } \\ \text { grub pa } & \text { To be established } \\ \text { 'gal ba } & \text { Incompatible } \\ \text { 'gal ba } & \text { Contradictory (logical reason) } \\ \text { sgra don } & \text { Verbal object } \\ \text { sgro btags } & \text { Superimposed } \\ \text { sgro 'dogs } & \text { Superimposition } \\ \text { bsgrub bya } & \text { Thesis, property to be proven } \\ \text { nges pa } & \text { Determinate awareness } \\ \text { nges pa } & \text { To determine, to ascertain } \\ \text { nges shes } & \text { Determining cognition } \\ \text { dngos po } & \text { Real entity, real } \\ \text { dngos med } & \text { Unreal } \\ \text { mngon sum } & \text { Perception } \\ \text { mngon sum tshad ma } & \text { Perceptual knowledge } \\ \text { gcad pa'i yul can/bcad pa'i yul } & \text { Post-knowledge cognition } \\ \text { can } & \\ \text { gcod pa, bcad pa } & \text { To eliminate } \\ \text { gcod pa } & \text { To discern } \\ \text { bcad pa'i yul can/gcad pa'i yul } \\ \text { can }\end{array}$


chod pa

'char ba

'jal ba

'jug pa

'jug (pa'i) yul

rjes dpag

rjes dpag tshad ma

rjes su skyes pa'i nges shes

rjes su 'gro bas stong

$\mathrm{pa} /$ rjes 'gros stong $\mathrm{pa}$

nye bar btags pa

gtan tshigs

rtags

rtags can

rtags ltar snang

rtog bcas

rtog bcas (kyi) log shes

rtog pa

rtog pa bcad pa'i yul can/rtog

pa gcad pa'i yul can

rtog med 'khrul pa

rtog med 'khrul pa'i dmigs pa

rtog med ma 'khrul pa

rtogs pa

tha dad pas stong pa/tha dad

kyis stong pa

the tshom/the tsom

mthun phyogs

mthong pa

de las byung pa

dogs pa

don

don dam
To be eliminated

To arise

To evaluate

To engage

Engaged object

Inferential cognition

Inferential knowledge

Subsequently arising determining cognition

Devoid of commonality

Totally made up

Logical reason, evidence

Logical reason, evidence, valid logical reason

That for which a property is a logical reason

Pseudo-logical reason

Conceptual cognition

Conceptual mistaken cognition

Conceptual cognition

Conceptual post-knowledge

cognition

Non-conceptual erroneous cognition

Referent of non-conceptual erroneous cognition

Non-conceptual non-erroneous cognition

To understand

Devoid of distinction

Doubt

Similar instance

To observe

Causality

To consider

State of affairs

Ultimate 
don spyi

don byed nus pa

don byed pa

don byed mi nus pa

don rang gi mtshan nyid

bdag cig pa

bden pa

'dren pa, drangs pa

ldog pa

gnas lugs

gnod pa

rnam (pa dang) ldan pa

rnam (pa) med (pa)

rnal 'byor gyi mngon sum

rnal 'byor pa'i shes pa

snang pa

snang la ma nges pa

dpog pa, dpags pa

dpyod mi bzod pa

phyi rol

phyogs chos

blo

dbang po'i shes pa

'brel pa

ma 'khrul pa

ma grub pa

ma nges pa

ma gsal

mi 'gal ba

mi gsal

mig gi rnam shes

mig (gi) shes (pa)

med na mi 'byung pa

myong pa

rtsod gzhi

tshad ma
Concept

Capable of being causally active

Causally active

Incapable of being causally active

Real particular

Essential identity, having a

shared identity

Veridical

To bring about

Exclusion property

The actual way things are

To oppose

Manifest feature

Non-manifest feature

Yogic perception

Yogic cognition

To appear, appearing

Non-ascertaining perception

To conclude, to deduce, to infer

Not withstanding analysis

External

Being a property of the subject

Awareness

Sense cognition

Dependence

Non-erroneous

Unestablished (logical reason)

Inconclusive (logical reason)

Not clearly appearing

Compatible, not incompatible

Not clearly appearing

Visual cognition

Visual cognition

Invariably related

To experience

Locus

Knowledge, episode of

knowledge 
tshad ma'i yul

tshad ma ma yin

tshul gsum

tshogs pa

brdzun pa

zhen pa

zhen yul

gzhan dbang

gzhan rig (pa)

gzhan rig gi mngon sum

gzhan rig rtog pa

gzhan rig (gi) rtog med

gzhan sel pa

gzhal bya

gzhi

gzung (pa'i) don/bzung (pa'i)

don

gzung yul/bzung yul

bzlog pa

yid

yid kyi shes pa

yid gtad pa

yid dpyod

yul

yul can

yongs su grub pa

yongs su gcad pa'i gzhal bya

yongs su gcod pa

yongs su bcad pa'i don

rang rig (pa)

$\log \mathrm{pa}$

log pa'i kun rdzob
Object of knowledge

Not an instance of knowledge

Triple characteristic (of a logical reason), triply-characterized (logical reason)

Aggregate

Falsidical

To be directed, to conceive

Intentional object

Dependent

Transitive awareness

Transitive perception

Conceptual transitive episode of awareness

Non-conceptual transitive episode of awareness

Excluding others

Epistemic object

Locus

State of affairs to be apprehended

Apprehended object

To counter

Mind

Mental cognition

To focus one's mind

Factive assessment

Object, objective element

Subjective element

Perfected

Positively discerned epistemic object

To discern positively, to ascertain positively

Positively discerned state of af-

fairs

Reflexive awareness

Excluded

Mistaken conventionality 
log par nges pa

$\log$ shes

$\log \mathrm{sa}$

shes 'dod

shes pa

shes bya

shes bya la mi srid pa

shes bya la srid pa

sems

sems (las) byung (pa)

sel pa, bsal pa

gsal
Mistaken determinate awareness

Mistaken cognition

Counterpart

Desire to know

Cognition

Object to be cognized

Impossible, that is not the case

Possible, that is the case

Mind

Mental factors

To eliminate, to exclude

Clearly appearing

\section{English-Tibetan equivalents}

\section{ENGLISH}

Aggregate

(to) Appear

Appearing

Apprehended object

(to) Arise

(to) Ascertain positively, to discern positively

(to) Ascertain, to determine

Awareness

Being a property of the subject

(to) Bring about

Capable of being causally active

Causality

Causally active

Clearly appearing

Cognition

Compatible, not incompatible

Concealed

Concept

Conceptual cognition

\section{TIBETAN}

tshogs pa

snang pa

snang pa

gzung yul/bzung yul

'char ba

yongs su gcod pa

nges pa

blo

phyogs chos

'dren pa, drangs pa

don byed nus pa

de las byung pa

don byed pa

gsal

shes pa

mi 'gal ba

lkog gyur

don spyi

rtog bcas, rtog pa 
Conceptual mistaken cogni- $\quad$ rtog bcas (kyi) log shes tion

Conceptual post-knowledge rtog pa bcad pa'i yul can/rtog pa cognition gcad pa'i yul can

Conceptual transitive episode of awareness

(to) Conclude, to deduce, to dpog pa, dpags pa infer

(to) Consider

Contradictory (logical reason)

Conventional

Conventionally true

(to) Counter

Counterpart

Dependence

Dependent

Desire to know

Determinate awareness

(to) Determine, to ascertain

Determining cognition

Devoid of commonality

Devoid of distinction

(to be) Directed, to conceive (to) Discern

(to) Discern positively, to ascertain positively

Doubt

(to) Eliminate

(to) Eliminate

(to be) Eliminated

(to) Engage

Engaged object

Entailed item

Entailing item

Entailment (of the property to be proven)

Epistemic object

dogs pa

'gal ba

kun rdzob

kun rdzob kyi bden pa

bzlog pa

$\log \mathrm{sa}$

'brel pa

gzhan dbang

shes 'dod

nges pa

nges pa

nges shes

rjes su 'gro bas stong

pa/rjes 'gros stong pa

tha dad pas stong pa/tha dad

kyis stong pa

zhen pa

gcod pa

yongs su gcod pa

the tshom/the tsom

gcod pa, bcad pa

sel pa, bsal pa

chod pa

'jug pa

'jug (pa'i) yul

khyab byed

khyab bya

khyab pa

gzhal bya 
Erroneous

Essential identity, having a shared identity

(to be) Established

(to) Evaluate

Excluded

Excluding others

Exclusion property

(to) Experience

External

Factive assessment

Falsidical

(to) Focus one's mind

Imagined

Impossible, that is not the case

Incapable of being causally

active

Incompatible

Inconclusive (logical reason)

Inferential cognition

Inferential knowledge

Intentional object

Invariably related

Knowledge, episode of

knowledge

Locus

Logical reason, evidence, valid logical reason

Manifest feature

Mental cognition

Mental cognition that is oriented outwards

Mental factors

Mind

Mistaken cognition

Mistaken conventionality

Mistaken determinate awareness

Non-ascertaining perception 'khrul pa

bdag cig pa

grub pa

'jal ba

$\log \mathrm{pa}$

gzhan sel pa

ldog pa

myong pa

phyi rol

yid dpyod

brdzun pa

yid gtad pa

kun brtags

shes bya la mi srid pa

don byed mi nus pa

'gal ba

ma nges pa

rjes dpag

rjes dpag tshad ma

zhen yul

med na mi 'byung pa

tshad ma

rtsod gzhi, gzhi

rtags

rnam (pa dang) ldan pa

yid kyi shes pa

kha phyir ltas kyi yid

sems (las) byung (pa)

yid, sems

log shes

log pa'i kun rdzob

log par nges pa

snang la ma nges pa 
Non-conceptual erroneous cognition

Non-conceptual non-erroneous rtog med ma 'khrul pa cognition

Non-conceptual transitive episode of awareness

Non-erroneous

Non-manifest feature

Not an instance of knowledge

Not clearly appearing

Not withstanding analysis

Object of knowledge

Object to be cognized

Object, objective element

(to) Observe

(to) Oppose

Perception

Perceptual knowledge

Perceptual post-knowledge cognition

Perfected

Positively discerned epistemic object

Positively discerned state of affairs

Possible, that is the case

Post-knowledge cognition

Property to be proven

Pseudo-logical reason

Real

Real entity

Real particular

Referent of non-conceptual erroneous cognition

Reflexive awareness

Sense cognition rtog med 'khrul pa

gzhan rig (gi) rtog med

ma 'khrul pa

rnam (pa) med (pa)

tshad ma ma yin

$\mathrm{mi}$ gsal/ma gsal

dpyod mi bzod pa

tshad ma'i yul

shes bya

yul

mthong pa

gnod pa

mngon sum

mngon sum tshad ma

bcad pa'i yul can gyi mngon

sum

yongs su grub pa

yongs su gcad pa'i gzhal bya

yongs su bcad pa'i don

shes bya la srid pa

gcad pa'i yul can/bcad pa'i yul

can

bsgrub bya (used in the sense of bsgrub bya'i chos)

rtags ltar snang, gtan tshigs ltar

snang

dngos po

dngos po

don rang gi mtshan nyid

rtog med 'khrul pa'i dmigs pa

rang rig (pa)

dbang po'i shes pa 
Similar instance

State of affairs

State of affairs to be appre-

hended

Subjective element

Subsequently arising determining cognition

Superimposed

Superimposition

That for which a property is a

logical reason

Thesis

Totally made up

Transitive awareness

Transitive perception

Triple characteristic (of a logical reason), triply-characterized (logical reason)

Ultimate

(to) Understand

Unestablished (logical reason)

Unreal

Verbal object

Veridical

Visual cognition

Yogic cognition

Yogic perception mthun phyogs

don

gzung (pa'i) don/bzung (pa'i)

don

yul can

rjes su skyes pa'i nges shes

sgro btags

sgro 'dogs

rtags can

bsgrub bya

nye bar btags pa

gzhan rig (pa)

gzhan rig gi mngon sum

tshul gsum

don dam

rtogs pa

ma grub pa

dngos med

sgra don

bden pa

mig gi rnam shes, mig (gi) shes

(pa)

rnal 'byor pa'i shes pa

rnal 'byor gyi mngon sum 

VIII

Bibliographical references 



\section{Abbreviations: journals, publishing houses, etc.}

ATBS - Arbeitskreis für tibetische und buddhistische Studien, Universität Wien

CTRC — China Tibetology Research Center

EA - Etudes Asiatiques/Asiatische Studien

JBP — Journal of Buddhist Philosophy

JIABS - Journal of the International Association of Buddhist Studies

JIP — Journal of Indian Philosophy

STTAR - Sanskrit Texts from the Tibetan Autonomous Region

TBRC - Tibetan Buddhist Resource Center (now called Buddhist

Digital Resource Center)

VÖAW - Verlag der Österreichischen Akademie der Wissenschaften

WSTB - Wiener Studien zur Tibetologie und Buddhismuskunde

WZKS - Wiener Zeitschrift für die Kunde Südasiens

WZKSO — Wiener Zeitschrift für die Kunde Süd- und Ostasiens 



\section{Primary sources}

\subsection{Indian works}

AAS - Śankkaranandana, Anyāpohasiddhi (or Apohasiddhi). Tib. in D 4256 (tshad ma, zhe 281a6-302b1) and P 5754 (tshad ma, ze 302b3325a7).

AK/AKBh — Vasubandhu, Abhidharmakośakārikāabhidharmakośabhāssya. Skt. see Pradhan (ed.) 1967. Tib. in D 4089 (mngon pa, ku 1b1-25a7) and D 4090 (mngon pa, ku 26a1-258a7 and khu 1b195a7).

BCA — Śāntideva, Bodhicaryāvatāra. Skt. see Minaev 1889.

BPP — Śañkaranandana, Bṛhatprāmānyaparīkșāa.

$\mathrm{D}$ - sDe dge bKa' 'gyur and bsTan 'gyur. bsTan 'gyur: Ed. J. Takasaki, Z. Yamaguchi, N. Hakamaya. Sde dge Tibetan Tripitaka bsTan 'gyurPreserved at the Faculty of Letters, University of Tokyo. Tokyo: Sekai seiten kankō kyōkai, 1980.

DhP — Durvekamiśra, Dharmottarapradīpa. See Malvania (ed.) 1955.

HB - Dharmakīrti, Hetubindu. Skt. see Steinkellner (ed.) 2016. Tib. see Steinkellner (ed.) 1967.

NB — Dharmakīrti, Nyāyabindu. See DhP.

NBT - Dharmottara, Nyāyabinduțikkā. Skt. see DhP. Tib. in D 4231 (tshad ma, we 36b2-92a2) and P 5730 (tshad ma, zhe 43b3-113a1).

$\mathrm{P}$ - Peking bKa' 'gyur and bsTan 'gyur. The Tibetan Tripitaka, Peking Edition, Reprinted under the Supervision of the Otani University, Kyoto. Ed. D.T. Suzuki. Tokyo/Kyoto: Tibetan Tripitaka Research Institute, 1957.

PPar II — Dharmottara, Prāmānyaparīkṣā II ( Laghuprāmānyaparīkṣā). See Krasser 1991 (Teil 1).

PS - Dignāga, Pramānasamuccaya. See PSV.

PSV - Dignāga, Pramānasamuccaya. Tib. (Kanakavarman and Dad pa'i shes rab) in P 5702 (tshad ma, ce 93b4-177a7); Tib. (Vasudhararakșita and Seng rgyal) in D 4204 (tshad ma, ce 14b1-85b7) and P 5701 (tshad ma, ce 13a6-93b4). 
PV — Dharmakīrti, Pramānavāarttika.

PV 1 - Dharmakīrti, Pramānavārttika, chapter 1. See Gnoli (ed.) 1960.

PV 2,3,4 - Dharmakīrti, Pramānavārttika, chapter 2 (pramānasiddhi), chapter 3 (pratyakșa), chapter 4 (parārthānumāna). See Miyasaka (ed.) 1971/1972.

PVin - Dharmakīrti, Pramānaviniścaya.

PVin 1 - Dharmakīrti, Pramānaviniścaya, chapter 1. Skt. see Steinkellner (ed.) 2007. Tib. see Vetter 1966.

PVin 2 - Dharmakīrti, Pramānaviniścaya, chapter 2. Skt. see Steinkellner (ed.) 2007. Tib. see Steinkellner (ed.) 1973.

PVinṬ — Dharmottara, Pramānaviniścayațīkā.

PVinṬ 2 - Dharmottara, Pramānaviniścayațīkā, chapter 2 (svārthānumāna). Tib. in D 4229 (tshad ma, dze 1-289a7), P 5752 (tshad ma, dze 1a1-we $209 \mathrm{~b} 8$.

PVinṬ 3 - Dharmottara, Pramānaviniścayațīkā, chapter 3 (parārthānumāna). Skt. Photostat copy of the Sanskrit manuscript in the library of CTRC. Tib. in D 4227 (tshad ma, tshe 1a1-178a3), P 5727 (tshad ma, we 1a1-209b5).

PVSV — Dharmakīrti, Pramānavārttikasvavrtti. See Gnoli (ed.) 1960.

PVṬ - Śañkaranandana, Pramānavārttikațīkā. Tib. in D 4223 (tshad ma, pe 1a1-293a7).

Tarkamudgara - Jayānanda, Tarkamudgara. Tib. in D 3869 (dbu ma, ya $374 b 2-375 a 7$.

\subsection{Tibetan works}

Klong rdol ming grangs — Klong rdol bla ma Ngag dbang blo bzang, Tshad ma rnam 'grel sogs gtan tshigs rig pa las byung ba'i ming gi grangs. In dPyad gzhi'i yig cha phyogs bsgrigs - Historical Materials of Tibetan Buddhism. Ed. Ningxia Academy of Social Sciences, Tianjin, s.d. Vol. 36, pha 1a-23b (= pp. 137-148).

dKa' gnas — rNgog Lo tsā ba Blo ldan shes rab, Tshad ma rnam nges kyi dka' ba'i gnas rnam par bshad pa. Ed. Sun Wenjing. Xining, Qinghai: Krung go'i bod kyi shes rig dpe skrun khang, 1994. 
bKa' gdams gsung 'bum - bKa' gdams gsung 'bum phyogs sgrig thengs dang po/gnyis pa/gsum pa/bzhi pa. Ed. dPal brtsegs bod yig dpe rnying zhib 'jug khang. Chengdu: Si khron mi rigs dpe skrun khang, Vols. 1-30: 2006; vols. 31-60: 2007; vol. 61-90: 2009; vol. 91-120: 2015.

Grub mtha' mdzod - Klong chen Rab 'byams pa Dri med 'od zer, Theg pa mtha' dag gi don gsal bar byed pa grub mtha' rin po che'i mdzod. In Klong chen rab 'byams pa dri med 'od zer gyi gsung 'bum. 5 vols. sDe dge: sDe dge par khang chen mo, s.d. TBRC: W00EGS1016299, vol. 2, 969-1264.

rGyan mun sel - mKhas grub rje dGe legs dpal bzang po, Tshad ma sde bdun gyi rgyan yid kyi mun sel (= sDe bdun yid kyi mun sel or Tshad ma yid kyi mun sel). In Collected Works - mKhas grub rje'i gsung 'bum, Lhasa. Vol. tha 1a-185b.

sGron ma - mTshur ston gZhon nu seng ge, Tshad ma shes rab sgron ma. See Hugon (ed.) 2004.

Ngor chos 'byung - Ngor chen dKon mchog lhun grub and Ngor chen Sangs rgyas phun tshogs, Dam pa'i chos kyi byung tshul legs par bshad pa bstan pa rgya mtshor 'jug pa'i gru chen zhes bya ba rtsom 'phro kha skong bcas. New Delhi, 1973.

rNgog lo rol mo - gSer mdog pan chen Śākya mchog ldan, rNgog lo tsha ba chen pos bstan pa ji ltar bskyangs pa'i tshul mdo tsam du bya ba ngo mtshar gtam gyi rol mo. In gSer mdog gsung 'bum, 1975. Vol. 16, 443-456.

'Jam dbyangs bzhad pa'i blo rigs — 'Jam dbyangs bzhad pa Ngag dbang brtson 'grus, Blo rigs kyi rnam gzhag nyung gsal legs bshad gser gyi phreng mdzes. In The Collected Works of 'Jam-dbyañs-bźad-pa'i-rdorje. New Delhi, 1973. Vol. 15, 303-376.

sNying po — Phya pa Chos kyi seng ge, dBu ma de kho na nyid kyi snying po. $\mathrm{A}=$ Tauscher (ed.) 1999; $\mathrm{B}=b K a$ ' gdams gsung 'bum, vol. 7, 15129.

Tho yig - A khu ching Shes rab rgya mtsho, dPe rgyun dkon pa 'ga' zhig gi tho yig. See Chandra (ed.) 1963, part 3.

De nyid snang ba - rMa bya Byang chub brtson 'grus, $d B u$ ma rigs pa' $i$ tshogs kyi rgyan de kho na nyid snang ba. In bKa' gdams gsung 'bum, vol. $13,745-820$. 
Deb sngon — 'Gos lo tsā ba gZhon nu dpal, Bod gangs can yul du chos dang chos smra ji ltar byung ba'i rim pa bstan pa'i deb ther sngon po. Chengdu: Si khron mi rigs dpe skrun khang, 1984.

Don gnyer mun sel - (Ascribed to) Tsong kha pa, sDe bdun la 'jug pa'i sgo don gnyer yid kyi mun sel. In Collected Works of Tsong kha paKhams gsum chos kyi rgyal po Tsong kha pa chen po'i gsung 'bum, Tashi lhunpo edition. Delhi (Ge den sung rab mi nyam gyun phel series 79-105), 1975-79. Vol. tsha, 1a-25b.

bsDus pa - gTsang nag pa brTson 'grus seng ge, Tshad ma rnam par nges pa'i ți ka legs bshad bsdus pa. Kyoto: Rinsen Book Co (Otani University Tibetan Works Series 2), 1989.

rNam rgyal - Chu mig pa Seng ge dpal, gZhan gyi phyogs thams cad las rnam par rgyal ba. $\mathrm{A}=b K a$ ' gdams gsung 'bum, vol. 87, 315-448; $\mathrm{B}=$ bKa' gdams gsung 'bum, vol. 45, 11-163.

Pham byed I/II - gSer mdog paṇ chen Śākya mchog ldan, Tshad ma rigs pa'i gter dgongs rgyan lung dang rigs pa' $i$ 'khor los lugs ngan pham byed. In gSer mdog gsung 'bum, vol. 9 (ta) and 10 (tha).

dBu ma rgya mtsho - gSer mdog paṇ chen Sākya mchog ldan, Theg pa chen po dbu ma rnam par nges pa'i mdzod lung dang rigs pa'i rgya mtsho las dbu ma thal rang gi gyes 'tshams dang grub mtha'i gnas rnams gsal bar bstan pa'i le'u gnyis pa. In gSer mog gsung 'bum, vol. 14 (pha), 413-647 and vol. 15 (ba), 1-695.

dBu ma de kho na nyid - rGya dmar ba Byang chub grags, dBu ma'i de kho na nyid gtan la dbab pa. In bKa' gdams gsung 'bum, vol. 31, 8-67.

'Bras spungs dkar chag — 'Bras spungs dgon du bzhugs su gsol ba'i dpe rnying dkar chag, 2 Vols. Ed. dPal brtsegs bod yig dpe rnying zhib 'jug khang. Beijing: Mi rigs dpe skrun khang, 2004.

Mun sel - Phya pa Chos kyi seng ge, Tshad ma yid kyi mun pa sel pa. In bKa' gdams gsung 'bum, vol. 8, 434-626. Mun sel-Lhasa= edition of the former in Phya pa chos kyi seng ge'i gsung gces btus dbu tshad kyi yig cha. Lhasa: Bod ljongs bod yig dpe rnying dpe skrun khang (Byang chub ljon bzang 6), 2012. 585-916.

Tshad nye bsdus - Chos kyi bzhad pa, Tshad ma'i de kho na nyid bsdus pa 'i nye bar bsdus pa. In bKa' gdams gsung 'bum, vol. 88, 436-476. 
Tshad bsdus - (Ascribed to) Klong chen Rab 'byams pa, Tshad ma'i de kho na nyid bsdus pa. Ed. Padma tshul khrims. Chengdu: Si khron mi rigs dpe skrun khang, 2000.

Tshad ma rgyan gyi me tog - bCom ldan Rig(s) pa'i ral gri, Tshad ma'i bstan bcos sde bdun rgyan gyi me tog. In Tshad ma sde bdun rgyan gyi me tog. Ed. rDo rje rgyal po. Xining, Qinghai: Krung go'i bod kyi shes rig dpe skrun khang, 1991.

Tshad ma rigs rgyan - $\mathrm{dGe}$ 'dun grub, Tshad ma'i spyi don rigs rgyan chen mo. sKu 'bum byams pa gling, 2001. TBRC: W739-I1KG10850.

Tshad ma'i spyi skad - Tshad ma 'i spyi skad cung zad bsdus pa. In bKa' gdams gsung 'bum, vol. 44, 199-214.

Tshig mdzod chen mo — Bod rgya tshig mdzod chen mo. Ed. Zhāng Yísūn. Beijing: Mi rigs dpe skrun khang, 1985.

gZhung lugs rnam 'byed - Phya pa Chos kyi seng ge, bDe bar gshegs pa dang phyi rol pa 'i gzhung rnam par 'byed pa. In bKa' gdams gsung 'bum, vol. 9, 7-73.

'Od zer - Phya pa Chos kyi seng ge, Tshad ma rnam par nges pa'i 'grel bshad yi ge dang rigs pa'i gnad la 'jug pa'i shes rab kyi 'od zer. In bKa' gdams gsung 'bum, vol. 8, 35-427.

Yongs 'dzin blo rigs - Yongs 'dzin Phur bu lcog Byams pa tshul khrims rgya mtsho dpal bzang po, Tshad ma'i gzhung don 'byed pa'i bsdus grwa'i rnam bzhag rigs lam 'phrul gyi lde mig. In Textbooks of Se-ra Monastery for The Primary Course of Studies. Ed. Tshulkrim Kelsang and Shunzō Onoda. Kyoto: Nagata Bunshodo, 1985.

Rwa stod bsdus grwa - 'Jam dbyangs mChog lha 'od zer, Tshad ma rnam 'grel gyi bsdus gzhung shes bya'i sgo 'byed rgol ngan glang po 'joms pa gdong lnga'i gad rgyangs rgyu rig lde mig. In Rwa stod bsdus grwa. Dharamsala, 1980.

Rigs gter - Sa skya Paṇdita Kun dga' rgyal mtshan, Tshad ma rigs pa' $i$ gter and Tshad ma rigs pa'i gter gyi rang gi 'grel pa. Ed. Nor brang o rgyan. Lhasa: Bod ljongs mi dmangs dpe skrun khang, 1989.

Rigs gter nyi ma - Glo bo mkhan chen bSod nams lhun grub, sDe bdun mdo dang bcas pa 'i dgongs 'grel tshad ma rigs pa'i gter gyi 'grel pa'i rnam bshad rigs lam gsal ba'i nyi ma. In Tshad ma rigs gter gyi 'grel pa. Ed. rDo rje rgyal po. Xinning, Qinghai: Krung go'i bod kyi shes rig dpe skrung khang, 1991. 1-262. 
Rigs gter rab gsal — Go rams pa bSod nams seng ge, Tshad ma rigs pa'i gter gyi dka' ba'i gnas rnam par bshad pa sde bdun rab gsal. In Sa skya bka' 'bum, vol. 12 (ga).

Rigs thigs 'grel ți ka - rNgog Blo ldan shes rab, untitled text, bearing the indication mtshan nyid kyi chos on the cover folio. In bKa' gdams gsung 'bum, vol. 1, 369-409.

Rol mtsho - gSer mdog paṇ chen Śākya mchog ldan, Tshad ma rigs pa ’i gter gyi rnam par bshad pa sde bdun ngag gi rol mtsho. In gSer mdog gsung 'bum, vol. 19 (dza).

Sa skya bka' 'bum - Sa skya bka' 'bum: The Complete Works of the Great Masters of the Sa skya Sect of the Tibetan Buddhism (sDe dge edition). Compiled by bSod nams rgya mtsho. Tokyo: Toyo Bunko, 1968-1969.

gSal byed - gTsang drug pa rDo rje 'od zer, Yang dag rigs pa'i gsal byed sgron ma. In bKa' gdams gsung 'bum, vol. 47, 11-165.

gSer mdog gsung 'bum — gSer mdog pan chen Śākya mchog ldan, The Complete Works (gSung 'bum) of gSer mdog pan chen Śäkya mchog ldan. Ed. Kunzang Tobgey. Timphu, 1975 [Reprint Nagwang Topgyal, Delhi, 1988]. 


\section{Modern studies}

Almogi 2005 - Orna Amogi, "Analysing Tibetan Titles: Towards a Genre-based Classification of Tibetan Literature." Cahiers d'ExtrêmeAsie 15 (2005) 27-58.

Apple 2016 - James Apple, “An Early Bka'-gdams-pa Madhyamaka Work Attributed to Atiśa Dīpaṃkaraśrījñāāna.” JIP 44 (2016) 619-725.

Brentano 1874 - F.C. Brentano, Psychologie von empirischen Standpunkt. Ed. O. Kraus. Leipzig: Felix Meiner, 1874.

Brentano 1973 - F.C. Brentano, Psychology from an Empirical Standpoint. Trans. D.B. Terrell and L.L. McAlister. London: Routledge, 1973.

Brewer 2008 - Bill Brewer, "How to Account for Illusion." In Disjunctivism: Perception, Action, Knowledge. Ed. A. Haddock and F. Macpherson. Oxford: Oxford University Press, 2008.

Brewer 2011 - Id., Perception and its Objects. Oxford: Oxford University Press, 2011.

Buswell (ed.) 2004 - Robert E. Buswell, Jr. (editor in chief), Encyclopedia of Buddhism. New York: MacMillan Reference USA, 2004.

Byrne 2001 - Alex Byrne, "Intentionalism Defended." Philosophical Review 110 (2001) 199-240.

Caumanns 2015 - Volker Caumanns, Shakya-mchog-ldan, Mahapandita des Klosters gSer-mdog-can: Leben und Werk nach den tibetischen Quellen. Wiesbaden: Reichert Verlag (Contributions to Tibetan Studies 11), 2015.

Chandra (ed.) 1963 - Lokesh Chandra, Materials for a History of Tibetan Literature. New Delhi, 1963.

Chi 1969 - R.S.Y. Chi, Buddhist Formal Logic. A Study of Dignāga's Hetu-cakra and K'uei-chi's Great Commentary on the Nyāyapraveśa. Royal Asiatic Society of Great Britain, B.C. Law Trust Fund, vol. 1 [Reprint Delhi: Motilal Banarsidass, 1984].

Comesaña 2007 - Juan Comesaña, "Knowledge and Subjunctive Conditionals." Philosophy Compass 2 (2007) 781-791.

Crane 2001a - Tim Crane, Elements of Mind: An Introduction to the Philosophy of Mind. Oxford: Oxford University Press, 2001. 
Crane 2001b - Id., "Intentional Objects." Ratio 14 (2001) 336-349.

Crane 2009 - Id., "Intentionalism." In The Oxford Handbook of Philosophy of Mind. Ed. B. McLaughlin, A. Beckermann, and S. Walter. Oxford: Oxford University Press, 2009.

Cuevas 2015 - Bryan J. Cuevas, "Rwa lo tsa ba and His Biographers." In The Illuminating Mirror: Tibetan Studies in Honour of Per K. Sørensen on the Occasion of His 65th Birthday. Ed. O. Czaja and G. Hazod. Wiesbaden: Reichert Verlag, 2015. 57-79.

Dreyfus 1991 - Georges Dreyfus, "Dharmakīti's Definition of Pramāna and Its Interpreters." In Studies in the Buddhist Epistemological Tradition. Proceedings of the Second International Dharmakirti Conference. Vienna, June 11-16, 1989. Ed. E. Steinkellner. Vienna: VÖAW, 1991. 19-38.

Dreyfus 1996 - Id., "Can the Fool Lead the Blind? Perception and the Given in Dharmakīrti's Thought.” JIP 24 (1996) 209-229.

Dreyfus 1997a — Id., Recognizing Reality. Dharmakìti's Philosophy and Its Tibetan Interpretations. Albany, N.Y.: State University of New York Press, 1997.

Dreyfus 1997b - Id., "Tibetan Scholastic Education and the Role of Soteriology." JIABS 20.1 (1997) 31-62.

Dreyfus 2003 - Id., The Sound of Two Hands Clapping: The Education of a Tibetan Buddhist Monk. Berkeley and Los Angeles: University of California Press, 2003.

Dreyfus\&Thompson 2007 - Georges Dreyfus and Evan Thompson, "Asian Perspectives: Indian Theories of Mind." In The Cambridge Handbook of Consciousness. Ed. P.D. Zelazo, M. Moscovitch, and E. Thompson. New York: Cambridge University Press, 2006. Chapter 5, 89-114.

Dunne 2004 - John Dunne, Foundations of Dharmakirti's Philosophy. Boston: Widsom Publications (Studies in Indian and Tibetan Buddhism), 2004.

Dunne 2006 - Id., "Realizing the Unreal: Dharmakīrti's Theory of Yogic Perception." JIP 34 (2006) 497-519.

Eltschinger 2006 - Vincent Eltschinger, "Les œuvres de Śan்karanandana: Nouvelles ressources manuscrites, chronologie relative et 
identité confessionnelle." AION (Annali dell'Istituto Universitario Orientale di Napoli) 66 (2006) 83-122.

Eltschinger 2014 - Id., Buddhist Epistemology as Apologetics. Studies on the History, Self-understanding and Dogmatic Foundations of Late Indian Buddhist Philosophy. Wien: VÖAW, 2014.

Fish 2005 - William Fish, "Disjunctivism and Non-Disjunctivism: Making Sense of the Debate." Proceedings of the Aristotelian Society 105 (2005) 119-127.

Fish 2009 - Id., Perception, Hallucination, and Illusion. Oxford: Oxford University Press, 2009.

Franco 2006 - Eli Franco, "A New Era in the Study of Buddhist Philosophy." JIP 24 (2006) 221-227.

Franco\&Notake 2014 - Eli Franco and Miyako Notake, Dharmakīti on the Duality of the Object - Pramānavārttika III 1-63. Münster: LIT Verlag, 2014.

Gillon 1986 - Brendan S. Gillon, "Dharmakīti and His Theory of Inference." In Buddhist Logic and Epistemology. Studies in the Buddhist Analysis of Inference and Language. Ed. B.K. Matilal and R.D. Evans. Dordrecht: D. Reidel (Studies of Classical India 7), 1986.

Gnoli (ed.) 1960 - Raniero Gnoli (ed.), The Pramānavārttikam of Dharmakirti: The First Chapter with the Autocommentary. Rome: Istituto Italiano per il Medio ed Estremo Oriente (Serie Orientale Roma 23), 1960.

Haddock\&Macpherson 2008 - Adrian Haddock and Fiona Macpherson, "Introduction: Varieties of Disjunctivism." In Disjunctivism: Perception, Action, Knowledge. Ed. A. Haddock and F. Macpherson. Oxford: Oxford University Press, 2008. 1-24.

Hattori 1968 - Masaaki Hattori, Dignāga, On Perception, being the Pratyakșa-pariccheda of Dignāga's Pramānasamuccaya from the Sanskrit fragments and the Tibetan versions. Cambridge, MA: Harvard University Press, 1968.

Hayes 1988 - Richard P. Hayes, Dignāga on the Interpretation of Signs. Dordrecht: D. Reidel, 1988.

Hayes\&Gillon 1991 - Richard P. Hayes and Brendan S. Gillon, "Introduction to Dharmakirti's Theory of Inference as Presented in Pramānavārttika Svopajñāvrtti 1-10.” JIP 19 (1991) 1-73. 
Hinton 1973 - J.M. Hinton, Experiences. Oxford: Clarendon Press, 1973. Hugon 2004 - Pascale Hugon, "Interpretations of the Trairüpya in Tibet." Hōrin 11 (2004) 95-117.

Hugon (ed.) 2004 - Id. (ed.), mTshur ston gZhon nu seng ge, Tshad ma shes rab sgron ma. Wien: ATBS (WSTB 60), 2004.

Hugon 2008a - Id., "Arguments by Parallels in the Epistemological Works of Phya pa Chos kyi seng ge." Argumentation 22.1 (2008) 93114.

Hugon 2008b - Id., Trésors du raisonnement. Sa skya Pandita et ses prédécesseurs tibétains sur les modes de fonctionnement de la pensée et le fondement de l'inférence. Edition et traduction annotée du quatrième chapitre et d'une section du dixième chapitre $d u$ Tshad ma rigs pa'i gter. Wien: ATBS (WSTB 69.1 and 69.2), 2008.

Hugon 2009a - Id., "Phya pa Chos kyi seng ge's Synoptic Table of the Pramānaviniścaya." In Sanskrit Manuscripts in China. Proceedings of a panel at the 2008 Beijing Seminar on Tibetan Studies, October 13 to 17. Ed. E. Steinkellner, D. Qing, and H. Krasser. Beijing: China Tibetology Publishing House, 2009. 47-88.

Hugon 2009b - Id., "The Origin of the Theory of Definition and its Place in Phya pa Chos kyi seng ge's Epistemological System." In Tibetan Scholasticism in the $11^{\text {th }}$ and $12^{\text {th }}$ Centuries - Contributions to a panel at the $X V^{\text {th }}$ Congress of the International Association of Buddhist Studies, Atlanta, 23-28 June 2008. Ed. P. Hugon and K. Vose. JIABS 32 (2009) [2010] 319-368.

Hugon 2011a - Id., "Phya pa Chos kyi seng ge's Views on Perception." In Religion and Logic in Buddhist Philosophical Analysis. Proceedings of the Fourth International Dharmakirti Conference. Vienna, August 23-27, 2005. Ed. H. Krasser, H. Lasic, E. Franco, and B. Kellner. Wien: VÖAW, 2011. 159-176.

Hugon 2011b - Id., "Is Dharmakīti Grabbing the Rabbit by the Horns? A Reassessment of the Scope of prameya in Dharmakirtian Epistemology." JIP 39.4-5 (2011) 367-389.

Hugon 2011c - Id., "Argumentation Theory in the Early Tibetan Epistemological Tradition." JIABS 34.1-2 (2011)[2012] 97-148.

Hugon 2013a - Id., "On the Tibetan Translation of Dharmakīrti's Pramānaviniścaya - Attempting to Retrieve rNgog Blo ldan shes 
rab's Original Translation." China Tibetology 2 [General No. 21] (2013) 68-85.

Hugon 2013b - Id., "Phya pa Chos kyi seng ge on Argumentation by Consequence (thal 'gyur): The Nature, Function, and Form of Consequence Statements." JIP 41.6 (2013) 671-702.

Hugon 2014 - Id., "Tracing the Early Developments of Tibetan Epistemological Categories in Rngog Blo ldan shes rab's (1059-1109) Concise Guide to the Nyāyabinduțikka ." Journal of Tibetology 9 (2014) 194-234.

Hugon 2015a - Id., "Proving Emptiness - The Epistemological Background for the 'Neither One nor Many' Argument and the Nature of its Probandum in Phya pa Chos kyi seng ge's Works." JBP 1 (2015) 58-94.

Hugon 2015b - Id., "Text Re-use in Early Tibetan Epistemological Treatises." In Quotations, References and Re-use of Texts in Indian Philosophical Literature. Ed. Elisa Freschi. JIP 43.4 (2015) 453-491.

Hugon 2016a - Id., "Enclaves of Learning, Religious and Intellectual Communities in Tibet: The Monastery of gSang phu Ne'u thog in the Early Centuries of the Later Diffusion of Buddhism." In Meanings of Community Across Medieval Eurasia: Comparative Approaches. Ed. E. Hovden, C. Lutter, and W. Pohl. Leiden/Boston: Brill (Brill's Series on the Early Middle Ages 25), 2016. 289-308.

Hugon 2016b - Id., "Phya pa Chos kyi seng ge and His Successors on the Classification of Arguments by Consequence (thal 'gyur) Based on the Type of the Logical Reason." JIP 44.5 (2016) 883-938.

Hugon 2016c - Id., "Can one be a Mādhyamika, a crypto-Vaibhāṣika, and a faithful interpreter of Dharmakīti? On Phya pa Chos kyi seng ge's doxographical divisions and his own philosophical standpoint." Journal of Tibetology 15 (2016) 51-153.

Hugon 2015-2018 - Id., "Compiled Information on the Life and Works of Phya pa Chos kyi seng ge.” 19 pages (Version date: 6.6.2018). http://www.ikga.oeaw.ac.at/PhyaPaChosKyiSengGe.

Hugon forthcoming (1) — Id., "Vaibhāșika-Madhyamaka: A Fleeting Episode in the History of Tibetan Madhyamaka." In Felicitation Volume. Ed. V. Eltschinger, M. Sernesi, and V. Tournier. Naples: Università degli Studi di Napoli L'Orientale (Series Minor). 
Hugon forthcoming (2) - Id., "Who is the Proponent of Candrakīrti Portrayed by Phya pa Chos kyi seng ge in the sNying po?" In Memorial Volume for Helmut Krasser. Ed. V. Eltschinger, J. Kramer, P.G. Patil, L. van der Kuijp, and C. Yoshimizu. Cambridge, MA: Harvard University Press (Harvard Oriental Series).

Jackson 1987 - David P. Jackson, The Entrance Gate for the Wise (Section III). Sa-skya Pandita on Indian and Tibetan Traditions of Pramāṇa and Philosophical Debate. Wien: ATBS (WSTB 17.1 and 17.2), 1987.

Jackson 1994 - Id., "The Status of Pramāṇa Doctrine According to Sa skya Pandita and Other Tibetan Masters: Theoretical Discipline or Doctrine of Liberation?" In The Buddhist Forum, vol. III, 1991-1993, Papers in Honour and Appreciation of Professor David Seyfort Ruegg's Contribution to Indological, Buddhist and Tibetan Studies. Ed. T. Skorupski and U. Pagel. London: School of Oriental and African Studies, 1994. 85-129.

Kajiyama 1958 - Yuichi Kajiyama, "On the Theory of Intrinsic Determination of Universal Concomitance in Buddhist Logic." Journal of Indian and Buddhist Studies (Indogaku bukkyogaku kenkyū) 7.1 (1958) 364-360.

Kajiyama 1966 - Id., An Introduction to Buddhist Philosophy: An annotated translation of the Tarkabhāșā of Mokșākaragupta. Kyoto: Kyoto University, 1966.

Kano 2008 - Kazuo Kano, "rNgog Blo ldan shes rab's Topical Outline of the Ratnagotravibhāga Discovered at Khara Khoto." In Contributions to Tibetan Buddhist Literature: Proceedings of the Eleventh Seminar of the International Association for Tibetan Studies, Königswinter 2006. Ed. O. Almogi. Halle: International Institute for Tibetan and Buddhist Studies, 2008. 127-194.

Kano 2016 - Id., Buddha-nature and Emptiness. rNgog Blo-ldan-shesrab and a Transmission of the Ratnagotravibhāga from India to Tibet. Wien: ATBS (WSTB 91), 2016.

Karma bde legs (ed.) 2006 - Karma bde legs (ed.), bKa' gdams gsung 'bum phyogs sgrig thengs dang po'i dkar chag. Cf. bKa' gdams gsung 'bum.

Katsura 1984 - Shōryū Katsura, "Dharmakīrti's Theory of Truth.” JIP 12 (1984) 215-235. 
Katsura 1993 - Id., "On Perceptual Judgement.” In Studies on Buddhism in Honour of Professor A.K. Warder. Ed. N.K. Wagle and F. Watanabe. University of Toronto: Centre for South Asian Studies (South Asian Studies Papers 5), 1993. 66-75.

Keira 2004 - Ryūsei Keira, Mādhyamika and Epistemology: A Study of Kamalaśila's Method for Proving the Voidness of All Dharmas. Wien: ATBS (WSTB 59), 2004.

Kramer 2007 - Ralf Kramer, The Great Tibetan Translator: Life and Works of rNgog Blo ldan shes rab (1059-1109). München: Indus Verlag (Collectanea Himalayica 1), 2007.

Krasser 1991 - Helmut Krasser, Dharmottaras kurze Untersuchung der Gültigkeit einer Erkenntnis. Laghuprāmānyaparīkșā. Teil 1: Tibetischer Text und Sanskritmaterialien. Teil 2: Übersetzung. Wien: VÖAW, 1991.

Krasser 1995 - Id., "Dharmottara's Theory of Knowledge in His Laghuprāmānyaparīkșā." JIP 23 (1995) 247-271.

Krasser 2001 - Id., "On Dharmakīrti's Understanding of pramānabhūta and His Definition of pramāna." WZKS 45 (2001) 15-43.

Krasser 2012 — Id., "Bhāviveka, Dharmakīrti and Kumārila." In Devadattiyam: Johannes Bronkhorst felicitation volume. Ed. F. Voegeli, V. Eltschinger, D. Feller, M. P. Candotti, B. Diaconescu, and M. Kulkarni. Bern, Berlin, Bruxelles, Frankfurt am Main, New York, Oxford, Vienna: Peter Lang Verlag (Worlds of South and Inner Asia 5), 2012. 535-594.

Kværne 1973 - Per Kværne, "Bonpo Studies: The A Khrid System of Meditation." Kailash 1 (1973) 19-50.

Lasic 2006 - Horst Lasic, "Fragments of Pramāna Texts Preserved in Tabo Monastery." In Text, Image and Song in Transdisciplinary Dialogue. Ed. D. Klimburg-Salter, K. Tropper and Ch. Jahoda. Leiden: Brill, 2006. 63-77.

Malvania (ed.) 1955 - Dalsukh Bhai Malvania, Nyāyabindu with Dharmottara's Nyāyabinduțīka and Durveka Miśra's Dharmottarapradīpa. Patna: Kashi Prasad Jayaswal Research Institute, 1955 [Second edition 1971]. 
Mathes 2008 - Klaus-Dieter Mathes, A Direct Path to the Buddha Within: Gö Lotsāwa's Mahāmudrā Interpretation of the Ratnagotravibhāga. Somerville: Wisdom Publications, 2008.

Matilal 1986 - Bimal Krishna Matilal, Perception: An Essay on Classical Indian Theories of Knowledge. Oxford: Clarendon Press, 1986.

Matilal 1990 - Id., Logic, Language and Reality: Indian Philosophy and Contemporary Issues. Delhi: Motilal Banarsidass Publishers, 1990.

McCrea\&Patil 2006 - Lawrence J. McCrea and Parimal G. Patil, "Traditionalism and Innovation: Philosophy, Exegesis, and Intellectual History in Jñānaśrīmitra's Apohaprakaraṇa." JIP 34 (2016) 303-366.

Mimaki 1976 - Katsumi Mimaki, La Réfutation Bouddhique de la Permanence des Choses (Sthirasiddhidūșaṇa) et la Preuve de la Momentanéité des Choses (Kṣanabhañgasiddhi). Paris: Institut de Civilisation Indienne, 1976.

Minaev 1889 - I.P. Minaev, "Bodhicaryāvatāra." Zapiski Vostočnago Otdělenija Imperatorskago Russkago Archeologičeskago Obščestva 4 (1889) 153-228.

Miyasaka (ed.) 1971/1972 - Yūshō Miyasaka (ed.), Pramānavārttikakārikā (Sanskrit and Tibetan). In Acta Indologica II. Narita: Naritasan Shinshōji 1971/1972. 1-206.

Nishizawa 2013 - Fumihito Nishizawa, "A Reconsideration of pratyakșa and niścaya: Dharmakirti's Inconsistent Accounts and the Interpretations of Śākyabuddhi and Arcața" (in Japanese). Journal of Indian and Buddhist Studies (Indogaku bukkyogaku kenkȳu) 61.3 (2013) 115-120.

Nishizawa 2016 - Id., "A Reconsideration of Perception and ObjectAscertaining Cognition: Dharmakīrti's Inconsistent Accounts and the Interpretations of His Followers in India and Tibet." Indian Logic (Indo ronrigaku kenkyū) 9 (2016) 145-164.

Nozick 1981 - Robert Nozick, Philosophical Explanations. Cambridge, MA: Harvard University Press, 1981.

Onoda 1992 - Shunzō Onoda, Monastic Debate: A Study on the History and Structures of bsdus grwa Logic. Wien: ATBS (WSTB 27), 1992.

Onoda 1996 - Id., "bsDus grwa Literature." In Tibetan Literature: Studies in Genre. Ed. J.I. Cabezón and R. Jackson. Ithaca, NY: Snow Lion (Studies in Indo-Tibetan Buddhism), 1996. 187-201. 
Patil 2011 - Parimal G. Patil, "Without Brackets: A Minimally Annotated Translation of Ratnakīrti's Demonstration of Exclusion" (Supplement to the book Apoha, cf. Siderits et al. [eds.] 2011). Accessed 21.6.2011, from http://cup.columbia.edu/media/7285/side15360_patil.pdf.

Pautz 2010 - Adam Pautz, "Why Explain Experience in Terms of Content?" In Perceiving the World. Ed. B. Nanay. New York: Oxford University Press, 2010. 254-309.

Pradhan (ed.) 1967 — Pralhad Pradhan (ed.), Abhidharmakośabhāṣya of Vasubandhu. Patna: Kashi Prasad Jayaswal Research Institute, 1967.

Pritchard 2008 - Duncan Pritchard, "Sensitivity, Safety, and Anti-Luck Epistemology." In The Oxford Handbook of Skepticism. Ed. J. Greco. Oxford: Oxford University Press, 2008. 437-455.

Rinbochay\&Napper 1980 - Lati Rinbochay and Elizabeth Napper, Mind in Tibetan Buddhism. Ithaca: Snow Lion Publications, 1980.

Schwabland 1995 - Peter A. Schwabland, "Direct and Indirect Cognition and the Definition of pramanna in Early Tibetan Epistemology." EA 49.4 (1995) 793-816.

Searle 1983 - John Searle, Intentionality: An Essay in the Philosophy of the Mind. Cambridge: Cambridge University Press, 1983.

Seyfort Ruegg 1992 - David Seyfort Ruegg, "Notes on Some Indian and Tibetan Reckonings of the Buddha's Nirvāna and the Duration of his teaching." In The Dating of the Historical Buddha/Die Datierung des historischen Buddha, Part 2. E. H. Bechert. Göttingen: Vandenhoeck und Ruprecht (Symposien zur Buddhismus-Forschung IV,2, Abhandlungen der Akademie der Wissenschaften in Göttingen, Philologisch-Historische Klasse, Dritte Folge 194), 1992. 263-290.

Seyfort Ruegg 2000 - Id. Three Studies in the History of Indian and Tibetan Madhyamaka Philosophy. Wien, ATBS (WSTB 59), 2000.

Siderits et al. (eds.) 2011 - Mark Siderits, Tom Tillemans, and Arindam Chakrabarti (eds.), Apoha: Buddhist Nominalism and Human Cognition. New York: Columbia University Press, 2011.

Siegel 2010 - Susanna Siegel, The Contents of Visual Experience. New York: Oxford University Press, 2010.

Smith 2010 - A.D. Smith, "Disjunctivism and Illusion." Philosophy and Phenomenological Research 80.2 (2010) 384-410. 
Solonin 2015 - Kirill Solonin, "Local Literatures: Tangut/Xixia." In Brill's Encyclopedia of Buddhism. Vol. I: Literature and Languages. Ed. J. Silk, O. Von Hinüber, and V. Eltschinger. Leiden: Brill, 2015. 844-859.

Sørensen\&Hazod 2007 - Per K. Sørensen and Guntram Hazod, in cooperation with Tsering Gyalbo, Rulers on the Celestial Plain: Ecclesiastic and Secular Hegemony in Medieval Tibet. A Study of Tshal Gung-thang. Vienna: VÖAW, 2007.

Sparham 1996 - Gareth Sparham, “A Note on Gnyal zhig 'Jam pa'i rdo rje, the Author of a Handwritten Sher phyin Commentary from about 1200." The Tibet Journal 21 (1996) 19-29.

Steinkellner (ed.) 1967 — Ernst Steinkellner (ed.), Dharmakirti's Hetubinduh, vol. I. Wien: VÖAW, 1967.

Steinkellner 1968 - Id., "Die Entwicklung des Kṣanikatvānumānam bei Dharmakīrti." WZKSO 12-13 (1968) 361-377.

Steinkellner (ed.) 1973/1979 — Id. (ed.), Dharmakīrti's Pramānaviniścayah. Zweites Kapitel: Svārthānumānam. Teil I. Tibetischer Text und Sanskrittexte, Teil II. Übersetzung und Anmerkungen. Wien: VÖAW, 1973/1979.

Steinkellner (ed.) 2007 — Id., Dharmakīrti's Pramāṇaviniścayah, Chapters 1 and 2. Beijing-Vienna: China Tibetology Publishing House / VÖAW (STTAR 2), 2007.

Steinkellner (ed.) 2016 - Id., Dharmakīrti's Hetubindu. Critically Edited by Ernst Steinkellner on the Basis of Preparatory Work by Helmut Krasser, with a Transliteration of the Gilgit Fragment by Klaus Wille. Beijing-Vienna: China Tibetology Publishing House / VÖAW (STTAR 19), 2016.

Steinkellner\&Krasser 1989 - Ernst Steinkellner and Helmut Krasser, Dharmottaras Exkurs zur Definition gültiger Erkenntnis im Pramāṇaviniścaya (Materialien zur Definition Gültiger Erkenntnis in der Tradition Dharmakirtis 1). Tibetischer Text, Sanskritmaterialien und Übersetzung. Wien: VÖAW, 1989.

Steinkellner\&Much (eds.) 1985 — Ernst Steinkellner and Michael Torsten Much (eds.), Texte der erkenntnistheoretischen Schule des Buddhismus - Systematische Übersicht über die buddhistische Sanskrit-Literatur II. Göttingen: Vandenhoeck \& Ruprecht 
(Abhandlungen der Akademie der Wissenschaften, PhilologischHistorische Klasse, Dritte Folge 214), 1985.

Stoltz 2006 - Jonathan Stoltz, "Sakya Pandita and the Status of Concepts." Philosophy East \& West 56.4 (2006) 567-582.

Stoltz 2007 - Id., "Gettier and Factivity in Indo-Tibetan Epistemology." The Philosophical Quarterly 57.228 (2007) 394-415.

Stoltz 2009 - Id., "Phywa Pa's Argumentative Analogy Between Factive Assessment (yid dpyod) and Conceptual Thought (rtog pa)." JIABS 32 (2009) [2010] 369-386.

Stoltz 2013 - Id., "Cognition, Phenomenal Character, and Intentionality in Tibetan Buddhism." In A Companion to Buddhist Philosophy. Ed. S. Emmanuel. Oxford: Wiley Blackwell, 2013. 405-418.

Stoltz forthcoming - Id., Cognition and its Objects: Externalism in Tibetan Philosophy of Mind. Manuscript in preparation.

Sweeney 2017 — Eileen Sweeney, "Literary Forms of Medieval Philosophy." In The Stanford Encyclopedia of Philosophy (Winter 2017 Edition), Edward N. Zalta (ed.). URL = https://plato.stanford.edu/archives/win2017/entries/medieval-literary/.

Tauscher (ed.) 1999 - Helmut Tauscher (ed.), Phya pa Chos kyi sen ge, dBu ma śar gsum gyi stoń thun. Wien: ATBS (WSTB 43), 1999.

Thakchoe 2017 - Sonam Thakchoe, "The Theory of Two Truths in India." In The Stanford Encyclopedia of Philosophy (Spring 2017 Edition), Edward N. Zalta (ed.). URL = https://plato.stanford.edu/archives/spr2017/entries/twotruths-india/.

Tillemans 1982 - Tom J.F. Tillemans, "The 'Neither One Nor Many' Argument for Ś́̄nyatā, and Its Tibetan Interpretations: Background Information and Source Materials." Études de Lettres 3 (1982) 103128.

Tillemans 1983 - Id., "The 'Neither One Nor Many' Argument for Śünyatā and Its Tibetan Interpretations." In Contributions on Tibetan and Buddhist Religion and Philosophy: Proceedings of the Csoma de Körös Symposium held at Velm-Vienna, Austria, 13-19 September 1981. Ed. E. Steinkellner and H. Tauscher. Wien: ATBS (WSTB 11), 1983. Vol. 2, 305-320. 
Tillemans 1999 - Id., Scripture, Logic, Language: Essays on Dharmakirti and his Tibetan Successors. Boston: Wisdom Publications (Studies in Indian and Tibetan Buddhism), 1999.

Tillemans 2000 - Id., Dharmakīrti's Pramānavārttika. An Annotated Translation of the Fourth Chapter (parārthānumāna). Vol. 1 (k. 1148). Wien: VÖAW, 2000.

Tshul khrims rgya mtsho 1997 - mKhan Rin po che Tshul khrims rgya mtsho, Presentation of Lorik and Takrik: The Essence of the Ocean of Traditions of Logic. New York: Nitartha Publications, 1997.

Tye 2007 - Michael Tye, "Intentionalism and the Argument from No Common Content." Philosophical Perspectives 21 (2007) 589-613.

van der Kuijp 1978 - Leonard W.J. van der Kuijp, "Phya-pa Chos-kyi Seng-ge's Impact on Tibetan Epistemological Theory." JIP 5 (1978) 355-369.

van der Kuijp 1983 - Id., Contributions to the Development of Tibetan Buddhist Epistemology. Wiesbaden: Franz Steiner Verlag, 1983.

van der Kuijp 1985 - Id., "Miscellanea Apropos of the Philosophy of Mind in Tibet: Mind in Tibetan Buddhism." The Tibet Journal 10.1 (1985) 32-43.

van der Kuijp 1987 - Id., "The Monastery of Gsang-phu ne'u-thog and Its Abbatial Succession from ca. 1073 to 1250." Berliner Indologische Studien 3 (1987) 103-127.

van der Kuijp 1989 - Id., “An Introduction to Gtsang-nag-pa's Tshadma rnam-par nges-pa'i ti-ka legs-bshad bsdus-pa. An Ancient Commentary on Dharmakīrti's Pramānaviniścaya, Otani University Collection No.13971." Kyoto: Rinsen Book Co (Otani University Tibetan Works Series 2), 1989. 1-39.

van der Kuijp 1994 - Id., "Review of: Tshad ma sde bdun rgyan gyi me tog. By bCom ldan Rigs pa'i ral gri." Journal of the American Oriental Society 114.2 (1994) 304-306.

van der Kuijp 2003 - Id., "A Treatise on Buddhist Epistemology and Logic Attributed to Klong chen Rab 'byams pa (1308-1364) and its Place in Indo-Tibetan Intellectual History." JIP 31 (2003) 381-437.

van der Kuijp 2009 - Id., "Classification of Non-Authoritative Cognitive Processes (tshad min) in the Ngog and Sakya Traditions." In 
Buddhist Philosophy: Essential Readings. Ed. W. Edelglass and J. Garfield. New York: Oxford University Press, 2009. 218-223.

van der Kuijp 2011 - Id. “A Hitherto Unknown Tibetan Religious Chronicle from Probably the Early Fourteenth Century," Journal of Tibetology 7 (2011) 69-91.

van der Kuijp\&McKeown 2013 - Leonard W.J. van der Kuijp and Arthur P. McKeown, bCom ldan Ral gri (1227-1305) on Indian Buddhist Logic and Epistemology: His Commentary on Dignāga's Pramānasamuccaya. Wien: ATBS (WSTB 80), 2013.

Vetter 1966 - Tilmann Vetter, Dharmakīrti’s Pramānaviniścayah, 1. Kapitel: Pratyakșam. Wien: VÖAW, 1966.

Vetturini 2007 - Gianpaolo Vetturini, The bKa' gdams pa School of Tibetan Buddhism (revised PhD dissertation, University of London, 2007).

http://himalaya.socanth.cam.ac.uk/collections/rarebooks/downloads/ Gianpaolo_Vetturini_PhD.pdf

Vitali 2015 - Roberto Vitali, "The Book of Names of Nyang stod bla ma-s: Masters and Events of the Years 997-1354." Revue d'Études Tibétaines 31 (2015) 511-576.

Vose 2009 - Kevin Vose, Resurrecting Candrakirti. Disputes in the Tibetan Creation of Prāsañgika. Boston: Wisdom Publications (Studies in Indian and Tibetan Buddhism), 2009.

Werner 2014 — Eric Werner, Phywa-pa Chos-kyi-seng-ge's (11091169) Depiction of Māhāyāna Philosophy: A Critical Edition and Annotated Translation of the Chapters on Yogācāra and Mädhyamaka Philosophy from the gZhung lugs rnam 'byed, a Doxography of the Twelfth Century. Wissenschaftliche Hausarbeit zur Erlangung des akademischen Grades Master of Arts der Universität Hamburg, unpublished.

Wood 1991 - Thomas E. Wood, Mind Only: A Philosophical and Doctrinal Analysis of the Vijñanavāda. Honolulu: University of Hawaii Press (Society for Asian and Comparative Philosophy, Monograph 9), 1991. 



\section{IX}

Selected indices 



\section{Indian names}

Note: All names below are listed according to the order of the Sanskrit alphabet.

\subsection{Persons}

Atiśa, 44, 46, 60, 65

Arcața, 102

Asanga, 52, 332

Kamalaśîla, 365

Kumārila Bhaț̣a, 45

Candrakīrti, 43

Jayanta Bhatta, 53

Jayānanda, 66, 67

Jinamitra, 265

Jinendrabuddhi, 145

Jñānaśrīmitra, 92, 104

Dānaśīla, 65

Dignāga, 3, 10, 19-20, 37, 45, 49, $52,53,79,117,120,145,333$, 349,362

Durvekamiśra, 240

Devendrabuddhi, 66, 223, 303

Dharmakīrti, 3, 4, 10, 15, 19-20, $25-26,37,43,45,47-50,52-$ $55,57,66,74-76,79,90,92-$ 93, 96-97, 102-104, 106-107, 110-111, 117, 120, 124, 127, 151, 162, 167-168, 176, 203,

\subsection{Schools}

Abhidharma, 52, 117, 121
240, 242-243, 332-334, 349, $355,358,360-363$

Dharmāloka, 240, 266-269

Dharmottara, 4, 46-47, 55-56, $66,77,92,94,108-109,115$, $149,151,223,227-228,230$, 239-240, 243, 248-249, 255, 257, 265, 267-269, 287, 301, $303,333-334,350-351$

Prajñākaragupta, 47, 66, 223, 303

Prajñāvarman, 240

Bhāviveka, 45

Manorathanandin, 76

Vasubandhu, 52, 116, 332, 361

Vinītadeva, 265

Śankkaranandana, 27, 47, 66, 81, 90, 96, 104-110, 162, 203, 291, 350, 351

Śākyabuddhi, 94, 97, 102, 108

Śākyaśrībhadra, 50

Śāntarakṣita, 365

Śāntideva, 127 
Madhyamaka, Mādhyamika, 4143, 46, 108, 110-111, 151, $163,213,230,350,352,360$, 362,365
Mīmāṃsā, 3, 45

Vaibhāṣika, 10, 116, 119 


\section{Tibetan names}

Note: All names below are listed according to the order of the Tibetan alphabet.

\subsection{Persons}

Kun dga' grol mchog, 42

Kun dga' rgyal mtshan (see Sa skya Paṇụita)

Klong chen Rab 'byams pa Dri med 'od zer, 42, 50

Klong rdol bla ma Ngag dbang blo bzang, 63, 249

sKyel nag Grags pa seng ge, 60, 65

Khu mdo sde 'bar, 66

Khyung Rin chen grags, 47, 230 mKhan Rin po che Tshul khrims rgya mtsho, 62

mKhas grub rje dGe legs dpal bzang, 65, 79, 91, 105, 233

mKhas pa'i 'byung gnas bSod nams dpal, 172

Gangs pa she'u, 47

Go rams pa bSod nams seng ge, 43, 176, 213, 234, 294-295

Grags pa bkra shis, 43

Grags pa seng ge (see sKyel nag) Glo bo mkhan chen bSod nams lhun grub, 176, 247, 249, 297 dGe 'dun grub pa, 91, 244, 263 dGe bshes 'Jam dpal bsam 'phal, 62,234

'Gos lo tsā ba gZhon nu dpal, 42
rGya dmar ba Byang chub grags, 47, 53, 67, 108-109, 121, $151,155,160,230,231-232$, 243, 247-249, 257-258, 269270, 274, 278-279, 281, 286287, 292, 350-351

rGyal ba'i 'byung gnas (see 'Brom ston)

rGyal tshab rje Dar ma rin chen, 91

Ngag dbang bkra shis, 63

Ngag dbang blo bzang (see Klong rdol bla ma)

Ngag dbang Blo bzang rgya mtsho, 44

Ngag dbang brtson 'grus (see'Jam dbyangs bzhad pa)

rNgog Blo ldan shes rab, 4, 19, 41, 47-48, 54-58, 61, 63-64, 66-67, 72, 88, 93-95, 97, 100, 105, 107-110, 133, 145, 160, 213, 227, 229-231, 234, 239241, 243, 247-249, 255, 257, 265-269, 299-301

rNgog Legs pa'i shes rab, 46

rNgog Lo (see rNgog Blo ldan shes rab)

bCom ldan ral gri, 45, 59, 65, 89, 263 
Chu mig pa Seng ge dpal, 19, 48-49, 59-60, 65, 90-91, 95, 133, 176, 203, 232-233, 237 , 241, 244, 258, 263, 275, 277, 279-281, 288, 368

Chos kyi bla ma (see Zhang tshes spong)

Chos kyi bzhad pa, 60, 90, 244, 263, 275, 277, 279-281, 297, 368

Chos dpal rgyal mtshan, 42 mChog lha 'od zer (see 'Jam dbyangs mChog tha 'od zer)

'Jam pa'i rdo rje (see gNyal zhig) 'Jam dpal bsam 'phal (see dGe bshes)

'Jam dbyangs mChog lha 'od zer, 63,91

'Jam dbyangs bzhad pa Ngag dbang brtson 'grus, 62-63

Nyi ma grags (see Pa tshab)

gNyag(s), 65

gNyal pa zhang tshes, 59

gNyal (ma) Yon tan seng ge, 51

gNyal zhig 'Jam pa'i rdo rje, 59-60

rTag/sTag pa Kha che, 149, 230

Dan bag pa sMra ba'i seng ge, $51,59-60,263,269-270$

Dam chos rnam rgyal (see gSer khang pa)

Dar ma rgyal mtshan (see bCom ldan ral gri)

rDo rje rgyal po (see Phag mo gru pa rDo rje rgyal po)
rDo rje dbang grags, 60, 275, 277, 279-281, 368

rDo rje 'od zer (see gTsang drug rdo rje)

Pa tshab Nyi ma grags, 213

dPal ldan rtsang pa 'bre, 59

dPal brtsegs rakșita, 240

Phag mo gru pa rDo rje rgyal po, 243

Phur bu lcog (see Yongs 'dzin)

Phya pa Chos kyi seng ge, passim

'Phags pa Blo gros rgyal mtshan, 60

Byang chub skyabs, 249, 257258, 279, 286, 367

Byang chub grags (see rGya dmar ba)

Bru sha bSod nams seng ge, 51

Blo gros rgyal mtshan (see'Phags pa)

Blo bzang grags pa (see Tsong kha pa)

Blo bzang tshul khrims byams pa rgya mtsho (see Yongs 'dzin)

'Byung gnas ye shes (see Zhang thang sag pa)

'Brom ston rGyal ba'i 'byung gnas, 46

rMa bya Byang chub brtson 'grus, 52,67

rMa bya rTsod pa'i seng ge , 52

rMe'u dgongs mdzod ri khrod chen po, 230

sMra ba'i seng ge (see Dan bag pa) 
Tsong kha pa Blo bzang grags pa, 91, 244, 263

gTsang drug (pa) rdo rje ('od zer) 59-60, 90, 144, 149, 176, 230-231, 235, 244, 247, 249, $259,263,269,274,276,278$, 280-281, 287, 341, 368

gTsang nag pa brTson 'grus seng ge, 45, 51-52, 58-61, 77, 89-90, 203, 230, 235, 241, 243-244, 246-247, 258, 270, 274, 276, 278, 280-281, 291, 294, 353, 368

gTsang pa gru gu, 59

bTsan dgon (see Slob dpon bTsan dgon)

brTson 'grus seng ge (see gTsang nag pa)

mTshur ston gZhon nu seng ge, $45,49,51-52,58,60,63,88-$ 90, 95, 149, 176, 203, 230, 235, 241, 243, 246-247, 274 , 276, 278, 280-281, 295, 353, 368

Zhang thang sag pa 'Byung gnas ye shes, 213

Zhang sna chung ston pa, 213

Zhang (')tshal pa, 213

Zhang tshes spong Chos kyi bla ma, 213, 270, 281, 286

gZhon nu dpal (see 'Gos lo tsā ba) gZhon nu seng ge (see mTshur ston) 'U yug pa bSod nams seng ge, 51 Ye shes sde, 265
Yongs 'dzin Phur bu lcog Blo bzang tshul khrims byams pa rgya mtsho, 62, 63

g.Yor gnyan, 150, 242-243

Rin chen grags (see Khyung)

Rin chen dpal (see 1Ho pa kun mkhyen)

Rin chen bzang po, 44

Lati Rinbochay, 62, 241

Sākya mchog ldan (see gSer mdog pạ̣ chen Śākya mchog ldan)

Sa skya Panditita Kun dga' rgyal mtshan, 15, 43, 45-46, 50, 52, 60-61, 63-65, 75, 90-93, 95, 98-101, 104, 118, 121, 233, 241, 244-245, 249, 271, 353, 358

Sa paṇ (see Sa skya Paṇdita)

Seng ge dpal (see Chu mig pa)

Slob dpon bTsan dgon, 42

gSer khang pa Dam chos rnam rgyal, 63

gSer mdog paṇ chen Śākya mchog ldan, 42-43, 49, 51, 56, 90-91, 106, 109, 150, 176, 213, 234, 243, 249-250, 288

bSod nams dpal (see mKhas pa'i 'byung gnas)

bSod nams rtse mo, 60

bSod nams seng ge (see Go rams pa, see 'U yug pa, see Bru sha) 1Ha rje rgya nag, 230

1 Ho pa kun mkhyen Rin chen dpal, 52 


\subsection{Schools}

bKa' brgyud, 62

bKa' gdams pa, 43-44, 46, 65, 230

\subsection{Places and monasteries}

rGyal rtse dpal 'khor chos sde, 44

Nyang stod, 230

Tabo, 266, 268

sTod lung, 47, 242-243, 247

Thang sag, 213

gNas bcu lha khang, 44, 171

sNar thang, 51

Bri'u las gTsug lag khang, 172

Blo gsal gling, 62
dGe lugs pa, 50, 62-65, 91, 110, 233, 358

rNying ma pa, 42

Sa skya pa, 15, 50, 62, 65
'Bras spungs, 44, 62, 171

Mi nyag, 41

Mi dbang lha khang, 44

Zha lu, 44

Rwa sgreng, 46

Rwa ba stod, 63

Se ra, 44

gSang phu Ne'u thog, 41-43, 46-48, 52, 59, 61-63, 65, $89,91,233$ 